\title{
Current Emission Trends for Nitrogen Oxides, Sulfur Dioxide, and Volatile Organic Compounds by Month and State: Methodology and Results
}

by E.J. Kohout, D.J. Miller, L.A. Nieves, D.S. Rothman, C.L. Saricks, "F. Stodolsky, " and D.A. Hanson

Policy and Economic Analysis Group,

Environmental Assessment and Information Sciences Division,

Argonne National Laboratory, 9700 South Cass Avenue, Argonne, Illinois 60439

August 1990

Work sponsored by United States Department of Energy,

Assistant Secretary for Fossil Energy, Office of Planning and Environment

Report prepared for National Acid Precipitation Assessment Program

'Saricks and Stodolsky are affiliated with Argonne's Energy Systems Division. 


\section{Contents}

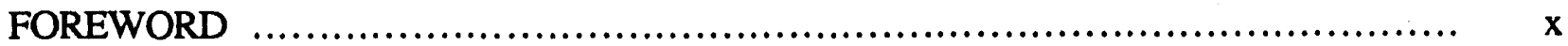

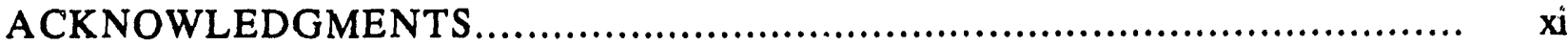

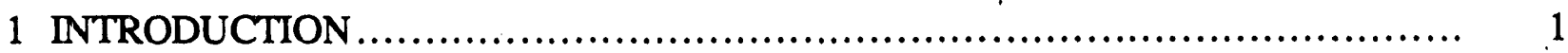

1.1 Month and State Current Emission Trends Program............................ 1

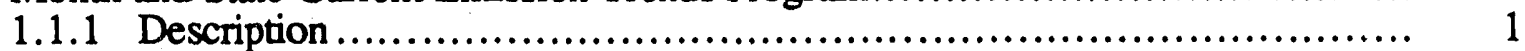

1.1 .2 Recent Enhancements................................................... 2

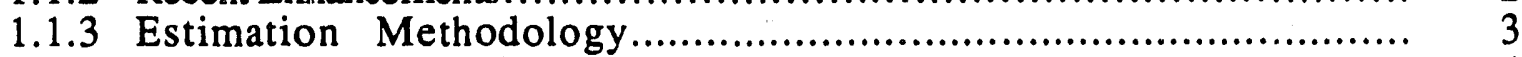

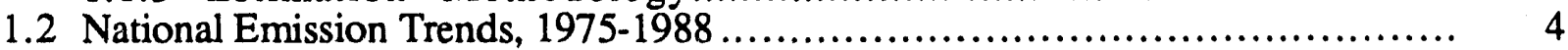

1.2 .1 Nitrogen Oxides ....................................................... 5

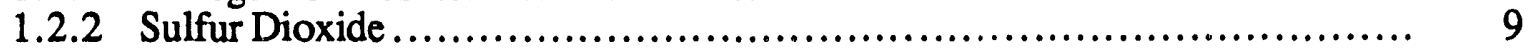

1.2.3 Volatile Organic Compounds............................................. 10

1.3 Electric Utility Sector Emissions ................................................. 11

1.3 .1 Nitrogen Oxides .......................................................... 14

1.3 .2 Sulfur Dioxide ....................................................... 15

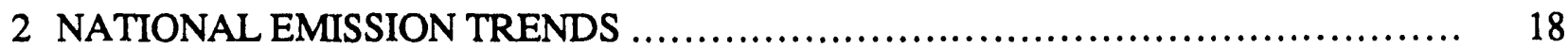

2.1 Nitogen Oxides ............................................................ 18

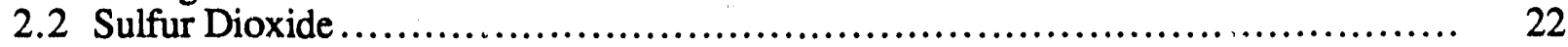

2.3 Volatile Organic Compounds ............................................... 23

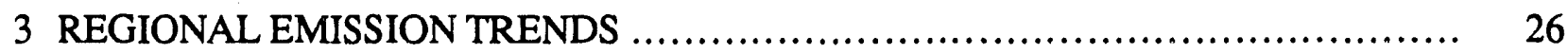

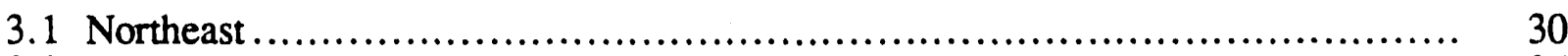

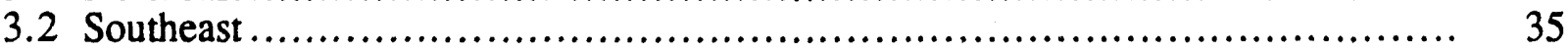

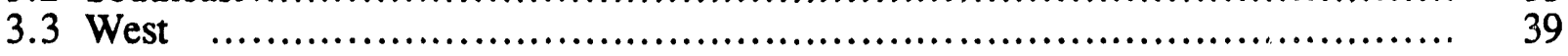

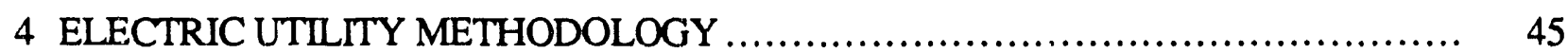

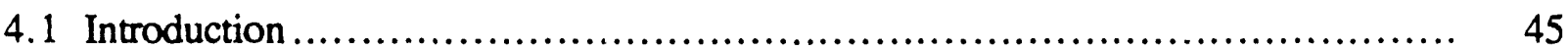

4.1.1 Primary Drivers of Electric Utility Emissions.............................. 45

4.1.2 Sulfur Dioxide ....................................................... 46

4.1 .3 Nitrogen Oxides ........................................................ 47

4.2 Selecting the Methodology ..................................................... 48

4.3 Data Sources .............................................................. 50

4.4 Calculating Fuel Consumption.................................................. 52

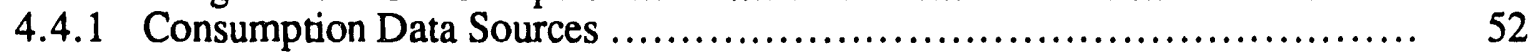

4.4.2 Preparing the Consumption Data ...................................... 55

4.4.3 Projecting EIA Form 767 Data onto Earlier Years............................. 58

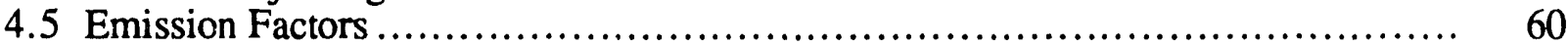

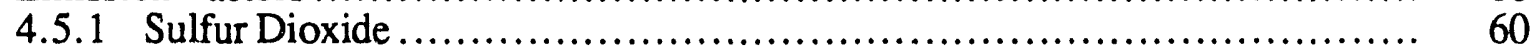

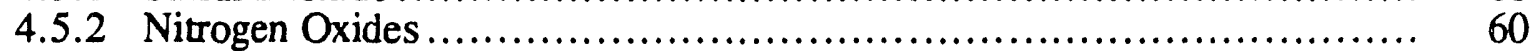

4.5.3 Volatile Organic Compounds....................................... 63 


\section{Contents (Cont'd)}

4.6 Calculating Emissions .................................................... 63

4.7 Important Methodological Assumptions................................... 64

5 NONUTILITY STATIONARY SOURCE METHODOLOGY............................... 67

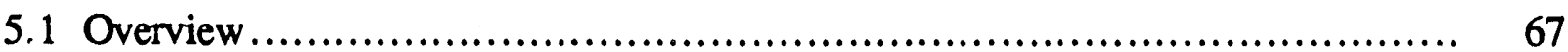

5.2 Implementing the ICRIM Methodology ........................................... 68

5.2.1 Identifying Emission Trend Indicators............................................ 69

5.2.2 Defining the Emission Source Groups............................................... 70

5.2.3 Constructing the Emission Source Groups......................................... 71

5.2 .4 Computing Annual Trends ........................................... 74

5.2.5 Estimating Nonconstant State Emission Shares ............................. 75

5.2 .6 Computing Monthly Indexes .................................................... 77

5.2.7 Computing Monthly State Emission Series ................................... 78

5.3 Estimating Emissions for the Most Recent Year................................... 78

5.4 Comparison of MSCET with EPA and NAPAP Emissions........................... 80

5.5 Alternative Estimation Techniques ............................................... 86

5.5.1 Key Factors Influencing the Estimation Results.................................. 87

5.5.2 Hypothetical Example.................................................... 87

5.5.3 Realistic Example................................................................... 90

6 COPPER SMELTER METHODOLOGY .......................................... 92

6.1 Background ..................................................................... 92

6.2 Approach ....................................................................... 93

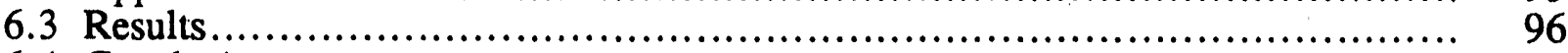

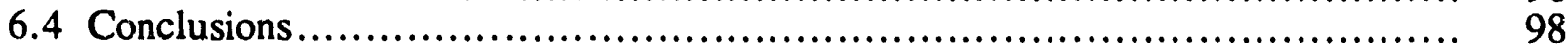

7 MOBILE SOURCE METHODOLOGY ........................................... 100

7.1 Estimating Emissions from On-Highway Sources ............................. 100

7.1 .1 Estimating Highway Activity ................................................... 101

7.1.2 Estimating VMT for the Flash Report........................................... 104

7.1.3 Calculating On-Highway Emission Factors.............................. 104

7.2 Estimating Emissions from Off-Highway Sources....................................... 105

7.2.1 Locomotive Operation.............................................................. 105

7.2.2 Commercial Aviation................................................................... 106

7.2.3 General Aviation................................................................. 106

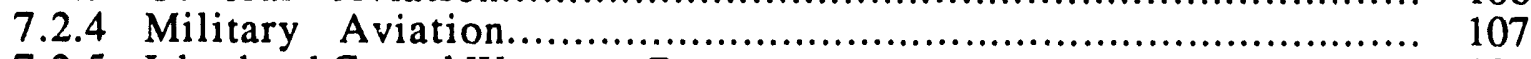

7.2.5 Inland and Coastal Waterway Barges..................................... 107

7.2.6 Great Lakes and Coastwise Steamships and Large Diesel Motorships ......... 107

7.2.7 Miscellaneous Off-Highway Sources.................................... 109

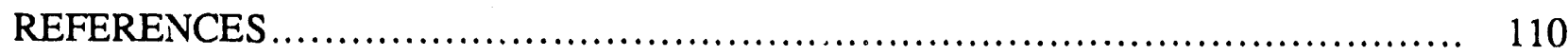

APPENDIX A: Emission Source Groups: Source Codes and Data Sources for Annual Emission Trends, State Shares, Monthly Shares, and

Annual Extender Methodology 


\section{Contents (Cont'd)}

APPENDIX B: $\quad \mathrm{NO}_{\mathrm{X}}, \mathrm{SO}_{2}$, and VOC Emissions............................... 151

APPENDIX C: $\quad$ MSCET Copper Smelter Plant-Level $\mathrm{SO}_{2}$ Emissions Inventory .......... 411

\section{Tables}

1.1a Emission Trends for 1975-1988 in Million Metric Tons...................................... 6

1.1b Emission Trends for 1975-1988 in Million Short Tons................................... 7

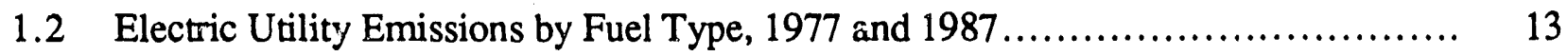

2.1 National $\mathrm{NO}_{\mathbf{x}}$ Emissions for 1978, 1980, 1985, and 1988 ..................... 19

2.2 National SO2 Emissions for 1977, 1980, 1985, and 1988............................ 21

2.3 National VOC Emissions for 1978, 1980, 1985, and 1988.................... 24

3.1 Regional $\mathrm{NO}_{\mathrm{x}}$ Emissions for 1978, 1980, 1985, and 1988.......................... 27

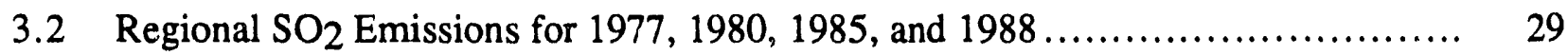

3.3 Regional VOC Emissions for 1978, 1980, 1985, and $1988 \ldots \ldots \ldots \ldots \ldots \ldots \ldots \ldots . \quad 30$

4.1 Fuel Types in EIA Form 759 and This Analysis......................................... 53

4.2 Fuel Types in FERC Form 423 and This Analy is............................. 54

4.3 Fuel Types in EIA Form 767 and This Analysis...................................... 54

4.4 Uncontrolled $\mathrm{SO}_{2}$ Emission Factors for Electric Utility Combustors............... 60

4.5 Uncontrolled $\mathrm{NO}_{\mathrm{x}}$ Emission Factors for Electric Utility Combustors ................ 62

4.6 Percent Reduction in $\mathrm{NO}_{\mathrm{x}}$ Emissions Resulting from the Use of Low-NO $\mathrm{NO}_{\mathrm{X}}$ Burners.............................................. 63

4.7 Uncontrolled VOC Emission Factors for Electric Utility Combustors ................ 64

4.8 National Electric Utility Sector Emissions Assuming Scrubbers Are Operated

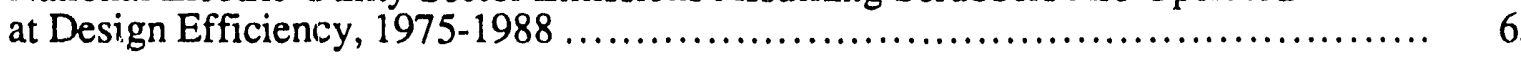

4.9 National Electric Utility Sector Emissions Assuming Scrubbers Are Operated Only to Meet Standards, 1975-1988 


\section{Tables (Cont'd)}

5.1 National Commercial/Institutional and Residential Fuel Combustion

Sector Emissions by Emission Source Group, 1985...................................... 72

5.2 National Industrial Fuel Combustion Sector Emissions

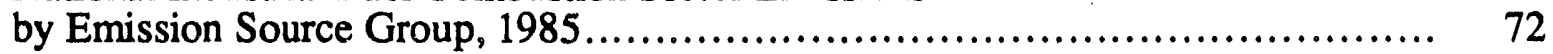

5.3 National Industrial Process Sector Emissions by Emission Source Group, 1985..... 73

5.4 National Miscellaneous Sector Emissions by Emission Source Group, 1985 ........ 74

5.5a National Sectoral Emissions from the 1985 NAPAP Emissions Inventory, MSCET, and EPA Trends Report for 1985 in Thousand Metric Tons ........................

5.5b National Sectoral Emissions from the 1985 NAPAP Emissions Inventory, MSCET, and EPA Trends Report for 1985 in Thousand Short Tons ..........................

5.6 National Industrial Fuel Combustion Sector $\mathrm{SO}_{2}$ Emissions from NAPAP/MSCET and EPA Trends Report....

5.7 1980 Emission Result Matrix for the Percent-Change Method and

Level-Change Method.

5.8 Hypothetical Emission Trend Indicator Values

5.9 Comparison of Emission Trend Estimation Methods

5.10 Industrial Fuel Combustion Emission Trend Indicator Data from the EPA Trends Report

5.11 Comparison of Emission Trend Estimation Techniques for the Industrial Fuel Combustion Sector

6.1 Copper Smelter $\mathrm{SO}_{2}$ Emission Data Sources........................................... 97

6.2 Effect of Reporting Methods on Copper Smelter $\mathrm{SO}_{2}$ Emission Estimates.............. 98

7.1 Seasonal Efficiency Coefficients..................................................... 103

\section{Figures}

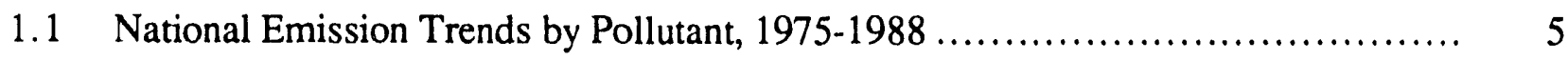

1.2 National $\mathrm{NO}_{\mathrm{x}}$ Emission Trend Showing Sectoral Contribution, 1975-1988............ 8

1.3 National $\mathrm{NO}_{\mathrm{x}}$ Emission Trend Showing Seasonal Variation, 1975-1988............ 8

1.4 National $\mathrm{SO}_{2}$ Emission Trend Showing Sectoral Contribution, 1975-1988 ........... 9 


\section{Figures (Cont'd)}

1.5 National $\mathrm{SO}_{2}$ Emission Trend Showing Seasonal Variation, 1975-1988 ........... 10

1.6 National VOC Emission Trend Showing Sectoral Contribution, 1975-1988 ......... 11

1.7 National VOC Emission Trend Showing Seasonal Variation, 1975-1988............... 12

1.8 National Electric Utility $\mathrm{NO}_{\mathrm{x}}$ and. $\mathrm{SO}_{2}$ Emission Trends, $1975-1988 \ldots \ldots \ldots \ldots \ldots \ldots .12$

1.9 National Electric Utility Energy Consumption, $1975-1988 \ldots \ldots \ldots \ldots \ldots \ldots \ldots \ldots \ldots$

1.10 National Electric Utility Coal Consumption and Related Emissions, 1975-1988...... 14

1.11 National Electric Utility $\mathrm{NO}_{\mathrm{x}}$ Emissions by Month and Annual Average, $1975-1988$

1.12 Average Sulfur Content of Fueis Consumed at Electric Utilities, 1975-1988_..... 16

1,13 Installed Capacity Equipped with Flue-Gas Desulfurization Units, 1975-1987 ...... 16

1.14 National Electric Utility $\mathrm{SO}_{2}$ Emissions by Month and Annual Average, 1975-1988.

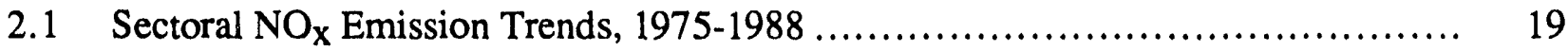

2.2 Sectoral $\mathrm{NO}_{\mathrm{x}}$ Emission Trends Showing Seasonal Variations, 1975-1988.......... 20

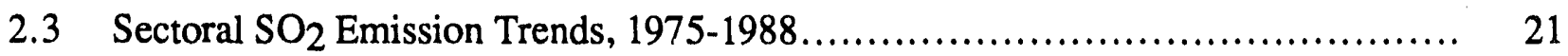

2.4 Sectoral $\mathrm{SO}_{2}$ Emission Trends Showing Seasonal Variations, 1975-1988 .......... 22

2.5 Sectoral VOC Emission Trends, 1975-1988 ..................................... 23

2.6 Sectoral VOC Emission Seasonal Trends Showing Seasonal Variations,

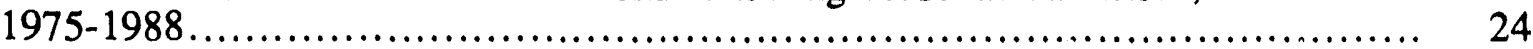

3.1 Regions Used in This Study ........................................... 26

3.2 Regional $\mathrm{NO}_{\mathrm{x}}$ Emission Trends, 1975-1988 ................................... 27

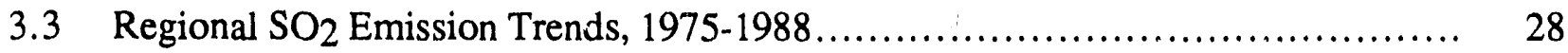

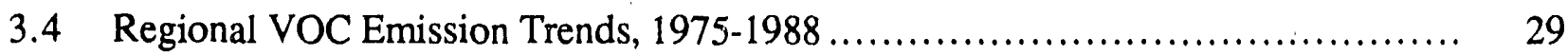

3.5 Northeast Emission Trends by Pollutant, 1975-1988............................ 31

3.6 Northeast Sectoral $\mathrm{NO}_{\mathrm{x}}$ Emission Trends, 1975-1988 ......................... 31

3.7 Northeast Sectoral $\mathrm{NO}_{\mathrm{x}}$ Emission Trends Showing Seasonal Variations, 1975-1988. 


\section{Figures (Cont'd)}

3.8 Northeast Sectoral $\mathrm{SO}_{2}$ Emission Trends, 1975-1988................................. 32

3.9 Northeast Sectoral $\mathrm{SO}_{2}$ Emission Trends Showing Seasonal Variations,

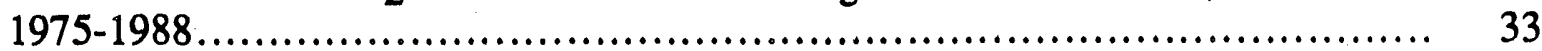

3.10 Nnrtheast Sectoral VOC Emission Trends, 1975-1988_.......................... 34

3.11 Northeast Sectoral VOC Emission Trends Showing Seasonal Variations, 1975-1988.

3.12 Southeast Emission Trends by Pollutant, $1975-1988 \ldots \ldots \ldots \ldots \ldots \ldots \ldots \ldots \ldots \ldots \ldots . \ldots \ldots$

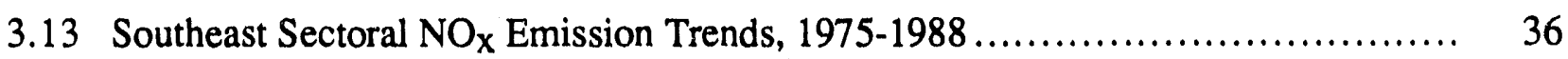

3.14 Southeast Sectoral $\mathrm{NO}_{\mathrm{x}}$ Emission Trends Showing Seasonal Variations, 1975-1988.

3.15 Southeast Sectoral $\mathrm{SO}_{2}$ Emission Trends, 1975-1988................................ 37

3.16 Southeast Sectoral $\mathrm{SO}_{2}$ Emission Trends Showing Seasonal Variations, $1975-1988$.

3.17 Southeast Sectoral VOC Emission Trends, 1975-1988

3.18 Southeast Sectoral VOC Emission Trends Showing Seasonal Variations, 1975-1988.

3.19 West Emission Trends by Pollutant, 1975-1988 ................................. 40

3.20 West Sectoral $\mathrm{NO}_{\mathbf{x}}$ Emission Trends, 1975-1988...................................... 40

3.21 West Sectoral $\mathrm{NO}_{\mathrm{x}}$ Emission Trends Showing Seasonal Variations, 1975-1988.

3.22 West Sectoral $\mathrm{SO}_{2}$ Emission Trends, 1975-1988.

3.23 West Sectoral $\mathrm{SO}_{2}$ Emission Trends Showing Seasonal Variations, 1975-1988

3.24 We it Sectoral VOC Emission Trends, 1975-1988 .................................. 43

3.25 West Sectoral VOC Emission Trends Showing Seasonal Variations,

4.1 Average Sulfur Content of Fuels Consumed at Electric Utilities, 1975-1988......... 46

4.2 Electric Utility Fossil Fuel Consumption by Type, 1975-1988................... 47

4.3 Installed Capacity Equipped with Flue-Gas Desulfurization Units, 1975-1987 ....... 48 


\section{Figures (Cont'd)}

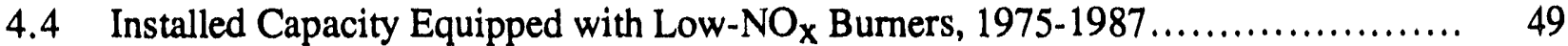

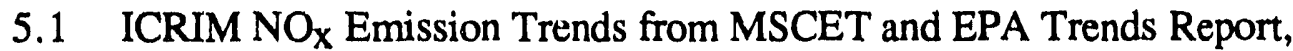
$1975-1987$

5.2 ICRIM SO 2 Emission Trends from MSCET and EPA Trends Report, $1975-1987$

5.3 ICRIM VOC Emission 'Trends from NISCET and EPA Trends Report, $1975-1987$

6.1 Comparison of $\mathrm{SO}_{2}$ Emissions from Copper Smelters with Those from the Total Industrial Process Sector in Region 9, 1980

6.2 Region 9 Industrial Process Sector $\mathrm{SO}_{2}$ Emission Trend, 1975-1986. 


\section{Foreword}

This report presents estimates of monthly sulfur dioxide $\left(\mathrm{SO}_{2}\right)$, nitrogen oxides $\left(\mathrm{NO}_{\mathrm{x}}\right)$, and nonmethane volatile organic compound (VOC) emissions by sector, region, and state in the contiguous United States for the years 1975 through 1988. This work has been funded as part of the National Acid Precipitation Assessment Program's Emissions and Controls Task Group by the U.S. Department of Energy (DOE) Office of Fossil Energy (FE). The DOE project officer is Edward C. Trexler, DOE/FE Office of Planning and Environment.

This report, the fourth in a series of reports that have examined emission trends by month and state, replaces the earlier three. The first report, Estimated Monthly Emissions of Sulfur Dioxide and Oxides of Nitrogen for the 48 Contiguous States, 1975-1984, Argonne National Laboratory report ANL/EES-TM-318 (1986), described a methodology developed by ANL to estimate seasonal $\mathrm{NO}_{\mathrm{x}}$ and $\mathrm{SO}_{2}$ trends. The second report, Estimated Monthly Emissions of Sulfur Dioxide, Oxides of Nitrogen, and Volatile Crganic Compounds for the 48 Contiguous States, 1985-1986, Argonne report ANL/EES-TM-335 (1987), described how the methodology was expanded to include VOC emissions and included estimates of seasonal VOC emission trends. The third, Estimated Monthly Emissions of Sulfur Dioxide, Oxides of Nitrogen, and Volatile Organic Compounds for the 48 Contiguous States, 1987, Argonne report ANL/EES-TM-362 (1988), presented monthly estimates by sector, region, and state for 1987 and highlighted recent trends. This fourth report describes the updated methodology now used in the Month and State Current Emission Trends (MSCET) program to estimate $\mathrm{NO}_{\mathrm{x}}, \mathrm{SO}_{2}$, and VOC emission trends from 1975 through 1988 by month and state. Appendix A contains specific data used in the methodology. Appendix B provides emission estimates. Estimates aggregated by month and state can be found in Secs. B.1-B.3. Emissions data aggregated by geographic region (Northeast, Southeast, and West) and season are provided in Secs. B.4-B.6. Emissions data aggregated by the 10 federal regions and season are provided in Secs. B.7-B.9. Cross-sectional annual emissions data from 1975-1988 can be found in Sec. B.10. Appendix C contains the MSCET copper smelter $\mathrm{SO}_{2}$ plant-level emissions inventory.

The MSCET system underwent a third-party review by Resource Dynamics Corporation (RDC) during the last quarter of 1989. The review covered the methodology presented in this report and the preliminary emissions data. RDC published its findings in a report titled Review of the Month and State Emissions Trends (MSCET) Data Bases for the National Acid Precipitation Assessment Program (1990). In addition, RDC conducted a review workshop from February 28 through March 2, 1990, in Washington, D.C. Comments and suggestions made in the third-party review and the workshop are incorporated in the methodology described and data provided in this report. 


\section{Acknowledgments}

The authors would like to thank Edward Trexler and Denise Swink, DOE Office of Fossil Energy, for their assistance and support. We would also like to thank Ted Williams (DOE, Office of Environmental Analysis) for his comments and encouragement; John L. Malanchuk, Depuly Director of NAPAP, for the interest that he has shown in the project; Jeffrey Price (President, Rescurce Dynamics Corp.), for his thorough review of the MSCET system; arid Janice Wagner and Tom Rosendahl (U.S. Environmental Protection Agency) and Gerhard Gschwandtner (E.H. Pechan and Associates) for their in-depth review of the MSCET methodology and their detailed comments.

As is the case for any large project, many people contributed their time and effort. The authors would like to thank the following Argonne National Laboratory staff members: David Streets, Marylynn Placet, and Gilbert Bassett, for their valuable comments and suggestions; Judy Anderson, Stella Cheung, Chuck Cilek, Kelly Hughes, and Wes Maciorowski for their programming and computer-related support; Anita Jandula and Diane Cockburn for their secretarial skills; Marita Moniger and John Cleland, for their editorial assistance; and Judith Robson and Barbara Salbego, for their word processing expertise. 


\title{
Current Emission Trends for Nitrogen Oxides, Sulfur Dioxide, and Volatile Organic Compounds by Month and State: Methodology and Results
}

\author{
by \\ E.J. Kohout, D.J. Miller, L. Nieves, D.S. Rothman, \\ C.L. Saricks, F. Stodolsky, and D.A. Hanson
}

\section{Introduction}

\subsection{Month and State Current Emission Trends (MSCET) Program}

\subsubsection{Description}

Available data on national emission trends may not be representative of regional or state trends. And when only annual data are available, information about seasonal emission patterns may become lost or ignored. Therefore, the Month and State Current Emission Trends (MSCET) system was developed to meet the data needs of researchers and policy analysts interested in examining regional and seasonal trends of emissions of oxides of nitrogen $\left(\mathrm{NO}_{\mathrm{x}}\right)$, sulfur dioxide $\left(\mathrm{SO}_{2}\right)$, and nonmethane volatile organic compounds (VOC). The MSCET program provides data on monthly trends of $\mathrm{NO}_{\mathrm{x}}, \mathrm{SO}_{2}$, and VOC emissions at the state level for 68 emission source categories. Emission estimates are made from 1975 onward, and they are updated annually.

The MSCET system was designed to be quick and flexible. It can calculate preliminary emission estimates within a few weeks after the necessary data are obtained, such as those used for "flash" reports, and it can be used to prepare updates for portions of a current year for special policy studies. For example, when U.S. President Bush went to Canada in February 1989, MSCET was used to prepare estimates of emissions from electric utility plants in the northeastern United States for the first 10 months of 1988 (which was the extent of the data available at that time). This information was compared with that from the same period in earlier years to analyze recent emission trends in the region. Thus, the MSCET system was able to quickly provide region-specific and sector-specific emissions data for a fraction of the year.

The state-level data in MSCET enable researchers to analyze emission trends for regions smaller than the nation. One example of such an analysis was a regional study of the correlation between acid emissions and deposition (see Butler and Likens 1990). Another example would be an analysis of the regional impacts of federal air emission regulations. 
Many pollution-generating activities have seasonal cycles, so the emissions related to these activities show seasonal variation components. Because the data in MSCET are provided by month, researchers do not have to use arbitrary assumptions about seasonal emission trends. They can use MSCET monthly data to examine the seasonal impact of emissions on acidic deposition, ambient air quality, and other phenomena.

For researchers interested in conducting a cross-sectional analysis of emission trends, MSCET can provide industry-specific data at both regional (state) and national levels. An example would be a study of energy efficiency improvements and conservation by industry or sector. Researchers could use the data in MSCET for determining the relative emissions in each sector and hence could examine the environmental benefits of energy-use reductions.

\subsubsection{Recent Enhancements}

In 1989, the MSCET methodology was updated to incorporate the recently released 1985 National Acid Precipitation Assessment Program (NAPAP) Emissions Inventory into its data base (EPA 1989a). In addition, changes to improve the methodology that were proposed in earlier Argonne National Laboratory (ANL) reports were made (see Kohout et al. 1987). For example, the system now contains a module that uses state-level activity data to shift state emission shares from base-year (1985) values (nonutility state shares were previously assumed to remain constant). At present, $93 \%$ of $\mathrm{NO}_{\mathrm{x}}, 89 \%$ of $\mathrm{SO}_{2}$, and $47 \%$ of VOC emissions are calculated with nonconstant state shares. Other enhancements include these:

- U.S. Department of Energy (DOE) Form 767 data were incorporated into the electric utility methodology to enable MSCET to estimate emissions at the individual boile- level.

- The transportation emission factor model was updated from MOBILE3.9 to MOBILE4.0.

- A plant-level copper smelter $\mathrm{SO}_{2}$ emissions inventory was developed from data supplied by either the plants or the state air-pollution-control agencies.

- An improved "flash" emission estimation algorithm, to more accurately estimate emissions in the latest inventory year, was developed.

This report documents these and other methodology enhancements and discusses the MSCET emission trends.

Although a great deal of care and attention was taken in developing the system and emissions data base, a significant level of uncertainty still remains with respect to MSCET emission estimates, and presumably this uncertainty is greater in the more disaggregated estimates. Researchers who have worked in the area of air-pollution emission estimation for any length of time are acutely aware of the difficulty in obtaining high-quality data. The MSCET system is intended to provide initial estimates of state and seasonal emission trends for sources and regions 
for which, in many cases, no other estimates exist. The MSCET estimates have heen computed in a consistent manner across geographic regions and over the time period covered by the data base, so meaningful comparisons may be made across regions and over time. However, in many cases, other emission estimates exist, and these alternative estimates may, in fact, be more accurate for a particular locale or emission source. Therefore, the MSCET estimates should be used with appropriate caution and an awareness of the uncertainty inherent in particular estimates. For example, it is not recommended that MSCET estimates of VOC emissions be used in state regulatory analyses.

\subsubsection{Estimation Methodology}

Emissions arise from numerous sources. To deal with them effectively and efficiently yet still obtain an adequate level of detail, one must classify the emission sources into a reasonable number of categories. Other emissions data bases, such as the U.S. Environmental Protection Agency (EPA) National Emissions Data System (NEDS) and the NAPAP emission inventories, employ hundreds of distinct emission source categories, each identified by an eight-digit source classification code (SCC). MSCET uses the data in the NAPAP emission inventories. However, since developing a time series for each of the several hundred NAPAP SCCs was beyond the resources of this project, related SCCs were grouped together into 68 categories, referred to as emission source groups (ESGs). This degree of sectoral aggregation was considered optimal for increasing the accuracy of the emission estimates, yet the sources remained disaggregated enough so that data for many important sources were still maintained separately.

The 68 ESGs covered by MSCET can be categorized under six broad sectors:

1. Commercial and residential fuel combustion,

2. Electric utilities,

3. Industrial fuel combustion,

4. Industrial processes,

5. Miscellaneous, and

6. Transportation.

Separate MSCET methodologies were developed for the electric utility sector and transportation sector because of their relative size and importance in influencing emission trends. For similar reasons, a separate methodology was also developed for the copper smelting industry (within the industrial process sector). The remaining sectors (industrial fuel combustion, commercial/residential fuel combustion, industrial processes, and miscellaneous sources, collectively referred to as the ICRIM sectors) are covered by a common methodology based on the 1985 NAPAP Emissions Inventory (EPA 1989a). 
The electric utility methodology was developed on the basis of the "emission factor" method. Monthly fuel-consumption data are combined with fuel-quality data and an emission factor to calculate uncontrolled emissions. If a utility plant has pollution control devices (flue-gas desulfurization units [FGDs]), the amount of pollution removed is calculated and a final emission estimate is computed. Recent improvements in this methodolozy allowed MSCET to calculate emissions at the boiler level from 1985 to 1988 and to use boiler-specific design parameters and fuel consumption patterns in other years. The electric utility methodology is described in detail in Sec. 4.

Emissions from the ICRIM sectors represent numerous and diverse processes. Sometimes these sources individually have emissions too low to justify the effort to estimate emissions trends separately, and sufficient data to do so are frequently lacking. A "shift-share" methodology based on the state-level emissions data in the 1985 NAPAP Emissions Inventory was developed to estimate ICRIM emissions. This 1985 inventory was chosen because it represents the most comprehensive effort to date of estimating the emission levels for $\mathrm{NO}_{\mathbf{x}}, \mathrm{SO}_{2}$, and $\mathrm{VOC}$ from the hundreds of emission sources throughout the country. In addition, it is the only data base that provides emissions data at the level of detail needed for the MSCET program. The 1985 NAPAP Emissions Inventory provides base-year emission estimates by state for the MSCET ESGs. Then, trends are created from the base-year values using ESG-specific growth rates. These growth rates are often derived from National Air Pollutant Emission Estimates, 1940-1987 (EPA 1989c), which is called the EPA Trends Report in this report. However, in many cases, they are also derived from industrial production indexes, fuel consumption data, or other economic activity variables. This methodology, referred to as the ICRIM methodology, is described in detail in Sec. 5.

The copper smelter methodology uses emission estimates provided by the states, which were computed using a plant-level sulfur mass balance technique. In this technique, the amount of sulfur entering the plant via the copper ore and the amount leaving the plant (after control devices have been employed) are estimated. The difference is assumed to be equal to the fugitive or uncontrolled emissions, which are assumed to have been converted to $\mathrm{SO}_{2}$. The $\mathrm{NO}_{x}$ and VOC emissions from this industry are insignificant, so they are estimated using the ICRIM methodology described above. The copper smelter methodology for $\mathrm{SO}_{2}$ emissions is presented in Sec. 6 .

The transportation methodology was also developed on the basis of the emission factor method and uses separate algorithms to estimate on-highway and off-highway emissions. On-highway emissions are calculated from vehicle-miles-traveled (VMT) data and emission factors from the EPA's MOBILE4 model (EPA 1989b). Off-highway emissions are calculated from fuelconsumption and/or activity data (e.g., landing and take-off cycles for aircraft) and emission factors from EPA's AP-42 report (EPA 1985). The estimation of transportation emissions uses the TEEMS methodology (Saricks 1985) and is reviewed in Sec. 7. This TEEMS methodology has been reviewed by Cambridge Systematics, Inc. (CSI 1988).

\subsection{National Emission Trends, 1975-1988}

Figure 1.1 presents MSCET national $\mathrm{NO}_{\mathrm{x}}, \mathrm{SO}_{2}$, and VOC emission trends for 1975 to 1988. The plot shows that from the late 1970 s to the early 1980 s, emission levels of all three 
pollutants declined. Since about 1982, however, the trends showed both increases and decreases, and only VOC emissions showed a decline between 1982 and 1988 . National emission trend estimates by sector are presented for each pollutant in Table 1.1a. Throughout this report, the emissions data are presented in terms of metric tons, but for the convenience of the reader, this table is also presented in terms of short tons (Table 1.1b).

\subsubsection{Nitrogen Oxides}

Figure 1.2 presents national $\mathrm{NO}_{\mathrm{x}}$ emissions by sector. After reaching a peak of 21.1 million metric tons or megatons $(\mathrm{Mt})$ in $1978, \mathrm{NO}_{\mathbf{x}}$ emissions fell at an average annual rate of $2.1 \%$ to $17.9 \mathrm{Mt}$ in 1986 . Then $\mathrm{NO}_{\mathrm{X}}$ emissions increased slightly, reaching $18.2 \mathrm{Mt}$ in 1988. Declines in emissions from the transportation and industrial fuel combustion sectors caused much of the reduction, but increasing emissions from electric utilities somewhat offset the declining trend. Transportation, electric utility, and industrial fuel combustion were the predominant $\mathrm{NO}_{\mathrm{X}}$ emitting sectors and together accounted for $92 \%$ of nationil $\mathrm{NO}_{\mathrm{X}}$ emissions in 1985.

Figure 1.3 presents the seasonal profile for $\mathrm{NU}_{\mathrm{X}}$, which is moderately smooth due to counter-cyclical patterns at the sectoral level. Increased travel activity and higher emission factors caused a strong summer maximum to occur in emissions from the transportation sector, and

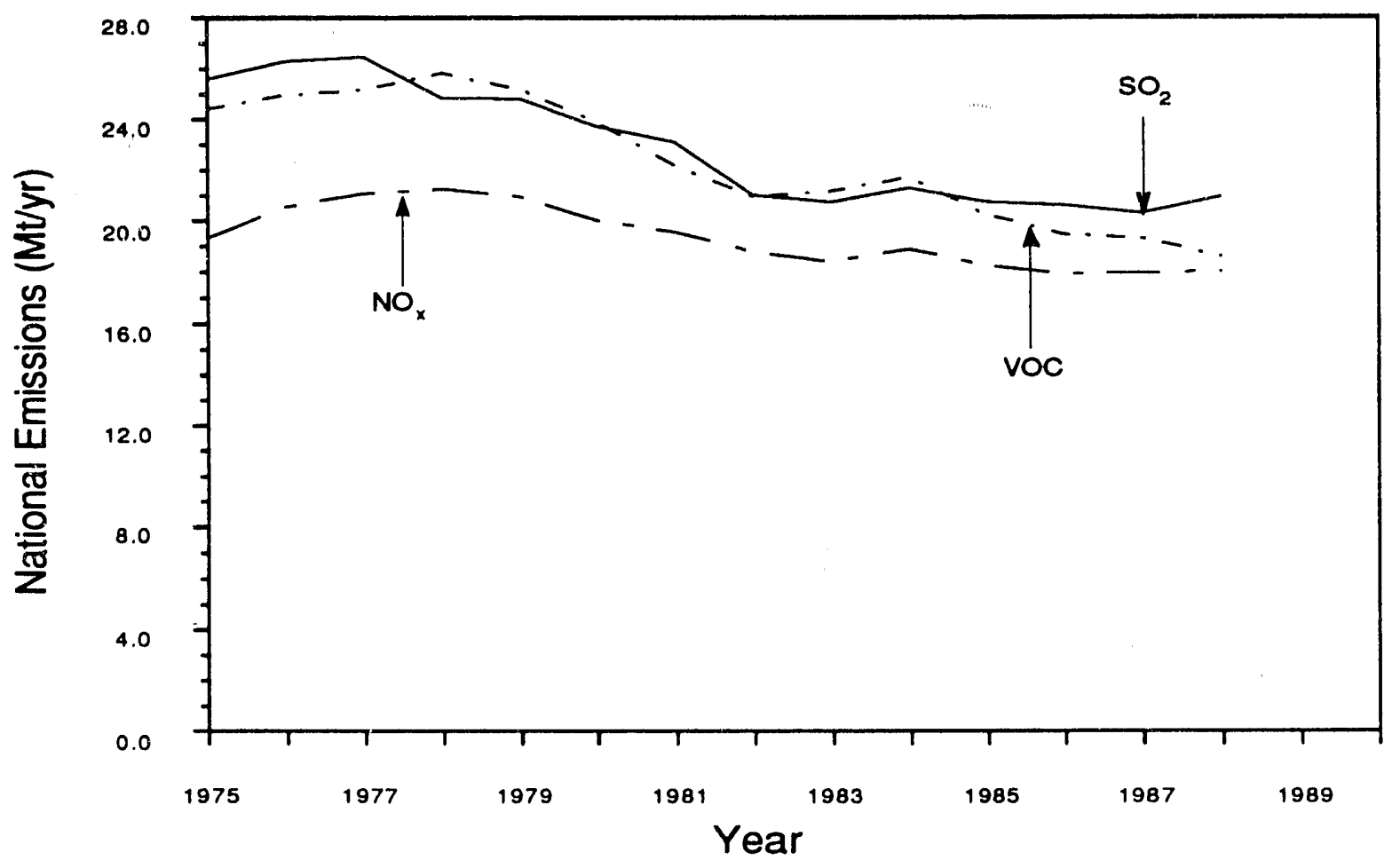

FIGURE 1.1 National Emission Trends by Pollutant, 1975-1988 


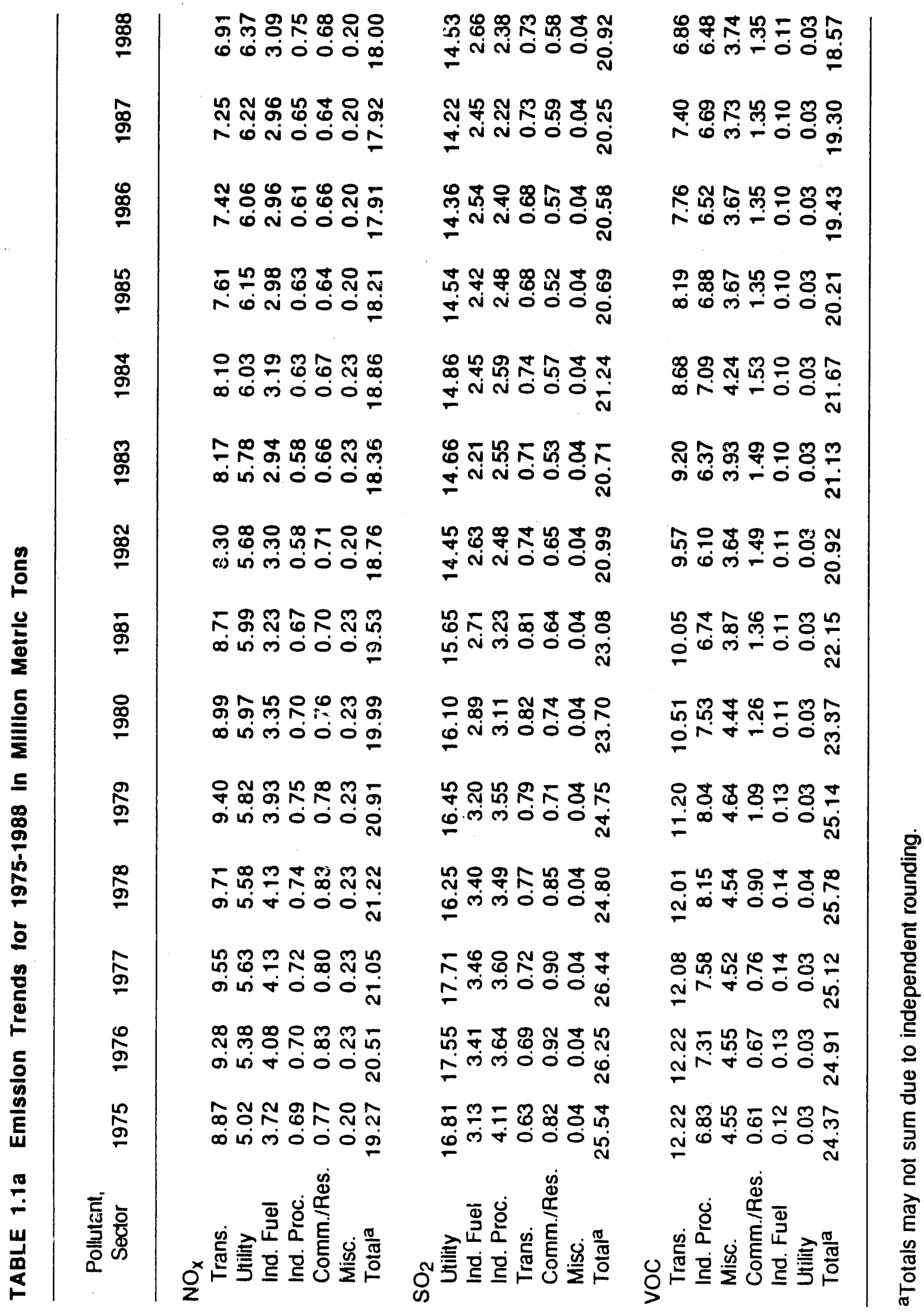




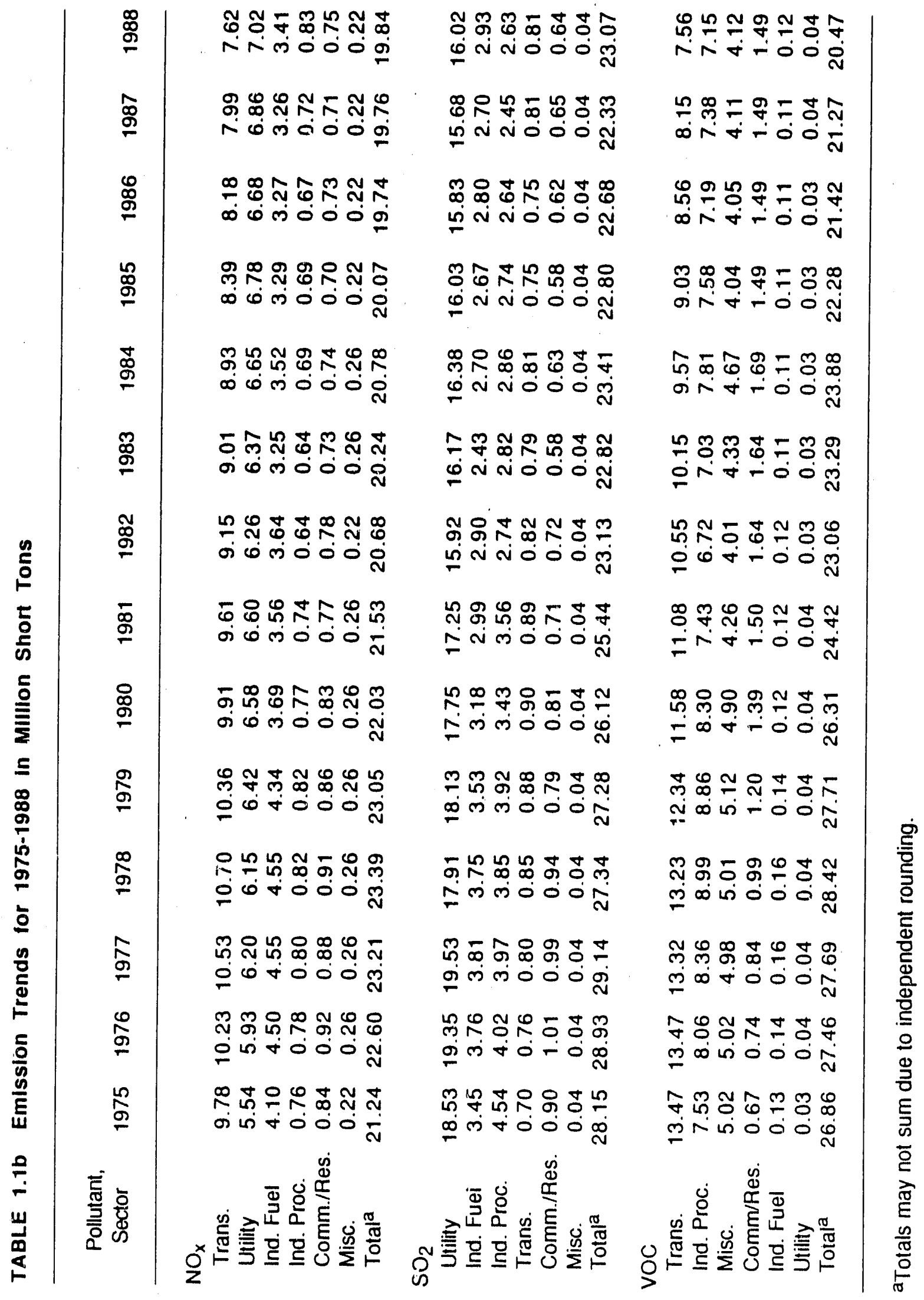




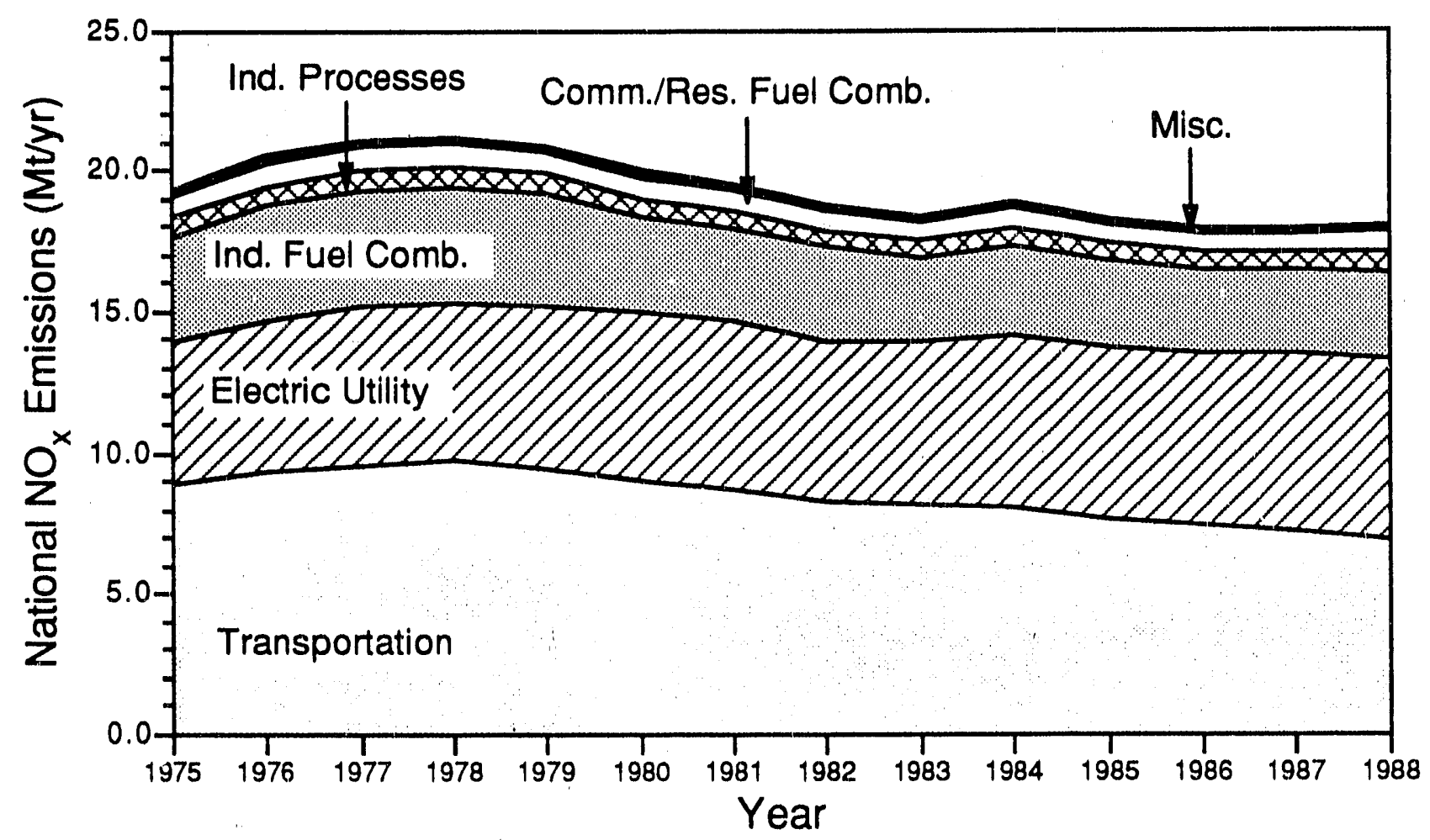

FIGURE 1.2 National NO Emission Trend Showing Sectoral Contribution, 1975-1988

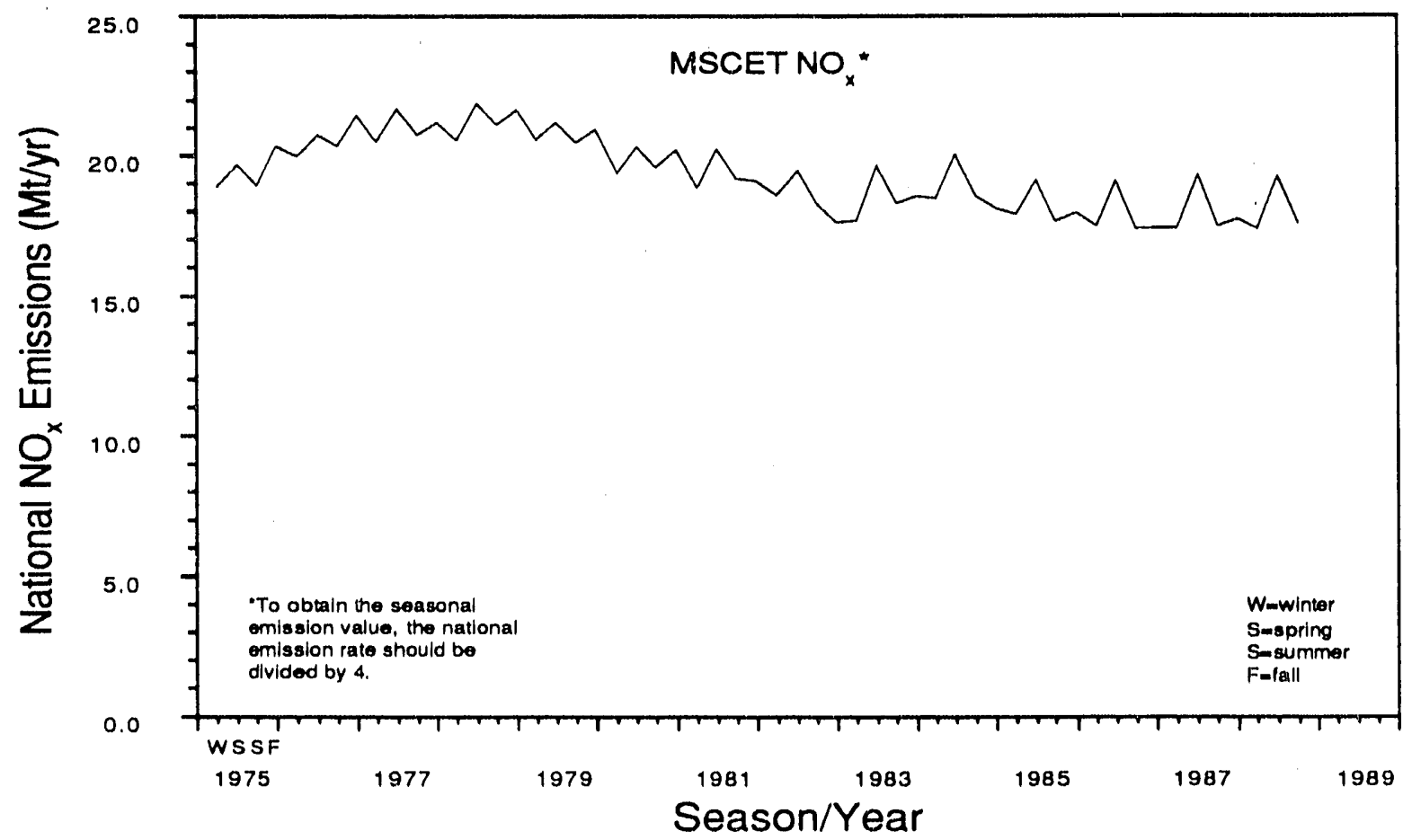

FIGURE 1.3 National NO Emission Trend Showing Stasonal Variation, 1975-1988 
increased fuel consumption for space heating caused a strong winter maximum to occur in commercial/residential fuel combustion emissions. The net effect for the national total was mixed in the early part of the series, but after about 1982 , the maximum $\mathrm{NO}_{\mathrm{x}}$ emission ${ }_{\mathrm{s}} \mathrm{vel}$ occurred in summer.

\subsubsection{Sulfur Dioxide}

Figure 1.4 shows national $\mathrm{SO}_{2}$ emission trends by sector. These emissions reached their post-1975 peak level in 1977 at $26.4 \mathrm{Mt}$ and then fell to a low of $20.3 \mathrm{Mt}$ in 1987. This decline represents an average annual reduction of $2.6 \%$. However, MSCET estimates that $\mathrm{SO}_{2}$ emissions totaled $20.9 \mathrm{Mt}$ in 1988, an increase of 3.3\% over the previous year. This ircrease was caused primarily by increased emissions in the electric utility sector, which emits slightly more than twothirds of national $\mathrm{SO}_{2}$ emissions and strongly influences emission trends. In 1988, electric utility emissions were high because of the hot summer. Growth in the industrial fuel combustion and industrial process sectors also contributed to the 1988 gain. Before $1988, \mathrm{SO}_{2}$ emission levels in all sectors $\mathrm{h}$,d either remained steady or fallen since the late 1970s. The electric utility sector emits the largest share of emissions; it alone was responsible for $71 \%$ of the nation's $\mathrm{SO}_{2}$ emissions in 1985. The three largest emitting sectors -- electric utilities, industrial processes, and industrial fuel combustion -- accounted for 94\% of the nation's total emissions in 1985.

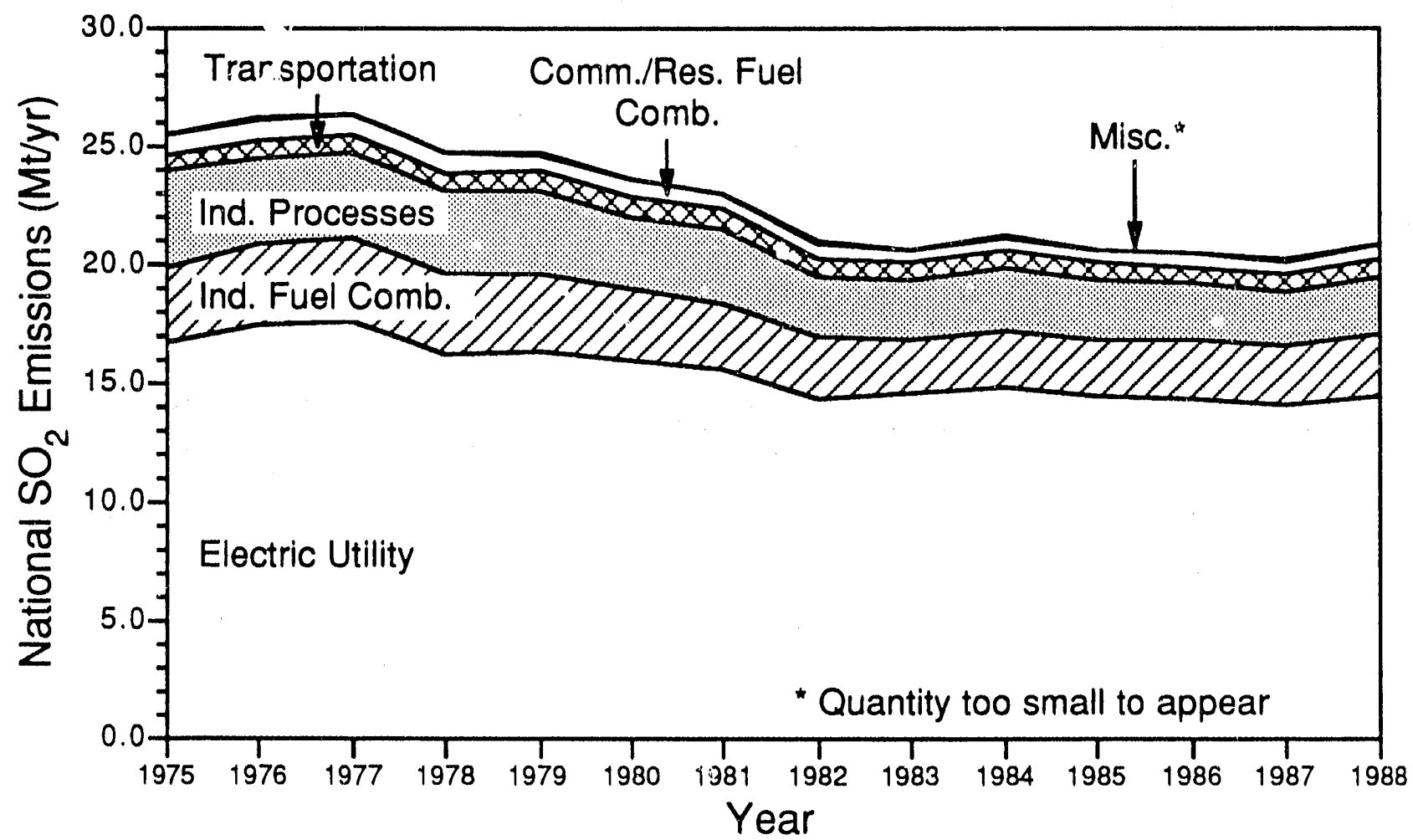

Figure 1.4 National $\mathrm{SO}_{2}$ Emission Trend Showing Sectoral Contribution, 1975-1988 
Figure 1.5 presents the seasonal profile for $\mathrm{SO}_{2}$ emissions. The seasonal trend component of total $\mathrm{SO}_{2}$ is driven by seasonal trends in the electric utility sector and, to a lesser degree, in the commercial/residential fuel combustion sector. The seasonal emission pattern for the late 1970s and early 1980s exhibited a winter maximum, but this dampened somewhat in the mid 1980s, when summer and winter emission rates were about equal.

\subsubsection{Volatile Organic Compounds}

Figure 1.6 shows national VOC emission trends by sector. Emissions of VOC reached a post-1975 peak in 1978 at $25.8 \mathrm{Mt}$ and then fell to a low of an estimated $18.6 \mathrm{Mt}$ in 1988. This decline represents an average annual reduction of $3.2 \%$. It was caused primarily by a $5-\mathrm{Mt}$ decrease in emissions from the transportation sector between 1978 and 1988. The sectoral share for transportation, which is the sector that emits the most VOC, fell from $50 \%$ in 1975 to $37 \%$ in 1988. Emissions from the industrial process and miscellaneous sectors dropped from 1978 levels, although moderate increases in 1983 and 1984 caused the national total for VOC emissions to rise in these years. Emissions of VOC from the commercial/residential fuel combustion sector rose in the late 1970s and early 1980s because of increased wood burning activity. The three largest VOC-emitting sectors -- transportation, industrial processes, and miscellaneous sectors -- emitted 93\% of the nation's VOC in 1985.

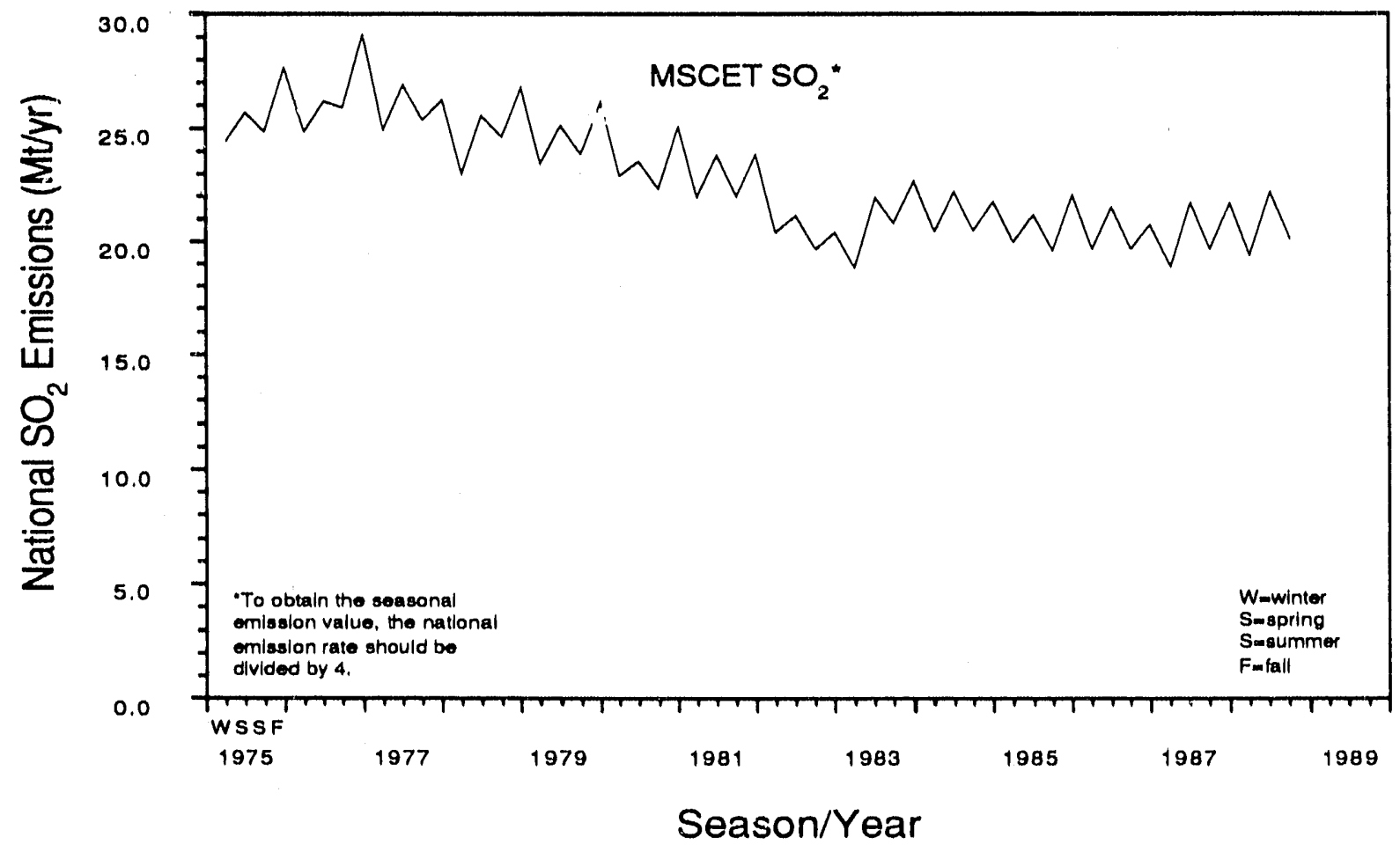

FIGURE 1.5 National $\mathrm{SO}_{2}$ Emission Trend Showing Seasonal Variation, 1975-1988 


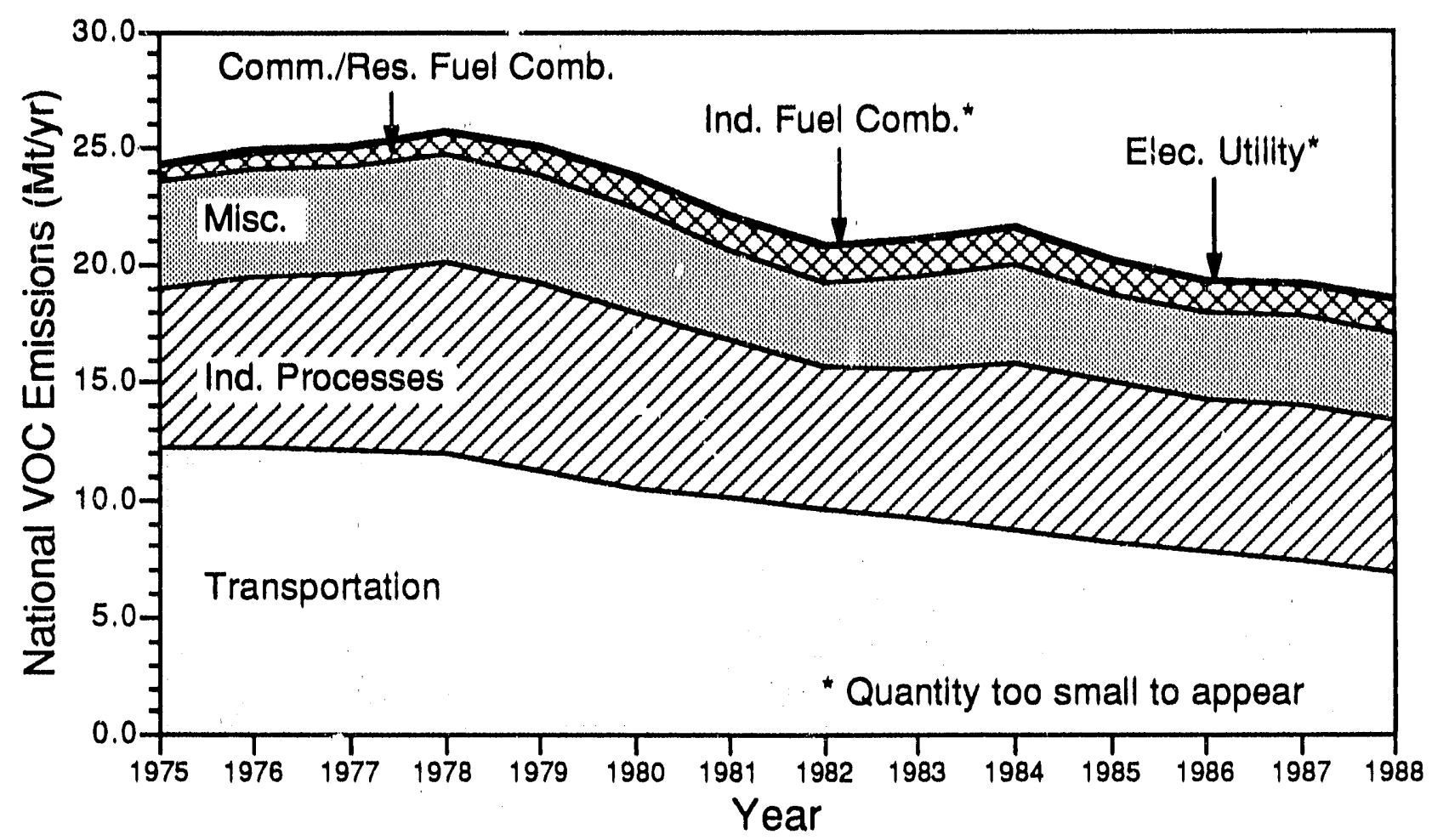

Figure 1.6 National VOC Emission Trend Showing Sectoral Contribution, 1975-1988

The seasonal series for VOC emissions presented in Figure 1.7 exhibits strong seasonality. This is caused oy trends in the transportation sector, which has its maximum emission level in summer. The difference between the summer high and the winter low was greater in the early years of the time period, because VOC emissions from the commercial/residential fuel combustion sector, which has a winter maximum, increased in the later years.

\subsection{Electric Utility Sector Emissions}

The electric utility sector generates about $30 \%$ of national $\mathrm{NO}_{\mathrm{x}}$ emissions and about $70 \%$ of $\mathrm{SO}_{2}$ emissions. Electric utilities are large point sources that are required by federal law to report a considerable amount of information about their operations. Because this sector emits such large amounts of two major acid rain precursors and because the data from this sector are so widely available, interest in this sector is great.

Figure 1.8 shows electric utility $\mathrm{NO}_{\mathrm{x}}$ and $\mathrm{SO}_{2}$ emission trends. (VOC ernissions from electric utilities are relatively low.) Electric utility $\mathrm{SO}_{2}$ emission levels are two to three times greater than $\mathrm{NO}_{\mathrm{x}}$ levels. Emissions of both pollutants result from the combustion of fossil fuels. during the electricity generation process. 


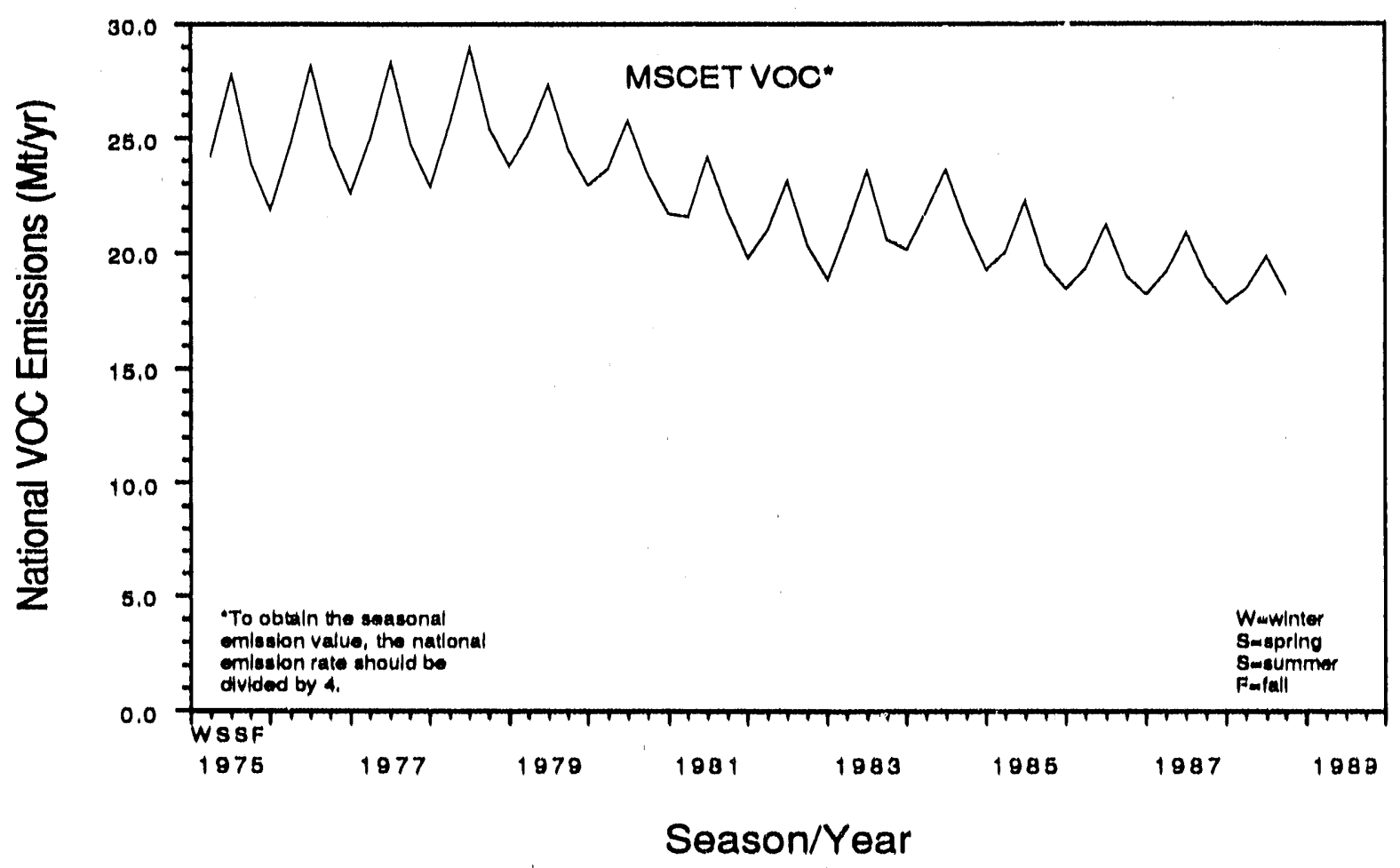

FIGURE 1.7 National VOC Emission Trend Showing Seasonal Varlation, 1975-1988

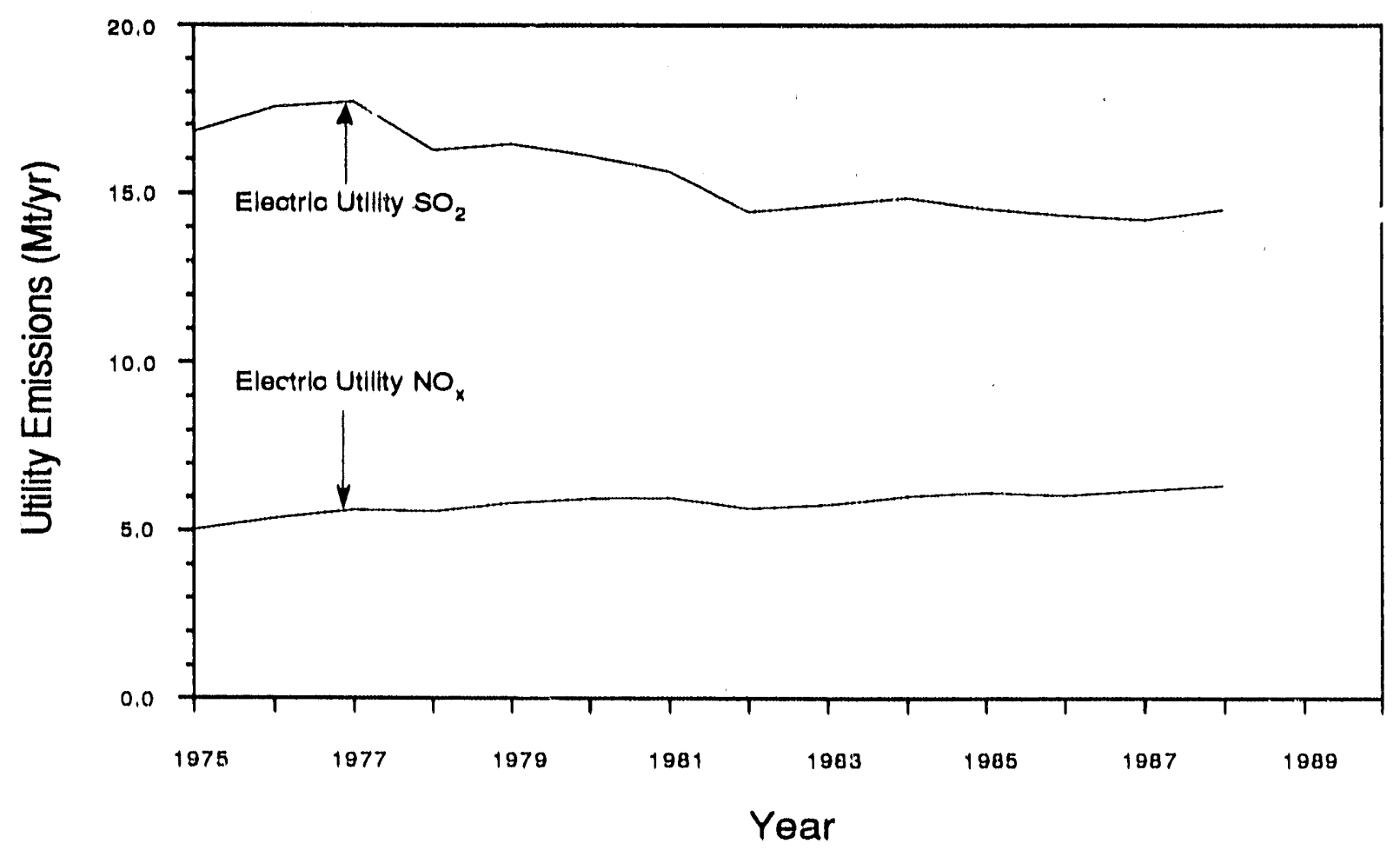

FIGURE 1.8 National Electrio Utility $\mathrm{NO}_{x}$ and $\mathrm{SO}_{2}$ Emission Trends, 1975-1988 
Figure 1.9 illustrates trends in electric utility fossil fuel combustion. Coal was the predominant fuel burned, and coal consumption steadily increased while oil consumption decreased. Table 1.2, which provides data in thousand metric tons or kilotons (kt) on electric utility $\mathrm{NO}_{\mathrm{x}}$ and $\mathrm{SO}_{2}$ emissions by fuel type, shows that a large share of emissions resulted from coal combustion. In $1977,75 \%$ of electric utility $\mathrm{NO}_{\mathrm{x}}$ and $91 \%$ of $\mathrm{SO}_{2}$ emissions were a result of coal combustion. In 1987, these figures rose to $88 \%$ and $96 \%$, respectively. Figure 1.10 shows, however, that $\mathrm{SO}_{2}$ emissions from utility coal combustion declined despite an increase in coal consumption (measured in $\mathrm{Btu}$ ) and that $\mathrm{NO}_{\mathbf{x}}$ emissions increased at a slower rate than coal consumption. Reasons for these results are discussed below.

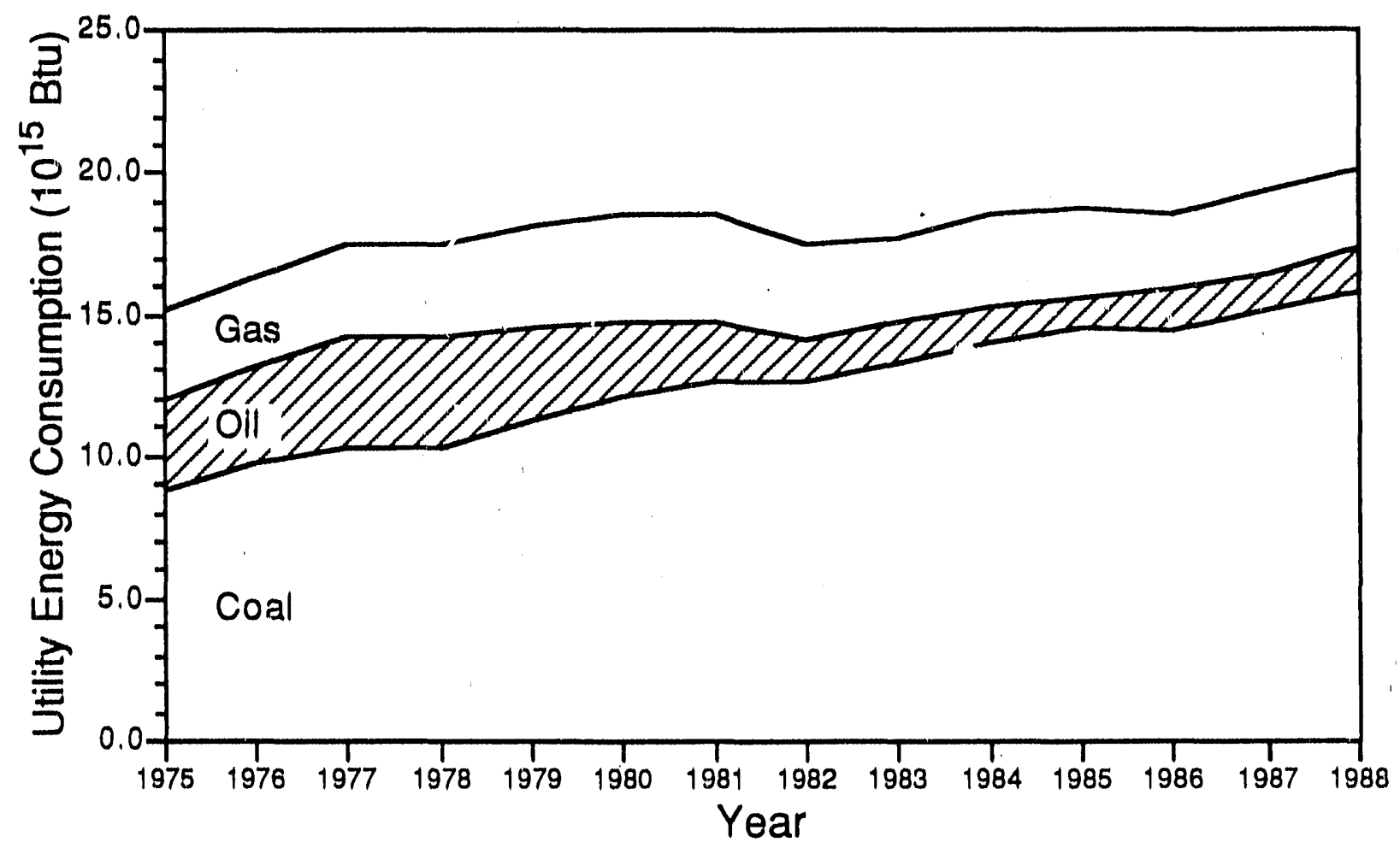

FIGURE 1.9 National Electric Utility Energy Consumption, 1975-1988

Table 1.2 Electric Utility Emisslons by Fuel Type, 1977 and 1987 (kt)

\begin{tabular}{|c|c|c|c|c|}
\hline Fuel Type & $\begin{array}{l}1977 \\
\mathrm{NO}_{\mathrm{x}}\end{array}$ & $\begin{array}{l}1987 \\
\mathrm{NO}_{x}\end{array}$ & $\begin{array}{l}1977 \\
\mathrm{SO}_{2}\end{array}$ & $\begin{array}{l}1987 \\
\mathrm{SO}_{2}\end{array}$ \\
\hline $\begin{array}{l}\text { Bituminous coal } \\
\text { Subbituminous coal } \\
\text { Lignite } \\
\text { Heavy fuel oil } \\
\text { Light fuel oil } \\
\text { Natural gas } \\
\text { Total }\end{array}$ & $\begin{array}{r}3,525 \\
605 \\
124 \\
605 \\
57 \\
710 \\
5,626\end{array}$ & $\begin{array}{r}3,780 \\
1,385 \\
285 \\
175 \\
18 \\
581 \\
6,224\end{array}$ & $\begin{array}{r}15,203 \\
657 \\
198 \\
1,610 \\
45 \\
1 \\
17,715\end{array}$ & $\begin{array}{r}12,222 \\
1,128 \\
304 \\
558 \\
12 \\
1 \\
14,225\end{array}$ \\
\hline
\end{tabular}




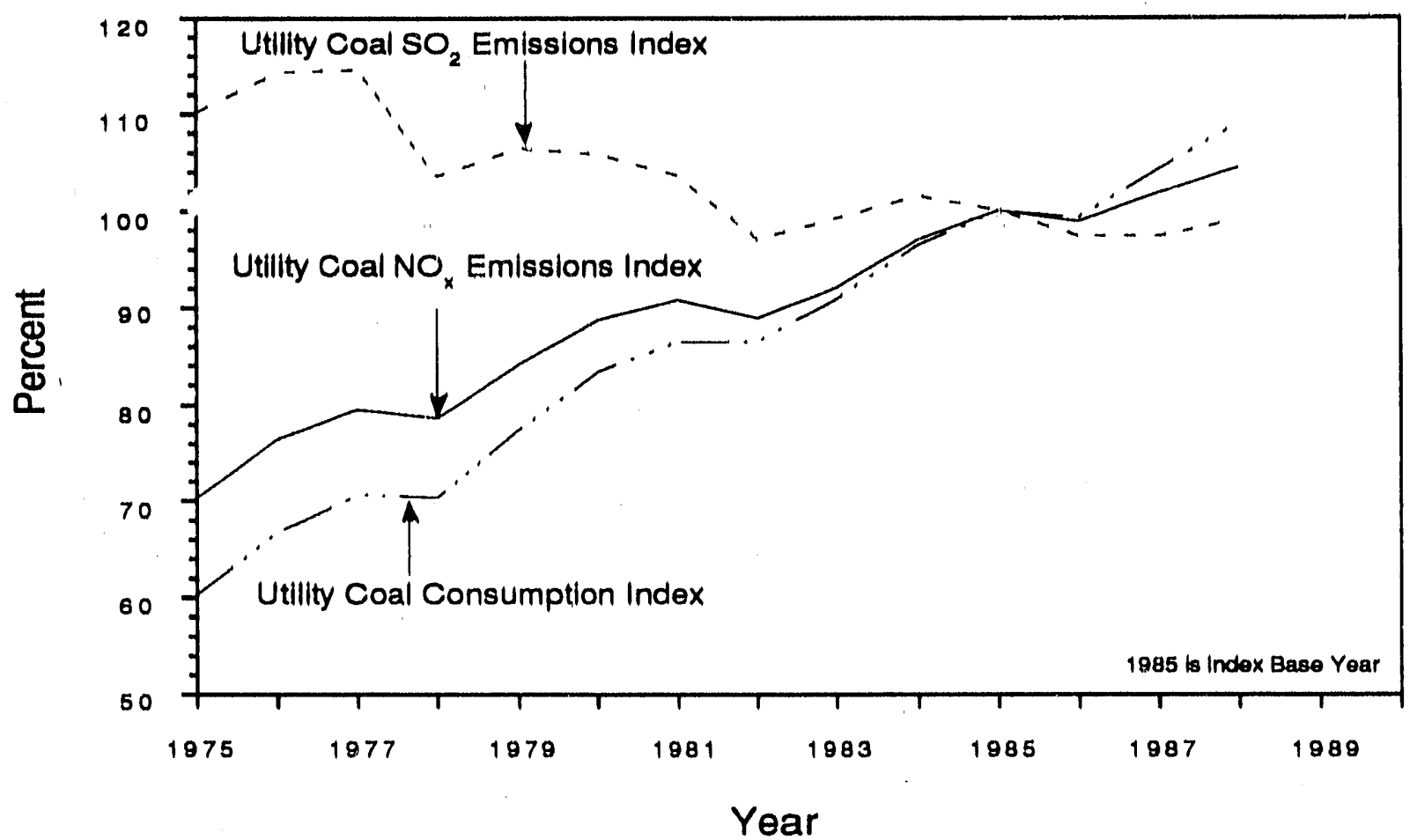

Figure 1.10 National Electric Utlity Coal Consumption and Related Emissions, 1975-1988

\subsubsection{Nitrogen Oxides}

Figure 1.8 shows that utility $\mathrm{NO}_{\mathrm{x}}$ emissions rose steadily from 1975 to 1988 . In that period, $\mathrm{NO}_{\mathrm{x}}$ emissions increased by $29.9 \%$. Although $\mathrm{NO}_{\mathrm{x}}$ emissions were affected by several factors (as described in the utility methodology section), the increase in fossil fuel consumption, shown in Figure 1.9, had the most impact. The increase between 1975 and 1988 in total fossil energy consumption was $32.5 \%$. The slightly lower rate of increase in $\mathrm{NO}_{x}$ emissions was partially caused by the use of low-NO $\mathrm{N}_{\mathrm{x}}$ burners, modinied combustion boilers, and other methods tro reduce $\mathrm{NO}_{\mathrm{x}}$ emissions.

Figure 1.11 shows the considerable seasonal variation that exists in $\mathrm{NO}_{\mathrm{x}}$ emissions from electric utilities. Emission patterns show two peaks, a large one in summer and one that is usually smaller in winter. These peaks can be explained by the variable demands in the residential, commercial, and industrial sectors for space cooling in summer and space heating in winter. Although $\mathrm{NO}_{\mathrm{x}}$ is produced in substantial quantities by coal-fired boilers, gas turbine and internal combustion units are also significant sources of $\mathrm{NO}_{x}$ emissions. These noncoal units are usually used only to meet peak demands, such as that for air conditioning in the summer, and they are the first to be taken off line as demand decreases. Some of these peaking units operate at high temperature and so produce more $\mathrm{NO}_{x}$ per unit of energy input than do coal fired units. The result is that $\mathrm{NO}_{\mathrm{x}}$ emissions reflect or accentuate seasonal differences in the underlying electricity demand. 


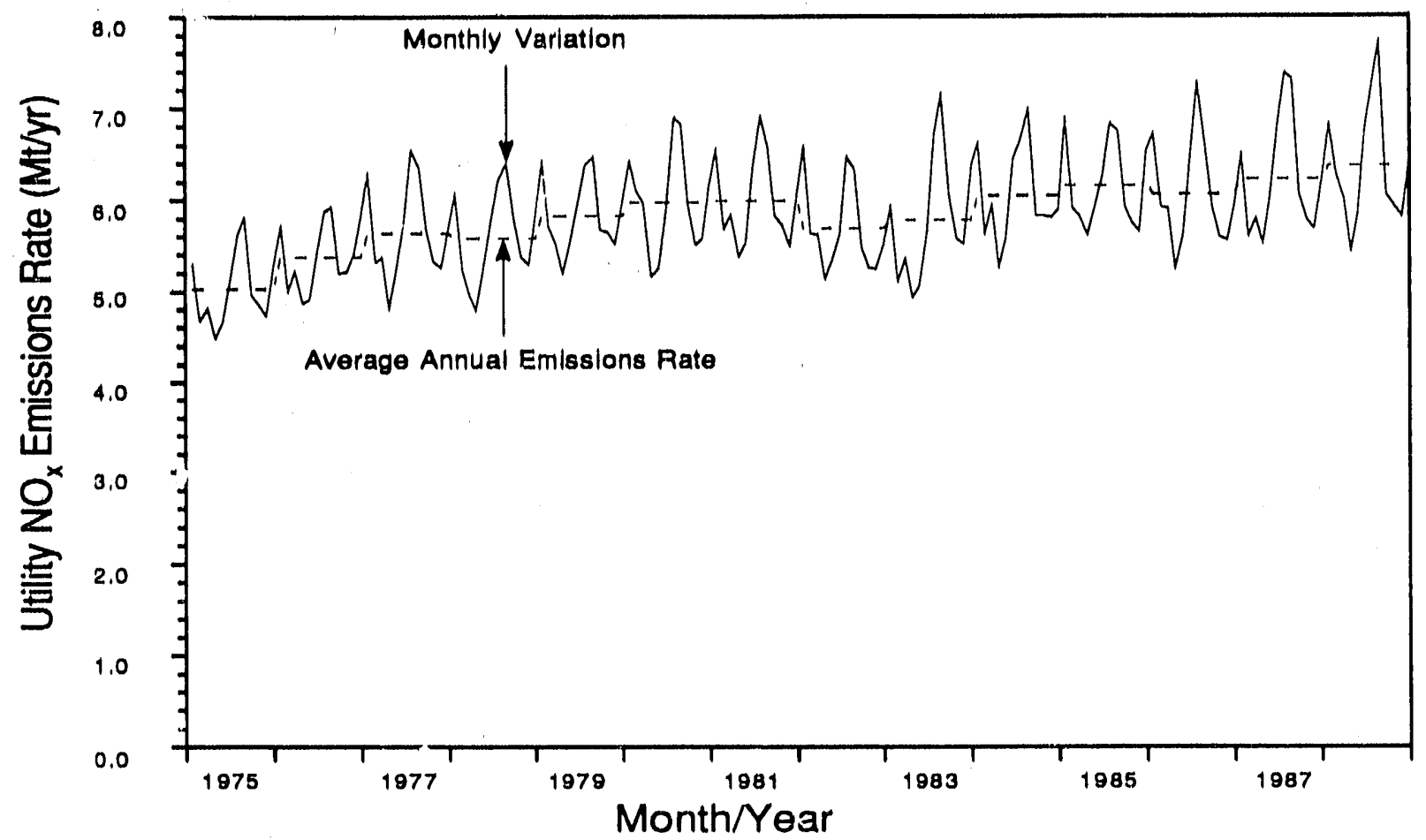

Figure 1.11 National Electric Utility NOX Emissions by Month and Annual Average, 1975-1988

\subsubsection{Sulfur Dioxide}

Figure 1.8 shows that between 1975 and $1988, \mathrm{SO}_{2}$ emissions rose in some periods and fell in others. Between 1977 and 1987, electric utility $\mathrm{SO}_{2}$ emissions decreased by $19.7 \%$. The two largest sources of $\mathrm{SO}_{2}$ at electric utilities are the sulfur in the coal and the sulfur in the oil that are burned as fuels, with coal sulfur being the larger source by far. Electric utility emissions decreased, while coal (and total energy) consumption increased.

One significant factor that contributed to the decrease in $\mathrm{SO}_{2}$ emissions relative to fuel use was the steady reduction in the sulfur content of the coal being used by electric utilities. Figure 1.12 shows the national average levels of sulfur in the fuel being consumed at electric utilities. The sulfur content of bituminous coal decreased between 1975 and 1988, while that of lignite increased. (Approximately $75 \%$ of all utility $\mathrm{SO}_{2}$ emissions were the result of bituminous coal consumption, while less than 5\% resulted from lignite coal consumption.) Another factor that led to $\mathrm{SO}_{2}$ reductions was the increased use of FGD (scrubber) units. FGD units remove sulfur from combustion boiler exhaust gases. Figure 1.13 shows the installed capacity of scrubbers during the period 1975-1987. Section 4 on the electric utility methodology describes in detail the effects that changes in coal type, heat value, and emission regulations can have on $\mathrm{SO}_{2}$ emissions. 


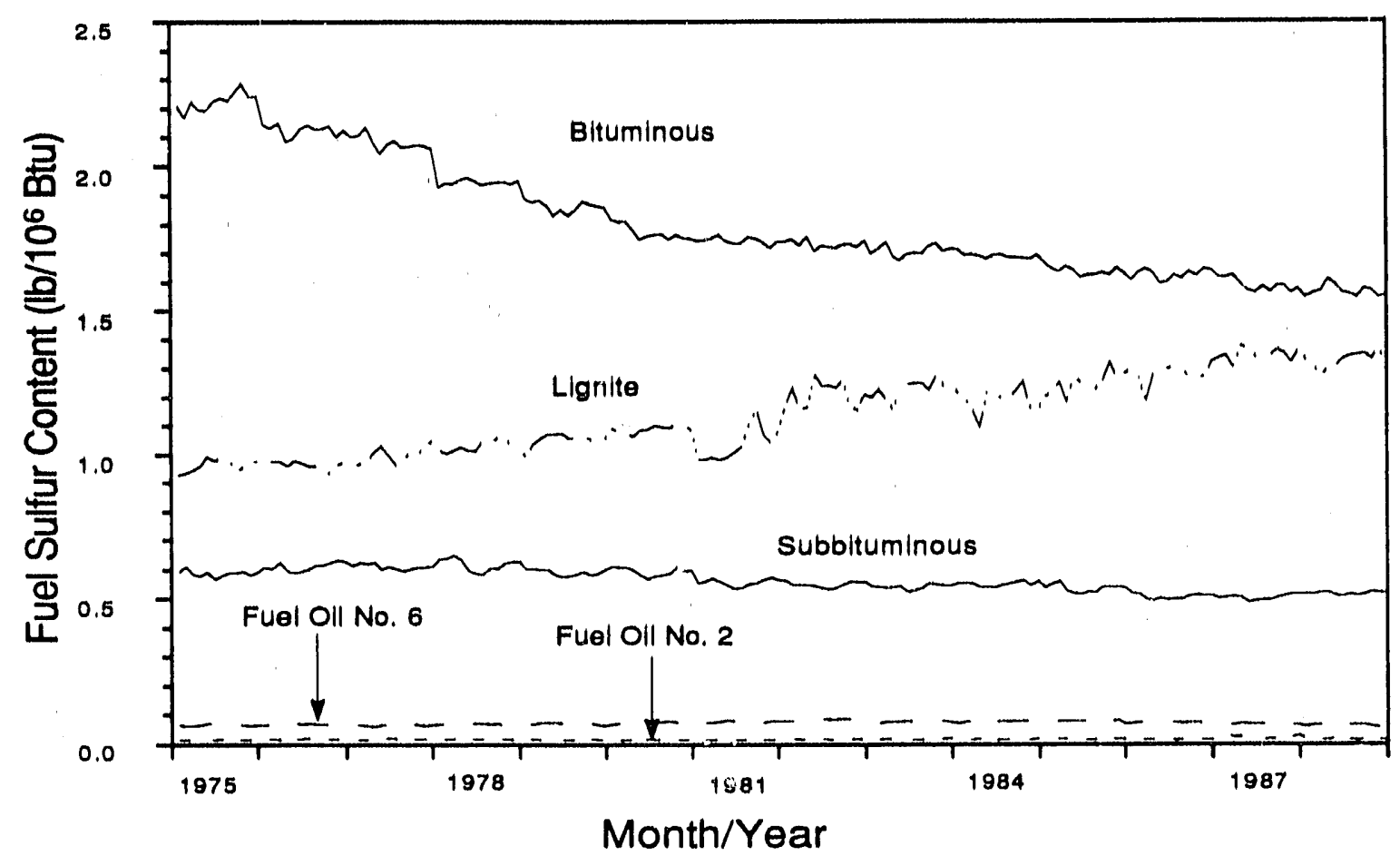

FIGURE 1.12 Average Sulfur Content of Fuels Consumed at Electric Utilities, 1975-1988

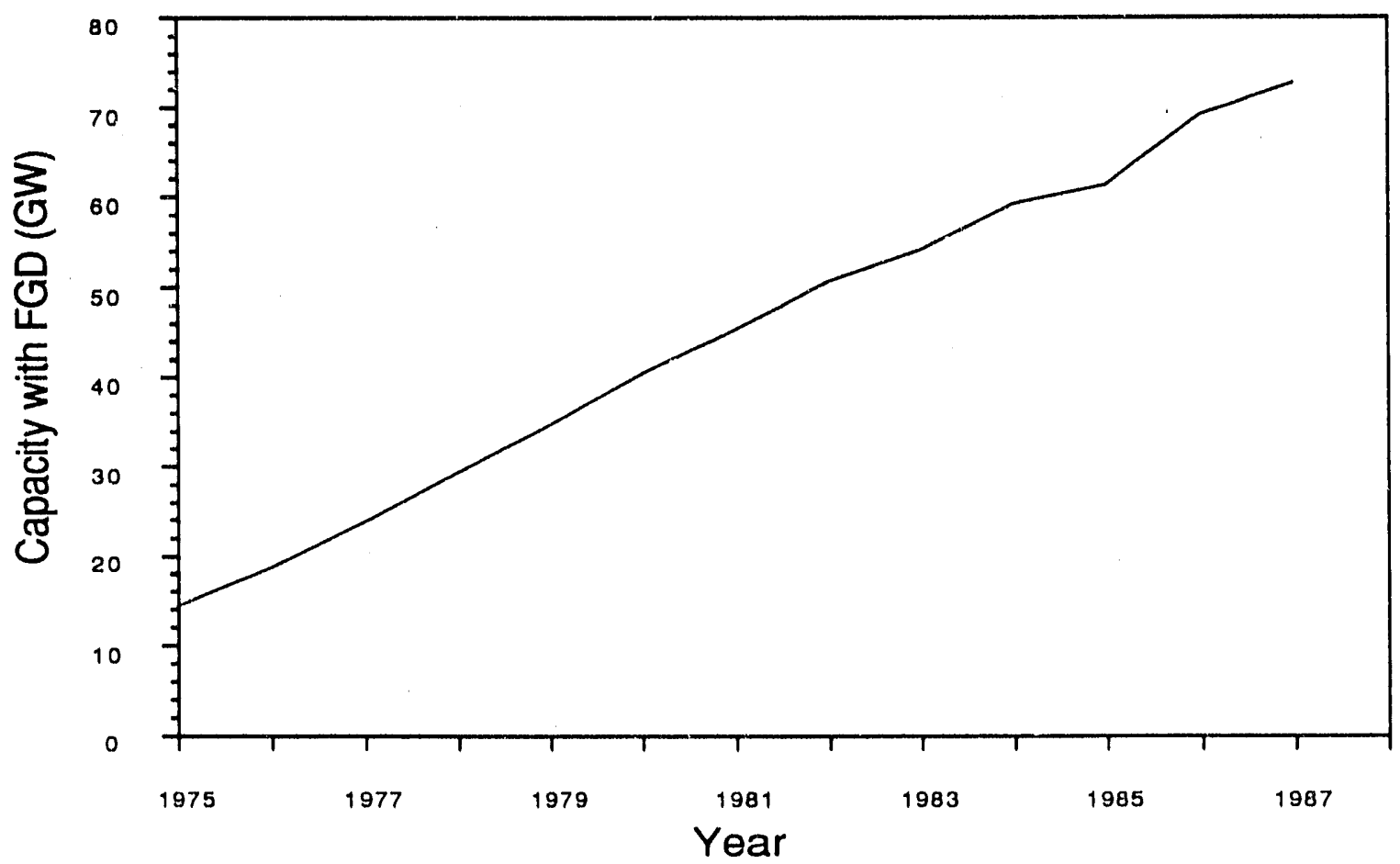

FIGURE 1.13 Installed Capacity Equipped with Flue-Gas Desulfurization Units, 1975-1987 
A monthly pattern similar to that for $\mathrm{NO}_{\mathbf{x}}$ can be seen in the graph of monthly $\mathrm{SO}_{2}$ emissions (Fig. 1.14). The monthly variation is slightly less for $\mathrm{SO}_{2}$ than $\mathrm{NO}_{\mathbf{x}}$. Because coal-fired units, which are the principal source of $\mathrm{SO}_{2}$ emissions, are usually relatively low-cost, baseline units, they are run almost c'sntinuously and at nearly the same rate throughout the year. Thus, although the monthly variation is significant, $\mathrm{SO}_{2}$ emissions show less variation than does electricity generation.

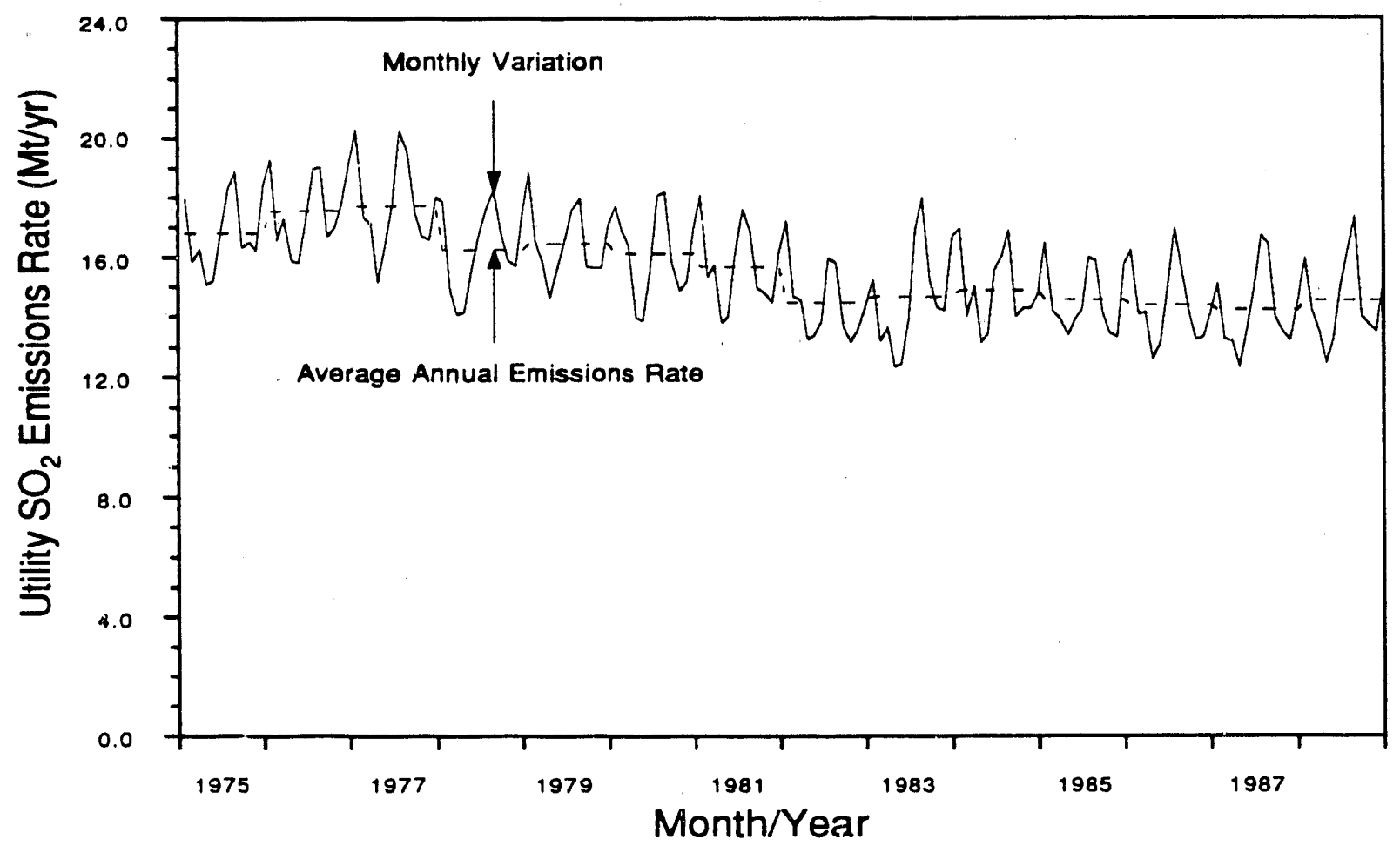

Figure 1.14 National Electric Utility $\mathrm{SO}_{2}$ Emissions by Month and Annual Average, 1975-1988 


\section{National Emission Trends}

This section presents a national summary of MSCET emission estimates, focusing on trends at the sectoral level. Regional emission trends are discussed in Sec. 3. These estimates were computed using the data and methodologies that are described in Secs. 4-7.

In the discussion that follows, emission trends are sometimes expressed as an average annual percent change. This is calculated using a simple annual compounding formula, $E_{t}=E_{0}(1+r)^{n}$, where $E_{t}=$ the emission level in year $t ; E_{0}=$ the emission level in the base year, $\mathrm{n}=$ the year $\mathrm{t}$ minus the base year, and $\mathrm{r}=$ the average annual percent change.

Seasons are defined as follows: winter $=$ December of the previous year, January, and February; spring = March, April, and May; summer = June, July and August; and fall = September, October, and November. Seasonal trends are presented in terms of an annual rate, which is equal to four times the seasonal rate. In other words, the annual rate is what the annual emission value would be if the seasonal rate continued over the whole year. Care must be used when interpreting the seasonal graphs so that annual rates provided for each season are not confused with annual values. The seasonal emission value can be recovered by dividing the annual rate stated for the season by four. One additional note of caution: For the seasonal data, winter includes December of the previous year. Therefore, the seasonal plots begin with spring 1975, since December 1974 information -- and thus complete information for winter 1975 -- was not included in the 1975-1988 time frame for the analysis.

\subsection{Nitrogen Oxides}

Figure 2.1 and Table 2.1 present MSCET national $\mathrm{NO}_{\mathrm{x}}$ emissions by sector. They show that $\mathrm{NO}_{\mathbf{x}}$ emissions from the transportation sector declined over the period. Transportation $\mathrm{NO}_{\mathbf{x}}$ emissions reached a peak of $9.7 \mathrm{Mt}$ in 1978 and then fell continuously, reachíng $6.9 \mathrm{Mt}$ in 1988. This decline is equivalent to an average annual decline of $3.3 \%$ per year. $\mathrm{New}^{\mathrm{NO}_{\mathrm{x}} \text { emission }}$ standards for automobiles were implemented in 1977, 1979, and 1980. These standards, coupled with increased penetration of catalytic converters and fleet turnover, caused emissions to decline.

Electric utility $\mathrm{NO}_{\mathrm{x}}$ emissions totaled $5.6 \mathrm{Mt}$ in 1978 and rose at an average rate of $1.6 \%$ per year to total $6.5 \mathrm{Mt}$ in 1988 . This sector's share of $\mathrm{NO}_{\mathrm{x}}$ emissions increased from $26 \%$ to $36 \%$ of the national total. Industrial fuel combustion $\mathrm{NO}_{\mathbf{x}}$ emissions, which reached a peak of 4.1 Mt in 1977 and 1978, fell at an annual average rate of 6.5\%, reaching $2.9 \mathrm{Mt}$ in 1983 . Since then, emissions have held steady, at around $3 \mathrm{Mt}$. 


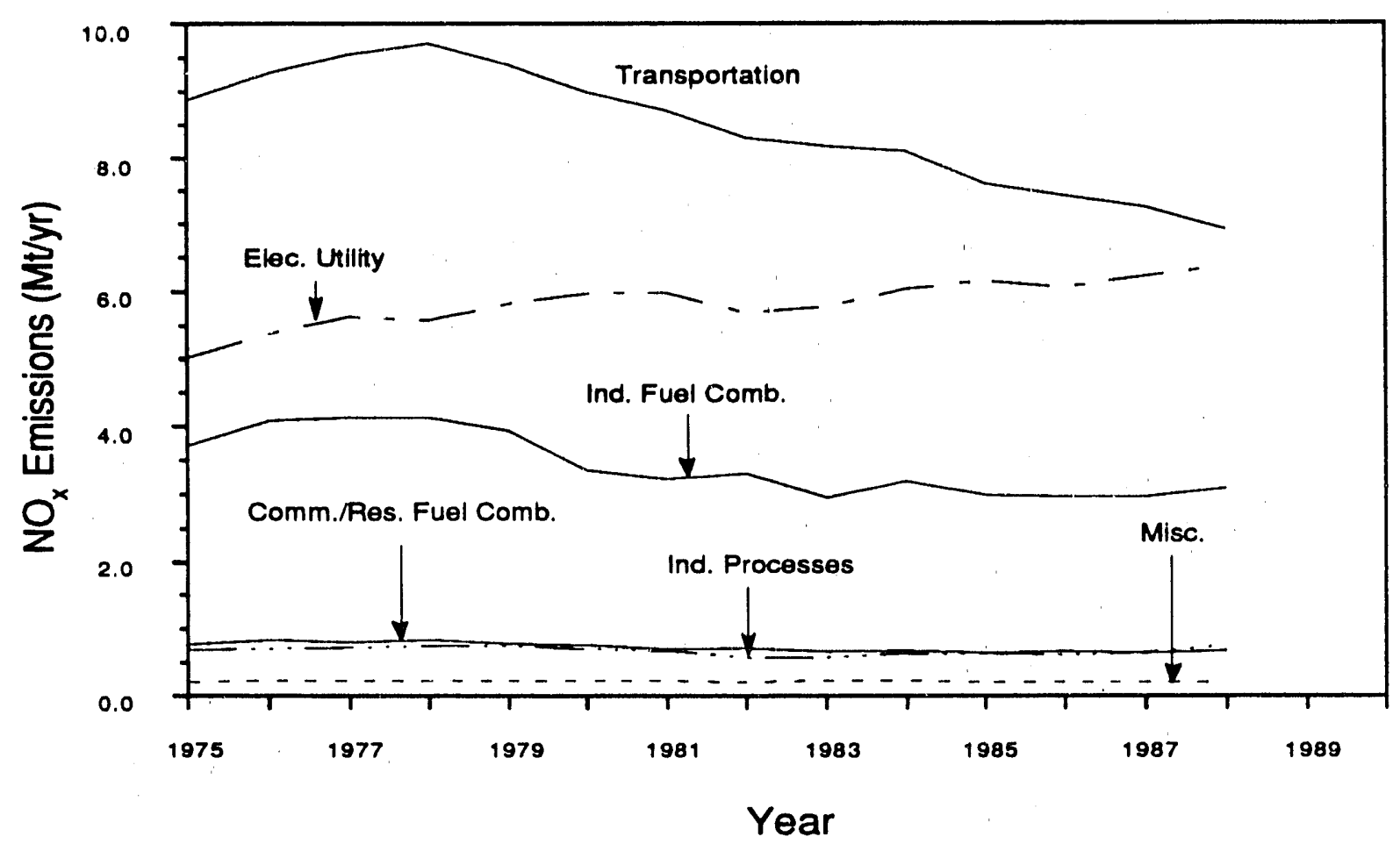

FIGURE 2.1 Sectoral NO Emission Trends, 1975-1988

TABLE 2.1 National NOx Emissions for 1978, 1980, 1985, and 1988 (Mt)

\begin{tabular}{lrrrr}
\hline \multicolumn{1}{c}{ Sector } & $1978^{\mathrm{a}}$ & 1980 & 1985 & 1988 \\
& & & & \\
\hline & 9.7 & 9.0 & 7.6 & 6.9 \\
Transportation & 5.6 & 6.0 & 6.2 & 6.5 \\
$\begin{array}{l}\text { Electric utility } \\
\text { Industrial fuel combustion }\end{array}$ & 4.1 & 3.3 & 3.0 & 3.1 \\
$\begin{array}{l}\text { Industrial processes } \\
\text { Commercial/residential fuel }\end{array}$ & 0.7 & 0.7 & 0.6 & 0.7 \\
$\quad$ combustion & 0.8 & 0.8 & 0.6 & 0.7 \\
$\begin{array}{l}\text { Miscellaneous } \\
\text { Totalb }\end{array}$ & 0.2 & 0.2 & 0.2 & 0.2 \\
& 21.2 & 20.0 & 18.2 & 18.2 \\
\hline
\end{tabular}

ayear of peak MSCET NO emission levels.

bTotals may not sum due to independent rounding. 
Figure 2.2 shows MSCET $\mathrm{NO}_{\mathbf{x}}$ emission trends, including seasonal variations. (The seasonal plots actually illustrate the equivalent annual emission rate, not the actual seasonal emission values.) The transportation sector exhibited a large variation from its winter emission minimum to its summer maximum. Transportation $\mathrm{NO}_{\mathrm{x}}$ emissions are approximately $0.5 \mathrm{Mt}$ higher in summer than in winter (i.e., the equivalent annual rate is higher by $2 \mathrm{Mt} / \mathrm{yr}$ in summer than in winter). The summer maximum was caused partially by increased travel and partially by a higher emission factor (due to higher ambient temperatures). The electric utility sector also displayed summer emission maximums, which were particularly pronounced in 1986,1987 , and 1988. The seasonal variation for this sector was usually around $0.25 \mathrm{Mt}(1 \mathrm{Mt} / \mathrm{yr}$ for the equivalent annual rate), although it was higher in the 19.86-1988 period. The industrial fuel combustion sector is interesting because its seasonal peak, which was originally in the fall, shifted to the winter in the early 1980s. The commercial/residential fuel combustion sector had a variation of almost $0.5 \mathrm{Mt}(2 \mathrm{Mt} / \mathrm{yr}$ for the annual rate) in its seasonal emission rate in the late $1970 \mathrm{~s}$, which dampened in the mid $1980 \mathrm{~s}$ to $0.4 \mathrm{Mt}$. The peak seasonal emission rate for this sector occurs in winter because of increased space heating needs.

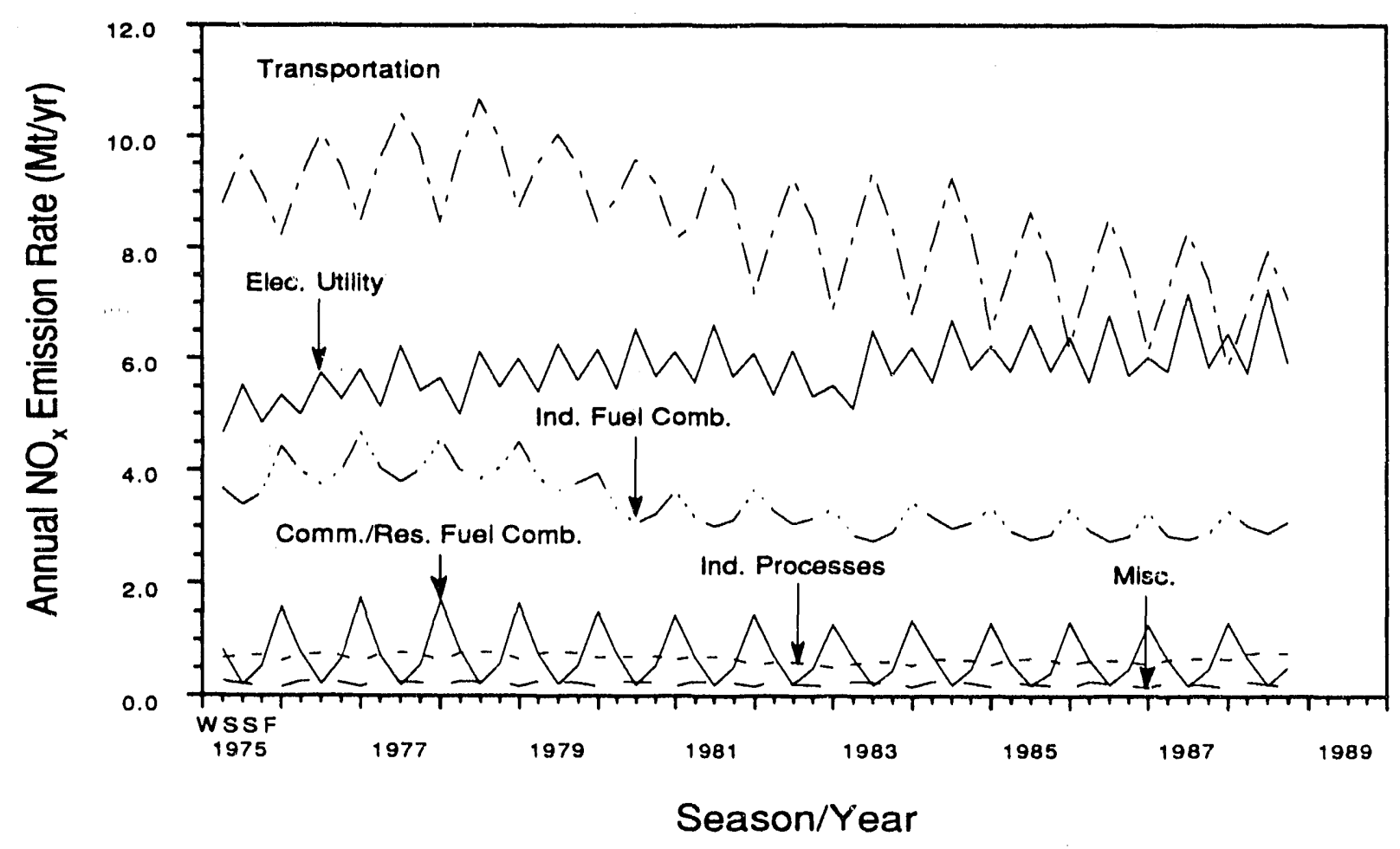

FIGURE 2.2 Sectoral NOx Emission Trends Showing Seasonal Variations, 1975-1988 


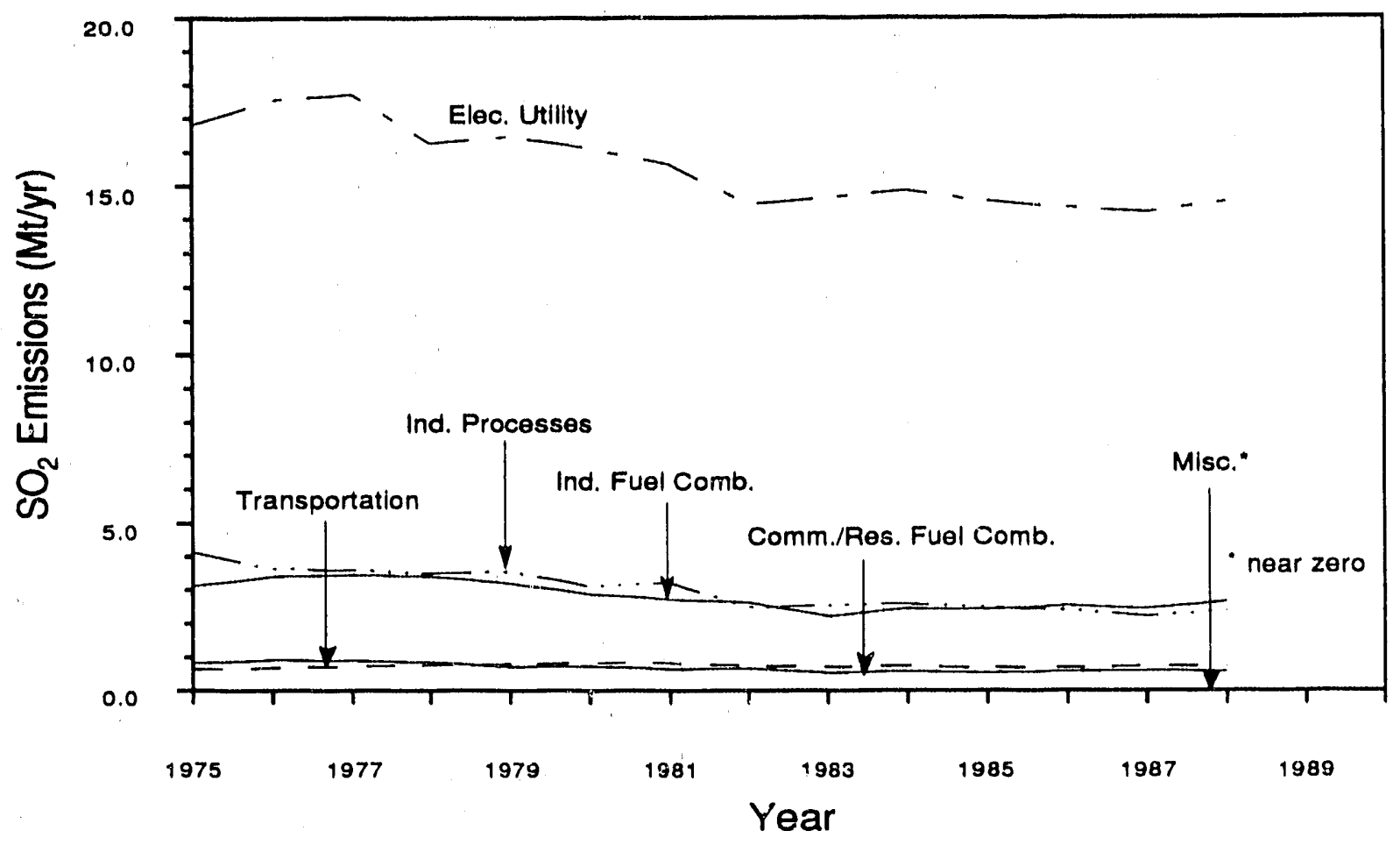

FIGURE 2.3 Sectoral $\mathrm{SO}_{2}$ Emission Trends, 1975-1988

TABLE 2.2 National $\mathrm{SO}_{2}$ Emissions for 1977, 1980, 1985, and $1988(\mathrm{Mt})$

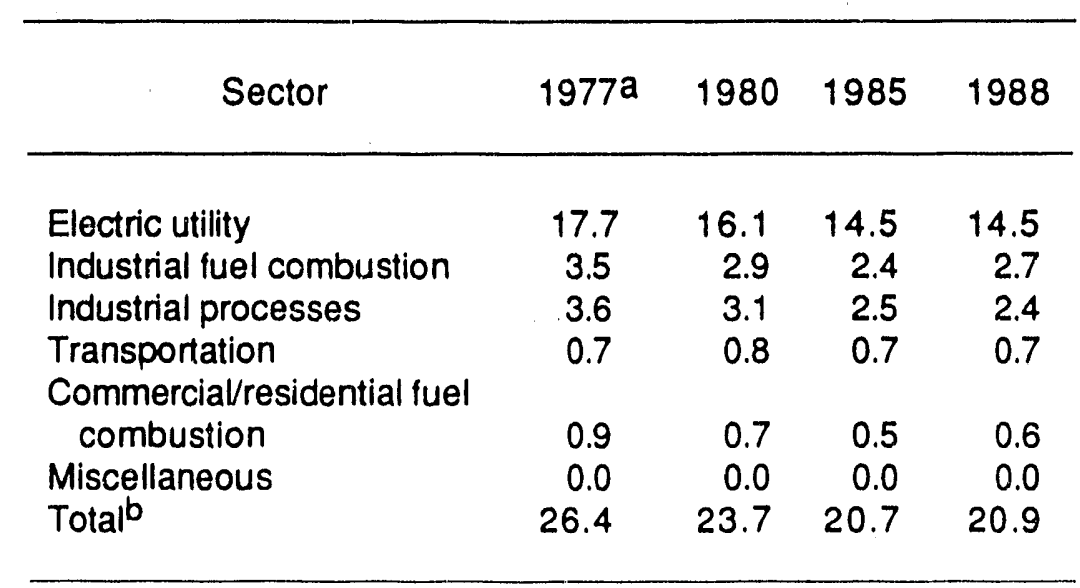

ayear of peak MSCET $\mathrm{SO}_{2}$ emission levels.

bTotals may not sum due to independent rounding. 


\subsection{Sulfur Dioxide}

Figure 2.3 and Table 2.2 present $\mathrm{SO}_{2}$ emission sectoral trends by individual sector. Electric utility $\mathrm{SO}_{2}$ emissions reached a post-1975 peak of $17.7 \mathrm{Mt}$ in 1977 and fell at an annual average rate of $2.2 \%$ to reach $14.2 \mathrm{Mt}$ in 1987 . Preliminary results indicate that in $1988, \mathrm{SO}_{2}$ emissions rose and nearly reached their 1985 levels. Although the amount of emissions in this sector has been declining on average, the sector's share of emissions has been increasing. In 1977 , electric utilities emitted $67 \%$ of the nation's $\mathrm{SO}_{2}$, and in 1988 they emitted $69 \%$. This situation occurred because $\mathrm{SO}_{2}$ emissions from the other sectors decreased even more rapidly over the period. These other sectors -- industrial fuel combustion, industrial process, and commercial/residential fuel combustion -- show average anuual reductions of $2.6 \%, 4.0 \%$, and 4.3\%, respectively, between 1977 and 1988 .

Figure 2.4 displays the MSCET $\mathrm{SO}_{2}$ seasonal profile for each sector. Only the electric utility and commercial/resiciential fuel combustion sectors showed any significant seasonal patterns. As was the case for $\mathrm{NO}_{\mathbf{x}}$, the emergence of a summer maximum for $\mathrm{SO}_{2}$ emissions in the electric utility sector was evident in 1986,1987, and 1988. Variation in the seasonal emission was about $0.6 \mathrm{Mt}(2.5 \mathrm{Mt} / \mathrm{yr}$ annual rate) through the mid 1980s and increased to $1 \mathrm{Mt}(4 \mathrm{Mt} / \mathrm{yr}$ annual rate) in 1986. For commercial/residential fuel combustion, the seasonal variation was $0.5 \mathrm{Mt}(2 \mathrm{Mt} / \mathrm{yr}$ annual rate) in the late $1970 \mathrm{~s}$ but moderated to around $0.25 \mathrm{Mt}(1 \mathrm{Mt} / \mathrm{yr}$ annual rate) in the late 1980s. As was the case for $\mathrm{NO}_{\mathbf{x}}$, the commercial/residential fuel combustion sector emitted the most $\mathrm{SO}_{2}$ in winter because of the increased demand for space heating.

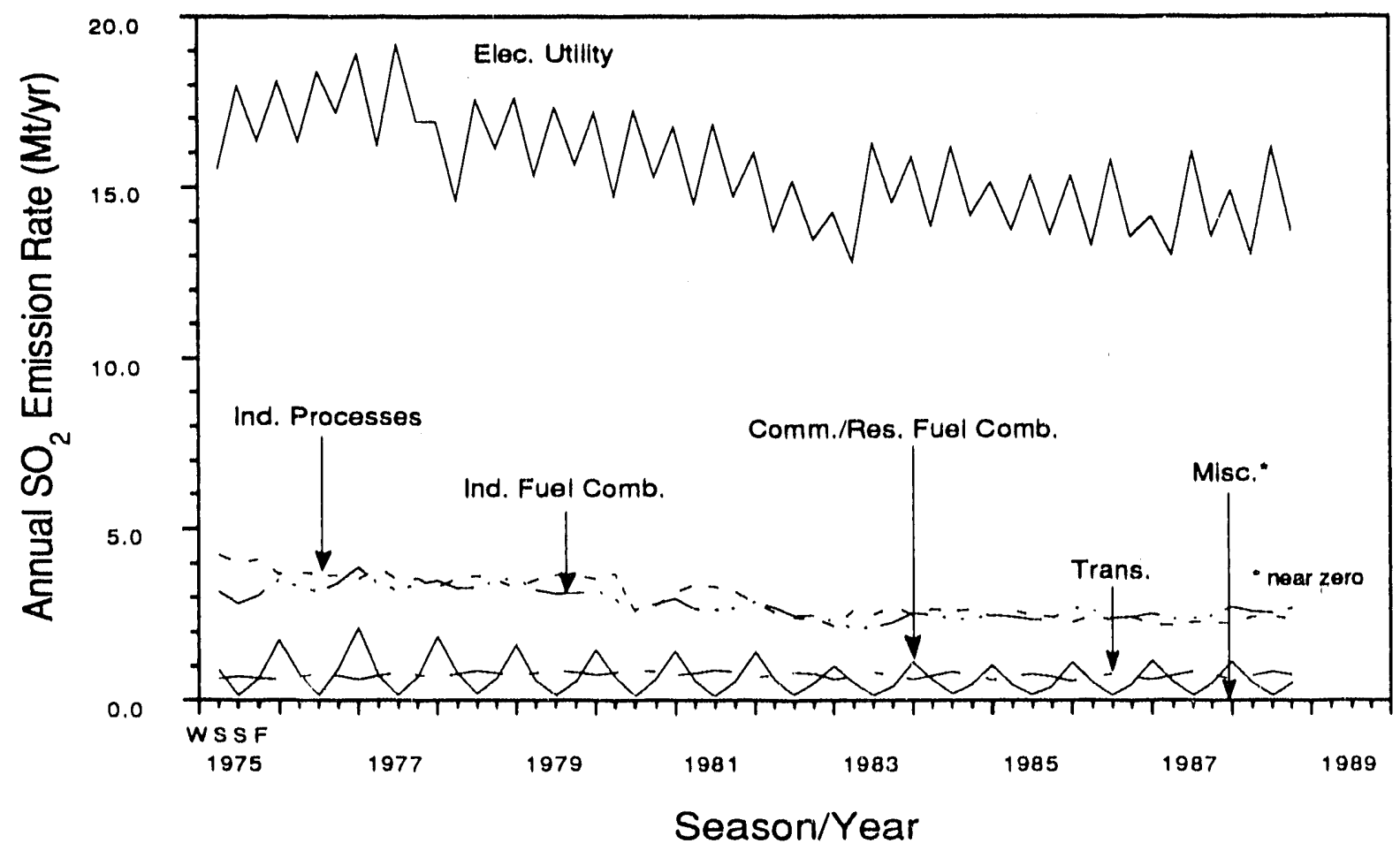

FIGURE 2.4 Sectoral $\mathrm{SO}_{2}$ Emission Trends Showing Seasonal Variations, 1975-1988 


\subsection{Volatile Organic Compounds}

Figure 2.5 and Table 2.3 show VOC emission trends for individual sectors. The transportation sector was the most influential sectur in reducing total VOC emissions. New vehicular VOC emission standards in 1975, 1979, and 1980 and the penetration of catalytic converters into the fleet helped reduce VOC emissions from the transportation sector. In addition, declining fuel consumption from 1978 to 1982 due to the increased fuel efficiency of cars further contributed to VOC emission reductions.

VOC emissions from the industrial process sector declined significantly in the early $1980 \mathrm{~s}$ after reaching a peak of $8.2 \mathrm{Mt}$ in 1978. Emissions from the sector reached a low of $6.1 \mathrm{Mt}$ in 1982 , and levels have fluctuated since then. Emissions from commercial/residential fuel combustion more than doubled between 1975 and 1984, from 0.6 to $1.5 \mathrm{Mt}$. This growth was caused by the increased use of wood in this sector.

Figure 2.6 presents MSCET VOC seasonal profiles by sector. Only the transportation and commercial/residential fuel combustion sectors displayed significant seasonal variation, and this seasonality was quite pronounced. Seasonal variation in the transportation sector was around 1.75 Mt (equivalent to a $7 \mathrm{Mt} / \mathrm{yr}$ difference in annual rate) in the late 1970s, but this moderated to $1.25 \mathrm{Mt}(5 \mathrm{Mt} / \mathrm{yr}$ annual rate) in the 1980s. The seasonal emission peak for the transportation sector occurs in summer, caused in part by increased activity in the sector and in part by increased

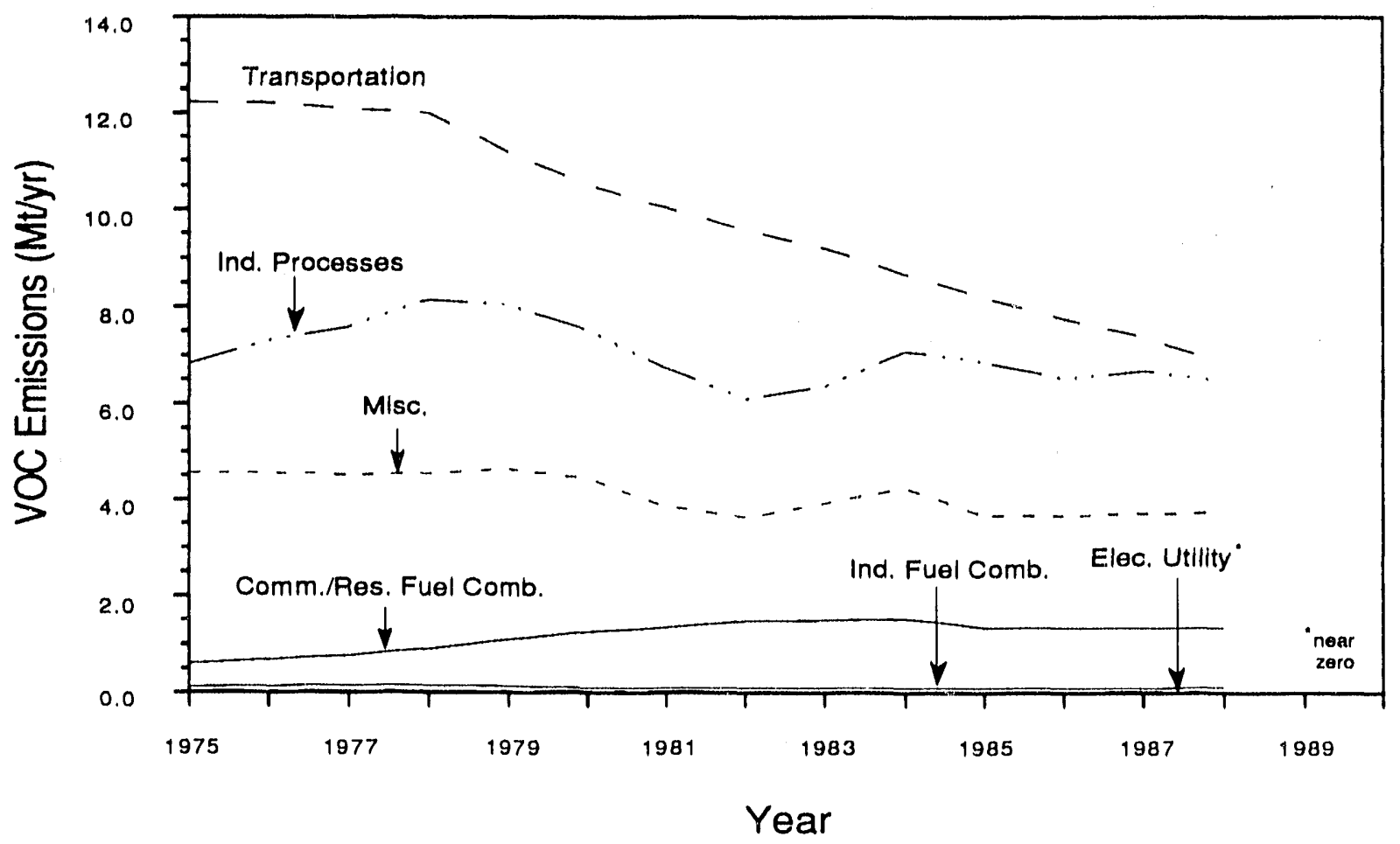

FIGURE 2.5 Sectoral VOC Emission Trends, 1975-1988 
TABLE 2.3 National VOC Emissions for 1978, 1980, 1985, and 1988 (Mt)

\begin{tabular}{lrrrr}
\hline Sector & $1978 \mathrm{a}$ & 1980 & 1985 & 1988 \\
\hline & 12.0 & 10.5 & 8.2 & 6.9 \\
$\begin{array}{lrrr}\text { Transportation } \\
\text { Industrial processes }\end{array}$ & 8.2 & 7.5 & 6.9 & 6.5 \\
$\begin{array}{l}\text { Miscellaneous } \\
\text { Commercial/residential fuel } \\
\quad \text { combustion }\end{array}$ & 4.5 & 4.4 & 3.7 & 3.7 \\
$\begin{array}{l}\text { Industrial fuel combustion } \\
\text { Electric utilities }\end{array}$ & 0.9 & 1.3 & 1.3 & 1.3 \\
Totalb & 0.1 & 0.1 & 0.1 & 0.1 \\
& 0.0 & 0.0 & 0.0 & 0.0 \\
\hline
\end{tabular}

aYear of peak MSCET VOC emission levels.

bTotals may not sum due to independent rounding.

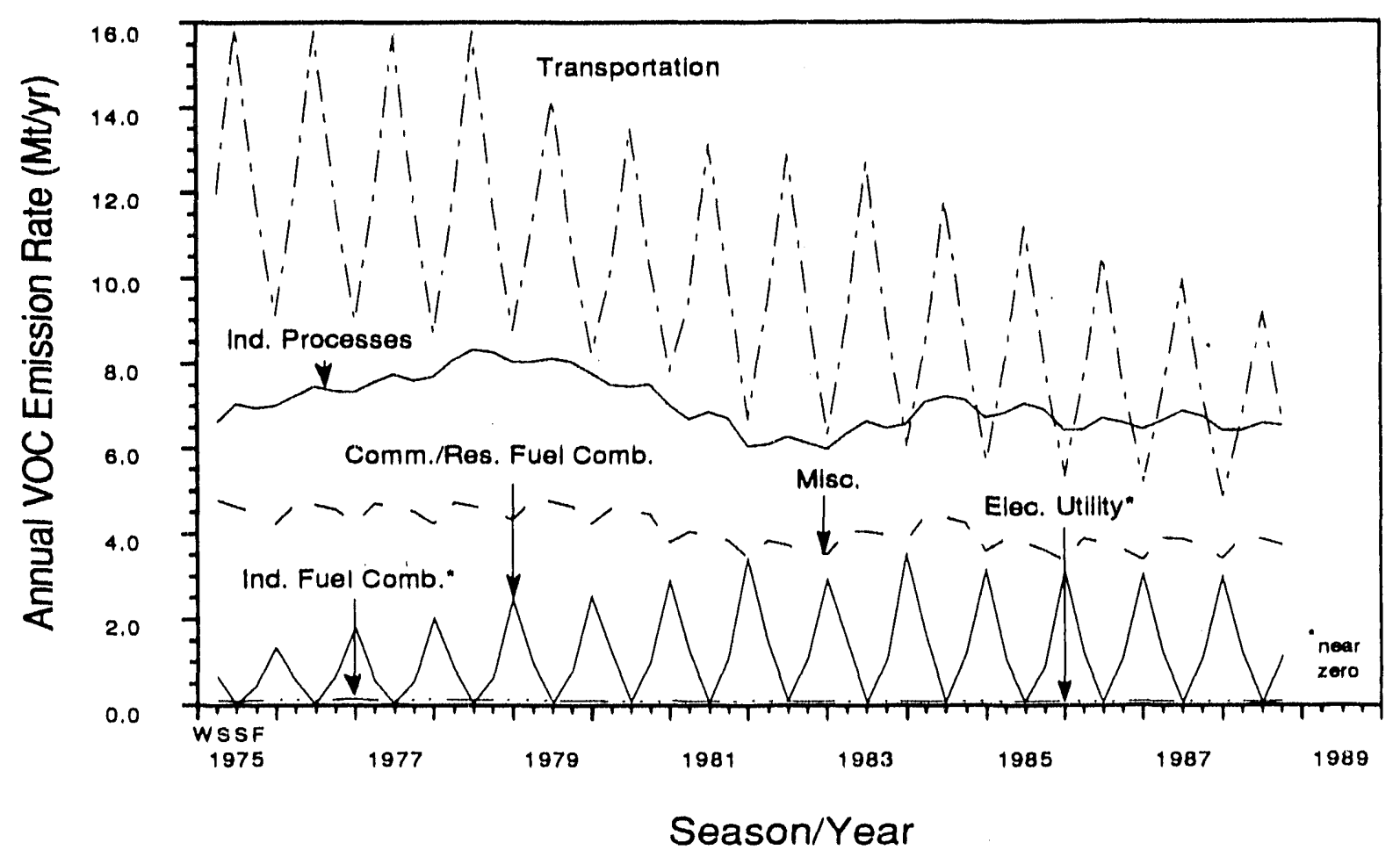

FIGURE 2.6 Sectoral VOC Emission Trends Showing Seasonal Variations, 1975-1988 
evaporative losses due to higher ambient temperatures. The commercial/residential fuel combustion sector had a moderate seasonal variation of $0.5 \mathrm{Mt}(2 \mathrm{Mt} / \mathrm{yr}$ annual rate) in the late $1970 \mathrm{~s}$, but this increased to $0.75 \mathrm{Mt}$ (3 Mt/yr annual rate) in the $1980 \mathrm{~s}$. The seasonal maximum for VOC emissions in this sector occurred in winter, caused by higher space heating demands and increased wood burning. The seasonal trend in the transportation sector was the reverse of the seasonal trend in the commercial/residential fuel combustion sector. These seasonal patterns offset each other somewhat, so the aggregate seasonality was reduced. 


\section{Reglonal Emission Trends}

The MSCET emission trends can be examined at subnational (regional) or state levels. Although many different regional compositions could be used, the nation was divided into three regions for this report (see Fig. 3.1). These regions were chosen to correspond to groups of federal regions. The Northeast is composed of states in federal regions 1, 2, 3, and 5. The states in federal region 4 are included in the Southeast, and states in the remaining federal regions $(6,7$, 8,9 , and 10) form the West. Analyses similar to the one discussed in this section could easily be done using different combinations of states.

Figure 3.2 presents MSCET NOx emission trends for each of the three regions. Emissions in all regions peaked in the late 1970s and declined through the early and mid 1980s. Table 3.1 presents $\mathrm{NO}_{\mathrm{x}}$ regional emission shares. The Northeast and West contribute similar shares to total $\mathrm{NO}_{\mathrm{x}}$ emissions, each about two-fifths, and the Southeast contributes the remaining fifth. Between 1980 and 1985, the Northeast lost a $2 \%$ share, while the other regions each gained a $1 \%$ share.

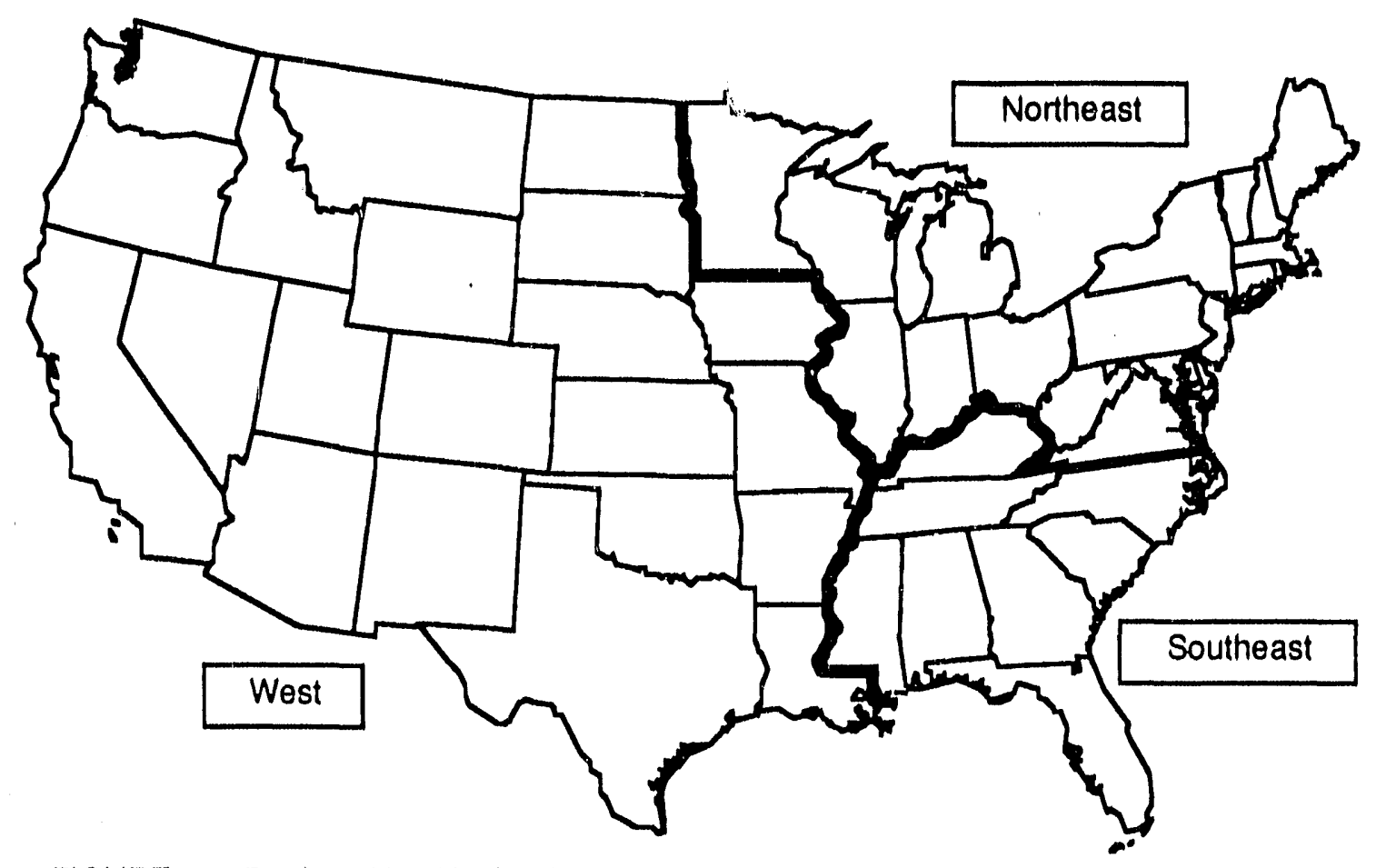

FIGURE 3.1 Regions Used in this Study 


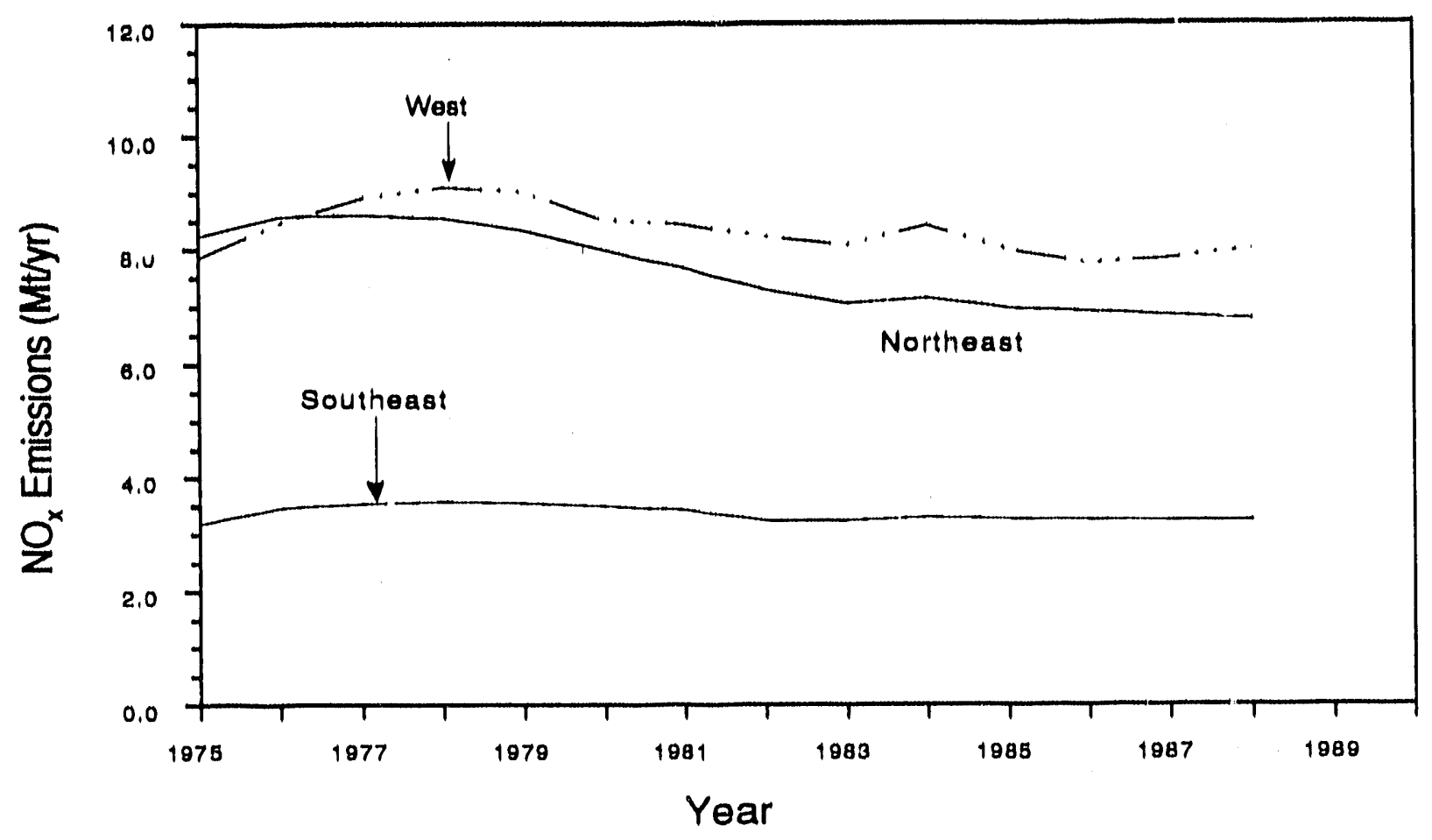

FIGURE 3.2 Regional NOx Emission Trends, 1975-1988

TABLE 3.1 Regional NOx Emissions for 1978, 1980,1985 , and 1988 (\%)

\begin{tabular}{lrrrr}
\hline Region & 1978 & 1980 & 1985 & 1988 \\
\hline & & & & \\
West & 43 & 43 & 44 & 44 \\
Northeast & 40 & 40 & 38 & 38 \\
Southeast & 17 & 17 & 18 & 18 \\
Totala & 100 & 100 & 100 & 100 \\
\hline
\end{tabular}

aTotals may not sum due to independent rounding. 
Figure 3.3 presents $\mathrm{MSCET} \mathrm{SO} 2$ emissions trends by region. The greatest share of emissions occurs in the Northeast. The trend in this region peaked at 14.2 Mt in 1976, then declined to $10.5 \mathrm{Mt}$ in 1987. Emissions then increased to $10.8 \mathrm{Mt}$ in 1988. The Wesi emitted the next largest share of $\mathrm{SO}_{2}$ emissions, and this trend peaked at $6.2 \mathrm{Mt}$ in 1981 . Emissions then fell to a low of $5.0 \mathrm{Mt}$ in 1987 before increasing to $5.2 \mathrm{Mt}$ in 1988 . Emissions of $\mathrm{SO}_{2}$ in the Southeast peaked at $6.0 \mathrm{Mt}$ in 1977 , then decreased to a low of $4.6 \mathrm{Mt}$ in 1982 . Since then, $\mathrm{SO}_{2}$ emissions have steadily risen at an average annual rate of $1.4 \%$, reaching $5.0 \mathrm{Mt}$ in 1988 . Table 3.2 presents $\mathrm{SO}_{2}$ regional shares for $1977,1980,1985$, and 1988. Between 1977 and 1988, the regional emission shares remained about the same.

Figure 3.4 presents MSCET VOC emission trends by region. All three regions have a similar profile. Emissions peaked in 1978 and have fallen, except for a two-year interruption in 1983 and 1984, up to the present. As was the case for $\mathrm{NO}_{\mathbf{X}}$, the Northeast and West emitted similar shares of the nation's VOC, each around two-fifths, and the Southeast contributed the remaining fifth. Regional shares remained consiant over the period. Table 3.3 presents VOC regional shares for 1978, 1980,1985, and 1988. Because of the uncertainties in the VOC emission estimates at disaggregated geographical scale, it should be reiterated that these data are not recommended to be used for state-specific regulatory purposes.

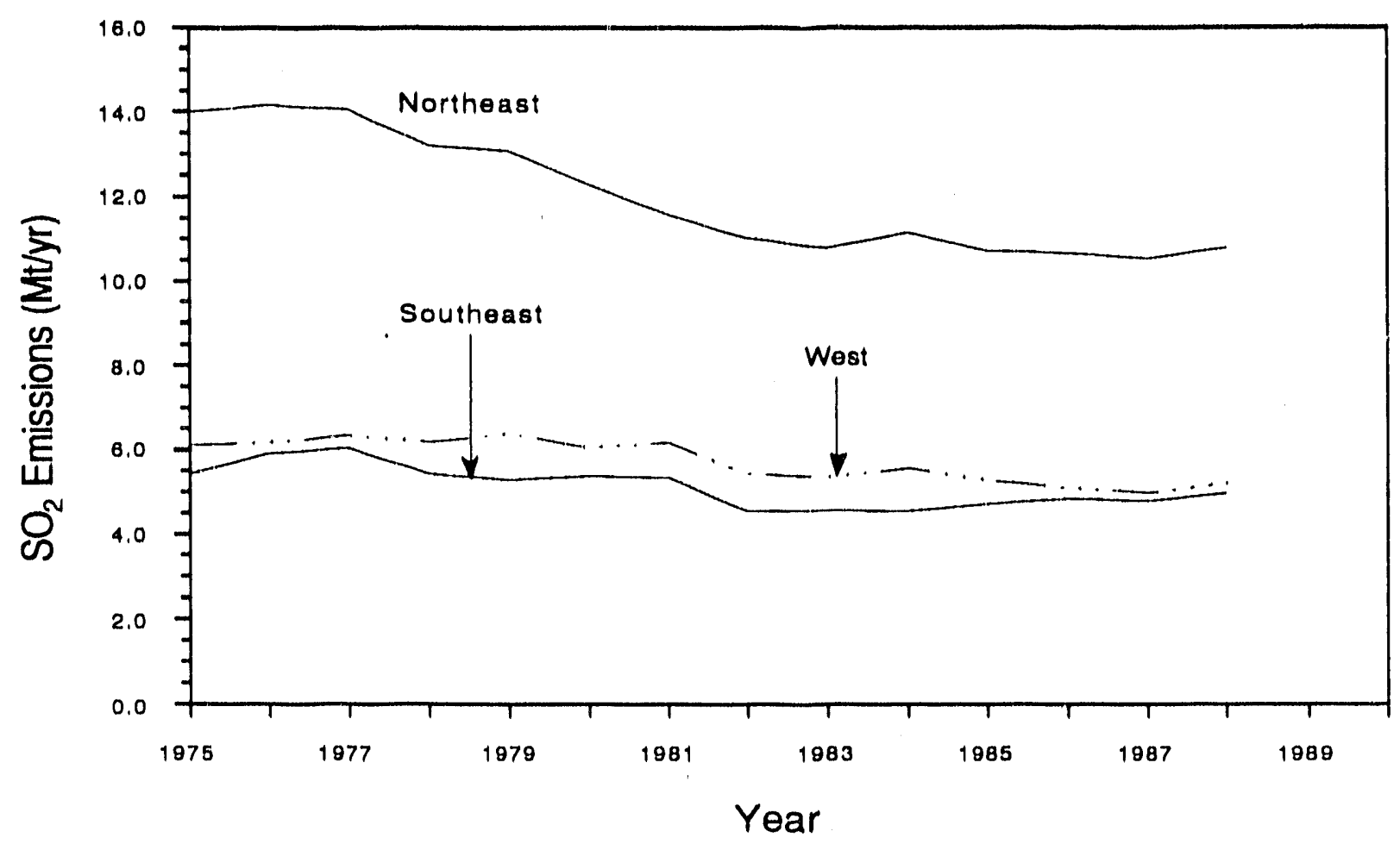

FIGURE 3.3 Regional $\mathrm{SO}_{2}$ Emission Trends, 1975-1988 
TABLE 3.2 Regional $\mathrm{SO}_{2}$ Emissions for $1977,1980,1985$, and 1988 (\%)

\begin{tabular}{lrrrr}
\hline Region & 1977 & 1980 & 1985 & 1988 \\
\hline Northeast & 53 & 52 & 52 & 52 \\
$\begin{array}{lrrr}\text { West } \\
\text { Southeast }\end{array}$ & 24 & 26 & 25 & 25 \\
Totala & 100 & 100 & 100 & 100 \\
\hline
\end{tabular}

aTotals may not sum due to independent rounding.

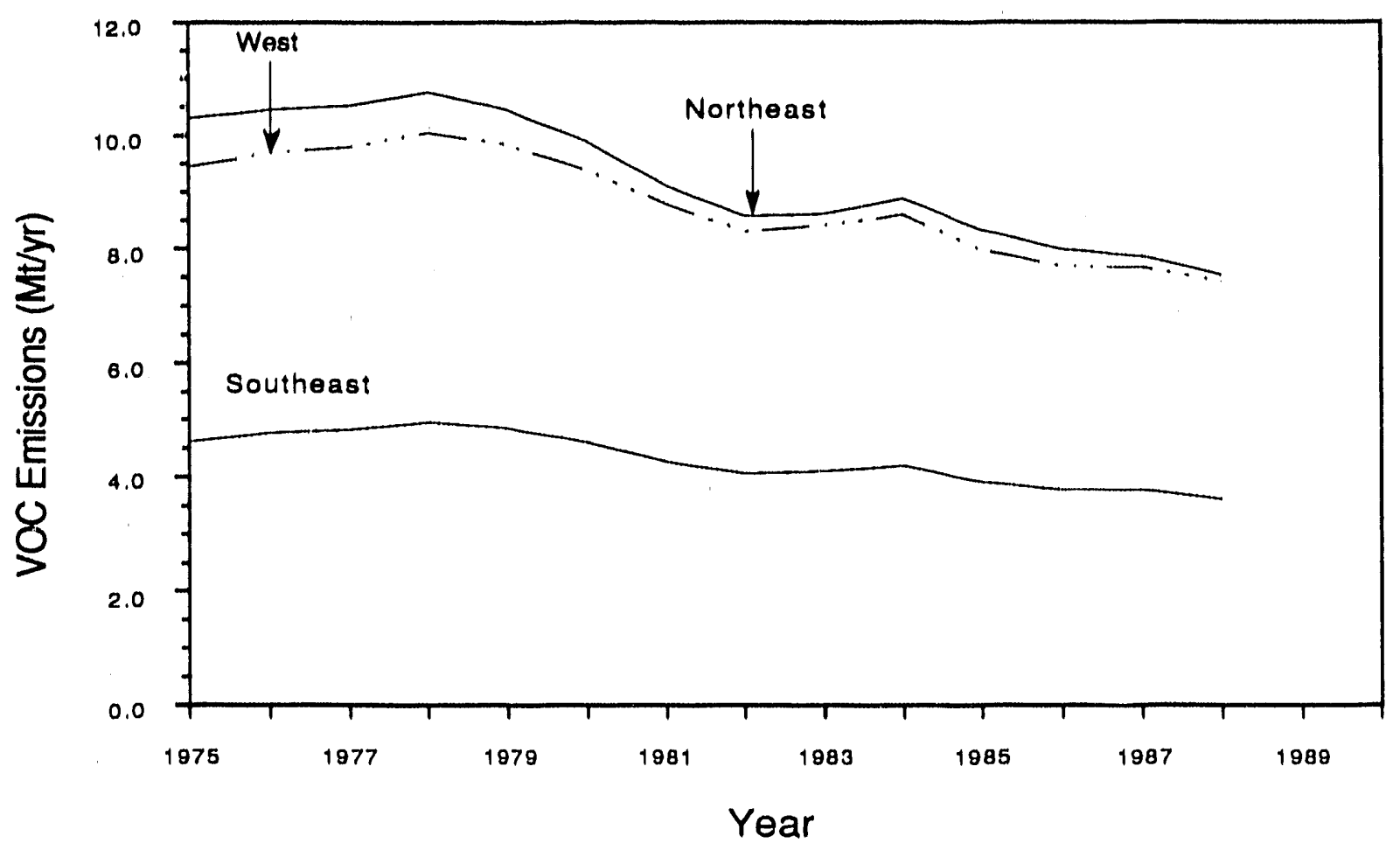

FIGURE 3.4 Regional VOC Emission Trends, 1975-1988 
TABLE 3.3 Regional VOC Emissions for $1978,1980,1985$, and $1988(\%)$

\begin{tabular}{lrrrr}
\hline Region & 1978 & 1980 & 1985 & 1988 \\
\hline Northeast & 42 & 41 & 41 & 41 \\
West & 39 & 39 & 39 & 40 \\
$\begin{array}{l}\text { Southeast } \\
\text { Totala }\end{array}$ & 19 & 19 & 19 & 19 \\
& 100 & 100 & 100 & 100 \\
\hline
\end{tabular}

aTotals may not sum due to independent rounding.

\subsection{Northeast}

Figure 3.5 presents MSCET emission trends for the Northeast. $\mathrm{SO}_{2}$ is the predominant pollutant in the region, followed by $\mathrm{VOC}$ and $\mathrm{NO}_{\mathrm{X}}$. In general, emissions declined in the region over the 1975 to 1988 period, although emissions of all pollutants rose in 1984. Northeast $\mathrm{SO}_{2}$ emissions peaked at 14.2 $\mathrm{Mt}$ in 1976, fell to $10.5 \mathrm{Mt}$ in 1987, and rose to $10.8 \mathrm{Mt}$ in 1988. Northeast VOC emissions peaked at $10.8 \mathrm{Mt}$ in 1978 and fell to $7.5 \mathrm{Mt}$ in 1988 . Northeast $\mathrm{NO}_{\mathrm{x}}$ emissions peaked at 8.6 Mt in 1977 and fell to 6.9 Mt in 1987, remaining at that level in 1988.

Figure 3.6 presents Northeast $\mathrm{NO}_{\mathrm{x}}$ emissions by sector. Over most of the period, transportation was the largest emitter of $\mathrm{NO}_{\mathbf{X}}$, but in 1988, electric utilities became the predominant source of $\mathrm{NO}_{\mathbf{x}}$. Emissions of $\mathrm{NO}_{\mathrm{x}}$ from the transportation sector peaked at $4.0 \mathrm{Mt}$ in 1977 and 1978 , then fell to $2.6 \mathrm{Mt}$ in 1988 . Electric utility $\mathrm{NO}_{\mathrm{X}}$ emissions remained steady at about $2.7 \mathrm{Mt}$ through the late 1970 s and early 1980 s and fell to $2.5 \mathrm{Mt}$ in 1982 , but since then, the trend has been upward. Industrial fuel $\mathrm{NO}_{\mathrm{X}}$ emissions peaked at $1.2 \mathrm{Mt}$ in 1976, declined to around $0.8 \mathrm{Mt}$ in the mid 1980s, and have remained steady since then.

Figure 3.7 presents the $\mathrm{NO}_{\mathrm{x}}$ seasonal profile for the Northeast. The transportation and commercial/residential sectors had the largest seasonal variation, about $0.25 \mathrm{Mt}(1 \mathrm{Mt} / \mathrm{yr}$ equivalent annual rate). The seasonal patterns indicate that emissions from transportation in winter declined well below those from electric utilities beginning in the mid 1980s, a few years ahead of the annual average (Fig. 3.6). The counter-cyclical seasonal patterns for transportation and commercial/residential fuel combustion $\mathrm{NO}_{\mathrm{x}}$ emissions tended to cancel each other when aggregated for the region.

Figure 3.8 presents Northeast $\mathrm{SO}_{2}$ emissions by sector. As mentioned earlier, electric utilities were the predominant emitters of $\mathrm{SO}_{2}$, emitting $78 \%$ of the region's total $\mathrm{SO}_{2}$ in 1985 . Electric utility $\mathrm{SO}_{2}$ emissions peaked at $10.3 \mathrm{Mt}$ in 1976 , then fell to $8.1 \mathrm{Mt}$ in 1987 . This reduction represents an average annual rate of decline of $2.4 \%$. Electric utility $\mathrm{SO}_{2}$ emissions 


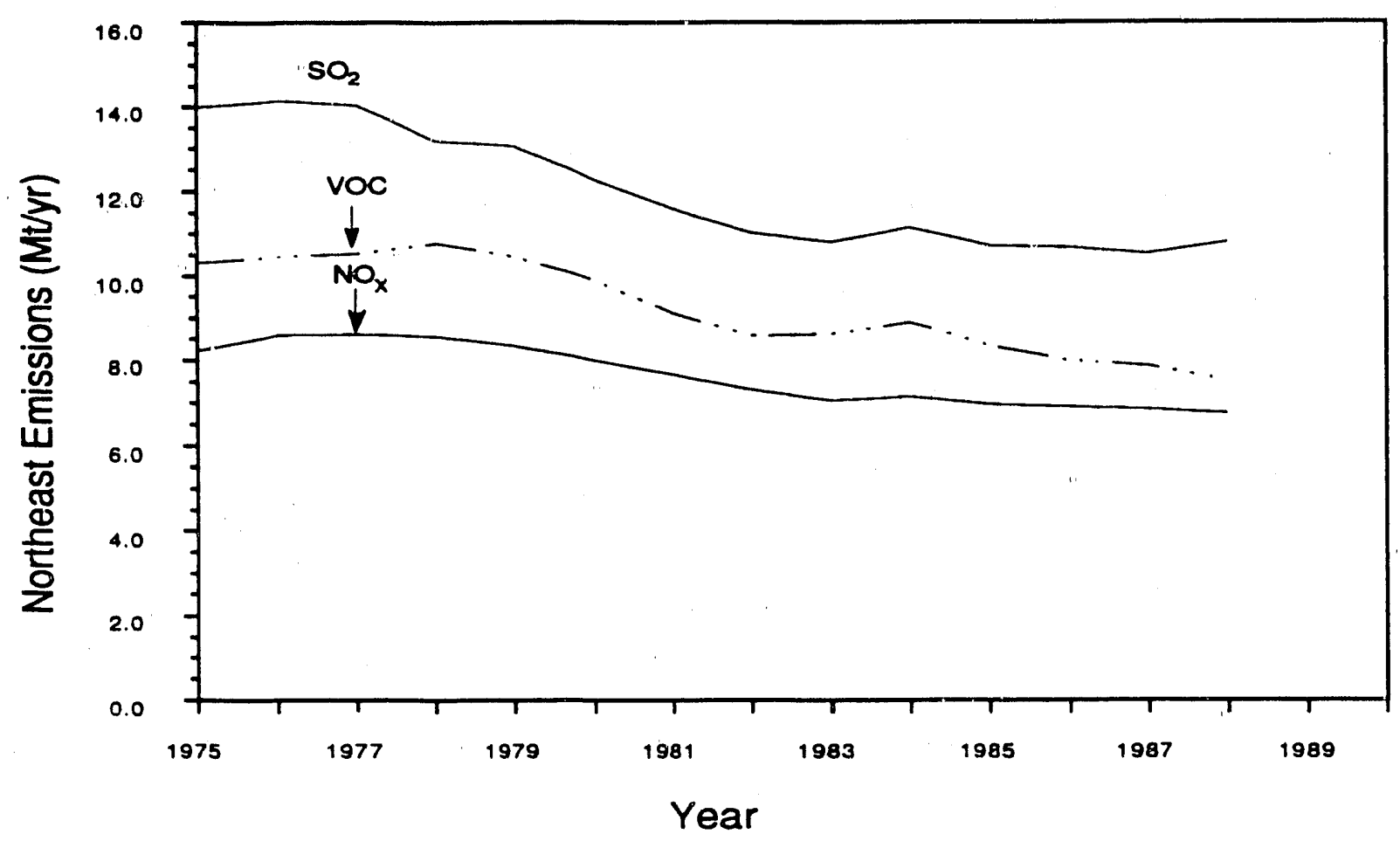

FIGURE 3.5 Northeast Emission Trends by Pollutant, 1975-1988

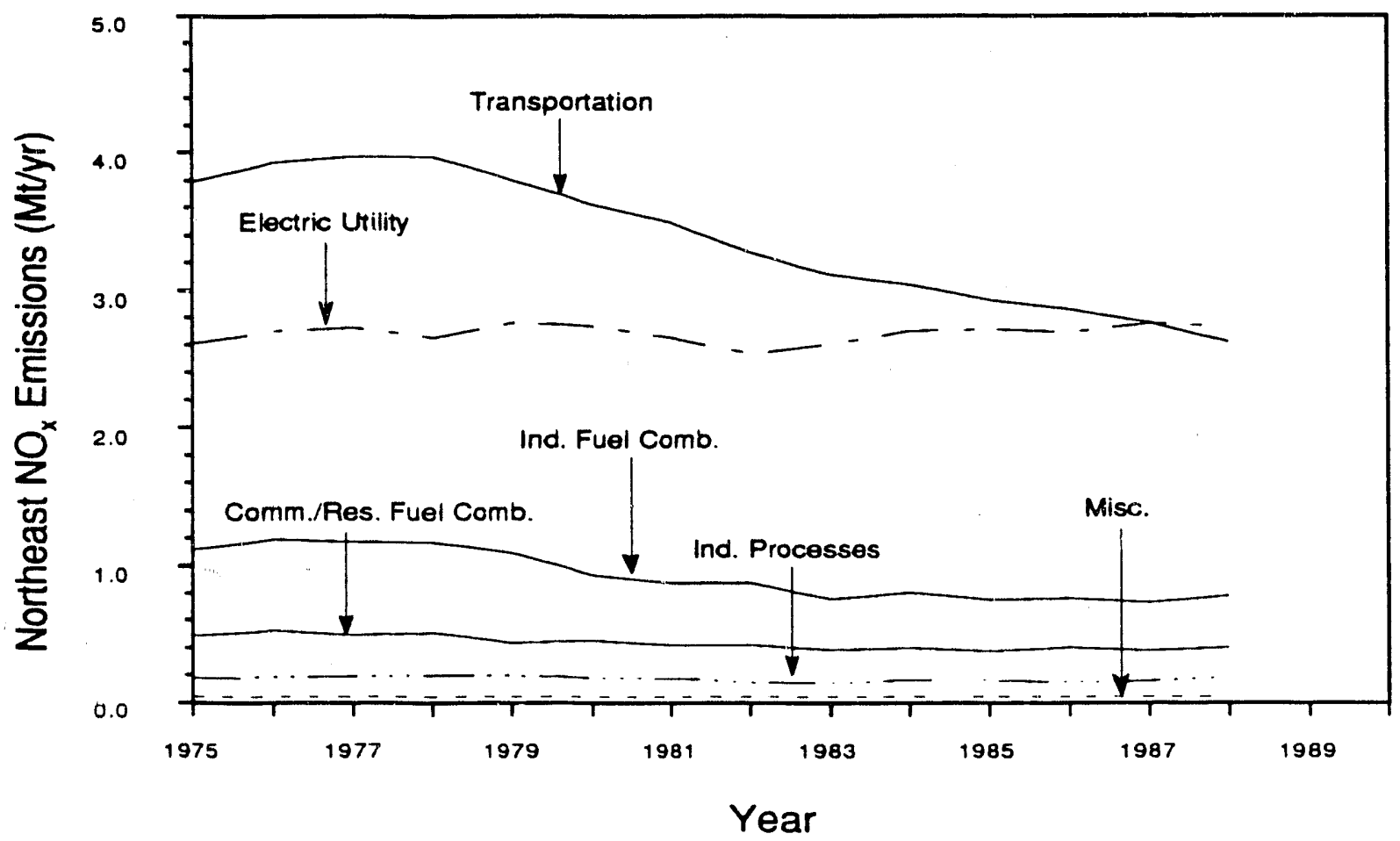

FIGURE 3.6 Northeast Sectoral NOx Emission Trends, 1975-1988 


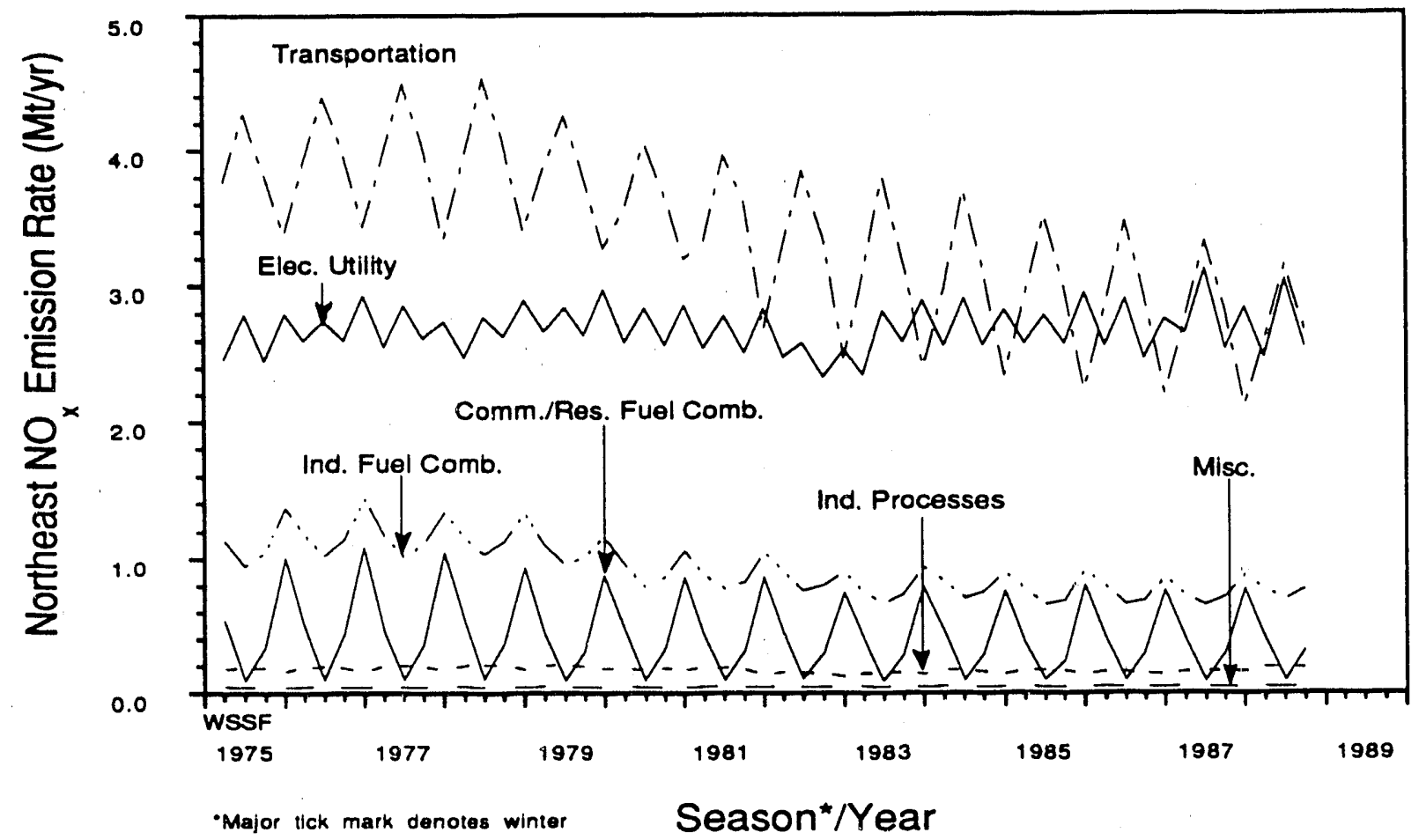

FIGURE 3.7 Northeast Sectoral NO Emission Trends Showing Seasonal Variations, 1975-1988

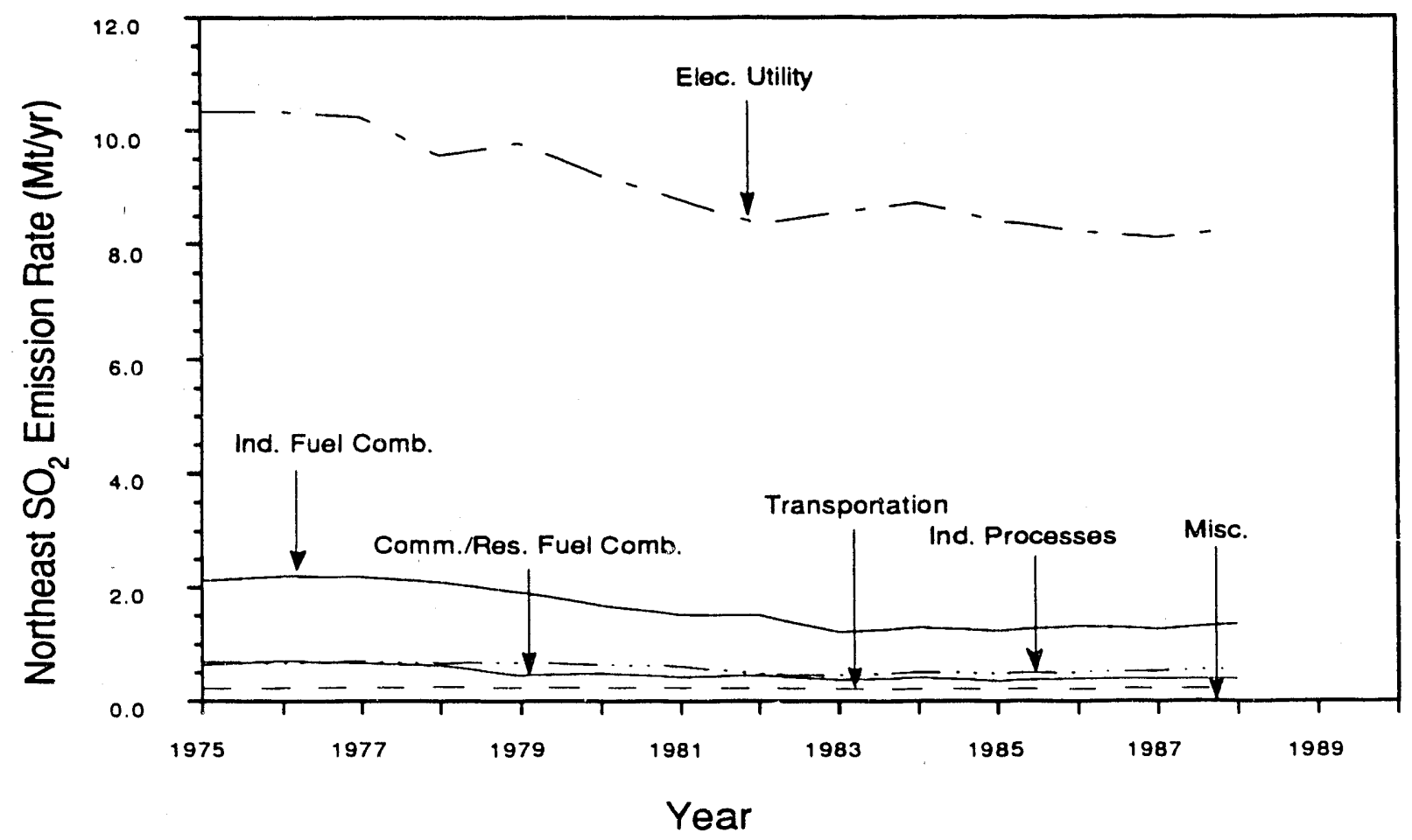

FIGURE 3.8 Northeast Sectoral $\mathrm{SO}_{2}$ Emission Trends, 1975-1988 
increased to 8.2 Mt in 1988. Industrial fuel combustion $\mathrm{SO}_{2}$ emissions decreased over the period, from $2.2 \mathrm{Mt}$ in 1976 to $1.2 \mathrm{Mt}$ in 1983 . Since then, emissions have held steady at around $1.3 \mathrm{Mt}$.

Figure 3.9 presents the seasonal profile for Northeast $\mathrm{SO}_{2}$ emissions. Only the electric utility and commercial/residential fuel combustion sectors exhibit significant seasonality. The variation was around $0.4 \mathrm{Mt}(1.5 \mathrm{Mt} / \mathrm{yr}$ annual rate) for electric utilities. It was $4.3 \mathrm{Mt}$ (1.7 Mt/yr annual rate) for the commercial/residential fuel combustion sector in the late 1970s before it fell to around $0.2 \mathrm{Mt}(0.7 \mathrm{Mt} / \mathrm{yr}$ annual rate $)$ in the mid $1980 \mathrm{~s}$.

Figure 3.10 presents Northeast VOC emissions by sector. Transportation was the predominant VOC-emitting sector, although these emissions fell from 5.3 Mt in 1978 to $2.9 \mathrm{Mt}$ in 1988. This decrease represents an annual average rate of decline of $5.7 \%$. Industrial process VOC emissions varied, decreasing from 3.4 Mt in 1978 to $2.5 \mathrm{Mt}$ in 1982, increasing to $3.0 \mathrm{Mt}$ in 1984 , and decreasing to $2.7 \mathrm{Mt}$ in 1988. Commercial/residential fuel combustion VOC emissions, mostly caused by wood burning, more than doubled, increasing from $0.3 \mathrm{Mt}$ in 1975 to $0.8 \mathrm{Mt}$ in 1984.

Figure 3.11 presents the seasonal profile for Northeast VOC emissions. Emissions from the transportation sector had a large seasonal variation; it was about $1 \mathrm{Mt}(4 \mathrm{Mt} / \mathrm{yr}$ annual rate) in the late $1970 \mathrm{~s}$ and about $0.8 \mathrm{Mt}$ ( $3 \mathrm{Mt} / \mathrm{yr}$ annual rate) in the late $1980 \mathrm{~s}$. The seasonal variation in commercial/residential fuel combustion VOC emissions rose from $0.25 \mathrm{Mt}$ in the late 1970s to

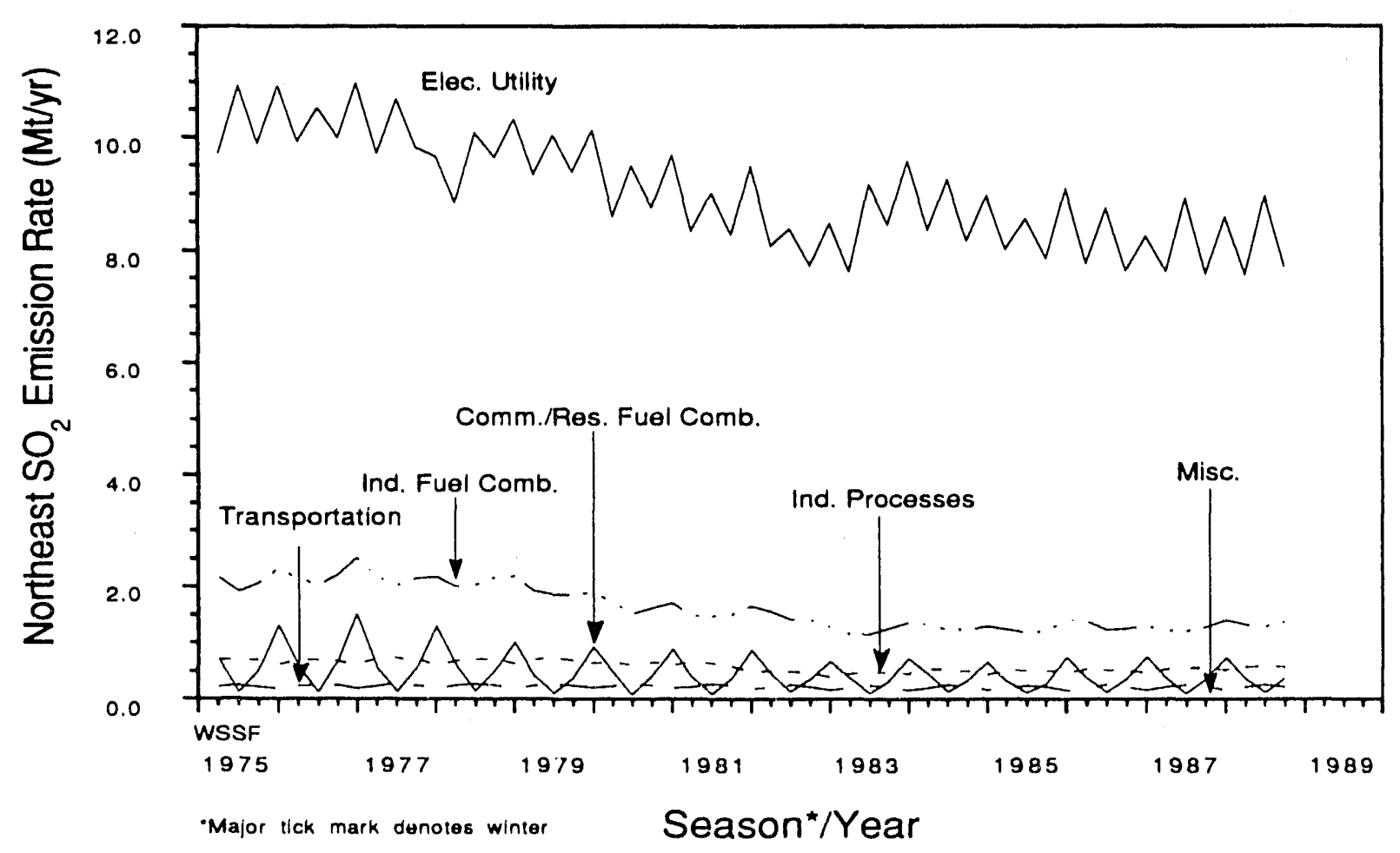

FIGURE 3.9 Northeast Sectoral $\mathrm{SO}_{2}$ Emissions Trends Showing Seasonal Variations, 1975-1988 


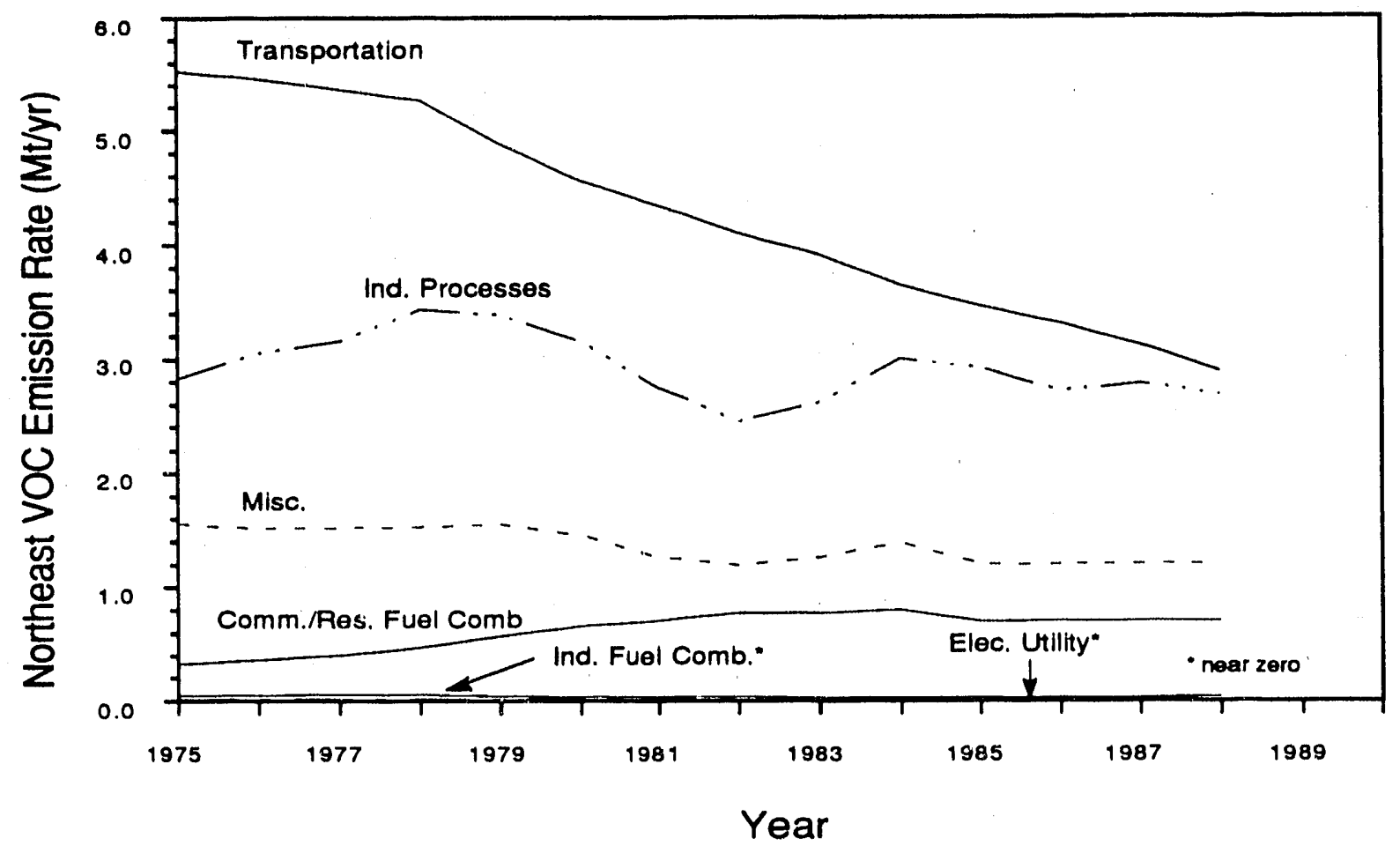

FIGURE 3.10 Northeast Sectoral VOC Emission Trends, 1975-1988

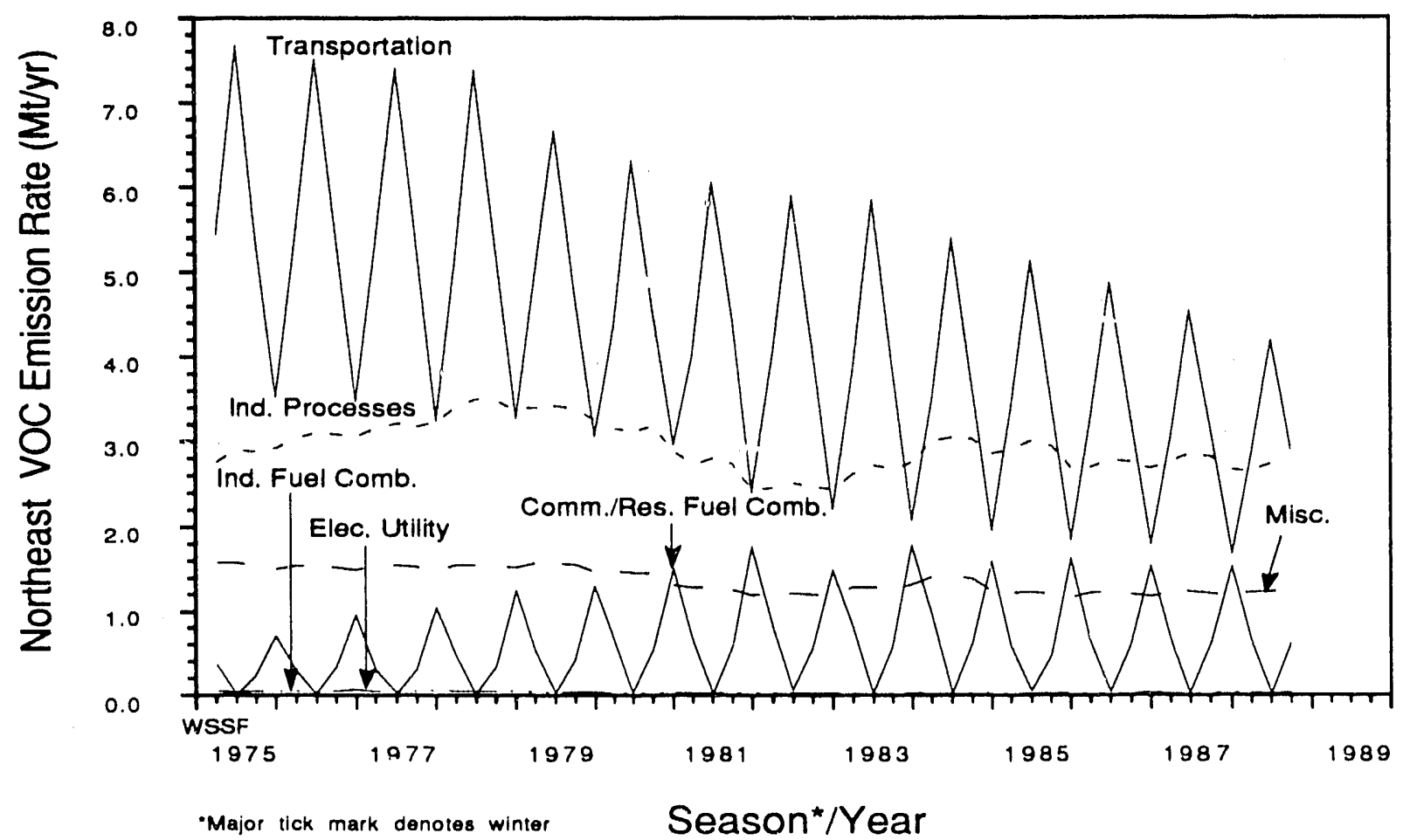

FIGURE 3.11 Northeast Sectoral VOC Emission Trends Showing Seasonal Variations, 1975-1988 
about $0.4 \mathrm{Mt}$ in the late 1980s. Transportation, which is the largest VOC-emitting sector on average, and commercial/residential fuel combustion, which is the fourth largest VOC-emitting sector on average, both emitted about the same amount of VOC in winter.

\subsection{Southeast}

Figure 3.12 presents MSCET emission trends for the Southeast. $\mathrm{SO}_{2}$ was the predominant pollutant in this region, followed by VOC and $\mathrm{NO}_{\mathrm{x}}$. Southeast $\mathrm{SO}_{2}$ emissions peaked at $6.0 \mathrm{Mt}$ in 1977 and fell to $4.6 \mathrm{Mt}$ in 1982. Since $1984, \mathrm{SO}_{2}$ emissions in the region have been rising; they reached 5.0 Mt in 1988. Southeast VOC emissions peaked at 5.0 Mt in 1978 and fell to $3.6 \mathrm{Mt}$ in 1988. Southeast $\mathrm{NO}_{\mathrm{x}}$ emissions peaked at $3.6 \mathrm{Mt}$ in 1978 , fell slightly to $3.2 \mathrm{Mt}$ in 1982 , and remained near 3.2 Mt through 1988.

Figure 3.13 presents Southeast $\mathrm{NO}_{\mathrm{x}}$ emissions by sector. For most of the 1975 to 1988 period, the transportation sector was the predominant source of $\mathrm{NO}_{\mathbf{x}}$, but in 1988 , it was surpassed by electric utilities. Transportation $\mathrm{NO}_{\mathrm{x}}$ emissions peaked at $1.8 \mathrm{Mt}$ in 1978 and fell to 1.3 $\mathrm{Mt}$ in 1988. Electric utility emissions reached an intermediate peak of $1.3 \mathrm{Mt}$ in 1981 before falling slightly to $1.2 \mathrm{Mt}$ in 1982 . Since then, $\mathrm{NO}_{\mathrm{x}}$ emissions have risen steadily; they reached $1.4 \mathrm{Mt}$ in 1988.

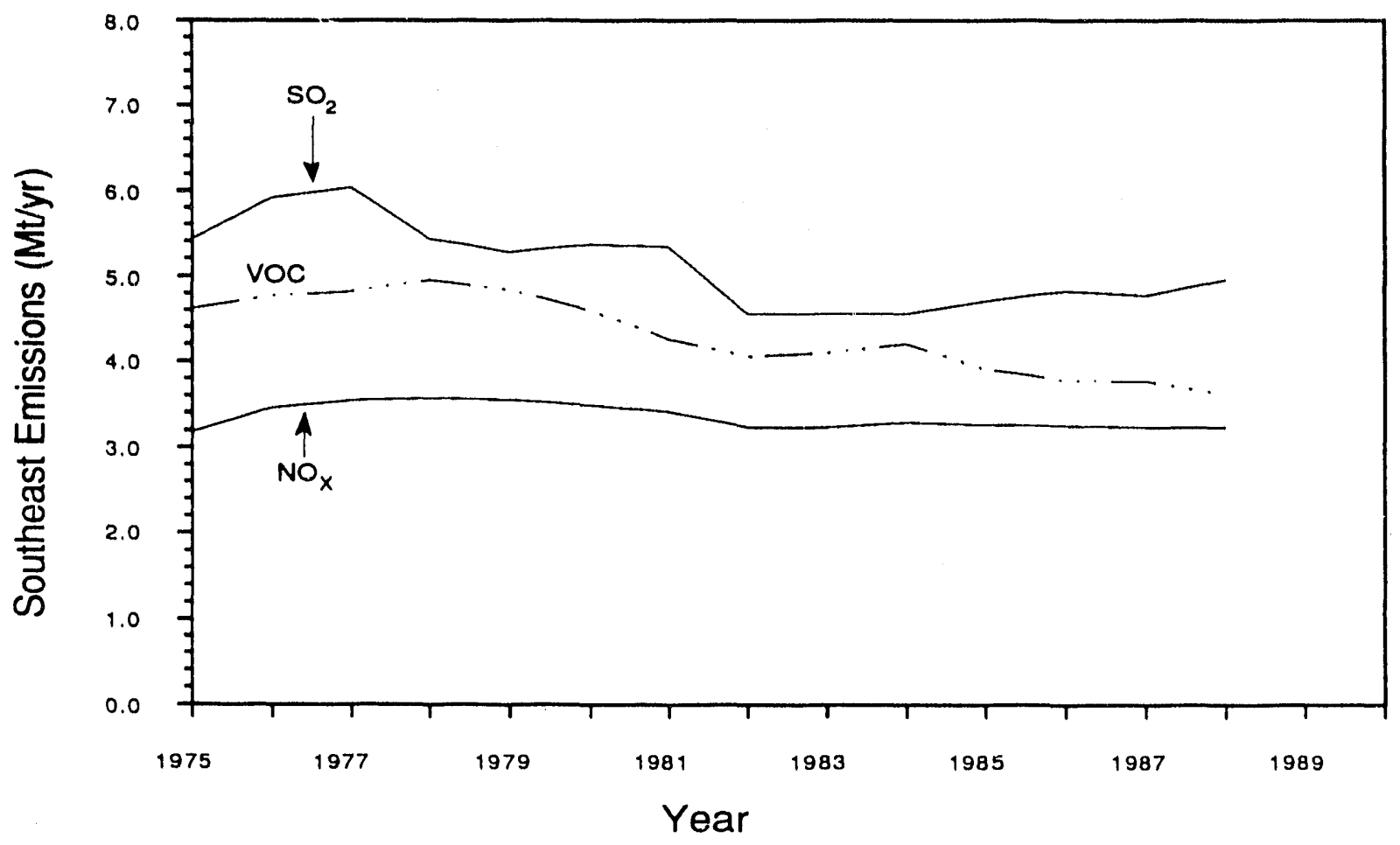

FIGURE 3.12 Southeast Emission Trends by Pollutant, 1975-1988 


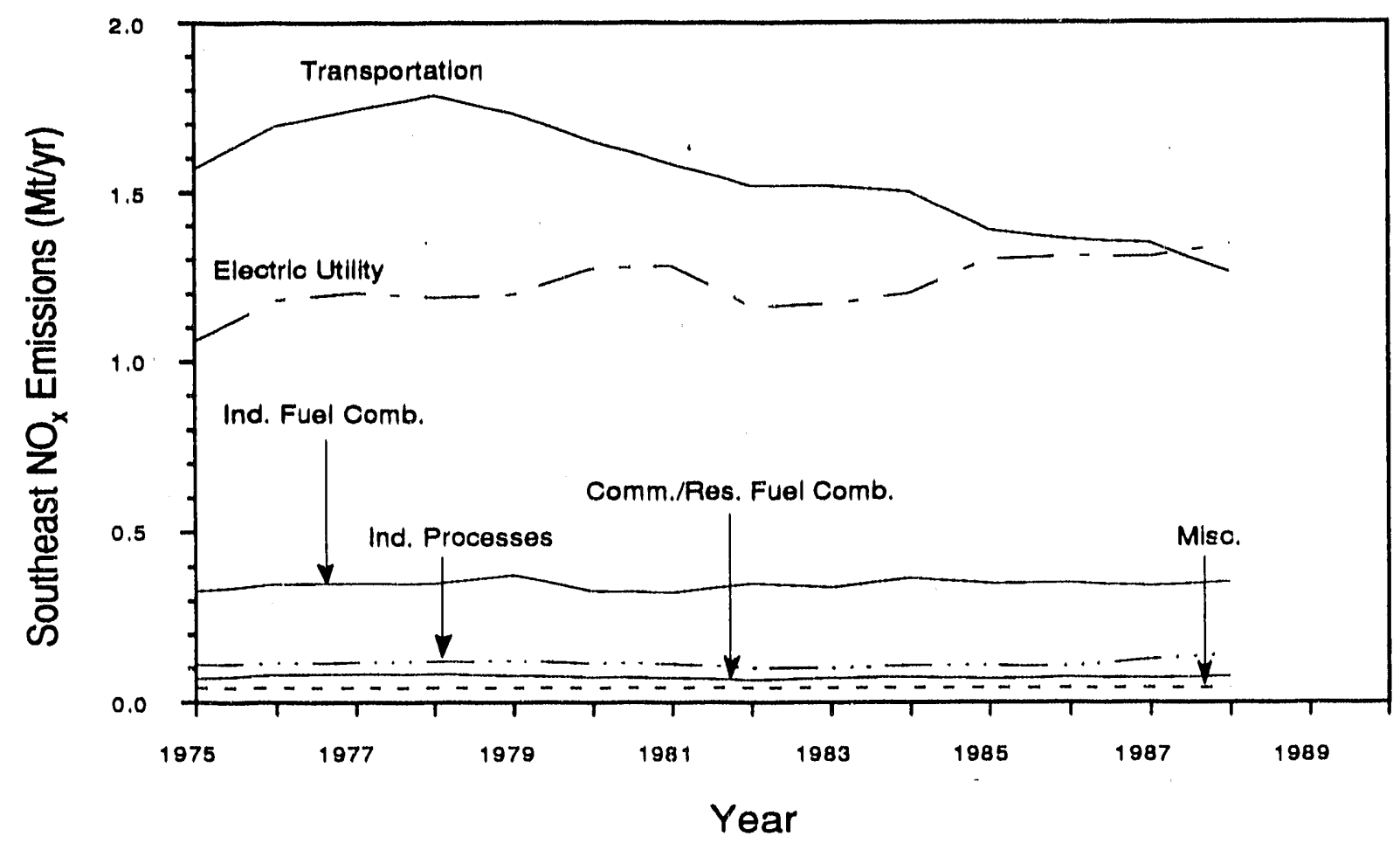

FIGURE 3.13 Southeast Sectoral NOX Emission Trends, 1975-1988

Figure 3.14 presents the Southeast $\mathrm{NO}_{\mathbf{x}}$ seasonal profile. The summer emission maximums for the electric utility and transportation sectors, when combined, would result in a $0.25 \mathrm{Mt}$ variation (1 Mt/yr variation at an annual equivalent rate) for the regional aggregate.

Figure 3.15 presents Southeast $\mathrm{SO}_{2}$ emissions by sector. As was the case for the Northeast, electric utilities were the predominant emitters. They emitted $81 \%$ of the region's $\mathrm{SO}_{2}$ in 1985. Electric utility SO2 emissions peaked at $5.0 \mathrm{Mt}$ in 1977, then fell to $3.7 \mathrm{Mt}$ in 1984. Since then, emissions rose, reaching 4.0 Mt in 1988.

Figure 3.16 presents the seasonal profile for Southeast $\mathrm{SO}_{2}$ emissions. The largest seasonal variation occurs in the electric utility sector; the variation averaged about $0.25 \mathrm{Mt}$ (1 Mt/yr at an annual equivalent rate), although it was as high as $0.4 \mathrm{Mt}$ or more for some years.

Figure 3.17 presents Southeast VOC emissions by sector. The transportation sector was the predominant source of 'VOC emissions in this region. However, the amount of VOC emissions from the transportation sector has been falling, most rapidly since 1978. Transportation VOC emissions decreased from $2.5 \mathrm{Mt}$ in 1978 to $1.5 \mathrm{Mt}$ in 1988. This represents an average annual rate of decline of $5.0 \%$. VOC emission trends in the industrial process and miscellaneous sectors (next largest after transportation) showed both increases and decreases, although emissions in 1988 were less than the maximums reached in the late 1970s. 


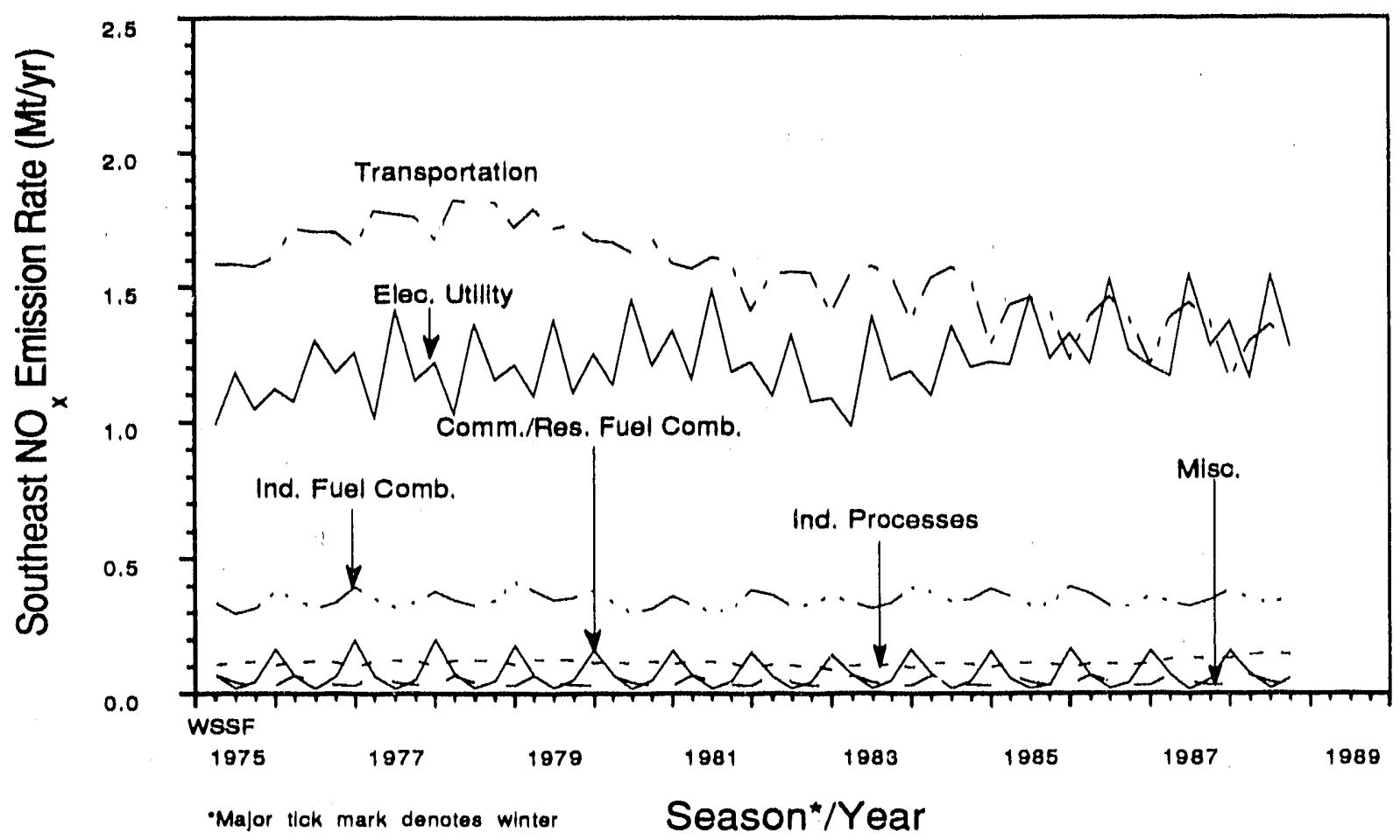

FIGURE 3.14 Southeast Sectoral NOX Emissions Trends Showing Seasonal Variations, 1975-1988

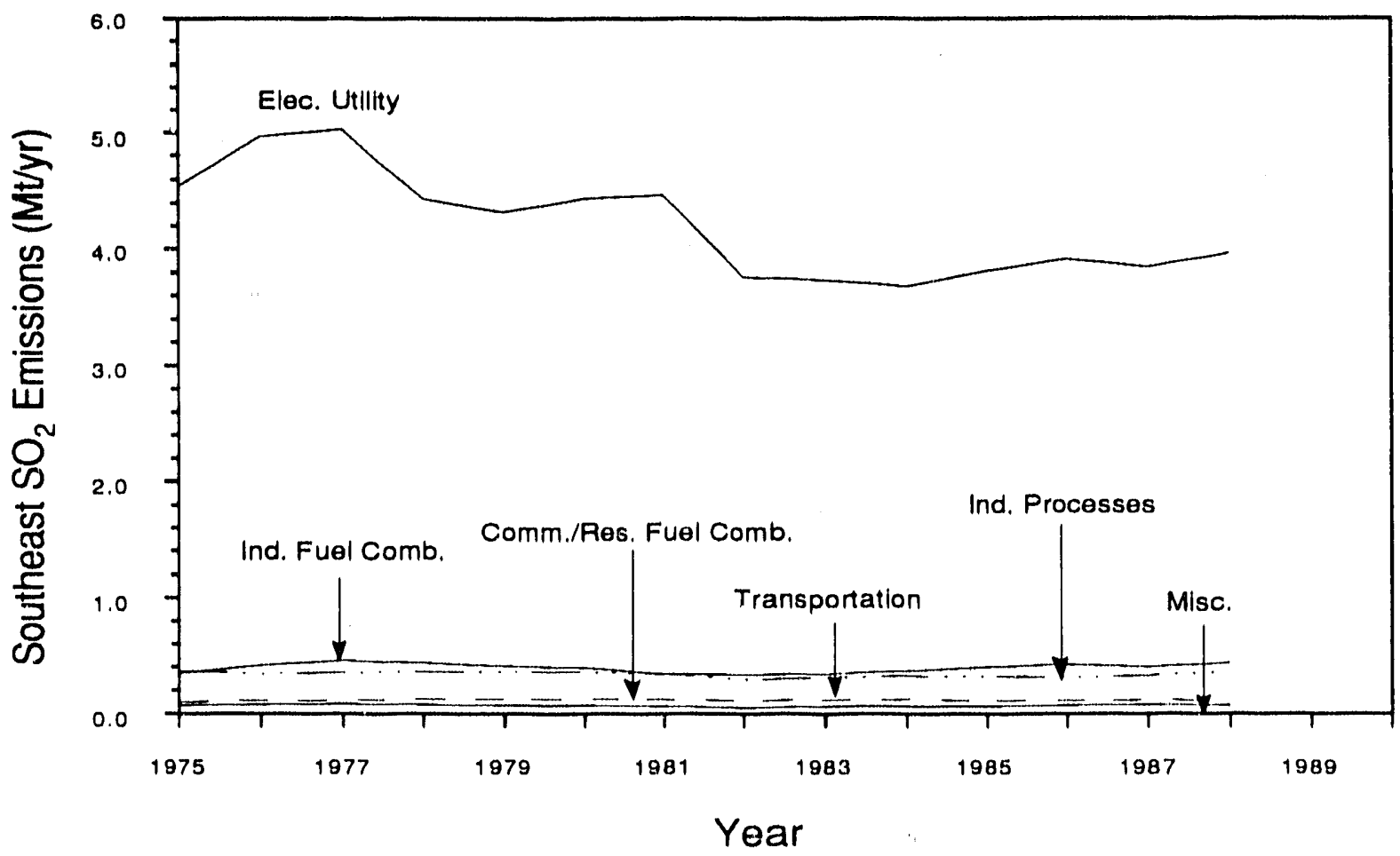

FIGURE 3.15 Southeast Sectoral $\mathrm{SO}_{2}$ Emission Trends, 1975-1988 


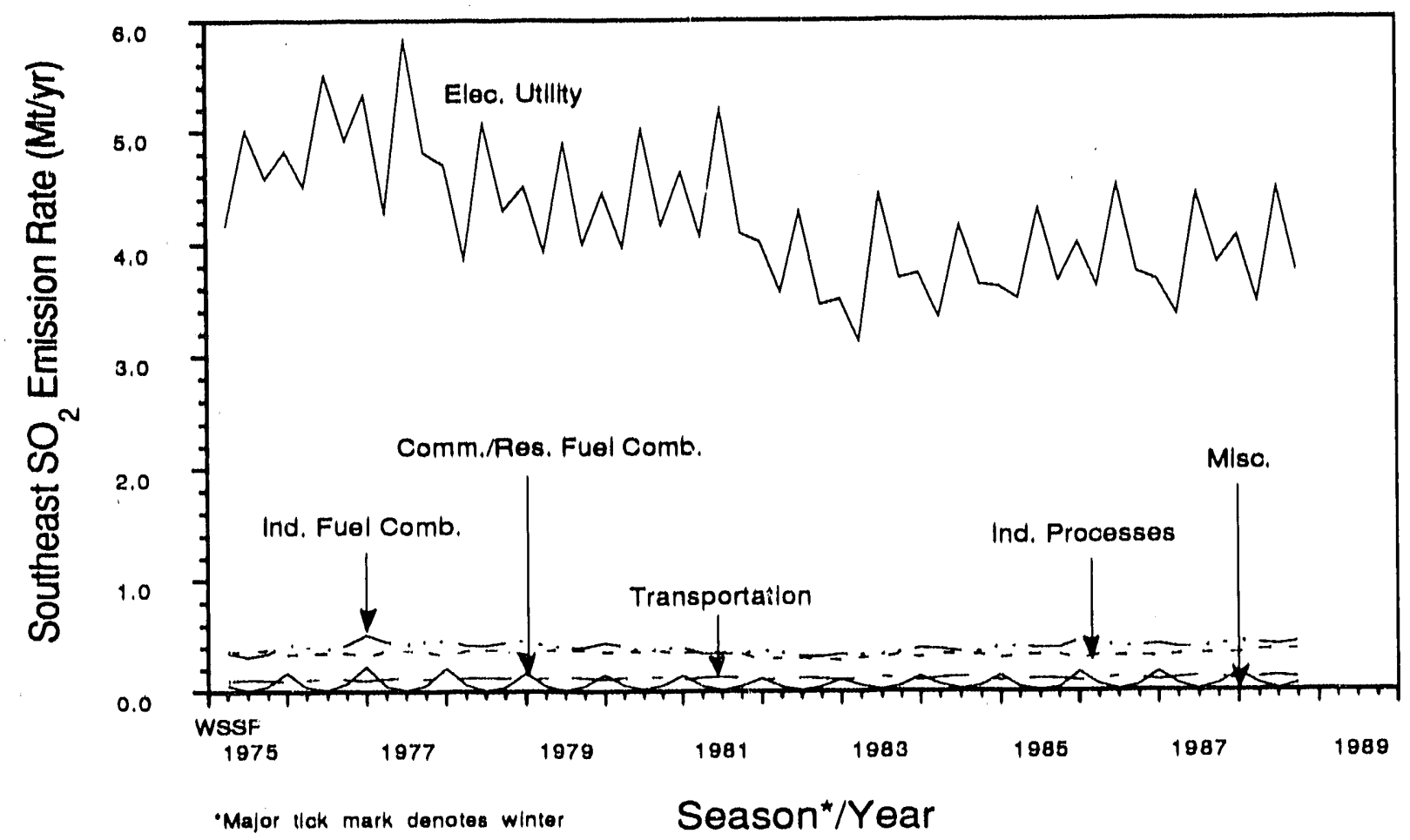

FIGURE 3.16 Southeast Sectoral $\mathrm{SO}_{2}$ Emission Trends Showing Seasonal Variations, 1975-1988

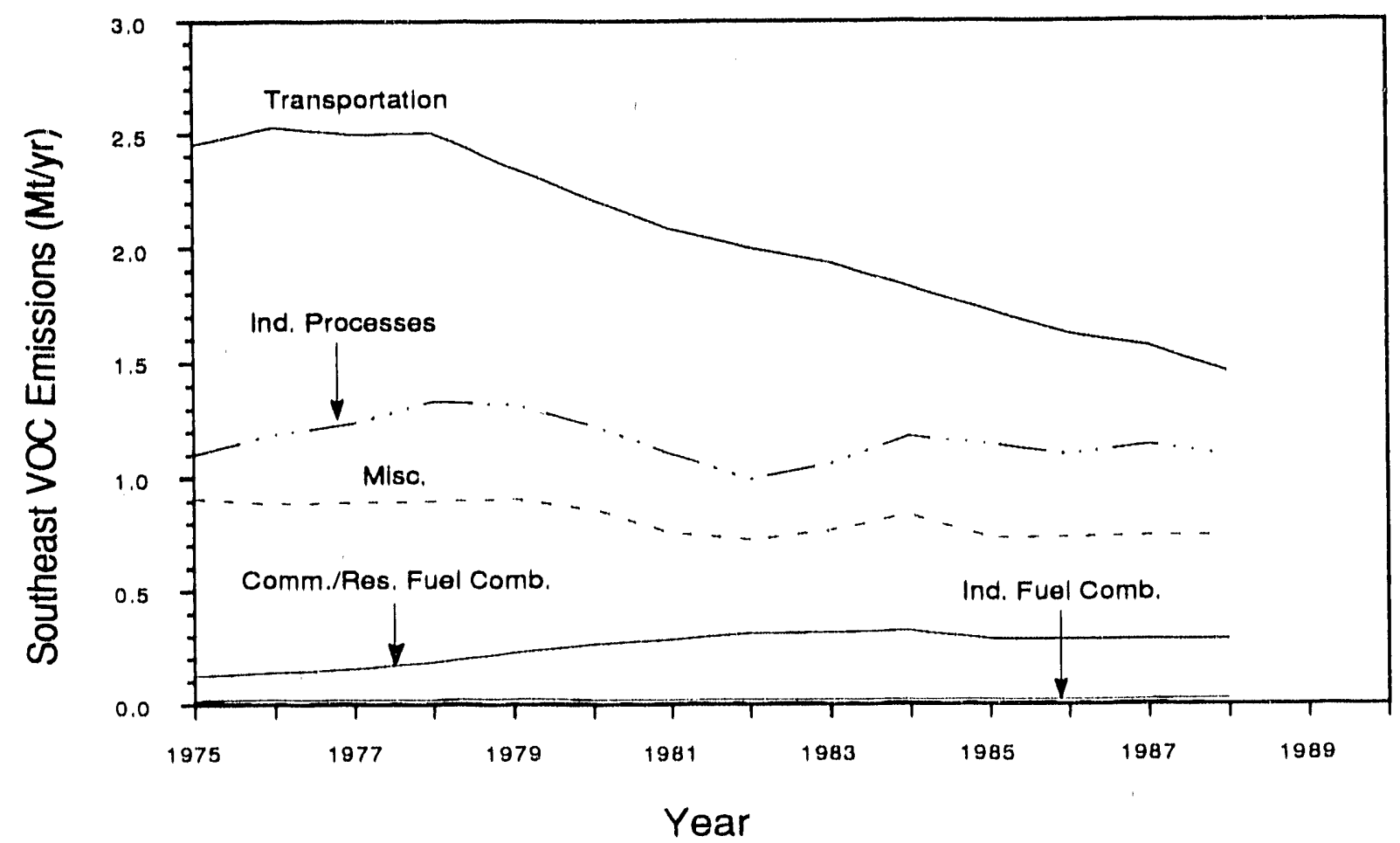

FIGURE 3.17 Southeast Sectoral VOC Emission Trends, 1975-1988 
Figure 3.18 presents the seasonal profile for Southeast VOC emissions. Both the transportation and commercial/residential fuel combustion sectors exhibited the largest seasonal variation, just less than $0.25 \mathrm{Mt}(1 \mathrm{Mt} / \mathrm{yr}$ at the annual rate) in the mid and late $1980 \mathrm{~s}$. (Their counter-cyclical patterns tend to cancel each other in the aggregate, so the trend of the regional total VOC emissions is smoother.)

\subsection{West}

Figure 3.19 presents the MSCET emission trends for the West. Unlike the case for other regions, VOC was generally the predominant pollutant, although VOC emissions were lower than $\mathrm{NO}_{\mathrm{x}}$ emissions after 1985. Emissions of VOC in the West peaked at $10.1 \mathrm{Mt}$ in 1978 and fell to 7.4 Mt in 1988. Western $\mathrm{NO}_{\mathrm{x}}$ emissions peaked at $9.1 \mathrm{Mt}$ in 1978 and fell to $7.8 \mathrm{Mt}$ in 1986. Since then, $\mathrm{NO}_{\mathrm{x}}$ emissions increased, reaching $8.1 \mathrm{Mt}$ in 1988 . Western $\mathrm{SO}_{2}$ emissions peaked at 6.4 $\mathrm{Mt}$ in 1979, fell to $5.0 \mathrm{Mt}$ in 1987, and increased to $5.2 \mathrm{Mt}$ in 1988.

Figure 3.20 presents western $\mathrm{NO}_{\mathrm{x}}$ emission trends by sector. The transportation sector was the predominant emitter of $\mathrm{NO}_{\mathrm{x}}$ in the region. Emissions from this sector reached a peak of 4.0 Mt in 1978 and fell to $3.0 \mathrm{Mt}$ in 1988. This decrease represents an average annual rate of decline of $2.6 \%$. Industrial fuel combustion $\mathrm{NO}_{\mathrm{x}}$ emissions reached a peak of $2.6 \mathrm{Mt}$ in 1978 and fell to $2.1 \mathrm{Mt}$ by 1980 . Since then, these emissions have remained relatively constant. Electric utility $\mathrm{NO}_{\mathrm{x}}$ emissions increased almost continuously over the period, from 1.4 Mt in 1975 to

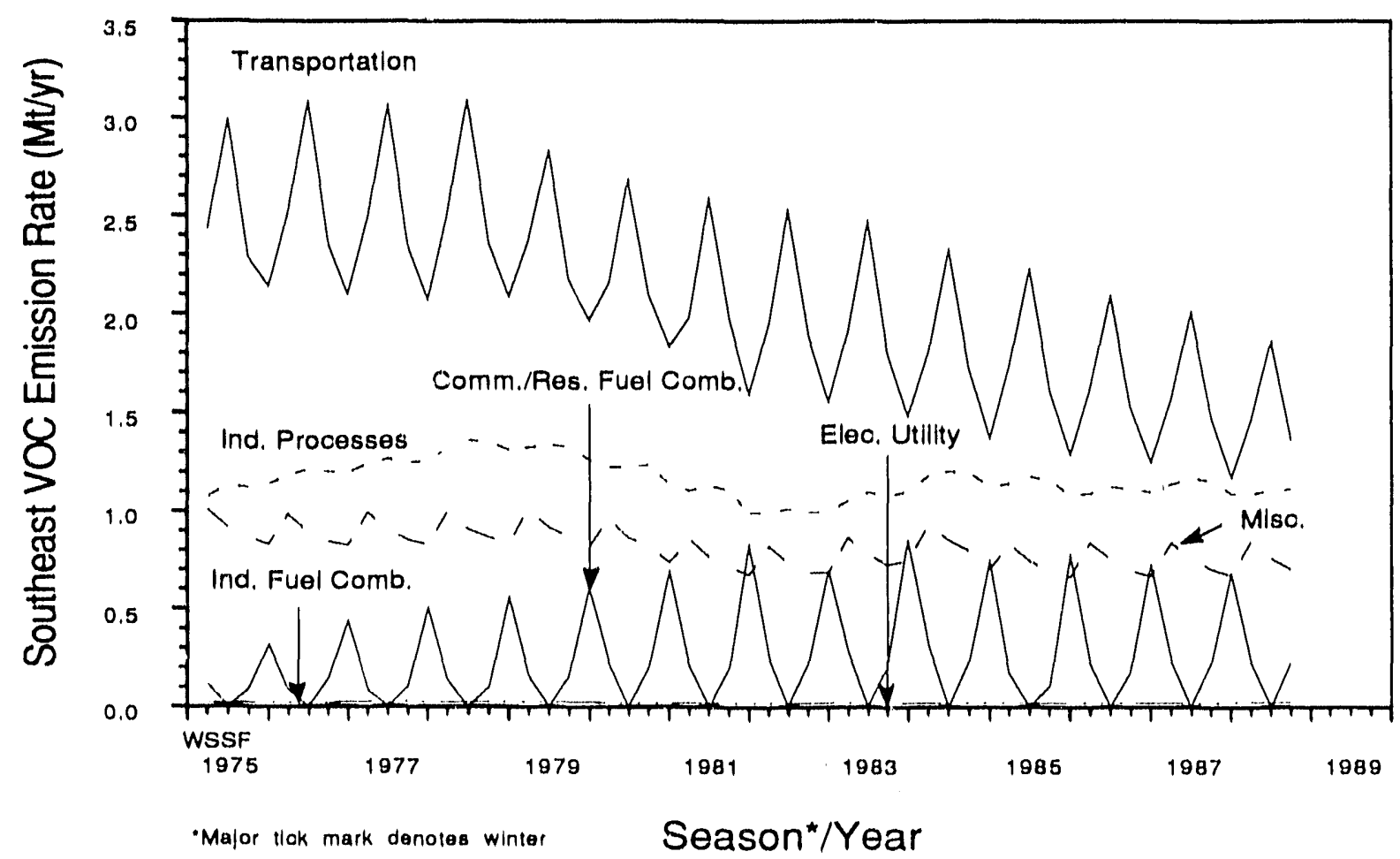

FIGURE 3.18 Southeast Sectoral VOC Emission Trends Showing Seasonal Variations, 1975-1988 


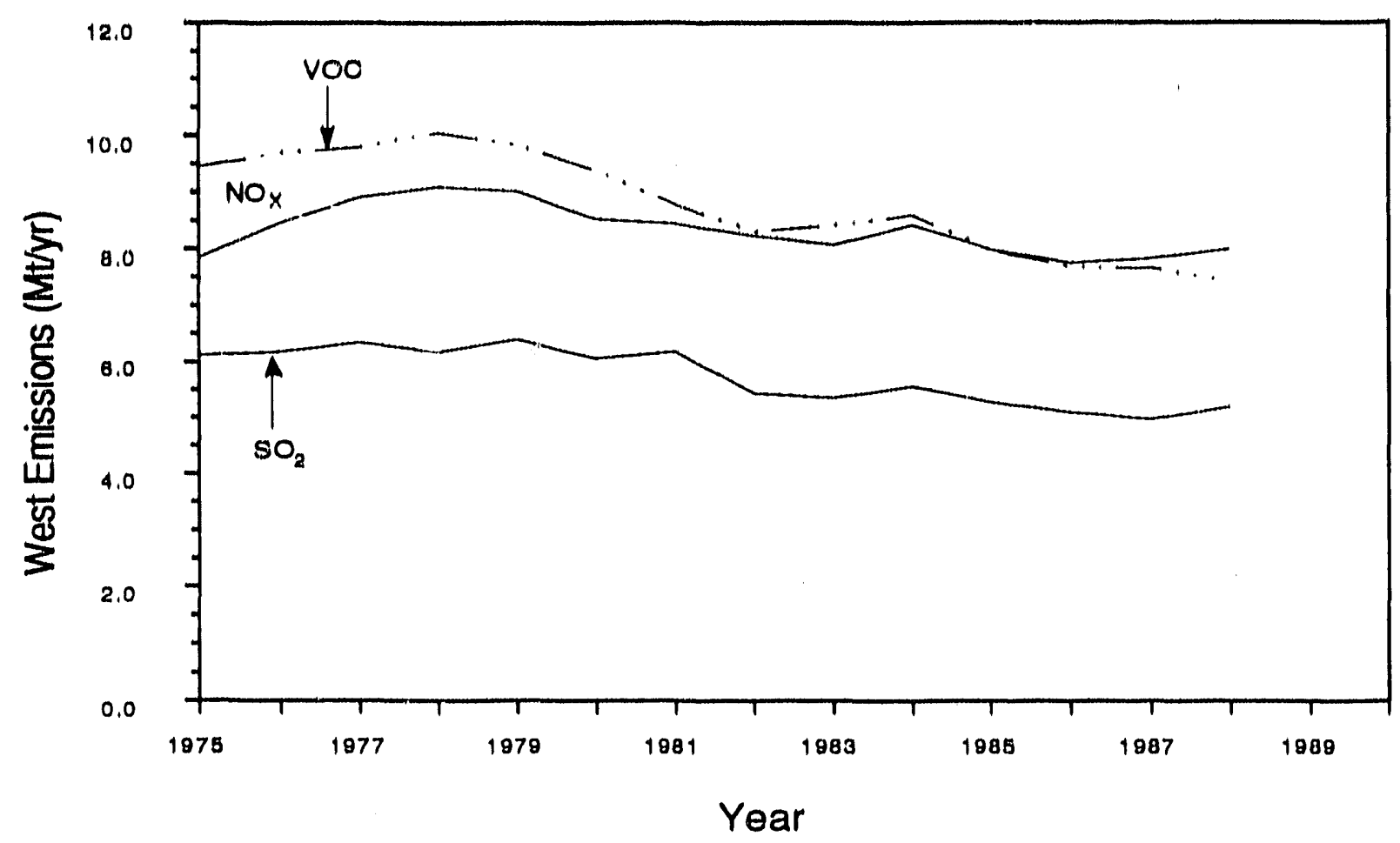

FIGURE 3.19 West Emlssion Trends by Pollutant, 1975-1988

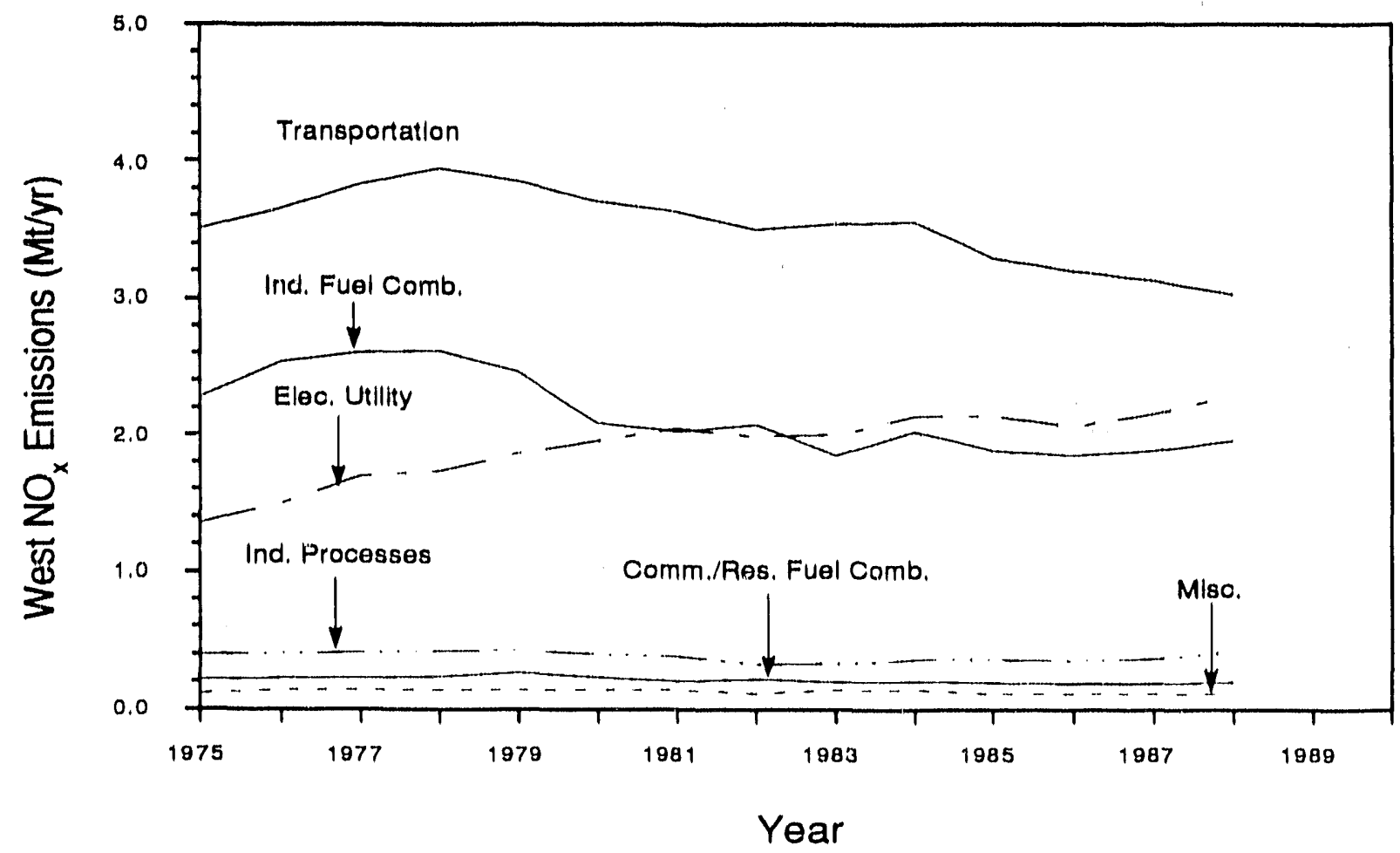

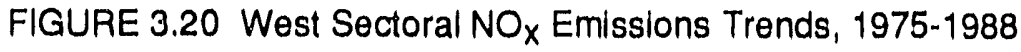


2.3 Mt in 1988. This increase represents an average annual rate of increase of $4.3 \%$. The $0.9 \cdot \mathrm{Mt}$ increase in this sector almost nullifled the 1-Mt reduction in the transportation sector.

Figure 3.21 presents the seasonal profile for western $\mathrm{NO}_{\mathrm{x}}$ emissions. Four sectors -transportation, industrial fuel combustion, electric utility, and commercial/residential fuel combustion -- exhibited some seasonality; transportation had the largest variation, at about $0.25 \mathrm{Mt}$ ( $1 \mathrm{Mt} / \mathrm{yr}$ on an equivalent annual rate basis).

Figure 3.22 presents western $\mathrm{SO}_{2}$ emissions by sector. In recent years, electric utilities have been the predominant source of $\mathrm{SO}_{2}$ emissions in the West. Their emissions rose from 2.0 $\mathrm{Mt}$ in 1975 to $2.5 \mathrm{Mt}$ in 1984. Electric utility $\mathrm{SO}_{2}$ emissions decreased to $2.2 \mathrm{Mt}$ in 1986, but reached 2.3 $\mathrm{Mt}$ in 1988. Industrial process $\mathrm{SO}_{2}$ emissions fell from 3.1 $\mathrm{Mt}$ in 1975 to $1.4 \mathrm{Mt}$ in 1987, a reduction of more than half. This decrease was caused primarily by reduced emissions from copper smelting plants, the largest of which are located in this region. Emissions from the copper smelting industry in the West totaled $1.9 \mathrm{Mt}$ in 1975 and fell to $0.3 \mathrm{Mt}$ in 1988.

Figure 3.23 presents the $\mathrm{SO}_{2}$ seasonal profile for the West. Electric utilities and commercial/residential fuel combustion exhibited the most significant seasonal variation; electric utility had the largest variation, at around $0.2 \mathrm{Mt}(0.7 \mathrm{Mt} / \mathrm{yr}$ on an equivalent annual rate basis).

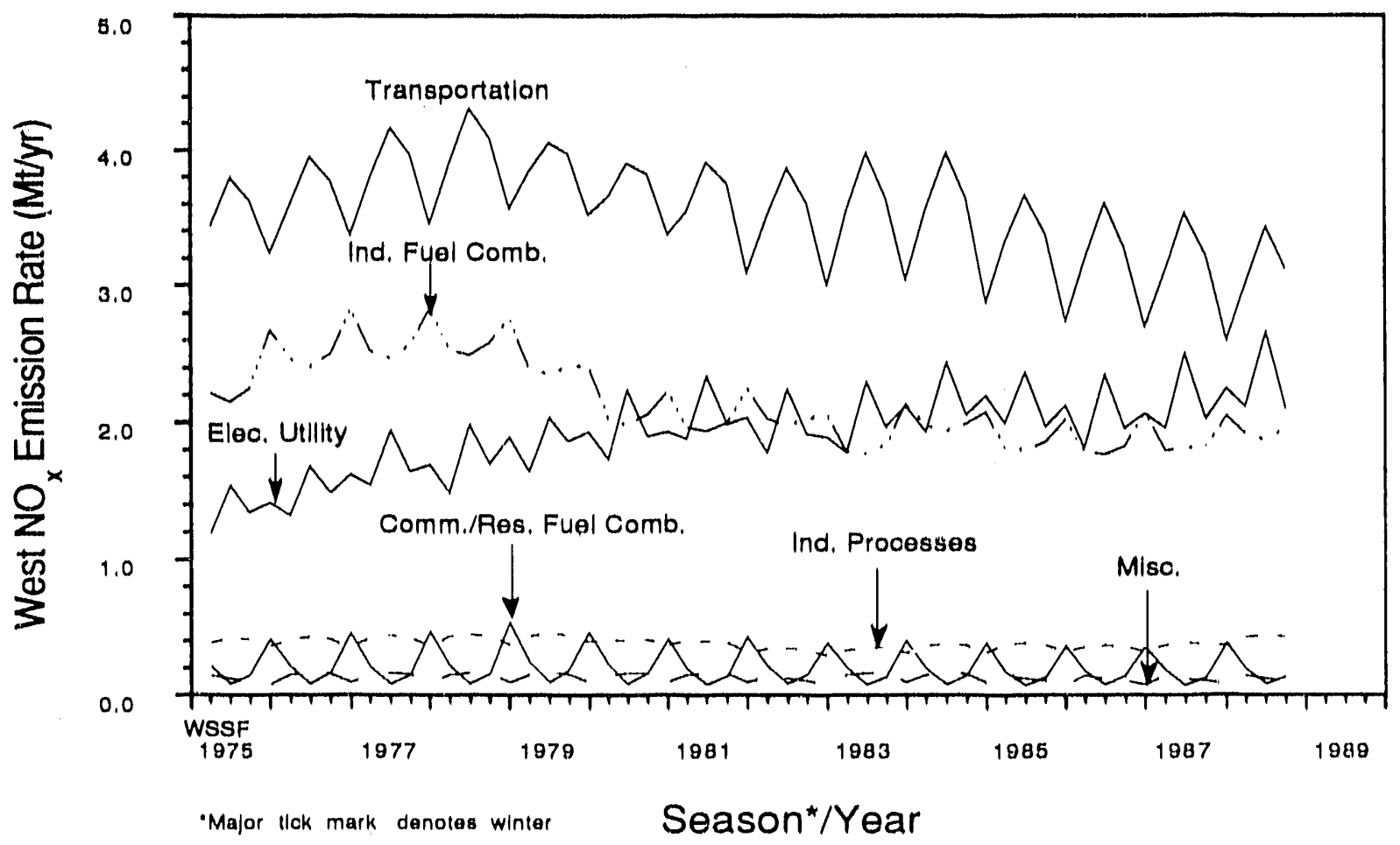

FIGURE 3.21 West Sectoral NO X Emission Trends Showing Seasonal Variatlons, 1975-1988 


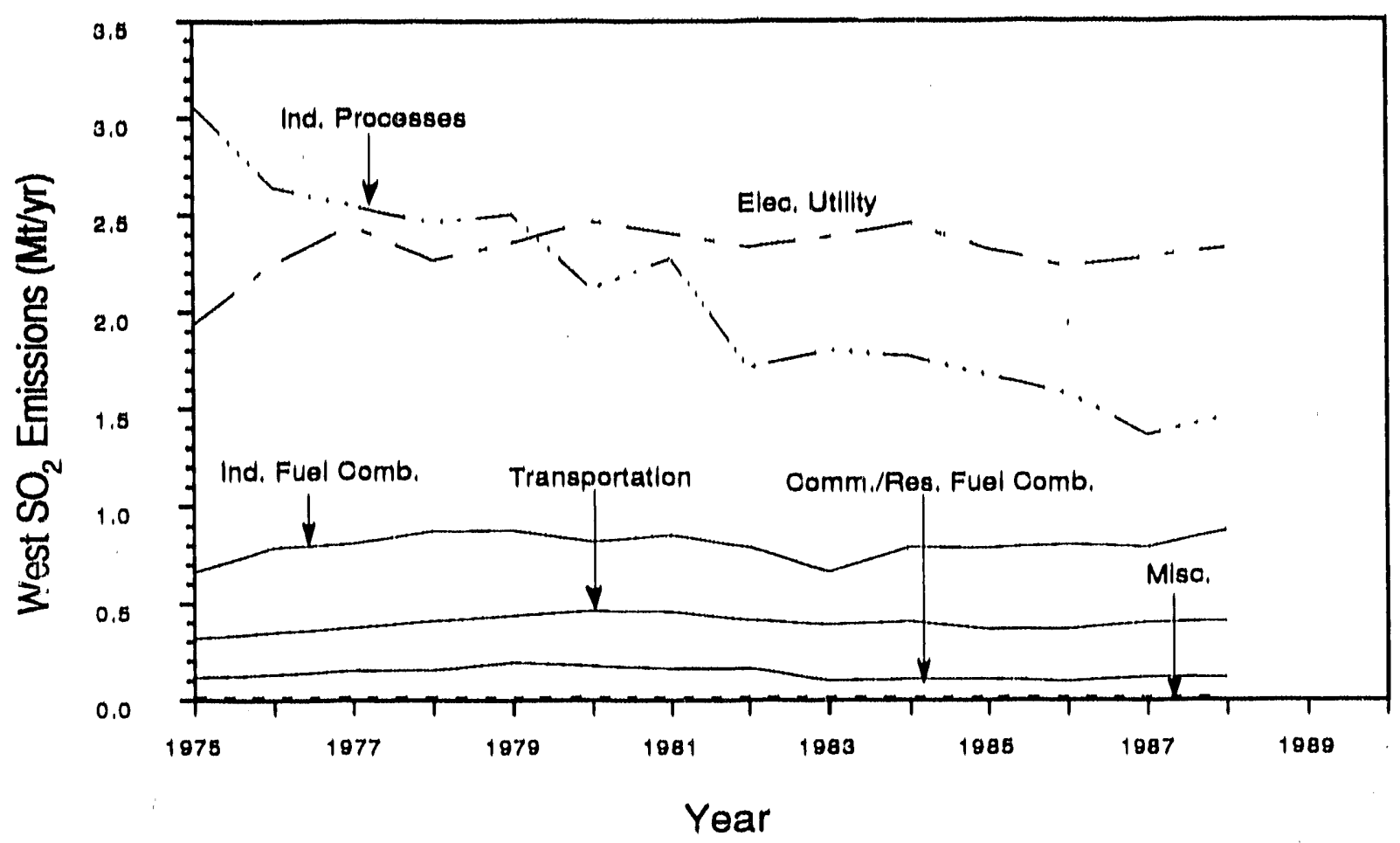

FIGURE 3.22 West Sectoral $\mathrm{SO}_{2}$ Emission Trends, 1975-1988

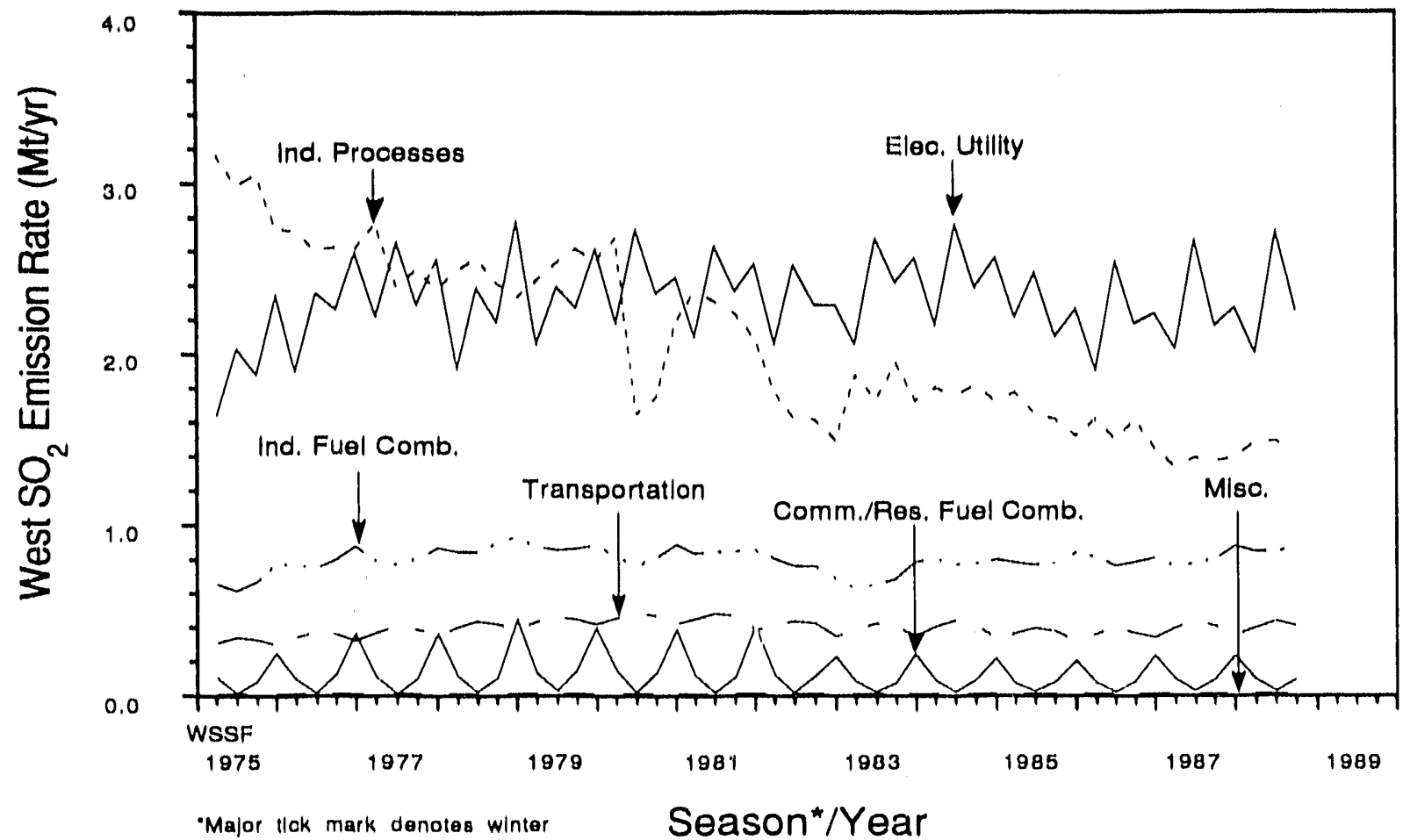

FIGURE 3.23 West Sectoral $\mathrm{SO}_{2}$ Emission Trends Showing Seasonal Variations, 1975-1988 
Figure 3.24 presents VOC emissions in the West, by sector. As was the case in the other regions, the transportation sector is the predominant source of VOC emissions for most of the period, but VOC emissions from this sector fell below those from the industrial process sector after 1986. Transportation VOC emissions declined most rapidly after 1978, when they totaled $4.2 \mathrm{Mt}$. They fell at an annual average rate of $5.1 \%$, reaching $2.5 \mathrm{Mt}$ in 1988 . Emission trends in the industrial process and miscellaneous sectors (next largest after transportation) showed both increases and decreases, although VOC emissions in 1988 were less than the maximums reached in the late 1970 s.

Figure 3.25 presents the VOC seasonal profile in the West. The transportation sector had a seasonal variation of almost $0.5 \mathrm{Mt}(2 \mathrm{Mt} / \mathrm{yr}$ on an equivalent annual rate basis) in the late $1970 \mathrm{~s}$, but this moderated slightly to around $0.6 \mathrm{Mt}$ in the late $1980 \mathrm{~s}$. The commercial/residential fuel combustion sector's seasonal variation averaged around $0.2 \mathrm{Mt}$ for most of the $1980 \mathrm{~s}$.

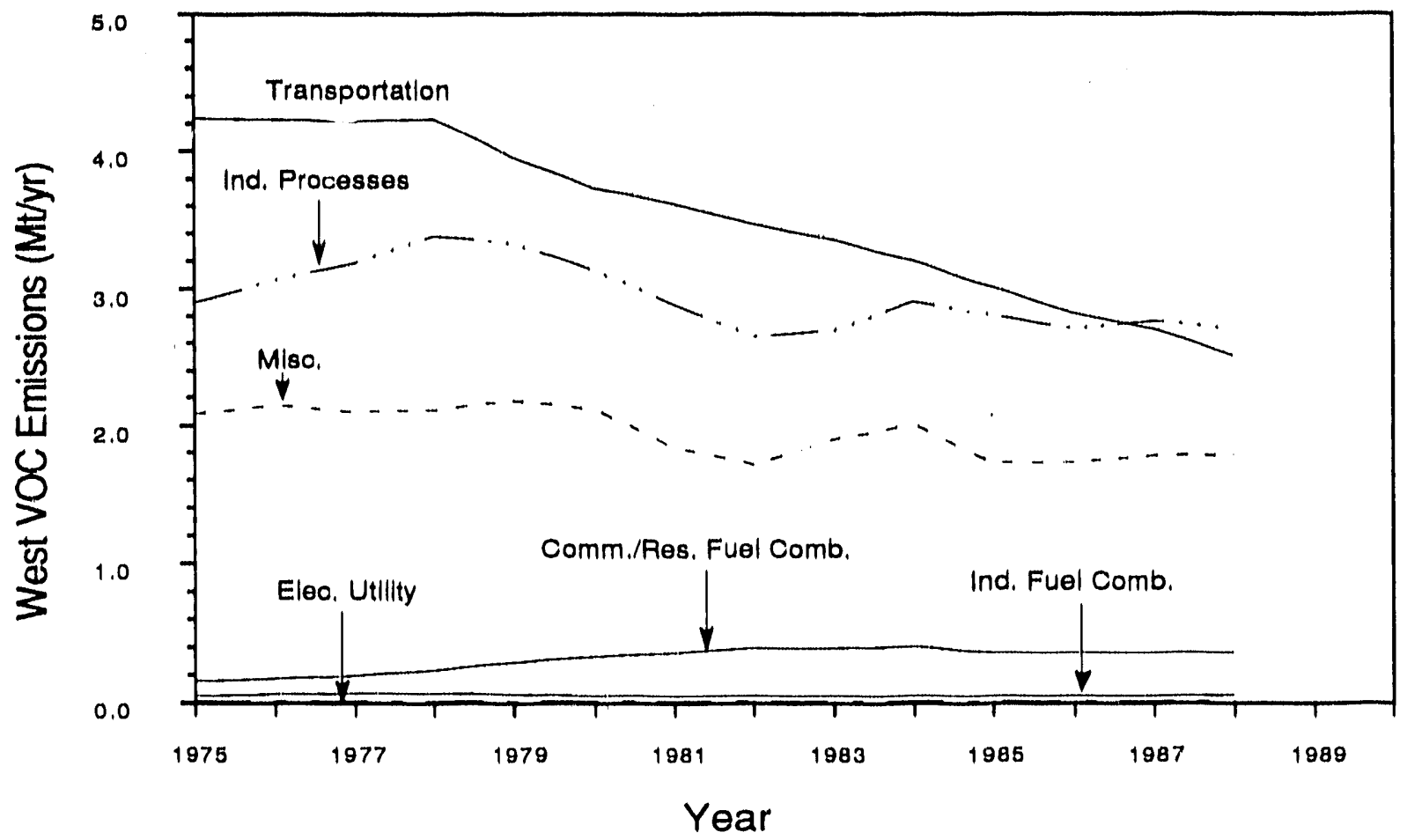

FIGURE 3.24 West Sectoral VOC Emission Trend, 1975-1988 


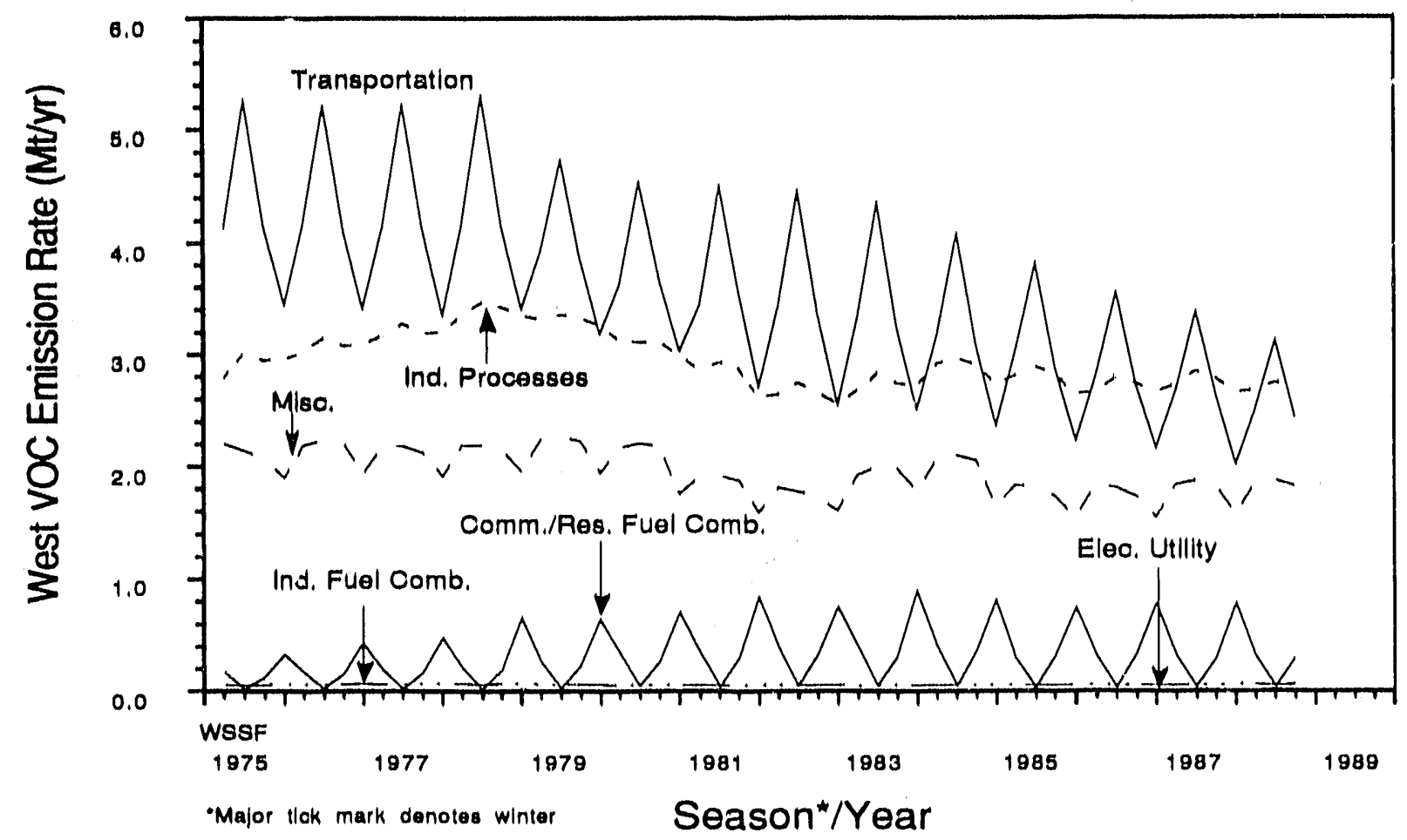

FIGURE 3.25 West Sectoral VOC Emission Trends Showing Seasonal Variations, 1975-1988 


\section{Electric Utility Methodology}

\subsection{Introduction}

This section describes the methodology used to compute emissions from elec ic utilities. The electric utility sector was treated separately for two reasons. First, it is a significant source of emissions, responsible for about two-thirds of all anthropogenic emissions of $\mathrm{SO}_{2}$ and about onethird of all $\mathrm{NO}_{\mathrm{x}}$ emissions. Second, because of various federal regulations, reliable detailed data on electric utilities are available for 1975 to the present.

Emissions were estimated by month and state for six fuel types: bituminous coal (Bit), subbituminous coal (Sub), lignite (Lig), light fuel oil (FO2), heavy fuel oil (FO6), and natural gas (Gas). In addition, emissions were estimated for three prime mover (combustor) technologies: steam boiler/turbine units (ST), gas turbine units (GT), and internal combustion units (IC). ${ }^{*}$ By analyzing the emission estimates from these fuels and prime movers, trends and patterns in the emissions from electric utilities could be examined in more detail.

\subsubsection{Primary Drivers of Electric Utility Emissions}

Emissions from electric utilities are primarily a result of the combustion process. Fuel is burned in a combustor (a boiler, reciprocating internal combustion device, or combustion turbine) that is directly or indirectly connected to a generator, and the generator produces electricity. Boilers as a group consume the greatest amount of fossil fuels and are the principal source of electric utility emissions. Boilers burn fossil fuels to boil water to produce steam, the steam drives a turbine (or turbines), and the turbine drives a generating unit, where the electricity is actually generated. ${ }^{\dagger}$ In addition to boiling water to produce steam, a boiler also produces exhaust gases, including the pollutants $\mathrm{NO}_{\mathrm{x}}, \mathrm{SO}_{2}$, and VOC. Postcombustion control devices are sometimes used to remove some of these pollutants before they are emitted to the atmosphere. With the exception of VOC emissions, fugitive and process emissions at electric utilities are insignificant when compared with combustion emissions. Electric utilities are not an important source of VOC emissions; therefore, the MSCET methodology focuses on $\mathrm{SO}_{2}$ and $\mathrm{NO}_{\mathrm{x}}$ emissions from fuel combustion.

* A prime mover technology may be used for several combustors at a given plant Ideally, emissions would be estimated by combustor, but frequently the data are aggregated across all combustors of the same prime mover technology and combustor-level information is lost. Thus a distinction is made between estimates at the combustor (boiler) level and at the prime mover technology level.

†ther combustors used at electric utilities, such as reciprocating internal combustion units, do not incorporate turbines; for simplicity they are not discussed above. Similarly, in gas turbines, combustion gases drive the turbine directly. 


\subsubsection{Sulfur Dioxide}

Emissions of $\mathrm{SO}_{2}$ are a result of sulfur-containing fuel being burned. The primary drivers of $\mathrm{SO}_{2}$ emissions are therefore the quanitity of fuel being consumed and the amount of sulfur in the fuel. Some sulfur is retained in the ash that remains after coal is combusted. Since the retention rate varies according to coal characteristics, the coal type can also affect $\mathrm{SO}_{2}$ emissions. Another major factor affecting $\mathrm{SO}_{2}$ emissions is the use of FGD (or scrubber) units. FGD units typically remove between $50 \%$ and $95 \%$ of the sulfur oxides from flue gas after the combustion process has taken place. Because an FGD unit is not necessarily operated throughout the period that the boiler(s) to which it is connected operate(s), and because the efficiency of FGDs can vary as a result of changes in bypass rates, recirculation rates, $\mathrm{pH}$, etc., estimating the amount of reduction in $\mathrm{SO}_{2}$ emissions that is achieved by FGD units necessitates that the FGD unit's operating rate be estimated first.

Data on the most important factor affecting $\mathrm{SO}_{2}$ emissions over time -- the amount of sulfur in the fuel -- are shown in Fig. 4.1. This graph shows the average pounds of sulfur per million Btu in fuel as-delivered, as reported on Federal Energy Regulatory Commission (FERC) Form 423 and its predecessor, Federal Power Commission (FPC) Form 423. Delivery data rather than consumption data are shown because as-delivered data on fuel quality were the only data available over the full period. A trend toward the use of bituminous coal with a lower sulfur

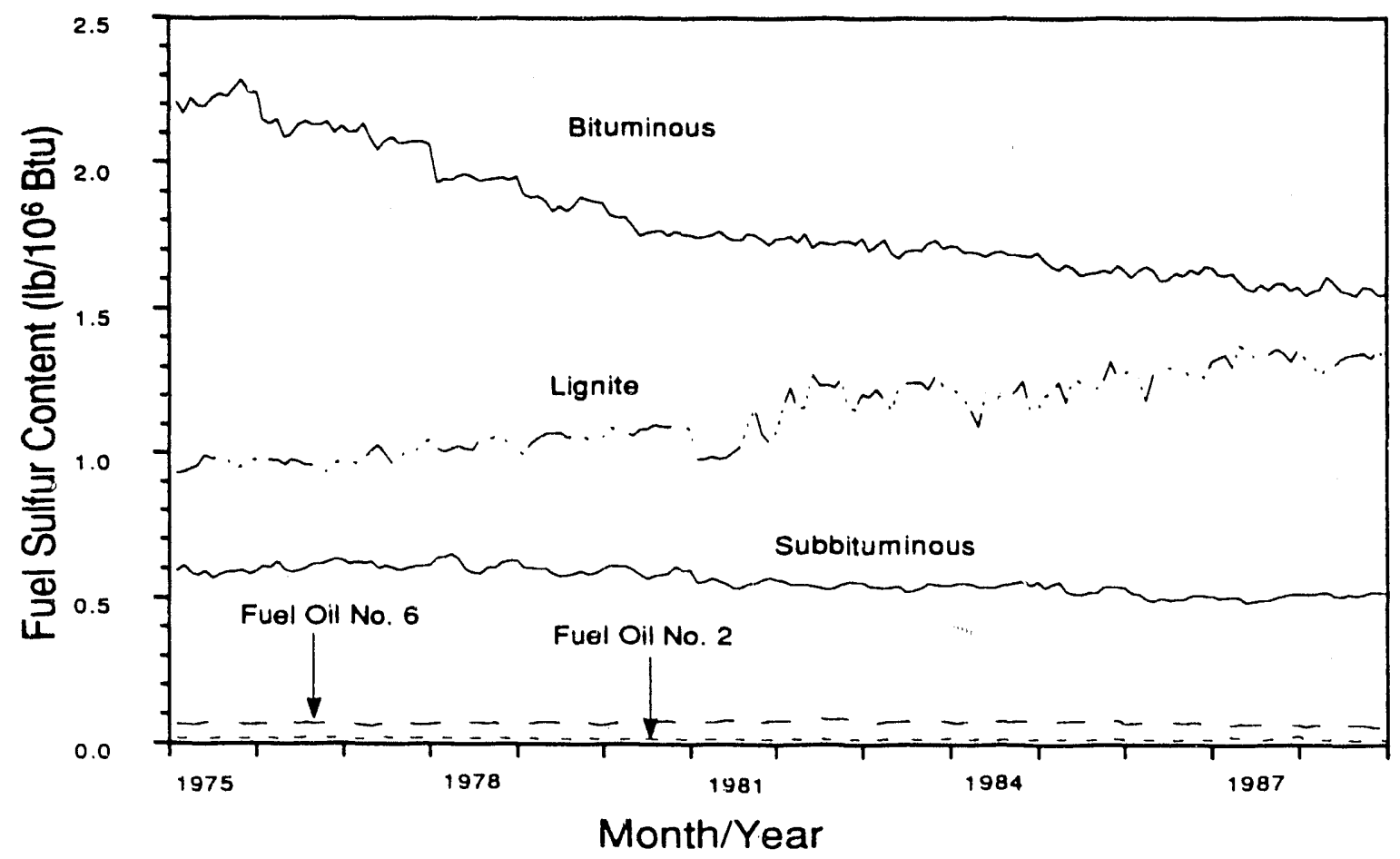

FIGURE 4.1 Average Sulfur Content of Fuels Consumed at Electric Utilities, 1975-1988 
content is evident. The sulfur content of coal is primarily dependent on the characteristics of the coal as mined. However, depending on the coal, about one third of the sulfur can be removed through coal cleaning. The coal sulfur content of cleaned coal is reflected in both as-delivered data (Form 423) and as-consumed data (Form 767). A detailed description of the delivery and consumption data is provided in Sec. 4.4. Because most $\mathrm{SO}_{2}$ emissions are a result of coal rather than oil or gas combustion, changes in total coal consumption have a large effect on $\mathrm{SO}_{2}$ emissions. Monthly consumption of fossil fuels by electric utilities over the period 1975 to 1988 is shown in Fig. 4.2.

The other important factor that has affected $\mathrm{SO}_{2}$ emissions over the period has been the increasing penetration of flue-gas desulfurization (FGD) units. Fig. 4.3 shows installed electric utility FGD capacity by year since 1975. Between 1975 and 1988, the percentage of fossil-fuelfired boiler capacity equipped with scrubbers increased from $4 \%$ to $15 \%$. The growing use of low-sulfur coal and the increasing penetration of scrubbers have been the main factors driving changes in $\mathrm{SO}_{2}$ emissions from 1975 to 1988.

\subsubsection{Nitrogen Oxides}

Most $\mathrm{NO}_{\mathrm{x}}$ emissions are produced when cnal, oil, or gas is burned and atmospheric nitrogen is oxidized during the combustion process. The remaining $\mathrm{NO}_{\mathrm{x}}$ emissions come from

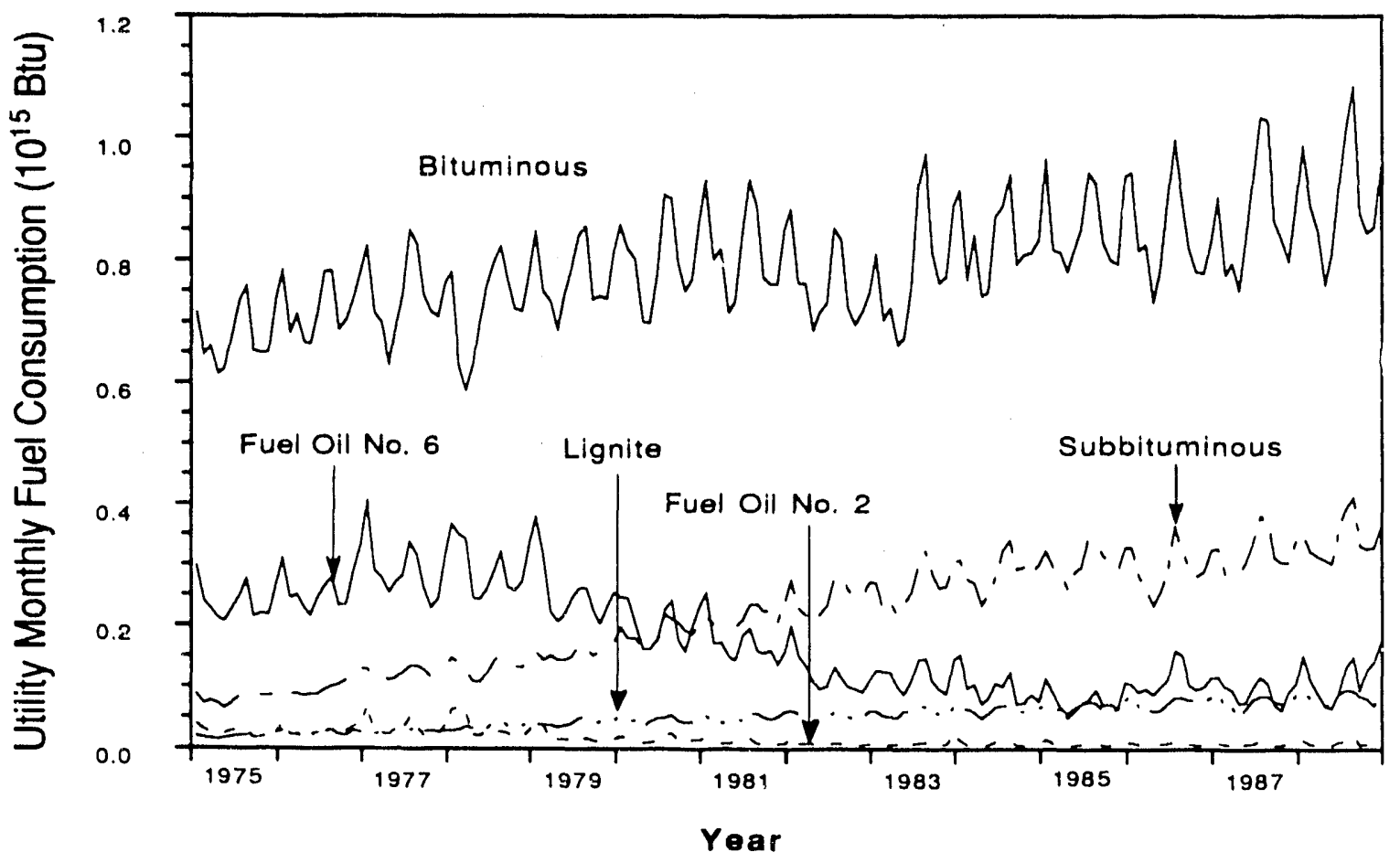

FIGURE 4.2 Electric Utility Fossil Fuel Consumption by Type, 1975-1988 


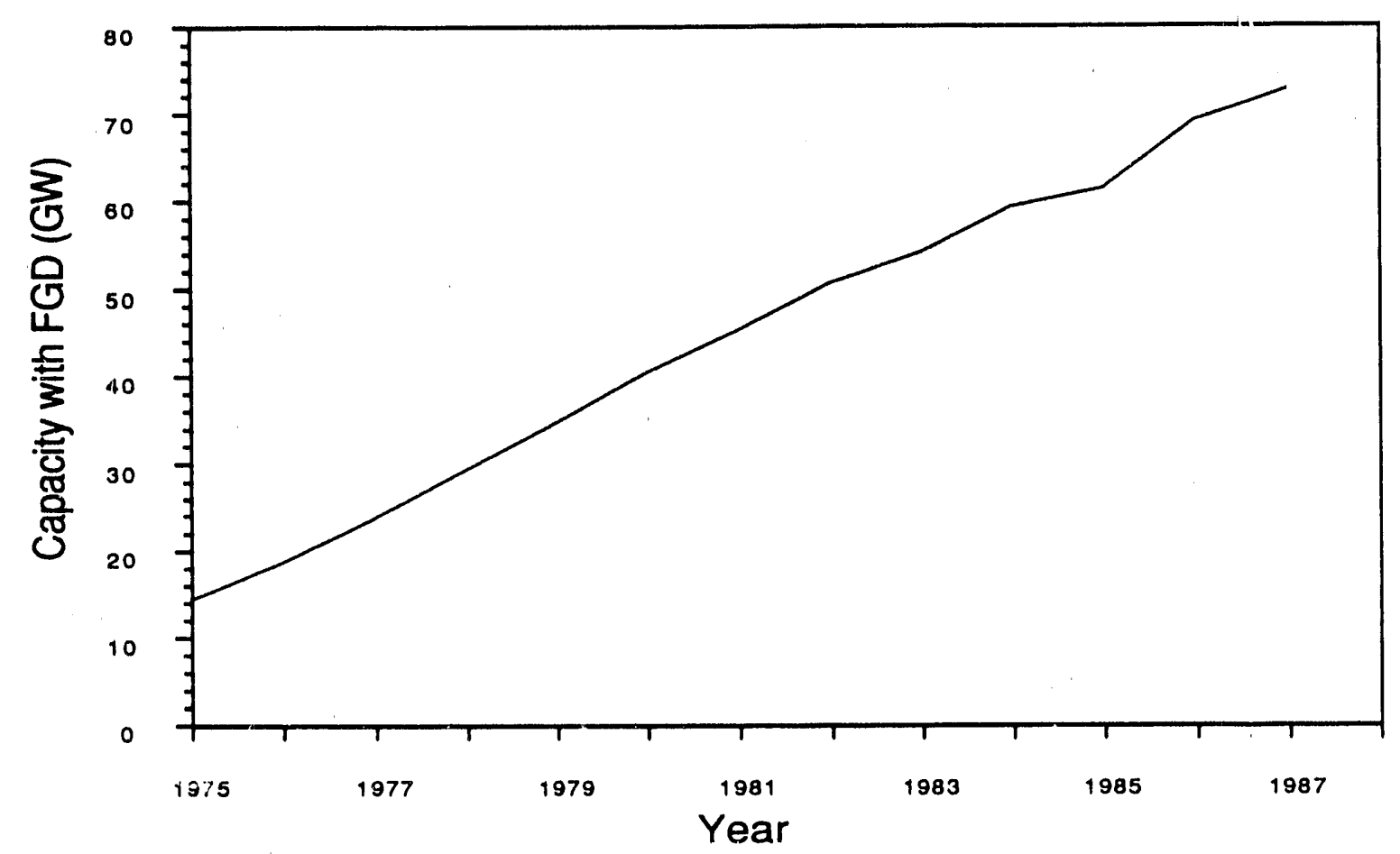

FIGURE 4.3 Installed Capacity Equipped with Flue-Gas Desulfurization Units, 1975-1987

organic nitrogen in the fuel. In both cases, $\mathrm{NO}_{\mathrm{x}}$ emissions are proportional to the amount of fuel consumed. The rate at which nitrogen is oxidized is generally proportional to the combustion temperature, with the emission rate increasing as the temperature increases. Because different combustors run at different temperatures, and because data were available on combustor type but not on combustor operating temperatures, for the purpose of emission estimation, $\mathrm{NO}_{\mathrm{x}}$ emission rates are correlated with combustor design in AP-42. A detailed description of the methods used to select $\mathrm{NO}_{\mathrm{x}}$ emission factors is provided in Sec. 4.6. Boilers and other combustors can be designed to minimize $\mathrm{NO}_{\mathrm{x}}$ emissions. Electric utilities have been incorporating low- $\mathrm{NO}_{\mathrm{x}}$ burners into new or retrofit boilers because the importance of reducing emissions has become evident and, in many cases, because of regulatory requirements. Fig. 4.4 shows the penetration of low- $\mathrm{NO}_{\mathrm{x}}$ burners over the period. Between 1975 and 1988, the percentage of fossil-fuel-fired boilers equipped with low- $\mathrm{NO}_{x}$ burners increased from $3.5 \%$ to $20 \%$.

\subsection{Selecting the Methodology}

It is not practical to capture all the gases produced during combustion, subject them to direct chemical analysis, and thereby actually measure emissions. Therefore, emissions at operating utilities are estimated. Several strategies for estimating emissions exist, including both direct and indirect methods. Direct estimation is possible using continuous emission monitors 


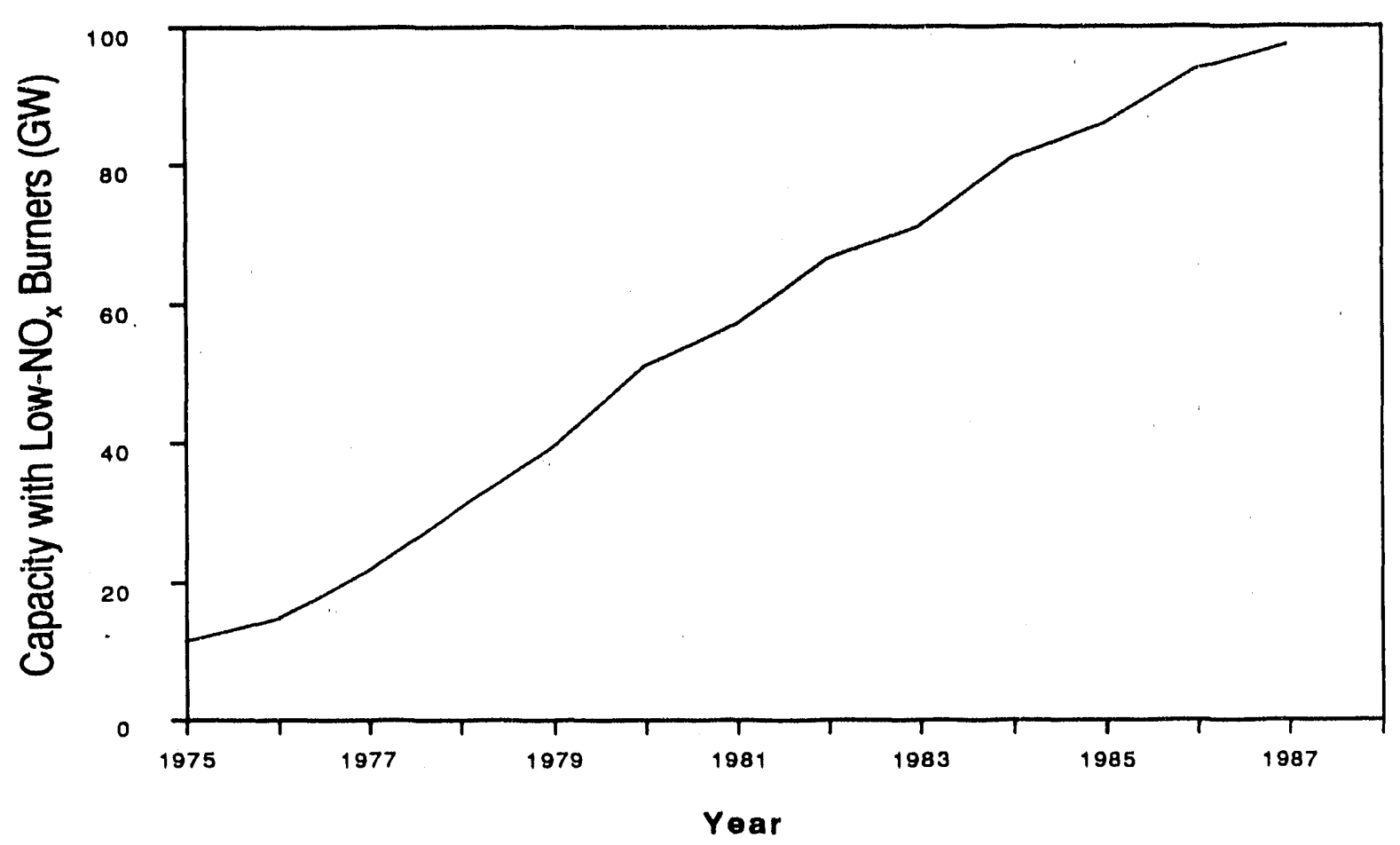

FIGURE 4.4 Installed Capacity Equipped with Low-NOX Bumers, 1975-1987

(CEMs). Most CEMs estimate emissions directly by monitoring the attenuation of a beam of light as it passes through a sample of the combustor's exhaust gases. Emissions can be estimated indirectly by a method called the consumption/emission factor (CEF) method, in which (1) data on fuel consumption are collected, (2) emission factors per unit of fuel consumption are assigned, and (3) the emission factors are applied to the consumption data to estimate emissions. A set of emission factors appropriate for estimating electric utility emissions was compiled and discussed in report AP-42 (EPA 1985); these are described in more detail below.and the sample being analyzed is representative. Using CEM data was found to be a good method for estimating emissions from the limited subset of plants that have such data available. CEMs were first used for process monitoring and control, then incorporated into emission monitoring programs in the late 1970s. Cooperative efforts between the electric utility industry and the EPA led, after several intermediate steps, to CEM design specifications that have been stable since May 1983 (Eggleston and Gray 1988). The necessary CEM data have not been collected for all plants for the entire estimation period, however, which eliminates the possibility of using CEM data alone to estimate utility emissions. Therefore, the choices that remained were either the CEF method alone or a combination of the CEF method and CEM data.

CEF methods can produce emission estimates that are somewhat different from CEM estimates. These differences are sometimes but not always systematic and predictable. To avoid the risk of systematic differences biasing some subset of the estimates, the limited CEM data available were not used in combination with CEF methods. Instead, the method chosen to estimate 
utility emissions was the CEF method. (The MSCET methodology makes provisions for special cases. One plant of particular interest is in Homer City, Pennsylvania. At this plant, experimental on-site coal cleaning technology has substantially affected actual emissions and rendered the reported consumption data incomplete. For this plant, for the years in which the coal-cleaning facility has been in operation, CEM-based data from the plant are used.)

In the MSCET/CEF utility methodology, emissions of $\mathrm{NO}_{\mathrm{x}}, \mathrm{SO}_{2}$, and $\mathrm{VOC}$ are calculated by multiplying the amount of fuel consumed each month by an appropriate emission factor. Since fuel consumption is the primary activity driver for the CEF methodology, much of the MSCET effort is concerned with obtaining data on fuel consumption. In the cases where emissions control occurs, a factor that represents the amount of emissions that are removed is included. The CEF methodology is reflected in Eq. 4.1 below:

$$
E_{i, b, m, f, p}=C_{i, b, m, f} \times E F_{b, f, p} \times\left(1-R_{i, b, m, f, p}\right)
$$

where:

$$
\begin{aligned}
E & =\text { pollutant emissions; } \\
\mathrm{C} & =\text { fuel consumption; } \\
\mathrm{EF} & =\text { emission factor: emissions per unit of fuel consumed; } \\
\mathrm{R} & =\text { emissions reduction due to control: fraction removed; } \\
\mathrm{i} & =\text { plant; } \\
\mathrm{b} & =\text { individual boiler or prime mover technology within a plant: ST, GT, or IC; } \\
\mathrm{m} & =\text { month; } \\
\mathrm{f} & =\text { specific fuel: } \mathrm{Bit}, \mathrm{Sub}, \mathrm{Lig}, \mathrm{FO} 2, \mathrm{FO} 6, \text { or Gas; } \\
\mathrm{p} & =\text { pollutant: } \mathrm{NO}_{\mathrm{x}}, \mathrm{SO}_{2}, \text { or } \mathrm{VOC} .
\end{aligned}
$$

The emission factors are fuel specific and are a function of the prime mover technology and, in the case of $\mathrm{SO}_{2}$, fuel quality. The emission standards that a boiler is required to meet also play a role in determining the $\mathrm{NO}_{\mathrm{x}}$ emission factors. The only emissions control incorporated into this analysis is the removal of $\mathrm{SO}_{2}$ by FGD units and the use of low- $\mathrm{NO}_{\mathrm{x}}$ burners.

\subsection{Data Sources}

The MSCET electric utility CEF methodology requires data on consumption, emission factors, and emission control. Historically, some electric utility data have been collected at the plant level, some at the prime-mover level, and, for most boilers since 1983, at the combustor 
level. Boiler-specific consumption data affect the methodology for $\mathrm{NO}_{\mathrm{x}}$ emission estimation, because $\mathrm{NO}_{x}$ emission rates depend on boiler design, particularly if some but not all boilers at a plant are equipped with low- $\mathrm{NO}_{\mathrm{x}}$ burners. For $\mathrm{SO}_{2}$ emission estimation, boiler-specific consumption data are important if some but not all boilers at a plant are equipped with FGD units. The methodology developed for calculating emissions is driven in large part by the form of the available data. The following data sources are used to produce the MSCET utility emission estimates.

1. EIA Form 759: Monthly Power Plant Report (EIA 1975-87). Form 759 was called FPC-4 when the data were collected by the FPC. It was renamed in 1982 when the DOE/Energy Information Administration (EIA) assumed responsibility for data collection. Form 759 data are collected each month from electric utilities of all sizes. The form is submitted by each plant. Data on the quantity of fuel consumed are reported by specific fuel type and prime mover technology.

2. FERC Form 423: Monthly Report of Cost and Quality of Fuels for Electric Plants (FERC 1975-88). FERC Form 423 (originally FPC-423) is a monthly report on deliveries of fuels to plants by fuel type. Included on the form are data on the heat content, sulfur content, and cost of the delivered fuels. Because (1) consumption does not vary directly with deliveries and (2) there is monthly variation in the quality of the delivered fuel, the monthly fuelquality data from Form 423 are used only to provide annual average fuelquality data. Form 423 provides plant summary data only; neither combustorlevel nor prime-mover-level data are provided.

3. EIA Form 767: Steam-Electric Plant Operation and Design Report (EIA 198588a). Form 767 was originally Form 67 . It was redesigned and renamed in 1983. Its requirements for consumption data apply only to steam-electric units at plants with at least $10 \mathrm{MW}$ of installed capacity (100 MW before 1986). These plants are responsible for about $99 \%$ of all coal consumption at electric utilities, so the coverage is substantial. Consumption data are reported for individual boilers according to general fuel type (coal, oil, or gas). Form 767 provides a detailed report on the design and configuration of combustors, generators, and FGD units at the plants that submit the form. Being a complex, 16-page form, it is subject to misinterpretation, and it has different requirements for large and small plants. Before 1985, only limited funding was allocated to the collection and processing of this form, and there were errors and omissions in the submitted data. A system of quality assurance was instituted by EIA in 1988 for checking data submitted for 1985 and later. Therefore, only the data from 1985 and later are used for the MSCET estimates.

4. EPA Report AP-42: Compilation of Air Pollutant Emission Factors (EPA 1985). AP-42 reports estimated emission factors for stationary point and area sources. These factors are generally reported in terms of the weight of the 
pollutant produced divided by a unit weight or volume of fuel consumed (e.g., in pounds of pollutant per ton of coal, barrel of oil, or cubic foot of gas burned). AP-42 is an ongoing project, and estimated emission factors are periodically updated as better information becomes available or when the nature of a category changes in a way that would affect the old estimates.

5. Report EPRI-CS-4277-SR, $\mathrm{SO}_{2}$ and $\mathrm{NO}_{x}$ Retrofit Control Technologies Handbook (EPRI 1985), and Report EPRI-CS-5361, Retrofit Combustion Controls for Gas/Oil-Fired Utility Boilers (Pepper et al. 1987). These two Electric Power Research Institute (EPRI) reports on retrofit controls provide estimates of the potential reductions in $\mathrm{NO}_{x}$ emissions that can be achieved by using low- $\mathrm{NO}_{x}$ burners. These estimates are used in conjunction with the boiler design information reported on Form 767 and the AP-42 data to estimate $\mathrm{NO}_{\mathrm{x}}$ emission factors.

The MSCET system uses data on energy consumption from EIA Forms 759 and 767 to produce estimates of the quantity of fuel consumed. Both forms provide monthly data, but for different aggregations of fuel types. MSCET uses fuel-quality data from FERC Form 423 and EIA Form 767. Fuel quality refers to the heat content and sulfur content of the fuel. The monthly fuelquality data from Form 423 are used only to provide annual average data on quality. Coals are ranked (typed) according to their quality and the amount and kind of impurities they contain. Because consumption information is reported by coal type, and the emission factors used for estimating $\mathrm{NO}_{x}$ emissions are also reported by type, no other fuel-quality data are required to estimate $\mathrm{NO}_{\mathrm{x}}$ emissions from coal. The data needed to estimate $\mathrm{NO}_{\mathrm{x}}$ emissions from oil and gas are similar. In contrast, $\mathrm{SO}_{2}$ emissions depend on the percentage of sulfur in the fuel, and sulfur content varies widely within types and can be reduced by coal cleaning. Therefore, sulfur content, unlike heat content, is a fuel-quality parameter that is necessary to estimate $\mathrm{SO}_{2}$ emissions when a CEF estimation system is used.

\subsection{Calculating Fuel Consumption}

\subsubsection{Consumption Data Sources}

EIA Form 759 collects monthly data on the consumption of fossil fuels from all electricity generating plants in the United States. Data on consumption are provided for a number of fuel types at the prime-mover level. The fuel types designated by Form 759 and their relationship to the fuel types used in this analysis are shown in Table 4.1. Several fuel types included in Form 759 are aggregated into the bituminous and natural gas categories for this analysis. Form 759 does not distinguish between bituminous and subbituminous coal, and before 1980, it did not distinguish between light and heavy fuel oil. The methodology used to share out these data into the more detailed fuel types is described below. 
TABLE 4.1 Fuel Types in ElA Form 759 and This Analysis

\begin{tabular}{|c|c|c|}
\hline Time Perlod & EIA Form 759 & This Analysis \\
\hline \multirow[t]{3}{*}{ All years } & $\begin{array}{l}\text { Bituminous } \\
\text { Anthracite } \\
\text { Petroleum coke }\end{array}$ & $\begin{array}{l}\text { Bltuminous (Blt) } \\
\text { Subbitiminous (Sub) }\end{array}$ \\
\hline & Lignite & Lignite (Lig) \\
\hline & $\begin{array}{l}\text { Natural gas } \\
\text { Synthetic natural gas }\end{array}$ & Natural gas (Gas) \\
\hline Pre-1980 only & Oll & $\begin{array}{l}\text { Light fuel oil (FO2) } \\
\text { Heavy fuel oil (FO6) }\end{array}$ \\
\hline Post-1980 only & $\begin{array}{l}\text { Fuel oll No. } 2 \\
\text { Fuel oll No. } 6\end{array}$ & $\begin{array}{l}\text { Llght fuel oll (FO2) } \\
\text { Heavy fuel oll (FO6) }\end{array}$ \\
\hline
\end{tabular}

FERC Form 423 collects data on the cost and quality of deliveries of fossil fuels to electric utility plants. The form is filled out by all electric generating plants that have a rated steam-electric generating capacity of $50 \mathrm{MW}$ or greater. The fuel types used by Form 423, and how they are mappeci into the fuel types used in the MSCET analysis, are shown in Table 4.2. Several of the fuel types included in Form 423 are aggregated into the bituminous coal, light fuel oil, heavy fuel oil, and natural gas categories for this analysis.

ELA Form 767 now collects information from electricity generating plants with a total existing or planned steam-electric generating capacity of $10 \mathrm{MW}$ or more. The data cover consumption and configuration. Before 1986, only plants with a total existing or planned steamelestric generating capacity of $100 \mathrm{MW}$ or larger were required to fill out this form. In this analysis, boiler-level consumption data from Form 767 are used directly for the years 1985 through 1988 and are projected onto other years. The configuration data for individual boilers include on-line dates and can therefore be used in estimating emissions before 1985. The boilerspecific configuration data cover boiler design parameters, pollution control standards, and FGD design parameters and operating characteristics. All the boilers included in Form 767 are assumed to fire fossil steam turbine units. The fuel types reported in Form 767 and their relationships to the fuel types used in this analysis are shown in Table 4.3. Form 767 aggregates all coal consumption into one variable and does the same for oil. How these data are shared out to the more detailed fuel types is described below.

The forms and the availability of the data used in this analysis varied from year to year. Form 767 data were available only for 1985 through 1988. In Form 759, the manner in which oil consumption was reported was better in 1980-1988 than in 1975-1979 for one factor (fuel oil disaggregation). Therefore, the algorithms used to estimate consumption also differed from year to year. The most significant difference is that when 767 data were available, it was possible to estimate boiler-specific fuel consumption and quality directly; when 767 data were not available, 
TABLE 4.2 Fuel Types in FERC Form 423 and This Analysis

\begin{tabular}{ll}
\hline FERC Form 423 & This Analysis \\
\hline $\begin{array}{l}\text { Bituminous } \\
\text { Anthracite } \\
\text { Petroleum coke }\end{array}$ & Bltuminous (Bit) \\
Subbituminous & Subbituminous (Sub) \\
Lignite & Lignite (Lig) \\
Fuel oll No. 2 & \\
Jet fuel & \\
Kerosene \\
Liquifled gas \\
$\begin{array}{l}\text { Fuel oll No. } 4 \\
\text { Fuel oll No. } 5 \\
\text { Fuel oll No. } 6 \\
\text { Bunker oll } \\
\text { Crude oll } \\
\text { Re-refined motor oll } \\
\text { Top orude }\end{array}$ \\
$\begin{array}{l}\text { Natural gas } \\
\text { Refinery gas } \\
\text { Coke oven gas } \\
\text { Blast furnace gas }\end{array}$ \\
\hline
\end{tabular}

TABLE 4.3 Fuel Types in ElA Form 767 and This Analysis

\begin{tabular}{ll}
\hline ElA Form 767 & \multicolumn{1}{c}{ This Analysis } \\
\hline Coal & $\begin{array}{l}\text { Bituminous (BIt) } \\
\text { Subbituminous (Sub) } \\
\text { Lignite (Lig) } \\
\text { Oll }\end{array}$ \\
Natural gas & $\begin{array}{l}\text { Light fuel oll (FO2) } \\
\text { Neavy fuel oll (FO6) }\end{array}$ \\
\hline
\end{tabular}


this direct estimation was not possible. To best use the available data, and because the avail. ability of boiler-level data is always delayed," boiler-level patterns of fuel consumption and quality are projected back to 1975 and projected forward one year for flash reports. The flash report provides preliminary estimates based upon plant level data when boiler level data from Form 767 have not yet been released. As discussed earlier and detalled in Eq. 4.1, given the required data, emissions can be estimated at a level of individual combustor or prime-mover technology within a plant.

\subsubsection{Preparing the Consumption Data}

Because MSCET estimates emissions for each of three prime mover technologies, it has to function at this level of detail or lower. The estimation parameters for burner configuration and scrubber association can be different for different combustors, even if they are located at a single plant. Some combustors can also have an attached FGD unit, while others of the same type may not be so equipped. Because of these possible differences, MSCET' estimates emissions at the individual combustor level whenever possible. In other cases, it estimates emissions at the level of prime-mover technology. Special treatment is given to plants that have FGD units attached to some but not all of their boilers. (FGD units are associated only with steam boiler/turbine prime-mover types.) Boiler-level emission estimates are aggregated at the prime-mover level to provide consistent data reports.

Separate estimates of bituminous coal, subbituminous coal, lignite, light fuel oil, heavy fuel oil, and natural gas consumption are made at the lowest level of detail possible. For the years 1975-1984, the fuel consumption data were taken from Form 759 and adjusted with data from Form 423. As shown in Table 4.1, for the years 1975-1979, Form 759 provided monthly estimates of consumption by prime-mover type for lignite and natural gas but did not distinguish between bituminous and subbituminous coal or between light and heavy fuel oil. For the same years, Form 423 provided data on the delivered quantities, sulfur content, and heat value by plant for all six of the fuel types used in this analysis, as shown in Table 4.2.

The data from Form 423 were used to estimate separate fractions of bituminous and subbituminous coal consumption and light and heavy fuel oil consumption from the aggregated data provided by Form 759. This method, shown in Eq. 4.2, began with the combined bituminous and subbituminous monthly coal consumption as reported in Form 759. This value was then multiplied by the annual shares of the deliveries of each of these two fuels as reported in Form 423 to estimate the monthly consumption of each of these two coal types.

\footnotetext{
*Form 767 is submitted May 1 each year for the previous year; Forms 759 and 423 are submitted each month. The considerable volume and complexity of the data reported on Form 767 require that several months be spent in the quality-assurance and format-preparation process before the data can be ready for use. MSCET produces flash estimates until Form 767 data are available.
} 


$$
C_{i, v, f, m}^{759}=C_{i, v, F, m}^{759} \times \frac{\sum_{d} D_{i, f, d}^{423}}{\sum_{d} \sum_{f} D_{i, f, d}^{423}}
$$

where:

$$
\begin{aligned}
C^{759} & =\text { adjusted consumption, } \\
C^{759} & =\text { consumption from Form } 759, \\
D^{423} & =\text { quantity of fuel delivered (by type), } \\
v & =\text { prime mover technology in Form } 759, \\
F & =\text { aggregated fuel type, and } \\
d & =\text { delivery. }
\end{aligned}
$$

When no bituminous or subbituminous coal was delivered to the plant during the year, all the coal consumption (except lignite) reported in Form 759 was assigned to bituminous coal -- the coal most commonly consumed by electric utility boilers. For the years before 1980, the same basic algorithm was used to disaggregate light and heavy fuel. If there were no deliveries of light or heavy fuel oil to the plant during the year, then all the oil consumption reported in Form 759 was assigned to heavy fuel oil.

The sulfur content and heat values were taken from Form 423 and applied to the fuel consumption reported in Form 759. The method used was a simple weighted average, shown in Eq. 4.3. For a plant with consumption reported in Form 759 but without data from Form 423, average state-level sulfur-content values and heat values for the specific fuel type were used. In the absence of available data from Form 423 at the state level, national-level sulfur-content values and heat values for the specific fuel type were used.

$$
s_{i, f}^{423}=\frac{\sum_{d}\left(D_{i, f, d}^{423} \times S_{i, f, d}^{423}\right)}{\sum_{d} D_{i, f, d}^{423}}
$$

where $S^{423}=$ adjusted plant-level annual average sulfur content and $S^{423}=$ sulfur content by fuel type and delivery reported on Form 423. 
Beginning in 1985, monthly boiler-level consumption data from Form 767 were avallable for most of the plants being analyzed. (For the small set of plants for which no 767 data were available, estimates were made as before.) Form 767 consumption data are reported only by general fuel types: coal, oil, and gas. Using the monthly consumption date estimated using Form 759 and data adjusted using an annual average of Form 423 's delivery data, the coal consumption reported in Form 767 was divided into bituminous, subbituminous, and lignite coal consumption. The oil consumption reported in Form 767 was similarly separated into light and heavy fuel oil. The disaggregation of the coal and oil consumption is shown in Eq. 4.4.

$$
C_{i, b, m, f}^{767}=C_{i, b, m, F}^{767} \times \frac{C_{i, v, m, f}^{759}}{\sum_{f} C_{i, v, m, f}^{759}}
$$

where $\mathrm{C}^{767}=$ adjusted consumption and $\mathrm{C}^{767}=$ consumption reported on Form 767. The prime mover technology $(v)$ is that which is associated with the combustor (b).

After the coal and oil consumption were disaggregated, the percent sulfur and heat values assigned to these fuels were estimated. The ratio of the weighted average sulfur content (or heat value) for each specific fuel type from Iorm 423 was used to adjust the sulfur content reported on Form 767 for the more aggregated fuel types. This adjustment is shown in Eq. 4.5.

$$
\hat{s}_{i, b, m, f}^{767}=s_{i, b, m, F}^{767} \times \frac{\hat{S}_{i, f}^{423} \times \hat{C}_{i, v, m, f}^{759}}{\sum_{f}\left(\hat{S}_{i, f}^{423} \times \hat{C}_{i, v, m, f}^{759}\right)}
$$

where $\hat{S}^{767}=$ adjusted sulfur content and $S^{767}=$ sulfur content reported on Form 767. The prime mover technology $(v)$ is that which is associated with the combustor (b).

Before 1985, the sulfur content of the fuel was taken from Form 423. These data were in the form of coal receipts by plant. In 1985 and later, the percent sulfur values for boilers were taken from Form 767 consumption data reported for each boiler. Boiler-level differences in the sulfur content of fuel can affect emissions if a plant operates both scrubbed and unscrubbed boilers. For plants containing no FGD units, the prime-mover-level data that were available for all years were sufficient. The data in Form 767, detailing each plant's complement of boilers and scrubbers and their configuration, include on-line dates and were therefore a source of information for years before 1985. For plants with all boilers scrubbed, this configuration data, in combination 
with Form 759 and Form 423, directly provided all the data required for $\mathrm{SO}_{2}$ emission estimates. For the subset of plants containing boilers with and without attached scrubbers, boiler-level consumption and percent sulfur values were important.

\subsubsection{Projecting EIA Form 767 Data onto Earller Years}

For estimating $\mathrm{SO}_{2}$ emissions, Form 767 boller-specific energy consurnption data were significant in two cases: (1) if the boilers with scrubbers were operated at a higher (or lower) capacity factor than the boilers without them and (2) if the boilers with scrubbers consumed fuel with a higher (or lower) sulfur content than did the boilers without scrubbers at the plant. If either of these two cases is present, it indicates that the boilers have different rates of consumption of fuel sulfur per unit of installed capacity. This information can be captured by the variables fuel consumption and fuel sulfur, and the product of these two boiler-level variables is proportional to total fuel sulfur. For years when no boiler-level consumption data were available, fuel consumption and quality were estimated at the boiler level. The years 1985, 1986, and 1987 were selected to analyze patterns of boiler-level fuel consumption to be applied to plants with both scrubbed and unscrubbed units in the pre-1985 period. An evaluation of these data for 77 plants equipped with scrubbers led to several conclusions. At 40 (53\%) of the plants, either the plant was a single-boiler plant (in which case, the available plant-level data were, effectively, boiler-level data) or all the boilers were scrubbed. If all the fuel at the plant was consumed by boilers with similar scrubbers, the emission estimates were not affected by which particular boiler consumed the fuel.

The rem ining 37 plants had both scrubbed and unscrubbed boilers. Boiler-level data were important at all mixed plants. All mixed plants either operated their scrubbed and unscrubbed boilers at different capacity factors and/or used fuel with different sulfur contents. The following characteristics were present at the mixed plants:

1. At 10 of the mixed plants, the scrubbed boilers consumed fuel with a significantly higher sulfur content than did the unscrubbed boilers. At another 4 of the mixed plants, scrubbed boilers consumed fuel with a lower sulfur content than the unscrubbed boilers. At another 22 of the plants, both scrubbed and unscrubbed boilers used coal with a similar sulfur content.

2. At 19 of the mixed plants, scrubbed boilers were operated at a higher rate than unscrubbed boilers. At 7 of these 19 plants, the unscrubbed boilers consumed little or no fuel over the 3-year period; nearly all the fuel was consumed by scrubbed boilers. At another 14 of the mixed plants, scrubbed boilers were operated at a lower rate than unscrubbed boilers. At 2 of these 14 plants, the scrubbed boilers consumed little or no fuel over the period. At 1 plant, the scrubbed and unscrubbed boilers were operated at nearly identical capacity factors.

3. Some mixed plants show both Characteristic 1 and Characteristic 2 . 
To best use the available data, and because the availability of boiler-level data is always delayed, a methodology for projecting boiler-level patterns of fuel consumption and quality onto years other than 1985-1987 was developed. This methodology projected the fuel-dispatch pattern by volume and sulfur content. To apply the information described above to estimating emissions at affected plants, the ratio of total fuel sulfur consumed by scrubbed versus unscrubbed capacity was computed from the 1985-1987 Form 767 data and was then held constant over time at scrubbed plants. This value was used to estimate the dispatch rate of scrubbed boilers at the plant for years in which no boiler-specific fuel-consumption data were available. Equation 4.6 shows the value that was used to apportion plant average-quality fuel to scrubbed versus unscrubbed boilers.

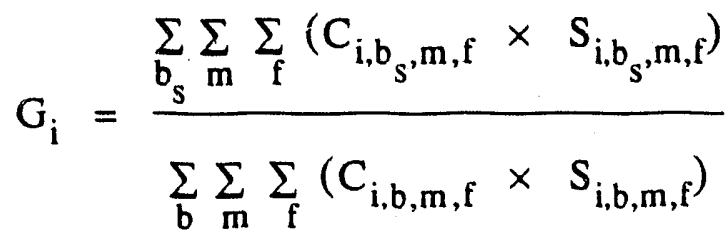

where $G_{i}=$ scrubbed share of consumption of plant average fuel by scrubbed boilers and $b_{s}$ denotes a scrubbed boiler.

An advantage of this method is that systematic differences between scrubbed and unscrubbed boilers in capacity factors and in the percentage of sulfur consumed can be captured with the single variable, total sulfur. This can occur because, as the AP- 42 emission factor approach shows, emissions are proportional to the product of fuel consumption and the percentage of sulfur for each coal type. Additionally, emissions vary linearly with consumption and will therefore vary directly with the product of the two factors. Form 767 data for 1985-1987 showed that when scrubbed and unscrubbed boilers at mixed plants were compared over the 3-year period, consumption patterns of both the capacity factor and percent sulfur were stable. The share of total sulfur consumed by scrubbed boilers, implemented as a single factor, was applied to other years to improve estimates of emissions at mixed plants. The total sulfur emitted at a plant for years in which no Form 767 data were available could be determined from consumption data on Form 759 and the percent sulfur data on Form 423. By holding the shares of total sulfur at scrubbed and unscrubbed boilers constant in the years for which no Form 767 data were available, systematic differences were more correctly modeled and emission estimates were improved. There remains a significant uncertainty in this method since patterns in 1985-1987, although stable through this period, could have differed in earlier years. The lack of boiler-specific data for the earlier years necessitated this approach. 


\subsection{Emission Factors}

\subsubsection{Sulfur Dioxide}

The $\mathrm{SO}_{2}$ emission factors are listed in Table 4.4. The emission factors for bituminous, subbituminous, and lignite coals in Table 4.4 reflect the differences in ash characteristics associated with these different coals. In some coals, the ash retains more of the sulfur originally in the coal, so the emission factor is lower. For different grades of oil, the emission factors were taken from AP-42 and were a function of the type of fuel, sulfur content of the fuel, and the prime-mover type.

\subsubsection{Nitrogen Oxides}

The $\mathrm{NO}_{\mathrm{x}}$ emission factors used were based on AP-42 emission factors, information on boiler configuration from Form 767, burner type, reported $\mathrm{NO}_{x}$ emission standards, and two EPRI studies on low- $\mathrm{NO}_{\mathrm{x}}$ burners. Boiler configuration refers to the location and orientation of the

TABLE 4.4 Uncontrolled $\mathrm{SO}_{2}$ Emission

Factors for Electric Utility Combustors

\begin{tabular}{|c|c|c|}
\hline $\begin{array}{l}\text { Emission } \\
\text { Source }\end{array}$ & $\begin{array}{l}\text { Source } \\
\text { Factor }\end{array}$ & $\begin{array}{l}\text { AP-42 } \\
\text { Table }\end{array}$ \\
\hline \multicolumn{3}{|l|}{ Steam boiler } \\
\hline Bituminous (lb/ton) & $39 s^{a}$ & $1.1-1$ \\
\hline $\begin{array}{l}\text { Subbituminous (Ib/ton) } \\
\text { Lignite (lb/ton) }\end{array}$ & $\begin{array}{l}35 S \\
30 S\end{array}$ & $\begin{array}{l}1.1-1 \\
1.7-2\end{array}$ \\
\hline Light fuel oil (lb/103 gal) & $142 S$ & $1.3-1$ \\
\hline Heavy fuel oil (b/ $\left.10^{3} \mathrm{gal}\right)$ & $157 S$ & $1.3-1$ \\
\hline Natural gas $\left(\mathrm{b} / 10^{6} \mathrm{t}^{3}\right)$ & 0.6 & $1.4-1$ \\
\hline \multicolumn{3}{|l|}{ Gas turbine } \\
\hline Light fuel oil (lb/10 3 gal) & $140 S$ & $3.1-2$ \\
\hline Heavy fuel oil (lb/10 3 gal) & $140 S$ & $3.1-2$ \\
\hline Natural gas $\left(\mathrm{lb} / 10^{6} \mathrm{ft}^{3}\right)$ & 0.6 & $3.2-1$ \\
\hline \multicolumn{3}{|l|}{ Internal combustion } \\
\hline Light fuel oil (lb/10 3 gal) & $140 S$ & $3.1-2$ \\
\hline Heavy fuel oil (lb/10 3 gal) & $140 S$ & $3.1-2$ \\
\hline Natural gas $\left(1 \mathrm{~b} / 10^{6} \mathrm{ft}^{3}\right)$ & 0.6 & $3.2-1$ \\
\hline
\end{tabular}

as = percent sulfur in fuel.

Source: EPA 1985. 
burners within the firing zone and to whether it is a wet-bottom or dry-bottom boiler. Examples are front-fired and tangentially fired boilers. Boiler configuration parameters can affect the rate at which $\mathrm{NO}_{\mathrm{x}}$ is produced. Burner type refers to whether the burner is low-NO $\mathrm{x}$ or conventional. Because boiler-specific consumption data were used only for the years 1985-1987, it is only for these years that boiler-specific emission factors were developed. Boiler-level $\mathrm{NO}_{\mathrm{x}}$ emission factors calculated for 1985 were used for earlier years, as described below.

The general strategy for calculating $\mathrm{NO}_{\mathrm{x}}$ emission factors for 1985-1987 was to (1) calculate the uncontrolled $\mathrm{NO}_{\mathrm{x}}$ emission factors, (2) adjust for the presence of a low- $\mathrm{NO}_{\mathrm{x}}$ burner, and (3) compare the adjusted emission factor to the standard that the boiler is required to meet and its date of compliance. The procedure for implementing this strategy is described below.

Table 4.5 summarizes the uncontrolled $\mathrm{NO}_{\mathrm{x}}$ emission factors for these prime-mover types: steam turbine, gas turbine, and internal combustion. This table shows that some of these emission factors require knowledge of the boiler's bottom type and firing type. This information is provided on Form 767. For those boilers included on Form 767 for which there was no information, and for those plants and prime-mover types that were included on Form 759 but not on Form 767, the values listed in the column under the heading "No Data" were used.

The "no data" values shown in Table 4.5 were calculated by taking a weighted average of the emission factors for the boilers for which data were included on Form 767 in 1985. 'The weighting factors used were simply the number of boilers of each firing and/or bottom type that listed the fuel in question as a primary fuel. Table 4.6 indicates the level of reduction typically achieved with the use of low-NO $\mathrm{N}_{\mathrm{x}}$ burners for different fuels as reported in the EPRI studies. If a boiler was reported to have a low- $\mathrm{NO}_{x}$ burner on Form 767 , its uncontrolled $\mathrm{NO}_{\mathrm{x}}$ emission factors were adjusted to reflect these values.

The third step in estimating the $\mathrm{NO}_{\mathrm{x}}$ emission factors was to compare the calculated emission factors with the $\mathrm{NO}_{\mathrm{x}}$ standards that the boiler is required to meet. Form 767 provides boiler-specific information on $\mathrm{NO}_{x}$ emission standards and dates of compliance and reports on whether the boiler is currently in compliance. A boiler is considered to be in compliance for the month and year being modeled if the boiler is reported as meeting the standard in Form 767 for that month and year. The $\mathrm{NO}_{\mathrm{x}}$ standards reported were based on several units of measurement, the predominant one being pounds per million Btu. Only those boilers for which the standards were reported in this unit of measurement were compared with the $\mathrm{NO}_{\mathrm{x}}$ emission factors as calculated. If a boiler was reported as being in compliance with a standard measured in pounds per million Btu, that boiler's $\mathrm{NO}_{\mathrm{x}}$ emission factor was adjusted to meet that value. 
TABLE 4.5 Uncontrolled $\mathrm{NO}_{x}$ Emission Factors for Electric Utility Combustors

\begin{tabular}{|c|c|c|c|c|c|}
\hline \multirow{2}{*}{$\begin{array}{c}\text { Emission Source, } \\
\text { Firing Type }\end{array}$} & \multicolumn{3}{|c|}{$\begin{array}{c}\text { Coal, by Bottom Type } \\
\text { (lb/on) }\end{array}$} & \multirow{2}{*}{$\begin{array}{c}\text { Oil } \\
\text { (lb/10 } \\
\text { gal) }\end{array}$} & \multirow{2}{*}{$\begin{array}{c}\text { Gas } \\
\left(\mathrm{lb} / 10^{6} \mathrm{tt}^{3}\right)\end{array}$} \\
\hline & Wet & Dry & No Data & & \\
\hline \multicolumn{6}{|l|}{ Steam boiler } \\
\hline \multicolumn{6}{|l|}{$\begin{array}{l}\text { Fired with bituminous } \\
\text { and subbituminous coal }\end{array}$} \\
\hline Tangential firing & 34.0 & 15.0 & 16.1 & - & - \\
\hline Spreader stoker & 14.0 & 14.0 & 14.0 & - & - \\
\hline Cyclone & 37.0 & 37.0 & 37.0 & - & - \\
\hline Other & 34.0 & 21.0 & 22.3 & - & - \\
\hline No data & 35.5 & 18.3 & 21.0 & - & - \\
\hline \multicolumn{6}{|l|}{ Fired with lignite } \\
\hline Tangential firing & 8.0 & 8.0 & 8.0 & - & - \\
\hline Spreader stoker & 6.0 & 6.0 & 6.0 & - & - \\
\hline Cyctone & 17.0 & 17.0 & 17.0 & - & - \\
\hline Oiner & 14.0 & 14.0 & 14.0 & - & - \\
\hline No data & 11.8 & 11.8 & 11.8 & - & - \\
\hline \multicolumn{6}{|l|}{ Fired with heavy fuel oil } \\
\hline Tangential firing & - & - & - & 42.0 & - \\
\hline Vertical firing & - & - & - & 105.0 & - \\
\hline Others & - & - & - & 67.0 & - \\
\hline No data & - & - & - & 60.4 & - \\
\hline $\begin{array}{l}\text { Fired with light fuel oil, } \\
\text { all firing types }\end{array}$ & - & - & - & 20.0 & - \\
\hline \multicolumn{6}{|l|}{ Fired with natural gas } \\
\hline Tangential firing & - & - & - & - & 275.0 \\
\hline Others & - & - & - & - & 550.0 \\
\hline No data & - & - & - & - & 487.4 \\
\hline \multicolumn{6}{|l|}{ Gas turbine } \\
\hline Fueled with gas & - & - & - & - & 413.0 \\
\hline Fueled with oil & - & - & - & 67.8 & 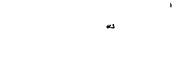 \\
\hline \multicolumn{6}{|l|}{ Internal combustion } \\
\hline Fueled with gas & - & - & - & - & 3,400 \\
\hline Fueled with oil & - & - & - & 500.0 & - \\
\hline
\end{tabular}

Source: EPA 1985. 
TABLE 4.6 Percent Reduction in NOx Emissions Resulting from the Use of Low-NOX Burners

\begin{tabular}{|c|c|c|c|c|}
\hline $\begin{array}{l}\text { Fuel } \\
\text { Type }\end{array}$ & Boller Design & Typical & Maximum & $\begin{array}{l}\text { This } \\
\text { Study }\end{array}$ \\
\hline Coal & $\begin{array}{l}\text { Single-face fired } \\
\text { Horizontally opposed fired } \\
\text { Tangentially fired }\end{array}$ & $\begin{array}{l}40 \\
40 \\
50\end{array}$ & $\begin{array}{l}60 \\
60 \\
70\end{array}$ & $\begin{array}{l}40 \\
40 \\
50\end{array}$ \\
\hline Gas & $\begin{array}{l}\text { Wall fired } \\
\text { Tangentially fired }\end{array}$ & $\begin{array}{c}46-66 \\
17\end{array}$ & $\dot{-}$ & $\begin{array}{l}56 \\
17\end{array}$ \\
\hline Oll & Wall fired & $46-58$ & - & 52 \\
\hline
\end{tabular}

Sources: EPRI 1985 and Pepper et al. 1987.

The $\mathrm{NO}_{\mathrm{x}}$ emission factors for the years 1975-1984 were computed using the emission factors calculated for the year 1985. For each month during 1975-1984, the model year and month were compared with the on-line year, on-line month, and year of compliance reported for the boiler on Form 767 in 1985. Because the fuel consumption data taken from Form 759 were only at the prime-mover level and not at the boiler level for these years, the boiler-specific emission factors had to be aggregated to the level of prime mover. This aggregation was done by taking an average of each of the fuel-specific $\mathrm{NO}_{\mathrm{x}}$ emission factors for all prime movers of a given prime-mover type in the plant, weighted by the size of each boiler. The value used for the size of a boiler was the maximum continuous steam flow rate as reported on Form 767. Some plants and prime-mover types that reported fuel-consumption data did not report data on emission factors by boiler from Form 767. For these plants and prime-mover types, the uncontrolled $\mathrm{NO}_{\mathrm{x}}$ emission factors from AP-42 were used.

\subsubsection{Volatile Organic Compounds}

The emission factors used to estimate VOC emissions are listed in Table 4.7. These were taken from $\lrcorner$ AP-42 and were a function solely of the fuel type and prime-mover type.

\subsection{Calculating Emissions}

The final step in calculating emissions of $\mathrm{NO}_{\mathrm{x}}, \mathrm{SO}_{2}$, and $\mathrm{VOC}$ from electric utilities was to use Eq. 4.1 with the compiled data on fuel consumption, fuel quality, emission factors, and pollutant removal efficiencies. For $\mathrm{NO}_{\mathbf{x}}$, the fraction of emissions removed due to control (R) has already been incorporated into the emission factor, as explained above. For $\mathrm{SO}_{2}$, data on emission 
TABLE 4.7 Uncontrolled VOC Emission Factors for Electric Utility Combustors

\begin{tabular}{|c|c|c|}
\hline Emission Source, Fuel & $\begin{array}{l}\text { Source } \\
\text { Factor }\end{array}$ & $\begin{array}{l}\text { AP }-42 \\
\text { Table }\end{array}$ \\
\hline \multicolumn{3}{|l|}{ Steam boller } \\
\hline Bituminous (lb/ton) & 0.07 & $1.4-1$ \\
\hline Subbituminous(Ib/ton) & 0.07 & $1.1 \cdot 1$ \\
\hline Lignite (lb/ton) & 0.07 & $1.7-2$ \\
\hline Light fuel oil ( $\left(\mathrm{b} / 10^{3} \mathrm{gal}\right)$ & 0.20 & $1.3-1$ \\
\hline Heavy fuel oll (lb/10 $0^{3}$ gal) & 0.76 & $1.3-1$ \\
\hline Natural gas $\left(\left(\mathrm{b} / 10^{6} \mathrm{ft}^{3}\right)\right.$ & 1.40 & $1.4-1$ \\
\hline \multicolumn{3}{|l|}{ Gas turbine } \\
\hline Light fuel oil (lb/103 gal) & .5 .57 & $3.1-2$ \\
\hline Heavy fuel oil (lb/10 $0^{3}$ gal) & 5.57 & $3.1-2$ \\
\hline Natural gas $\left(\mathrm{lb} / 10^{6} \mathrm{tt}^{3}\right)$ & 42.00 & $3.2-1$ \\
\hline \multicolumn{3}{|l|}{ Internal combustion } \\
\hline Light fuel oil (lb/10 30 gal) & 13.00 & $3.4-4$ \\
\hline Heavy fuel oil (lb/103 gal) & 13.00 & $3.4-1$ \\
\hline Natural gas $\left(\mathrm{lb} / 10^{6} \mathrm{ft}^{3}\right)$ & 105.00 & $3.2-1$ \\
\hline
\end{tabular}

Source: EPA 1985.

control by FGD is taken from Form 767. Equation 4.1 calculates emissions by either individual boiler or prime-mover type within a plant. The emissions may be summed temporally and/or spatially to any level of aggregation that is desired. National annual results are provided in Table 4.8 .

\subsection{Important Methodological Assumptions}

Several aspects of the MSCET electric utility methodology are based on assumptions that had to be made in the absence of certain information. The assumption with the most potential impact is the assumption that utilities operate FGD units at the removal efficiency rate reported as the "annual operating efficiency" on Form 767. This reported value is usually either the maximum design efficiency or the most recently reported test efficiency. Plants also report the sulfur emission limit that they must not exceed based on federal, state, or local regulations. In some cases, this limit is significantly higher than the emission factor that would be calculated by assuming that the plant's scrubbers operate at the annual operating efficiency reported on Form 767. Scrubbers are costly to operate because they consume both electric power and chemical sorbent. As more sulfur is removed by scrubbers, more waste material is produced. This waste can be difficult and expensive to dispose of. Therefore, some utilities may operate 


\begin{tabular}{|c|c|c|c|}
\hline Yoar & $\mathrm{SO}_{2}$ & $\mathrm{NO}_{x}$ & VOC \\
\hline $\begin{array}{l}1975 \\
1976 \\
1977 \\
1978 \\
1979\end{array}$ & $\begin{array}{l}16.81 \\
17.55 \\
17.71 \\
16.25 \\
16.45\end{array}$ & $\begin{array}{l}5.02 \\
5.38 \\
5.63 \\
5.58 \\
5.82\end{array}$ & $\begin{array}{l}0.03 \\
0.03 \\
0.04 \\
0.04 \\
0.03\end{array}$ \\
\hline $\begin{array}{l}1980 \\
1981 \\
1982 \\
1983 \\
1984\end{array}$ & $\begin{array}{l}16.10 \\
15.65 \\
14.45 \\
14.66 \\
14.86\end{array}$ & $\begin{array}{l}5.97 \\
5.99 \\
5.68 \\
5.78 \\
5.03\end{array}$ & $\begin{array}{l}0.03 \\
0.03 \\
0.03 \\
0.03 \\
0.03\end{array}$ \\
\hline $\begin{array}{l}1985 \\
1986 \\
1987 \\
1988\end{array}$ & $\begin{array}{l}14.54 \\
14.36 \\
14.22 \\
14.53\end{array}$ & $\begin{array}{l}6.15 \\
6.06 \\
6.22 \\
6.37\end{array}$ & $\begin{array}{l}0.03 \\
0.03 \\
0.03 \\
0.03\end{array}$ \\
\hline
\end{tabular}

these devices only to the extent that they consistently emit below the regulated limit, so as to reduce cost. The argument in favor of operating at design efficiency is that the process of fine-tuning a scrubber so that a unit does not over-comply with a standard may involve complex adjustments to the scrubber. Utilities have been contacted during this study by the authors and by members of Resources Dynamics Corporation, and they have responded differently to questions about their actual operating behavior. Argonne received comments on earlier work questioning the assumption that utilities operate their FGDs at their design operating rate. It was suggested that FGDs are utilized only enough to meet the applicable emission standard for the plant. To test the sensitivity of the $\mathrm{SO}_{2}$ emission estimates to different assumptions about FGD operating practices, ANL conducted a sensitivity run based on the assumption that scrubbers are operated only to meet applicable $\mathrm{SO}_{2}$ emission standards. The results of the sensitivity run, provided in Table 4.9, show that the scrub-to-standard assumption results in uniformly higher emission estimates than those obtained with the assumption of Form 767 removal rates (Table 4.8). 
TABLE 4.9 National Electrio Utility

Sector Emissions Assuming

Sorubbers Are Operated Only to

Meet Standards, 1975-1988 (Mt)

\begin{tabular}{rrrr}
\hline Year & $\mathrm{SO}_{2}$ & $\mathrm{NO}_{x}$ & VOC \\
\hline 1975 & 16.90 & 5.02 & 0.03 \\
1976 & 17.70 & 5.33 & 0.03 \\
1977 & 17.90 & 5.63 & 0.04 \\
1978 & 16.60 & 5.58 & 0.04 \\
1979 & 16.90 & 5.82 & 0.03 \\
& & & \\
1980 & 16.70 & 5.97 & 0.03 \\
1981 & 16.40 & 5.99 & 0.03 \\
1982 & 15.20 & 5.68 & 0.03 \\
1983 & 15.60 & 5.78 & 0.03 \\
1984 & 15.80 & 5.03 & 0.03 \\
1985 & 15.10 & 6.15 & 0.03 \\
1986 & 14.90 & 6.06 & 0.03 \\
1987 & 14.80 & 6.22 & 0.03 \\
1988 & NA & 6.37 & 0.03 \\
& & & \\
\hline
\end{tabular}

$a_{N A}=$ not available. 


\section{Nonutility Stationary Source Methodology}

This section describes the methodology used to compute emissions from the industrial fuel combustion, commercial/residential fuel combustion, industrial processes, and miscellaneous sectors (collectively referred to as ICRIM). Compiling a data base of state-level emission trends for the ICRIM sectors was difficult because neither emissions data nor sufficient data to calculate emissions were available at the state level for these sectors. Calculating emission trends involved collecting activity data by emission source category and collecting emission factors for each source category to relate emissions to activities. Emission trends over time depend on changes in both activities and emission factors. Emission factors change as a result of process changes, the implementation of emission-control technology and environmental regulations, and the changing degree of control coverage. Only the electric utility sector, which is highly regulated, has sufficient data (i.e., on fuel consumption, fuel sulfur content, fuel type, pollution control) to allow the plantlevel computation of emission estimates (see Sec. 4). The transportation sector is a special case because the EPA has developed very sophisticated models to estimate emission factors; however, the activity data needed (vehicle miles traveled or VMT) to apply these emission factors did not exist for all years and had to be imputed from fuel consumption data (see Sec. 6). In some ICRIM sectors, an industry responsible for a large amount of emissions had a small number of plants. In these cases, it was possible to construct a plant-level emissions data set by obtaining data from the plants or from governmental agencies. This approach was used in MSCET to estimate $\mathrm{SO}_{2}$ emissions from the copper smelting industry (see Sec. 7). For the remaining sectors, which represent a large number of diverse sources, consistent time-series data do not exist, so a new approach had to be devised.

A shift-share methodology based on the state-level emissions data in the 1985 NAPAP Emissions Inventory (EPA 1989a) was developed to estimate ICRIM emissions. Trends were created from the base-year emission values in the inventory using ESG-specific growth rates. These growth rates were often derived from the EPA Trends Report (EPA 1989c) but were also derived from industrial production indexes, fuel consumption data, or other economic activity data. The monthly emissions were estimated by disaggregating annual emissions based on monthly activity data. The result was monthly emission estimates by state for the ICRIM ESGs.

Every model is based on certain assumptions, and the choice of these assumptions can affect the model's results, sometimes significantly. Section 5.5 provides a discussion of some alternative techniques and assumptions and their consequences.

\subsection{Overview}

A number of methods can be used to estimate state-level ICRIM emissions trends. One method would be to produce a detailed inventory of emissions, like the NAPAP emissions inventory, for every year. This so-called "bottom-up" approach would track all large point sources individually, and minor area sources would be estimated at the county level. With such data, 
emission trends could be accurately estimated down to the county level, and a precise picture of emission trends could be mapped out for practically any region of interest. This bottom-up approach has several drawbacks, however, the first being that it would be very expensive and require vast amounts of effort and resources. Another drawback is that it cannot be done for past years, since the data required by this method do not exist in most cases.

Another method would be to take published data on national emission trends and disaggregate them to the state level using state emission shares data. With this "top-down" approach, for example, a national time series of emissions from iron and steel production and the relative shares of these emissions from each state could be used to estimate an emission time series by state.

A third alternative is to combine the bottom-up and top-down methods by combining the detailed emissions data in the recently completed 1985 NAPAP Emissions Inventory, the national emission trends estimates, and, where available, the state-level activity data. This unique combination top-down/bottom-up approach was implemented in the revised ICRIM methodology. Emissions were "benchmarked" to match those in the 1985 NAPAP Emissions Inventory, and emissions in years other than 1985 were estimated using data on national emission trends, which were frequently derived from the EPA Trends Report (EPA 1989c). The state shares taken from the 1985 NAPAP Emissions Inventory (EPA 1989a) were changed over time if state-level activity data were available. If reliable state-level activity data were not available, the NAPAP state shares were assumed to be constant. This revised ICRIM methodology is described in detail below.

\subsection{Implorimenting the ICRIM Methodology}

For simplicity, the ICRIM methodology is presented below as a series of seven steps:

1. Identify the emission or activity series (emission trend indicators). Often these were national emission trends from the EPA Trends Report (EPA 1989c). In some cases, trends in activity levels were used to compute emission trends. Whenever possible, state-level information on trends was employed, usually from the State Energy Data System (SEDS) data base (EIA 1975-88a). Each annual trends series additionally required a monthly trend series.

2. On the basis of the trend indicators, define the emissions source groups (ESGs). The ESG forms the basic unit for which the MSCET system's emission estimates were developed and reported. The industries or activities included in each series were determined from the series' documentation.

3. Construct emission values for ESGs from the 1985 NAPAP Emissions Inventory. All emission sources, identified by source classification code (SCC) in the 1985 NAPAP Emissions Inventory (EPA 1989a), were assigned to an ESG. The 1985 emissions from the sources in these ESGs were the benchmark from which emissions in other years were estimated. 
4. Estimate annual emissions. For each ESG, the annual percentage changes in the trend indicators were applied to the 1985 emissions derived from the 1985 NAPAP Emissions Inventory.

5. Estimate state emission shares. For each ESG, state-level trends data (if available) and state-level data in the 1985 NAPAP Emissions Inventory were used to estimate the state emission shares for each year. State shares changed from year to year when state-level time series data were avallable.

6. Estimate monthly state emission indexes. For each ESG, monthly indexes were computed from monthly time-series data. Because some times series were state specific, some month indexes were state specific.

7. Estimate monthly state emissions. The results of Steps 5 and 6 were applied to the annual estimates of Step 4 to estimate monthly state emission time series.

Details on these steps are provided below.

\subsubsection{Identifying Emission Trend Indicators}

To estimate emission trends for the ICRIM sectors, emission trend indicators were developed from time-series data. Often these time series were emissions trends from the EPA Trends Report (EPA 1989c). Otherwise, they were data on industrial production or some other activity related to emissions. The possibility of using the 1980 NAPAP Emissions Inventory in conjunction with the 1985 NAPAP Emissions Inventory to estimate emission trends was explored but rejected because these two data bases were not comparable. If emissions (by SCC) were to be calculated on the basis of a comparison of these two inventories, any changes that occurred between 1980 and 1985 would probably be the result of improvements in data quality rather than actual changes in emissions. In addition, this method would not provide the data necessary for estimating emissions before 1980 and after 1985. Since emission trends could not be inferred from these two NAPAP inventories, alternative sources of information on emission trends were developed.

The EPA Trends Report employs available government and industry data to develop annual emission trends for broad categories of sources. The EPA Trends Report was the first choice for developing the emission trend indicator series. During the development of the ESGs, however, it became apparent that some emission sources were not covered by the Trends Report. For these sources (usually industrial process sources), the Federal Reserve Board (FRB) indexes of industrial production were used (FRB 1975-88). Other sources of information were the Monthly Energy Review (EIA 1975-88b) for fuel consumption and the U.S. Department of Commerce Survey of Current Business (DOC 1985-88) for industrial production. If no appropriate trend indicator could be identified, or if the source was relatively minor $(<10 \mathrm{kt})$, emissions were held constant at the levels reported in the 1985 NAPAP Emissions Inventory. This situation occurred primarily when an ESG emitted a significant amount of one or two pollutants and little or none of the other(s). For example, in 1985 the cement industry emitted 125.1, 250.1, and $0.4 \mathrm{kt}$ of $\mathrm{NO}_{\mathrm{x}}$, 
$\mathrm{SO}_{2}$, and VOC," respectively. Therefore, only $\mathrm{NO}_{x}$ and $\mathrm{SO}_{2}$ emissions were modeled, and VOC emissions were held constant for the cement ESG. A complete listing of emission trend indicators by ESG and pollutant can be found in App. A, Tables A.5-A.8.

In most cases, the trend indicators were national series. To estimate state trends, an additional state-level index had to be found for each ESG. For the commercial/residential and industrial fuel combustion sectors, and for the asphalt paving ESG (in the miscellaneous sector), the SEDS data base provided state-level data through 1987 (EIA 1975-88a). If no state-level indexes could be found, state shares were assumed to remain constant at their 1985 levels. A complete listing of the state trend indicators by ESC and pollutant can be found in App. A, Table A.13. The application of these state indexes is discussed later in the section on estimating state shares.

Most of the above-mentioned indexes were annual serles; therefore, to estimate monthly emissions, a corresponding monthly series had to be identified. The monthly indexes came from a number of sources. A complete listing of the monthly trend indicators by ESG and pollutant can be found in App. A, Tables A.9-A.12. Application of the monthly indexes is discussed later in the section on estimated monthly emissions.

\subsubsection{Defining the Emission Source Groups}

The ESG formed the basic unit for which the MSCET system's emission estimates were developed and reported. ESGs were constructed to reflect the available trend indicator series. When an emission trend indicator had been identified, a corresponding ESG was created. A definition for each ESG was developed by researching the indicator series' documentation to determine which industries or activities the series was intended to represent or measure.

Because the EPA Trends Report was an important source of emission trends data, many of the ESGs were defined to correspond to the emission categories in that report. The Trends Report sometimes lists one or more Standard Industrial Classification (SIC) codes along with the emission category name, and these SIC codes help to clarify which industries are included in the category. For example, the EPA Trends category "pulp mills" corresponds to SIC codes 261 and 262. Some Trends categories span several industries, however, so SIC codes could not be used to define an ESG. The "degreasing" category is one that spans several industries and has emissions from many SIC codes. Thus some judgment was used in devising the ESG definitions.

The NAPAP Emissions Inventory also influenced the definitions of the ESGs. As emission trend indicator series were identified, NAPAP SCCs were assigned to these ESGs on the basis of SCC descriptors in the inventory. The inventory contains classification codes for several hundred emission sources, and many of these sources did not relate precisely to one of the

\footnotetext{
*Emissions data were taken from the 1985 NAPAP Emissions Inventory for the cement industry as defined in MSCET. See App. A., Tables A.1-A.4, for a list of the emission source classification codes (SCCs) that make up each ESG and their definitions.
} 
emission indicator series from the EPA Trends Report. However, many of these sources could be logically related to an indicator series, because the processes or descriptors were similar to those defined in the EPA Trends Report. An assumption was made that emission trends for similar sources could be expected to be similar. This assumption enabled the number of ESGis to be kept to a reasonable minimum. Typically, the ESG definitions were expanded to include logically related sources from the 1985 NAPAP Emissions Inventory.

\subsubsection{Constructing the Emission Source Groups}

After the ESGs were defined and the appropriate emission SCCs were assigned to the ESGs, the ESGs were constructed from the emissions data in the 1985 NAPAP Emissions Inventory. All the emission sources in the inventory, except for the electric utility, transportation, and copper smelter sources, were used. Emission sources that could not be associated with specific ESGs were assigned to a miscellaneous group. The ESGs and their constituent SCCs are listed in App. A, Tables A.1-A.4.

Tables 5.1-5.4 list the ESGs and their emissions for the commercial/residential fuel combustion, industrial fuel combustion, industrial process, and miscellaneous sectors, respectively. The source of the emissions data was the 1985 NAPAP Emissions Inventory data base, which was obtained by ANL on January 25, 1989, in computer tape format (EPA 1989a). Some of the terms and phrases in Tables 5.1-5.4 need clarification. "Fuel oil" includes residual oil and distillate oil. "Other fuels" includes wood, liquefied petroleum gas (LPG), propane, process gas, gasoline, kerosene, jet fuels, bagasse, and liquid and solid waste. The industrial fuel combustion ESGs include external combustion boilers, internal combustion engines, some process heaters, and in-process fuel use. "Miscellaneous industrial processes" include construction, electrical equipment manufacturing, flat wood products, fabricated metals, furniture, transportation equipment manufacturing, textiles, machinery manufacturing, and other industries. "Organic chemicals" includes both their manufacture and storage. "Other chemicals" includes the manufacture and storage of agricultural chemicals, inorganic chemicals, carbon black, synthetic rubber and fibers, drugs, paints, varnishes, and explosives. "Other burning" includes managed burning, agricultural burning, and structural fires. "Nonindustrial organic solvent use and disposal" includes miscellaneous nonindustrial organic solvent use, publicly owned treatment works, and hazardous-waste treatment, storage, and disposal facilities. Finally, "other miscellaneous sources" include miscellaneous solid-waste disposal and orchard heaters. 
TABLE 5.1 National Commerolal/Institutional and Residential Fuel Combustion Sector Emissions by Emission Source Group, 1985 (kt)

\begin{tabular}{lrrr}
\hline \multicolumn{1}{c}{ Emission Source Group } & $\mathrm{NO}$ & \multicolumn{1}{c}{$\mathrm{SO}_{2}$} & VOC \\
\hline Commerclal/institutional coal & 33.1 & 143.3 & 1.1 \\
Commerclalinstitutional fuel oll & 92.8 & 215.1 & 3.0 \\
Commerclal/instifutional natural gas & 122.7 & 1.1 & 2.6 \\
Commerclal/institutional wood and other fuels & 3.9 & 0.4 & 0.4 \\
Residential coal & 2.7 & 33.7 & 9.3 \\
Residential fuel oll & 68.1 & 116.8 & 5.2 \\
Residential natural gas & 225.2 & 1.1 & 0.0 \\
Residentlal wood and other fuels & 73.2 & 10.0 & 1324.0 \\
& 621.7 & 521.5 & 1345.6 \\
\hline
\end{tabular}

a Totals may not sum due to independent rounding.

TABLE 5.2 National Industrial Fuel Combustion Seutor Emissions by Emission Source Group, 1985 (kt)

\begin{tabular}{lrrr}
\hline \multicolumn{1}{c}{ Emission Source Group } & $\mathrm{NO}_{x}$ & $\mathrm{SO}_{2}$ & VOC \\
\hline Industrial coal & 487.2 & 1372.8 & 4.7 \\
Industrial fuel oll & 275.5 & 740.1 & 14.6 \\
Industrial natural gas & 1917.3 & 53.4 & 37.0 \\
Industrial wood and other fuels & 316.6 & 255.3 & 44.6 \\
& & & \\
Totala & 2996.6 & 2421.6 & 100.9 \\
\hline
\end{tabular}

a Totals may not sum due to iridependent rounding. 
TABLE 5.3 National Industrial Process Sector Emissions by Emission Source Group, 1985 (kt)

\begin{tabular}{|c|c|c|c|}
\hline Emission Source Group & $\mathrm{NO}_{x}$ & $\mathrm{SO}_{2}$ & VOC \\
\hline $\begin{array}{l}\text { Cement production } \\
\text { Legreasing operations } \\
\text { Dry cleaning operations } \\
\text { Food processing / agricultural operations } \\
\text { Gasoline marketing } \\
\text { Glass manufacturing } \\
\text { Industrial organic solvent use } \\
\text { Iron and steel production } \\
\text { Lime production } \\
\text { Mineral products processing } \\
\text { Mining operation } \\
\text { Miscellaneous industrial processes } \\
\text { Oil and natural gas extraction } \\
\text { Organic chemicals manufacture } \\
\text { Other chemicals manufacture } \\
\text { Paper and pulp mills operations } \\
\text { Plastics manufacture } \\
\text { Petroleurn product storage and transfer } \\
\text { Petroleum rr.iviti } \\
\text { Primary aluminitu smelting } \\
\text { Primary copper smelting } \\
\text { Primary lead and zinc smelting } \\
\text { Other primary metal smelting } \\
\text { Printing operations } \\
\text { Rubber and miscellaneous plastics manufacture } \\
\text { Secondary lead smelting } \\
\text { Other secondary metals smelting } \\
\text { Surface coating }\end{array}$ & $\begin{array}{r}125.1 \\
0.0 \\
0.0 \\
4.3 \\
0.1 \\
48.7 \\
0.0 \\
47.2 \\
26.3 \\
10.4 \\
11.3 \\
5.9 \\
62.6 \\
26.9 \\
105.8 \\
65.0 \\
16.4 \\
0.8 \\
54.3 \\
2.1 \\
0.9 \\
1.6 \\
0.9 \\
0.2 \\
0.0 \\
0.8 \\
4.1 \\
7.1\end{array}$ & $\begin{array}{r}250.1 \\
0.0 \\
0.0 \\
3.0 \\
1.1 \\
21.7 \\
0.0 \\
155.4 \\
28.8 \\
20.2 \\
26.3 \\
6.3 \\
242.0 \\
14.7 \\
434.0 \\
118.3 \\
2.4 \\
0.3 \\
326.9 \\
53.0 \\
675.3 \\
96.5 \\
11.4 \\
0.0 \\
0.0 \\
18.8 \\
7.1 \\
0.7\end{array}$ & $\begin{array}{r}0.4 \\
354.9 \\
230.5 \\
90.9 \\
1007.0 \\
6.2 \\
70.7 \\
36.2 \\
0.9 \\
0.8 \\
3.9 \\
43.3 \\
97.1 \\
329.2 \\
411.5 \\
28.5 \\
424.1 \\
490.5 \\
836.5 \\
0.4 \\
0.0 \\
0.0 \\
0.0 \\
271.8 \\
26.4 \\
0.4 \\
8.0 \\
2105.8\end{array}$ \\
\hline Total $^{\mathrm{a}}$ & 628.8 & 2514.3 & 6875.9 \\
\hline
\end{tabular}

a Totals may not sum due to inciependent rounding. 
TABLE 5.4 National Miscellaneous Sector Emissions by Emission Source Group, 1985 (kt)

\begin{tabular}{lrrr}
\hline \multicolumn{1}{c}{ Emission Source Group } & $\mathrm{NO}_{x}$ & $\mathrm{SO}$ & $\mathrm{V} O \mathrm{C}$ \\
\hline & 0.0 & 0.0 & 174.1 \\
Paving operations & 30.5 & 1.1 & 146.5 \\
Forest fires & 86.9 & 2.7 & 356.0 \\
Other burning & 5.0 & 1.9 & 2652.3 \\
Nonindustrial organic solvent evaporation & 24.3 & 22.5 & 55.8 \\
Solid-iNaste incineration & 53.9 & 7.6 & 280.7 \\
Solid-waste open burning & 0.6 & 1.3 & 0.8 \\
Other miscellaneous sources & & & \\
& 201.2 & 37.1 & 3666.2 \\
Totala & & & \\
\hline
\end{tabular}

a Totals may not sum due to independent rounding.

\subsubsection{Computing Annual Trends}

Annual ICRIM emission estimates were computed by scaling the 1985 ESG totals by the annual activity index developed from the associated trend indicator series. This index is simply the ratio of activity in year $t$ to activity in 1985. Frequently, the emission trend indicator was the EPA Trends Report emissions estimate, and the ratio of the EPA emission estimate in year $t$ to 1985 was used. In most cases, this ratio was approximately equal to the ratio of activity levels. ${ }^{\dagger}$ The ICRIM method uses the percent change in the activity index because it is an unbiased estimate of the trend and adjusts for size and/or measurement errors in the trend indicator series. (Alternative methods of estimating trends are discussed at the end of this section.)

The combined bottom-up/top-down nature of the ICRIM methodology is most easily seen in the annual trends computation. The bottom-up nature of the methodology can be observed in the

\footnotetext{
*Activity variables are also included in the NAPAP data base. The problems with using them is that they are not always reported, their quality has not been fully checked, and they are typically at a micro level of detail (i.e., specific to an eight-digit SCC). Nevertheless, it would be informative to analyze these mecosures of activity by sector. These measures would aid in interpreting and understanding emission data and trends. They would also allow the calculation of average emission rates over broad categories and characterize the changes in the average emission rate over time, since imissions and activity in a sector typically grow at different rates. The Divisia index is an approuch that has been used in energy modeling to characterize trends based on micro data (see Boyd et al. 1987).

†The EPA Trends Renort uses the same emission factor in all years and essentially no control for industrial processes.
} 
ESG emissions, which were constructed with detailed bottom-up data from the 1985 NAPAP Emissions Inventory. The emission trend computation employed national top-down time-series data for the trend indicators. The result was an estimate that used the best available data for both emissions (1985 NAPAP Emissions Inventory) and emission trends (EPA Trends Report and other sources).

\subsubsection{Estimating Nonconstant State Emission Shares}

Because emission-producing activities sometimes shift among states over time, it was desirable for the ICRIM methodology model to adjust state activity shares. Several methods could be developed to change state shares. One method would be to compare the state shares in the 1980 NAPAP Emissions Inventory with those in the 1985 NAPAP Emissions Inventory by ESG. The ESGs would be made up of the same SCCs for both years. Although on the surface this method seems attractive, in practice, it does not seem advisable. Some portion of the change in emissions by SCC that occurred between the 1980 and 1985 inventories wotild probatly be a result of changes in data quality rather than actual changes in emissions. In the industrial and commercial sectors, dramatic differences, which scoped outside a plausible range for the differences, occurred for some SCCs. In addition, in the 1980 Emissions Inventory, the year of record was often not 1980. The 1985 Emissions Inventory did not have this year-of-record problem and, in general, is considered the best available source of information. Therefore, implementing a method that would be based on changes between the 1980 and 1985 inventories would not be advisable.

Another option is to select an activity variable available by state whose growth is logically related to emissions. This activity variable can be used in a shift-share formula; that is, states with a higher relative growth in the related activity will gain in share. The shift-share formula is used in the ICRIM methodology and is described in detail in Hanson et al. (1988). It is given by Eq. 5.1:

$$
S_{i, s, y}=\frac{E M_{i, s} \times A_{i, s, y}}{\sum_{s=1}^{49}\left(E M_{i, s} \times A_{i, s, y}\right)}
$$

where:

$$
\begin{aligned}
S & =\text { state share } \\
E M & =\text { emissions from } 1985 \text { NAPAP Emissions Inventory, } \\
A & =\text { activity growth index }\left(A_{i, s, 1985}=1.0\right) \\
i & =\text { emission source group }(E S G) \\
S & =\text { state }
\end{aligned}
$$




$$
\begin{aligned}
y & =\text { year, and } \\
49 & =\text { the } 48 \text { contiguous states plus Washington, D.C. }
\end{aligned}
$$

Having the activity index A equal 1.0 in 1985 means that the state shares in 1985 equal the state shares in the 1985 NAPAP Emissions Inventory. In other years, state shares can change on the basis of different relative growth rates in activity. For more discussion of the properties of this formula, see Hanson et al. (1988). The data bases used to calculate state share shifts for MSCET subsectors are listed in App. A, Table A.13. State consumption data from the DOE/EIA SEDS were available for most of the fuel categories in the commercial/institutional, residential, and industrial fuel combustion sectors. These data were used for all but the "wood" and "other" fuel categories, which are treated as having constant state shares.

In the industrial process sector, state shares for gasoline marketing were computed from "state sales of highway gasoline" in the Federal Highway Administration publication, Highway Statistics (FHW.A 1985-88). The other sector for which annual state shares were calculated is the primary copper sector, for which plant-specific data gathered by ANL were used. State shares for all other sectors were treated as being constant because there was a lack of appropriate data. State shares for some of the industrial process subsectors could have been developed from data from the Bureau of Economic Analysis, but such data represent the value of production rather than the physical units of production. Physical units are more closely related to emissions.

Only one of the miscellaneous sector ESGs had the available data to shift state shares. This was paving, for which SEDS data on "industrial--asphalt and road oil quantities" were used.

A third approach would be a bottom-up method of estimating emissions at the state level. This method could be applied in a few instances, in which there are a few large emission sources and for which the state environmental agencies have historically kept emission records. Argonne National Laboratory is currently examining the plant data contained in the 1985 NAPAP Emissions Inventory (EPA 1989a) for internal consistency and compatibility with other sources of information (e.g., trade association data). To date, only state-level emissions from the copper smelter sector were treated with this plant-level data approach instead of the top-down approach described above.

Finally, for cases in which none of the above approaches are applicable or judged to be reliable, or for cases in which total emissions from an ESG were low, state shares were held constant at the values in the 1985 NAPAP Emissions Inventory. The equation for this approach follows:

$$
S_{i, s}=\frac{E M_{i, s}}{\sum_{s=1}^{49} E M_{i, s}}
$$




\subsubsection{Computing Monthly Indexes}

The data sources used to develop the monthly indexes varied across the MSCET sectors and are listed in App. A, Tables A.9-A.12. As was the case for annual trends, the assumption was that monthly emission trends are driven by economic and fuel consumption activity. Thus, the monthly data series were chosen to logically correlate with the activity that causes emissions in an ESG. For example, monthly steel production data were used to estimate monthly shares of emissions from the iron and steel production ESG. The monthly indexes were a simple ratio of activity in a month divided by annual activity levels. The relationship is as follows:

$$
M_{i, m, s, y}=\frac{A_{i, m, s, y}}{\sum_{m=1}^{12} A_{i, m, s, y}}
$$

where $\mathrm{M}=$ monthly activity index and $\mathrm{m}=$ month.

For the commercial/institutional and residential fuel combustion sectors, the monthly shares were derived primarily from state-specific, population-weighted, heating-degree-day data collected by the National Climatic Data Center (NCDC 1987). The population-weighted series was chosen because the relative population density in the regions within a state where temperature measurements were taken was assumed to be correlated with the quantities of fuel used. These data were considered particulariy appropriate for the residential fuel combustion SCC groups because of the high proportion of total fuel combustion that is associated with space heating. The heating-degree-day data were not used for the commercial/institutional coal and natural gas or residential natural gas combustion categories. Because the heating-degree-day data were state-level data, state-specific monthly indexes could be computed.

For the commercial/institutional coal combustion sector, data from the Quarterly Coal Report (EIA 1982-89) were used. These data were available by state and region, quarterly, for the commercial/residential sector, with many state values withheld. (The data were withheld to protect the confidentiality of firms operating in states with only a few coai suppliers.) This data base was most complete for the states that are major users of coal in the commercial sector and least complete for most of the western U.S. states. To make use of these data, an algorithm was developed to estimate values for the withheld data. This procedure involved using the U.S. total as a control for the regional totals, allocating unidentified coal use equally among the regions for which data were withheld. A similar procedure was employed to allocate the unassigned remainder of a region's total coal consumption to states for which data were withheld. The quarterly data were then divided equally among the three months in each quarter. Thus, while the resulting shares were monthly, the trends were actually seasonal.

Monthly consumption data for coal and fuel oil for the industrial fuel combustion sector were taken from the Monthly Energy Review (EIA 1975-88b). These data have been available in terms of physical units since 1975. The Natural Gas Monthly (EIA 1985-88b) provided month and state-share data for 1985-1988. The monthly shares were held constant before 1985 because 
the data are missing. Because data on the combustion of wood and other fuels in the industrial sector were unavailable, the FRB industrial production index (nonseasonally adjusted) was used.

A variety of methods were used to model monthly trends for the industrial process and miscellaneous sectors. The available data related to each specific ESG were evaluated, and a method was selected on the basis of the following ranking of data sources and methods:

1. Production data in physical units irstr the Survey of Current Business (DOC 1985-88) or a sector-specific scurcio,

2. Production index data (nonseasonally adjusted) from the FRB (1975-88),

3. 1985 NAPAP Emissions Inventory seasonal allocation factors, or

4. Even distribution of activity across all months.

Using this ranking, preferred data bases or methods were those for which the data are most directly related to the production activity associated with emissions. The data sources used for each ESG are listed in App, A, Tables A.14-A.17.

\subsubsection{Computing Monthly State Emission Series}

Using the relationships described above, the monthly emission time series were computed using the following equation:

$$
E_{i, m, s, y}=E M_{i} \times s_{i, s, y} \times G_{i, y} \times M_{i, m, s, y} .
$$

Equation 5.4 allowed state shares to change through time, thus capturing regional differences in emission trends.

\subsection{Estimating Emissions for the Most Recent Year (Flash Methodology)}

One of the goals of the MSCET project is to estimate recent emissions data in a timely fashion. Emission estimates for the previous year are scheduled to be released at the end of the first quarter of the current year. For the ICRIM sectors, the MSCET program must usually provide a forecast for one additional year beyond the year cited in the most recently published EPA Trends Report. This one-year forecast, or "flash" methodology, is described in this section.

Several methods were used to extend the ICRIM series to the most recently completed calendar year. Preliminary annual emission trend estimates were usually based on economic and fuel consumption activity data. The secondary annual trend indexes are called "annual extenders," since they extend the annual emissions data from the previous year. In most cases, the annual extender used the same economic and fuel consumption data as those used to calculate the monthly activity indexes. Tables A.14-A.17 in App. A list the data sources for each ESG. For the fuel 
combustion sectors, fuel consumption data from the Monthly Energy Review (EIA 1975-88b) instead of heating-degree-days were used to compute the annual extender, because regression analysis showed the former to be more closely related to the annual emission trend for several sectors. The five major types of methods used are listed below by order of selection. Underlying this ranking is a preference for the method that most directly reflects the relationship between emissions and their associated activity.

1. Prediction of emissions from a dynamic, estimated emission factor. This algorithm examines the behavior of a pseudo "emission factor" constructed by dividing the data on annual emissions from the EPA Trends Report by the corresponding activity data. For example, the emissions from the iron and steel industry in a given year $t$ were divided by the SCB steel production data for that year. Emission factors are expected to change through time because of evolving production technologies, emission-control laws, production mixes, and fuel-use efficiencies. To capture these changes, the natural $\log$ of the emission factor is regressed versus time so it can be determined whether one can reasonably estimate the emission factor for the next year. The natural log of the emission factor is used because the emission factor is probably changing by some percentage each year rather than by an absolute amount. If the fit is judged to be adequate $\left(R^{2}>0.60\right)$, this algorithm is used to estimate an emission factor for the latest year. The estimated emission factor is then multiplied by the activity series to estimate emissions for the latest year.

2. Prediction of emissions from activity levels. This method also involves estimating a regression model, with emissions being the independent variable and activity being the dependent variable. This regression examines the relationship of emissions to activity, and it assumes that the emission factor is constant with respect to time but may vary with respect to scale. Again, because changes are assumed to be some percentage of the base value, the natural $\log$ of emissions is regressed versus the natural log of activity. This relationship captures changes in the emissions resulting from the scale of the activity (which may cause differing efficiencies for production, fuel consumption, or emission control). If the fit is judged to be adequate $\left(\mathrm{R}^{2}>0.60\right)$ and the first algorithm is not used, this algorithm is used to estimate emissions for the latest year. If the constant term of the regression result is some number other than zero, this implies that the emission factor is not proportional to activity and that emissions do not change at the same rate as activity.

3. Scaling to 1985 activity data. For the subsectors for which the EPA Trends Report data are unavailable to develop the annual trends, the activity data that were used for the annual trend are also used for the extender. The 1985 NAPAP Emissions Inventory data were scaled by the ratio of the activity level in the latest calendar year to the 1985 activity level. This is the same method that was used to project the annual trend for these sectors. 
4. Scaling to the previous year's activity data. For some ESGs for which data on emissions are available, neither the first or second algorithm yields significant results. When the EPA Trends Report data are used for the annual trend, the emission value for the latest year is scaled by an activity-data ratio of the latest calendar year to the previous year. In most cases, the activity data source is the same as that used for the monthly trend.

5. Holding emissions constant. For subsectors for which none of the above methods is feasible, emissions are held constant at either the value for the last year for which data are available or at the 1985 NAPAP Emissions Inventory level.

A list of the ESGs and their corresponding annual extender data sources and regression coefficients is provided in App. A, Tables A.14-A.17. The extended monthly emission estimates are computed using the following equation:

$$
P E_{i, m, s, y}=E M_{i} \times s_{i, s, y} \times G_{i, y-1} \times X_{i, y} \times M_{i, m, s, y}
$$

where $P E=$ preliminary emissions estimate and $X=$ the annual extender. In Eq. 5.5, the state share $S_{s, y, i}$ is estimated for the current year $y$. If data are not available, however, $S_{s, y-1, i}$ can be substituted.

\subsection{Comparison of MSCET with EPA and NAPAP Emissions}

Table 5.5a compares the emission estimates from MSCET, the NAPAP Emissions Inventory, and the EPA Trends Report for 1985. (Note: Table 5.5b presents an identical comparison in terms of short tons rather than metric tons.) The top part part of the table compares emissions from sectors other than ICRIM. The bottom half compares the ICRIM sectors. Because MSCET was based on the 1985 NAPAP Emissions Inventory for the ICRIM sectors, MSCET and NAPAP agree. Differences do exist between the MSCET and the EPA Trends Report data (some small and some large), but because only the annual emission growth rates were taken from the EPA Trends Report, it was not expected that the absolute emission values from the two data sets would agree. In fact, the differences between the MSCET and EPA Trends Report data are a function of the differences between the NAPAP Emissions Inventory and EPA Trends Report data. The reasons for these differences are not well understood but were expected, because the NAPAP data were constructed from the bottom up (i.e., from records for individual emission sources) and the EPA estimates were computed from the top down (i.e., using aggregate data).

Figures 5.1-5.3 present annual trends for $\mathrm{NO}_{\mathrm{x}}, \mathrm{SO}_{2}$, and VOC emissions in the ICRIM sectors from the EPA Trends Report and MSCET. Differences between the values (or height of the lines) were expected because of the differences between the EPA Trends and NAPAP data; nevertheless, the trends seem to compare well, especially those for $\mathrm{NO}_{\mathrm{x}}$ and VOC. A few 


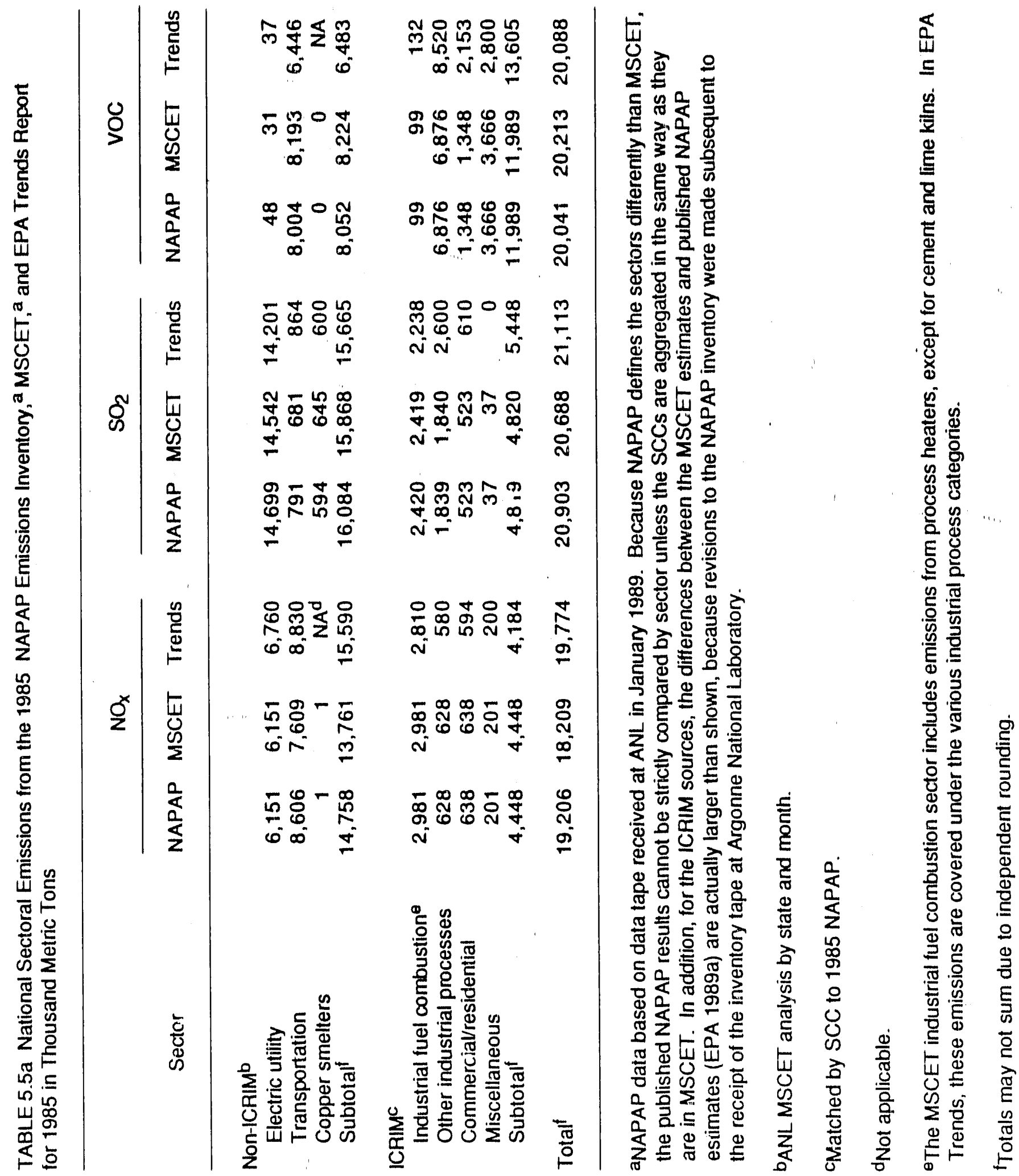




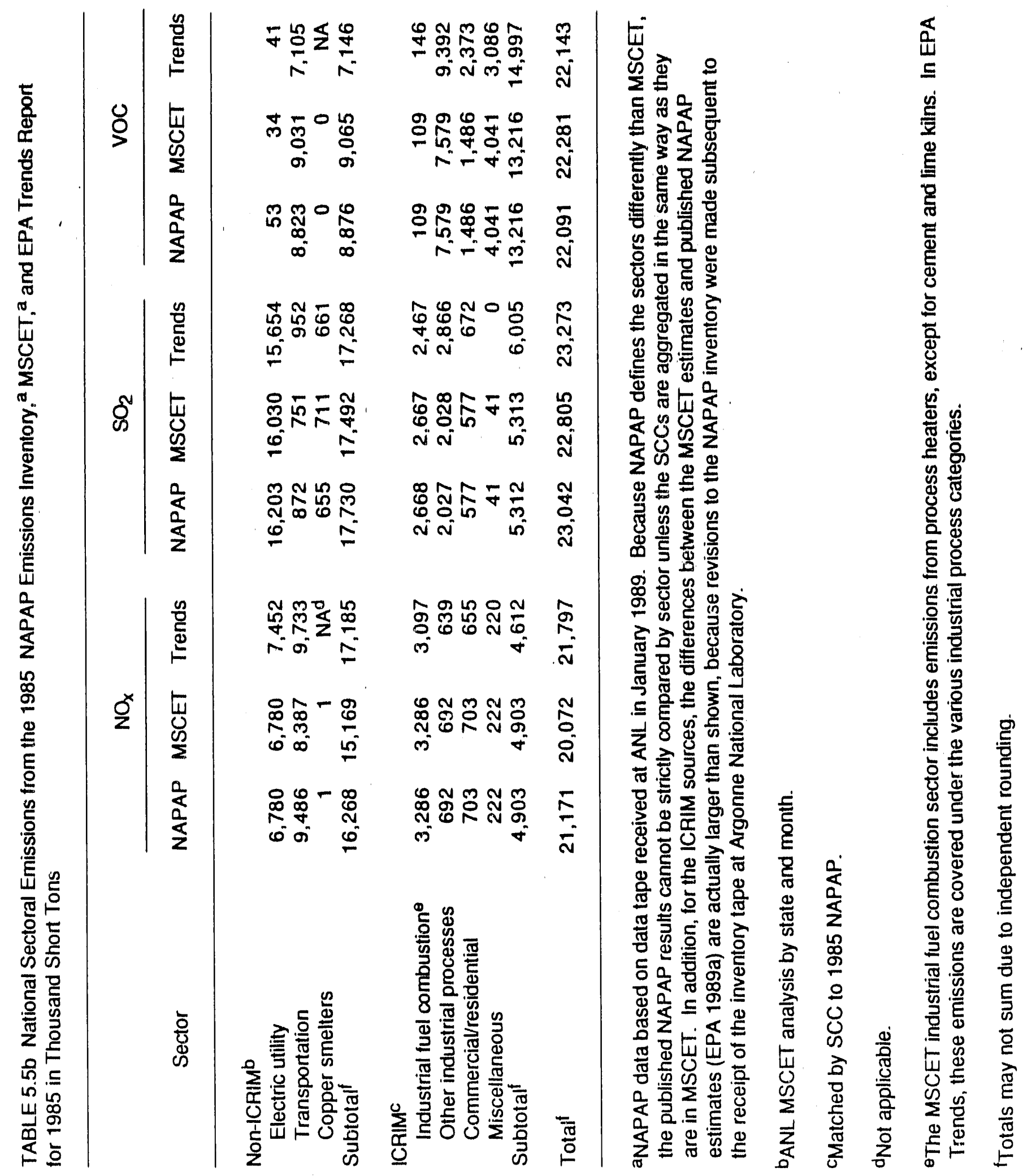




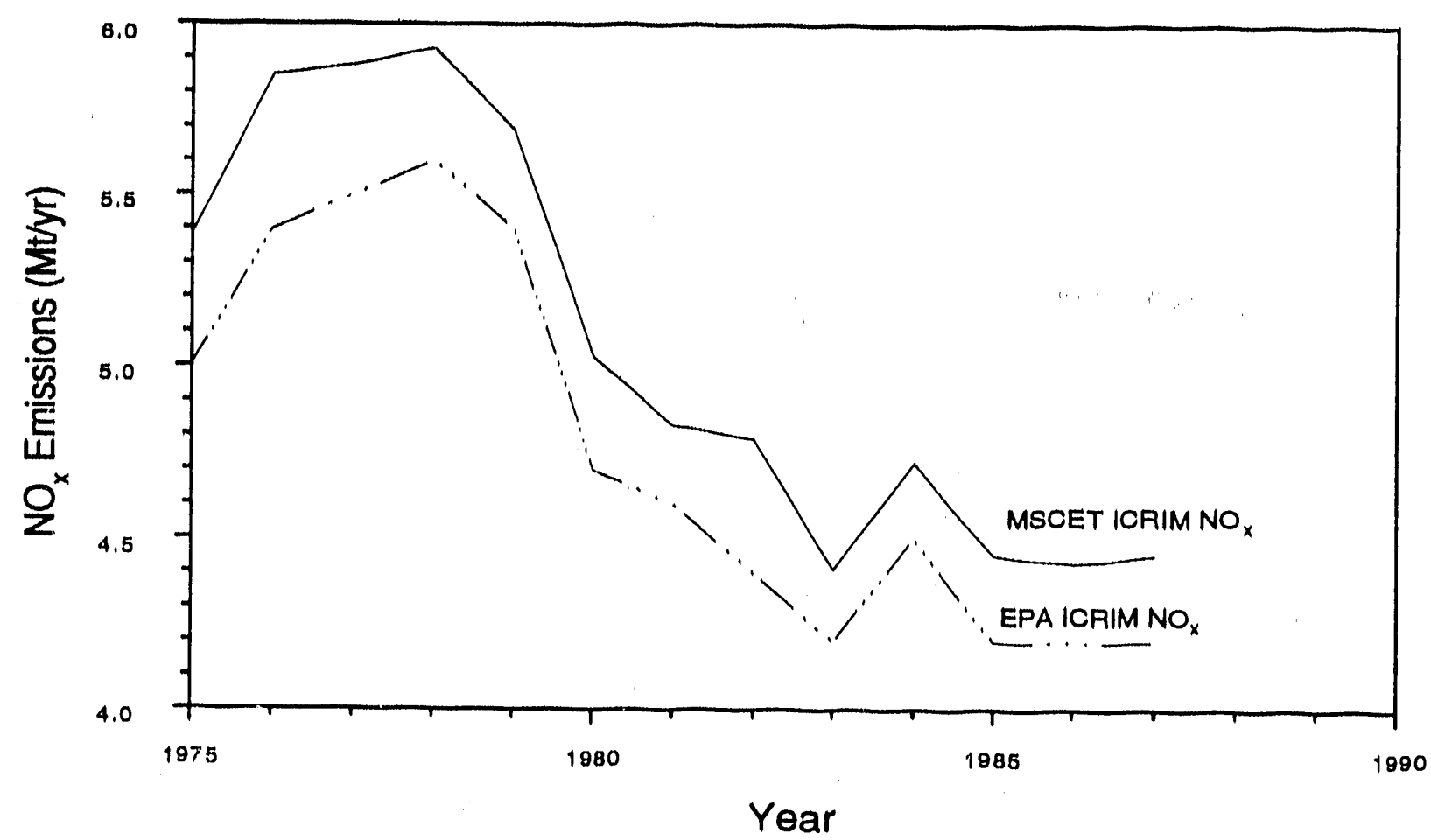

FIGURE 5.1 ICRIM NOX Emission Trends from MSCET and EPA Trends Report, 1975-1987

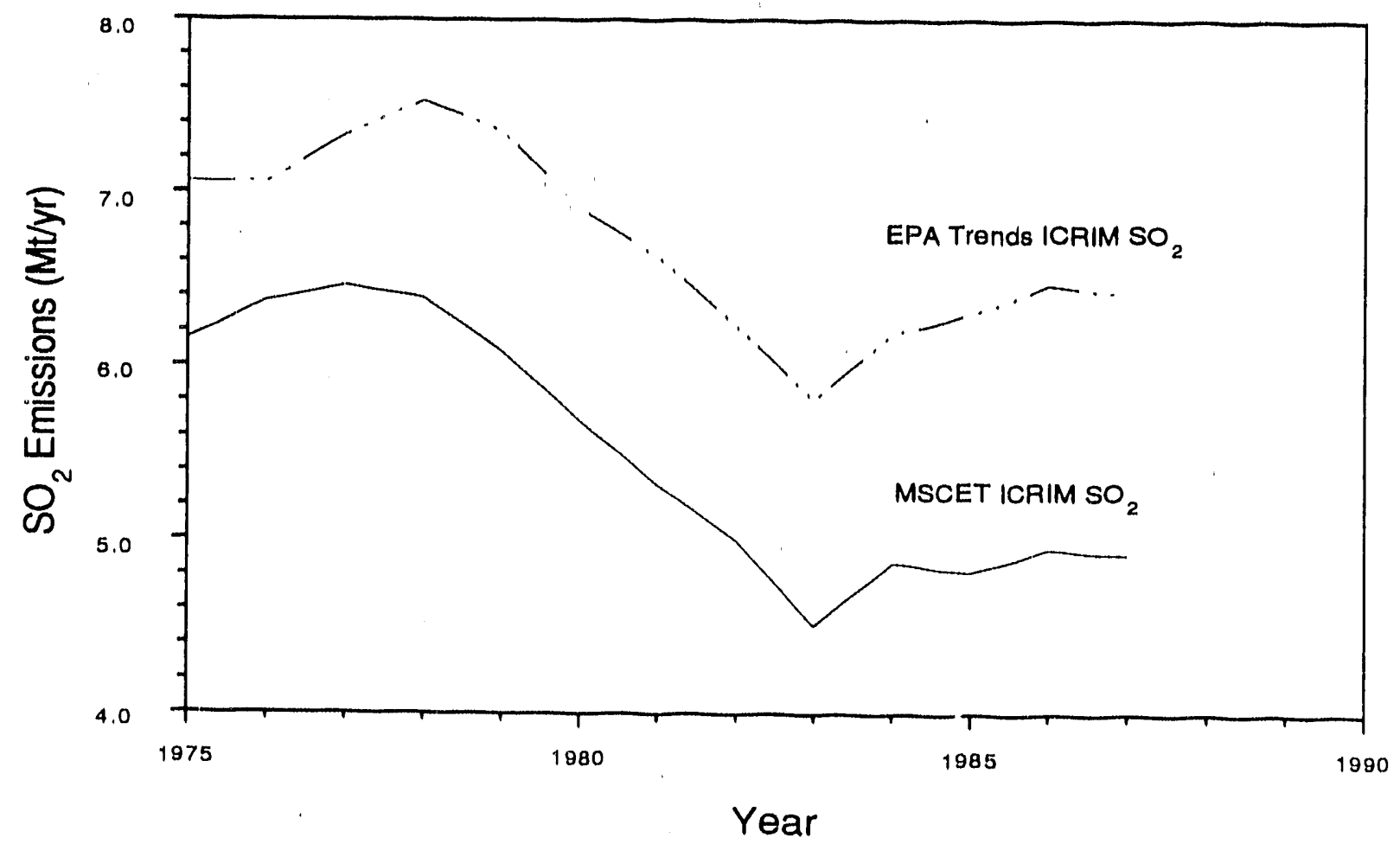

FIGURE 5.2 ICRIM SO 2 Emission Trends from MSCET and EPA Trends Report, 1975-1987 


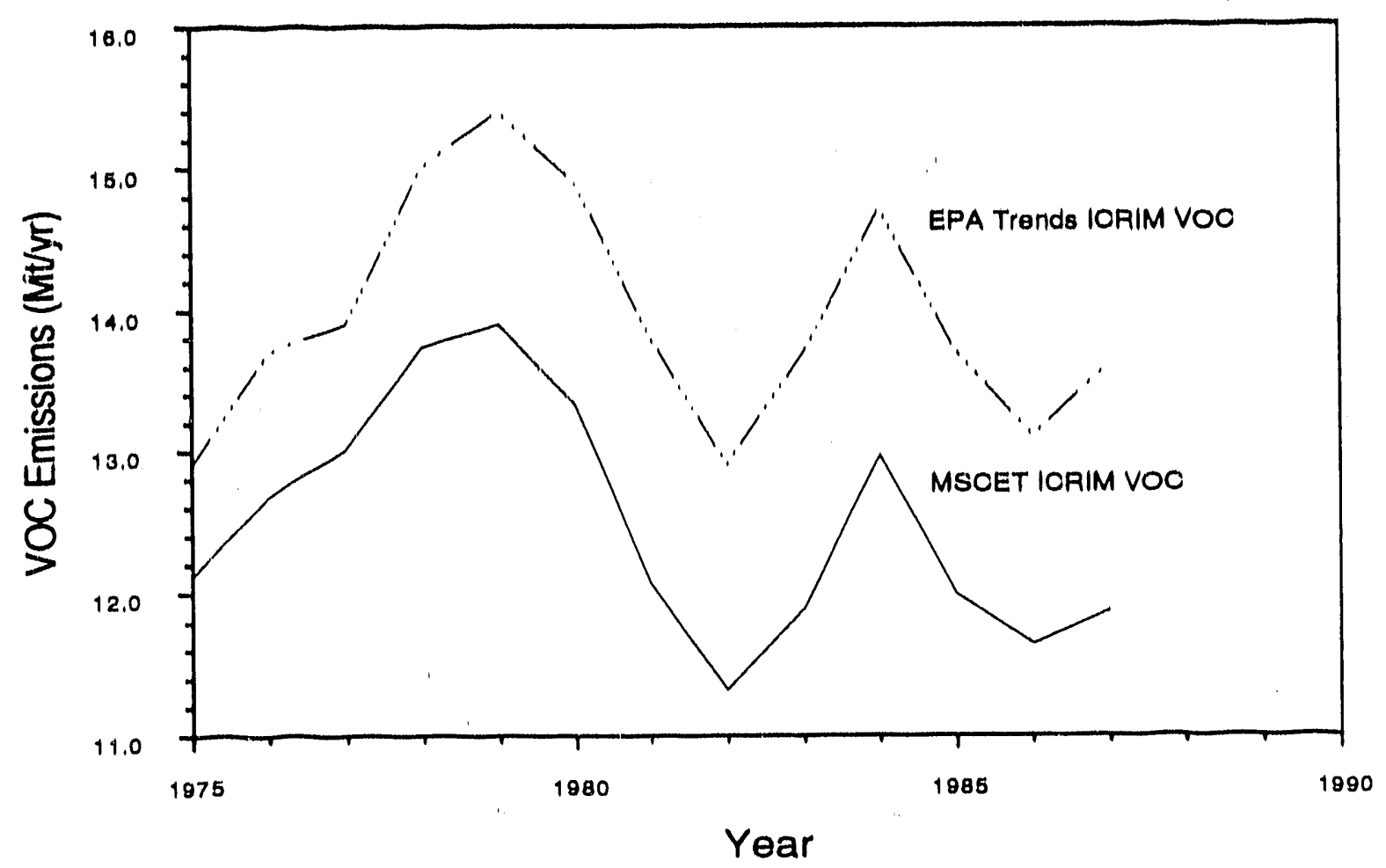

FIGURE 5.3 ICRIM VOC Emission Trends from MSCET and EPA Trends Report, 1975-1987

exceptions do exist. As shown in Fig. 5.2, the $\mathrm{SO}_{2}$ trend peaks a year earlier in MSCET than in the EPA Trends Report, and the MSCET emissions decrease from 1984 to 1985, while the EPA trend rises. Thus, although the overall trends seem to agree, the trends do not match exactly. The reason is that the trends shown in Figs. 5.1-5.3 are actually the sum of many trends, each representing the trend for a particular ESG. In MSCET, these ESG trends were derived separately by applying the percent change of some emission trend indicators to the base-year (1985) value for the ESG. The percent change (or growth rate) was used because it is a standard way to adjust for size effects between different data sources. (Alternate ways of making these adjustments are presented in the next section.) The base-year ESG emission values in the 1985 NAPAP Emissions Inventory and EPA Trends Report differed, sometimes significantly. The reasons for these differences are not known. They may be a result of measurement error, differences in the applied ernission factors, categorization differences, or, more likely, some combination of all three. MSCET'S ICRIM methodology applies the percent change of the emission trend indicators to its base-year emission value. Some of these emission trend indicators are taken from the EPA Trends Report, but others are derived from other sources, as explained earlier. Two factors -(1) applying the percent change of the emission trend indicators to base-year values in MSCET that are different from those in the EPA Trends Report and (2) modeling sectors not covered in the EPA Trends Report -- explain the different emission trend estimates. 
Differences between MSCET and EPA Trends Report data can perhaps be best lllustrated with an example. Table 5.6 provides MSCET and EPA Trends Report emission estimates for the industrial fuel combustion sector in 1985 and 1980. This sector has four ESGs, which are based on the type of fuel burned: coal, oil, natural gas, or other fuels. Table 5.6 shows that the emissions for individual ESGs changed at the same rates in MSCET and the EPA Trends Report. This correlation occurred because the percent change in MSCET was taken directly from EPA Trends Report data. The base-year values, however, were sometimes quite different. The ESG base-year values for oil and other fuels were very different; together they accounted for a large share of the industrial fuel combustion sector's emissions (41\% in MSCET versus $25 \%$ in the EPA Trends Ruport). These two ESGs also had the grectest change (in terms of percentage) between 1980 and $1985,-42 \%$ for oil and $-39 \%$ for other fuels. Because oil and other fuels had a larger sector share in MSCET than in EPA Trends, the negative trend was weighted more heavily in MSCET, and the sector total fell more, both in absolute level and in percentage terms.

TABLE 5.6 National Industrial Fuel Combustion Sector $\mathrm{SO}_{2}$ Emissions from NAPAP/MSCET and EPA Trends Report

\begin{tabular}{|c|c|c|c|}
\hline \multirow[b]{2}{*}{ Source, Fuel } & \multicolumn{2}{|c|}{$\mathrm{SO}_{2}$ Emissions (kt) } & \multirow[b]{2}{*}{$\begin{array}{c}\text { Percent Change } \\
1980-1985\end{array}$} \\
\hline & $\begin{array}{l}\text { Base Year, } \\
1985\end{array}$ & 1980 & \\
\hline $\begin{array}{l}\text { EPA trends report } \\
\text { Coal } \\
\text { Natural gas } \\
\text { Oil } \\
\text { Other fuels } \\
\text { Industrial fuel total }\end{array}$ & $\begin{array}{r}1670 \\
2 \\
490 \\
76 \\
2238\end{array}$ & $\begin{array}{r}1380 \\
2 \\
850 \\
125 \\
2357\end{array}$ & $\begin{array}{r}21.01 \\
0.00 \\
-42.35 \\
-39.20 \\
-5.05\end{array}$ \\
\hline $\begin{array}{l}\text { MSCET data base } \\
\text { Coal } \\
\text { Natural gas } \\
\text { Oil } \\
\text { Other fuels } \\
\text { Industrial fuel total }\end{array}$ & $\begin{array}{r}1372.8 \\
53.4 \\
738.6 \\
255.1 \\
2419.8\end{array}$ & $\begin{array}{r}1134.4 \\
53.4 \\
1281.2 \\
419.6 \\
2888.5\end{array}$ & $\begin{array}{r}21.02 \\
0.00 \\
-42.35 \\
-39.20 \\
-16.23\end{array}$ \\
\hline $\begin{array}{l}\text { avalues for } 1985 \text { In M } \\
\text { Emissions Inventon } \\
\text { January } 1989 \text { (EPA }\end{array}$ & $\begin{array}{l}\text { ET were de } \\
\text { (ersion 2) ta } \\
\text { 89a). }\end{array}$ & $\begin{array}{l}\text { rived from } \\
\text { pe recelve }\end{array}$ & $\begin{array}{l}\text { e NAPAP } \\
\text { at Argonne in }\end{array}$ \\
\hline
\end{tabular}


Although the emission values for 1985 from the NAPAP Emissions Inventory are generally considered superior to those from the EPA Trends Report, changes from year to year estimated by the EPA Trends Report may be used with some confidence, since the EPA methodology is consistent over time. In addition, possible systematic errors in the emission factors used in the EPA Trends Report would not affect the percent change between years, although emission-factor errors would affect the validity of the emission levels. MSCET uses EPA Trends and other data by applying percentage changes in these data to the base-year (1985) value for each ESG. Alternative methods have been suggested; these use absolute, or level, changes rather than percent changes; changes applied at a more aggregated level; or both methods. The sensitivity to alternative estimation techniques is discussed below.

\subsection{Alternative Estimation Techniques}

This section describes and compares three emission-trend estimation techniques. These techniques are the (1) percent-change method, (2) level-change method, and (3) aggregate-change method. All three use an emission trend indicator series to project an emission series from a baseyear value. Sometimes this emission indicator series is another emission trend series; other times it is an economic or fuel consumption series.

To estimate emissions in year $t$, the percent-change method applies the percent change of the emission trend indicator between the base-year (1985) and year $t$ to an appropriate emission level derived from the 1985 NAPAP Emissions Inventory (EPA 1989a). The MSCET system uses the percent-change method for the ICRIM sectors because the MSCET developers perceived it to be the best method to adjust for size differences between data sets. However, an alternative approach based on the absolute emission level change has also been proposed.

This alternative, called the level-change method here, would use the absolute change in emissions rather than the percent change. For example, if the EPA Trends Report showed that emission levels in year $t$ were 20,000 units less than emission levels in 1985 for a particular ESG, 20,000 units (converted to metric tons) would be subtracted from the 1985 emissions value derived from the NAPAP Emissions Inventory for that ESG to obtain the emissions in year t. Obviously, this method could not be used when energy consumption or production statistics are used as emission trend indicators.

Both the level-change and the percent-change methods can be used at various levels of aggregation; i.e., they can be used for each ESG or for aggregated totals (such as the total industrial fuel sector or total nonutility sector). If aggregated totals are used, the trend could be estimated either by the percent-change method or the level-change method. For this discussion, these choices will be considered separate versions of a more general method, called the aggregatechange method. 


\subsubsection{Key Factors Influencing the Estimation Results}

Regardless of the technique used to estimate emission trends, two factors play a pivotal role in influencing the outcome of one technique relative to another. The first factor is whether the 1985 NAPAP Emissions Inventory estimate is greater than or less than the associated 1985 estimate from the EPA Trends Report. If the two estimates are equal, all the estimation techniques described above will yield the same results. However, because the estimates in the 1985 NAPAP Emissions Inventory were constructed differently from those in the EPA Trends Report, it would be surpirising if the estimates were equal. In fact, the estimates are usually quite different, and these differences tend to be greater (in percentage terms) with greater disaggregation. At higher levels of aggregation, estimates from the two data sets tend to be closer to one another. The other key factor is whether the EPA emissions trend is positive or negative from 1980 to 1985 . If there is no emissions trend, then all of the estimation techniques will yield the same results. All possible combinations of these two factors result in nine possible outcomes, four of which are interesting and are discussed more thoroughly.

Table 5.7 presents a comparison matrix for the nine possible cases. The matrix cells show the results of a comparison of a 1980 estimate computed by the percent-change method with an estumate computed by the level-change method. The 1985 NAPAP Emissions Inventory (EPA 1989a) value may be higher than, lower than, or equal to the 1985 EPA Trends Report value. When the values are the same, all the alternatives will yield the same result (so this case is not discussed). The time-series trend may be negative, steady (zero), or positive. When the emission trend is zero (no trend), the question is moot. Thus, the four interesting cases are the possible combinations of higher or lower base-year values and a positive or negative trend.

This section concludes with some examples of the three techniques. First, a hypothetical example is presented that uses fictitious emission estimates designed to illustrate the four interesting situations described above. Table 5.8 presents the hypothetical emissions values, and Table 5.9 presents the results of estimating emission trends with each of the three techniques. Then, a realistic example using 1985 NAPAP Emissions Inventory and EPA Trends Report emission estimates for the industrial fuel combustion sector is presented. Table 5.10 presents industrial fuel sector emission estimates from the EPA Trends Report (the same as those in Table 5.6), and Table 5.11 presents results for the industrial fuel sector estimated using each of the three techniques.

\subsubsection{Hypothetical Example}

Table 5.8 presents some hypothetical emission trend indicator values, which would correspond to the emission values in the EPA Trends Report. The emission values are shown for four hypothetical sectors: A, B, C, and D. These would correspond to the ESGs in the MSCET methodology. The 1985 EPA Trt:nds Report emission values for all four sectors in this example are the same $(100)$ to simplify the $c$ smparison. 
TABLE 5.7 Comparison of 1980 Emission Results: Matrix for the Percent-Change Method and Level-Change Method

\begin{tabular}{|c|c|c|c|}
\hline \multirow{2}{*}{$\begin{array}{l}1985 \text { NAPAP Base- } \\
\text { Year Value Compared } \\
\text { with EPA Trends } \\
\text { Report Value }\end{array}$} & \multicolumn{3}{|c|}{ Trend Direction } \\
\hline & Positive & Negative & No Trend \\
\hline $\begin{array}{l}\text { Higher } \\
\text { Lower } \\
\text { Same }\end{array}$ & $\begin{array}{l}\text { Lower } \\
\text { Higher } \\
\text { Same }\end{array}$ & $\begin{array}{l}\text { Higher } \\
\text { Lower } \\
\text { Same }\end{array}$ & $\begin{array}{l}\text { Same } \\
\text { Same } \\
\text { Same }\end{array}$ \\
\hline
\end{tabular}

TABLE 5.8 Hypothetical Emission Trend Indicator Values

\begin{tabular}{|c|c|c|c|c|}
\hline \multirow[b]{2}{*}{ Sector } & \multicolumn{2}{|c|}{$\begin{array}{l}\text { Emission Trend } \\
\text { Indicator Value }\end{array}$} & \multirow{2}{*}{$\begin{array}{c}\text { Percent } \\
\text { Change of } \\
\text { Indicator, } \\
\begin{array}{c}1980-1985 \\
(\%)\end{array}\end{array}$} & \multirow{2}{*}{$\begin{array}{l}\text { Level Change } \\
\text { of Indicator, } \\
1980-1985 \\
\text { (units) }\end{array}$} \\
\hline & 1980 & 1985 & & \\
\hline $\begin{array}{l}\text { A } \\
B \\
C \\
D \\
\text { Total }\end{array}$ & $\begin{array}{r}74 \\
154 \\
67 \\
143 \\
437\end{array}$ & $\begin{array}{l}100 \\
100 \\
100 \\
100 \\
400\end{array}$ & $\begin{array}{r}35 \\
-35 \\
50 \\
-30 \\
-9\end{array}$ & $\begin{array}{r}26 \\
-54 \\
33 \\
-43 \\
-37\end{array}$ \\
\hline
\end{tabular}

Table 5.9 presents results for each of the three methods (percent-, level-, and aggregatechange). The 1985 NAPAP values in Table 5.9 may be higher or lower than the 1985 EPA values shown in Table 5.8 (i.e., 100). They are lower and higher to reflect alternative cases. In the top part of Table 5.9, which shows the percent-change method, each of the four cases has the same percent changes as those in the indicator series (Table 5.8, corresponding to the EPA Trends Report). The level-change method is shown in the middle part of Table 5.9. The percent-change column is different than that for the indicator series, but the level-change column is the same as that in Table 5.8. The numerical example demonstrates the conclusion shown in Table 5.7, which gives the conditions for which the 1980 emissions estimate will be higher or lower from using the percent-change method instead of the level-change method. For example, for Sector $\mathrm{A}$, the percent-change method yielded a higher value for 1980 emissions than the level-charige method because the trend was positive and the base-year (1985) NAPAP value was lower than the value from EPA Trends. This example demonstrates that neither the percent-change nor the level-change method is biased. 
TABLE 5.9 Comparison of Emission Trend Estimation Methods

\begin{tabular}{|c|c|c|c|c|c|c|c|}
\hline \multirow{2}{*}{$\begin{array}{l}\text { Method, } \\
\text { Verson }\end{array}$} & \multirow[b]{2}{*}{ Sector } & \multirow{2}{*}{$\begin{array}{c}\text { Base-Year } \\
1985 \\
\text { Value }^{\mathrm{a}}\end{array}$} & \multirow[b]{2}{*}{ Trend } & \multicolumn{2}{|c|}{$\begin{array}{c}\text { Emissions } \\
\text { (units) }\end{array}$} & \multirow{2}{*}{$\begin{array}{c}\text { Percent } \\
\text { Change of } \\
\text { Estimated } \\
\text { Trend, } \\
\text { 1980-1985 } \\
(\%)\end{array}$} & \multirow{2}{*}{$\begin{array}{c}\text { Level } \\
\text { Change of } \\
\text { Estimated } \\
\text { Trend, } \\
\text { 1980-1985 } \\
\text { (units) }\end{array}$} \\
\hline & & & & 1985 & 1980 & & \\
\hline $\begin{array}{l}\text { Percent- } \\
\text { change }\end{array}$ & $\begin{array}{c}\text { A } \\
\text { B } \\
\text { C } \\
\text { D } \\
\text { Total }\end{array}$ & $\begin{array}{l}\text { Lower } \\
\text { Lower } \\
\text { Higher } \\
\text { Higher }\end{array}$ & $\begin{array}{l}\text { Pos. } \\
\text { Neg. } \\
\text { Pos. } \\
\text { Neg. }\end{array}$ & $\begin{array}{r}50 \\
75 \\
200 \\
150 \\
475\end{array}$ & $\begin{array}{r}37 \\
115 \\
133 \\
214 \\
500\end{array}$ & $\begin{array}{r}35 \\
-35 \\
50 \\
-30 \\
-5\end{array}$ & $\begin{array}{r}13 \\
-40 \\
67 \\
-64 \\
-25\end{array}$ \\
\hline $\begin{array}{l}\text { Level- } \\
\text { change }\end{array}$ & $\begin{array}{c}\text { A } \\
\text { B } \\
C \\
D \\
\text { Total }\end{array}$ & $\begin{array}{l}\text { Lower } \\
\text { Lower } \\
\text { Higher } \\
\text { Higher }\end{array}$ & $\begin{array}{l}\text { Pos. } \\
\text { Neg. } \\
\text { Pos. } \\
\text { Neg. }\end{array}$ & $\begin{array}{r}50 \\
75 \\
200 \\
150 \\
475\end{array}$ & $\begin{array}{r}24 \\
129 \\
167 \\
193 \\
512\end{array}$ & $\begin{array}{r}108 \\
-42 \\
20 \\
-22 \\
-7\end{array}$ & $\begin{array}{r}26 \\
-54 \\
33 \\
-43 \\
-37\end{array}$ \\
\hline $\begin{array}{l}\text { Aggregate- } \\
\text { change } \\
\text { Percent } \\
\text { change } \\
\text { Level }^{b} \\
\text { changec }\end{array}$ & All & - & - & 475 & 519 & -9 & -44 \\
\hline
\end{tabular}

aComparison of MSCET 1985 base-year values with 1985 estimates from the EPA Trends Report, shown in Table 5.8 (except for aggregate-change method).

bPercent-change version of the aggregate-change method.

'Level-change version of the aggregate-change method.

The aggregate-change method data are presented at the bottom of Table 5.9. The 1980 estimate of 519 for the value of the percent-change version of the aggregate-change method (bottom of table) is different than the 500 value for the sum of the percent-change method (top of table). This difference demonstrates, as did the earlier example for the industrial fuel sector, that when the percent-change version of the aggregate-change method is applied to the sectoral total, the result (519) may not be the same as when the appropriate rate of change is applied separately to each individual sector (500). The aggregate-change method was not used in this report because it is more reasonable to assume emissions are related to the activities that cause them (e.g., iron and steel industry emissions are related to iron and steel production). The aggregate-change method ignores the increased confidence that can be gained by examining emission trends at the ESG level. 
TABLE 5.10 Industrial Fuel Combustion Emission Trend Indicator Data from the EPA Trends Report

\begin{tabular}{|c|c|c|c|c|}
\hline \multirow[b]{2}{*}{ Fuel } & \multicolumn{2}{|c|}{$\begin{array}{l}\text { Emission Trend } \\
\text { Indicator Value } \\
\left.\text { (kt of } \mathrm{SO}_{2}\right)\end{array}$} & \multirow{2}{*}{$\begin{array}{c}\text { Percent Change } \\
\text { of Indicator, } \\
1980-1985 \\
(\%)\end{array}$} & \multirow{2}{*}{$\begin{array}{l}\text { Level Chang } \\
\text { of Indicator, } \\
1980-1985 \\
\text { (kt of } \mathrm{SO}_{2} \text { ) }\end{array}$} \\
\hline & 1980 & 1985 & & \\
\hline $\begin{array}{l}\text { Coal } \\
\text { Natural gas } \\
\text { Oil } \\
\text { Other fuels } \\
\text { Industrial fuel total }\end{array}$ & $\begin{array}{r}1,380 \\
2 \\
850 \\
125 \\
2,357\end{array}$ & $\begin{array}{r}1,670 \\
2 \\
490 \\
76 \\
2,238\end{array}$ & $\begin{array}{r}21 \\
0 \\
-42 \\
-39 \\
-5\end{array}$ & $\begin{array}{r}290 \\
0 \\
-360 \\
-49 \\
-119\end{array}$ \\
\hline
\end{tabular}

It can be seen from Table 5.9 that the percent-change method and the level-change method can yield different results based on the same data. The choice of which method to use in a given case depends on the nature of the difference between the indicator data and the NAPAP data; specifically, if this difference were known to be proportional to emissions from year to year, then the percent-change method would be preferable, whereas the level-change method would apply if the difference were known to be constant from year to year. (However, if the difference were known to be constant, the actual time trend data would also have to be known, and they are not.) In the present case, the reasons for the difference between the data from NAPAP and from EPA Trends are not known. The difference could be systematic or random, it might or might not be proportional to emissions, and it could result from differences in coverage, emission factors, quality control, or other unknown factors. The percent-change method was used for this report, and it results in emission level changes from year to year that differed from those in the EPA Trends Report; if the level-change method had been used, the MSCET emission trends for the ICRIM sectors would show nearly the same emission level change from year to year as those in the EPA Trends Report. The trends would not be exactly the same, because some MSCET ICRIM ESGs use trend indicators that are not derived from EPA Trends.

\subsubsection{Realistic Example}

Tables 5.10 and 5.11 are equivalent to Tables 5.8 and 5.9, respectively, but use actual data for the industrial fuel combustion sector, presented earlier in Table 5.6. A key point revealed by Tables 5.10 and 5.11 is that the 1985 NAPAP emissions estimates and the 1985 estimates from the EPA Trends Report differ substantially at the disaggregated ESG level (particularly the "other fuels" ESG). Because the ESGs do not match, the methodology chosen to estimate emissions with these data ought to include some form of normalization, such as using the percent-change method. Otherwise, adding or subtracting absolute tons from an ESG in one data set based on an 
TABLE 5.11 Comparison of Emission Trend Estimation Methods for the Industrial Fuel Combustion Sector

\begin{tabular}{|c|c|c|c|c|c|c|c|}
\hline \multirow{2}{*}{$\begin{array}{l}\text { Method, } \\
\text { Version }\end{array}$} & \multirow[b]{2}{*}{ Sector } & \multirow{2}{*}{$\begin{array}{c}\text { Base-Year } \\
1985 \\
\text { Value }^{a}\end{array}$} & \multirow[b]{2}{*}{ Trend } & \multicolumn{2}{|c|}{$\begin{array}{l}\text { Emissions } \\
\left.\text { (kt of } \mathrm{SO}_{2}\right)\end{array}$} & \multirow{2}{*}{$\begin{array}{c}\text { Percent } \\
\text { Change of } \\
\text { Estimated } \\
\text { Trend, } \\
\text { 1980-1985 } \\
\text { (\%) }\end{array}$} & \multirow{2}{*}{$\begin{array}{c}\text { Level } \\
\text { Change of } \\
\text { Estimated } \\
\text { Trend, } \\
1980-1985 \\
\left(\mathrm{kt} \text { of } \mathrm{SO}_{2}\right)\end{array}$} \\
\hline & & & & 1985 & 1980 & & \\
\hline \multirow[t]{2}{*}{$\begin{array}{l}\text { Percent- } \\
\text { change }\end{array}$} & \multirow{2}{*}{$\begin{array}{l}\text { Coal } \\
\text { Natural gas } \\
\text { Oil } \\
\text { Other } \\
\text { fuels } \\
\text { Total }\end{array}$} & $\begin{array}{l}\text { Lower } \\
\text { Higher } \\
\text { Higher }\end{array}$ & $\begin{array}{l}\text { Pos. } \\
\text { None } \\
\text { Neg. }\end{array}$ & $\begin{array}{r}1,373 \\
53 \\
739\end{array}$ & $\begin{array}{r}1,134 \\
53 \\
1,281\end{array}$ & $\begin{array}{r}21 \\
0 \\
-42\end{array}$ & $\begin{array}{r}239 \\
0 \\
-542\end{array}$ \\
\hline & & Higher & Neg. & $\begin{array}{r}255 \\
2,420\end{array}$ & $\begin{array}{r}420 \\
2,889\end{array}$ & $\begin{array}{l}-39 \\
-16\end{array}$ & $\begin{array}{l}-165 \\
-469\end{array}$ \\
\hline \multirow[t]{2}{*}{$\begin{array}{l}\text { Level- } \\
\text { change }\end{array}$} & \multirow{2}{*}{$\begin{array}{l}\text { Coal } \\
\text { Natural gas } \\
\text { Oil } \\
\text { Other } \\
\text { fuels } \\
\text { Total }\end{array}$} & $\begin{array}{l}\text { Lower } \\
\text { Higher } \\
\text { Higher }\end{array}$ & $\begin{array}{l}\text { Pos. } \\
\text { None } \\
\text { Neg. }\end{array}$ & $\begin{array}{r}1,373 \\
53 \\
739\end{array}$ & $\begin{array}{r}1,083 \\
53 \\
1,099\end{array}$ & $\begin{array}{r}27 \\
0 \\
-33\end{array}$ & $\begin{array}{r}290 \\
0 \\
-360\end{array}$ \\
\hline & & Higher & Neg. & $\begin{array}{r}255 \\
2,420\end{array}$ & $\begin{array}{r}304 \\
2,539\end{array}$ & $\begin{array}{r}-16 \\
-5\end{array}$ & $\begin{array}{r}-49 \\
-119\end{array}$ \\
\hline \multirow{3}{*}{$\begin{array}{l}\text { Aggregate- } \\
\text { change } \\
\text { Percent } \\
\text { change }^{b} \\
\text { Level }^{\text {change }}\end{array}$} & & & & & & & \\
\hline & All & - & - & 2,420 & 2,549 & -5 & -129 \\
\hline & All & $\cdot$ & - & 2,420 & 2,539 & -5 & -119 \\
\hline
\end{tabular}

aComparison of MSCET 1985 base-year values with 1985 estimates from the EPA Trends Report, shown in Table 5.10 (except for aggregate-change method).

bpercent-change version of the aggregate-change method.

CLevel-change version of the aggregate-change method.

absolute change in an associated category (which is not an exact match) from another data set is not appropriate. For example, if the level-change method were applied in the "primary lead and zinc smelting" ESG, the resulting 1980 estimate would be negative. (The 1985 NAPAP Emissions Inventory estimate for $\mathrm{SO}_{2}$ from the "primary lead and zinc smelting" ESG is $96.5 \mathrm{kt}$. The EPA Trends Report estimates that emissions for this ESG rose $150 \mathrm{kt}$ between 1980 and 1985 -- from $70 \mathrm{kt}$ in 1980 to $220 \mathrm{kt}$ in 1985 . Applying this increase to the 1985 NAPAP estimate would result in a negative $53.5 \mathrm{kt}$ estimate for $\mathrm{SO}_{2}$ emissions from the primary lead and zinc smelting industry in 1980.) A second point revealed by the tables, as mentioned earlier, is that the results for the percent-change and the level-change versions of the aggregate-change method compare fairly well. This method, however, conveys no information about emission trends at the ESG level. 


\section{Copper Smelter Methodology}

This section describes the methodology used to estimate plant-level data for copper smelters. A goal of the MSCET program has been to improve the methodology for making estimates of monthly $\mathrm{SO}_{2}$ emissions from copper smelters in the United States. Because the plantspecific data required to apply the sulfur mass balance method are proprietary to protect copper smelter plant confidentiality, the states collected the necessary information and performed the actual computations. In most cases, state and local air-pollution control agencies then supplied ANL with the sulfur mass balance data. These data were usually supplied in terms of tons of sulfur emitted, which can easily be converted to tons of $\mathrm{SO}_{2}$. These copper smelter emissions data supplement the emissions data base for NAPAP. The MSCET copper smelter $\mathrm{SO}_{2}$ inventory can be found in App. C.

\subsection{Background}

Kohout et al. (1987) estimated that the West accounted for $25 \%$ of total national $\mathrm{SO}_{2}$ emissions in 1986. In particular, industrial processes in two regions of the southwestern United States played a significant role. In $1986,71 \%$ of $\mathrm{SO}_{2}$ emissions from California, Nevada, and Arizona (Federal Region 9) were from the industrial process sector. In Federal Region 6 (New Mexico, Texas, Oklahoma, Arkansas, and Louisiana), this figure was 39\%. Together, $50 \%$ of the total estimated $\mathrm{SO}_{2}$ emissions from these regions were from industrial processes. Regions 9 and 6 emitted about $46 \%$ of the nation's total industrial process $\mathrm{SO}_{2}$ emissions and about $7 \%$ of the total $\mathrm{SO}_{2}$ emitted in the United States. As Fig. 6.1 shows, copper smelting was the major contributor to $\mathrm{SO}_{2}$ emissions in this sector in these regions (Kohout et al. 1987). From 1975 to 1988, there were eight copper smelters in Region 9 (seven in Arizona and one in Nevada) and three in Region 6 (two in New Mexico and one in Texas). All but one were located within a 200-mile radius of each other.

Correlations between $\mathrm{SO}_{2}$ emissions and acid precipitation can be made by studying the conditions that occurred in the 10-yr period, 1976-1986. During this time, the $\mathrm{SO}_{2}$ emissions from copper smelters, concentrated in a relatively small area, decreased significantly (Fig. 6.2), while the corresponding $\mathrm{SO}_{2}$ emissions from other sources to the east stayed relatively stable (Kohout et al. 1987). During this decade, $\mathrm{SO}_{2}$ emissions from industrial processes in Region 9 actually decreased by $56 \%$-- from about $1.6 \mathrm{kt}$ to $0.7 \mathrm{kt}$. This decrease was a result of emission controls coming on stream and a decline in copper production. In the western United States (federal regions west of the Mississippi), $\mathrm{SO}_{2}$ emissions from the utility sector increased only $3 \%$ diring this time. Therefore, appropriate historical, meteorological, and water-body $\mathrm{pH}$ data and wet/dry sulfuric acid deposition data from this decade could be used to assess the impact of the significant change in $\mathrm{SO}_{2}$ emissions on acid precipitation. 


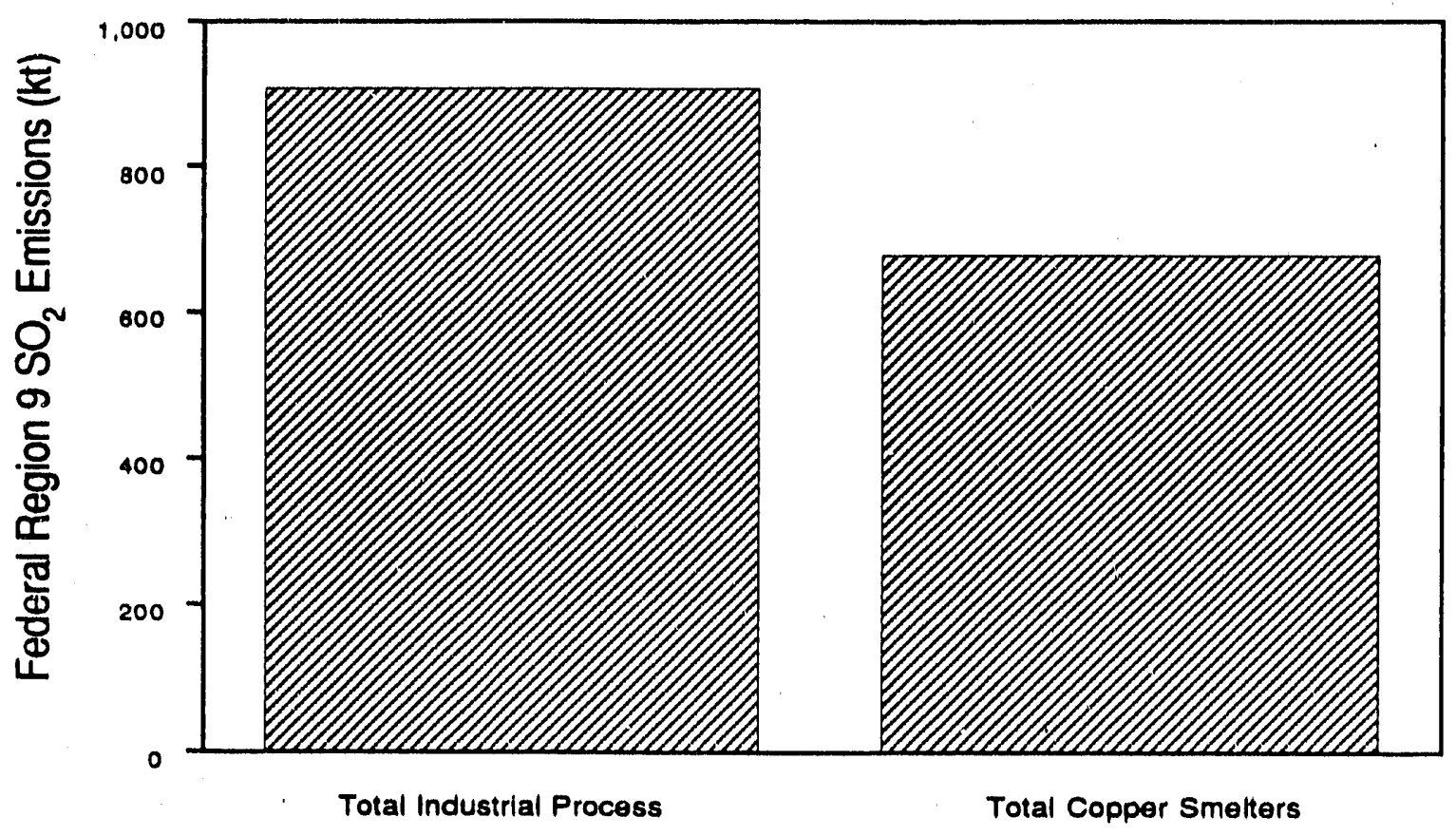

FIGURE 6.1 Comparison of $\mathrm{SO}_{2}$ Emissions from Copper Smelters with Those from the Total Industrial Process Sector in Region 9, 1980 (Source: Kohout et al. 1987)

Emissions from copper smelters are determined by the production level and the level of emission control at the individual smelters. An emission estimation methodology for nonferrous smelters that better accounts for industry fluctuations has been suggested. Emission estimates for nonferrous smelters could be improved if actual sulfur mass balance data were collected directly from state environmental agencies and nonferrous producers. These data could also be a source of information for acidic deposition correlation studies.

\subsection{Approach}

The AP-42 report (EPA 1985) is frequently used for estimating emissions. It is based on verages obtained from a wide range of data with varying degrees of accuracy (Zimmerman et al. 190. I In AP-42, emission factors for primary copper smelters are given separately for unconiru. "ed stack gases and for fugitive emissions. Emission factors are expressed in pounds of uncontrollea $: \mathrm{O}_{2}$ produced per unit weight of concentrated ore. This ore is assumed to contain a constant $30 \%$ suni $\cdot r$. The factor is based on normalized test data for several furnaces followed by

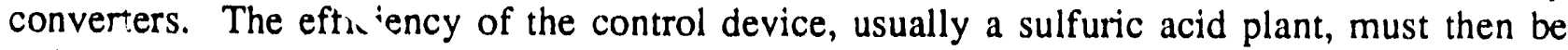
estimated and the emissio. factor must be adjusted to account for the control. 


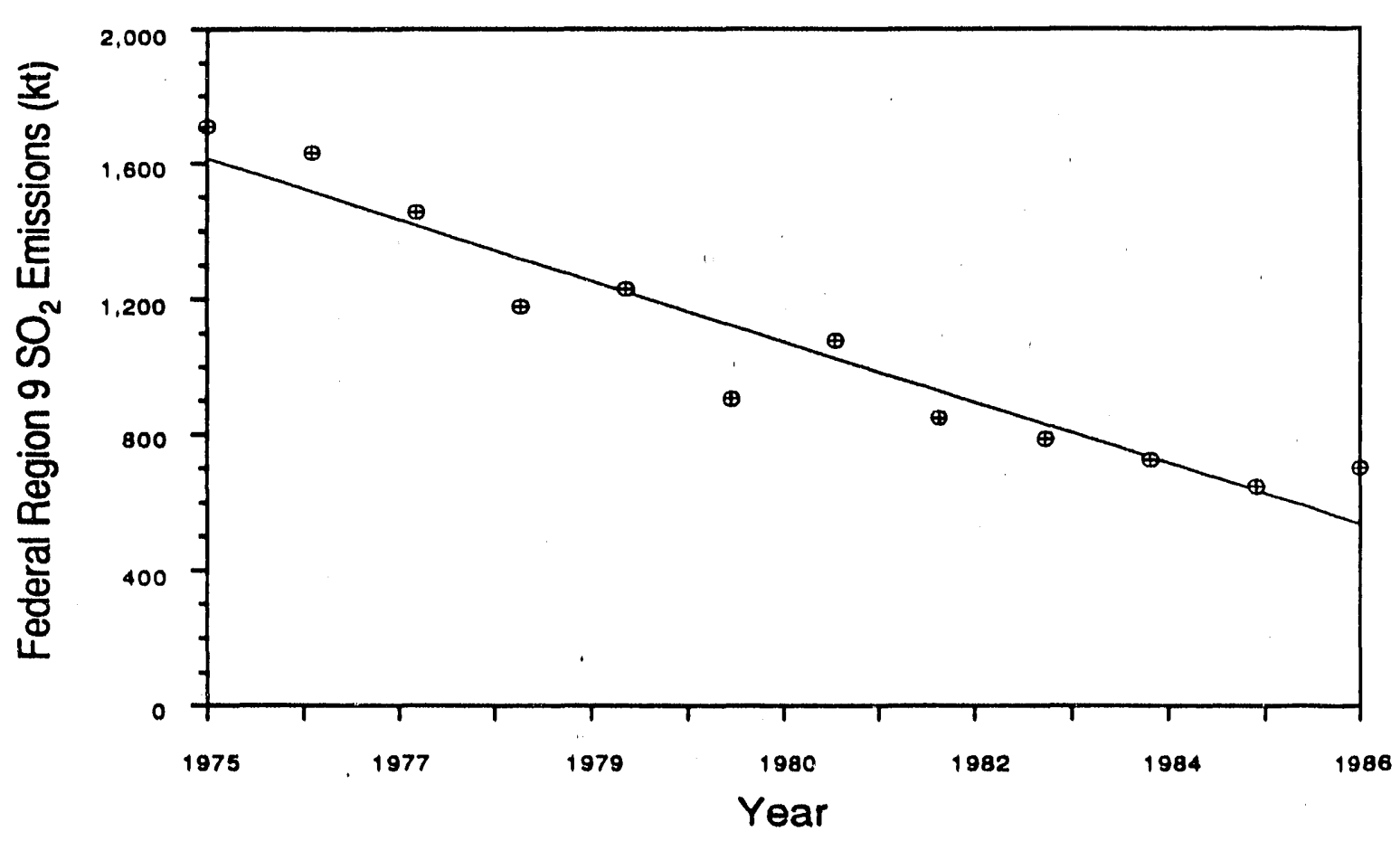

FIGURE 6.2 Region 9 Industrial Process Sector $\mathrm{SO}_{2}$ Emission Trend, 1975-1986

(Source: Kohout et al. 1987)

Fugitive $\mathrm{SO}_{2}$ emissions come from the uncontrolled processes in copper smelting -roasting, smelting, converting, fire refining, and slag cleaning (EPA 1985). The collection and removal efficiencies for fugitive emissions are inherently variable. First, procedures for matte tapping and slag skimming operations at smelting furnaces can vary from plant to plant or run to run. For example, tapping frequencies will vary within an eight-hour shift depending on furnace capacity and type -- from 5 to 20 times for tapping and from 10 to 25 times for slag skimming. Since tapping accounts for about $90 \%$ of the total $\mathrm{SO}_{2}$ fugitive emissions, a significant variability is introduced, even assuming the same hood capture efficiency and collection efficiency at the acid plant. Collection or "capture" efficiency ranges from 50\% to $75 \%$ but levels as low as $40 \%$ have been experienced (Hargraves 1989). This variability adds even more potential inaccuracy to estimates that use AP-42 emission factors together with estimated control efficiencies. In addition, when emission factor estimates are being applied, changes that occur in process design must be carefully accounted for. For example, the replacement of a reverberatory furnace with a state-ofthe-art Outokumpu flask furnace would greatly reduce fugitive emissions while improving the collection efficiency of an existing acid plant.

The AP-42 procedure results in data that are less reliable than those obtained using the sulfur mass balance approach, an approach in which all fugitive and collected sulfur are accounted for. Therefore, whenever they were available, sulfur mass balance data were used for the MSCET inventory. Sulfur mass balances can be obtained from normal process monitoring information. 
Sulfuric acid plants monitor sulfur in the off-gases during the smelting process because the quantity of acid produced and the plant efficiency depend to a large degree on the $\mathrm{SO}_{2}$ volume concentration of the off-gases (Nochumson and Williams 1983). Plants closely and regularly monitor the sulfur input from the ore, the sulfur content of the slag, and the amount of sulfuric acid produced (Towle 1989). From the net difference, the amount of $\mathrm{SO}_{2}$ lost from all sources -fugitive and stack -- can be directly calculated. This method, although not generally useful for determining emissions compliance on a day-to-day basis, is useful when net total $\mathrm{SO}_{2}$ data are required for the analysis of actual, long-term plant emission trends. The accuracy of this method in determining monthly emissions, however, depends on how accurately the ores used in the smelting process are accounted for. Sometimes plants report $\mathrm{SO}_{2}$ levels less than zero. These values account for the quantity of ore sent to the drier (typically the point of entry into the smelting plant) but not the quantity actually smelted. The negative values occur when no ore is shipped to the drier during the month, but copper production is sustained because dried ore already in inventory is used. Conversely, emissions are overstated when ore inventories are built up faster than the quantity smelted. A three-month average is typically considered representative of actual $\mathrm{SO}_{2}$ emissions in this case (Leverock 1989). However, data have revealed that the average required could range up to six months.

Monthly sulfur mass balance data were collected for each copper smelter plant for the years 1975-1988. State and local air-pollution control agencies and copper producers were contacted for sulfur mass balance data. In most cases, the data supplied were given in terms of tons of sulfur emitted, which can easily be converted to tons of $\mathrm{SO}_{2}$ emitted by multiplying by two (the molecular weight of $\mathrm{SO}_{2}$ is exactly twice that of $\mathrm{S}$ ). In cases where data were missing, an estimate was made by interpolating the emissions between values for bounding periods, except for periods in which a strike affected industry-wide production or for periods of annual maintenance shutdowns (usually in August and September). In some cases, sulfur mass balance data could not be obtained -- either the agencies did not have the information, the company was not willing to divulge the information, or the company did not have the information. These cases occurred primarily at sites that were outside the southwestern United States. In these cases, the state-reported, AP-42-derived emission estimates and information from continuous emission monitors (CEMs) for each site were used. (CEM information was used primarily for compliance purposes. Inaccuracies in flow rate measurements, the primary disadvantage of CEM information, limit its usefulness in determining overall plant emissions.) Company-reported smelter emissions data obtained by the Environmental Defense Fund were used only when state data were not available. When only annual data were available, the average monthly shares (percent of the annual total) for the three years closest to the missing period were used. When monthly data were not available for any year (only annual data or only data for one year available), production was assumed to be evenly divided throughout the period. This method relies on the states (and others) to correctly perform the sulfur mass balance computations. Confidentiality of plant-level data prevented further quality assurance checks. 


\subsection{Results}

Data sources by state and year are shown in Table 6.1. Some of these sources (AssarcoHayden, Miami, and Ray-Hayden plants in Arizona and Garfield plant in Utah) reported negative values in some sulfur mass-balance data for some months. These values resulted from the way the data were computed, as explained above. The values for as many months bounding the negative value as were required to produce a positive number were added and then the emission values were averaged over the period. In the case of negative values before shutdown (such as the Garfield plant in 1985), only the values preceding the negative value were averaged -- representing the depletion of the inventory of ore.

Emission estimates conflicted in some cases, even though all the sources reported that their data were obtained from the company. As an example, the 1984 data for the Kennecott plant located in Garfield, Utah, were analyzed for sources of discrepancy (EDF undated; Kennecott 1985a,b; Dalley undated; Bradford 1986). A comparison is shown in Table 6.2. $\mathrm{SO}_{2}$ from this plant was emitted from a variety of sources, including processes not directly related to the smelting process. The annual emissions inventory reported by the company to the state in 1984 (Kennecott 1985a) listed the contribution of all sources to emissions of total suspended particulates (TSP), $\mathrm{SO}_{2}, \mathrm{NO}_{\mathbf{x}}$, hydrocarbons (HC), and carbon monoxide (CO). It stated that the following processes contribute to plant $\mathrm{SO}_{2}$ emissions, in order of decreasing contribution. The percent of the total $\mathrm{SO}_{2}$ contribution is shown in parentheses.

1. Copper smelting vessels $(73 \%)$,

2. Fugitive emissions from copper smelting vessels to stack via secondary hood $(15 \%)$,

3. Molybdenum heat treater at concentrator (4\%),

4. Coal-fired power plant (4\%), and

5. Roof vent fugitive emissions from smelting vessels (3\%).

The company estimated that Source 2 was $20 \%$ of Source 1. In Table 6.2, the first column shows the sum of $\mathrm{SO}_{2}$ emissions from all sources; column 2 shows the sum from Sources 1, 2, and 5; and column 3 shows the sum from Source 1 and from the reactor vent stacks and rotary drier sources (both contributing less than $1 \%$ to total $\mathrm{SO}_{2}$ emissions). Column 4 shows the sum from Source 1, smelting vessel emissions only, excluding fugitive emissions. It can be inferred that the Environmental Defense Fund (EDF) report (Oppenheimer et al. 1985) and data (EDF undated) are based on smelting vessel stack emissions only and thus understate the plant-reported total emissions data by' almost $27 \%$.

Monthly sulfur mass balance data must be used with caution, especially the data from plants that used only the input ore to calculate monthly sulfur input. The impact of negative emissions data from Cyprus Minerals Company in Miami, Arizona, was evaluated. This plant 
TABLE 6.1 Copper Smelter $\mathrm{SO}_{2}$ Emission Data Sources

\begin{tabular}{|c|c|c|c|}
\hline State & Year & Primary Source & Secondary Source \\
\hline Arizona & $\begin{array}{l}1975-1976 \\
1977-1988\end{array}$ & $\begin{array}{l}\text { Annual data, state } \\
\text { Monthly mass balance data, } \\
\text { state }\end{array}$ & $\begin{array}{l}1977-1978 \text { monthly trend } \\
\text { None }\end{array}$ \\
\hline Michigan & $1975-1988$ & Emission inventory, state & None \\
\hline Montana & $1975-1988$ & $\begin{array}{l}1974 \text { emission inventory, } \\
\text { state }\end{array}$ & None \\
\hline \multirow[t]{3}{*}{ New Mexico } & $1975 \cdot 1978$ & $\begin{array}{l}\text { Tons/day average by quarter, } \\
\text { no. of days in quarter, state }\end{array}$ & $\begin{array}{l}\text { (1) Average days in quarter } \\
\text { (2) Equal monthly production } \\
\text { in quarter }\end{array}$ \\
\hline & & $\begin{array}{l}\text { Monthly data from EDF } \\
\text { (undated) }\end{array}$ & None \\
\hline & $1982 \cdot 1988$ & $\begin{array}{l}\text { Tons/day average, no. of days } \\
\text { in quarter }\end{array}$ & $\begin{array}{l}\text { (1) Average days ' }) \text { quarter } \\
\text { (2) Equal monthly production } \\
\text { in quarter }\end{array}$ \\
\hline $\begin{array}{l}\text { New Mexico } \\
\text { (Playas plant) }\end{array}$ & $\begin{array}{l}1977.1979 \\
\text { and }\end{array}$ & Mass balance/quarter & $\begin{array}{l}\text { Equal monthly production in } \\
\text { quarter }\end{array}$ \\
\hline & 1980 & $\begin{array}{l}\text { Monthly data from EDF } \\
\text { (undated) }\end{array}$ & \\
\hline Nevada & $\begin{array}{l}1975-1978 \\
1979-1983\end{array}$ & $\begin{array}{l}\text { Tons/day data, state } \\
\text { Monthly date from EDF } \\
\text { (undated) }\end{array}$ & None \\
\hline Tennessee & $1975-1987$ & Emission inventory, state & Stack Ib/h data, state \\
\hline \multirow[t]{4}{*}{ Utah } & 1975 & $\begin{array}{l}\text { Annual data from Nochumson } \\
\text { and Williams (1983) }\end{array}$ & 1982-1984 monthly trend \\
\hline & $\begin{array}{l}1976-1978 \\
1979-1981\end{array}$ & $\begin{array}{l}\text { Annual data, state } \\
\text { Annual data, state }\end{array}$ & $\begin{array}{l}\text { 1982-1984 monthly trend } \\
\text { Monthly prorated data from } \\
\text { EDF (undated) }\end{array}$ \\
\hline & $1982-1986$ & Monthly smelter vessel data & $\begin{array}{l}\text { Scaled up with annual total } \\
\text { plant data }\end{array}$ \\
\hline & $1987-1988$ & $\begin{array}{l}\text { Monthly smelter vessel data, } \\
\text { state }\end{array}$ & $\begin{array}{l}\text { Added } \mathrm{Ib} / \mathrm{h} \text { limits for misc. } \\
\text { sources and power plant } \\
\text { emissions as } 5.4 \% \text { of vessel } \\
\text { emissions }\end{array}$ \\
\hline \multirow[t]{2}{*}{ Texas } & $1975-1985$ & $\begin{array}{l}1985 \text { emission inventory, } \\
\text { state and from Nochumson } \\
\text { and Williams (1983) }\end{array}$ & $\begin{array}{l}\text { Straight line trend, 1975-1985 } \\
\text { assumption }\end{array}$ \\
\hline & $1986-1987$ & 1987 verbal report, state, & $\begin{array}{l}\text { Assume equal emissions in } \\
1988\end{array}$ \\
\hline Washington & $1975-1985$ & $\begin{array}{l}\text { Monthly mass balance data, } \\
\text { plant }\end{array}$ & None \\
\hline
\end{tabular}


TABLE 6.2 Effect of Reporting Methods on Copper Smelter $\mathrm{SO}_{2}$ Emission Estimates (ton/yr)

\begin{tabular}{|c|c|c|c|c|c|}
\hline Source & Planta & $\begin{array}{c}\text { Total } \\
\text { Copper } \\
\text { Smeltingb }\end{array}$ & $\begin{array}{c}\text { Smelter } \\
\text { Vessels, } \\
\text { Reactor } \\
\text { Vent } \\
\text { Stacks, } \\
\text { and } \\
\text { Rotary } \\
\text { Drier }\end{array}$ & $\begin{array}{l}\text { Copper } \\
\text { Smelter } \\
\text { Vessels } \\
\text { Only }\end{array}$ & $\begin{array}{c}\text { Not } \\
\text { Stated }\end{array}$ \\
\hline $\begin{array}{l}\text { Company } \\
\text { Annual report } \\
\text { Monthly run average }\end{array}$ & 45,812 & 41,690 & 33,678 & $\begin{array}{l}33,406 \\
33,406\end{array}$ & \\
\hline $\begin{array}{l}\text { State } \\
\text { Undated report to EPA } \\
11 / 15 / 86 \text { report to EPA }\end{array}$ & 45,812 & & & & $3.7,575^{c}$ \\
\hline EDF (undated) & & & & & $33,538^{c}$ \\
\hline
\end{tabular}

ancludes all plant $\mathrm{SO}_{2}$ emissions including those from copper smelters, coal-fired boilers, molybdenum recovery at concentrators, and refinery for ores recovery.

bIncludes fugitive emission estimate (20\% of smelter vessel emissions) and roof-vent emission estimaies scaled from 1982 emission inventory.

CAssumed to be the sum of smelting vessels, reactor vent stacks, and rotary drier.

Source: Kennecott 1985a,b.

temporarily suspended operations in September 1982. Before this, its $\mathrm{SO}_{2}$ emissions were reported to be $-4.81 \mathrm{kt}$ in August, $3.57 \mathrm{kt}$ in July, and $2.15 \mathrm{kt}$ in June. This period was chosen because it could be assumed that the plant was consuming the in-house stock of ore in the month before it shut down. Assuming (1) a three-month average period in which all ore inputs were consumed and were therefore reflected in sulfur output and (2) levelized production, an average of $1.75 \mathrm{kt}$ of $\mathrm{SO}_{2}$ was emitted each month. Under these assumptions, emissions were understated by $128 \%$ in August (on a relative scale), overstated by $100 \%$ in July, and overstated by $23 \%$ in June.

\subsection{Conclusions}

The sulfur mass balance method is an effective way to obtain monthly plant emission estimates, providing the sulfur mass inputs to the smelter are accurate. They must be accurate because the actual measured data on plant sulfur inputs and outputs are used to obtain data on fugitive emissions. If this method is not used, using averages over a three- to six-month interval in the data series is an acceptable method for reflecting emissinn trends. The AP-42 emission factor 
estimating method is generally less reliable, because the emission factors $\mathrm{rel}_{j}$ on estimates rather than actual measurements of fugitive emissions.

Whenever possible, the sulfur mass balance method was used for this inventory. Using a similar method for estimating emissions from other nonferrous smelters would enhance the MSCET program. In a broader perspective, a uniform method of plant reporting, similar to the production activity reports required of plants by the U.S. Department of Commerce would greatly improve the various emissions data bases. 


\section{Mobile Source Methodology}

Because VOC and $\mathrm{NO}_{x}$ emissions from the transportation sector and other mobile sources are so important in forming ozone and acid rain, a separate methodology for estimating these emissions was developed for the MSCET program. The methodology described here was built on earlier work done for the MSCET program, with some important changes. These are:

1. On-highway emission factors were estimated using the EPA's MOBILE4 model rather than its MOBILE3 model.

2. On-highway emission factors were calculated for four speed classes rather than the previous two, and for five vehicle types rather than the pre:ious three.

3. New state-level information on vehicle miles traveled (VMT) by vehicle type were included in the VMT estimation routine, which enabled the algorithm to account for above- or below-average vehicle-type VMT shares in a particular state.

4. The effect of diurnal temperature variation on on-highway emissions was incorporated through the use of EPA's MOBILE4 emission factors.

5. The effect of seasonal temperatures on overall fuel efficiency (and estimated VMT) was incorporated into the model, since lower-than-average fuel efficiency in colder months lowers the estimated VMT from a given amount of fuel consumed, and higher-than-average fuel efficiency in warmer months raises estimated VMT.

The following sections describe the MSCET methodology for mobile sources and further explain the points listed above.

\subsection{Estimating Emissions from On-Highway Sources}

On-highway transportation emissions were estimated using activity (VMT) and MOBILE4 emission factors. From state annual totals, the VMT data were shared out to 5 vehicle types, 4 speed classes, and 12 months. Emission factors were computed using the MOBILE4 program, and a separate emission factor was computed to take into account each state's monthly diurnal temperature ranges for each of the 12 months. In addition, the emission factors were dependent on vehicle type, speed class, year, and altitude (low or high). Thus, emissions were calculated using the following equation:

$$
E_{s, j, m, y}=\sum_{i=1}^{4}\left[V_{s, i, j, m, y} \times E_{s, i, j, m, y}\right]
$$


where:

$$
\begin{aligned}
E= & \text { on-highway transportation emissions, } \\
V= & \text { vehicle miles traveled (VMT), } \\
E F= & \text { MOBILE4 emission factor (month-specific and state-specific to account for } \\
& \text { average monthly temperatures in the state and are year-specific to account for } \\
& \text { changes in fleet turnover and average control efficiency), } \\
& =\text { state, } \\
\mathrm{i}= & \text { speeci range, } \\
\mathrm{j}= & \text { vehicle type, } \\
\mathrm{m}= & \text { month, and } \\
\mathrm{y}= & \text { year. }
\end{aligned}
$$

In other wora's, emissions from vehicle type $\mathrm{j}$ in state $\mathrm{s}$ and month $\mathrm{m}$ of year $\mathrm{y}$ were the sum over all speed ranges of the product of that vehicle type's VMT and the appropriate emission factor. The algorithm used a state's monthly average temperature range as one variable to select an emission factor. This enabled the algorithm to account for the nonlinear relationship between emission factors and temperature. Another variable that was used was altitude, since the emission factor changes with altitucie. High-altitude emission factors were used in four states (Colorado, New Mexico, Utah, and Wyoming).

\subsubsection{Estimating Highway Activity}

As noted above, monthly VMT provided the measure of on-highway transportation activity. Estimating this VMT was a multistep process. The first step involved estimating statelevel VMT by vehicle type. The U.S. Department of Transportation (DOT) publication Highway Statistics (FHWA 1975-87) provided VMT by state and road type in its Table VM-2. Statespecific VMT shares were computed from 1985 state VMT data by vehicle type provided by the FHWA through Cambridge Systematics, Inc. Although using these 1985 values held VMT shares by vehicle type constant, these data were considered to be the best available. (It is believed that this methodology overestimates light-duty diesel truck VMT somewhat for the years 1975 to 1978 or 1979.) These state VMT totals were combined with their state-specific VMT shares by vehicle type to compute annual state VMT by vehicle type. The formula for state VMT by vehicle type is: 


$$
\hat{V}_{s, j, y}^{n F H W A}=V_{s, y}^{\text {FHWA }} \times \frac{V_{s, j, 1985}^{C S I}}{\sum_{j=1}^{5} V_{s, j, 1925}^{C S I}}
$$

where:

$$
\begin{aligned}
\hat{V}^{\text {FHWA }} & =\text { adjusted vehicle miles traveled, } \\
\mathrm{V}^{\text {FHWA }} & =\text { vehicle miles traveled (from Table VM-2), and } \\
V^{\mathrm{CSI}} & =\text { vehicle miles traveled in } 1985 \text { (from CSI 1988). }
\end{aligned}
$$

The next step involved apportioning the annual VMT across months on the basis of monthly fuel consumption. Highway Statistics (FHWA 1975-87) provided monthly estimates of fuel consumed on U.S. highways in its Tables MF-25 (special fuels) and MF-26 (gasoline). In addition, a seasonal efficiency coefficient was developed as a refinement to the methodology. It has long been known that average vehicular fuel efficiency declines in cold weather, partly because of the greater amount of fuel consumed in starting (and the longer idling time characteristic of winter warm-up) and partly because more difficult driving conditions tend to reduce average travel speeds. It was therefore advisable to adjust the interpolation algorithm for those states with cold winters to account for lower-than-average fuel efficiency in cold months and higher-than-average efficiency in warmer months, since the fuel consumption totals shown for the cold months represented less actual VMT than did the identical fuel consumption totals (in gallons) in the warmer months. Table 7.1 presents the seasonal efficiency coefficients used in this study. These coefficients lowered VMT in the winter months and raised it in the summer months, relative to just a simple monthly allocation on the basis of fuel consumption. The monthly state VMT totals were then scaled so their annual sum conformed to the totals in Table VM-2. The formula for unscaled VMT was:

$$
\overrightarrow{u \hat{V}_{s, m, j, y}^{F H W A}}=\hat{V}_{s, j, y}^{F H W A} \times \frac{F_{s, m, y}}{\sum_{m=1}^{12} F_{s, m, y}} \times S E_{s, m, j}
$$

where:

$$
\begin{aligned}
\mathrm{uV} \hat{V}^{\mathrm{FHWA}}= & \text { unscaled vehicle miles traveled, } \\
\mathrm{F}= & \text { fuel consumption by on-highway vehicles (from table MF-25 for } \\
& \text { diesel vehicles or MF-26 for gasoline vehicles), and } \\
\mathrm{SE}= & \text { seasonal efficiency coefficient. }
\end{aligned}
$$


TABLE 7.1 Seasonal Efficiency Coefficientsa

\begin{tabular}{|c|c|c|c|c|}
\hline \multirow[b]{2}{*}{ Month } & \multicolumn{4}{|c|}{ Vehicle Type b } \\
\hline & Auto & LDT & HDGT & HDDT \\
\hline $\begin{array}{l}\text { Jan., Feb., } \\
\text { and March }\end{array}$ & 0.80 & 0.90 & 0.80 & 0.90 \\
\hline April and May & 1.10 & 1.05 & 1.10 & 1.00 \\
\hline $\begin{array}{l}\text { June, July, } \\
\text { and Aug. }\end{array}$ & 1.20 & 1.20 & 1.20 & 1.10 \\
\hline Sept. and Oct. & 1.10 & 1.05 & 1.10 & 1.00 \\
\hline Nov. and Dec. & 0.80 & 0.90 & 0.80 & 0.90 \\
\hline \multicolumn{5}{|c|}{$\begin{array}{l}\text { aThese coefficients are applied for the } \\
\text { following states: CO, CT, DE, DC, ID, IL, IN, } \\
\text { IA, KS, KY, ME, MD, MA, MI, MN, MO, MT, } \\
\text { NE, NH, NJ, NY, ND, OH, OR, PA, RI, SD, UT, } \\
\text { VT, WA, WV, WI, and WY. }\end{array}$} \\
\hline $\begin{array}{l}\text { bLDT = light-du } \\
\text { trucks; HDGT } \\
\text { HDDT = heav }\end{array}$ & gasol & $\begin{array}{l}\text { le and } \\
\text { uty ga } \\
\text { sel truc }\end{array}$ & ght-duty & $\begin{array}{l}\text { diesel } \\
\text { cks; }\end{array}$ \\
\hline
\end{tabular}

Due to the seasonal efficiency coefficient, the monthly VMT no longer summed to the state totals in VM-2, so a simple scaling was done to bring the totals back in line. This scaling was:

$$
\overline{\mathrm{V}}_{\mathrm{s}, \mathrm{m}, \mathrm{j}, \mathrm{y}}^{\mathrm{FHWA}}=u \hat{\mathrm{V}}_{\mathrm{s}, \mathrm{m}, \mathrm{j}, \mathrm{y}}^{\mathrm{FHWA}} \times \frac{\mathrm{V}_{\mathrm{s}, \mathrm{y}}^{\mathrm{FHWA}}}{\sum_{\mathrm{m}=1}^{12} \sum_{\mathrm{j}=1}^{5} \mathrm{u} \hat{\mathrm{V}}_{\mathrm{s}, \mathrm{m}, \mathrm{j}, \mathrm{y}}^{\mathrm{FHWA}}}
$$

where $\overline{\mathrm{V}}^{\mathrm{FHWA}}=$ scaled vehicle miles traveled. 
The final step in the VMT estimation algorithm involved splitting the VMT into four speed regimes. VMT for four road types per vehicle type, each with an average speed, were obtained from FHWA through CSI. As with the steps above, these data were incorporated through a simple sharing-out formula. In this case, the formula was:

$$
v_{s, i, j, m, y}=\vec{v}_{s, m, j, y}^{F H W A} \times \frac{v_{i, j, 1985}^{C S I}}{\sum_{i=1}^{4} v_{i, j, 1985}^{C S I}}
$$

\subsubsection{Estimating VMT for the Flash Report}

The lag between the activity reported on in Highway Statistics and the availability of that publication is from 10 to 22 months. Therefore, FHWA's publication Monthly Gasoline Reported by States (FHWA 1975-88). reported by states was used, since it provides data on state-level highway gasoline and diesel fuel sales at only about a 4-month lag. VMT were extrapolated using the ratio of VMT to fuel sales for the last year of data and multiplying by present fuel sales. This procedure was used to develop 1,988 monthly on-highway activity estimates by state.

\subsubsection{Calculating On-Highway Emission Factors}

State-specific sets of emission rates for highway activity were developed by computing an emission factor for each monthly average temperature and diurnal temperature range in each year from 1975 to 1988 for each of four operating speed groups classified by road type through the MOBILE4 model (EPA 1989b). For each of five vehicle types (automobile, light-duty gasolinepowered truck, heavy-duty gasoline-powered truck, light-duty diesel-powered truck, and heavyduty diesel-powered trucks and buses), a set of 48 emission factors per pollutant was used for each year. Each set of four was appropriate to a given state and month based on the state's monthly average temperature and altitude.

The MOBILE4 program incorporates a number of features that increase the accuracy of its emission factor estimates over older versions of the MOBILE model. One feature is related to the impact of diurnal temperature variation on emission factors. Although the MSCET algorithm always accounted for regional differences in monthly average temperature, MOBILE4's built-in diurnal temperature-rise feature now accounts for the effect of daily maximum and minimum temperatures on the emission factors. For use in MSCET, a file of data on 30-year average temperature ranges by state and month was created from the Statistical Abstract (B of C 1988) as provided from the National Climatic Data Center and used as input to the MOBILE4 program; this 30-year average was used for each year in the 1975-1988 period. 
Another feature of the MOBILE4 program concerned the impact of changing fuel volatility on $\mathrm{HC}$ emissions from running losses. It is generally acknowledged that the amount of gasoline that evaporates from motor vehicles is much higher than that accounted for in MOBILE3 emission factors. Therefore, state-specific and month-specific Reid vapor pressure (RVP) limits by ASTM volatility class from the Annual Book of ASTM Standards (Section 5: Petroleum Products, Lubricants, Fossil Fuels; Volume 05.01: Petroleum Products and Lubricants (I): D56-D1947), were used as MOBILE4 inputs.

\subsection{Estimating Emissions from Off-Highway Sources}

The methodology used to estimate emissions was basically the same as described in Report ANL/EES-TM-335 (Kohout et al. 1987), but it is described again here for completeness. The offhighway transportation sources considered were:

1. Locomotive line-haul operations,

2. Locomotive switching operations,

3. Commercial aviation (passenger and dedicated freight),

4. General aviation,

5. Military aviation,

6. Inland and coastal waterway barge operation, and

7. Great Lakes and coastwise steamship and large diesel motorship operation.

For this new version of MSCET, an additional eighth ESG for miscellaneous off-highway sources was added to cover such sources as heavy off-road vehicles, industrial internal combustion engines (not electric utility), natural gas pipeline compressors, and small gasoline engines. After emissions were estimated for the eight sources, they were collapsed into three ESGs (aviation, locomotives, and shipping), whicn together with the miscellaneous ESG, resulted in four off-highway ESGs. Monthly state-level allocation procedures are described for each category below.

\subsubsection{Locomotive Operation}

The EIA annually (most recent year: 1988) reports sales of special fuels (including distillate and residual fuels) to states by utilization category (EIA 1975-88a). One such category is railroads. Even though less than $100 \%$ of the distillate fuel purchased by railroads is used for locomotive operation, and, furthermore, although much of this fuel is actually consumed by linehaul operations in states other than the state of recorded purchase, the allocation of locomotive activity by state is more reliable when it is done on the basis of fuel sales data rather than total track milt ?ge because of the large quantity of relatively idle track in many states. Therefore, locomotive 
emissions (per thousand gallons of fuel burned) were assigned to states on the basis of fuel purchase, with line-haul and switching components apportioned equally to each state on the basis of the 1985 national share from the TEEMS model's energy demand outputs (Vyas and Saricks 1986). The graph of monthly shipment activity data from the journal Progressive Railroading (undated) was used to divide the annual fuel consumption into 12 components. The peak month for rail hauls (in 1985, with similar results shown for 1984 and 1986) was October, with significant downturns occurring regularly at the year's end, Memorial Day, and July 4 holidays. These effects were incorporated in the state-level activity rates. Emission factors were provided by the AP-42 report (EPA 1985). The factors were weighted on the basis of the distribution of locomotive equipment currently in service. These factors were updated with more recent locomotive emissions and utilization data, which resulted in a net increase in $\mathrm{NO}_{\mathrm{x}}$ per volume of fuel burned but a significant decrease in total fuel utilization (i.e., increase in fuel efficiency).

\subsubsection{Commercial Aviation}

The annual Federal Aviation Administration (FAA) publication Statistical Handbook of Aviation (FAA 1985-88) reports total civil airport operations as well as commercial aircraft departures (a subset of the foregoing) by state. Because the basis of AP-42 emission factors for aircraft activity is the full landing/takeoff (LTO) cycle (two operations), arrivals by state were assumed to equal departures, and the commercial total given for each state was used directly with the (weighted) emission factor. This total was doubled and then subtracted from the state's civil operations total, however, to derive net general aviation activity (see Sec. 7.2.3).

One additional refinement was needed to compute commercial aviation emissions, because emission-factor weighting by aircraft type (i.e., share of population in service) produced different values if wide-body aircraft were included in the mix. Wide-body aircraft generally operate out of major hub airports, which are found in only about 20 states. For these states, an emission factor characteristic of long-runway-type operations was applied to the commercial total. As a result, average emissions per LTO cycle differed from those in nonhub states.

\subsubsection{General Aviation}

As stated, net state civil airport operations minus commercial aircraft operations was assumed to represent LTOs by general aviation aircraft. In fact, a share of this total was probably helicopter traffic and Air National Guard aircraft using FAA airports, but this share was sufficiently small so that it could be ignored. The net operations were therefore divided by two (to give the actual LTO total) and multiplied by the weighted AP-42 factor used in TEEMS for general aviation aircraft.

Monthly activ. ty allocations for commercial and general aviation were handled identically, with peak travel months (determined by passenger boardings) in August, November, December, July, and June (in approximately descending order). Movements were distributed approximately equally over the remainder of the year. 


\subsubsection{Milltary Aviation}

At present, no reliable data are available for military aircraft operations by state during 1985. Until they are, state shares from the 1980 NAPAP Emissions Inventory are being used, with total national operations being estimated from military air operations data in the Statistical Handbook of Aviation for 1985 (FAA 1985-88). State-level activity was distributed equally over 12 months and multiplied by tho TEEMS-weighted emission factor for military aircraft derived from AP-42.

\subsubsection{Inland and Coastal Waterway Barges}

Barge movements were assumed to be powered almost exclusively by distillate fuel. Therefore, for states located exclusively on inland waterways, $100 \%$ of the distillate fuel sold for vessel bunkering as reported in the 1987 ELA data (EIA 1975-88a) was assigned to river barge and tow operations, and the corresponding AP-42 factor (emission loading per thousand gallons burned) was used directly, with the result being assigned totally to the state of sale (as occurred with locomotive operation). The share of barge activity and resultant distillate consumption in states with both inland waterway and Great Lakes activity, or waterway and coastwise shipping, was determined as an artifact of bunkering of residual and distillate oil for steamship operations and large diesel motorship operations, as described in the following text.

Movements on inland waterways are highly constrained by seasonal river conditions. Thus, state-level activity was most intense from April through October (accounting for more than $80 \%$ of total movement) and relatively dormant in the winter months. In other words, even though many reaches remained ice-free year-round, the shipments that would otherwise originate from northern sections of the waterway network did not move by water.

\subsubsection{Great Lakes and Coastwise Steamships and Large Diesel Motorships}

Steamships and diesel motorships (most prominent in international trade) use mostly heavy residual oil in their burners, with a small proportion of distillate oil (up to 10\%) blended in for smooth flow and operation. Combustion of residual oils, with their high average sulfur content (up to $3 \%$ by weight), contribute significantly to total $\mathrm{SO}_{2}$ loading; for this reason, vessels bunkering residual fuel were the single most important generator of this pollutant in the transportation sector. On the other hand, only a fraction of the residual fuel bunkered at U.S. ports was actually burned by vessels in U.S. waters; thus, only that fraction would contribute to the national air pollutant inventory. According to Table 1.5 of the Transportation Data Book: Edition 8 , about $84 \%$ of the residual fuel and $38 \%$ of the distillate fuel consumed during waterborne activity was by vessels involved in U.S.-foreign trade (Hanchey and Holcomb 1985). If $100 \%$ of the total was used by vessels entering and leaving U.S. ports, only about $17 \%$ of total residual fuel combustion and $63 \%$ of total distillate fuel combustion by these commercial vessels occurred in U.S. waters. (Distillate combustion in U.S. waters may actually have been somewhat higher because of ship in-port "hoteling" power requirements.) Consequently, the 
following adjustments were made to the state-level vessel bunkering totals for 1987 (from EIA 1975-88a) for those states with Great Lakes and ocean port operations.

1. If a state had at least one major port involved in international trade, it was assigned $17 \%$ of the 1987 value (from EIA 1975-88a) of residual sales (in gallons) for vessel bunkering as its "fuel burned" commitment.

2. Ten percent (actually, $10.39 \%$ on a Btu equivalency basis) of this $17 \%$ was subtracted from the 1987 EIA state total of distillate sales for vessel bunkering and assigned to steamship and motorship combustion. (Emission factors for steamship and motorship combustion differed from those for diesel barges.)

3. If a state had a coastal location but no major international port, $75 \%$ of the residual fuel sales to the state were assigned as the "fuel burned" commitment, in recognition of the fact that most of the residual consumption would result from coastwise operations. Again, $10 \%$ of this $75 \%$ was allocated from distillate vessel bunkering fuel use to steamship and motorship combustion.

4. The amount of distillate fuel remaining for coastal states was assigned to barge movements; however, if the state was not on the inland waterway network or had a negligible mileage of navigable rivers, it was assumed that the distillate fuel was consumed in coastwise movements, with only a $50 \%$ chance that its combustion would contribute to 48-state pollutant loading. This adjustment was necessary to ensure that no more than about $66 \%$ of total distillate combustion was assigned to U.S. waters.

5. For Great Lakes states, $90 \%$ of the residual fuel sold was assumed to be burned in U.S. waters. Again, $10 \%$ of this $90 \%$ was deducted from distillate vessel bunkering fuel use and allocated to steamship and motorship operation, with the balance assigned $100 \%$ to waterway barges unless the state was also on the coast (for example, New York), in which case, the 50\% rule was applied.

The results of this allocation procedure were very encouraging. Even without normalization, the total distillate combustion commitment for barge and steam/motorship operations nationwide was about $65 \%$ of 1987 sales to vessel bunkering, and residual combustion commitment was $18 \%$ of total sales. The procedure described essentially paralleled the routine programmed into TEEMS, the primary difference being that TEEMS used forecasted demand for fuel types in British thermal units, which were converted to galions, while the allocation procedure used empirical consumption data for 1987.

Coastal states are assumed to maintain ice-free port facilities throughout the year; therefore, monthly activity shares are the same for all years in the emissions input file. Great Lakes states were assigned the same monthly activity profile as inland waterway movements because of the seasonal constraint. As appropriate, then, each state had up to three activity values for maritime transportation, each with its own AP-42 emission factor set, which were in thousand-gallon units of (1) distillate fuel consumed by tug/tow barge movements in U.S. waters, (2) distillate fuel 
consumed in steamship and motorship burners operatirg in U.S. ports and waters, or (3) residual fuel consumed in those burners in U.S. waters.

\subsubsection{Miscellaneous Off-HIghway Sources}

Unlike the other mobile emission source categortes, this ESG relied on the1985 NAPAP Emissions Inventory for state-share information and the EPA Trends Report (EPA 1989c) for annual tend information. The annual estimates were allocated uniformly across the months. This methodology followed the same algorithm as that for other nonutility and nontransportation sources in the MSCET program. 


\section{References}

Boyd, G., et al., 1987, Separating the Changing Composition of U.S. Manufacturing Production from Energy Improvements: A Divisia Index Approach, The Energy J., April.

B of C, 1988, Statistical Abstract of the United States, 108th edition, Department of Commerce, Bureau of the Census.

Bradford, B.C., 1986, Utah Air Conservation Committee, personal communication to L. Svoboda, U.S. Environmental Protection Agency, Region 8, Nov., available from Bureau of Air Quality, Utah Department of Health, Salt Lake City.

Butler, T.J., and G.E. Likens, 1990, The Impact of Changing Regional Emissions on Precipitation Chemistry in the Eastern United States, Institute of Ecosystem Studies, Millbrook, N.Y.; also in Atmospheric Environment, 24A(7), July 1990.

CSI, 1988, Evaluation of the Transportation Energy and Emissions.Modeling System (TEEMS), Final Report, Cambridge Systematics, Inc., Berkeley, Calif., Dec. 30.

Dalley, R.P., undated, Bureau of Air Qualicy, Utah Department of Health, personal communication regarding Kennecott sulfur mass balance data for the years 1974-1984, to L. Hanley, U.S. Environmental Protection Agency, Region 8, available from Bureau of Air Quality, Utah Department of Health, Salt Lake City.

DOC, 1985-88, Survey of Current Business Monthly Statistics, U.S. Department of Commerce, Bureau of Economic Analysis reports covering the period Jan. 1985 through Dec. 1988.

EDF, undated, Environmental Defense Fund, Washington, D.C., unpublished information.

Eggleston, T. E., and Gray, W. C., 1988, Continuous Emission Monitoring Guidelines: Update, Electric Power Research Institute Report EPRI-CS-5998, Palo Alto, Calif., Sept.

EIA, 1975-87, Monthly Power Plant Report, EIA Form 759 data on magnetic tape supplied by U.S. Department of Energy, Energy Information Administration.

EIA, 1975-88a, State Energy Data Report, U.S. Department of Energy, Energy Information Administration Report DOE/EIA-0214, reports covering the period Jan. 1975 through Dec. 1987.

EIA, 1975-88b, Monthly Energy Review, U.S. Department of Energy Energy Information Administration Report DOE/EIA-0035, reports covering the period Jan. 1975 through Dec. 1988.

EIA, 1982-89, Quarterly Coal Report, U.S. Department of Energy, Energy Information Administration Report DOE/E/A-0121, reports covering the period Jan. 1982 through Dec. 1988. 
EIA, 1985-88a, Steam-Electric Plant Operation and Design Report, EIA Form 767 data on magnetic tape supplied by U.S. Department of Energy, Energy Information Administration.

ELA, 1985-88b, Natural Gas Monthly, U.S. Department of Energy, Energy Information Administration Report DOE/EIA-0130, reports covering the period Jan. 1985 through Dec. 1988.

EPA, 1985, Compilation of Air Pollutant Emission Factors, U.S. Environmental Protection Agency Report AP-42, 4th Ed., Sept.

EPA, 1989a, The 1985 NAPAP Emissions Inventory (Version 2): Development of the Annual Data and Modelers' Tapes, U.S. Environmental Protection Agency Report EPA-600/7-89-012a, Research Triangle Park, N.C., Nov.

EPA, 1989b, User's Guide to MOBILE4 (Mobile Source Emission Factor), U.S. Environmental Protection Agency Report EPA-AA-TEB-89-01, Motor Vehicle Emission Laboratory, Ann Arbor, Mich., Feb.

EPA, 1989c, National Air Pollutant Emission Estimates, 1940-1987, U.S. Environmental Protection Agency Report EPA-450/4-88-022, March.

EPRI, 1985, $\mathrm{SO}_{2}$ and $\mathrm{NO}_{x}$ Retrofit Control Technologies Handbook, Electric Power Research Institute Report EPRI-CS-4277-SR, Palo Alto, Calif., Oct.

FAA, 1985-88, Statistical Handbook of Aviation, U.S. Department of Transportation, Federal Aviation Administration Report DOT-515, reports covering the period Jan. 1985 through Dec. 1988.

FERC, 1975-88, Monthly Report of Cost and Quality of Fuels for Electric Plants, FERC Form 428 data on magnetic tape supplied by Federal Energy Regulatory Commission.

FRB, 1975-88, Federal Reserve Board production indexes from 1975 through 1988.

FHWA, 1975-87, Highway Statistics, U.S. Department of Transportation, Federal High 'vay Administration Report HPM-10, reports covering the period Jan. 1975 through Dec. 1987.

FHWA, 1975-88, Monthly Gasoline Reported by States, U.S. Department of Transportation, Federal Highway Administration Report DOT-512, reports covering the period Jan. 1975 through Dec. 1988.

Hanchey, C.M., and M.C. Holcomb, 1985, Transportation Energy Data Book: Edition 8, Oak Ridge National Laboratory Report ORNL-2605 (Edition 8 of ORNL-5198), Nov.

Hanson, et al., 1988, A Regionalization Methodology for Sector Model Input Data: Derivation and Applications, Argonne National Laboratory Report ANL/EES-TM-301, Nov. 
Hargraves, W.R., 1989, Health and Environment Division, New Mexico, personal communication, Feb.

Kennecott, 1985a, Kennecott Smelter Annual Emission Inventory, 1984, available from Bureau of Air Quality, Utah Department of Health, Salt Lake City.

Kennecott, 1985b, Kennecott Smelter Sulfur Monthly Running Average, 1984, available from Bureau of Air Quality, Utah Department of Health, Salt Lake City.

Kohout, E.J., et al., 1987, Estimated Monthly Emissions of Sulfur Dioxide, Oxides of Nitrogen, and Volatile Organic Compounds for the 48 Contiguous States, 1985-1986, Vols. 1 and 2, Argonne National Laboratory Report ANL/EES-TM-335, Nov.

Leverock, A.C., 1989, Department of Health Services, Arizona, personal communication, April.

NCDC, 1987, State, Regional, and National Monthly and Seasonal Heating Degree Days Weighted by Population (1980 census) July 1931-June 1987, with supplement for last six months of 1987, National Climatic Data Center, Asheville, N.C., Oct.

Nochumson, D.H., and M.D. Williams, 1983, Copper Smelters and Atmospheric Visibility in the Southwest, Seasonal Analysis, Presented at 76th Annual Meeting, Air Pollution Control Association, Atlanta.

Oppenheimer, M., et al., 1985, Acid Deposition, Smelter Emissions, and the Linearity Issue in the Western United States, Science, pp. 859-862, Aug. 30.

Pepper, W., et al., 1987, Retrofit Combustion Controls for Gas/Oil-Fired Utility Boilers, Electric Power Research Institute Report EPRI-CS-5361, Vol. 2, Palo Alto, Calif., Aug.

Progressive Railroading, undated, How Traffic Is Going, graph in each monthly issue.

RDC, 1990, Review of the Monthly and State Emission Trends (MSCET) Data Bases for the National Acid Precipitation Assessment Program, Resource Dynamics Corp.

Saricks, C.L., 1985, The Transportation Energy and Emissions Modeling System (TEEMS): Selection Process, Structure, and Capabilities, Argonne National Laboratory Report ANL/EESTM-295, Nov.

Towle, S., 1989, Materials Availability Field Office, Bureau of Mines, U.S. Department of the Interior, personal communication, March.

Vyas, A.D., C.L. Saricks, 1986, Transportation Energy and Emissions Modeling System (TEEMS): Configuration for Forecasting Transportation Source Emissions for the 1985 Test Runs, Argonne National Laboratory Report ANL-EES-TM-321, Oct.

Zimmerman, et al., 1988, Anthropogenic Emissions Data for the 1985 NAPAP Inventory, U.S. Environmental Protection Agency Report EPA-600/7-88-022, Nov. 


\section{Appendix A:}

Emission Source Groups: Source Codes and Sources of Data on Annual Emission Trends, Monthly Emission Trends, State Shares, and Annual Extender Methodology 
TABLE A.1 Emission Source Codes for the Fuel Combustion Sectors

\begin{tabular}{|c|c|c|}
\hline Emission Source Group & $\begin{array}{l}\text { NAPAP } \\
\text { SCCa }\end{array}$ & Description \\
\hline $\begin{array}{l}\text { Commercial/institutional } \\
\text { coal }\end{array}$ & $\begin{array}{l}\text { AS7 } \\
\text { AS8 } \\
103001 \\
103002 \\
103003 \\
10500202\end{array}$ & $\begin{array}{l}\text { Anthracite } \\
\text { Bituminous } \\
\text { External combustion boiler, anthracite } \\
\text { Fixternal combustion boiler, bituminous } \\
\text { External combustion boiler, lignite } \\
\text { Space heating, coal }\end{array}$ \\
\hline $\begin{array}{l}\text { Commercial/institutional } \\
\text { fuel oil }\end{array}$ & $\begin{array}{l}\text { AS9 } \\
\text { AS10 } \\
103004 \\
103005 \\
203001 \\
10500205\end{array}$ & $\begin{array}{l}\text { Distillate } \\
\text { Residual } \\
\text { External combustion boiler, residual } \\
\text { External combustion boiler, distillate } \\
\text { Internal combustion, distillate/diesel } \\
\text { Space heating, comm./inst. fuel oil }\end{array}$ \\
\hline $\begin{array}{l}\text { Commercial/institutional } \\
\text { natural gas }\end{array}$ & $\begin{array}{l}\text { AS11 } \\
103006 \\
203002 \\
10500206\end{array}$ & $\begin{array}{l}\text { Natural gas } \\
\text { External combustion boiler, natural gas } \\
\text { Internal combustion, natural gas } \\
\text { Space heating, natural gas }\end{array}$ \\
\hline $\begin{array}{l}\text { Commercial/institutional } \\
\text { other }\end{array}$ & $\begin{array}{l}\text { AS12 } \\
103007 \\
103009 \\
103010 \\
103012 \\
103013 \\
203003 \\
203010 \\
10500209 \\
10500210\end{array}$ & $\begin{array}{l}\text { Wood } \\
\text { External combustion boiler, process gas } \\
\text { External combustion boiler, wood/bark waste } \\
\text { External combustion boiler, LPG } \\
\text { External combustion boiler, solid waste-specify } \\
\text { External combustion boiler, liquid waste-specify } \\
\text { Internal combustion, gasoline } \\
\text { Internal combustion, propane } \\
\text { Space heating, wood } \\
\text { Space heating, LPG }\end{array}$ \\
\hline Residential coal & $\begin{array}{l}\text { AS1 } \\
\text { AS2 }\end{array}$ & $\begin{array}{l}\text { Anthracite } \\
\text { Bituminous }\end{array}$ \\
\hline Residential fuel oil & $\begin{array}{l}\text { AS3 } \\
\text { AS4 }\end{array}$ & $\begin{array}{l}\text { Distillate } \\
\text { Residual }\end{array}$ \\
\hline Residential natural gas & AS5 & Natural gas \\
\hline Residential wood & AS6 & Wood \\
\hline Electric utility coal ${ }^{b}$ & $\begin{array}{l}101001 \\
101002 \\
101003\end{array}$ & $\begin{array}{l}\text { External combustion boiler, anthracite } \\
\text { External combustion boiler, bituminous } \\
\text { External combustion boiler, lignite }\end{array}$ \\
\hline Electric utility fuel oil & $\begin{array}{l}101004 \\
101005 \\
201001\end{array}$ & $\begin{array}{l}\text { External combustion boiler, residual } \\
\text { External combustion boiler, distillate } \\
\text { Internal combustion, distillate/diesel }\end{array}$ \\
\hline Electric utility natural gas ${ }^{b}$ & $\begin{array}{l}101006 \\
101010 \\
201002\end{array}$ & $\begin{array}{l}\text { External combustion boiler, natural gas } \\
\text { External combustion boiler, LPG } \\
\text { Internal combustion, natural gas }\end{array}$ \\
\hline
\end{tabular}


TABLE A.1 (Cont'd)

\begin{tabular}{|c|c|c|}
\hline Emission Source Group & $\begin{array}{c}\text { NAPAP } \\
\text { SCC }^{a}\end{array}$ & Description \\
\hline Electric utility otherb & $\begin{array}{l}101007 \\
101008 \\
101009 \\
101011 \\
101012 \\
101013 \\
201007 \\
201009 \\
201010\end{array}$ & $\begin{array}{l}\text { External combustion boiler, process gas } \\
\text { External combustion boiler, coke } \\
\text { External combustion boiler, wood/bark waste } \\
\text { External combustion boiler, bagasse } \\
\text { External combustion boiler, solid waste-specify } \\
\text { External combustion boiler, liquid waste-specify } \\
\text { Internal combustion } \\
\text { Internal combustion, keronaptha jet fuel } \\
\text { internal comibustion, geysers/geothermal }\end{array}$ \\
\hline Industrial coal & $\begin{array}{l}\text { AS96 } \\
\text { AS13 } \\
\text { AS14 } \\
102001 \\
102002 \\
102003 \\
10500102 \\
390001 \\
39000289 \\
39000299 \\
390003\end{array}$ & $\begin{array}{l}\text { Minor sources, coal } \\
\text { Anthracite } \\
\text { Bituminous } \\
\text { External combustion boiler, anthracite } \\
\text { External combustion boiler, bituminous } \\
\text { External combustion boiler, lignite } \\
\text { External combustion boiler, space heat, coal } \\
\text { Industrial process, in-process fuel, anthracite } \\
\text { Industrial process, in-process fuel, bituminous } \\
\text { Industrial process, in-process fuel, bituminous } \\
\text { Industrial process, in-process fuel, lignite }\end{array}$ \\
\hline industrial fuel oil & $\begin{array}{l}\text { AS16 } \\
\text { AS17 } \\
\text { AS97 } \\
102004 \\
102005 \\
10500105 \\
202001 \\
202004 \\
202005 \\
30190001 \\
30190002 \\
30190011 \\
30190012 \\
30290001 \\
30290002 \\
30390001 \\
30390002 \\
30390011 \\
30390012 \\
30490001 \\
30490002 \\
30490011 \\
30490012 \\
30590001 \\
30590002 \\
30590011 \\
30590012 \\
30600103 \\
30790001 \\
30790002 \\
30790011\end{array}$ & $\begin{array}{l}\text { Distillate } \\
\text { Residual } \\
\text { Minor sources, oil } \\
\text { External combustion boiler, residual } \\
\text { External combustion boiler, distillate } \\
\text { External combustion bolier, space heat, oil } \\
\text { Internal combustion, distillate/diesel } \\
\text { Internal combustion, large bore engine } \\
\text { Internal combustion, residual/crude oil } \\
\text { Chemical mfg., fuel-fired equip., process heaters, oil } \\
\text { Chemical mfg., fuel-fired equip., process heaters, oil } \\
\text { Chemical mfg., fuel-fired equip., process heaters, oil } \\
\text { Chemical mfg., fuel-fired equip., process heaters, oil } \\
\text { Food/agriculture, fuel-fired equip., process heaters, oil } \\
\text { Food/agriculture, fuel-fired equip., process heaters, oil } \\
\text { Primary metals, fuel-fired equip., process heaters, oil } \\
\text { Primary metals, fuel-fired equip., process heaters, oil } \\
\text { Primary metals, fuel-fired equip., process heaters, oil } \\
\text { Primary metals, fuel-fired equip., process heaters, oil } \\
\text { Secondary metals, fuel-fired equip., process heaters, oil } \\
\text { Secondary metals, fuel-fired equip., process heaters, oil } \\
\text { Secondary metals, fuel-fired equip., process heaters, oil } \\
\text { Secondary metals, fuel-fired equip., process heaters, oil } \\
\text { Mineral products, fuel-fired equip., process heaters, oil } \\
\text { Mineral prc Jucts, fuel-fired equip., process heaters, oil } \\
\text { Mineral products, fuel-fired equip., process heaters, oil } \\
\text { Mineral products, fuel-fired equip., process heaters, oil } \\
\text { Petroleum industry, petroleum refining, process heaters, oil } \\
\text { Wood products, fuel-fired equip., process heaters, oil } \\
\text { Wood products, fuel-fired equip., process heaters, oil } \\
\text { Wood products, fuel-fired equip., process heaters, oil }\end{array}$ \\
\hline
\end{tabular}


TABI-E A.1 (Cont'd)

\begin{tabular}{|c|c|c|}
\hline Emission Source Group & $\begin{array}{l}\text { NAPAP } \\
\text { SCC }^{a}\end{array}$ & Description \\
\hline $\begin{array}{l}\text { Industrial fuel oil } \\
\text { (Cont'd) }\end{array}$ & $\begin{array}{l}30790012 \\
30890001 \\
30890002 \\
30890011 \\
30890012 \\
30990001 \\
30990002 \\
30990011 \\
30990012 \\
31000401 \\
31000402 \\
31000403 \\
31000411 \\
31000412 \\
31000413 \\
31390001 \\
31390002 \\
39000489 \\
39000499 \\
39000501 \\
59000589 \\
39000598 \\
39000599 \\
39990001 \\
39990002 \\
39990011 \\
39990012\end{array}$ & $\begin{array}{l}\text { Wood products, fuel-fired equip., process heaters, oil } \\
\text { Rubber/plastics, fuel-fired equip., process heaters, oil } \\
\text { Rubbel/plastics, fuel-fired equip., process heaters, oil } \\
\text { Rubber/plastics, fuel-fired equip., process heaters, oil } \\
\text { Rubber/plastics, fuel-fired equip., process heaters, oil } \\
\text { Fabricated metals, fuel-fired equip., process heaters, oil } \\
\text { Fabricated metals, fuel-fired equip., process heaters, oil } \\
\text { Fabricated metals, fuel-fired equip., process heaters, oil } \\
\text { Fabricated metals, fuel-fired equip., process heaters, oil } \\
\text { Oll and gas prodn., fuel-fired equip., process heaters, oll } \\
\text { Oil and gas prodn., fuel-fired equip., process heaters, oll } \\
\text { Oil and gas prodn., fuel-fired equip., process heaters, oll } \\
\text { Oil and gas prodn., fuel-fired equip., process heaters, oil } \\
\text { Oil and gas prodn., fuel-fired equip., process heaters, oll } \\
\text { Oil and gas prodn., fuel-fired equip., process heaters, oll } \\
\text { Electrical equip., fuel-fired equip., process heaters, oll } \\
\text { Electrical equip., fuel-fired equip., process heaters, oil } \\
\text { Industrial process, in-process fuel, residual } \\
\text { Industrial process, in-process fuel, residual } \\
\text { Industrial process, in-process fuel, distillate } \\
\text { Industrial process, in-process fuel, distillate } \\
\text { Industrial process, in-process fuel, distillate } \\
\text { Industrial process, in-process fuel, distillate } \\
\text { Industrial process, misc. indus. fuel equip., process heaters, oil } \\
\text { Industrial process, misc. indus. fuel equip., process heaters, oil } \\
\text { Industrial process, misc. indus. fuel equip., process heaters, oll } \\
\text { Industrial process, misc. indus. fuel equip., process heaters, oil }\end{array}$ \\
\hline Industrial natural gas & $\begin{array}{l}\text { AS18 } \\
\text { AS98 } \\
102006 \\
10500106 \\
202002 \\
30190003 \\
30190013 \\
30290003 \\
30390003 \\
30390013 \\
30390023 \\
30490003 \\
30490013 \\
30490023 \\
30590003 \\
30590013 \\
30590023 \\
30600105 \\
30790003 \\
30790013 \\
30790023 \\
30890003 \\
30890013 \\
30890023 \\
30990003 \\
30990013\end{array}$ & $\begin{array}{l}\text { Natural gas } \\
\text { Minor sources, gas } \\
\text { External combustion boller, natural gas } \\
\text { External combustion boiler, space heat, gas } \\
\text { Internal combustion, natural gas } \\
\text { Chemical mfg., fuel-fired equip., process heaters, gas } \\
\text { Chemical mig., fuel-fired equip., process heaters, gas } \\
\text { Food/agriculture, fuel-fired equip., process heaters, gas } \\
\text { Primary metals, fuel-fired equip., process heaters, gas } \\
\text { Primary metals, fuel-fired equip., process heaters, gas } \\
\text { Primary metals, fuel-fired equip., process heaters, gas } \\
\text { Secondary metals, fuel-fired equip., process heaters, gas } \\
\text { Secondary metals, fuel-fired equip., process heaters, gas } \\
\text { Secondary metals, fuel-fired equip., process heaters, gas } \\
\text { Mineral products, fuel-fired equip., process heaters, gas } \\
\text { Mineral products, fuel-fired equip., process heaters, gas } \\
\text { Mineral products, fuel-fired equip., process heaters, gas } \\
\text { Petroleum industry, petroleum refining, process heaters, gas } \\
\text { Wood products, fuel-fired equip., process heaters, gas } \\
\text { Wood products, fuel-fired equip., process heaters, gas } \\
\text { Wood products, fuel-fired equip., process heaters, gas } \\
\text { Rubber/plastics, fuel-fired equip., process heaters, gas } \\
\text { Rubber/plastics, fuel-fired equip., process heaters, gas } \\
\text { Rubber/plastics, fuel-fired equip., process heaters, gas } \\
\text { Fabricated metals, fuel-fired equip., process heaters, gas } \\
\text { Fabricated metals, fuel-fired equip., process heaters, gas }\end{array}$ \\
\hline
\end{tabular}


TABLE A.1 (Cont'd)

\begin{tabular}{|c|c|c|}
\hline Emission Source Group & $\begin{array}{l}\text { NAPAP } \\
\text { SCC }^{a}\end{array}$ & Description \\
\hline $\begin{array}{l}\text { Industrial natural gas } \\
\text { (Cont'd) }\end{array}$ & $\begin{array}{l}30990023 \\
31000404 \\
31000414 \\
31390003 \\
39000605 \\
39000689 \\
39000699 \\
39990003 \\
39990013 \\
39990023\end{array}$ & $\begin{array}{l}\text { Fabricated metals, fuel-fired equip., process heaters, gas } \\
\text { Oil and gas prodn., fuel-fired equlp., process heaters, gas } \\
\text { Oil and gas prodn., fuel-flred equlp., process heaters, gas } \\
\text { Electrical equip., fuel-fired equip., process heaters, gas } \\
\text { Industrial process, in-process fuel, natural gas } \\
\text { Industrial proorss, in-process fuel, natural gas } \\
\text { Industrial process, in-process fuel, natural gas } \\
\text { Industrial process, misc. Indus, fuel equip., process heaters, gas } \\
\text { Industrial process, misc. Indus. fuel equip., process heaters, gas } \\
\text { Industrial process, misc. Indus, fuel equip., process heaters, gas }\end{array}$ \\
\hline Industrial other & $\begin{array}{l}\text { AS15 } \\
\text { AS19 } \\
\text { AS20 } \\
\text { AS95 } \\
102007 \\
102008 \\
102009 \\
102011 \\
102012 \\
102013 \\
102014 \\
102010 \\
10500110 \\
202003 \\
202009 \\
202010 \\
204001 \\
204002 \\
204003 \\
204004 \\
288888 \\
30190004 \\
30190014 \\
30390004 \\
30390014 \\
30390024 \\
30490004 \\
30490014 \\
30490024 \\
30600101 \\
30600102 \\
30600104 \\
30600106 \\
30600107 \\
30600108 \\
30600199 \\
31000405 \\
31000415 \\
390007 \\
390008 \\
390009 \\
390010 \\
390012 \\
390013 \\
\end{array}$ & 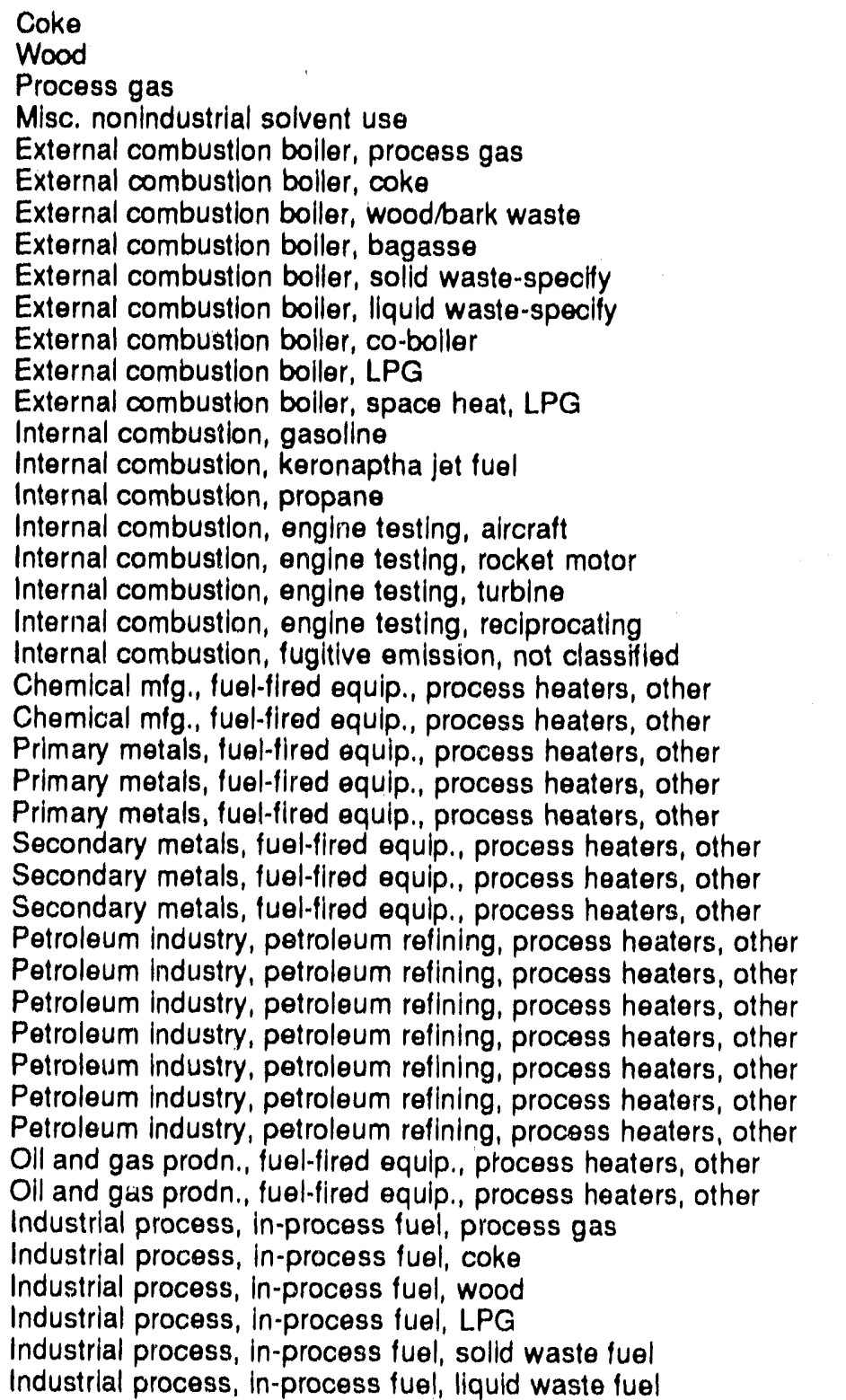 \\
\hline
\end{tabular}


TABLE A.1 (Cont'd)

\begin{tabular}{|c|c|c|}
\hline Emission Source Group & $\begin{array}{l}\text { NAPAP } \\
\text { SCC }^{a}\end{array}$ & Desoription \\
\hline $\begin{array}{l}\text { Industrial other } \\
\text { (Cont'd) }\end{array}$ & $\begin{array}{l}39990004 \\
39990014 \\
39990022 \\
39990024\end{array}$ & $\begin{array}{l}\text { Industrial process, misc. Indus. fuel equip., process heaters, other } \\
\text { Industrlal process, misc. Indus. fuel equlp., process heaters, other } \\
\text { Industrial process, miso. Indus. fuel equlp., process heaters, other } \\
\text { Industrial process, misc. Indus. fuel equlp., process heaters, other }\end{array}$ \\
\hline
\end{tabular}

aNAPAP SCC = Source classificatloil used in the National Aold Precipttation Assessment Program. The designation AS before a number indicates that the source is an area source. All numbers that are not preceded by AS refer to point sources.

bThe MSCET methodology for the electrlo utillty sector does not use the NAPAP inventory data. These SCC assignments are provlded for completeness. 
TABLE A.2 Emission Source Codes for the Industrial Process Sector

\begin{tabular}{|c|c|c|}
\hline Emission Source Group & $\begin{array}{l}\text { NAPAP } \\
\text { SCC }^{a}\end{array}$ & Description \\
\hline Cement production & $\begin{array}{l}305006 \\
305007 \\
39000201 \\
39000402 \\
39000502 \\
39000602\end{array}$ & $\begin{array}{l}\text { Mineral products, cement mig., dry process } \\
\text { Mineral products, cement mfg., wet process } \\
\text { Industrlal process, in-process fuel, bltuminous coal } \\
\text { Industrlal process, in-process fuel, residual oll } \\
\text { Industrlal process, in-process fuel, distllate oll } \\
\text { Industrlal process, in-process fuel, natural gas }\end{array}$ \\
\hline Degreasing & $\begin{array}{l}\text { AS78 } \\
401002 \\
401003\end{array}$ & $\begin{array}{l}\text { Degreasing } \\
\text { Organic solvent, vapor degreasing, open-top } \\
\text { Organic solvent, cold cleaning, methanol }\end{array}$ \\
\hline Dry cleaning & $\begin{array}{l}\text { AS79 } \\
401001\end{array}$ & $\begin{array}{l}\text { Dry cleaning } \\
\text { Organic solvent, dry cleaning, perchloroethylene }\end{array}$ \\
\hline $\begin{array}{l}\text { Food processing/ } \\
\text { agricultural operations }\end{array}$ & $\begin{array}{l}\text { AS71 } \\
\text { AS72 } \\
\text { AS73 } \\
\text { AS74 } \\
\text { AS75 } \\
\text { AS76 } \\
\text { AS77 } \\
\text { AS105 } \\
302001 \\
302002 \\
302003 \\
302004 \\
302005 \\
302006 \\
302007 \\
302008 \\
302009 \\
302010 \\
302011 \\
302012 \\
302013 \\
302014 \\
302015 \\
302016 \\
302017 \\
302018 \\
302019 \\
302020 \\
302021 \\
302022 \\
302026 \\
302028 \\
302030 \\
302031 \\
302032 \\
302033 \\
302036 \\
302038 \\
302888 \\
302999\end{array}$ & $\begin{array}{l}\text { Beef cattle manure fleld application } \\
\text { Dairy cattle manure fleld application } \\
\text { Hog and pig manure field application } \\
\text { Broiler chicken manure fleld application } \\
\text { Other chicken manure field application } \\
\text { Anhydrous ammonla fertllizer application } \\
\text { Beef cattle feed lots } \\
\text { Process emissions from bakeries } \\
\text { Alfalfa dehydrating, general } \\
\text { Coffee roasting, roaster } \\
\text { Coffee products, instant coffee } \\
\text { Agric. services, cotton ginning } \\
\text { Grain elevators, terminal elevator } \\
\text { Grain elevators, country elevators } \\
\text { Grain milling, corn meal } \\
\text { Feed mfg., barley feed } \\
\text { Fermentation, beer productlon } \\
\text { Fermentation, whiskey production } \\
\text { Fermentation, wine production } \\
\text { Fish processing, fish meal } \\
\text { Meat smoking, combined operations } \\
\text { Starch mfg., combined operations } \\
\text { Sugar cane process, general } \\
\text { Sugar beet process, dryer } \\
\text { Peanut processing, not classified } \\
\text { Candy mfg., not classified } \\
\text { Vegetable oil processing, corn oll } \\
\text { Agric. production, beef cattle } \\
\text { Poultry/egg production, manure handling } \\
\text { Agric. production, cotton-acid delin } \\
\text { Agric. production, seed processing } \\
\text { Agric. production, mushroom growing } \\
\text { Dairy products, milk } \\
\text { Grain elevators, export grain elevators } \\
\text { Bakeries, bread baking } \\
\text { Tobacco products, not classified } \\
\text { Deep fat frying, cooking vats } \\
\text { Animal/poultry rendering } \\
\text { Fugitlve omission, not classified } \\
\text { Misc., not classified }\end{array}$ \\
\hline
\end{tabular}


TABLE A.2 (Cont'd)

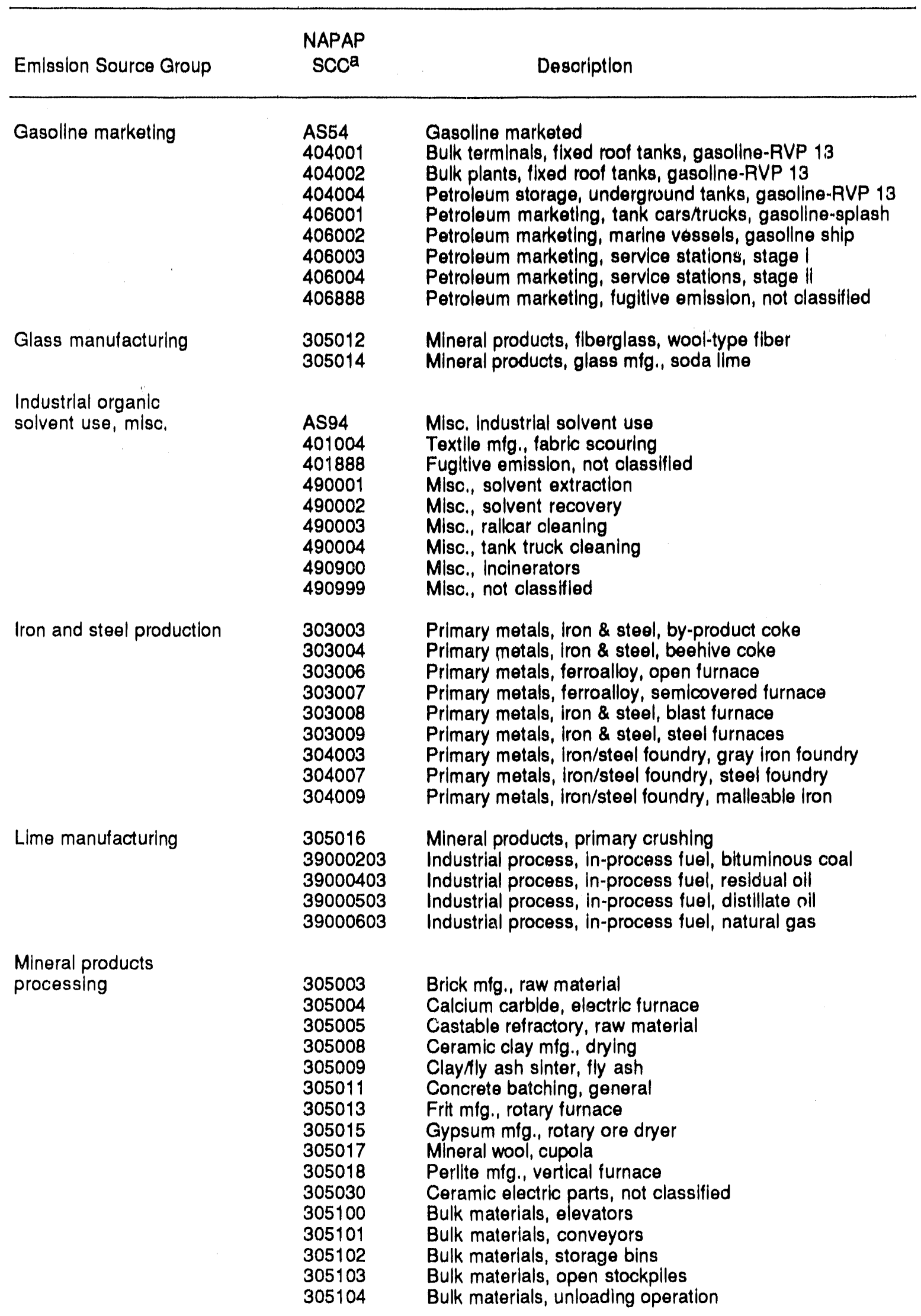


TABLE A.2 (Cont'd)

\begin{tabular}{|c|c|c|}
\hline Emission Source Group & $\begin{array}{l}\text { NAPAP } \\
\text { SCO }^{a}\end{array}$ & Desoription \\
\hline $\begin{array}{l}\text { Mineral products } \\
\text { processing } \\
\text { (Cont'd) }\end{array}$ & $\begin{array}{l}305105 \\
305150 \\
305888 \\
305999\end{array}$ & $\begin{array}{l}\text { Bulk materials, loading operation } \\
\text { Nonmetallio, caloining-general } \\
\text { Fugitive emlisslon, not classifled } \\
\text { Misc., not classitled }\end{array}$ \\
\hline Mining operations, & $\begin{array}{l}303000 \\
303011 \\
303012 \\
303013 \\
303014 \\
303023 \\
303024 \\
305010 \\
305019 \\
305020 \\
305021 \\
305022 \\
305024 \\
305025 \\
305026 \\
305031 \\
305032 \\
305033 \\
305040\end{array}$ & $\begin{array}{l}\text { Metal ore, bauxite } \\
\text { Metal ore, molybdenum } \\
\text { Metal ore, tltanlum ore } \\
\text { Metal ore, gold } \\
\text { Metal ore, barium ore } \\
\text { Metal ore, taconite Iron ore } \\
\text { Metal ore, low-muisture ore } \\
\text { Coal cleaning, thermal dryer minl } \\
\text { Nonmetallio minerals, phosphate rook } \\
\text { Nonmetallic minerals, stone quarrying } \\
\text { Nonmetallic minerals, salt } \\
\text { Nonmetallic rninerals, potash production } \\
\text { Nonmetallic minerals, magneslum carbonate } \\
\text { Nonmetallic minerals, sand/gravel } \\
\text { Nonmetallic minerals, diatomaceous earth } \\
\text { Nonmetallic minerals, asbestos } \\
\text { Nonmetallic minerals, asbestos milling } \\
\text { Nonmetallic minerals, vermiculite } \\
\text { Unspecified ore, see comment }\end{array}$ \\
\hline $\begin{array}{l}\text { Misc. Industrial } \\
\text { processes }\end{array}$ & $\begin{array}{l}\text { AS57 } \\
304005 \\
304020 \\
307005 \\
307007 \\
307008 \\
307020 \\
307030 \\
307888 \\
307999 \\
309001 \\
309002 \\
309003 \\
309010 \\
309011 \\
309015 \\
309016 \\
309020 \\
309025 \\
309030 \\
309040 \\
309060 \\
309888 \\
309999 \\
311001 \\
311002 \\
312999 \\
313070 \\
313999 \\
314009 \\
314010 \\
314011\end{array}$ & $\begin{array}{l}\text { Construction } \\
\text { Electrical equip., lead battery mig., overall process } \\
\text { Electrical equip., furnace electrode, calcinatlon } \\
\text { Wood products, wood press treat, creosote } \\
\text { Wood products, plywooci/particle board, veneer dryers } \\
\text { Wood products, sawmill operation, log debarking } \\
\text { Wood products, furniture mig., not classifled } \\
\text { Wood products, misc., woodwaste storage } \\
\text { Wood products, fugitive emission, not classifled } \\
\text { Wood products, misc., not classifled } \\
\text { Fabricated metals, iron/steel, not classifled } \\
\text { Fabricated metals, abrasive blasting of metal parts } \\
\text { Fabricated metals, abrasive cleaning of metal parts } \\
\text { Fabricated metals, electroplating, entire process } \\
\text { Fabricated metals, conversion coating, alkaline cleaning } \\
\text { Fabricated metals, chemical milling, of metal parts } \\
\text { Fabricated metals, pipe coating, asphalt dipping } \\
\text { Fabricated metals, can making operations, not classified } \\
\text { Fabricated metals, drums/barrels, drum cleaning } \\
\text { Fabricated metals, machining operations, grinding } \\
\text { Fabricated metals, metal deposition, metallizing wire } \\
\text { Fabricated metals, porcelain enamel, ceramic glaze } \\
\text { Fabricated metals, fugitive emission, not classifled } \\
\text { Fabricated metals, misc., not classifled } \\
\text { Construction, bldg. contractors, not classifled } \\
\text { Construction, spl. trade contract, not classifled } \\
\text { Machinery, misc., not classified } \\
\text { Electrical equip., windings reclamation, incinerator oven } \\
\text { Electrical equip., misc., not classified } \\
\text { Transportation equip., general processes, solder joint } \\
\text { Transportation equip., brake shoe debond, incinerator oven } \\
\text { Transportation equip., auto body salvage, body shredding }\end{array}$ \\
\hline
\end{tabular}


TABLE A.2 (Cont'd)

\begin{tabular}{|c|c|c|}
\hline Emission Source Group & $\begin{array}{l}\text { NAPAP } \\
\text { SCC }\end{array}$ & Desorlption \\
\hline $\begin{array}{l}\text { Mlso. Industrlal } \\
\text { prooesses(Cont'd) }\end{array}$ & $\begin{array}{l}314999 \\
315010 \\
315020 \\
320999 \\
330001 \\
330003 \\
330004 \\
330005 \\
330888 \\
399999\end{array}$ & $\begin{array}{l}\text { Transportatlon equip, miso, not olassifled } \\
\text { Miso. Industrles, photographlo equlp, photocopy maohine } \\
\text { Mlso, Industrles, hospltals, sterllizatlon } \\
\text { Leather products, mlso, not olasslfled } \\
\text { Textlle produots, general labrlos, not olassifled } \\
\text { Textlle products, carpet operatlons, not classifled } \\
\text { Textlle products, fabrlo flnlehing, not olassifled } \\
\text { Textlle products, apparel, not olassifled } \\
\text { Textlle products, fugitlve emission, not olassifled } \\
\text { Industrial process, miso, not olassilled }\end{array}$ \\
\hline $\begin{array}{l}\text { Oll and natural } \\
\text { gas extractlon }\end{array}$ & $\begin{array}{l}\text { AS108 } \\
310001 \\
310002 \\
310888 \\
404003\end{array}$ & $\begin{array}{l}\text { Crude oll and natural gas productlon flelds } \\
\text { Oll and gas prodn,, orude oll prodn, complete well } \\
\text { Oll and gas prodn., natural gas prodn, gas sweetening } \\
\text { Oll and gas prodn., fugltive emlsslon, not olassifled } \\
\text { Oll and gas prodn, orude oll storage, flxed roof tank }\end{array}$ \\
\hline $\begin{array}{l}\text { Organlo ohemloals } \\
\text { manufacture }\end{array}$ & $\begin{array}{l}\text { AS102 } \\
301001 \\
301006 \\
301019 \\
301031 \\
301034 \\
301042 \\
301043 \\
301050 \\
301091 \\
301100 \\
301112 \\
301120 \\
301121 \\
301124 \\
301125 \\
301126 \\
301127 \\
301132 \\
301133 \\
301137 \\
301140 \\
301152 \\
301153 \\
301156 \\
301157 \\
301158 \\
301167 \\
301169 \\
301174 \\
301176 \\
301181 \\
301190 \\
301195 \\
301197 \\
301202 \\
301205 \\
301206 \\
301210 \\
301211\end{array}$ & $\begin{array}{l}\text { Fugltive emlssions from synthetio organio ohem, mig. } \\
\text { Adlplo acld prod } \\
\text { Charcoal } \\
\text { Phthalio anhydrid } \\
\text { Terephthallo aold } \\
\text { Aniline } \\
\text { Lead alkyl-Na/Pb } \\
\text { Lead alkyls } \\
\text { Adhesives } \\
\text { Ketone production } \\
\text { Malelo anhydride } \\
\text { Elemental phosphorus } \\
\text { Formaldehyde } \\
\text { Organio dye/plgment } \\
\text { Chloroprene } \\
\text { Ethylene dichloride } \\
\text { Organohalogens } \\
\text { Fluorocarbons } \\
\text { Organic aclds production } \\
\text { Acetlo anhydride } \\
\text { Esters productlon } \\
\text { Acetylene production } \\
\text { Blsphenol a } \\
\text { Butadlene } \\
\text { Cumene } \\
\text { Cyclohexane } \\
\text { Cyolohexanone/cyo } \\
\text { Vinyl acetate } \\
\text { Ethylbenzene } \\
\text { Ethylene oxide } \\
\text { Glycerin (glycerl) } \\
\text { Toluene dilsocynt } \\
\text { Methyl methaorylt } \\
\text { Nitrobenzene } \\
\text { Ethylene production } \\
\text { Phenol } \\
\text { Propylene oxide } \\
\text { Styrene } \\
\text { Caprolactum } \\
\text { Linear alkylbenze }\end{array}$ \\
\hline
\end{tabular}


TABLE A.2 (Cont'd)

\begin{tabular}{|c|c|c|}
\hline Emlosion Source Group & $\begin{array}{l}\text { NAPAP } \\
\text { SCC }\end{array}$ & Desoriptlon \\
\hline $\begin{array}{l}\text { Organlo ohemioals } \\
\text { manufacture } \\
\text { (Cont'd) }\end{array}$ & $\begin{array}{l}301250 \\
301251 \\
301252 \\
301253 \\
301254 \\
301258 \\
301301 \\
301302 \\
301303 \\
301304 \\
301305 \\
301800 \\
301810 \\
301820 \\
301830 \\
301840 \\
407004 \\
407008 \\
407016 \\
407020 \\
407032 \\
407036 \\
407040 \\
407044 \\
407048 \\
407052 \\
407056 \\
407060 \\
407064 \\
407068 \\
407076 \\
407080 \\
407084 \\
407172 \\
407176 \\
407180 \\
407208 \\
407220 \\
407228 \\
407232 \\
407816 \\
407820 \\
407824 \\
407832 \\
407848 \\
407860 \\
407864 \\
407872 \\
407999 \\
408999\end{array}$ & 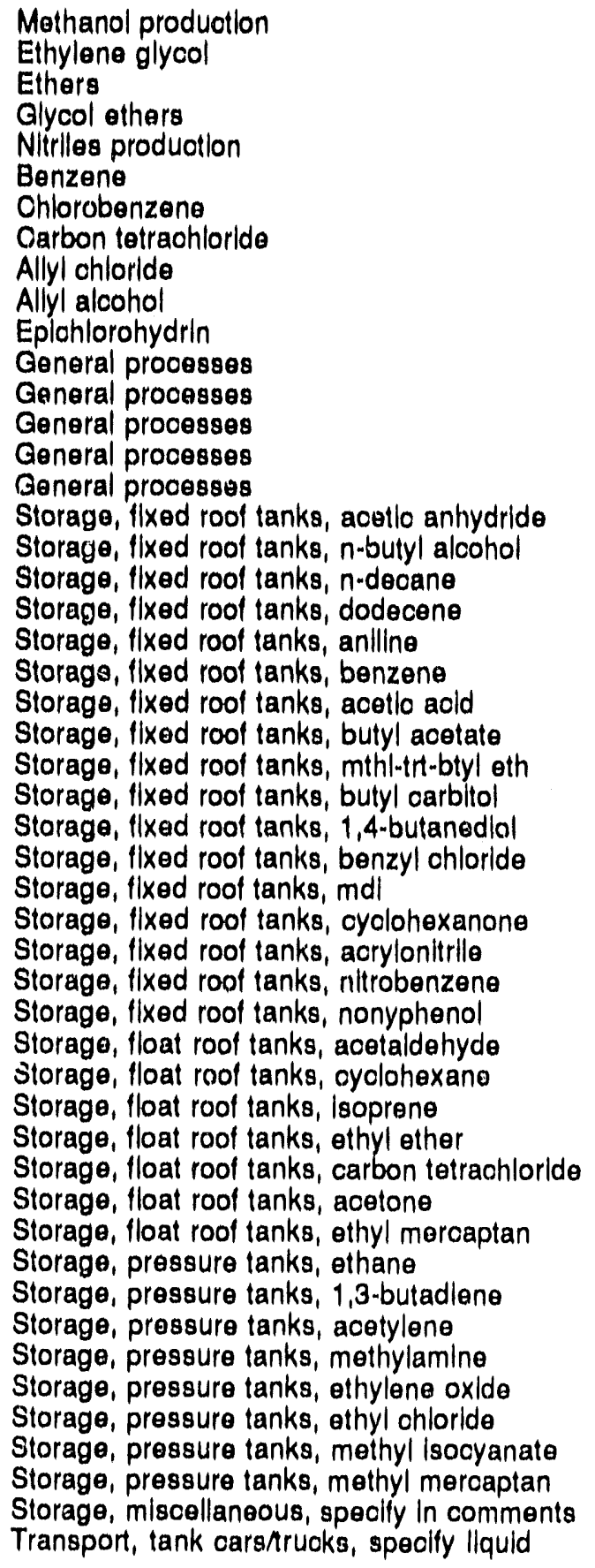 \\
\hline $\begin{array}{l}\text { Other ohemicals } \\
\text { manufaoture }\end{array}$ & $\begin{array}{l}\text { AS } 106 \\
\text { AS } 107 \\
301003 \\
301005 \\
301007 \\
301008\end{array}$ & $\begin{array}{l}\text { Prooess emissions from pharmaceutical mfg. } \\
\text { Prooess emissions from synthetlo-flbers mfg. } \\
\text { Agrloultural chemicals, ammonia } \\
\text { Carbon black, channel process } \\
\text { Inorganlo chemloals, chlorlne } \\
\text { Inorganto chemloals, chloro-alkall }\end{array}$ \\
\hline
\end{tabular}


TABLE A.2 (Cont'd)

\begin{tabular}{|c|c|c|}
\hline Emission Source Group & $\begin{array}{l}\text { NAPAP } \\
\text { SOCa }^{\mathrm{a}}\end{array}$ & Desoription \\
\hline $\begin{array}{l}\text { Other chemioals } \\
\text { manufaoture } \\
\text { (Cont'd) }\end{array}$ & $\begin{array}{l}301009 \\
301010 \\
301011 \\
301012 \\
301013 \\
301014 \\
301015 \\
301016 \\
301017 \\
301020 \\
301021 \\
301022 \\
301023 \\
301024 \\
301025 \\
301026 \\
301027 \\
301028 \\
301029 \\
301030 \\
301032 \\
301033 \\
301035 \\
301038 \\
301039 \\
301040 \\
301041 \\
301045 \\
301060 \\
301070 \\
301111 \\
301130 \\
301870 \\
301875 \\
301885 \\
301888 \\
301999 \\
30190099\end{array}$ & 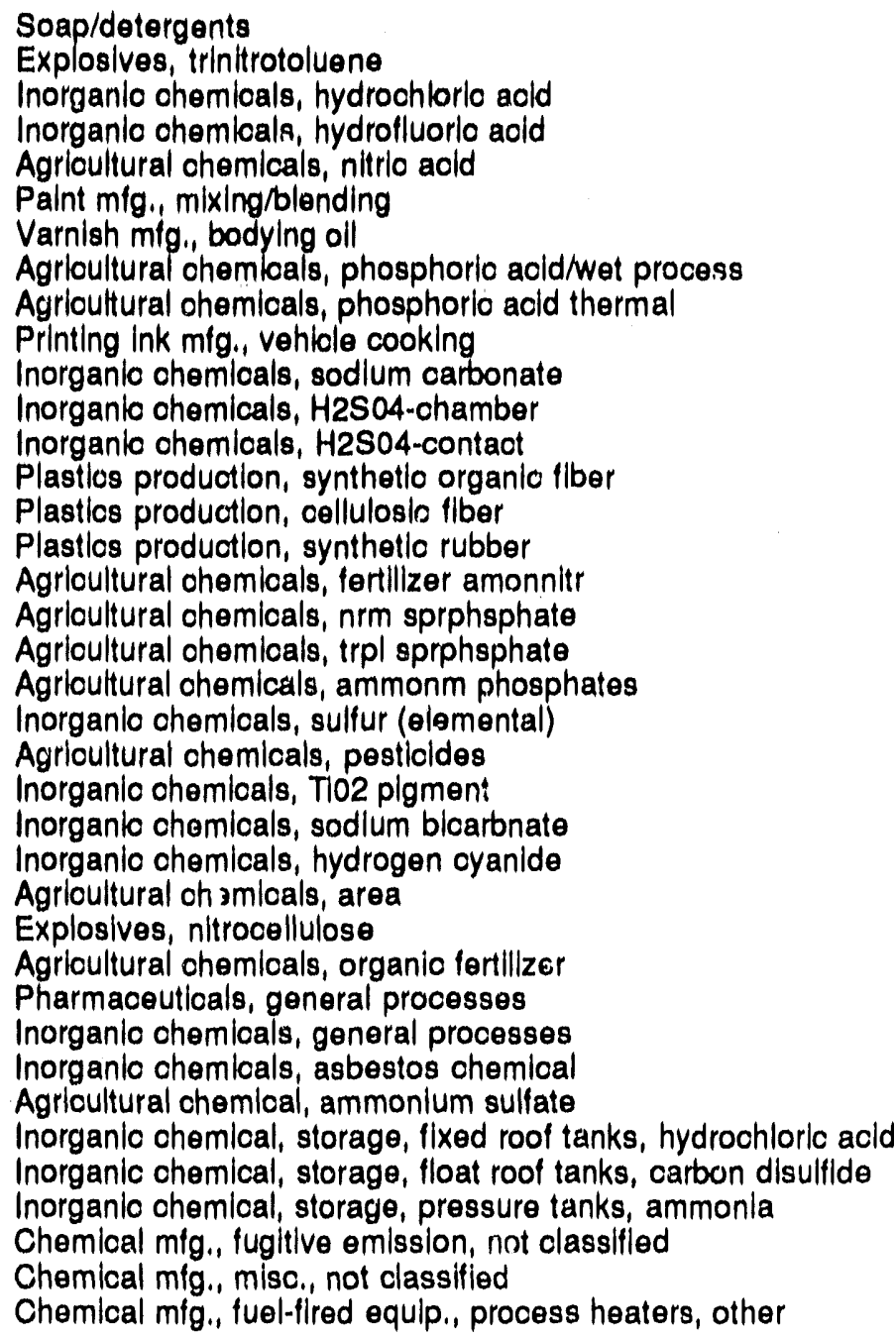 \\
\hline $\begin{array}{l}\text { Paper and pulp mills } \\
\text { operations }\end{array}$ & $\begin{array}{l}307001 \\
307002 \\
307003 \\
307004 \\
307011 \\
307013\end{array}$ & $\begin{array}{l}\text { Kraft pulping, digester/blow tank } \\
\text { Sulfite pulpling, digester/blow plt } \\
\text { Semichemical pulping, digester/blow plt } \\
\text { Pulpboard, paperboard } \\
\text { Paper coatling, extruslon coating } \\
\text { Mlso, paper prodn., insulation from }\end{array}$ \\
\hline Plastics production & $\begin{array}{l}\text { ASB1 } \\
301018 \\
308007\end{array}$ & $\begin{array}{l}\text { Rubber and plastlos mig. } \\
\text { Chemlcal mfg., plastlos production, polyvinyl } \\
\text { Rubber/plastlcs, fab. plastlc prodn., plastios machining }\end{array}$ \\
\hline $\begin{array}{l}\text { Petroleum product } \\
\text { storage and transfer }\end{array}$ & $\begin{array}{l}\text { AS103 } \\
403001 \\
403002 \\
403003 \\
403010 \\
403011\end{array}$ & $\begin{array}{l}\text { Bulk terminal and bulk plants } \\
\text { Storage, flxed roof tanks, breathing loss } \\
\text { Storage, float roof tanks, stand storage loss } \\
\text { Storage, var, vapor sp, tnks, working loss } \\
\text { Storage, flxed roof tanks, gasollne-RVP13 } \\
\text { Storage, float roof tanks, gasoline.AVP } 13\end{array}$ \\
\hline
\end{tabular}


TABLE A.2 (Cont'd)

\begin{tabular}{|c|c|c|}
\hline Emission Source Group & $\begin{array}{l}\text { NAPAP } \\
\text { SCCa }\end{array}$ & Desoription \\
\hline $\begin{array}{l}\text { Petroleum produot } \\
\text { storage and transfer } \\
\text { (Cont'd) }\end{array}$ & $\begin{array}{l}403012 \\
403888 \\
403999\end{array}$ & $\begin{array}{l}\text { Storage, var.vapor sp.tnks, gasollne-RVP } 13 \\
\text { Storage, fugitive emission, not classified } \\
\text { Storage, miso., not classifled }\end{array}$ \\
\hline Petroleum refining & $\begin{array}{l}\text { AS104 } \\
305001 \\
305002 \\
306002 \\
306003 \\
306004 \\
306005 \\
306006 \\
306007 \\
306008 \\
306009 \\
306010 \\
306011 \\
306012 \\
306014 \\
306015 \\
306099 \\
306100 \\
306888 \\
306999\end{array}$ & $\begin{array}{l}\text { Fugitive emissions from petroleum refinery operations } \\
\text { Asphatt roofing, asphalt blowing } \\
\text { Asphalt concrete, rotary dryer } \\
\text { Catalytic oracking } \\
\text { Catalytic oracking } \\
\text { Blowdown system } \\
\text { Fugitive HC emissions, process drains } \\
\text { Vacuum distillation } \\
\text { Cooling towers } \\
\text { Fugitive HC emissions, plpeline } \\
\text { Flares } \\
\text { Sludge converter } \\
\text { Asphalt blowing } \\
\text { Fluid osking } \\
\text { Petroleum coke } \\
\text { Bauxite burning } \\
\text { Inoinerators } \\
\text { Lube oll mfg., general } \\
\text { Fugitive emission, not classifled } \\
\text { Misc., not classifled }\end{array}$ \\
\hline Primary aluminum smelting & $\begin{array}{l}303001 \\
303002\end{array}$ & $\begin{array}{l}\text { Electro-reduction } \\
\text { Hydroxide calcing }\end{array}$ \\
\hline Primary copper smelting & 303005 & Multiple hearth \\
\hline $\begin{array}{l}\text { Primary lead and zinc } \\
\text { smelting }\end{array}$ & $\begin{array}{l}303010 \\
303030\end{array}$ & $\begin{array}{l}\text { Lead sintering } \\
\text { Zinc roasting }\end{array}$ \\
\hline $\begin{array}{l}\text { Other primary } \\
\text { metals smelting }\end{array}$ & $\begin{array}{l}303888 \\
303999 \\
304006 \\
304010\end{array}$ & $\begin{array}{l}\text { Fugitive emission, not classified } \\
\text { Miso., not classified } \\
\text { Magnesium, pot furnace } \\
\text { Nickel, flux furnace }\end{array}$ \\
\hline Printing operations & $\begin{array}{l}\text { AS80 } \\
360001 \\
405001 \\
405002 \\
405003 \\
405004 \\
405005 \\
405006 \\
405007 \\
405888\end{array}$ & $\begin{array}{l}\text { Graphic arts (printing) } \\
\text { Printing/publish, typesetting, lead remelting } \\
\text { Printing/publish, printing process, dryer } \\
\text { Printing/publish, printing process, letter press } \\
\text { Printing/publish, printing process, flexographic } \\
\text { Printing/publish, printing process, lithographic } \\
\text { Printing/publish, printing process, rotogravure } \\
\text { Printing/publish, printing process, ink mixing } \\
\text { Printing/publish, printing process, solvent storage } \\
\text { Printing/publish, fugitlive emission, not classified }\end{array}$ \\
\hline $\begin{array}{l}\text { Rubber and misc. } \\
\text { plastics manufacture }\end{array}$ & $\begin{array}{l}308001 \\
308005 \\
308006 \\
308999 \\
330002\end{array}$ & $\begin{array}{l}\text { Tire mfg., undertread and side } \\
\text { Tire retreading, tire butfing } \\
\text { Misc. rubber production, not classified } \\
\text { Misc., not classified } \\
\text { Rubberized fabric, impregnation }\end{array}$ \\
\hline Secondary load refining & $\begin{array}{l}304004 \\
304040\end{array}$ & $\begin{array}{l}\text { Secondary metals, kettle refining } \\
\text { Secondary metals, metallic coating, lead cable coating }\end{array}$ \\
\hline
\end{tabular}


TABLE A.2 (Cont'd)

\begin{tabular}{|c|c|c|}
\hline Emission Source Group & $\begin{array}{l}\text { NAPAP } \\
\text { SCC }^{a}\end{array}$ & Description \\
\hline $\begin{array}{l}\text { Other secondary metals } \\
\text { smelting and refining }\end{array}$ & $\begin{array}{l}304001 \\
304002 \\
304008 \\
304022 \\
304049 \\
304050 \\
304888 \\
304999\end{array}$ & $\begin{array}{l}\text { Secondary aluminum, sweating furnace } \\
\text { Secondary copper, electric induction furnace } \\
\text { Secondary zinc, retort furnace } \\
\text { Metal heat treating, furnace } \\
\text { Misc. cast/fabrication, wax burnout oven } \\
\text { Misc. cast/fabrication, not classified } \\
\text { Fugitive emission, not classified } \\
\text { Misc., not classified }\end{array}$ \\
\hline Surface coating & $\begin{array}{l}\text { AS82 } \\
\text { AS83 } \\
\text { AS84 } \\
\text { AS85 } \\
\text { AS86 } \\
\text { AS87 } \\
\text { AS88 } \\
\text { AS89 } \\
\text { AS90 } \\
\text { AS91 } \\
\text { AS92 } \\
\text { AS93 } \\
402001 \\
402002 \\
402003 \\
402004 \\
402005 \\
402006 \\
402007 \\
402008 \\
402009 \\
402010 \\
402011 \\
402013 \\
402014 \\
402015 \\
402016 \\
402017 \\
402018 \\
402019 \\
402020 \\
402021 \\
402022 \\
402023 \\
402024 \\
402025 \\
402026 \\
402888 \\
402900 \\
402999\end{array}$ & $\begin{array}{l}\text { Architectural coating } \\
\text { Auto body repair } \\
\text { Motor vehicle mig. } \\
\text { Paper coating } \\
\text { Fabricated metals } \\
\text { Machinery mfg. } \\
\text { Furniture mfg. } \\
\text { Flat wood products } \\
\text { Other transportation equipment mfg. } \\
\text { Electrical equip. mig. } \\
\text { Ship building and repairing } \\
\text { Misc. industrial mig. } \\
\text { Organic solvent, paint-general } \\
\text { Organic solvent, paint-general } \\
\text { Organic solvent, varnish/shellac } \\
\text { Organic solvent, lacquer } \\
\text { Organic solvent, enamel } \\
\text { Organic solvent, primer } \\
\text { Organic solvent, adhesive } \\
\text { Organic solvent, coating oven } \\
\text { Organic solvent, thinning solvent } \\
\text { Organic solvent, oven heater } \\
\text { Organic solvent, fabric coating } \\
\text { Organic solvent, paper coating } \\
\text { Organic solvent, large appliances } \\
\text { Organic solvent, magnet wire } \\
\text { Organic solvent, autos/light trucks } \\
\text { Organic solvent, can coating } \\
\text { Organic solvent, coil coating } \\
\text { Organic solvent, wood furniture } \\
\text { Organic solvent, metal furnituis } \\
\text { Organic solvent, flatwood products } \\
\text { Organic solvent, plastic parts } \\
\text { Organic solvent, large ships } \\
\text { Organic solvent, large aircraft } \\
\text { Organic solvent, misc. metal parts } \\
\text { Organic solvent, steel drums } \\
\text { Organic solvent, fugitive emission } \\
\text { Organic solvent, flares } \\
\text { Organic solvent, ....sc. }\end{array}$ \\
\hline
\end{tabular}

aNAPAP SCC $=$ Source classification code used in the National Acid Precipitation Assessment Program. The designation AS before a number indicates that the source is an area source. All numbers that are not preceded by AS refer to point sources. 
TABLE A.3 Emission Source Codes for Miscellaneous Sectors

\begin{tabular}{|c|c|c|}
\hline Emission Source Group & $\begin{array}{l}\text { NAPAP } \\
\text { SCC }^{\mathbf{a}}\end{array}$ & Description \\
\hline Asphalt paving operations & AS101 & Cutback operation \\
\hline Forest wild fires & AS60 & Forest wild fires \\
\hline $\begin{array}{l}\text { Nonindustrial organic } \\
\text { solvent use and disposal }\end{array}$ & $\begin{array}{l}\text { AS99 } \\
\text { AS100 } \\
\text { AS109 }\end{array}$ & $\begin{array}{l}\text { Minor industrial combustion sources, other } \\
\text { Publicly owned treatment works } \\
\text { Hazardous waste treatment, storage, and disposal facilities }\end{array}$ \\
\hline Other burning & $\begin{array}{l}\text { AS61 } \\
\text { AS62 } \\
\text { AS64 }\end{array}$ & $\begin{array}{l}\text { Managed burning, prescribed } \\
\text { Agricultural field burning } \\
\text { Structural fires }\end{array}$ \\
\hline $\begin{array}{l}\text { Other misc. } \\
\text { sources }\end{array}$ & $\begin{array}{l}\text { AS58 } \\
\text { AS59 } \\
\text { AS63 } \\
501006 \\
501007 \\
501900 \\
502006 \\
502900 \\
503006 \\
503007 \\
503008 \\
503009 \\
503900\end{array}$ & $\begin{array}{l}\text { Misc., wind erosion } \\
\text { Land tilling } \\
\text { Frost control, orchard heaters } \\
\text { Solid waste disposal, government, fire fighting } \\
\text { Solid waste disposal, government, sewage treatment } \\
\text { Solid waste disposal, government, aux. fuel/no emissions } \\
\text { Solid waste disposal, comm./inst., landfill durnp } \\
\text { Solid waste disposal, comm./inst., aux. fuel/no emissions } \\
\text { Solid waste disposal, industrial, landfill dump } \\
\text { Solid waste disposal, iridustrial, liquid waste } \\
\text { Solid waste disposal, industrial, surface impoundment } \\
\text { Solid waste disposal, industrial } \\
\text { Solid waste disposal, industrial, aux. fuel/no emissions }\end{array}$ \\
\hline Solid waste incineration & $\begin{array}{l}\text { AS21 } \\
\text { AS22 } \\
\text { AS23 } \\
501001 \\
501005 \\
502001 \\
502003 \\
502005 \\
503001 \\
503005\end{array}$ & $\begin{array}{l}\text { On-site incineration, residential } \\
\text { On-site incineration, industrial } \\
\text { On-site incineration, comm./inst. } \\
\text { Solid waste disposal, government, municipal } \\
\text { Solid waste disposal, government, other incinerator } \\
\text { Solid waste disposal, comm./inst., incineration-general } \\
\text { Solid waste disposal, comm./inst., apartment } \\
\text { Solid waste disposal, comm./inst., incineration-special } \\
\text { Solid waste disposal, industrial, incineration } \\
\text { Solid waste disposal, industrial, incinerator }\end{array}$ \\
\hline Solid waste open burning & $\begin{array}{l}\text { AS24 } \\
\text { AS25 } \\
\text { AS26 } \\
501002 \\
502002 \\
503002\end{array}$ & $\begin{array}{l}\text { Open burning, residential } \\
\text { Open burning, industrial } \\
\text { Open burning, comm./inst. } \\
\text { Solid waste disposal, government, open burning dump } \\
\text { Solid waste disposal, comm./inst., open burning } \\
\text { Solid waste disposal, industrial, open burning }\end{array}$ \\
\hline
\end{tabular}

aNAPAP SCC = Source classification code used in the National Acid Precipitation Assessmerti Frogram. The designation AS before a number indicates that the source is an area source. All numbers inat are not preceded by AS refer to point sources. 
TABLE A.4 Emission Source Codes for the Transportation Sectora

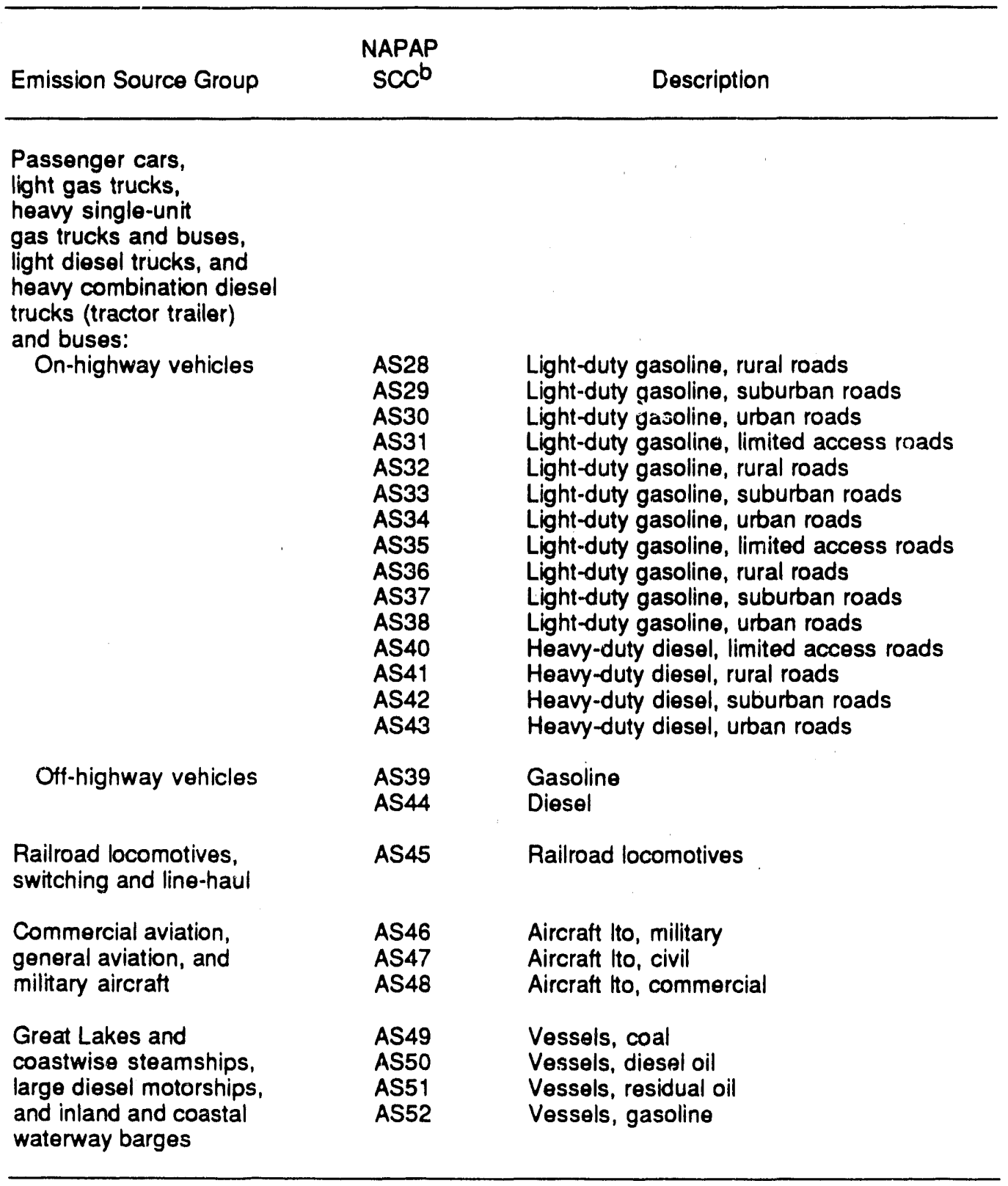

aThe MSCET methodology for the transportation sector does not use the NAPAP inventory data except for the "off-highway vehicles" emission source category. These SCC assignments are provided for completeness.

bNAPAP SCC = Source classification code used in the National Acid Precipitation Assessment Program. 
TABLE A.5 Sources of Data on Annual Emission Trends for the Fuel Combustion Sectors

\begin{tabular}{|c|c|c|}
\hline Emission Source Group & Pollutant & $\begin{array}{l}\text { Uata Source: } \\
\text { EPA Trends } \\
\text { unless noted }\end{array}$ \\
\hline Commercial/institutional coal & $\begin{array}{l}\mathrm{NO}_{x} \\
\mathrm{SO}_{2} \\
\text { VOC }\end{array}$ & $\begin{array}{l}\text { Table } 20 \\
\text { Table } 19 \\
\text { rable } 21\end{array}$ \\
\hline Commercial/institutional fuel oil & $\begin{array}{l}\mathrm{NO}_{x} \\
\mathrm{SO}_{2} \\
\mathrm{VOC}\end{array}$ & $\begin{array}{l}\text { Table } 20 \\
\text { Table } 19 \\
\text { Table } 21\end{array}$ \\
\hline Commercial/institutional natural gas & $\begin{array}{l}\mathrm{NO}_{x} \\
\mathrm{SO}_{2} \\
\text { VOC }\end{array}$ & $\begin{array}{l}\text { Table } 20 \\
\text { Table } 19 \\
\text { Table } 21\end{array}$ \\
\hline Commercial/institutional other & All & Constant at 1985 value \\
\hline Residential coal & $\begin{array}{l}\mathrm{NO}_{x} \\
\mathrm{SO}_{2} \\
\text { VOC }\end{array}$ & $\begin{array}{l}\text { Table } 20 \\
\text { Table } 19 \\
\text { Table } 21\end{array}$ \\
\hline Residential fuel oil & $\begin{array}{l}\mathrm{NO}_{x} \\
\mathrm{SO}_{2} \\
\text { VOC }\end{array}$ & $\begin{array}{l}\text { Table } 20 \\
\text { Table } 19 \\
\text { Table } 21\end{array}$ \\
\hline Residential natural gas & $\begin{array}{l}\mathrm{NO}_{x} \\
\mathrm{SO}_{2}\end{array}$ & $\begin{array}{l}\text { Table } 20 \\
\text { Table } 19\end{array}$ \\
\hline Residential wood & $\begin{array}{l}\mathrm{NO}_{x} \\
\mathrm{SO}_{2} \\
\text { VOC }\end{array}$ & $\begin{array}{l}\text { Table } 20 \\
\text { Table } 19 \\
\text { Table } 21\end{array}$ \\
\hline Electric utility - All ESGS & All & $\begin{array}{l}\text { EIA Form } 767 \text {, EIA Form } 759 \text {, and } \\
\text { FERC Form } 423\end{array}$ \\
\hline Industrial coal & $\begin{array}{l}\mathrm{NO}_{x} \\
\mathrm{SO}_{2} \\
\mathrm{VOC}\end{array}$ & $\begin{array}{l}\text { Table } 20 \\
\text { Table } 19 \\
\text { Table } 21\end{array}$ \\
\hline Industrial fuel oil & $\begin{array}{l}\mathrm{NO}_{x} \\
\mathrm{SO}_{2} \\
\text { VOC }\end{array}$ & $\begin{array}{l}\text { Table } 20 \\
\text { Table } 19 \\
\text { Table } 21\end{array}$ \\
\hline Industrial natural gas & $\begin{array}{l}\mathrm{NO}_{x} \\
\mathrm{SO}_{2} \\
\text { VOC }\end{array}$ & $\begin{array}{l}\text { Table } 20 \\
\text { Table } 19 \\
\text { Table } 21\end{array}$ \\
\hline
\end{tabular}


TABLE A.5 (Cont'd)

\begin{tabular}{lll}
\hline & & $\begin{array}{l}\text { Data Sources: } \\
\text { EPA Trends } \\
\text { Unless noted }\end{array}$ \\
\hline Industrial other & Pollutant & \\
& $\mathrm{NO}_{x}$ & Table 20 \\
& $\mathrm{SO}_{2}$ & Table 19 \\
VOC & Table 21 \\
\hline
\end{tabular}

aEPA Trends $=$ UJ.S. Environmental Protection Agency, National Air Pollutant Emission Estimates, up to latest one available; EIA $=U . S$. Department of Energy, Energy Information Administration. 
TABLE A.6 Sources of Data on Annual Emission Trends for the Industrial Process Sector

\begin{tabular}{|c|c|c|}
\hline Emission Source Group & Pollutant & Data Source ${ }^{\mathbf{a}}$ \\
\hline Cement production $b$ & $\begin{array}{l}\mathrm{NO}_{x} \\
\mathrm{SO}_{2} \\
\mathrm{VOC}\end{array}$ & $\begin{array}{l}\text { T: Table 25, cement } \\
\text { T: Table 24, cement } \\
\text { Constant at } 1985 \text { NAPAP values }\end{array}$ \\
\hline Degreasing ${ }^{c}$ & $\begin{array}{l}\mathrm{NOX} \\
\mathrm{SO}_{2} \\
\mathrm{VOC}\end{array}$ & $\begin{array}{l}\text { Constant at } 1985 \text { NAPAP values } \\
\text { Constant at } 1985 \text { NAPAP values } \\
\mathrm{T} \text { : Table 26, degreasing }\end{array}$ \\
\hline Dry cleaning ${ }^{c}$ & VOC & T: Table 26, dry cleaning \\
\hline Food processing/ & $\mathrm{NO}_{x}$ & Constant at 1985 NAPAP values \\
\hline agricultural operations $c$ & $\begin{array}{l}\mathrm{SO}_{2} \\
\mathrm{VOC}\end{array}$ & $\begin{array}{l}\text { Constant at } 1985 \text { NAPAP values } \\
T: \text { Table 26, food and beverages }\end{array}$ \\
\hline Gasoline marketing ${ }^{c}$ & $\begin{array}{l}\mathrm{NOx} \\
\mathrm{SO}_{2} \\
\text { VOC }\end{array}$ & $\begin{array}{l}\text { Constant at } 1985 \text { NAPAP values } \\
\text { Constant at } 1985 \text { NAPAP values } \\
\text { T: Table 26, petroleum product storage and transfer }\end{array}$ \\
\hline Glass manufacturing & $\begin{array}{l}\mathrm{NOx} \\
\mathrm{SO}_{2} \\
\mathrm{VOC}\end{array}$ & $\begin{array}{l}\text { T: Table } 25, \text { glass } \\
\text { T: Table } 24, \text { glass } \\
\text { Constant at } 1985 \text { NAPAP values }\end{array}$ \\
\hline Industrial organic solvent & NOX & Constant at 1985 NAPAP values \\
\hline use, misc. ${ }^{c}$ & $\begin{array}{l}\mathrm{SO}_{2} \\
\mathrm{VOC}\end{array}$ & $\begin{array}{l}\text { Constant at } 1985 \text { NAPAP values } \\
\text { T: Table 26, other organic solvent use }\end{array}$ \\
\hline Iron and steel production & $\begin{array}{l}\mathrm{NOX} \\
\mathrm{SO}_{2} \\
\mathrm{VOC}\end{array}$ & $\begin{array}{l}\text { T: Table 25, iron and steel } \\
\text { T: Table 24, iron and steel } \\
\text { T: Table 26, iron and steel }\end{array}$ \\
\hline Lime manufacturing & $\begin{array}{l}\mathrm{NO}_{x} \\
\mathrm{SO}_{2} \\
\mathrm{VOC}\end{array}$ & $\begin{array}{l}\text { Table 25, lime } \\
\text { Table 24, lime } \\
\text { Constant at } 1985 \text { NAPAP values }\end{array}$ \\
\hline Mineral products processing & All & FRB: Clay, glass and stone products \\
\hline Mining operations & All & FRB: Stone and earth minerals \\
\hline Misc. Industrial processes & All & Constant at 1985 NAPAP values \\
\hline Oil and natural gas extraction & $\begin{array}{l}\mathrm{NO}_{x} \\
\mathrm{SO}_{2} \\
\mathrm{VOC}\end{array}$ & $\begin{array}{l}\text { MER: Crude oll, total domestic fleld production } \\
\mathrm{T}: \text { Table 24, natural gas production } \\
\mathrm{T}: \text { Table 26, crude oll production, storage and transfer }\end{array}$ \\
\hline Organic chemicals manufacture & $\begin{array}{l}\mathrm{NO}_{x} \\
\mathrm{SO}_{2} \\
\mathrm{VOC}\end{array}$ & $\begin{array}{l}\text { T: Table } 25 \text {, organic chemicals } \\
\text { SCB: Methanol production } \\
T: \text { Table 26, organic chemicals }\end{array}$ \\
\hline Other chemicals manufacture & $\begin{array}{l}\mathrm{NO}_{X} \\
\mathrm{SO}_{2} \\
\mathrm{VOC}\end{array}$ & $\begin{array}{l}\text { T: Table 25, nitric acid and ammonia } \\
\text { T: Table 24, sulfuric acid and carbon black } \\
\text { T: Table 26, other chemicals }\end{array}$ \\
\hline
\end{tabular}


TABLE A.6 (Cont'd)

\begin{tabular}{|c|c|c|}
\hline Emission Source Group & Pollutant & Data Souroea \\
\hline Paper and pulp mills operations & $\begin{array}{l}\mathrm{NO}_{x} \\
\mathrm{SO}_{2} \\
\text { VaC }\end{array}$ & $\begin{array}{l}\text { T: Table 25, pulp mills } \\
\text { T: Table 24, pulp mills } \\
\text { SCB: Wood pulp produotion, total }\end{array}$ \\
\hline Plastics production & $\begin{array}{l}\mathrm{NO}_{x} \\
\mathrm{SO}_{2} \\
\text { VOC }\end{array}$ & $\begin{array}{l}\text { SCB: Polyvinyl chlorides } \\
\text { SCB: Polyvinyl ohlorides } \\
\text { T: Table 26, plastlos }\end{array}$ \\
\hline Petroleum product storage & $\mathrm{NO}_{x}$ & Constant at 1985 NAPAP values \\
\hline and transfer ${ }^{\mathrm{C}}$ & $\begin{array}{l}\mathrm{SO}_{2} \\
\mathrm{VOC}\end{array}$ & $\begin{array}{l}\text { Constant at } 1985 \text { NAPAP values } \\
\text { T: Table 26, petroleum product, storage and transter }\end{array}$ \\
\hline Petroleum refining & $\begin{array}{l}\mathrm{NO}_{x} \\
\mathrm{SO}_{2} \\
\text { VOC }\end{array}$ & $\begin{array}{l}\text { T: Table 25, petroleum refining } \\
\text { T: Table 24, petroleum refining } \\
\text { T: Table 26, petroleum refining }\end{array}$ \\
\hline Primary aluminum smelting $d$ & $\begin{array}{l}\mathrm{NO}_{x} \\
\mathrm{SO}_{2} \\
\text { VOC }\end{array}$ & $\begin{array}{l}\text { Constant at } 1985 \text { NAPAP values } \\
\text { T: Table 24, primary aluminum } \\
\text { Constant at } 1985 \text { NAPAP values }\end{array}$ \\
\hline Primary copper smelting & $\begin{array}{l}\mathrm{NO}_{x} \\
\mathrm{SO}_{2} \\
\text { VOC }\end{array}$ & $\begin{array}{l}\text { SCB: Copper refined from primary materials } \\
\text { ANL: Plant emissions inventory } \\
\text { Constant at } 1985 \text { NAPAP values }\end{array}$ \\
\hline Primary lead and $z$ inc smelting & $\begin{array}{l}\mathrm{NO}_{x} \\
\mathrm{SO}_{2} \\
\text { VOC }\end{array}$ & $\begin{array}{l}\text { Constant at } 1985 \text { NAPAP values } \\
\text { T: Table 24, primary lead and zine } \\
\text { Constant at } 1985 \text { NAPAP values }\end{array}$ \\
\hline Other primary metals smelting & All & FRB: Primary metals \\
\hline Printing operations ${ }^{c}$ & $\begin{array}{l}\mathrm{NO}_{x} \\
\mathrm{SO}_{2} \\
\text { VOC }\end{array}$ & $\begin{array}{l}\text { Constant at } 19 n \pi \text { NAPAP values } \\
\text { Constant at } 1985 \text { NAPAP values } \\
\text { T: Table 26, graphic arts }\end{array}$ \\
\hline Rubber and misc. & $\mathrm{NO}_{x}$ & Constant at 1985 NAPAP values \\
\hline plastics manufacture ${ }^{\mathrm{C}}$ & $\begin{array}{l}\mathrm{SO}_{2} \\
\mathrm{VOC}\end{array}$ & $\begin{array}{l}\text { Constant at } 1985 \text { NAPAP values } \\
\text { T: Table 26, rubber tires }\end{array}$ \\
\hline Secondary lead refining ${ }^{c}$ & $\begin{array}{l}\mathrm{NO}_{x} \\
\mathrm{SO}_{2} \\
\mathrm{VOC}\end{array}$ & $\begin{array}{l}\text { Constant at } 1985 \text { NAPAP values } \\
\text { T: Table 24, secondary lead } \\
\text { Constant at } 1985 \text { NAPAP values }\end{array}$ \\
\hline $\begin{array}{l}\text { Other secondary metals } \\
\text { smelting and refining }\end{array}$ & All & FRB: Secondary nonferrous metals \\
\hline
\end{tabular}


TABLE A.6 (Cont'd)
Emission Source Group
Pollutant
Data Source ${ }^{a}$

Surface coating ${ }^{\circ}$

$\begin{array}{ll}\mathrm{NO}_{x} & \text { Constant at } 1985 \text { NAPAP values } \\ \mathrm{SO}_{2} & \text { Constant at } 1985 \text { NAPAP values } \\ \text { VOC } & \text { T: Table 26, surface coating }\end{array}$

aT - U.S. Environmental Protection Agency, National Air Pollutant Emission Estimates, up to latest one avallable; SCB = U.S. Department of Commerce, Bureau of Economic Analysis, Survey of Current Business, up to latest one avallable; FRB = U.S. Department of Commerce, Federal Reserve Board, Industrial Production Index, up to latest one avallable; ANL = Argonne National Laboratory (see Sec. 7 of main report).

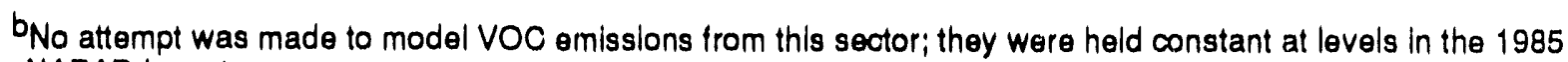
NAPAP Inventory.

'Emissions from this source group are primarily VOC. No attempt was made to model non-VOC emissions from this sector; they were held constant at levels in the 1985 NAPAP inventory.

dEmisstons from this source group are primarlly $\mathrm{SO}_{2}$. No attempt was made to model non- $\mathrm{SO}_{2}$ emissions from this sector; they were held constant at levels in the 1985 NAPAP Inventory. 
TABLE A.7 Sources of Data on Annual Emission Trends for Miscellaneous Sectors

\begin{tabular}{|c|c|c|}
\hline Emission Source Group & Pollutant & Data Source ${ }^{a}$ \\
\hline Asphatt paving operations $b$ & VOC & SCB: Asphalt production \\
\hline Forest wild fires & $\begin{array}{l}\mathrm{NO}_{x} \\
\mathrm{SO}_{2} \\
\text { VOC }\end{array}$ & $\begin{array}{l}\text { T: Table 9, forest fires } \\
\text { T: Table } 8 \text {, forest fires } \\
\text { T: Table 10, forest fires }\end{array}$ \\
\hline $\begin{array}{l}\text { Nonindustrlal organlo solvent } \\
\text { use and disposal }\end{array}$ & $\begin{array}{l}\mathrm{NO}_{x} \\
\mathrm{SO}_{2} \\
\mathrm{VOC}\end{array}$ & $\begin{array}{l}\text { T: Table 9, miso, organic solvent } \\
\text { T: Table 8, misc. organic solvent } \\
\text { T: Table 10, misc. organic solvent }\end{array}$ \\
\hline Other burning & $\begin{array}{l}\mathrm{NO}_{x} \\
\mathrm{SO}_{2} \\
\text { VOC }\end{array}$ & $\begin{array}{l}\text { T: Table 9, misc. other burning } \\
\text { T: Table 8, misc. other burning } \\
\text { T: Table 10, misc, other burning }\end{array}$ \\
\hline Other mlsc. sources & $\begin{array}{l}\mathrm{NO}_{x} \\
\mathrm{SO}_{2} \\
\text { VOC }\end{array}$ & $\begin{array}{l}\text { T: Table 9, solld waste total } \\
\text { T: Table 8, solid waste total } \\
\text { T: Table 10, solld waste total }\end{array}$ \\
\hline Solld waste Inolneration & $\begin{array}{l}\mathrm{NO}_{x} \\
\mathrm{SO}_{2} \\
\mathrm{VOC}\end{array}$ & $\begin{array}{l}\text { T: Table 9, solld waste disposal incineration } \\
\text { T: Table 8, solld waste disposal Inoineration } \\
\text { T: Table 10, solld waste dlsposal Incineration }\end{array}$ \\
\hline Solld waste open burning & $\begin{array}{l}\mathrm{NO}_{x} \\
\mathrm{SO}_{2} \\
\mathrm{VOC}\end{array}$ & $\begin{array}{l}\text { T: Table 9, solid waste disposal, open burning } \\
\text { T: Table 8, solid waste disposal, open burning } \\
\text { T: Table 10, solld waste dlsposal, open burning }\end{array}$ \\
\hline
\end{tabular}

aT - U.S. Environmental Protection Agency, National Air Pollutant Emission Estimates, up to latest one avallable; SCB $=$ U.S. Department of Commerce, Bureau of Economic Analysis, Survey of Current Business, up to latest one avaliable.

bEmlssions from this source are primarily VOC. No attempt was made to model non-VOC emlssions from this sector; they were heid constant at levels in the 1985 NAPAP inventory. 
TABLE A.8 Souroes of Data on Annual Emission Trends for the Transportation Sector

\begin{tabular}{lll}
\hline Emission Source Group & Pollutant & Data Source a \\
\hline On-highway sources -- all ESGs & All & FHWA Highway Statistics \\
OHf-highway sources -- all ESGs & All & DOE fuel consumption data \\
\hline
\end{tabular}

aFHWA - Federal Highway Administration; DOE = Department of Energy, 
TABLE A.9 Sources of Data on Monthly Emlssion Trends for the Fuel Combustion Sectors

\begin{tabular}{|c|c|c|}
\hline Emission Source Group & Pollutant & Data Sourcea \\
\hline Commerclal//nstitutlonal coal & All & QCR: State rosidentlal-commercial coal \\
\hline Commerclal/Institutional fuel oll & All & State population-weighted heating degree days \\
\hline Commercla//Institutional natural gas & All & $\begin{array}{l}\text { NGM: National gas deliveries to commercial consumers } \\
\text { by state }\end{array}$ \\
\hline Commerclal/nstitutional other & All & State populatlon-weighted heating degree days \\
\hline Residentlal coal & All & State population-welghted heating degree days \\
\hline Residential natural gas & $\mathrm{NO}_{x} \mathrm{SO}_{2}$ & $\begin{array}{l}\text { NGM: National gas dellverles to commerolal consumers } \\
\text { by state }\end{array}$ \\
\hline Residential fuel oll & All & State population*weighted heating degree days \\
\hline Residentlal other & All & State population-weighted heating degree days \\
\hline Electric utillty -- all ESGs & All & EIA Form 767 or EIA Frorm 759 \\
\hline Industrial coal & All & MER: Coal consumptlon by end-use sector \\
\hline Industrial fuel oll & All & MER: Petroleum consumption by Industrial sector \\
\hline Industrial natural gas & All & $\begin{array}{l}\text { NGM: National gas dellverles to commercial consumers } \\
\text { by state }\end{array}$ \\
\hline Industrial other & All & FRB: Industrial productlon Index (nonseasonally adjusted) \\
\hline
\end{tabular}

aFRB - U.S. Department of Commerce, Federal Reserve Board, Industrial Production Index, up to latest one avallable; MER = U.S. Department of Energy, Energy Information Administration, Monthly Energy Revlew, up to latest one avallable; QCR = U.S. Department of Energy, Energy Informatlon Administration, Quarterly Coal Report, up to latest one avallable; NGM $=$ U.S. Department of Energy, Energy Information Administration, Natural Gas Monthly, up to latest one available. 
TABLE A.10 Sources of Data on Monthly Emlssion Trends for the Industrial Process Sector

\begin{tabular}{|c|c|c|}
\hline Emlasion Source Group & Pollutant & Data Sourcea \\
\hline $\begin{array}{l}\text { Coment } \\
\text { manulaoturing }\end{array}$ & All & SCB: Portland coment shlpments \\
\hline Degreasing & All & Evenly diatrlbuted \\
\hline Dry oleaning & Voo & Evenly distributed \\
\hline $\begin{array}{l}\text { Food processing/ } \\
\text { agrloultural operations }\end{array}$ & All & FRB: loods (nonseasonally adjusted) \\
\hline Gasoline marketing & All & HWS: State sales of hlghway gasollne \\
\hline Glass manufacturing & All & SCB: Glass containers produotion \\
\hline $\begin{array}{l}\text { Industrial organio } \\
\text { solvent use, miso. }\end{array}$ & All & Evenly dlatrlbuted \\
\hline Iron and steol production & All & SCB: Steol production \\
\hline Lime manufacturing & All & SCB: shlpments-brlok, unglazed \\
\hline Mineral produots processing & All & FRB: Clay, glass, and stone produots \\
\hline Mining operations & All & FRB: Stone and earth minerals \\
\hline Mlso. Industrlal procosses & All & Evenly dlstrlbuted \\
\hline Oll and natural gas extractlon & $\begin{array}{l}\mathrm{NO}_{x} \\
\mathrm{SO}_{2} \\
\mathrm{VOC}\end{array}$ & $\begin{array}{l}\text { MER: Crude oll, total domestio field production } \\
\text { MER: Natural gas, marketed produotion, wet } \\
\text { MER: Crude oll, total domestio field production }\end{array}$ \\
\hline Organlo ohemloals manufacture & All & SCB: Methanol production \\
\hline Other ohemicals manufaoture & $\begin{array}{l}\mathrm{NO}_{x} \\
\mathrm{SO}_{2} \\
\mathrm{VOC}\end{array}$ & $\begin{array}{l}\text { SCB: Nitrlo acid and ammonla (weighted composite) } \\
\text { SCB: Sulfur and sulfurlo acid productlon (welghted } \\
\text { composite) } \\
\text { FRB: Chemlcal produots (nonseasonally adjusted) }\end{array}$ \\
\hline Paper and pulp mills operations & All & SCB: woodpulp production, total \\
\hline Plastios productlon & All & SCB: Polyvinyl ohlorldes \\
\hline $\begin{array}{l}\text { Petroleum product } \\
\text { storage and transier }\end{array}$ & All & $\begin{array}{l}\text { MER: Finished motor gasoline supply and disposition } \\
\text { product }\end{array}$ \\
\hline Petroleum refining & All & MER: Crude oll supply and dispositlon, refinery Inputs \\
\hline Primary aluminum smelting & All & SCB: Aluminum productlon, primary \\
\hline Primary copper smelting & $\begin{array}{l}\mathrm{NO}_{x} \\
\mathrm{SO}_{2} \\
\text { VOC }\end{array}$ & $\begin{array}{l}\text { SCB: Copper production, primary } \\
\text { ANL: Plant emisions inventory } \\
\text { SCB: Copper production, primary }\end{array}$ \\
\hline Primary lead and zino smelling & All & SCB: Lead and zinc production (welghted composite) \\
\hline
\end{tabular}


TABLE A.10 (Cont'd)

\begin{tabular}{lll}
\hline \multicolumn{1}{c}{ Emission Source Group } & Pollutant & \multicolumn{1}{c}{ Data Souroea } \\
\hline $\begin{array}{l}\text { Other primary metals smelting } \\
\text { Printing operatlons }\end{array}$ & All & FRB: Prlmary metals \\
$\begin{array}{l}\text { Rubber and miso. } \\
\text { plastlos manufaoture }\end{array}$ & All & FRB: Printing and publlshing \\
$\begin{array}{l}\text { Secondary lead refining } \\
\begin{array}{l}\text { Other secondary metals } \\
\text { smelting and reflning }\end{array}\end{array}$ & All & SCB: Rubber tires and tubes, pneumatlo casings \\
Surface coatling & All & SCB: Lead, recovered from sorap \\
\hline
\end{tabular}

aSCB - U.S. Department of Commerce, Bureau of Economio Analysis, Survey of Current Business, up to latest one avallable; FRB - U.S. Department of Commerce, Federal Feserve Board, Industrial Production Index, up to latest one available; MER - U.S. Department of Energy, Energy Information Adminlstration, Monthly Energy Review, up to latest one avallable; HWS - U.S. Department of Transportation, Federal Highway Administration, Highway Statistics, up to latest one avaliable; ANL = Argonne Natlonal Laboratory data (see Sec. 7 of maln report). 
TABLE A.11 Souroes of Data on Monthly Emission Trends for Miscellaneous Sectors

\begin{tabular}{|c|c|c|}
\hline Emission Source Group & Pollutant & Data Source a \\
\hline Asphalt paving operations & VOC & SCB: Asphalt produotlon \\
\hline Forest wild fires & All & $\begin{array}{l}\text { NAPAP: Seasonal allocation tables in } 1985 \text { methodology } \\
\text { document }\end{array}$ \\
\hline $\begin{array}{l}\text { Nonindustrial organle } \\
\text { solvent use and disposal }\end{array}$ & All & Evenly distributed \\
\hline Other burning & All & $\begin{array}{l}\text { NAPAP: Seasonal allocatlon tables in } 1,985 \text { methodology } \\
\text { document }\end{array}$ \\
\hline Other misc. emissions & All & Evenly distributed \\
\hline Solid waste Incineration & All & Evenly distrlbuted \\
\hline Solld waste open burning & All & Evenly distrlbuted \\
\hline
\end{tabular}

asCB $=$ U.S. Department of Commerce, Bureau of Economic Analysis, Survey of Current Business, up to latest one avallable. 
TABLE A.12 Sources of Data on Monthly Emission Trends for the Transportation Sector

\begin{tabular}{|c|c|c|}
\hline Emission Source Group & Pollutant & Data Source ${ }^{a}$ \\
\hline On-highway sources -- all ESGs & All & $\begin{array}{l}\text { FHWWA Monthly Sales of } \\
\text { Gasoline and Special Fuels }\end{array}$ \\
\hline Off-highway sources -- all ESGs & All & DOE fuel consumption data \\
\hline
\end{tabular}

aFHWA $=$ Federal Highway Administration; DOE $=$ Department of Energy. 
TABLE A.13 Sources of Data on State Shares for All Emission Sectors ${ }^{a}$

\begin{tabular}{|c|c|c|}
\hline Sector & Emission Source Group & Data Sourceb \\
\hline \multirow[t]{9}{*}{ Fuel combustion } & Commercialinstitutional coal & SEDS: Commercial, total coal \\
\hline & Commercial/institutional fuel oil & $\begin{array}{l}\text { SEDS: Commercial, sum of residual, } \\
\text { distillate, and motor gasoline }\end{array}$ \\
\hline & Commercial/institutional natural gas & SEDS: Commercial, natural gas \\
\hline & Residential coal & SEDS: Residential, total coal \\
\hline & Residential fuel oil & SEDS: Residential, distillate \\
\hline & Residential natural gas & SEDS: Residential, natural gas \\
\hline & Industrial coal & SEDS: Industrial, total coal \\
\hline & Industrial fuel oil & $\begin{array}{l}\text { SEDS: Industrial, sum of residual and } \\
\text { distillate }\end{array}$ \\
\hline & Industrial natural gas & SEDS: Industrial, natural gas \\
\hline Electric utilities & All ESGs & ElA Form 767, EIA Form 759, FERC Form 423 \\
\hline \multirow{2}{*}{$\begin{array}{l}\text { Industrial } \\
\text { process }\end{array}$} & Gasoline marketing operations & HWS: state sales of highway gasoline \\
\hline & Primary copper smelting & ANL: Plant emissions inventory \\
\hline Miscellaneous & $\begin{array}{l}\text { Asphatt paving } \\
\text { operations }\end{array}$ & SEDS: Industrial, asphatt and road oil \\
\hline Transportation & On-highway ESGs & HWS: rable UM-2, Cambridge Systematics, Inc. \\
\hline
\end{tabular}


TABLE A.14 Sources of Data on Annual Extender Methodology for the Fuel Combustion Sectors

\begin{tabular}{|c|c|c|c|}
\hline Emission Source Group & Pollutant & Method & Data Source ${ }^{a}$ \\
\hline Commercial/institutional coal & $\begin{array}{l}\mathrm{NO}_{x} \\
\mathrm{SO}_{2} \\
\mathrm{VOC}\end{array}$ & $\begin{array}{l}E_{t}=E_{t-1} \\
E_{t}=A_{t}^{*} \exp (-4.230+0.026 T) \\
E_{t}=E_{t-1}\end{array}$ & $\begin{array}{l}\text { MER: Coal consumption, } \\
\text { residential and commercial }\end{array}$ \\
\hline Commercial/institutional fuel oil & $\begin{array}{l}\mathrm{NO}_{x} \\
\mathrm{SO}_{2} \\
\mathrm{VOC}\end{array}$ & $\begin{array}{l}\ln \left(E_{t}\right)=3.364+1.270 \ln \left(A_{t}\right) \\
\ln \left(E_{t}\right)=4.598+1.305 \ln \left(A_{t}\right) \\
\ln \left(E_{t}\right)=-0.051+0.805 \ln \left(A_{t}\right)\end{array}$ & $\begin{array}{l}\text { MER: Consumption of } \\
\text { energy, residential/ } \\
\text { commercial petroleum, } \\
\text { Btu (for all } 3 \text { pollutants) }\end{array}$ \\
\hline Commercial/institutional natural gas & $\begin{array}{l}\mathrm{NO}_{x} \\
\mathrm{SO}_{2} \\
\mathrm{VOC}\end{array}$ & $\begin{array}{l}\ln \left(E_{t}\right)=-4.517+1.180 \ln \left(A_{t}\right) \\
E_{t}=E_{t-1} \\
E_{t}=E_{t-1}\end{array}$ & $\begin{array}{l}\text { MER: Natural gas } \\
\text { delivered, commercial }\end{array}$ \\
\hline Commercial/institutional other & All & $E_{t}=$ Constant & NAPAP 1985 value \\
\hline Residential coal & $\begin{array}{l}\mathrm{NO}_{x} \\
\mathrm{SO}_{2} \\
\text { VOC }\end{array}$ & $\begin{array}{l}E_{t}=A_{t}\left(E_{t-1} / A_{t-1}\right) \\
E_{t}=A_{t}\left(E_{t-1} / A_{t-1}\right) \\
E_{t}=E_{t-1}\end{array}$ & $\begin{array}{l}\text { MER: Coal consumption, } \\
\text { residential/commercial } \\
\text { (for } \mathrm{NO}_{x} \text { and } \mathrm{SO}_{2} \text { ) }\end{array}$ \\
\hline Residential fuel oil & $\begin{array}{l}\mathrm{NO}_{x} \\
\mathrm{SO}_{2} \\
\text { VOC }\end{array}$ & $\begin{array}{l}\ln \left(E_{t}\right)=3.103+1.126 \ln \left(A_{t}\right) \\
\ln \left(E_{t}=3.788+1.064 \ln \left(A_{t}\right)\right. \\
\ln \left(E_{t}\right)=-0.563+1.417 \ln \left(A_{t}\right)\end{array}$ & $\begin{array}{l}\text { MER: Consumption oi } \\
\text { energy, residential/ } \\
\text { commercial petroleum, } \\
\text { Btu (for all } 3 \text { pollutants) }\end{array}$ \\
\hline Residential natural gas & $\begin{array}{l}\mathrm{NO}_{x} \\
\mathrm{SO}_{2}\end{array}$ & $\begin{array}{l}\ln \left(E_{t}\right)=-1.679+0.833 \ln \left(A_{t}\right) \\
E_{t}=A_{t *} \exp (-8.538+0.013 T)\end{array}$ & $\begin{array}{l}\text { MER: Natural gas } \\
\text { delivered, residential (for } \\
\text { both pollutants) }\end{array}$ \\
\hline Residential wood & All & $E_{t}=E_{t-1}$ & \\
\hline Electric utility & All & $\begin{array}{l}\text { No annual extenders } \\
\text { are needed }\end{array}$ & $\begin{array}{l}\text { MSCET electric utility } \\
\text { algorithm }\end{array}$ \\
\hline Industrial coal & $\begin{array}{l}\mathrm{NOX} \\
\mathrm{SO}_{2} \\
\text { VOC }\end{array}$ & $\begin{array}{l}E_{t}=A_{t}{ }^{*} \exp (-5.950+0.052 T) \\
E_{t}=A_{t}{ }^{*} \exp (-4.608+0.032 T) \\
E_{t}=E_{t-1}\end{array}$ & $\begin{array}{l}\text { MER: Coal consumption, } \\
\text { industrial (for } \mathrm{NO}_{x} \text { and } \\
\mathrm{SO}_{2} \text { ) }\end{array}$ \\
\hline Industrial fuel oil & $\begin{array}{l}\mathrm{NOX} \\
\mathrm{SO}_{2} \\
\text { VOC }\end{array}$ & $\begin{array}{l}E_{t}=A_{t}{ }^{*} \exp (3.674-0.068 T) \\
E_{t}=A_{t}^{*} \exp (4.856-0.061 T) \\
E_{t}=A_{t}^{*} \exp (-0.382-0.088 T)\end{array}$ & $\begin{array}{l}\text { MER: Consumption of } \\
\text { energy, industrial, } \\
\text { petroleum (for all } 3 \\
\text { pollutants) }\end{array}$ \\
\hline
\end{tabular}


TABLE A.14 (Cont'd)

\begin{tabular}{|c|c|c|c|}
\hline Emission Source Group & Pollutant & Method & Data Source ${ }^{a}$ \\
\hline Industrial natural gas & $\begin{array}{l}\mathrm{NOX}_{x} \\
\mathrm{SO}_{2} \\
\mathrm{VOC}\end{array}$ & $\begin{array}{l}E_{t}=A_{t}\left(E_{t-1} / A_{t-1}\right) \\
E_{t}=A_{t}^{*} \exp (-8.210+0.020 T) \\
E_{t}=A_{t}\left(E_{t-1} / A_{t-1}\right)\end{array}$ & $\begin{array}{l}\text { MER: Natural gas } \\
\text { consumption, inciustrial } \\
\text { (for all } 3 \text { pollutants) }\end{array}$ \\
\hline Industrial other & $\begin{array}{l}\mathrm{NOX}_{2} \\
\mathrm{SO}_{2} \\
\mathrm{VOC}\end{array}$ & $\begin{array}{l}E_{t}=A_{t}{ }^{*} \exp (-1.527-0.060 T) \\
E_{t}=A_{t}{ }^{*} \exp (-2.045-0.070 T) \\
E_{t}=A_{t}{ }^{*} \exp (-2.705-0.020 T)\end{array}$ & $\begin{array}{l}\text { FRB: Industrial } \\
\text { production (for all } 3 \\
\text { pollutants) }\end{array}$ \\
\hline
\end{tabular}

aMER = U.S. Department of Energy, Energy Information Administration, Monthly Energy Review, up to latest one available; FRB $=$ U.S. Department of Commerce, Federal Reserve Board Industrial Production Index, up to latest one available. 
TABLE A.15 Sources of Data on Annual Extender Methodology for the Industrial Process Sector

\begin{tabular}{|c|c|c|c|}
\hline Emission Source Group & Pollutant & Method & Data Source a \\
\hline Cement production & $\begin{array}{l}\mathrm{NOX} \\
\mathrm{SO}_{2} \\
\mathrm{VOC}\end{array}$ & $\begin{array}{l}E_{t}=A_{t}^{*} \exp (-8.369-0.013 T) \\
E_{t}=A_{t}^{*} \exp (-6.301-0.036 T) \\
E_{t}=\text { Constant }\end{array}$ & $\begin{array}{l}\text { SCB: Portland cement } \\
\text { shpmts. } \\
\text { NAPAP } 1985 \text { value }\end{array}$ \\
\hline Degreasing & $\begin{array}{l}\mathrm{NO}_{\mathrm{x}} \\
\mathrm{SO}_{2} \\
\mathrm{VOC}\end{array}$ & $\begin{array}{l}E_{t}=\text { Constant } \\
E_{t}=\text { Constant } \\
E_{t}=E_{t-1}\end{array}$ & $\begin{array}{l}\text { NAPAP } 1985 \text { value } \\
\text { NAPAP } 1985 \text { value }\end{array}$ \\
\hline Dry cleaning & VOC & $E_{t}=E_{t-1}$ & \\
\hline $\begin{array}{l}\text { Food processing/ } \\
\text { agricultural operations }\end{array}$ & $\begin{array}{l}\mathrm{NO}_{x} \\
\mathrm{SO}_{2} \\
\mathrm{VOC}\end{array}$ & $\begin{array}{l}E_{t}=\text { Constant } \\
E_{t}=\text { Constant } \\
E_{t}=A_{t}^{*} \exp (-1.799-0.039 T)\end{array}$ & $\begin{array}{l}\text { NAPAP } 1985 \text { value } \\
\text { NAPAP } 1985 \text { value } \\
\text { FRB: Foods }\end{array}$ \\
\hline Gasoline marketing & $\begin{array}{l}\mathrm{NO}_{x} \\
\mathrm{SO}_{2} \\
\mathrm{VOC}\end{array}$ & $\begin{array}{l}E_{t}=\text { Constant } \\
E_{t}=\text { Constant } \\
E_{t}=A_{t}^{*} \exp (-3.784-0.020 T)\end{array}$ & $\begin{array}{l}\text { NAPAP } 1985 \text { value } \\
\text { NAPAP } 1985 \text { value } \\
\text { MER: Finished motor } \\
\text { gasoline, supply and } \\
\text { disposition }\end{array}$ \\
\hline Glass manufacturing & $\begin{array}{l}\mathrm{NO}_{x} \\
\mathrm{SO}_{2} \\
\mathrm{VOC}\end{array}$ & $\begin{array}{l}E_{t}=E_{t-1} \\
E_{t}=E_{t-1} \\
E_{t}=\text { Constant }\end{array}$ & NAPAP 1985 value \\
\hline $\begin{array}{l}\text { Industrial organic } \\
\text { solvent use, misc. }\end{array}$ & $\begin{array}{l}\mathrm{NO}_{\mathrm{x}} \\
\mathrm{SO}_{2} \\
\mathrm{VOC}\end{array}$ & $\begin{array}{l}E_{t}=\text { Constant } \\
E_{t}=\text { Constant } \\
E_{t}=E_{t-1}\end{array}$ & $\begin{array}{l}\text { NAPAP } 1985 \text { value } \\
\text { NAPAP } 1985 \text { value }\end{array}$ \\
\hline Iron and steel production & $\begin{array}{l}\mathrm{NO}_{x} \\
\mathrm{SO}_{2} \\
\mathrm{VOC}\end{array}$ & $\begin{array}{l}\ln \left(E_{t}\right)=-9.248+1.148 \ln \left(A_{t}\right) \\
\ln \left(E_{t}\right)=-8.868+1.293 \ln \left(A_{t}\right) \\
\ln \left(E_{t}\right)=-11.247+1.436 \ln \left(A_{t}\right)\end{array}$ & $\begin{array}{l}\text { SCB: Ste日l production } \\
\text { SCB: Steel production } \\
\text { SCB: Steel production }\end{array}$ \\
\hline Lime manufacturing & $\begin{array}{l}\mathrm{NO}_{x} \\
\mathrm{SO}_{2} \\
\mathrm{VOC}\end{array}$ & $\begin{array}{l}E_{t}=E_{t-1} \\
E_{t}=E_{t-1} \\
E_{t}=\text { Constant }\end{array}$ & NAPAP 1985 value \\
\hline Mineral products processing & All & $E_{t}=A_{t}\left(E_{85} / A_{85}\right)$ & $\begin{array}{l}\text { FRB: Clay, glass, and } \\
\text { stone }\end{array}$ \\
\hline Mining operations & All & $E_{t}=A_{t}\left(E_{85} / A_{85}\right)$ & $\begin{array}{l}\text { FRB: Stone and earth } \\
\text { minerals }\end{array}$ \\
\hline Misc. industrial processes & All & $E_{t}=$ Constant & NAPAP 1985 values \\
\hline Oil and natural gas extraction & $\begin{array}{l}\mathrm{NO}_{\mathrm{X}} \\
\mathrm{SO}_{2} \\
\mathrm{VOC}\end{array}$ & $\begin{array}{l}E_{t}=A_{t}\left(E_{85} / A_{85}\right) \\
E_{t}=A_{t}\left(E_{t-1} / A_{t-1}\right) \\
E_{t}=A_{t}\left(E_{t-1} / A_{t-1}\right)\end{array}$ & $\begin{array}{l}\text { MER: Crude oil, total } \\
\text { domestic field production } \\
\text { MER: Natural gas, } \\
\text { marketed production, wet } \\
\text { MER: Crude oil, total } \\
\text { domestic field production }\end{array}$ \\
\hline
\end{tabular}


TABLE A.15 (Cont'd)

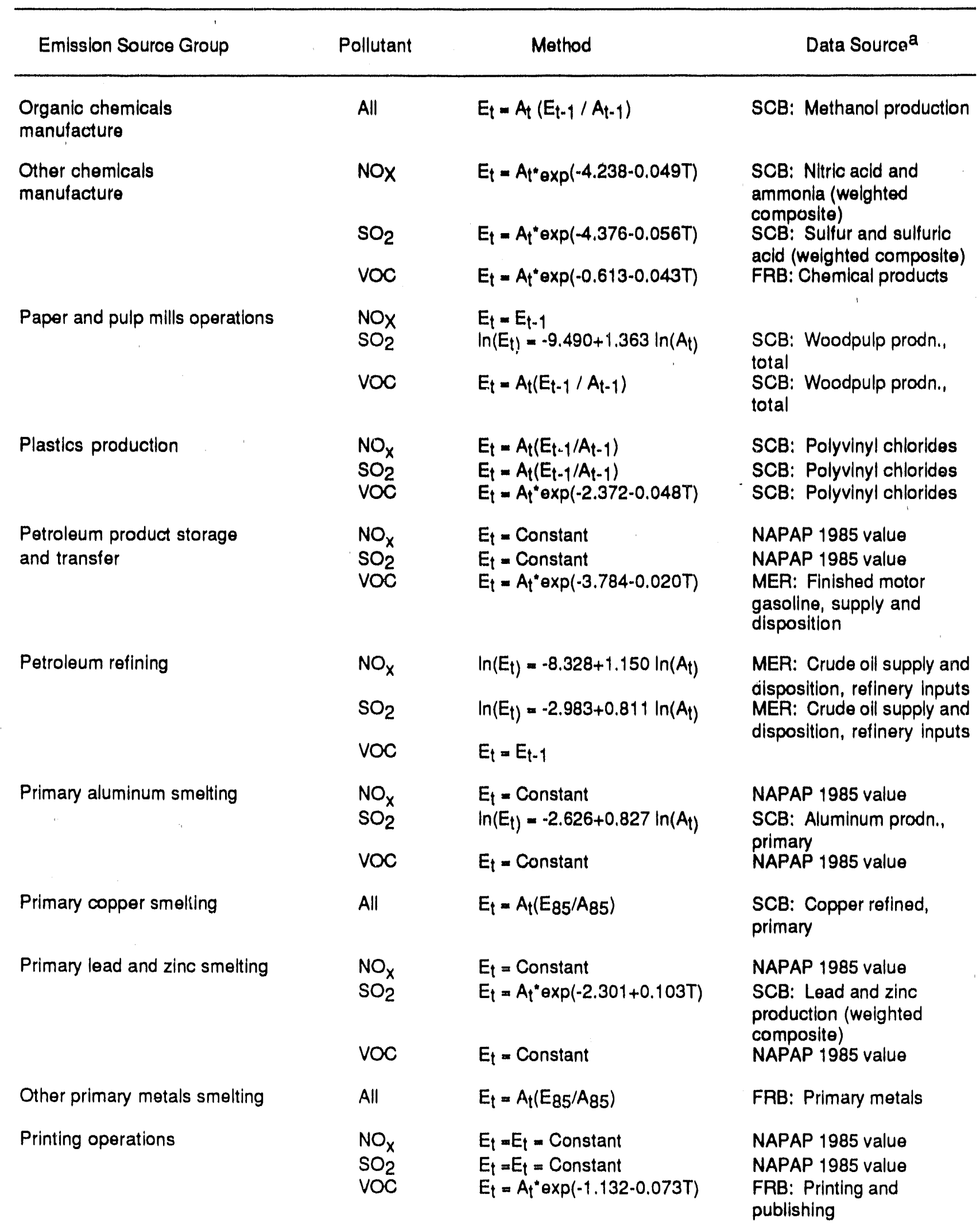


TABLE A.15 (Cont'd)

\begin{tabular}{|c|c|c|c|}
\hline Emission Source Group & Pollutant & Method & Data Souroe ${ }^{a}$ \\
\hline $\begin{array}{l}\text { Rubber and misc. } \\
\text { plastics manufacture }\end{array}$ & $\begin{array}{l}\mathrm{NO}_{x} \\
\mathrm{SO}_{2} \\
\mathrm{VOC}\end{array}$ & $\begin{array}{l}E_{t}=\text { Constant } \\
E_{t}=\text { Constant } \\
\ln \left(E_{t}\right)=-8,495+1.018 \ln \left(A_{t}\right)\end{array}$ & $\begin{array}{l}\text { NAPAP } 1985 \text { value } \\
\text { NAPAP } 1985 \text { value } \\
\text { SCB: Rubber tires and } \\
\text { tubes, pneumatic casings }\end{array}$ \\
\hline \multirow[t]{2}{*}{ Secondary lead refining } & $\begin{array}{l}\mathrm{NO}_{x} \\
\mathrm{SO}_{2}\end{array}$ & $\begin{array}{l}E_{t}=\text { Constant } \\
E_{t}=A_{t}\left(E_{t-1} / A_{t-1}\right)\end{array}$ & \multirow{2}{*}{$\begin{array}{l}\text { NAPAP } 1985 \text { value } \\
\text { SCB: Lead recovered from } \\
\text { scrap } \\
\text { NAPAP } 1985 \text { value }\end{array}$} \\
\hline & VOC & $E_{t}=$ Constant & \\
\hline Other secondary metals & All & $E_{t}=A_{t}\left(E_{85} / A_{85}\right)$ & $\begin{array}{l}\text { FRB: Secondary } \\
\text { nonferrous smelting and } \\
\text { refining metals }\end{array}$ \\
\hline Surface coating & $\begin{array}{l}\mathrm{NO}_{x} \\
\mathrm{SO}_{2} \\
\mathrm{VOC}\end{array}$ & $\begin{array}{l}E_{t}=\text { Constant } \\
E_{t}=\text { Constant } \\
E_{t}=A_{t}{ }^{*} \exp (-0.694-0.076 T)\end{array}$ & $\begin{array}{l}\text { NAPAP } 1985 \text { value } \\
\text { NAPAP } 1985 \text { value } \\
\text { SCB: Paints, varnish and } \\
\text { lacquer }\end{array}$ \\
\hline
\end{tabular}

aMER $=$ U.S. Department of Energy, Energy Information Administration, Monthly Energy Review, up to latest one available; FRB $=$ U.S. Department of Commerce, Federal Reserva Board, Industrial Production Index, up to latest one avallable; $S C B=$ U.S. Department of Commerce, Bureau of Economic Analysis, Sunvey of Current Business, up to latest one avallable. 
TABLE A.16 Souroes of Data on Annual Extender Methodology for Miscellaneous Sectors

\begin{tabular}{llll}
\hline \multicolumn{1}{c}{ Emission Source Group } & Pollutant & Method & Data Sourcea \\
\hline Asphatt paving operations & VOC & $E_{t}=A_{t}\left(E_{85} / A_{85}\right)$ & SCB: Asphalt production \\
Forest wild flres & All & $E_{t}=E_{t-1}$ \\
$\begin{array}{l}\text { Nonindustrial organic } \\
\text { solvent use and dlsposal }\end{array}$ & All & $E_{t}=E_{t-1}$ \\
Other burning & All & $E_{t}=E_{t-1}$ \\
Other miso, sources & All & $E_{t}=E_{t-1}$ \\
Solid waste incineration & All & $E_{t}=E_{t-1}$ \\
Solid waste open burning & All & $E_{t}=E_{t-1}$ \\
\hline
\end{tabular}

asCB - U.S. Department of Commerce, Bureau of Economic Analysis, Survey of Current Business, up to latest one avallable. 
TABLE A.17 Souroes of Data on Annual Extender Methodology for the Transportation Sector

\begin{tabular}{|c|c|c|c|}
\hline Emission Source Group & Pollutant & Method & Data Source \\
\hline On-hlghway souroes & All & $\begin{array}{l}\text { No annual estlmates } \\
\text { are needed }\end{array}$ & $\begin{array}{l}\text { MSCET transportation } \\
\text { algorithm }\end{array}$ \\
\hline $\begin{array}{l}\text { Off-highway sources } \\
\text { (except miso. off-highway } \\
\text { vehioles) }\end{array}$ & All & $\begin{array}{l}\text { No annual estlmates } \\
\text { are needed }\end{array}$ & $\begin{array}{l}\text { MSCET transportation } \\
\text { algorlthm }\end{array}$ \\
\hline $\begin{array}{l}\text { Miscellaneous off-highway } \\
\text { vehicles }\end{array}$ & All & $E_{1}=E_{k-1}$ & \\
\hline
\end{tabular}




\section{Appendlx B:}

$\mathrm{NO}_{x}, \mathrm{SO}_{2}$, and $\mathrm{VOC}$ Emissions

(In thousand metric tons) 
B.1 NOx Emissions by Month and State 


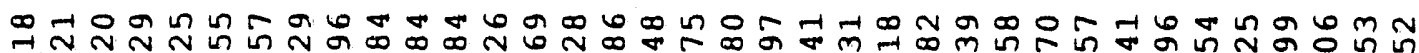

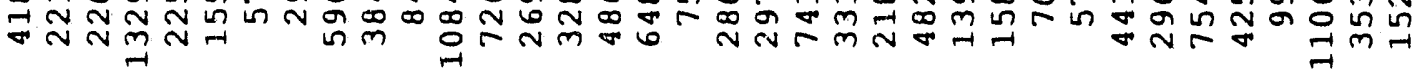

U م.

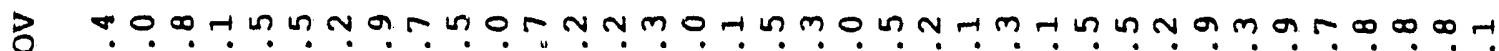

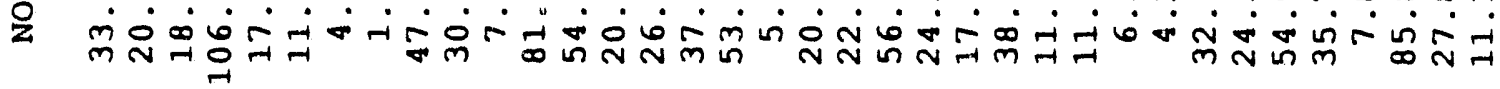

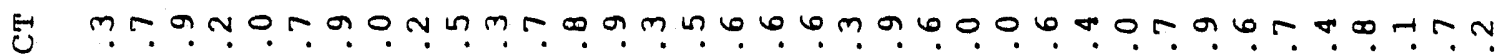

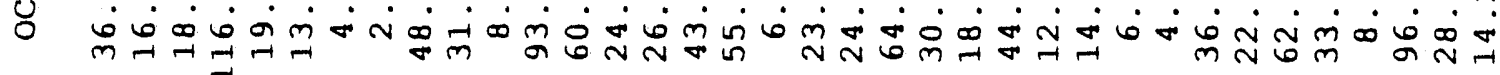

a 0 0.

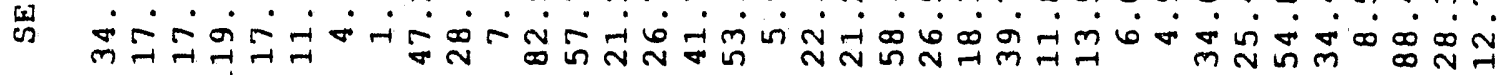

ט H?m

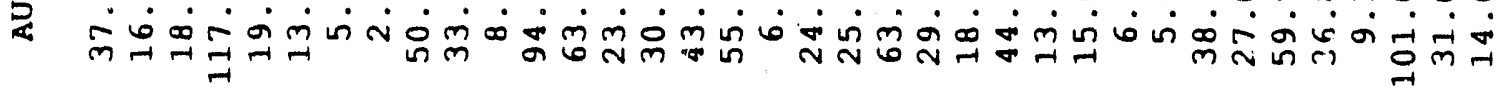

S

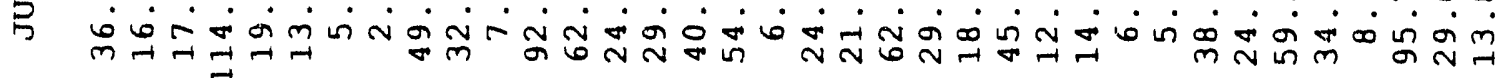

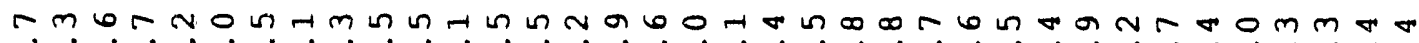
जि

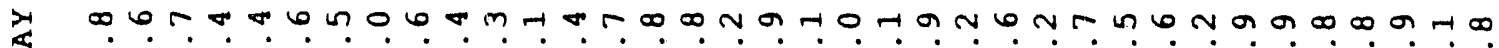

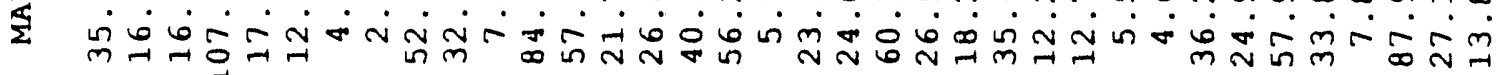

r.

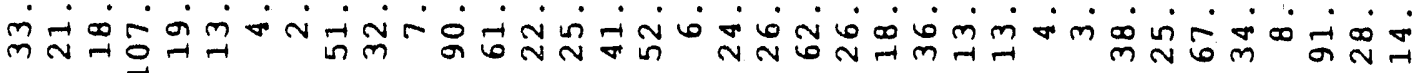

nomon 0 l

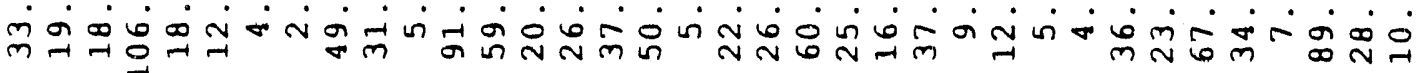

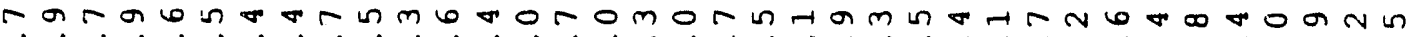

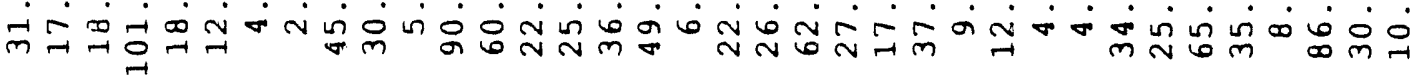

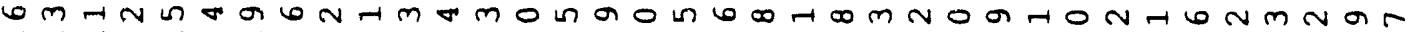

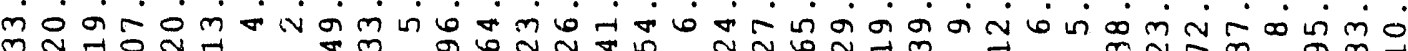

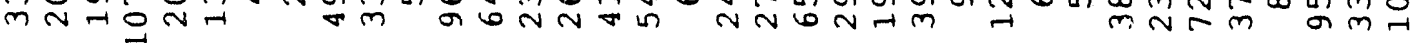




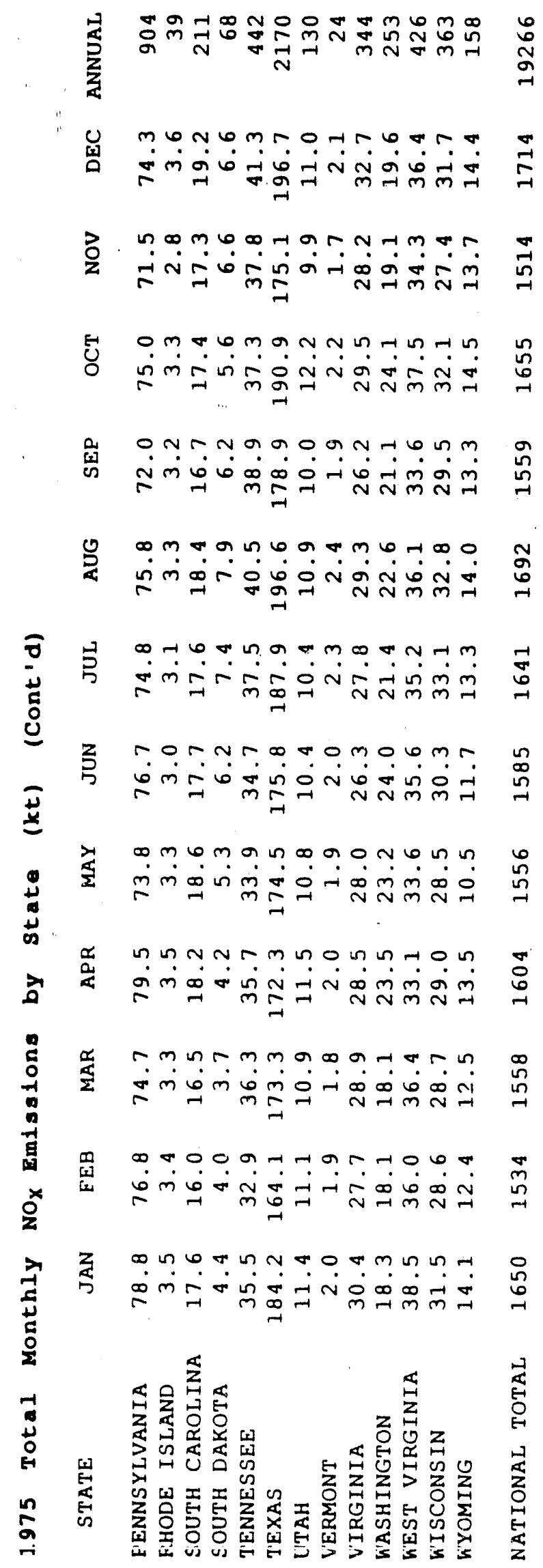


글

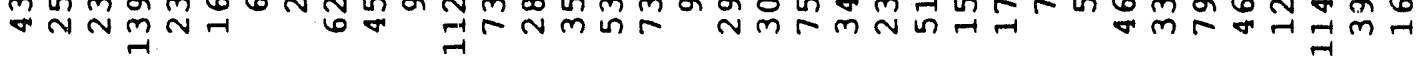

ararmmR nornmm- or

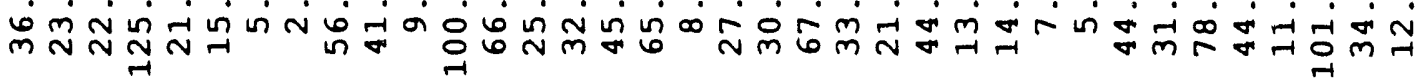

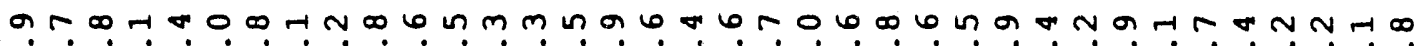

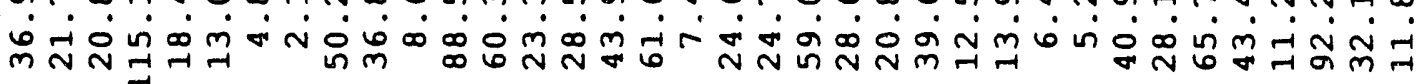

no 0 n

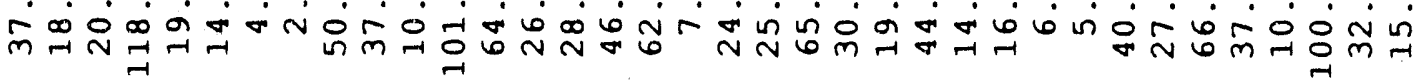

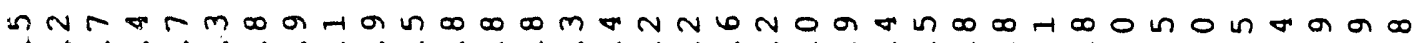

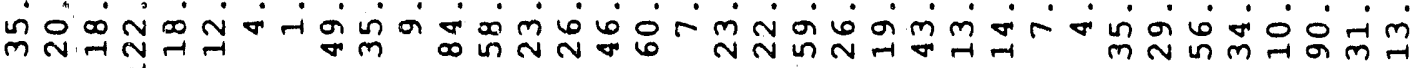

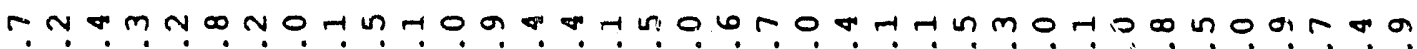

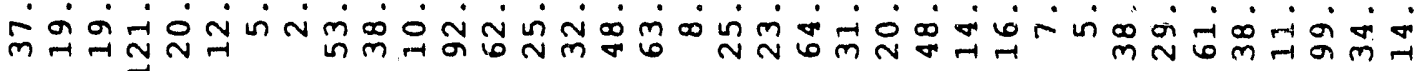

4 n m m

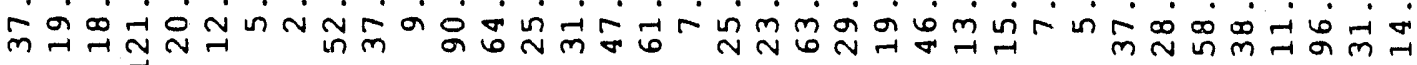

wanarm-tra

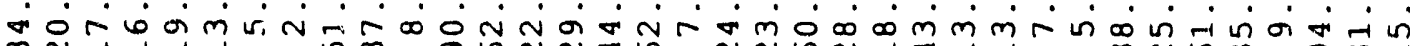

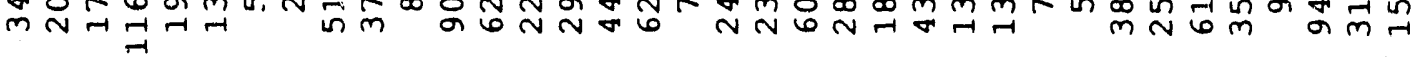

>

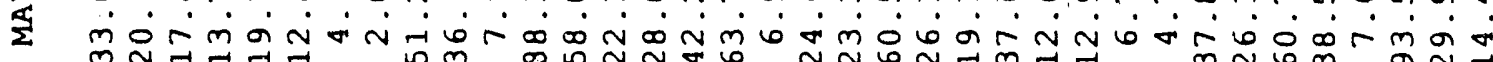

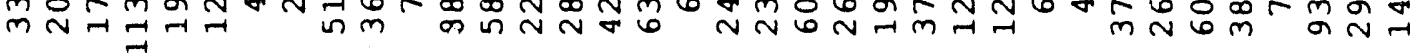

a

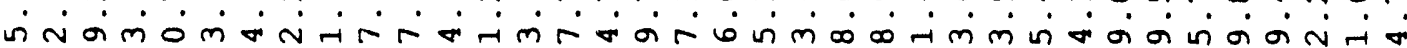
m N

a 0 o

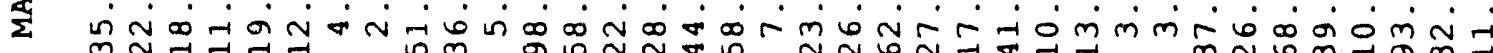

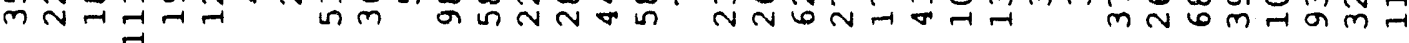

M $M$ n n

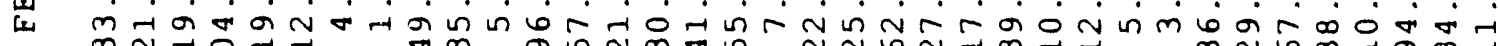

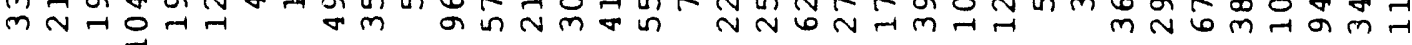

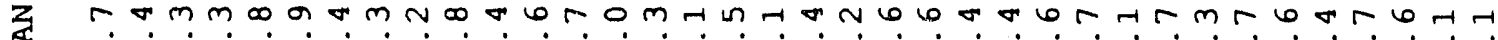

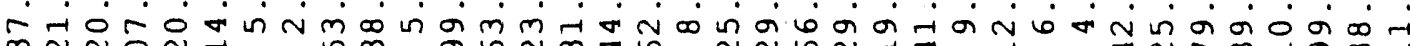

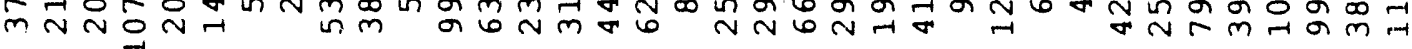




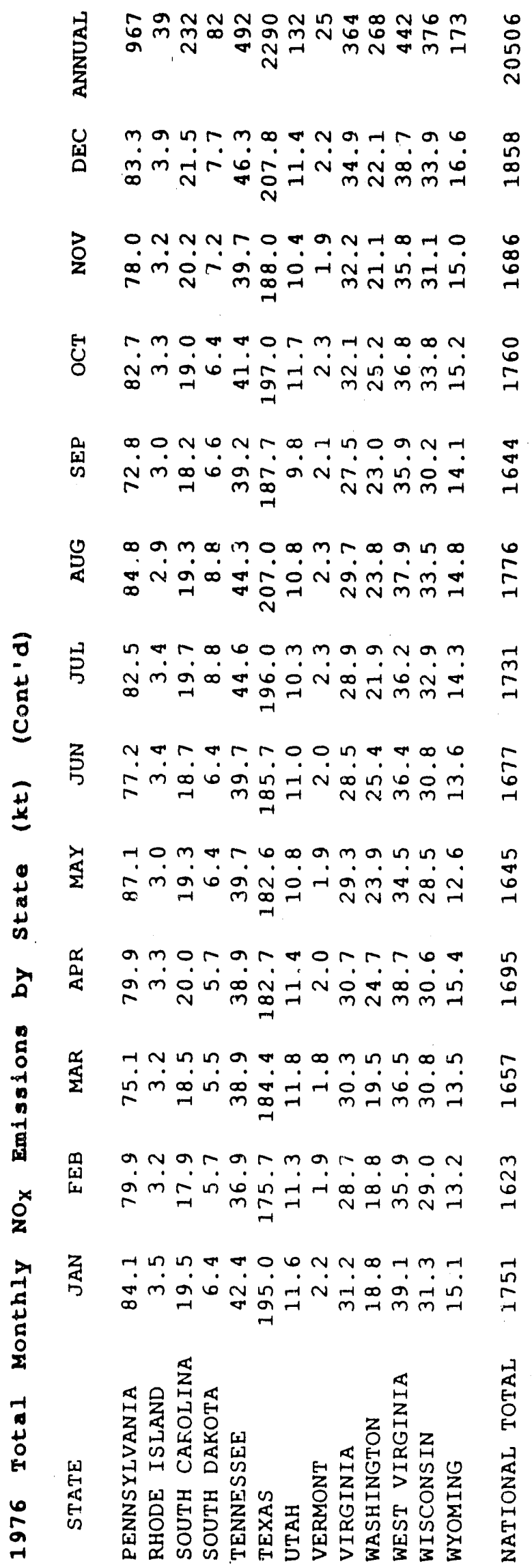




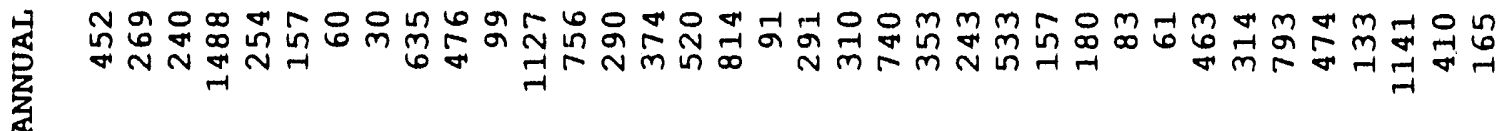

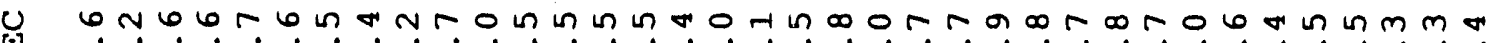

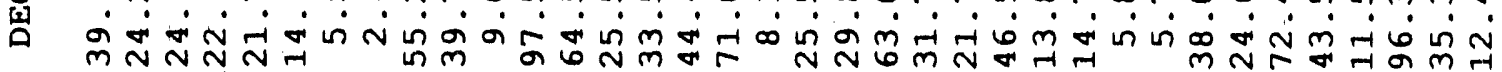

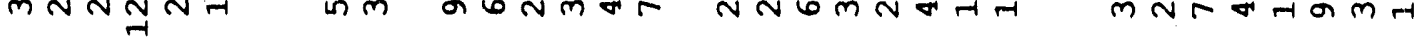

D Tm

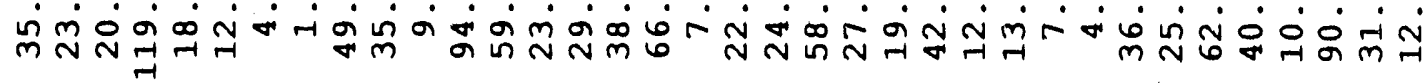

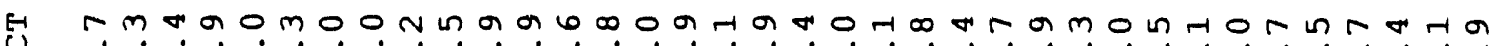

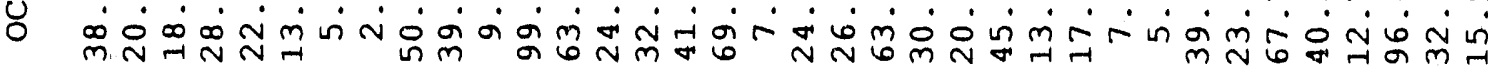

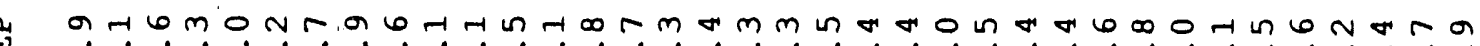
乌 ம்

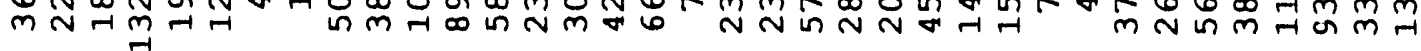

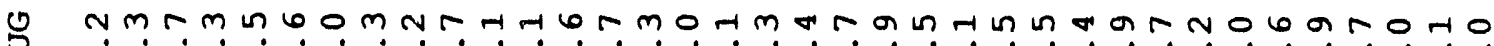

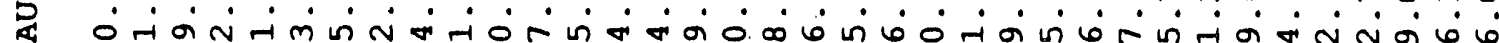

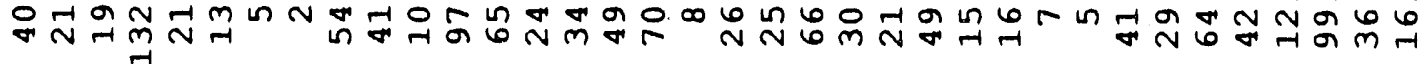

A TNON

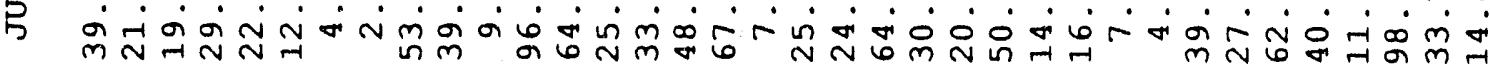

z 0 Hnd 万. m

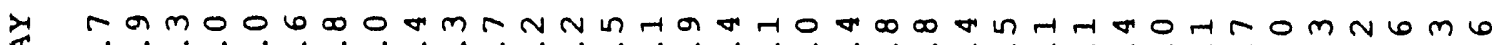
इ

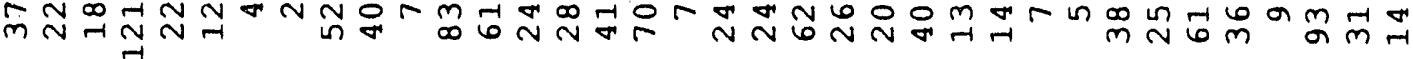

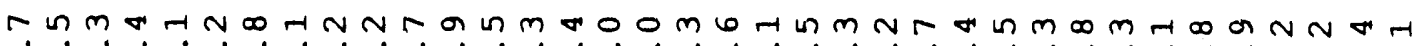

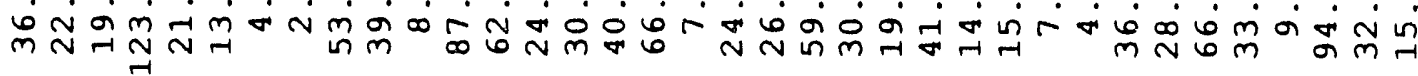

T. Tnm no

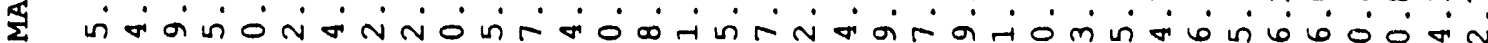

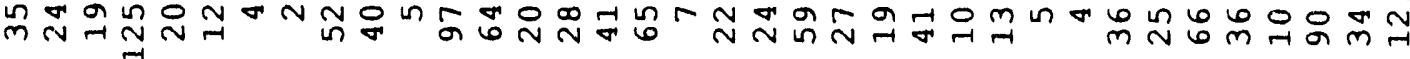

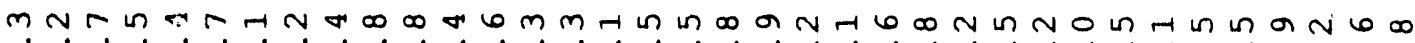

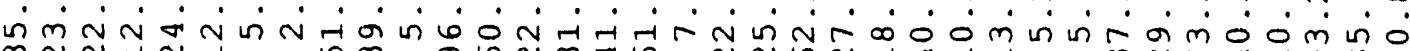

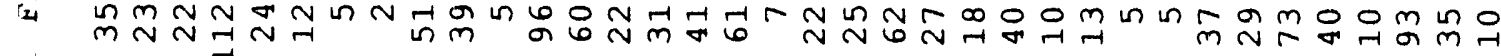

z

舟 


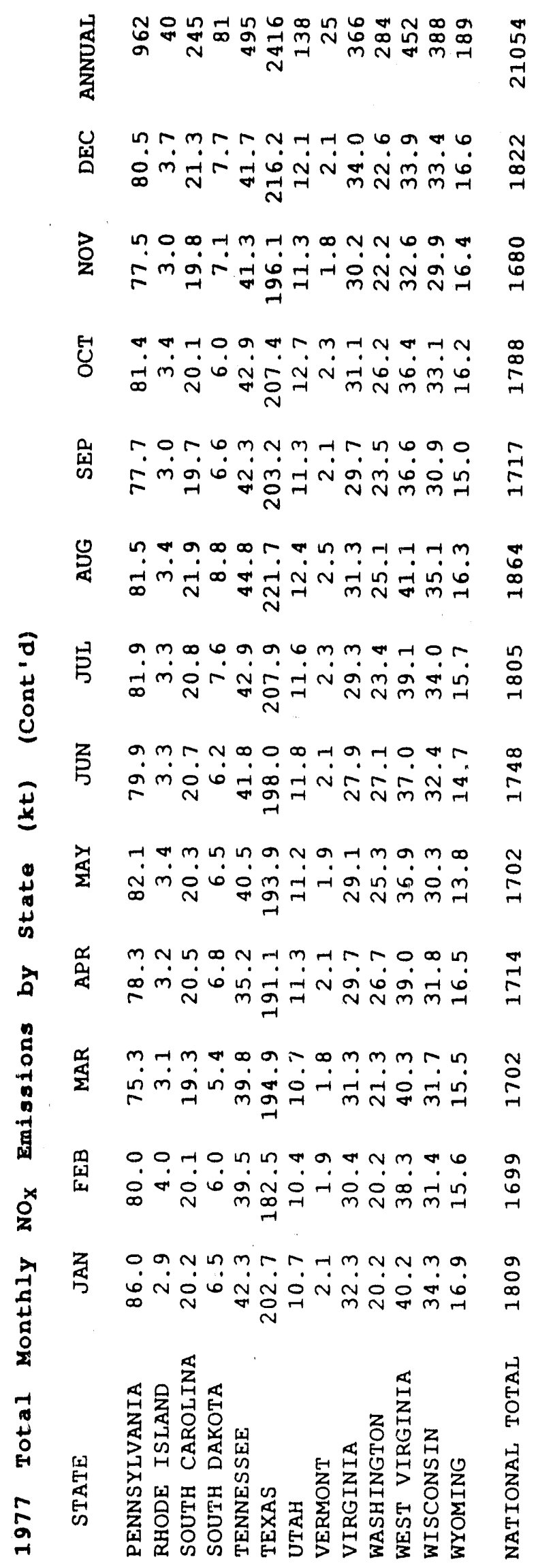




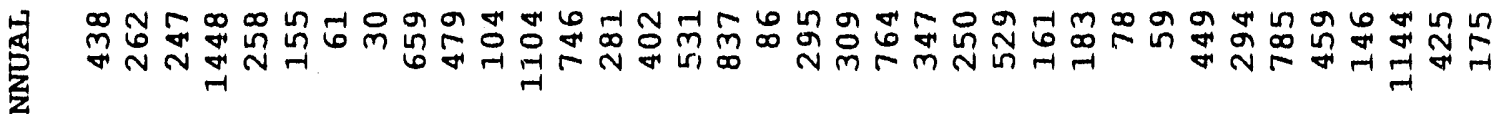

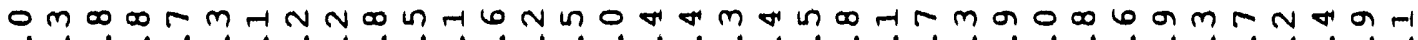
m

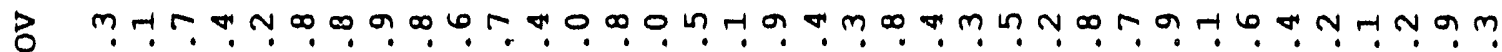

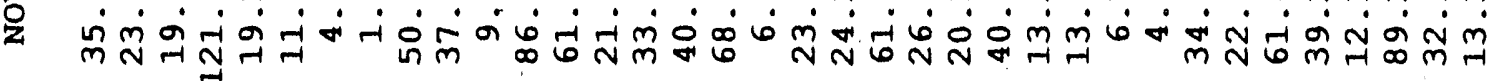

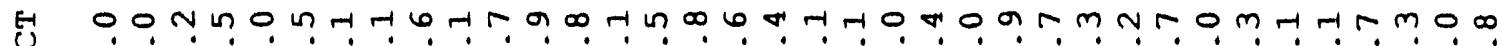

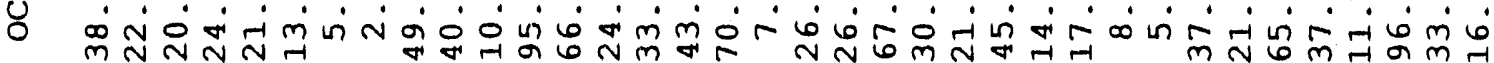

M

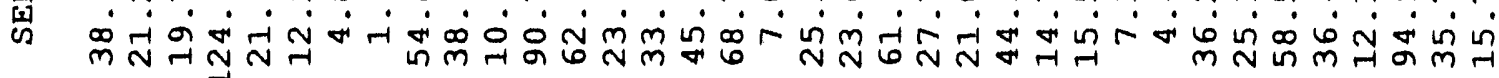

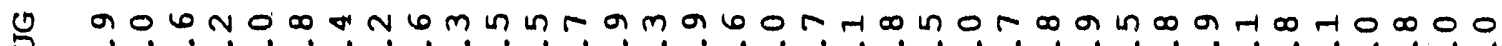

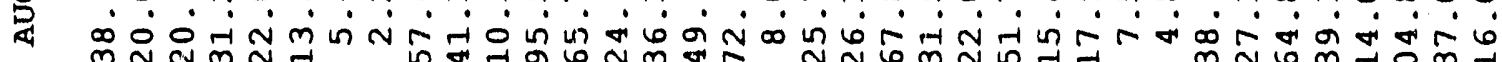

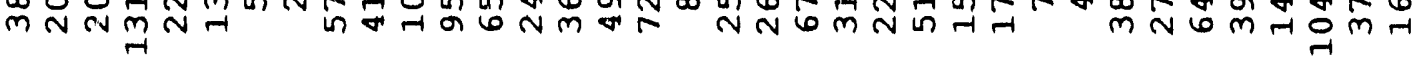

H

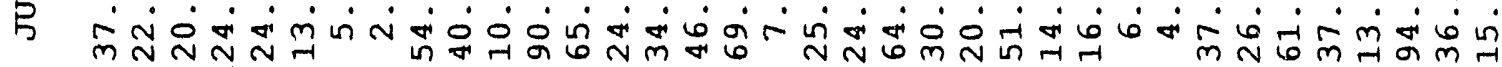

z In

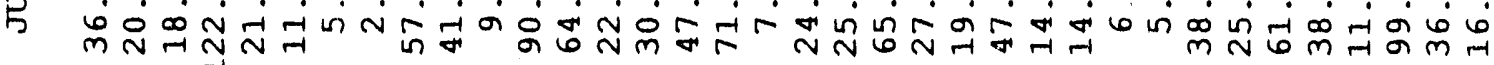

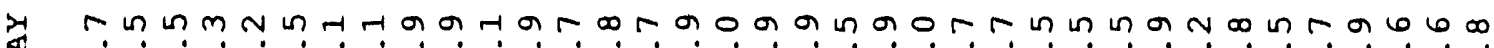

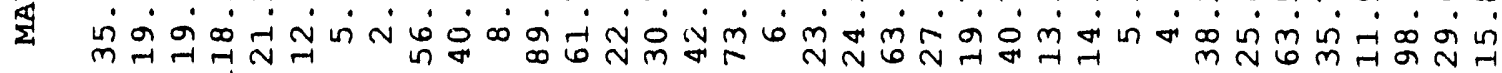

Wh

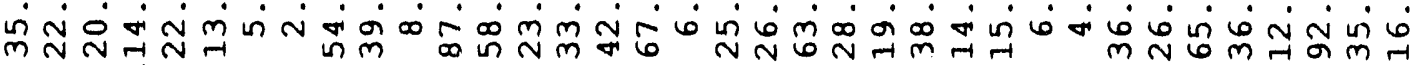

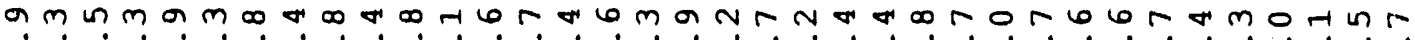

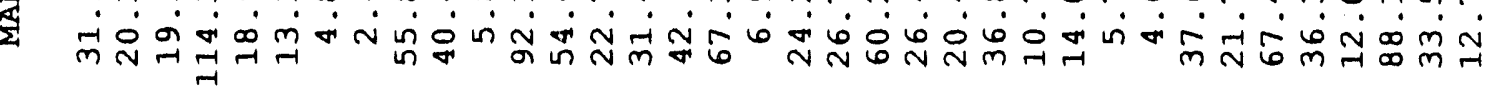

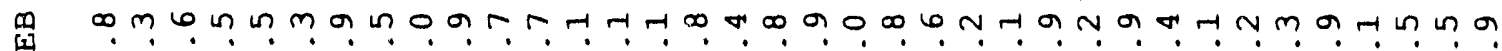

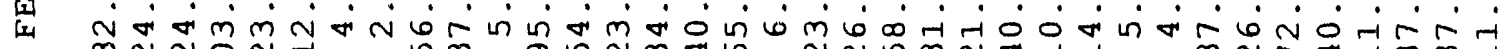

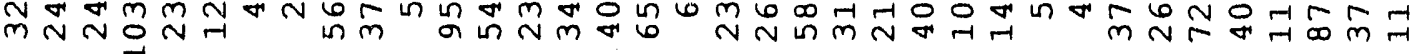

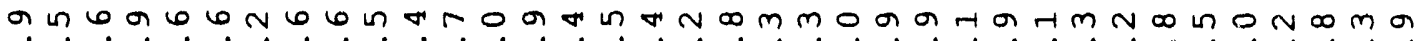

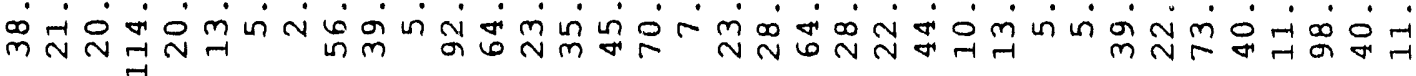

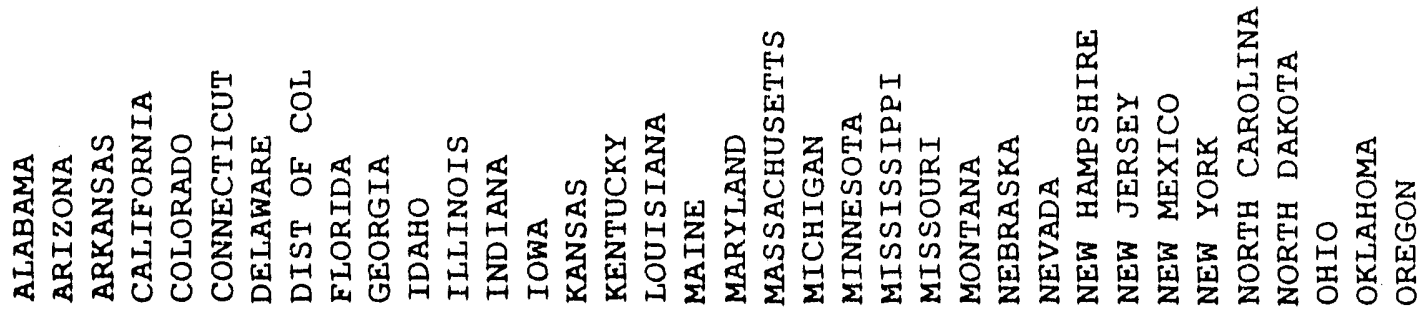




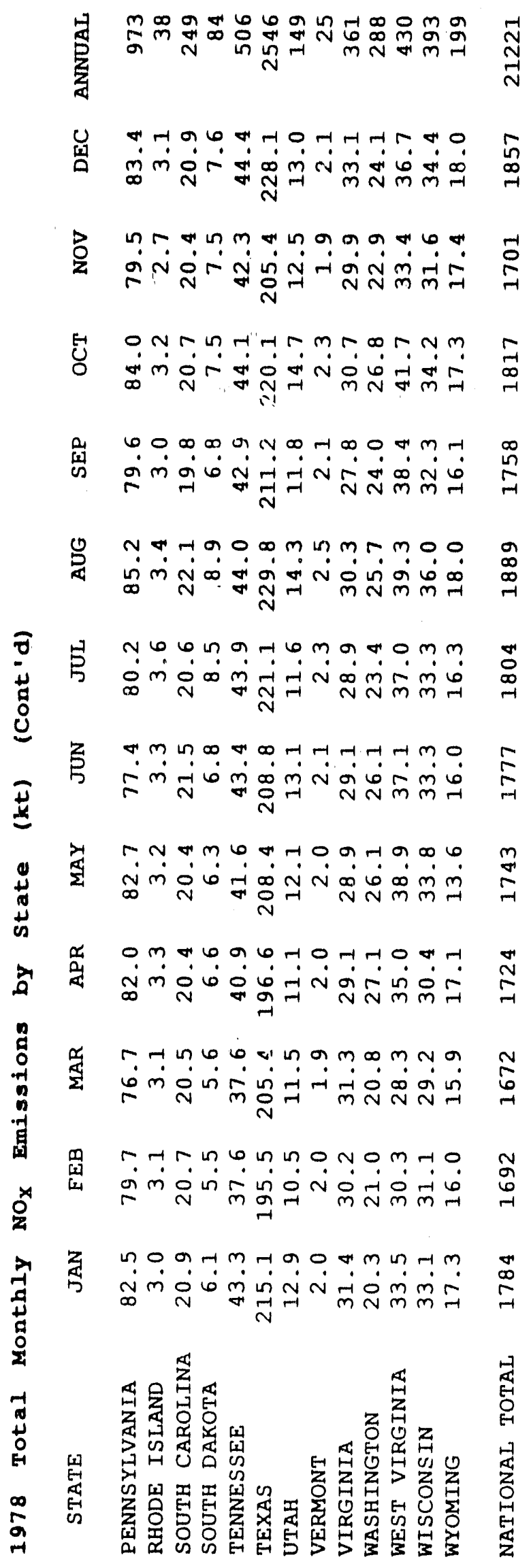




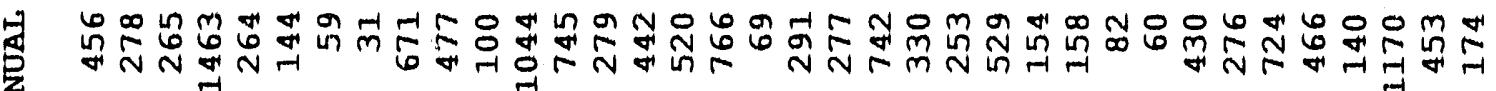

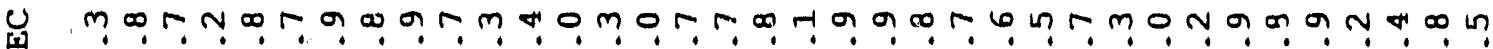

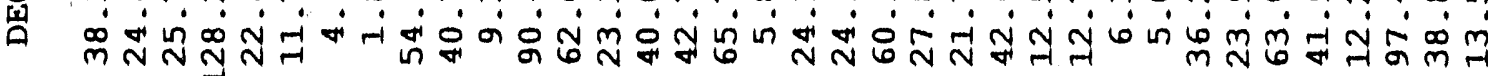

8 แn z

U一

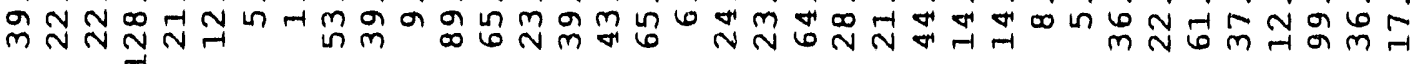
采

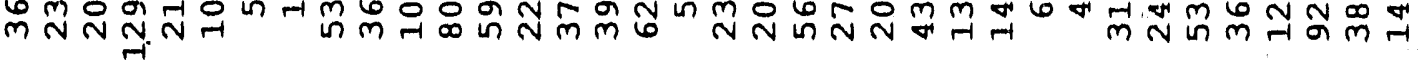

乌.

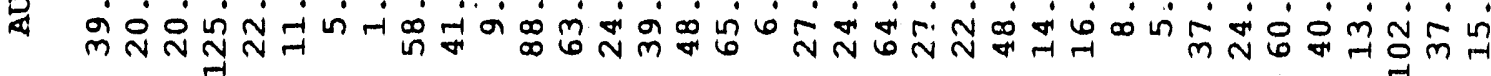

H TrR⿻ -

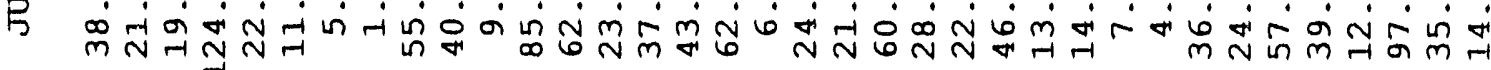
lom

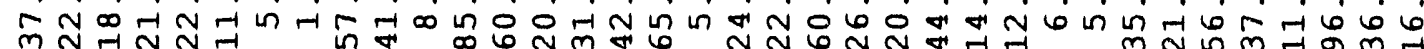

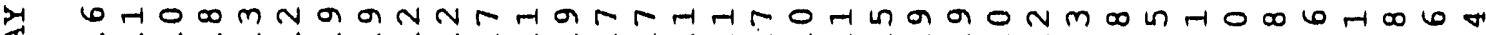

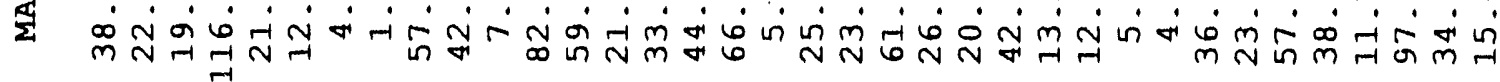

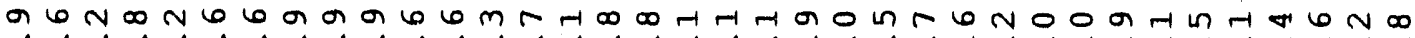

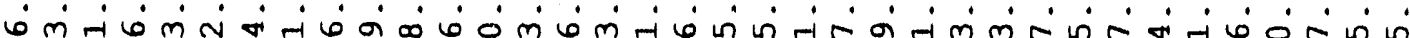

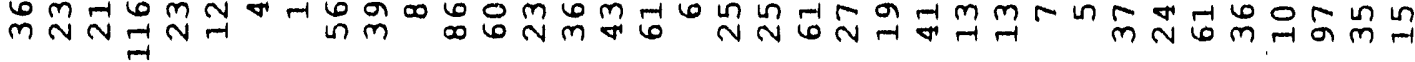

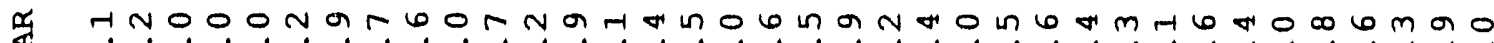

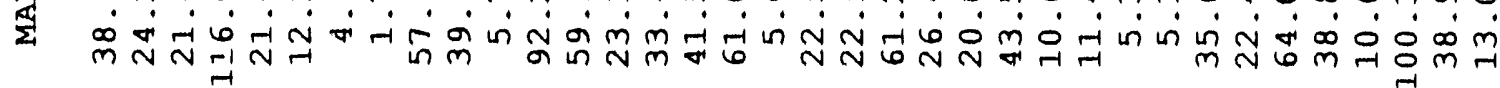

Hmb

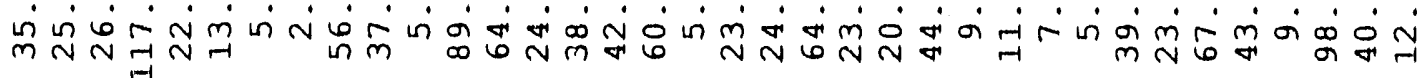

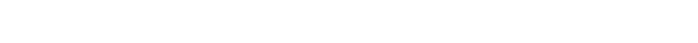

n!

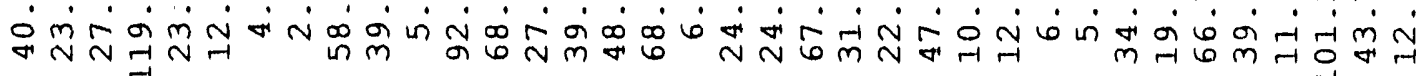




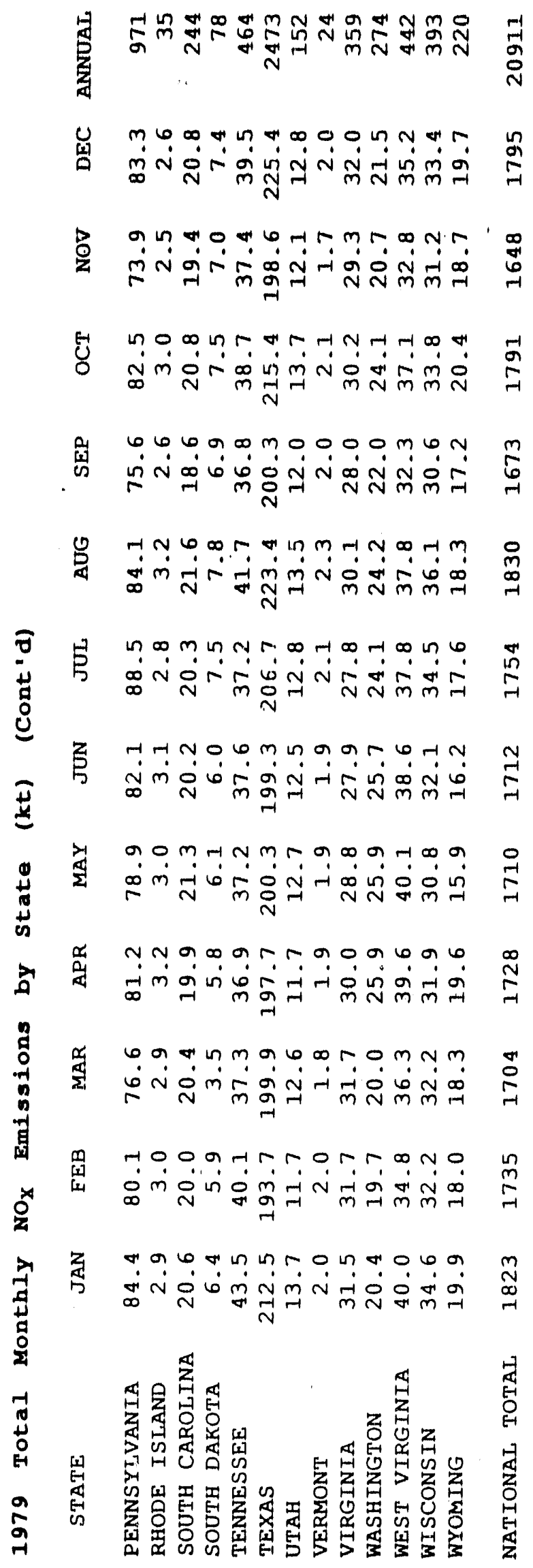




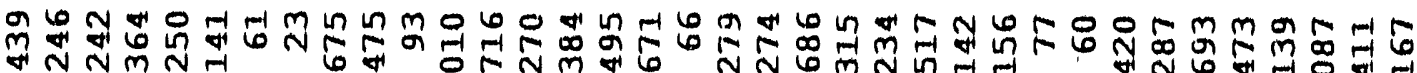

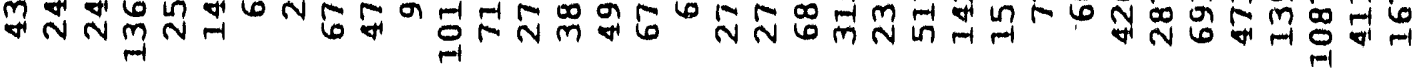

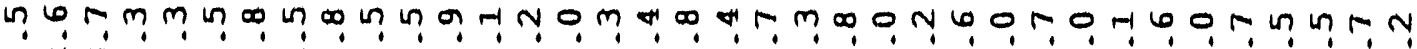

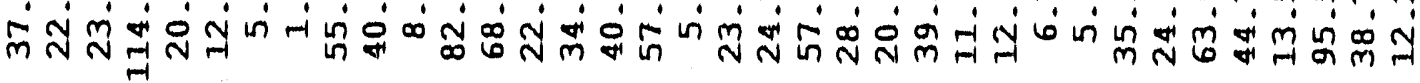

r!

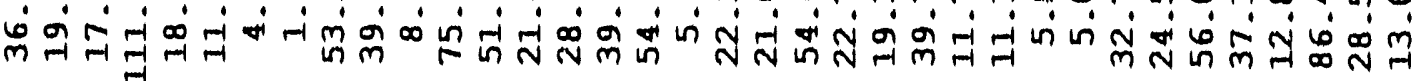

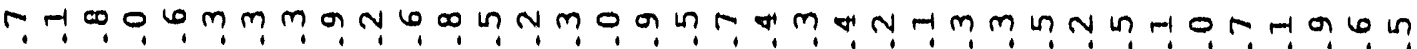

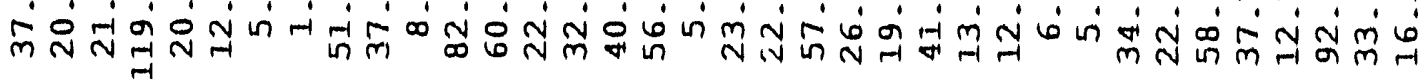

$r$ In 0 ,

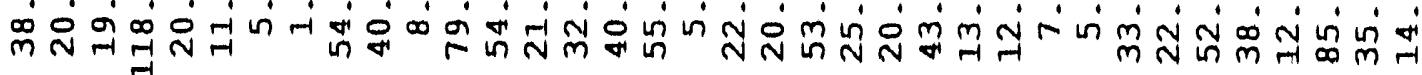

-16 $6 m$ \%

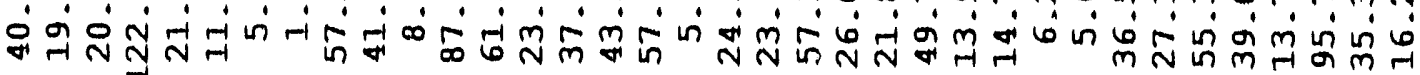

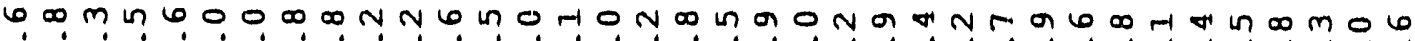

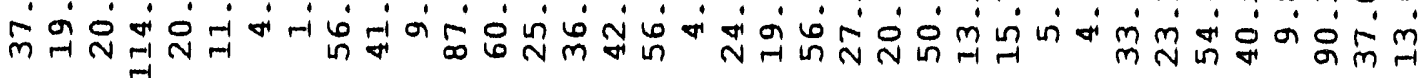

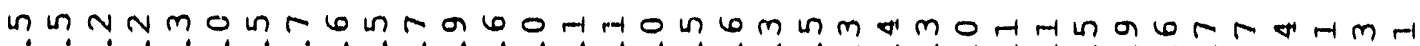

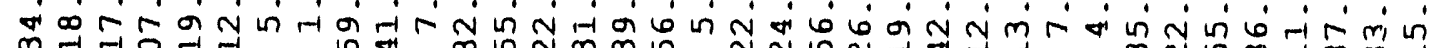
m

in

N

$m \mathbb{N}$ 岇

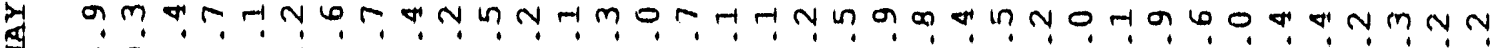

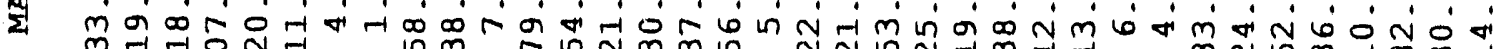

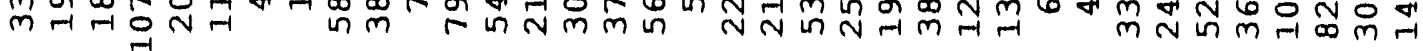

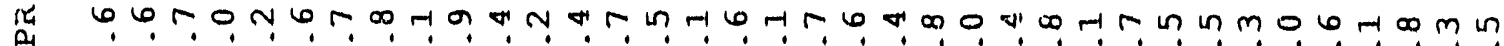

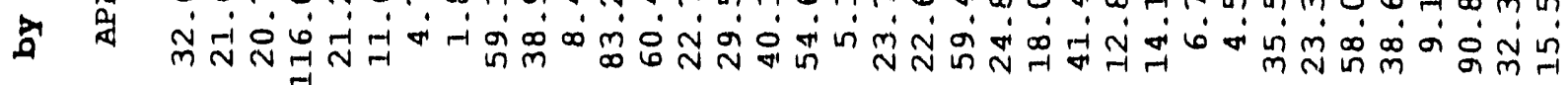

a

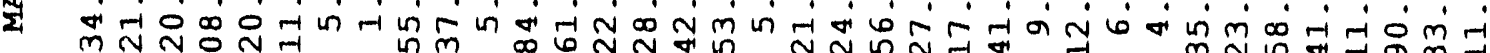
o

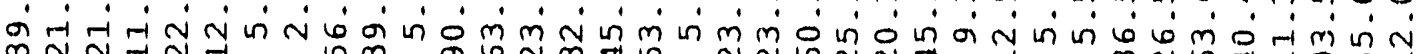

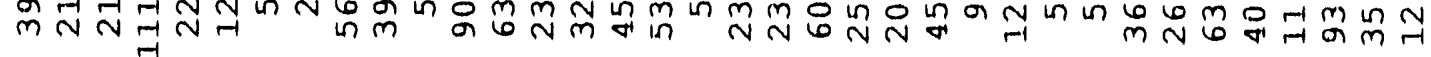

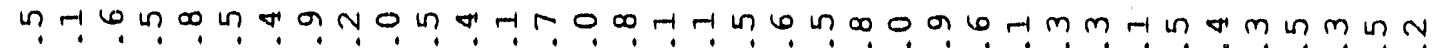

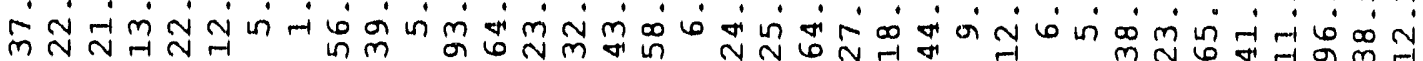
$\rightarrow$

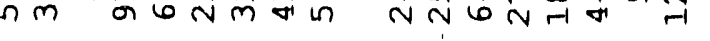
$m N$ N $\mathrm{N}$ a $m$-1

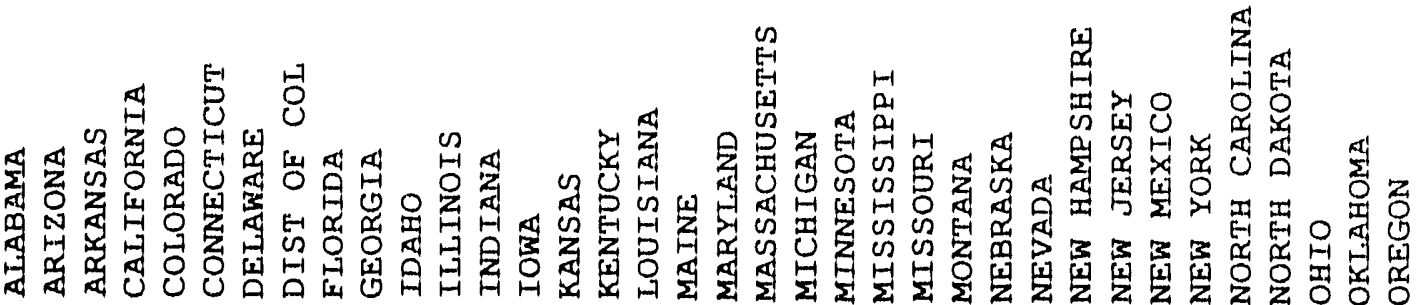




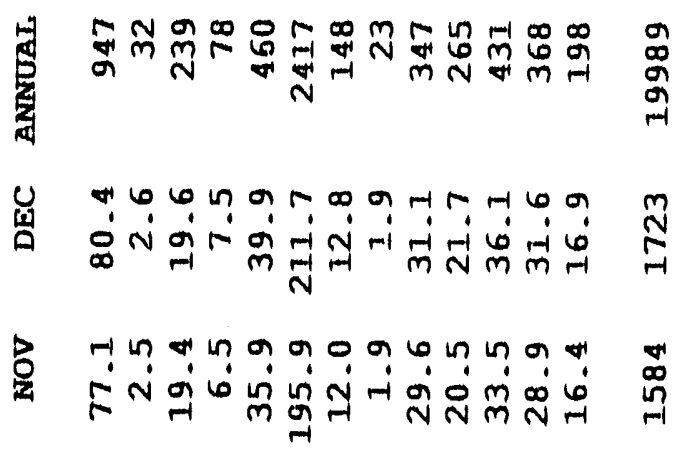

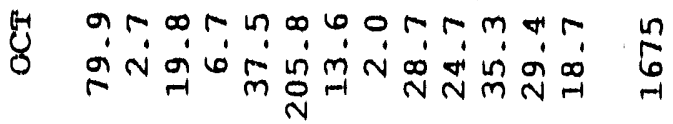

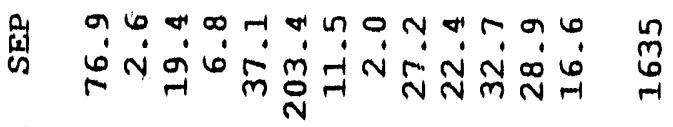

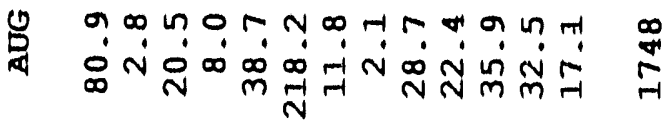

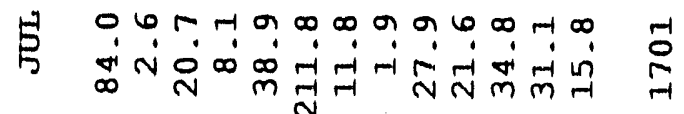

尔

$\underline{4}$

药 m

a anmo மัNo

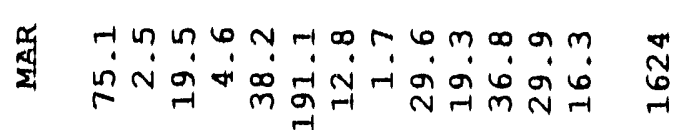

$m$ r

w

$\underset{2}{x}$

द rarogorom

杽 mín

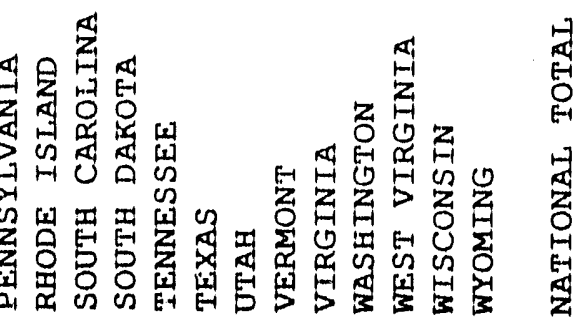




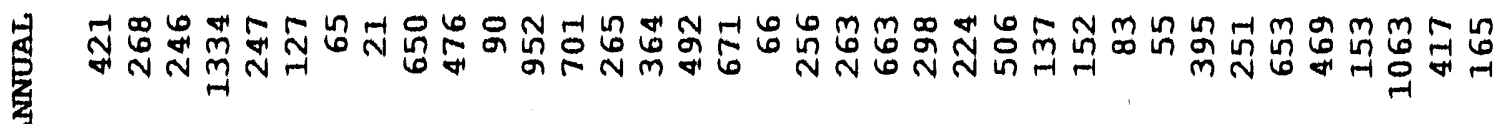

苔

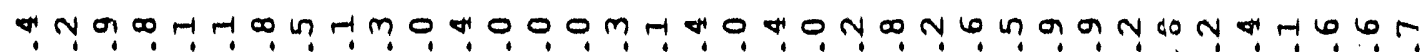

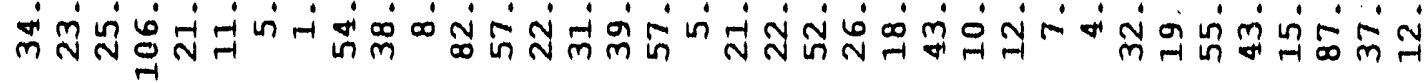

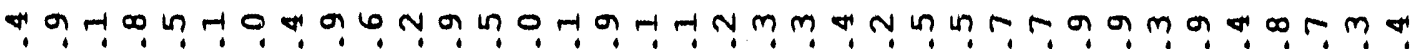
लें

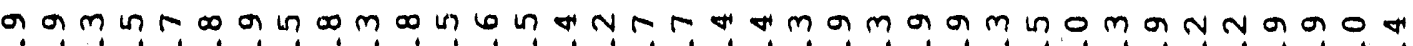

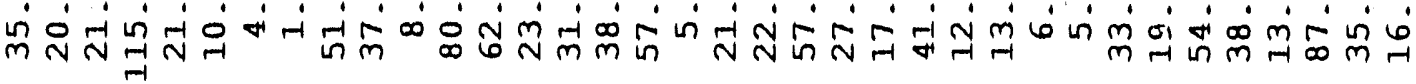

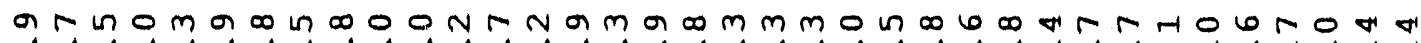
m

D य.

พ

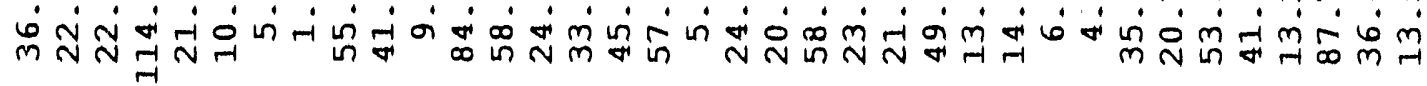

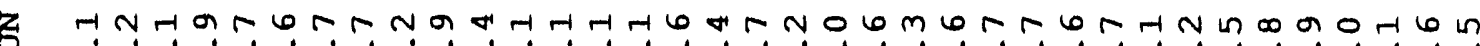
m

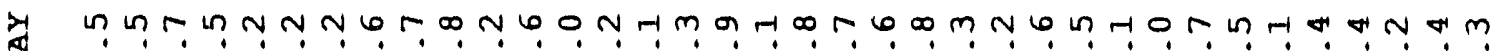
है m

荧

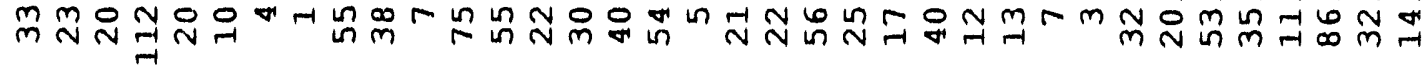

每

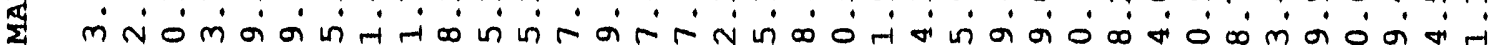

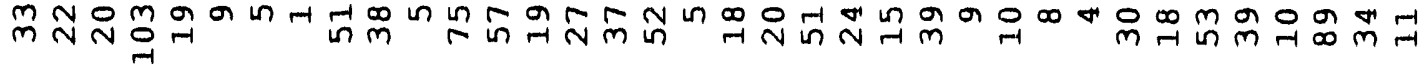

om mo or. n n

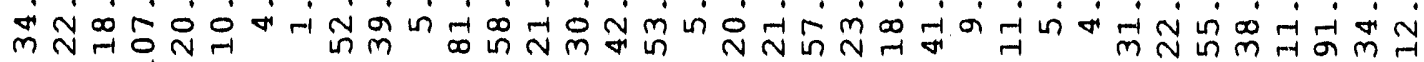

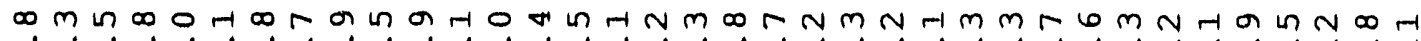

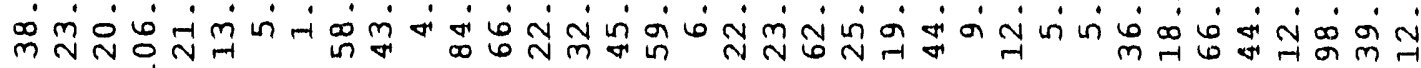

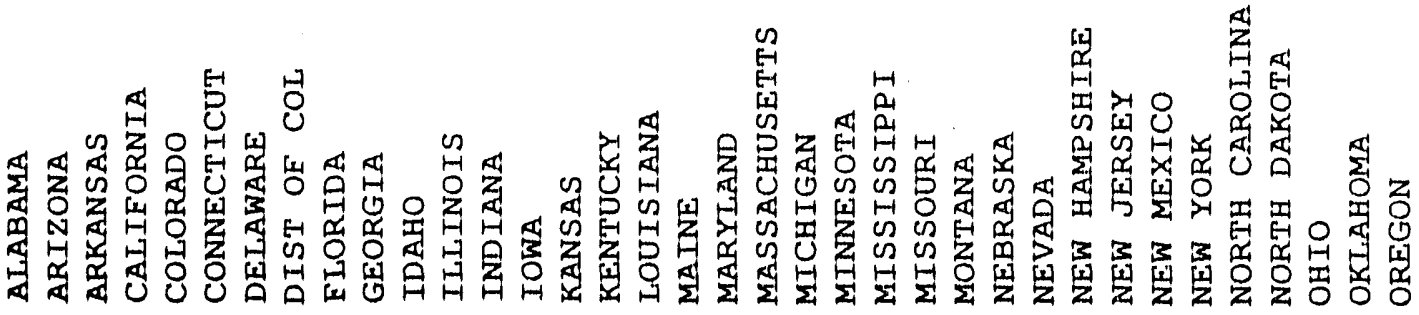




$$
\begin{aligned}
& \text { 罗 } \\
& \text { 畄 } \\
& \text { Z }
\end{aligned}
$$

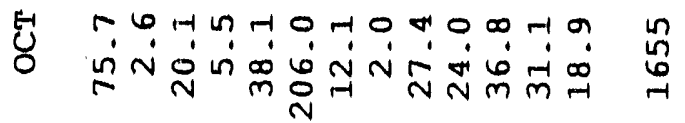

$$
\begin{aligned}
& \text { M } \\
& \text { Q }
\end{aligned}
$$

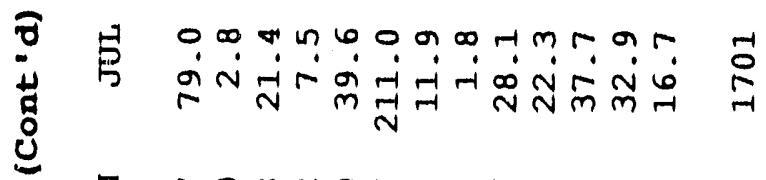

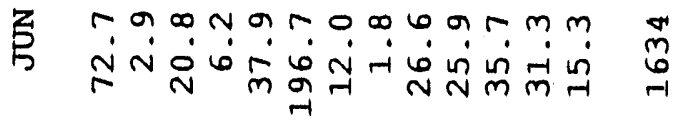

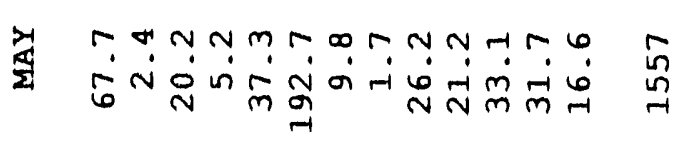

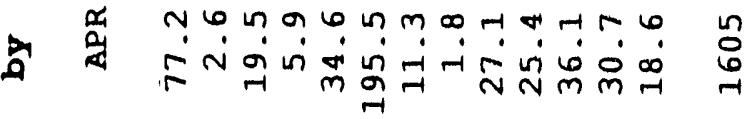

$$
\begin{aligned}
& \text { 量 }
\end{aligned}
$$

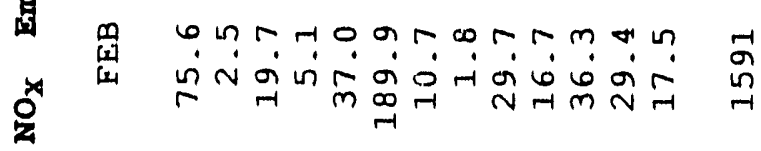

$$
\begin{aligned}
& \text { मु Z }
\end{aligned}
$$

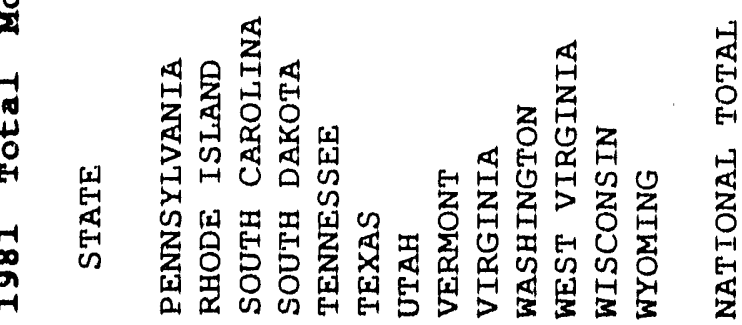




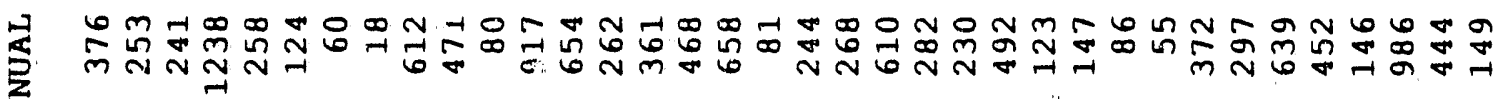

U $\div$ แ

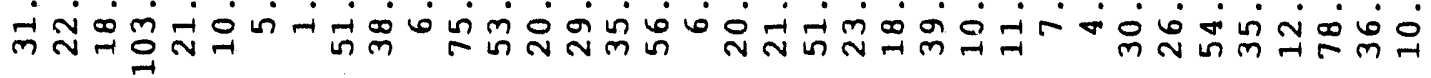

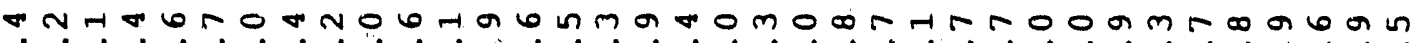

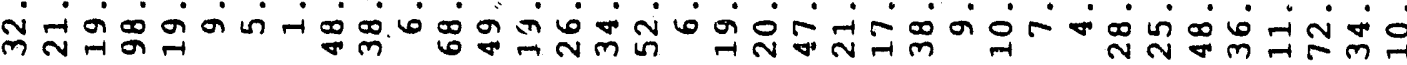

E H

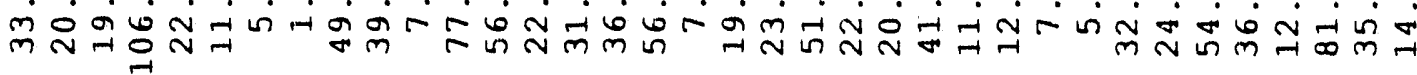

Dm

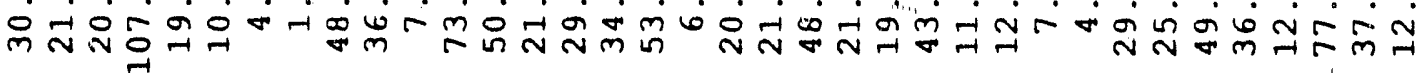

क

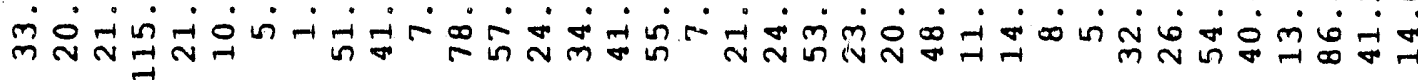

Hina 0 n

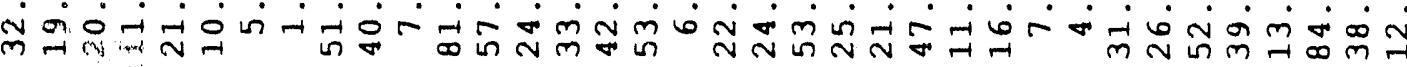

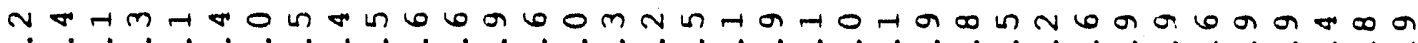

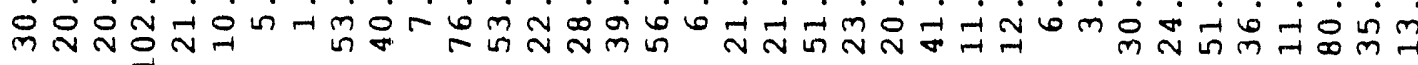

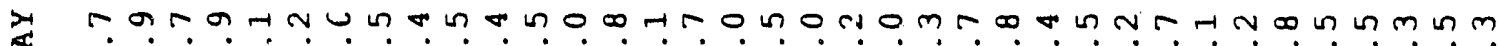

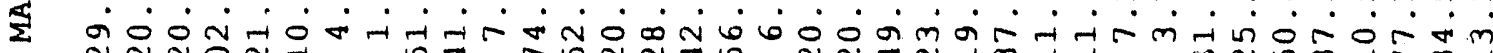

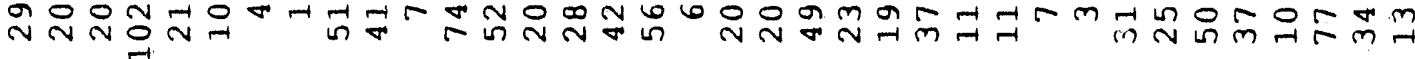

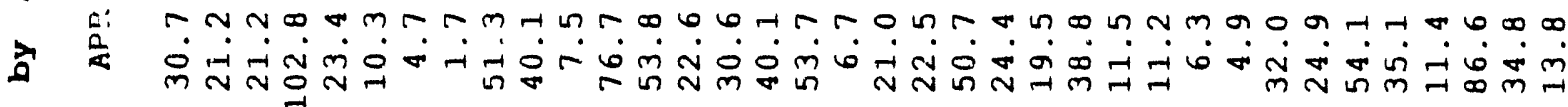

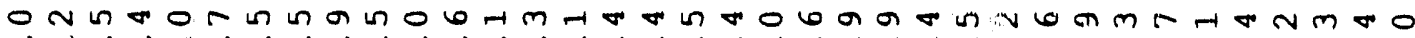

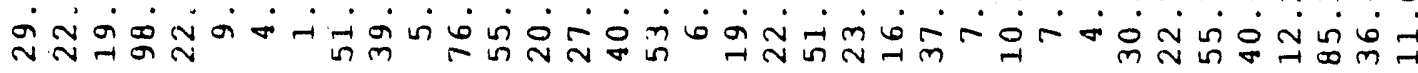

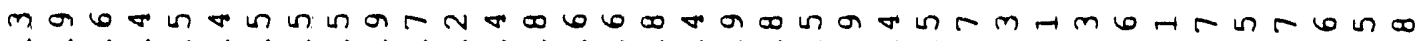

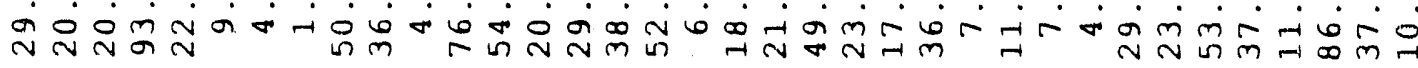

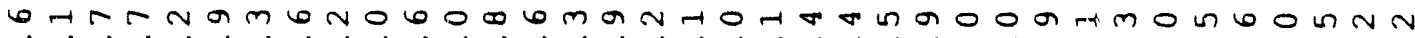

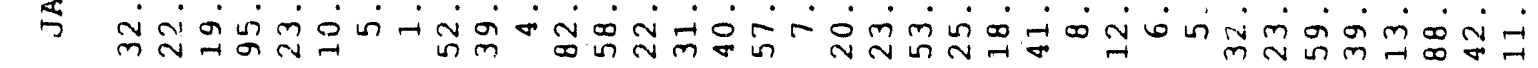

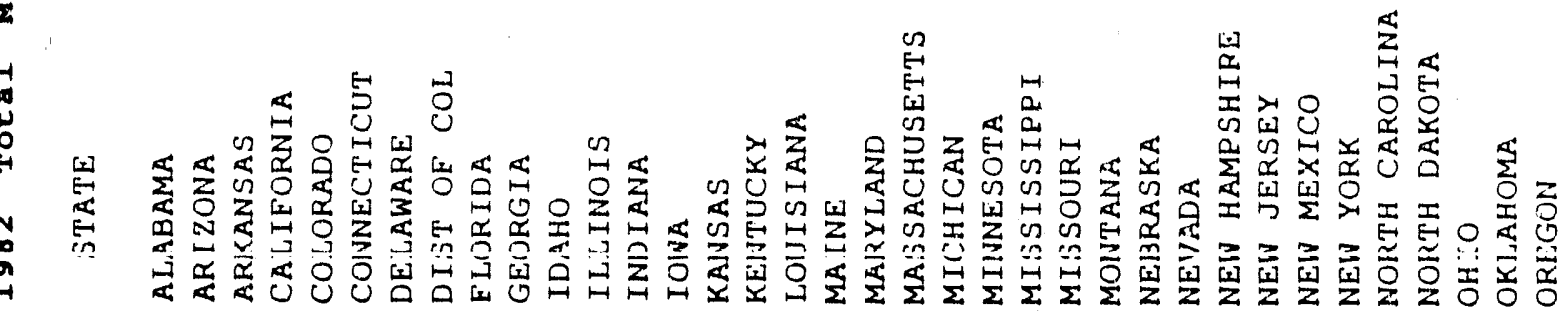




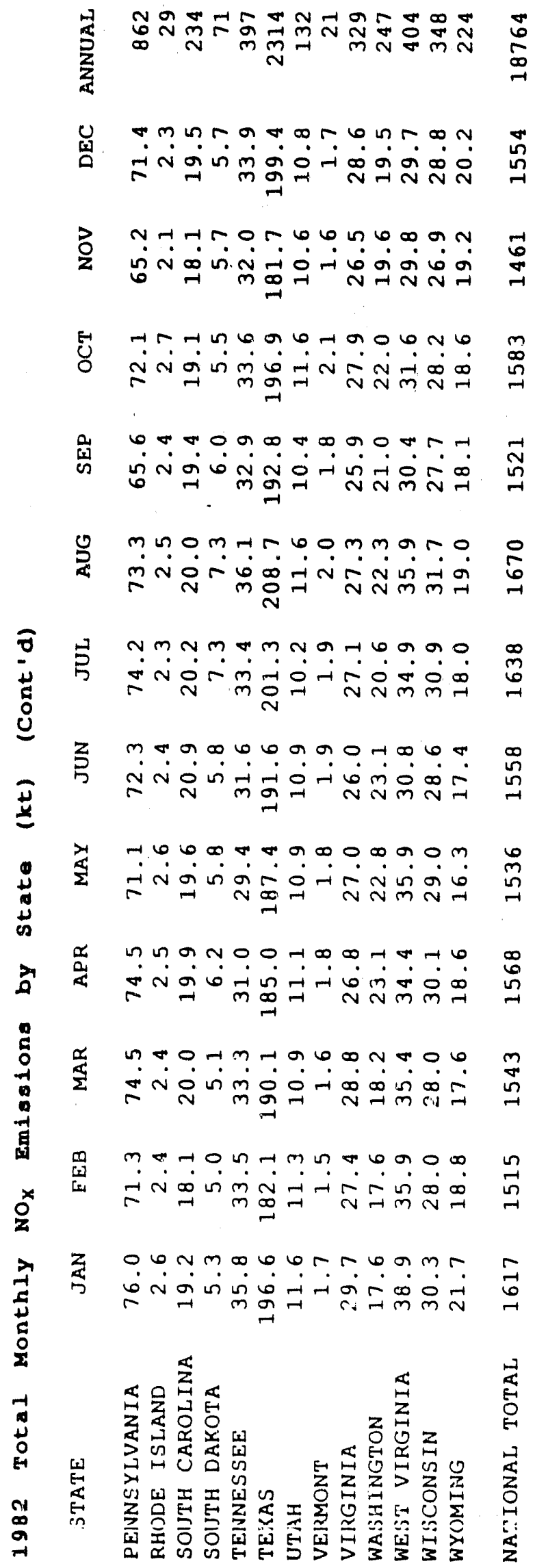




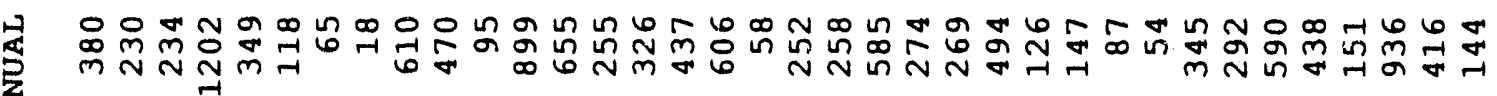
$\sum_{4}$

o $2 m \infty$ m

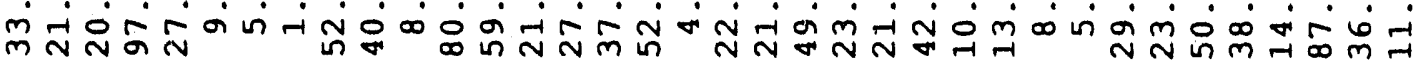

$3 \quad$ morotrm

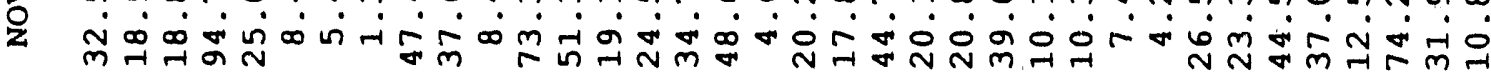

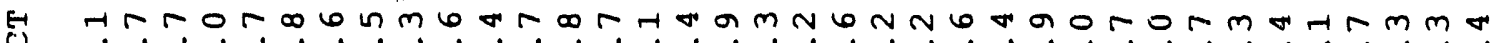

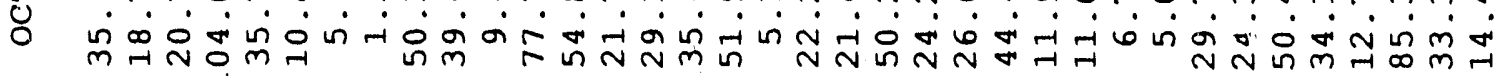

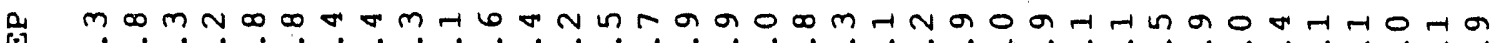
ص

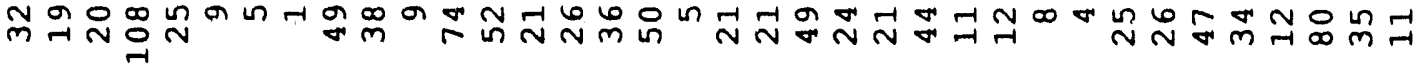

U m

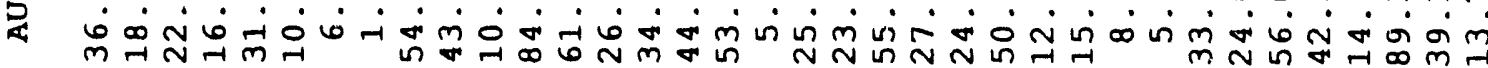

A $\quad \infty$ moram

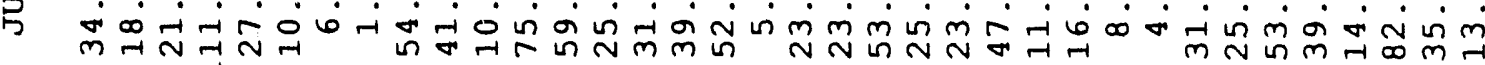

z

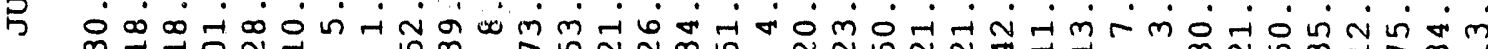

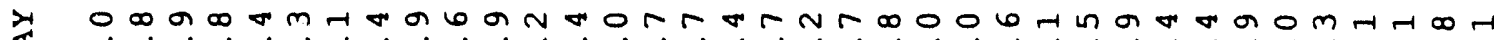

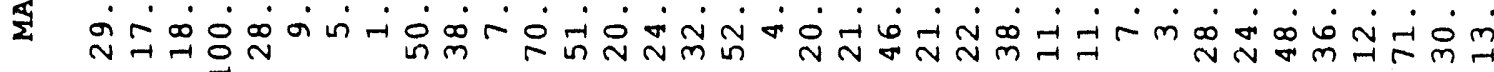

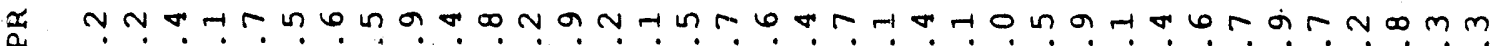
a

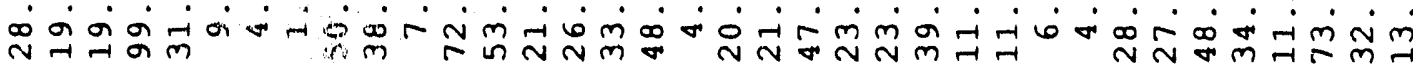

aramon-fan इ

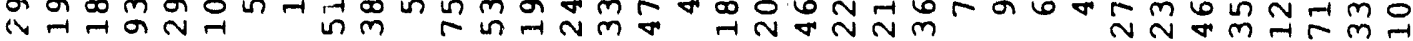

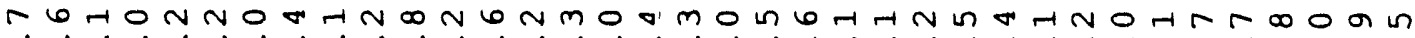

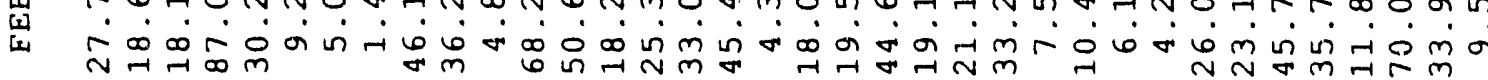

省 发 


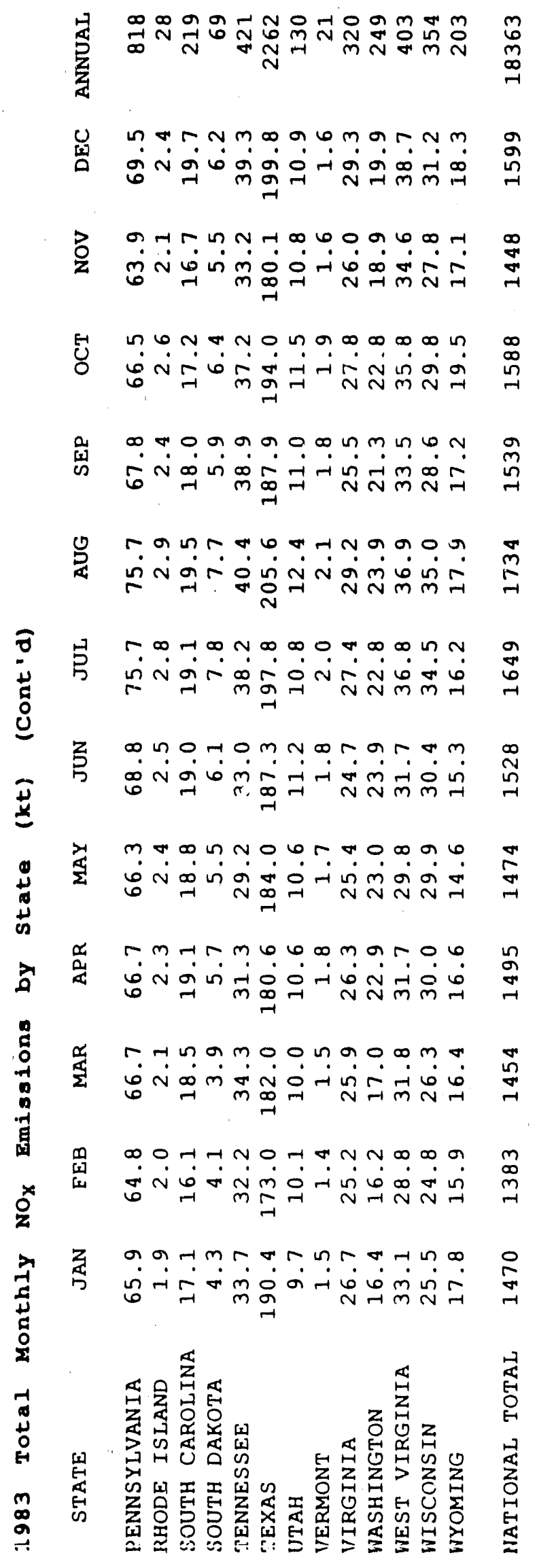


勾

U

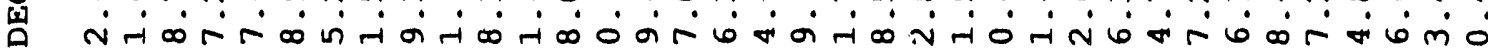

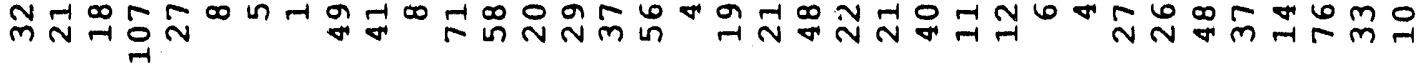

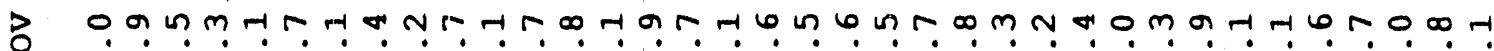

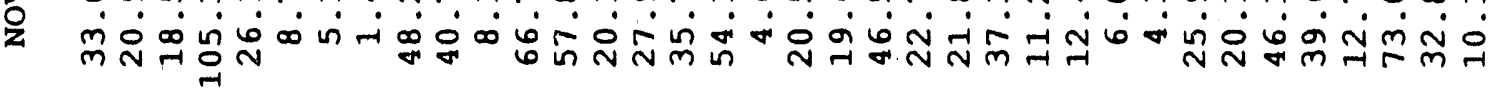

H mon

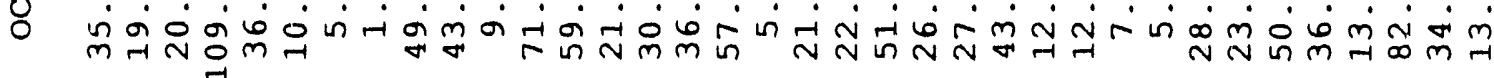

Mro.

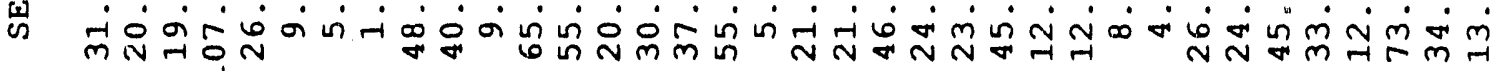

y n

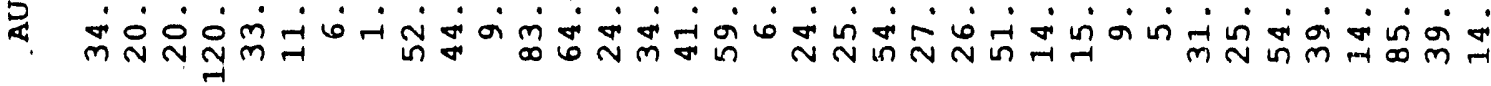

A m

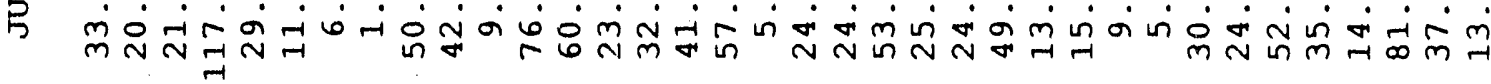

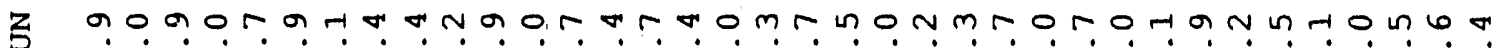

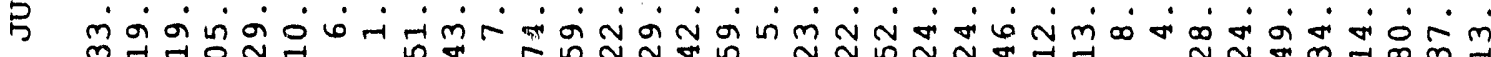

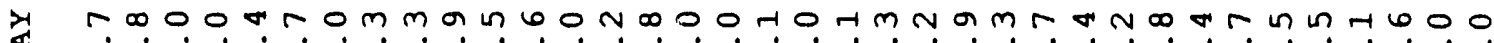

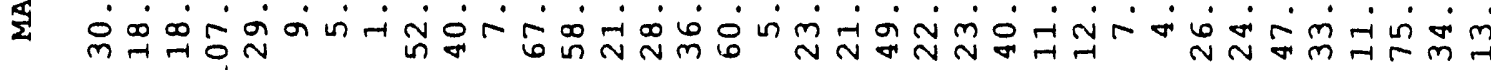

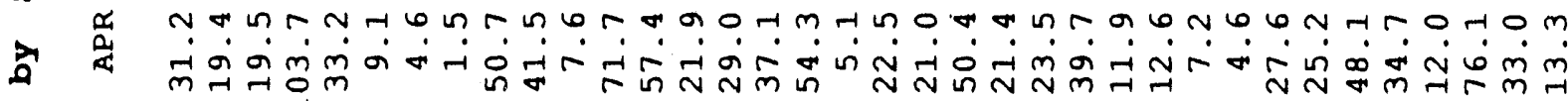

a $\ln m \sim N$ in

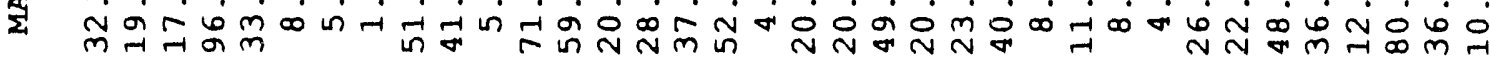

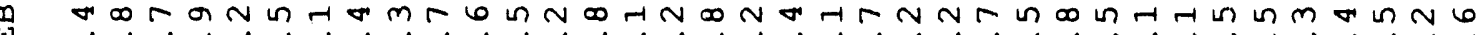

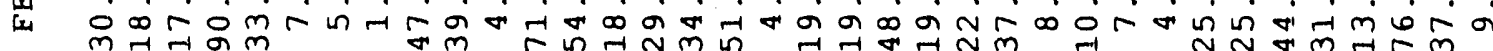

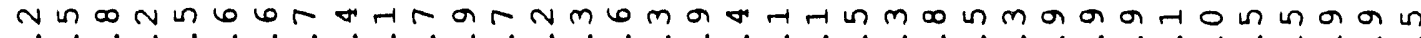

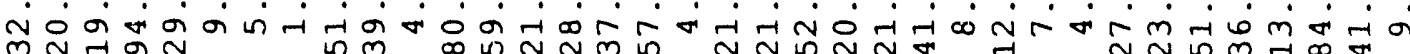




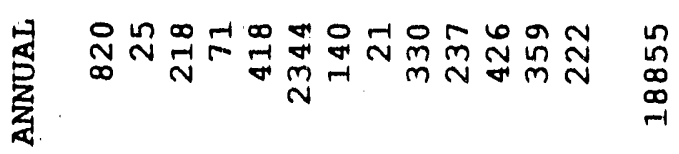

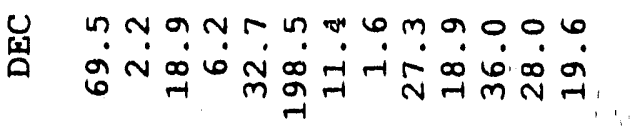

Z

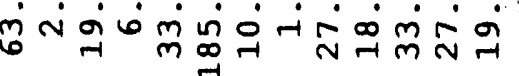

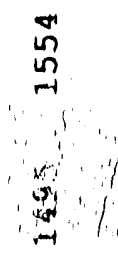

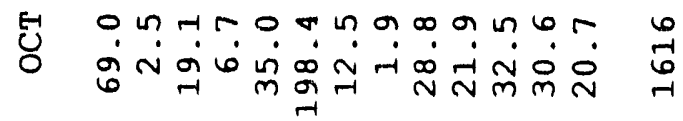

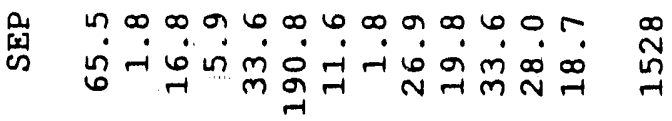

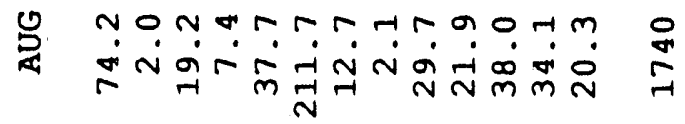

0

0
0
0

$\stackrel{ \pm}{ \pm}$

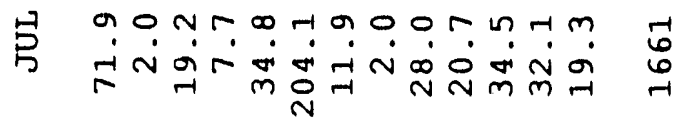

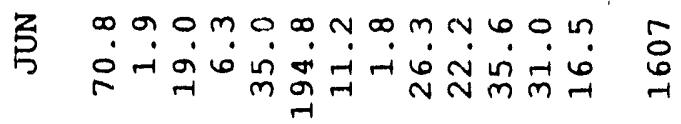

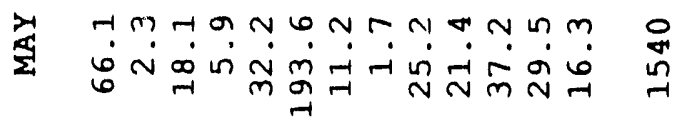

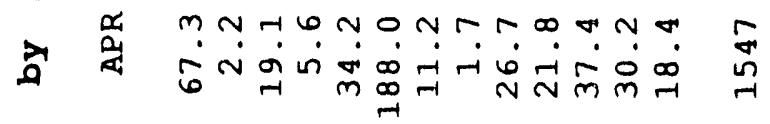

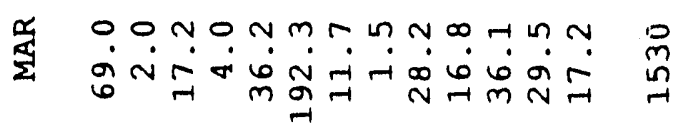

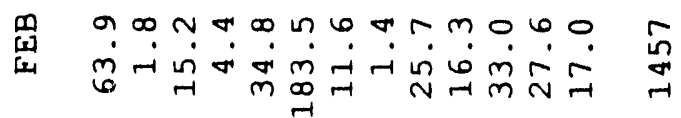

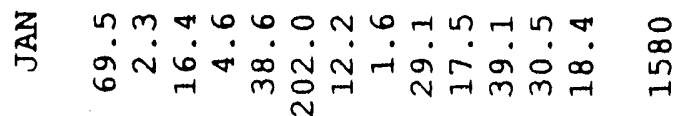

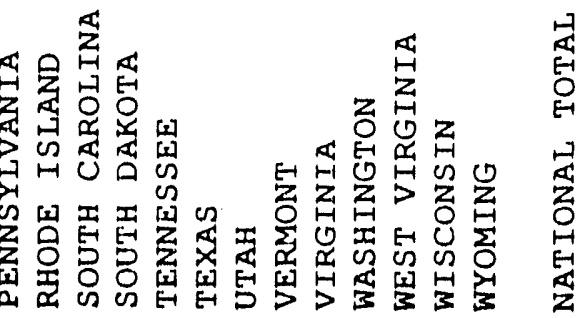




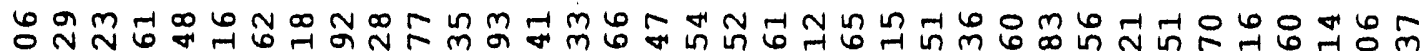

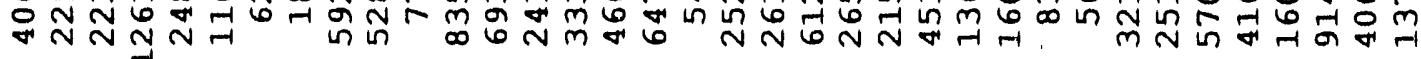

0 m

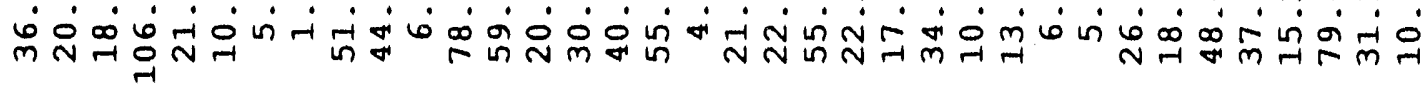

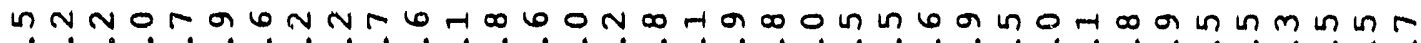

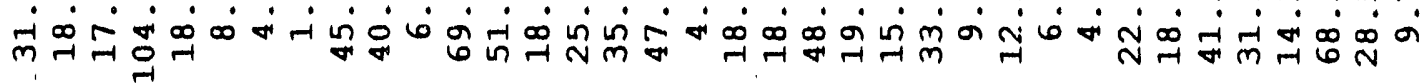

ammammm $m$ m n m

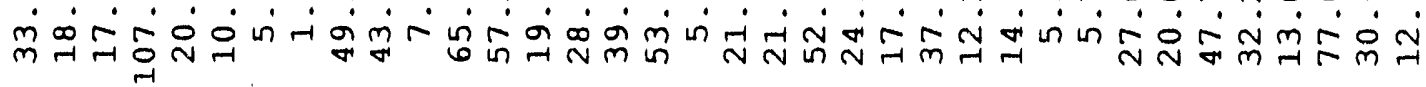

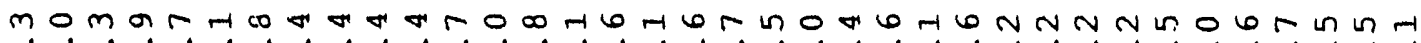

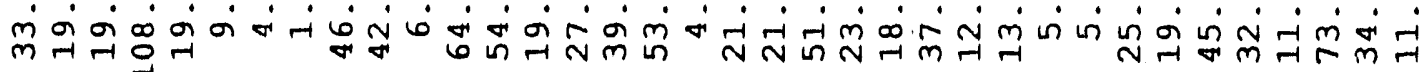

nm 2 n m

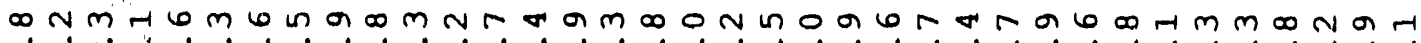

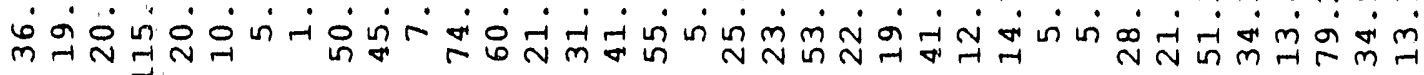

n Ho r.

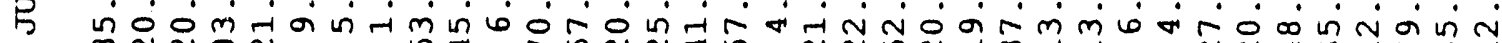

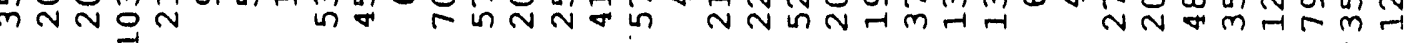

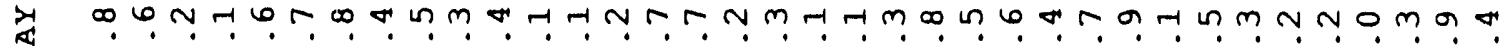
लि ने में

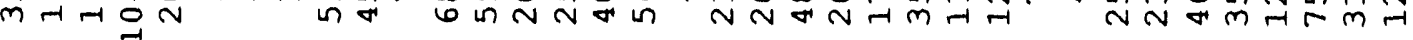

na

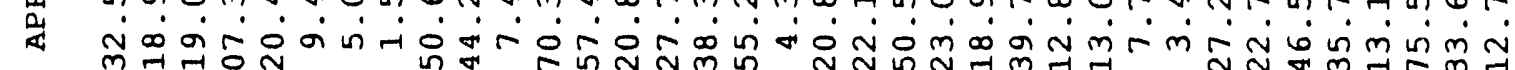

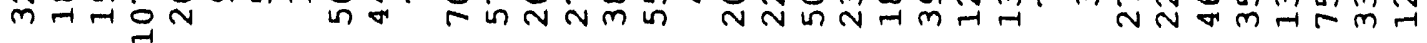

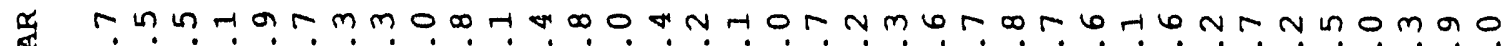

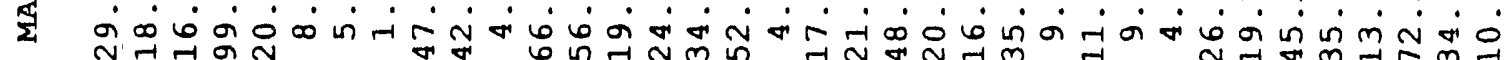

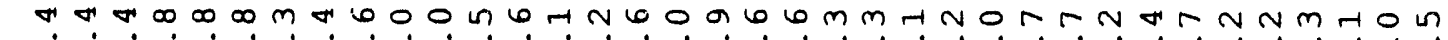
4

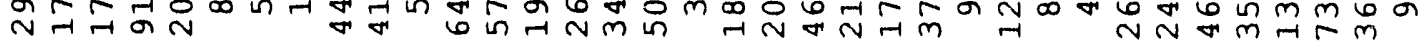

z

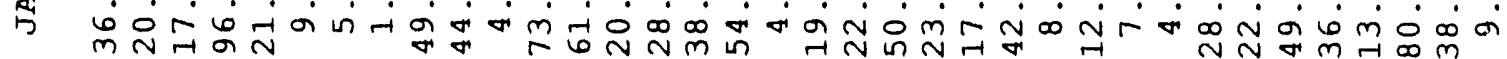

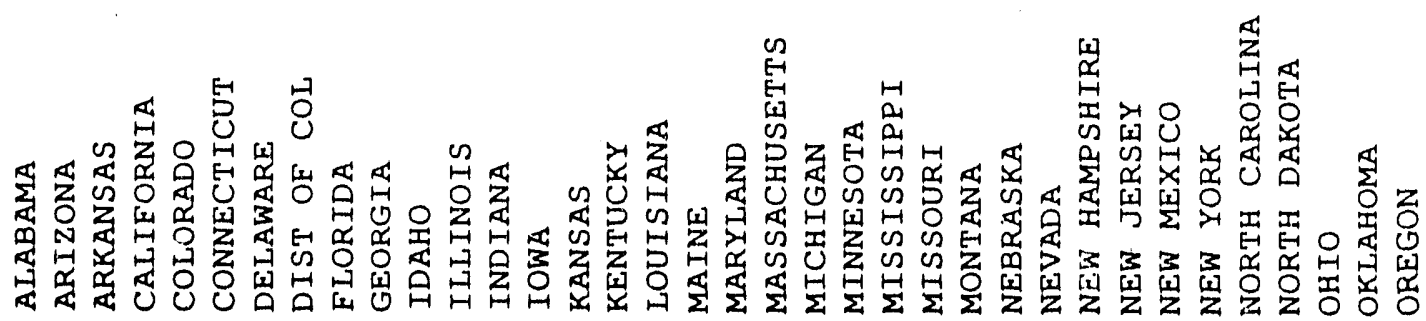




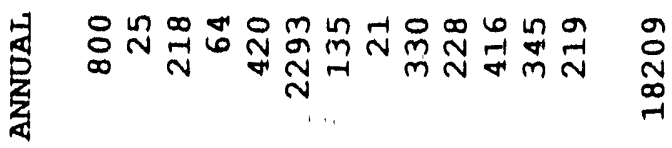

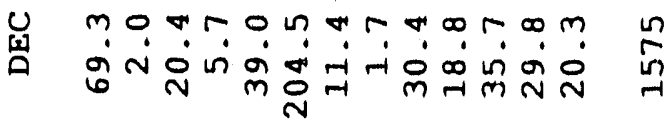

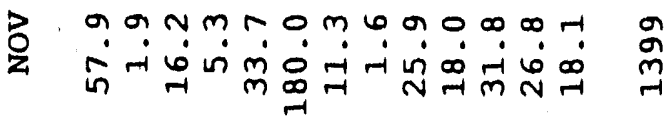

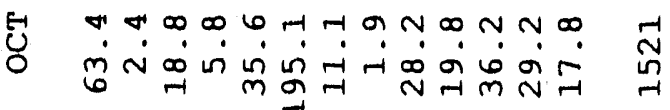

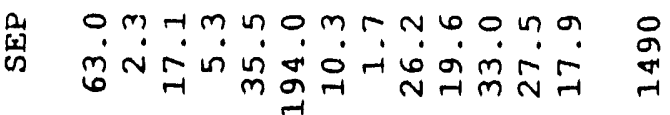

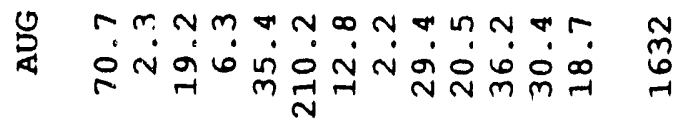

0
$\vdots$
0
0

$\underline{ \pm}$

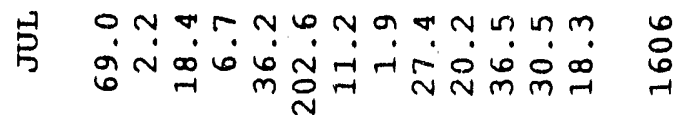

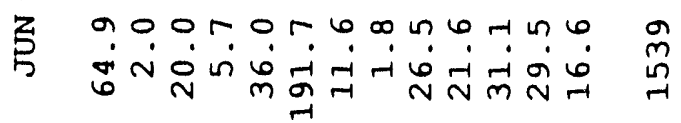

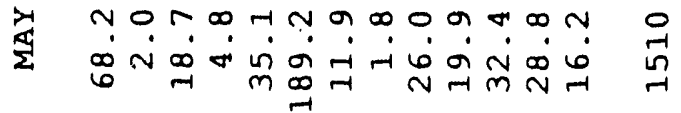

孚

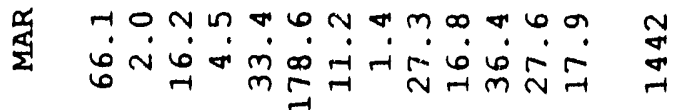

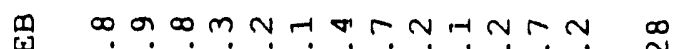

lu

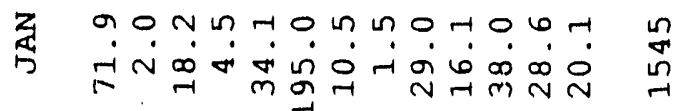

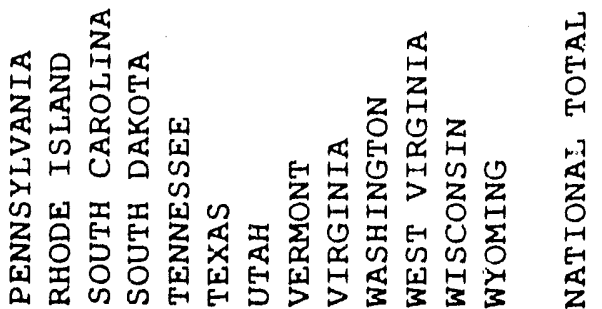


แn 4n

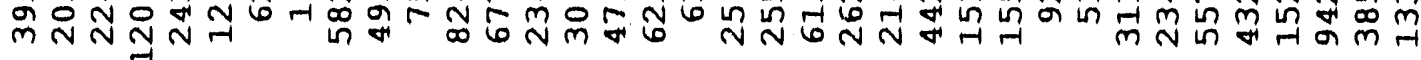

$\forall r \infty m a 0$,

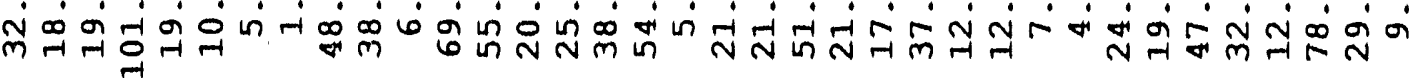

H

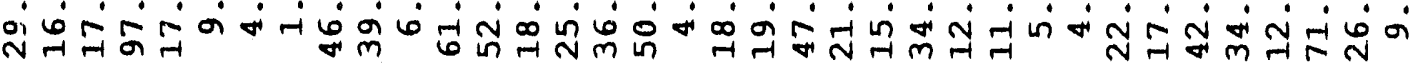

lo 0 in 00 H

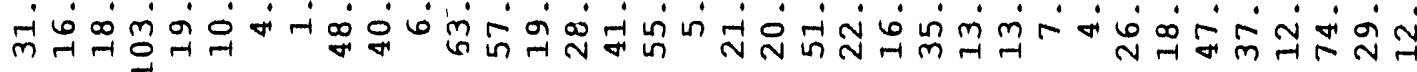

N.

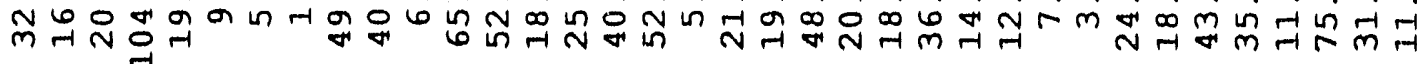

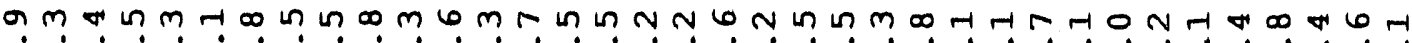
mㄷN

L

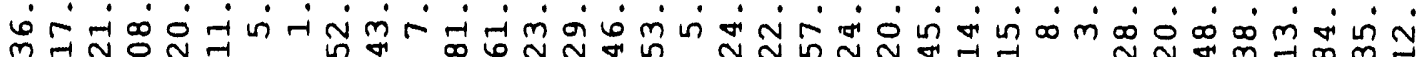

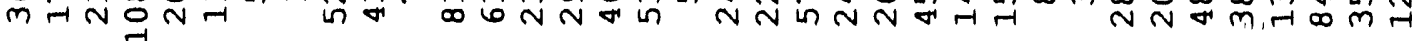

r

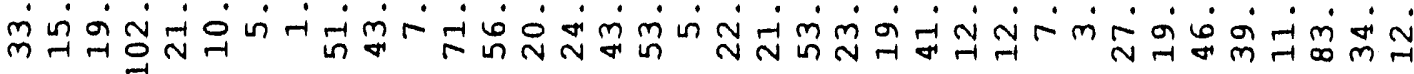

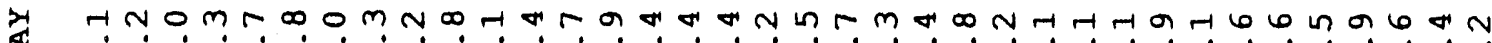

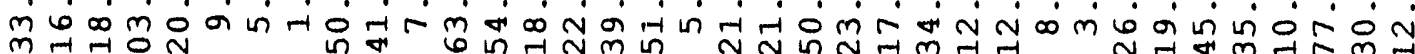
更

a $r$ in

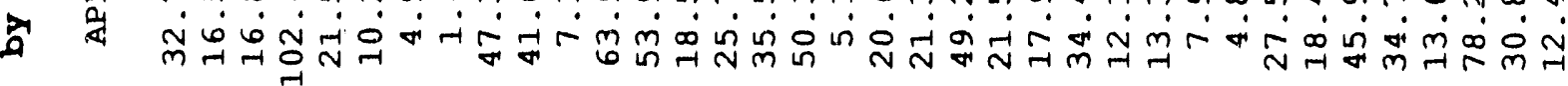

\$

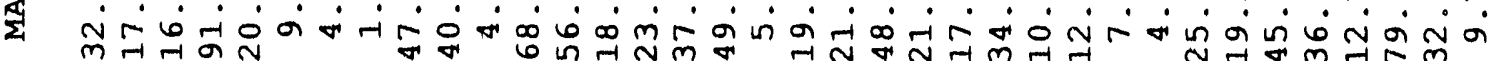

Ho

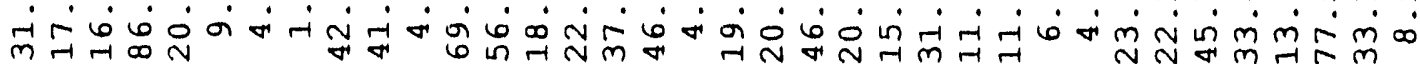

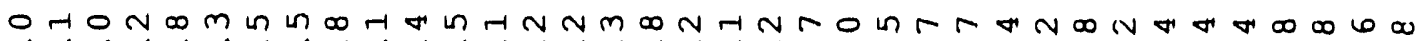

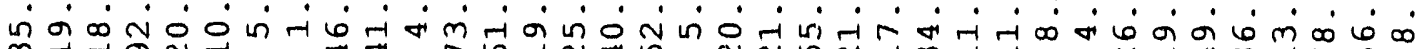

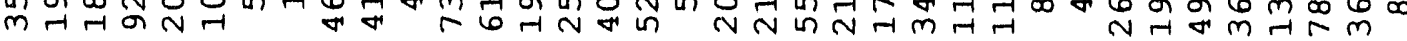

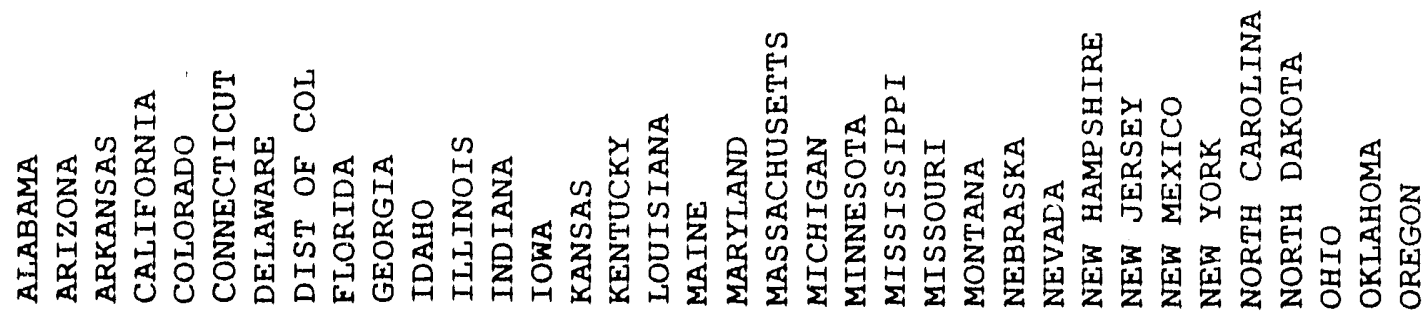




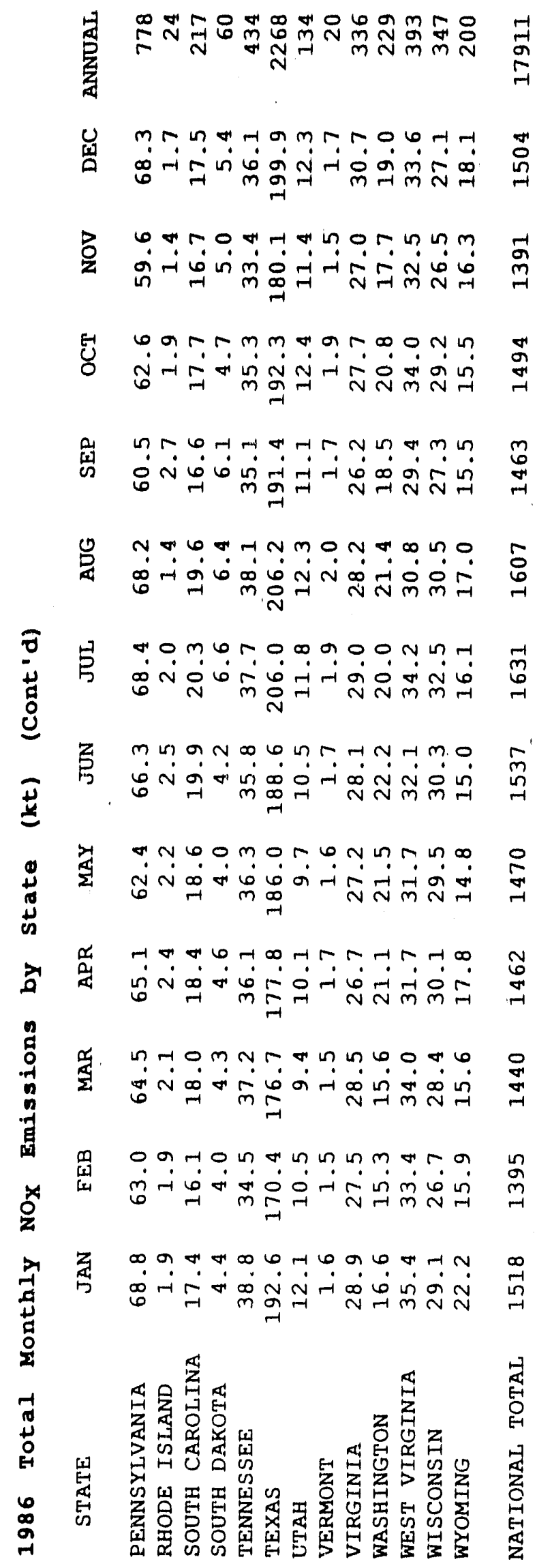




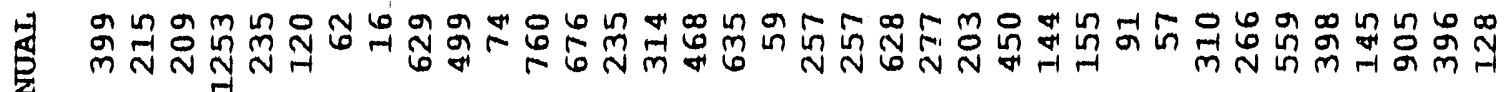

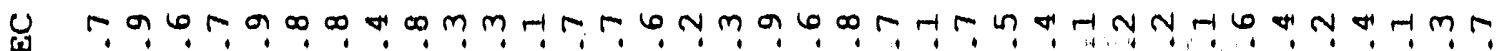

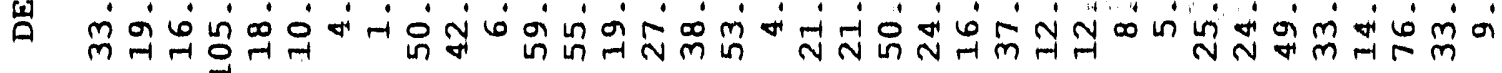

b $0 m a n$.

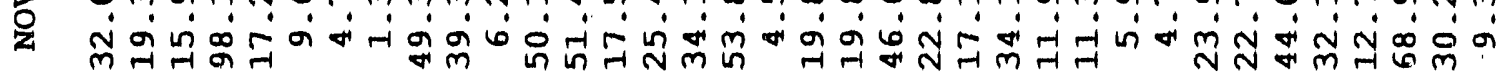

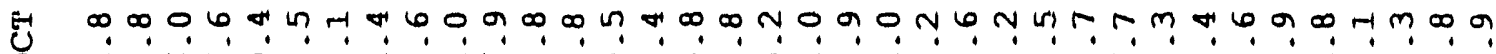
U

崖 $\infty$ m

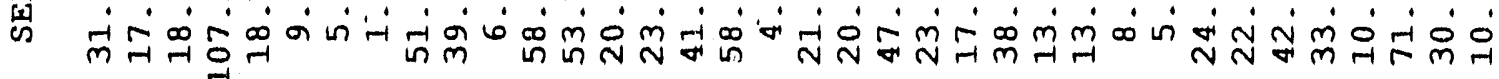

(1)

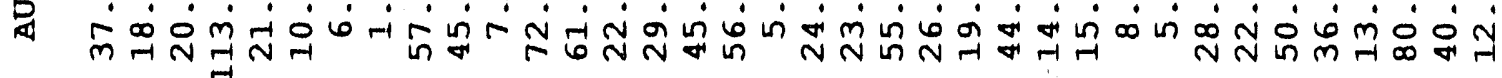

H $m \Gamma N$ n

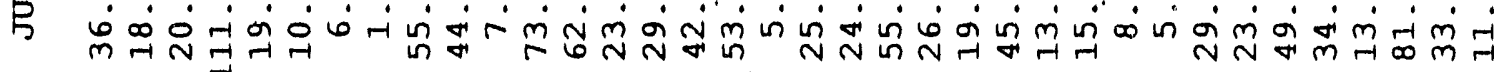

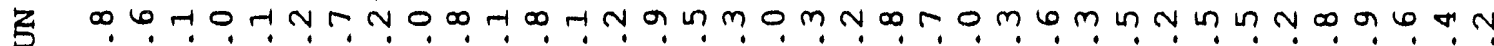

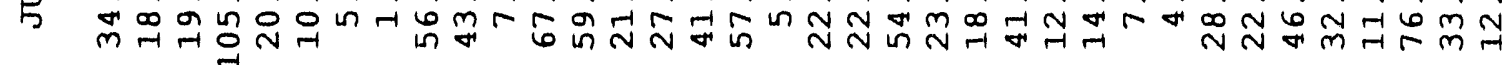

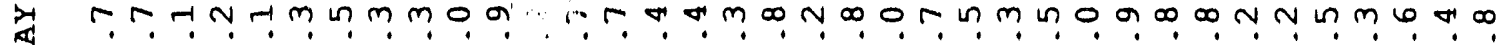
ड mं فं

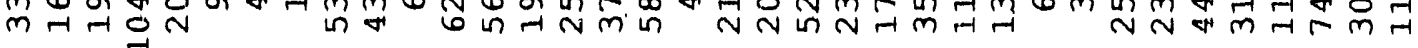

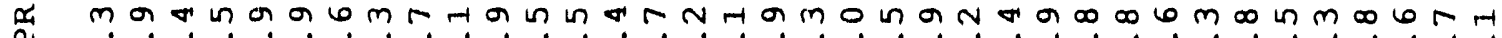

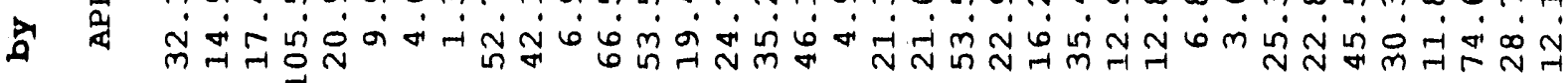

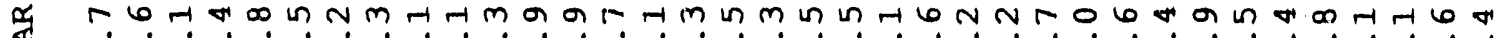

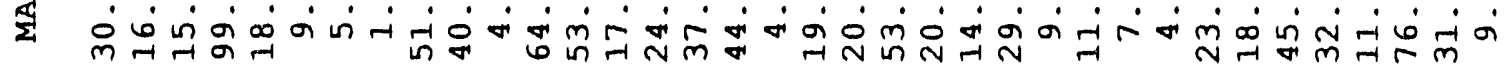

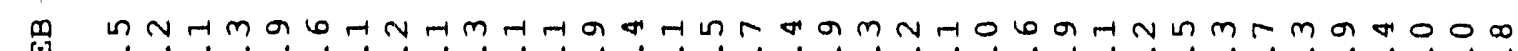

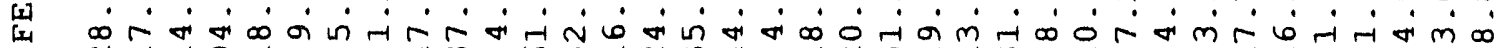

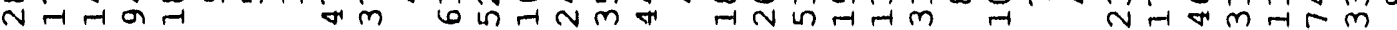

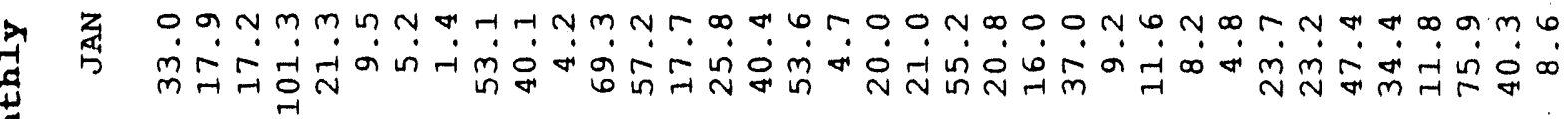




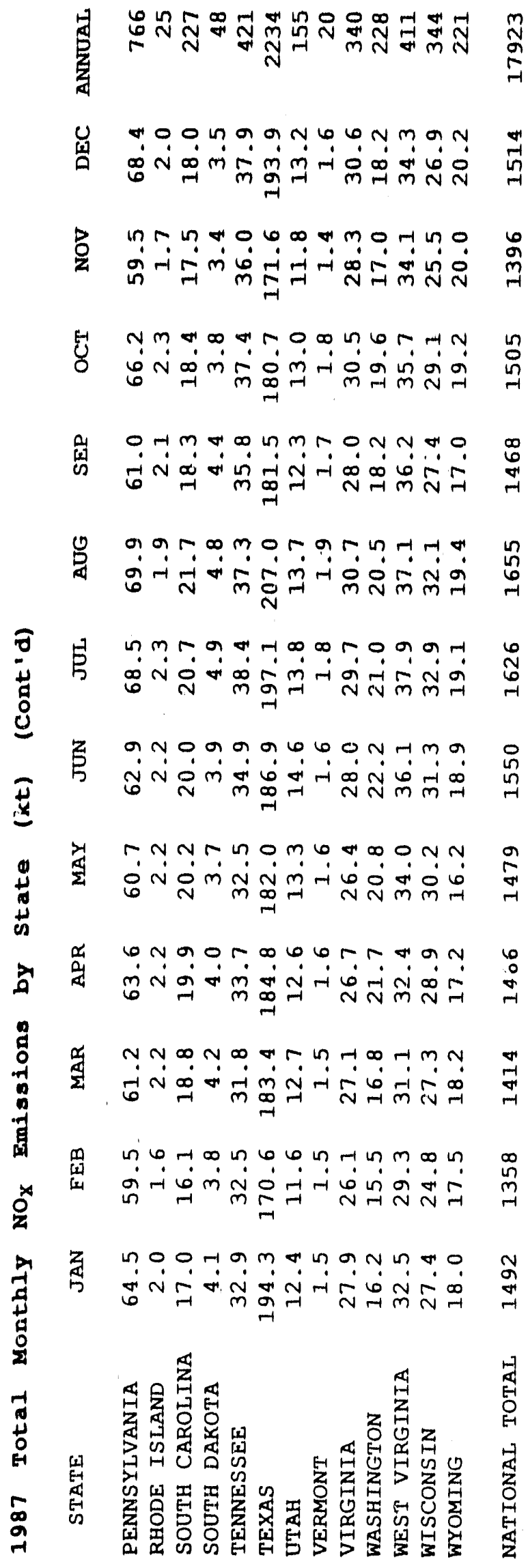




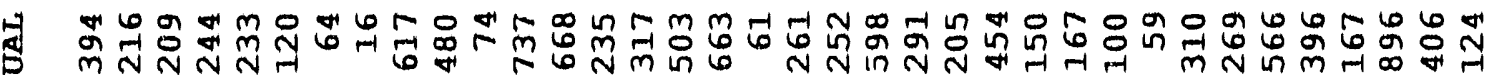
m N N

U $\infty m+6 m \infty 6 \pi+4 \pi 00$ n a mंrín்

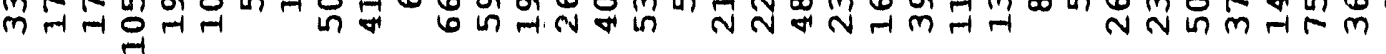

b $m 0$, z $\quad$ -

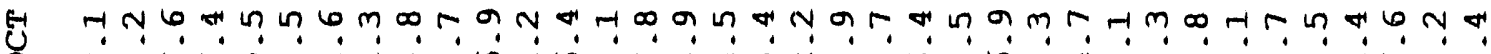

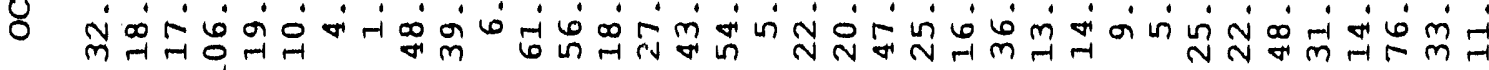

6.

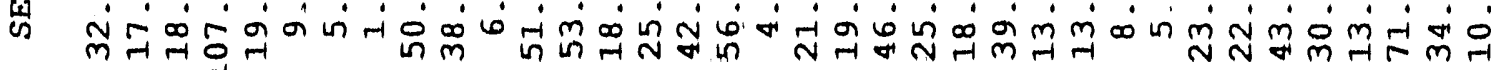

(b) क

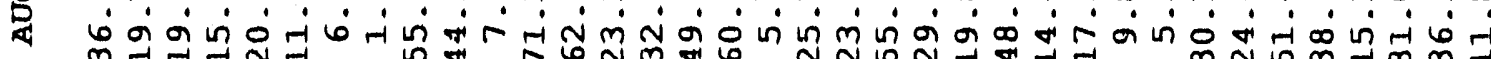

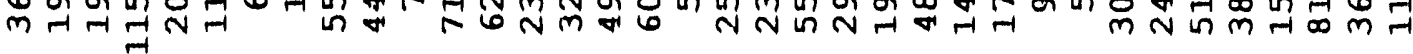

H Tomal

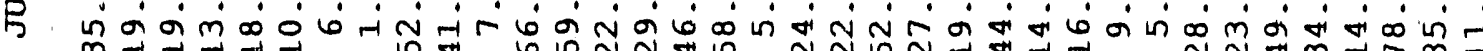

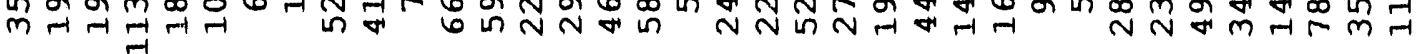

Nom

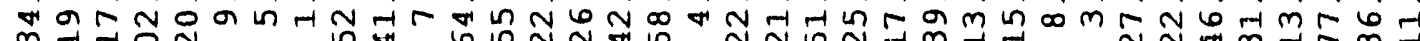
$m \rightarrow-10 N$ 何

M $0 m$ m m 0 m

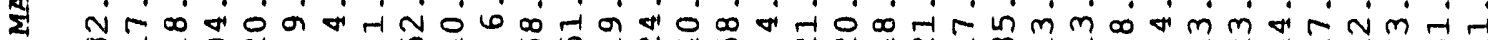

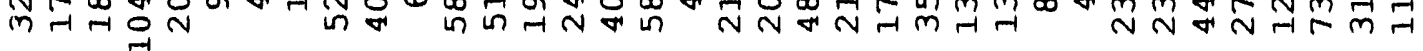

a In $m m$ a

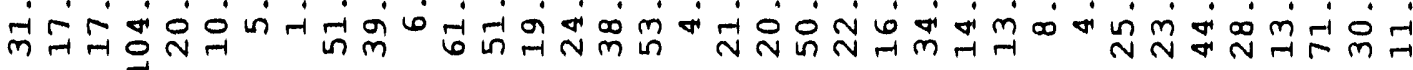

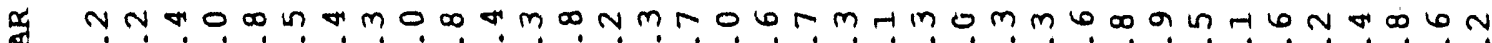

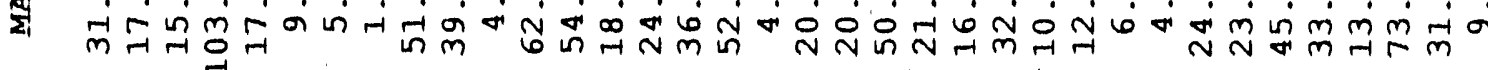

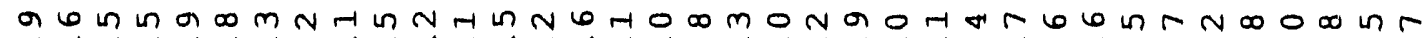
w

OHRm-

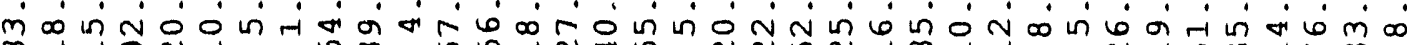

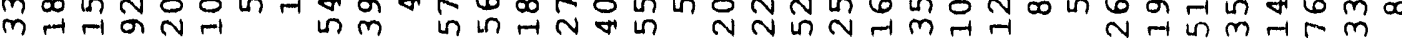




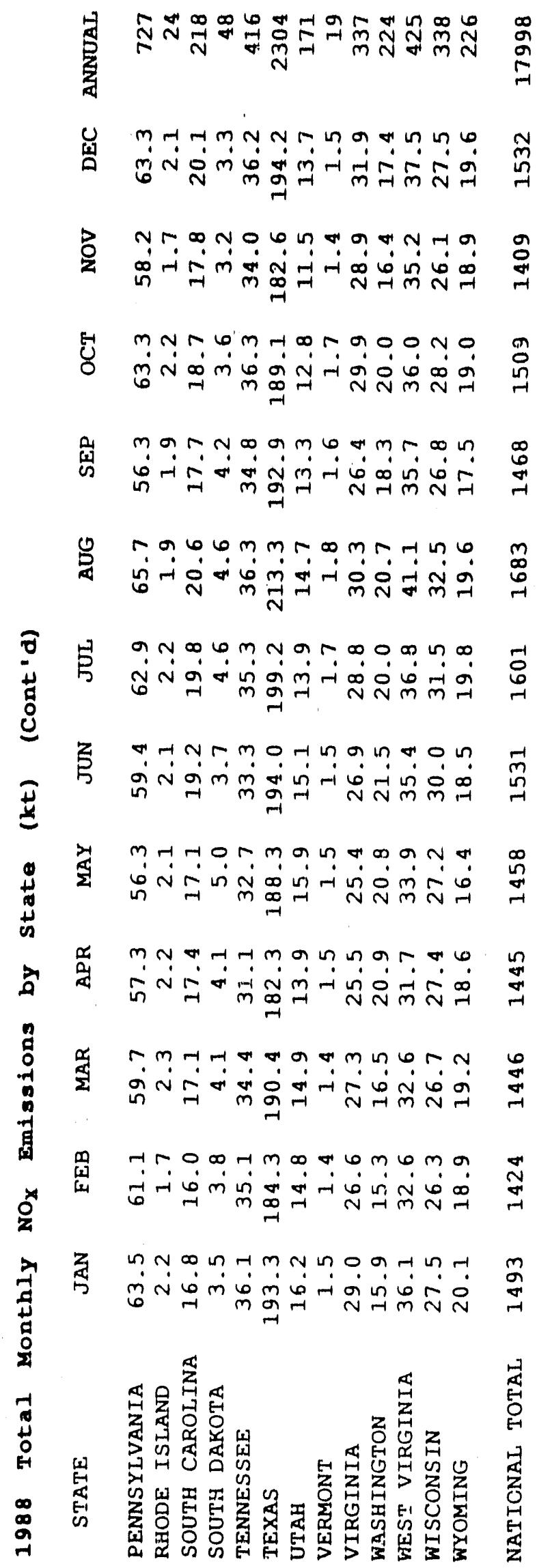


B.2 $\mathrm{SO}_{2}$ Emissions by Month and State 


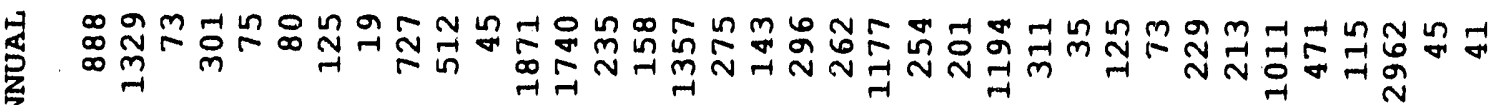

om $m$ o

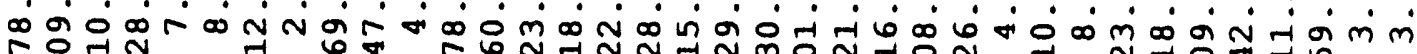

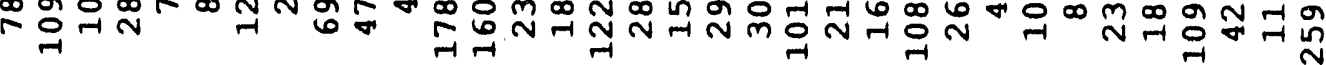

m. 0.00 . 0 .

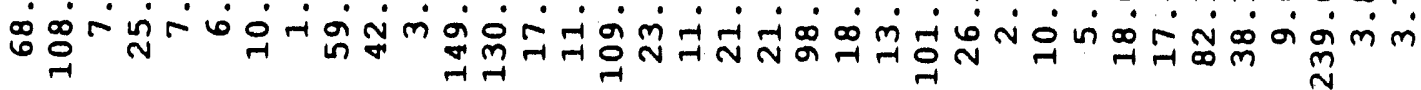

OH J Tm

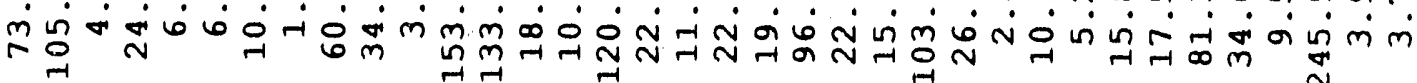

点

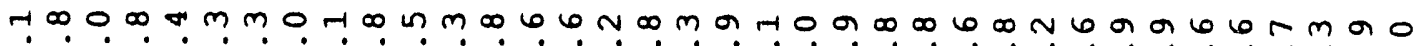

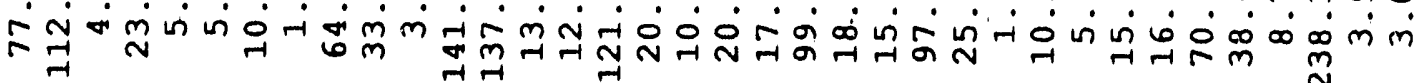

g

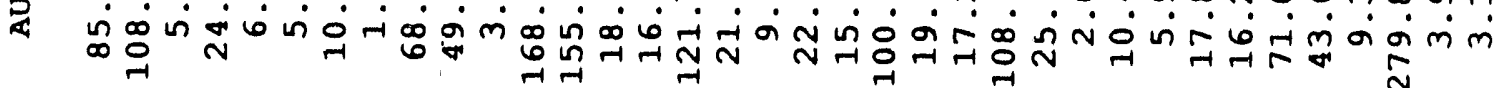

H $\quad \infty m 0,0$ m

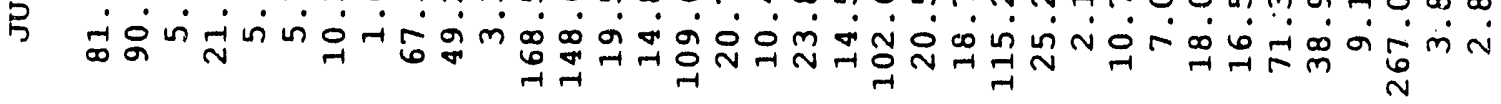

z

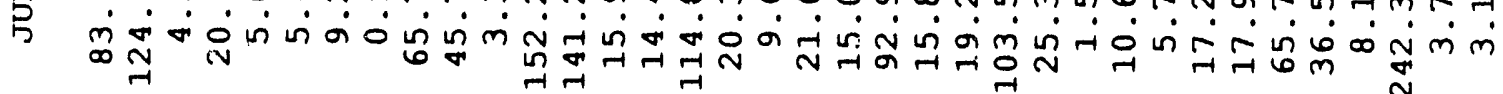

य)

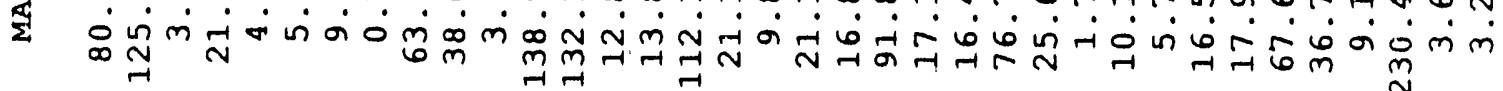

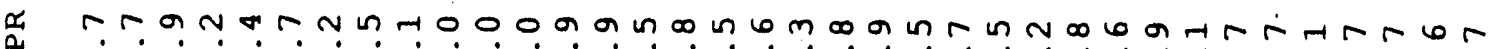

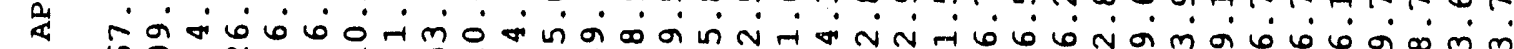
60ㄱㅁ

?

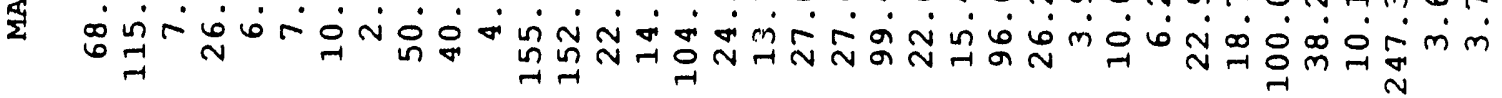

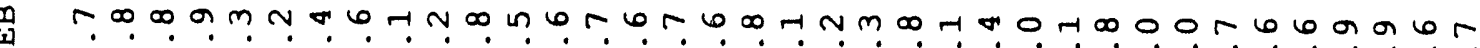

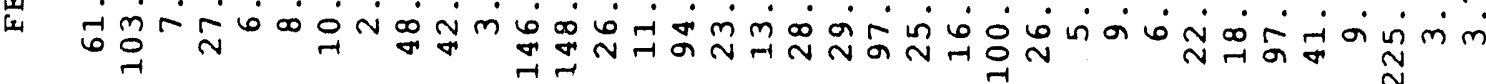
$\because m a r r$. N $n$ D

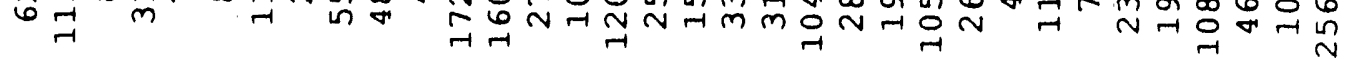

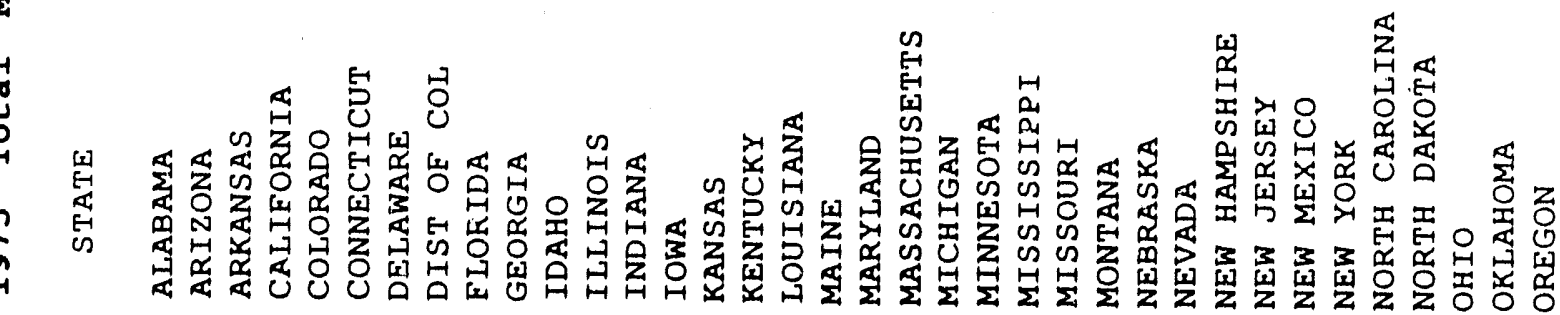




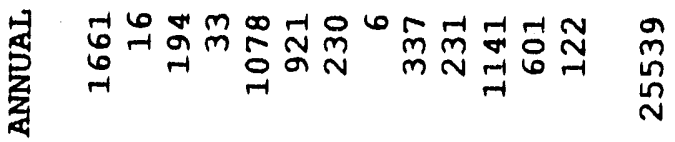

菌

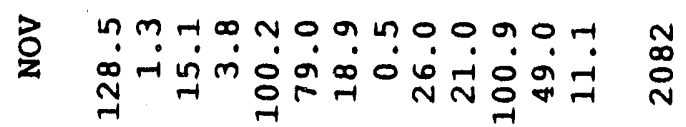

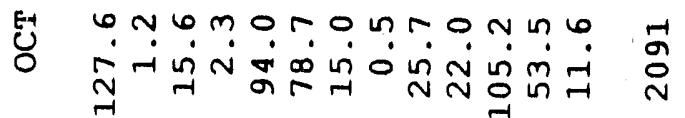

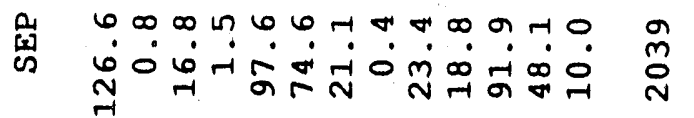

द⿱乛龰己

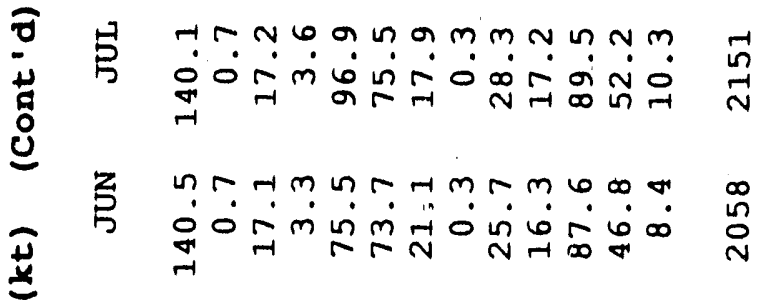

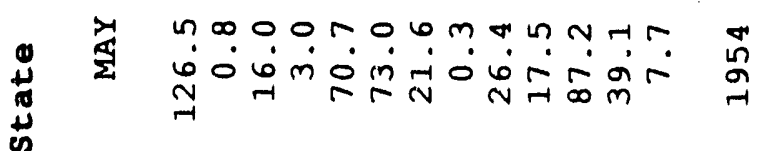

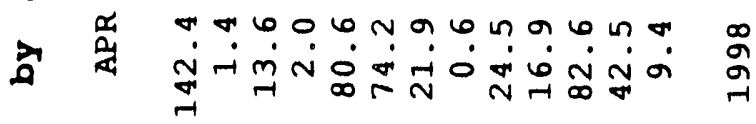

号

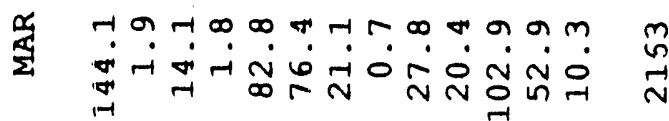

m $\begin{aligned} & 0+1 \\ & \text { m }\end{aligned}$

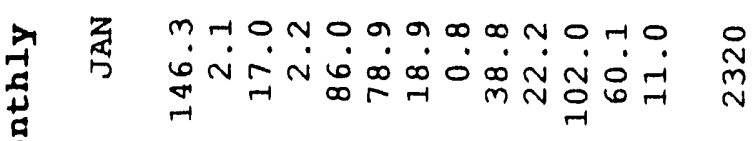

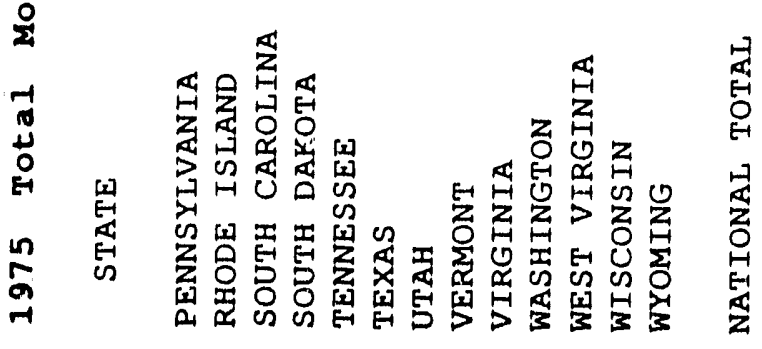




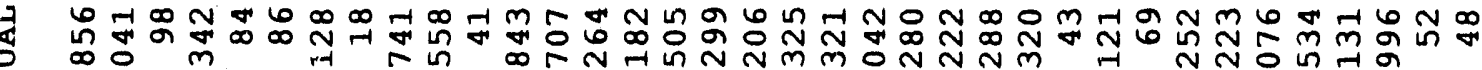

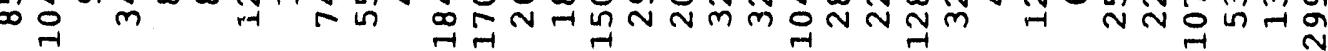

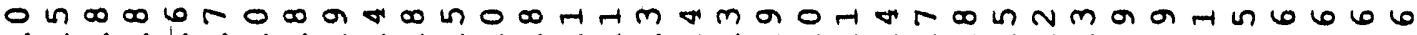

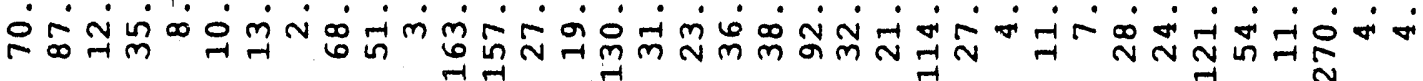

b H n

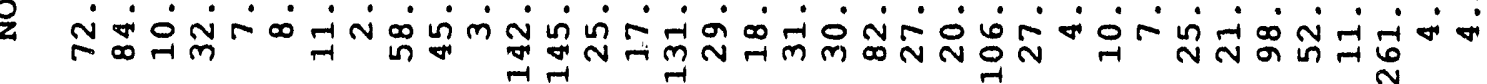

H $\infty N m$ m 요 숭

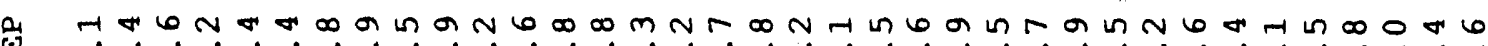

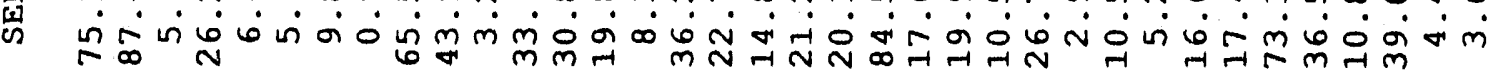

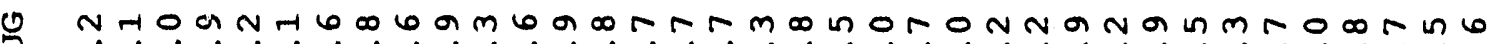

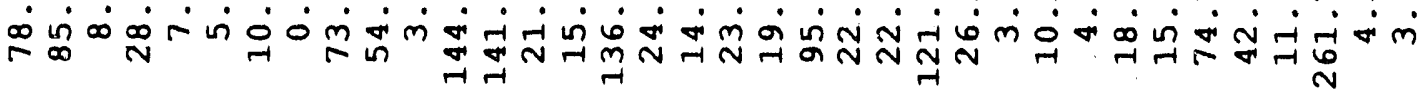

द on 0 ต m द

z $00 m 60$ n

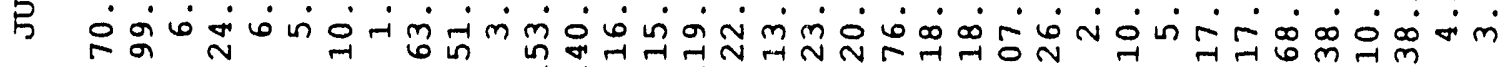

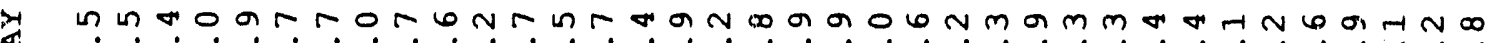
य oब $N$ in 㠃

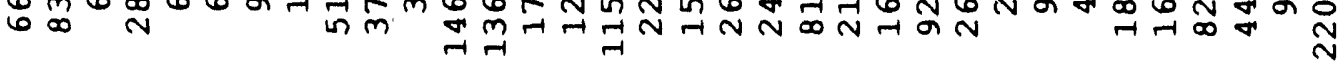

6o 0 n to tha

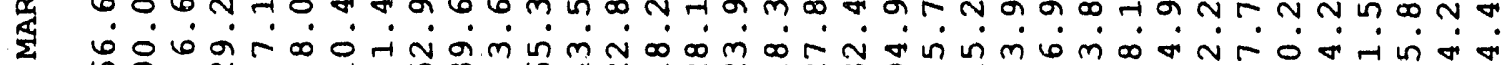
อㅇํ

$m$ m

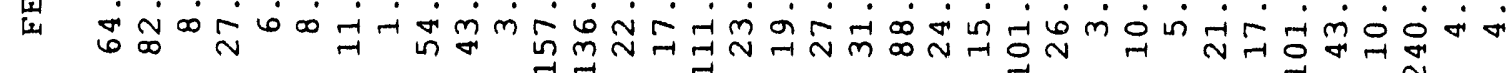

" m

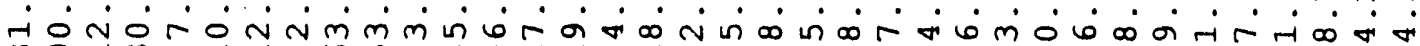

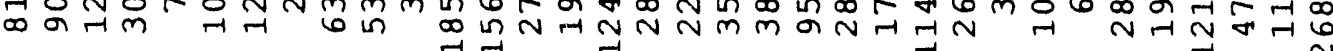




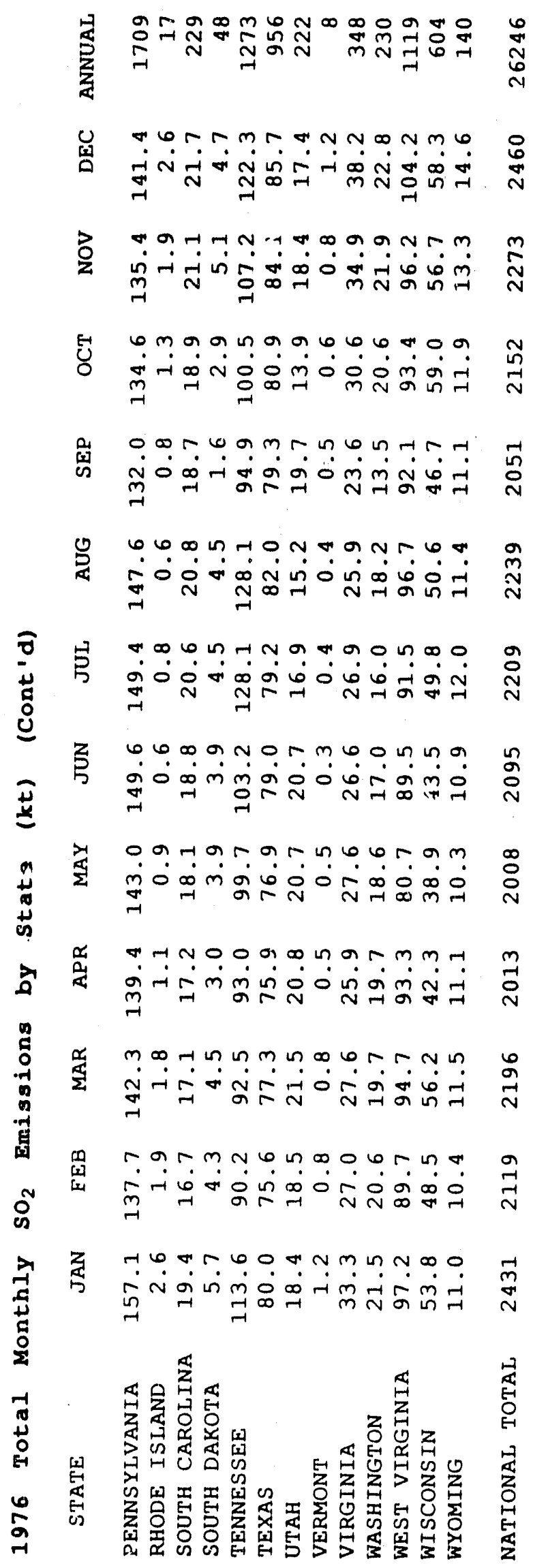




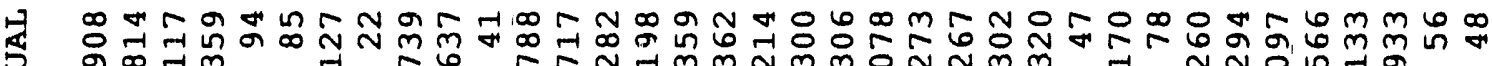

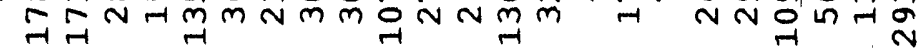

造

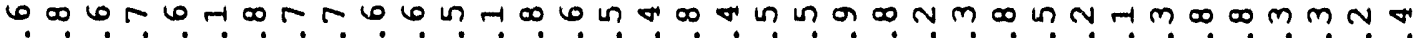

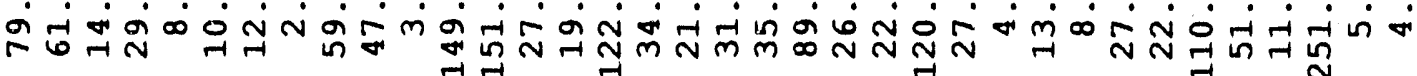

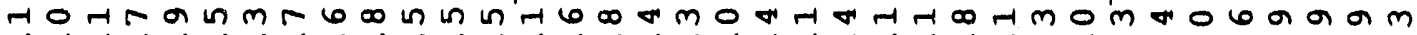

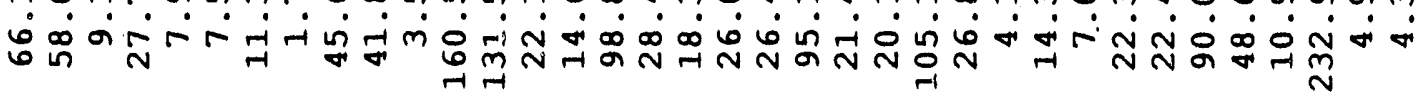

rmonathm

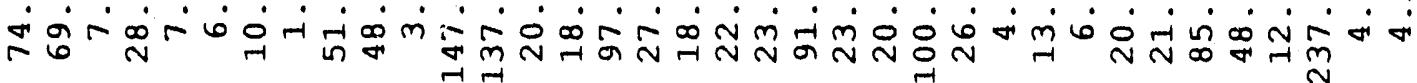

mor

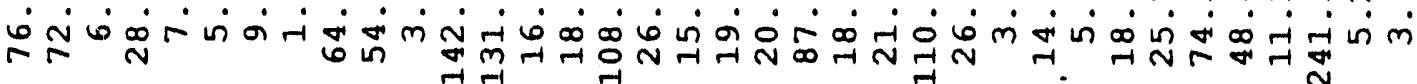

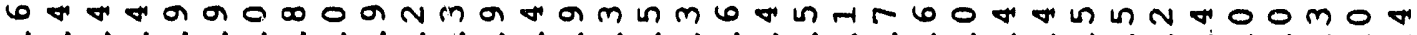

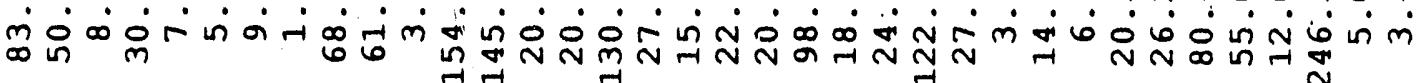

nо

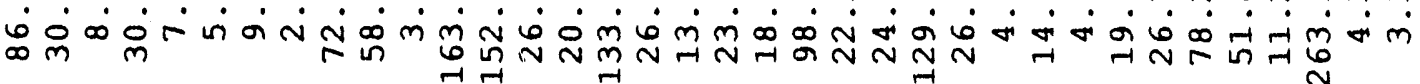

NmNabla a

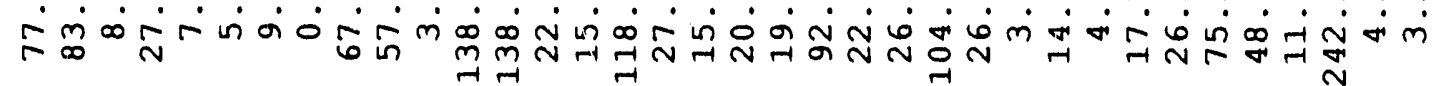

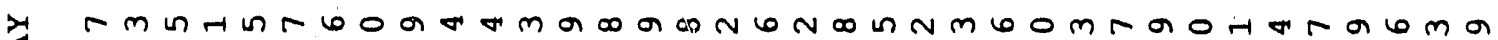

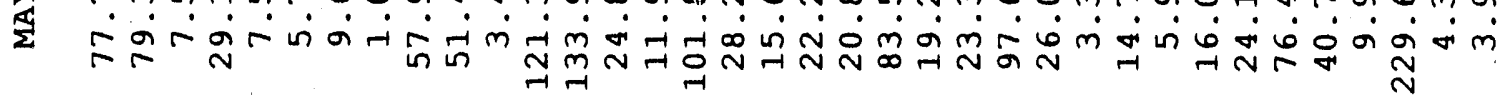

am m

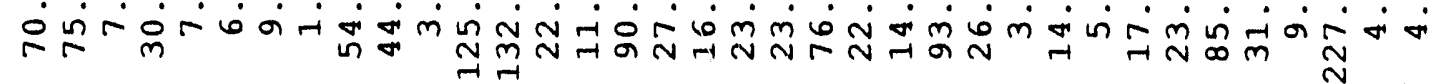

a $\quad$ and

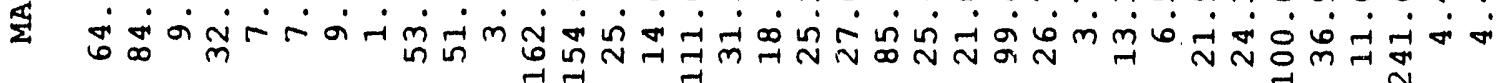

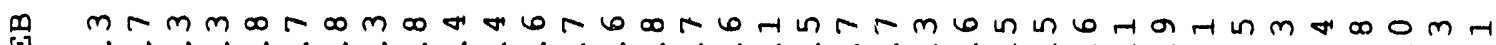

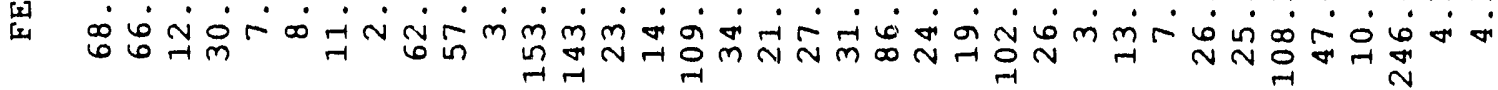
a Omb a Nm

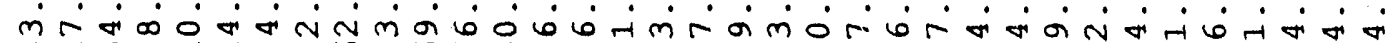

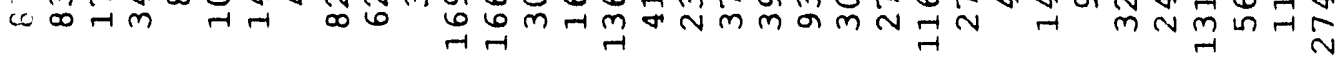




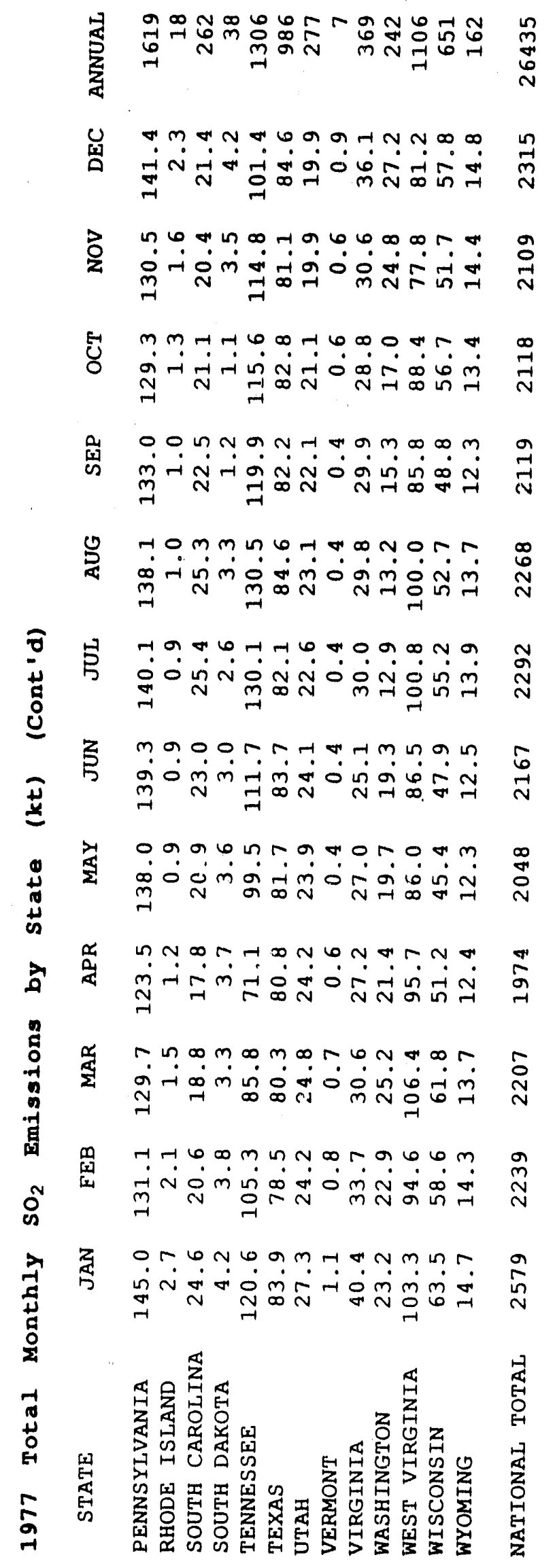




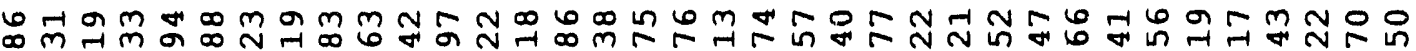

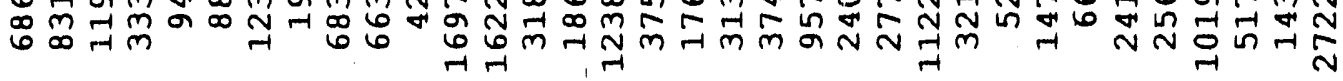

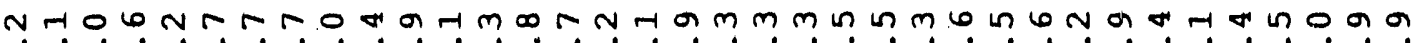

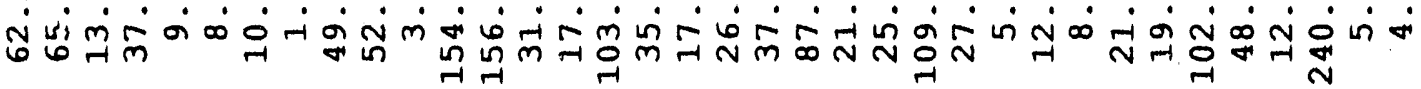
anm

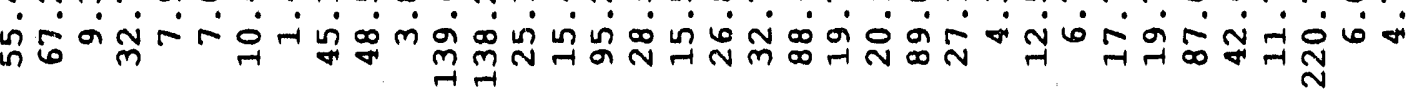

n

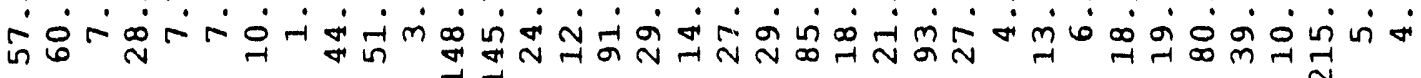
mrirrombrm bூ

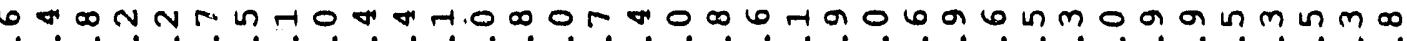

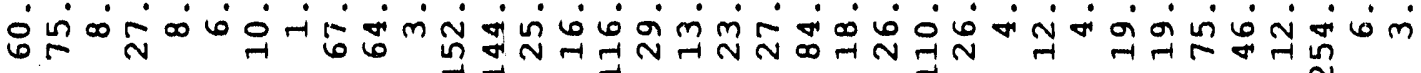
am

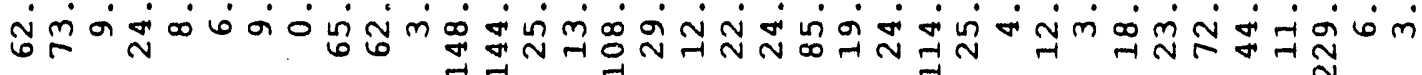
$\rightarrow-1$

z NNMmm

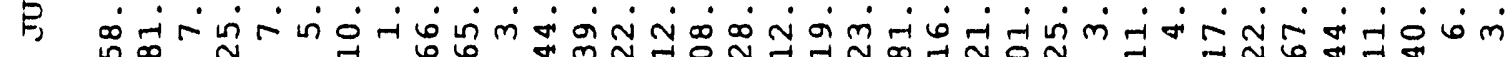

* rogowara

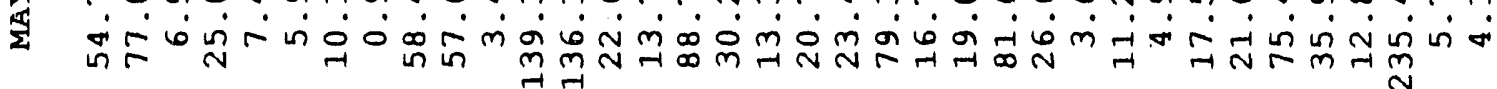

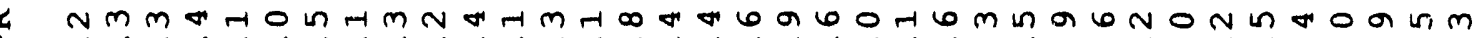

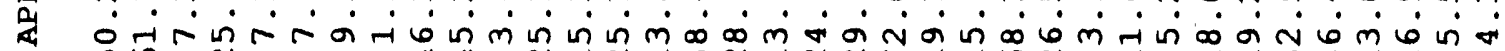

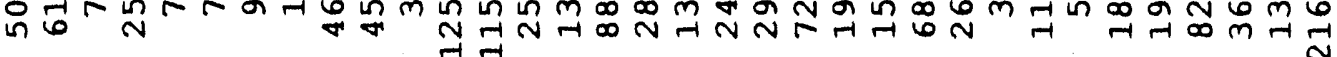

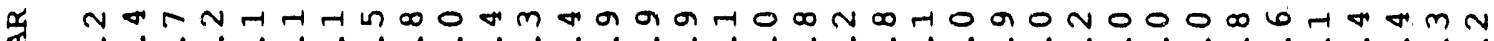

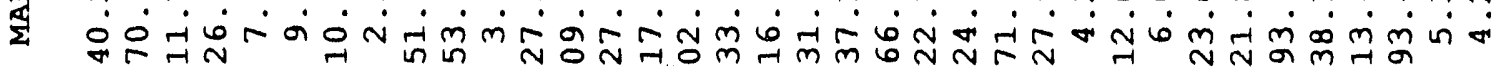
b

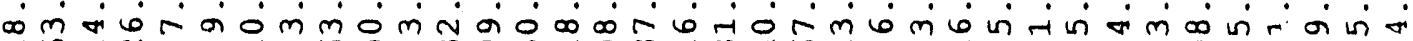

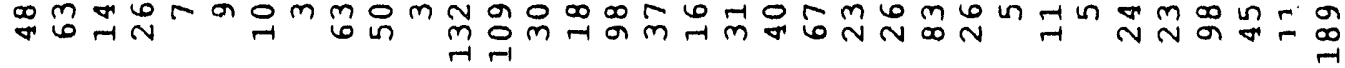

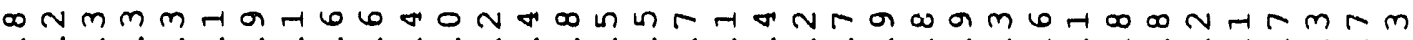

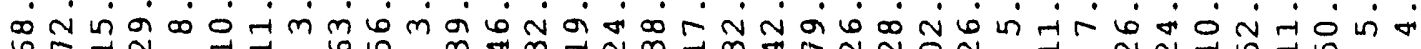

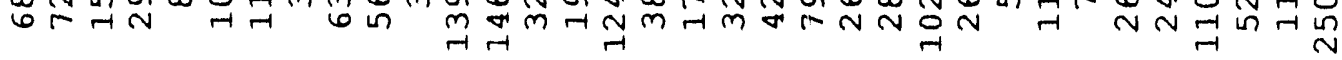

$$
\text { r }
$$

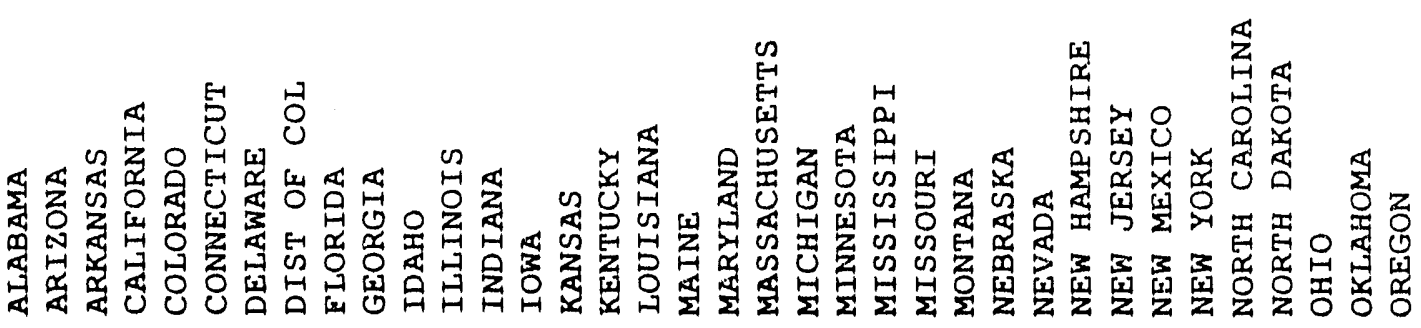


宏

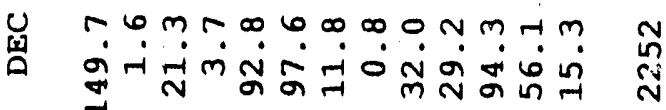

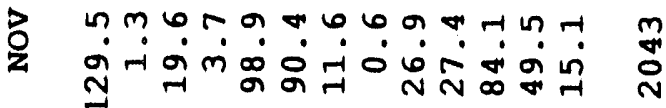

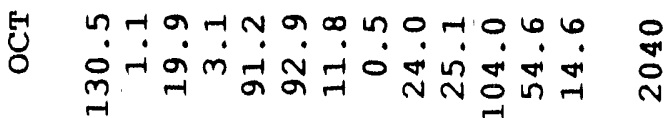

䎹

选

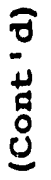

द

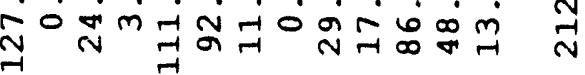

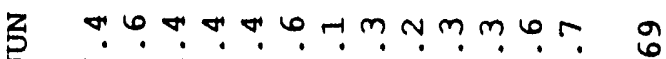
సิำกำ

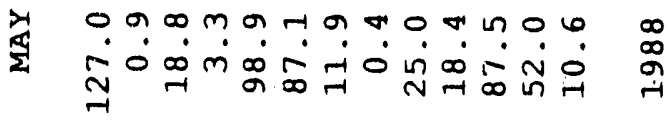

ब

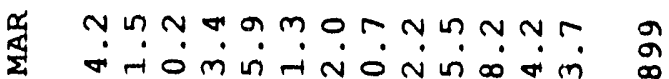

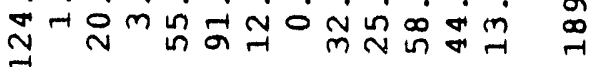

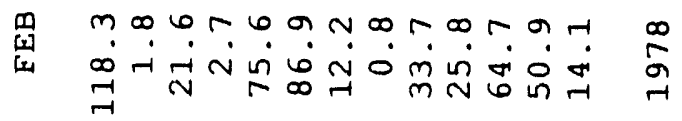

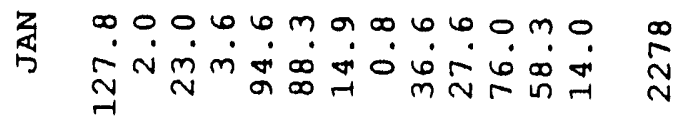

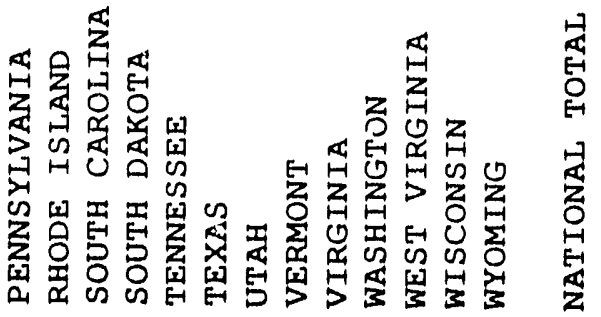




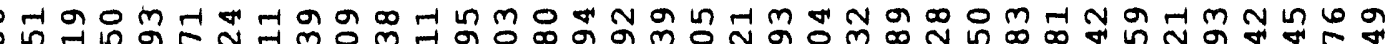

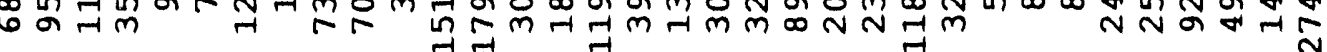

b $06 \mathrm{~N}$ \%

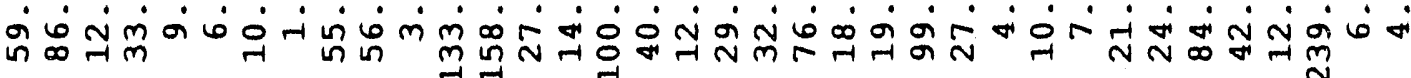
6 6 NOH Ha

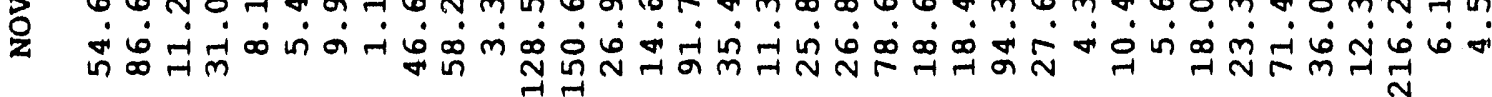

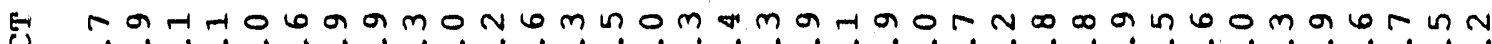
O ñ்

M $\quad$ H.

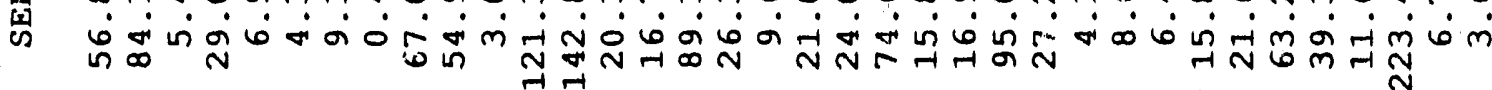

(1) No" a

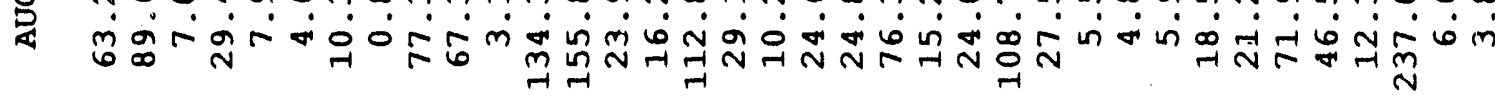

A r.

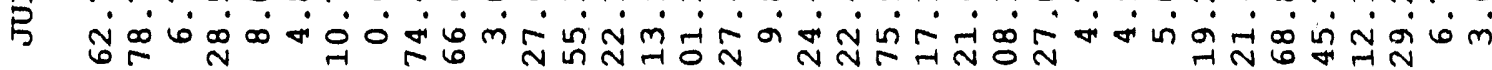

z

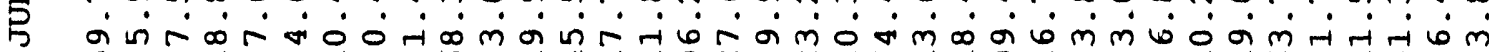

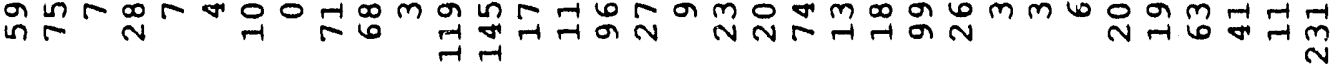

> $\quad \infty r a b m$ a

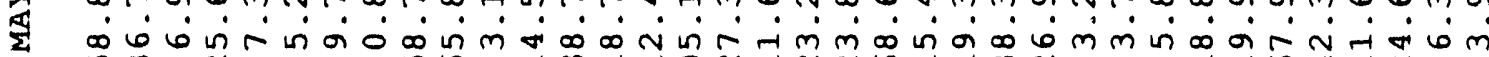

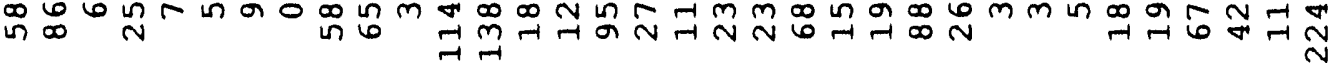

h

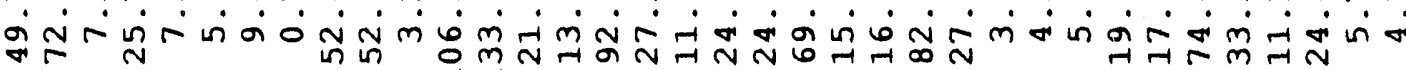

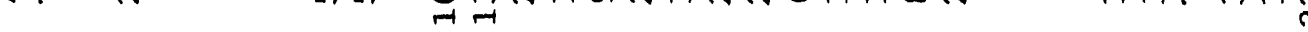

g r

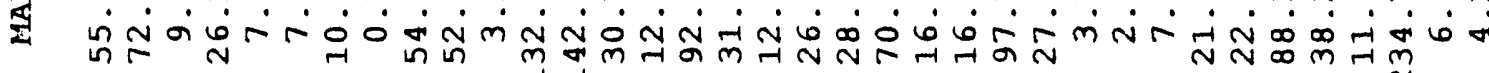
Hit

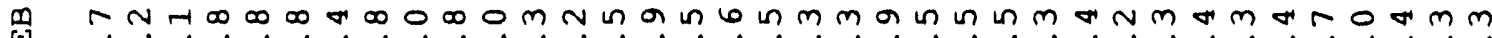

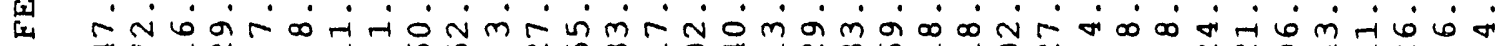

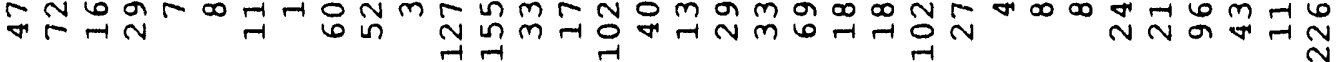

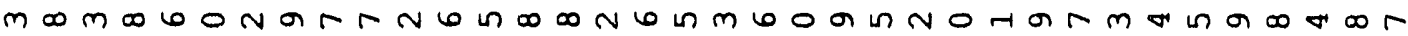
$N$ ט 6Nm

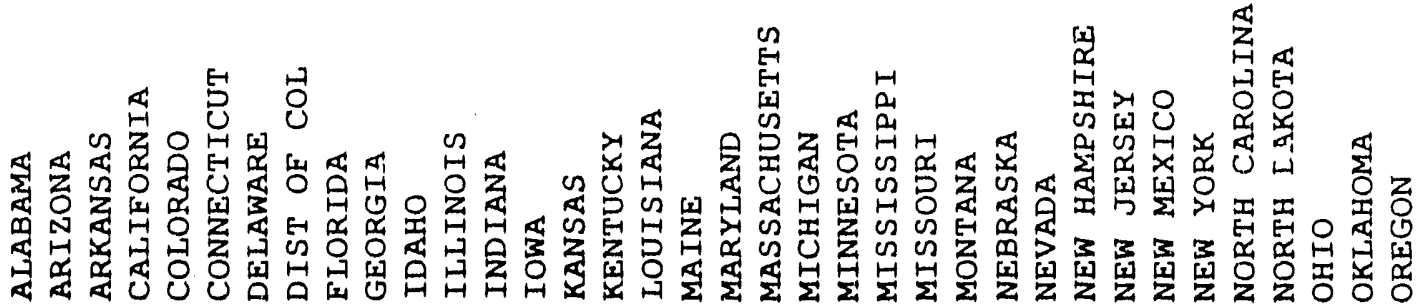




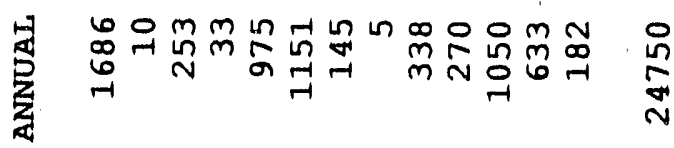

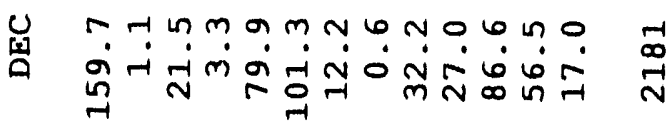

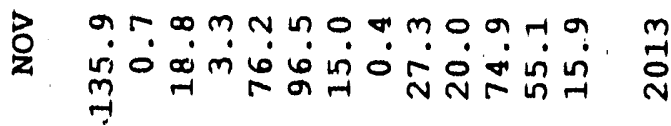

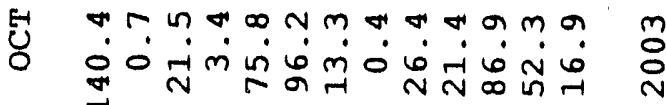

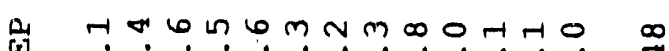

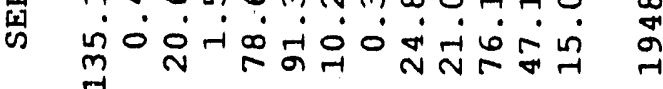

द

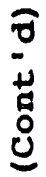

5 ก

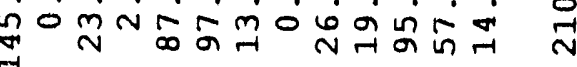

I Z $\begin{aligned} & \text { Z } \\ & \text { Z }\end{aligned}$

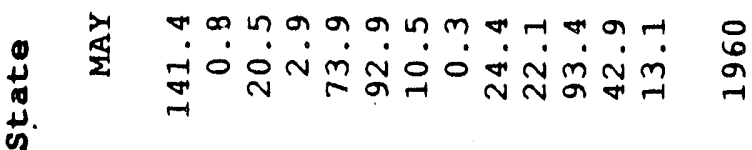

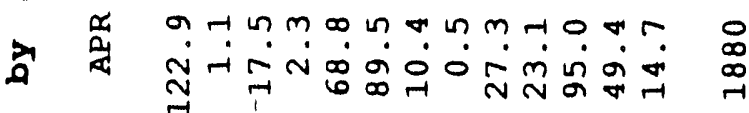

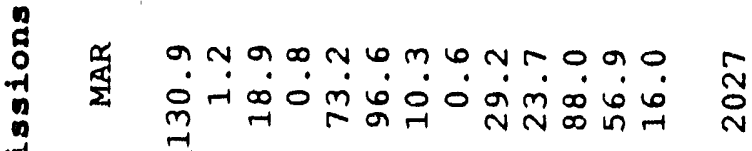

藏

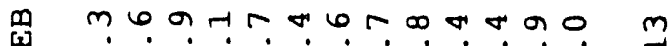

ज्ञ

存

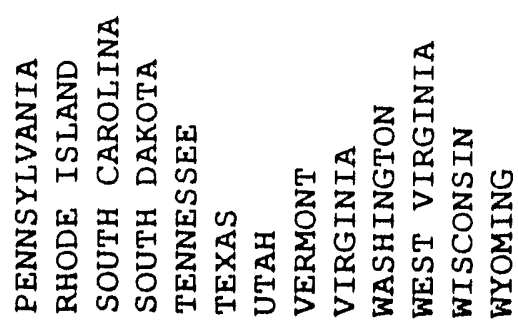

最 


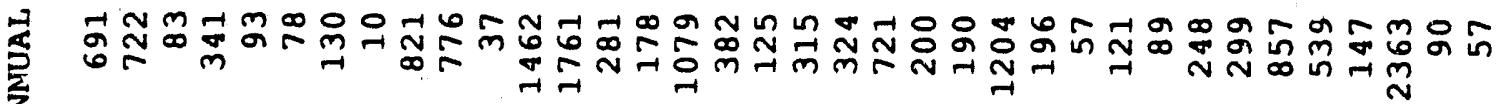

U 0 on 苟

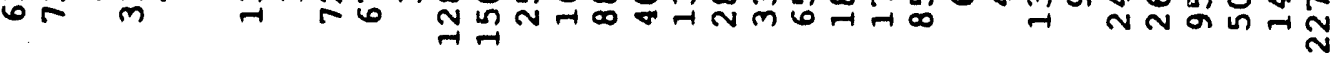

b n

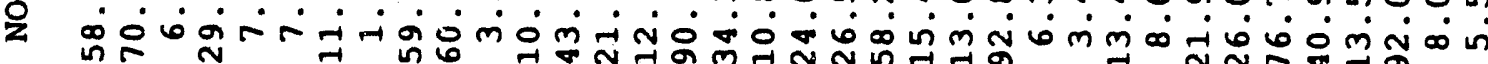
舟兄

岁

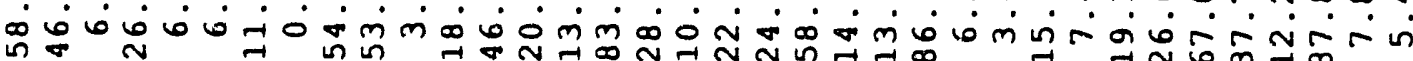

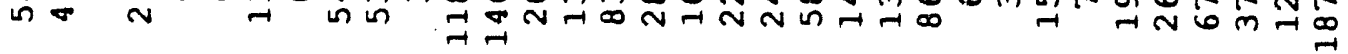

空

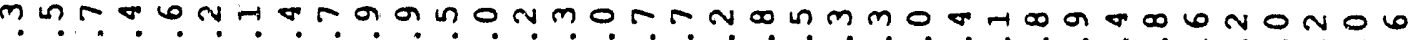

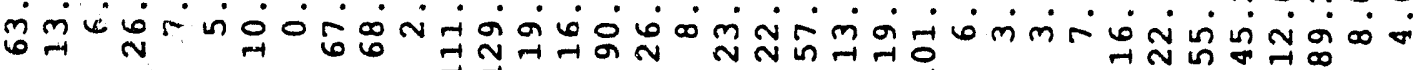
A

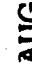

ma

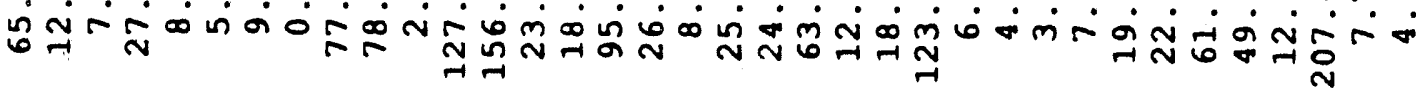

点

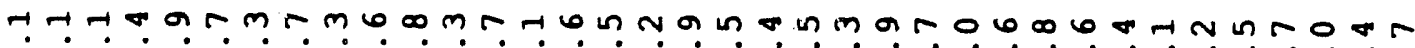

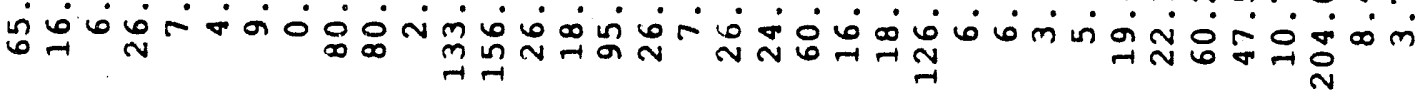

Z 0 ㄴ.?

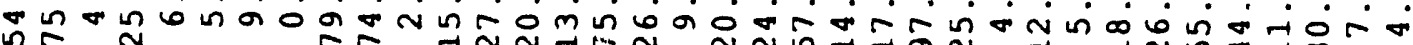

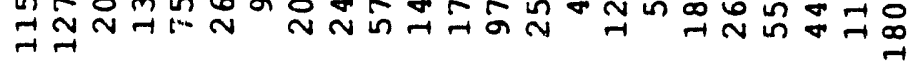

Z

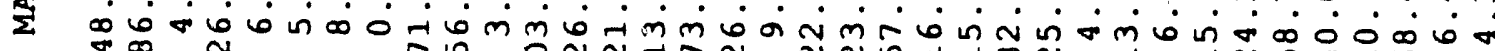

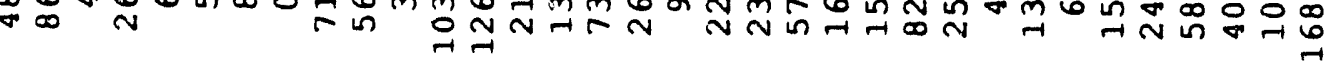

a H

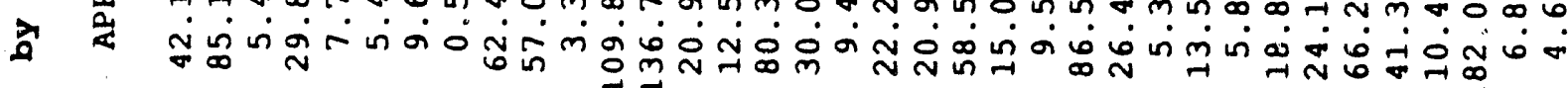

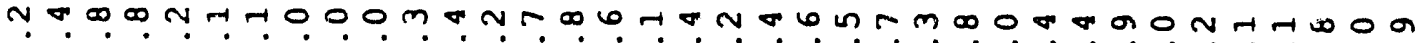

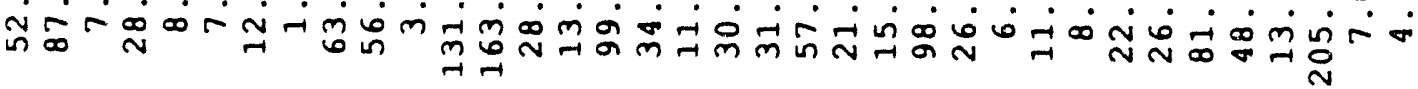

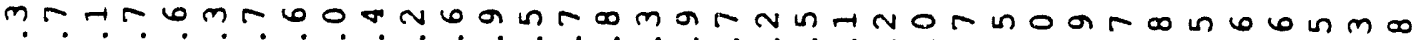

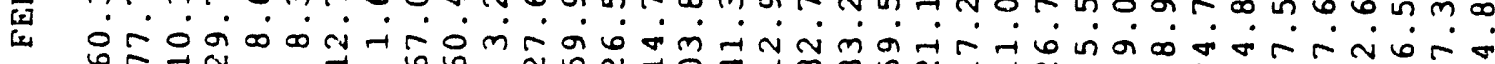

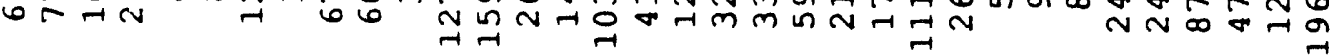

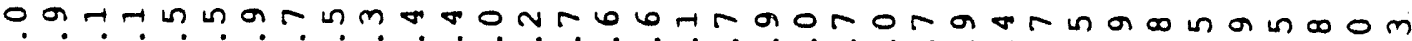
O̊㇒ 


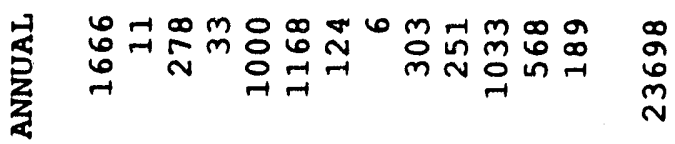

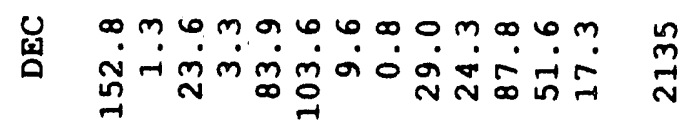

z

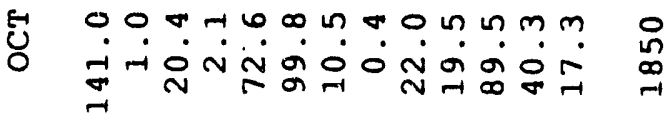

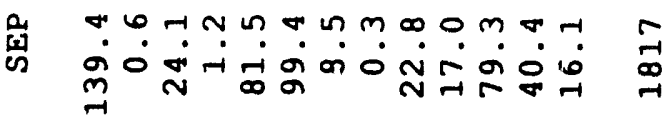

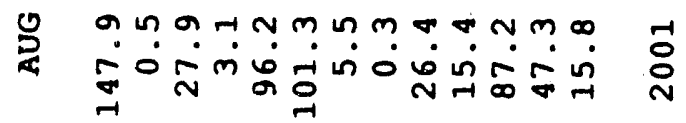

0

0
$ن$

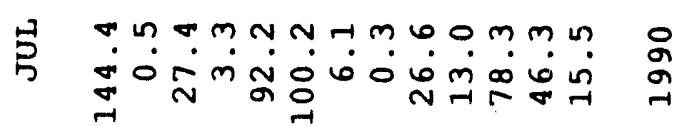

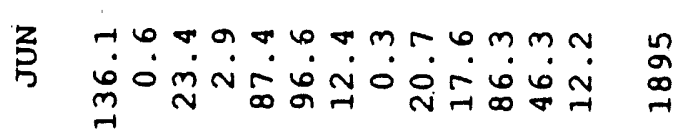

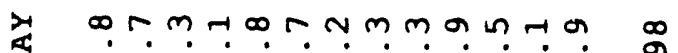

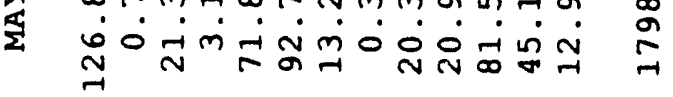

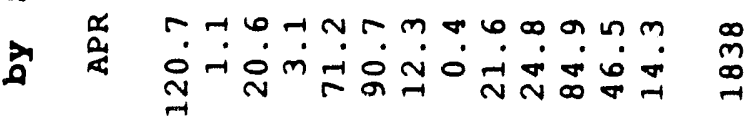

อุ

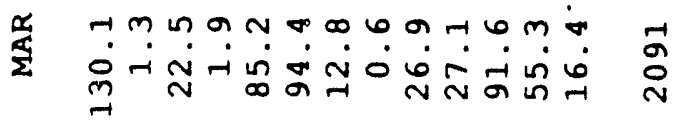

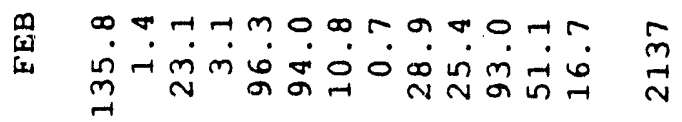

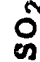

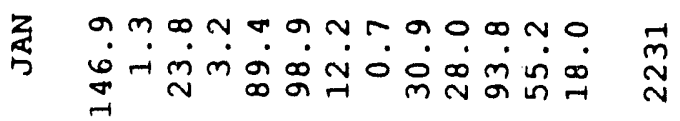

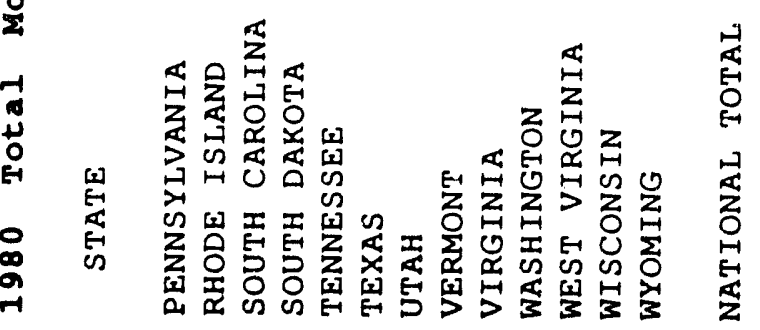


ת

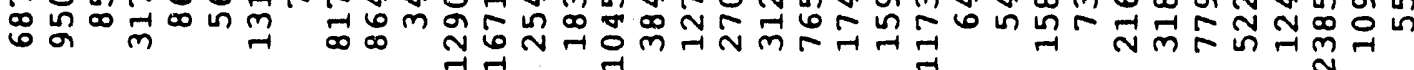
$\stackrel{-1}{N}$

?

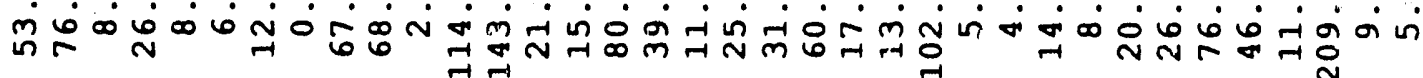

o

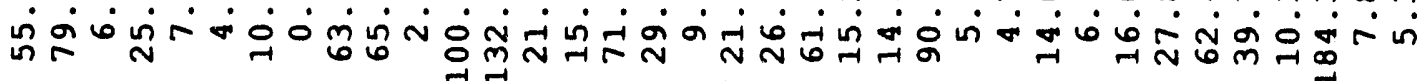

บ

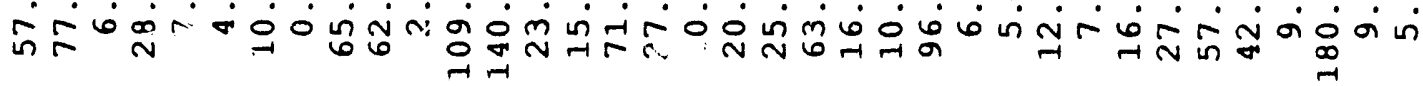

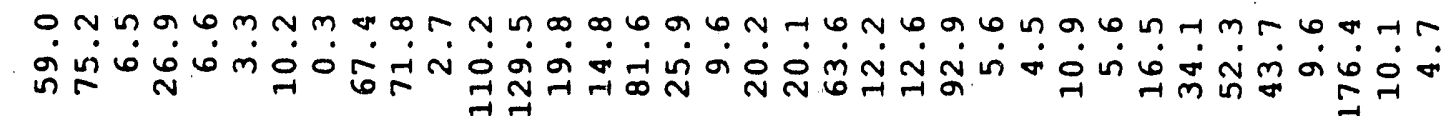

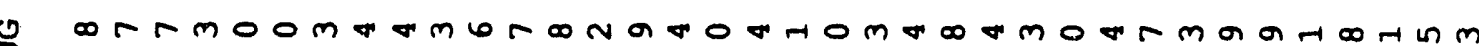

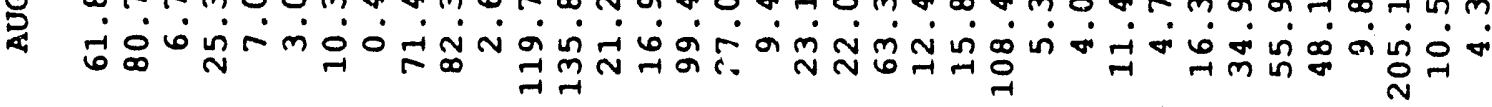

A ᄀ

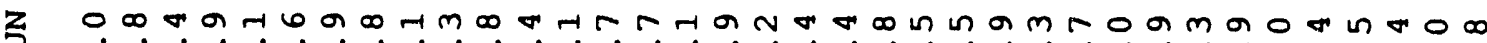

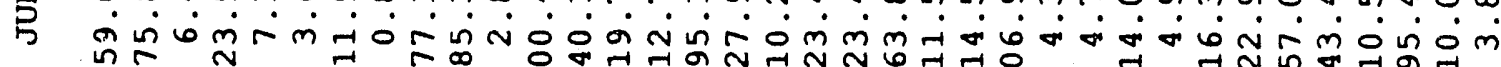

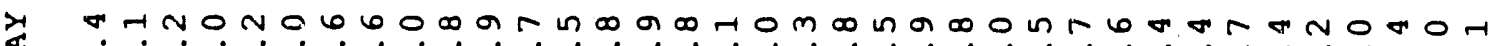

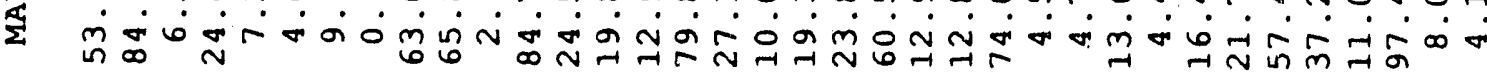

a

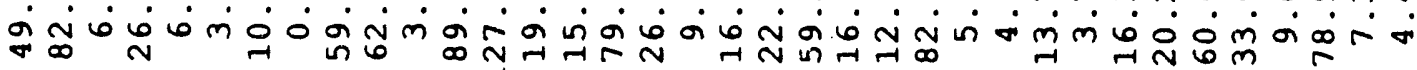

*Harm

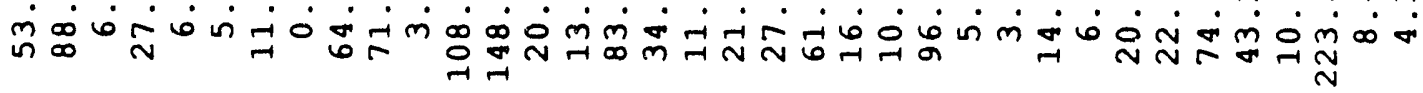
o a

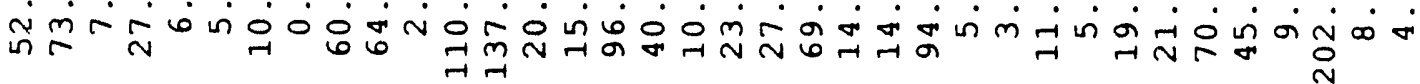
on क $\rightarrow-1$ $\rightarrow$ 


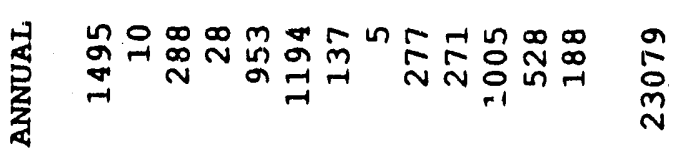

U.

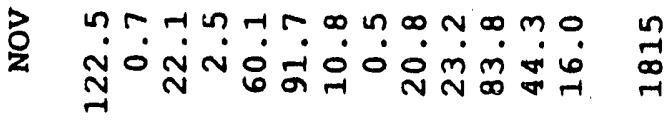

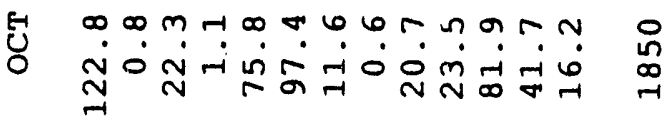

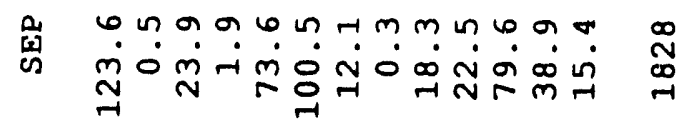

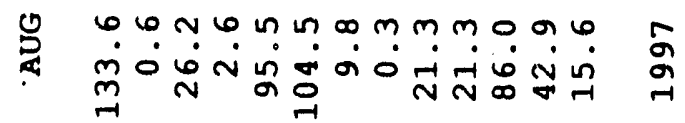

ฮ̊

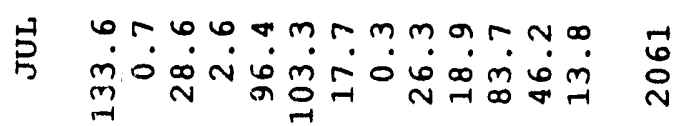

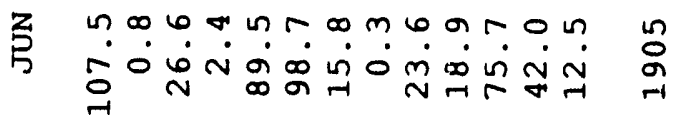

> m n

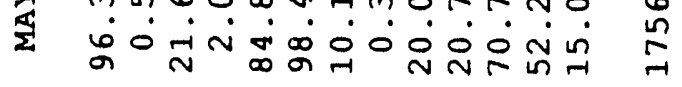

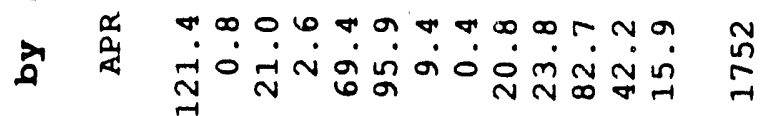

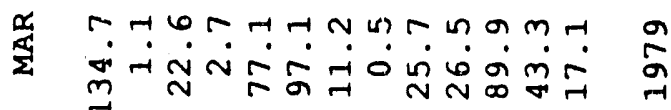

m $90, \pi \infty n m$ !

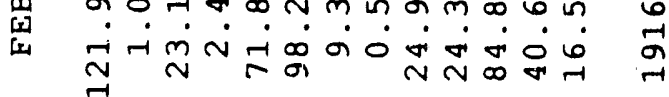

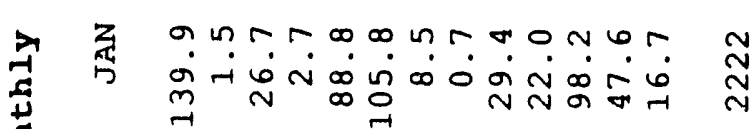

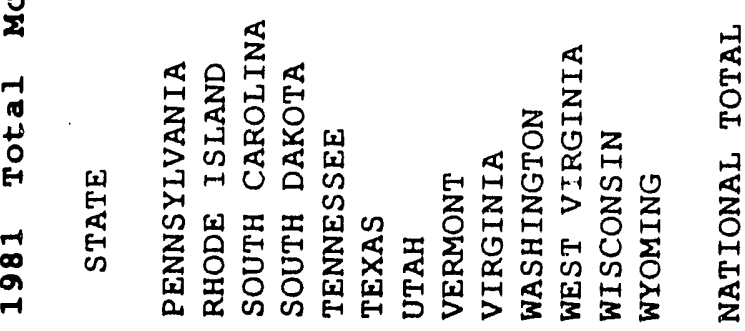



규세

ค

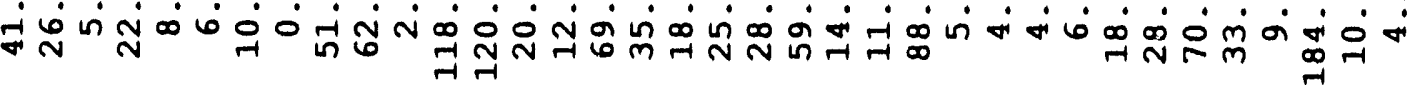

$\mathbf{z}$

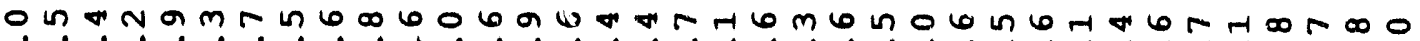

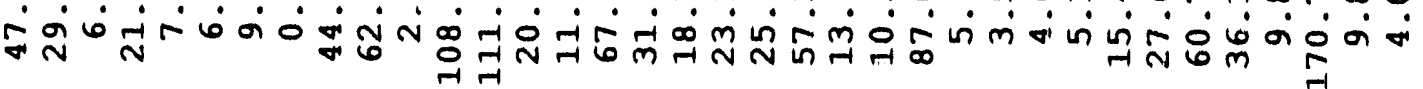

茯

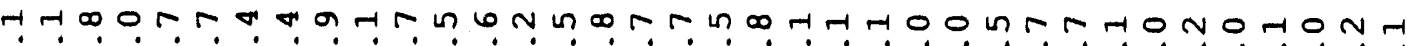
诲

趁

r

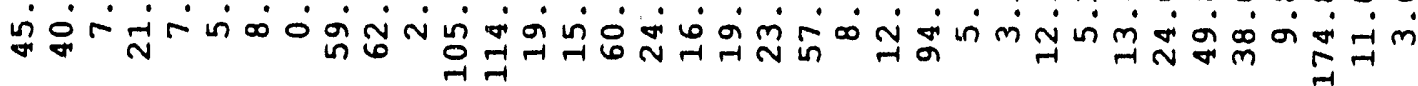

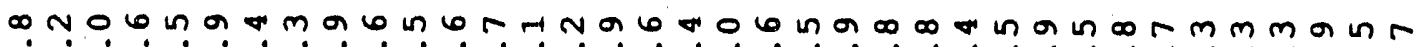

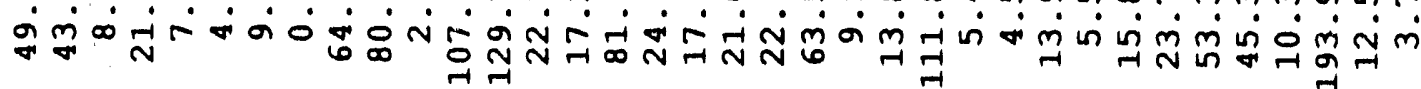

$\infty$ n

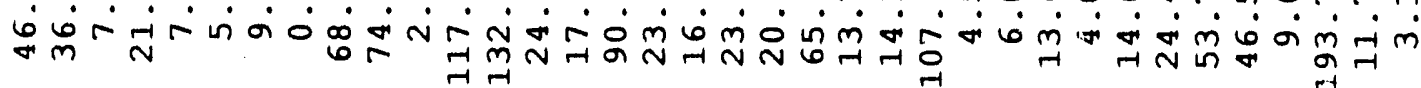

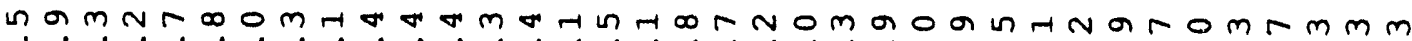

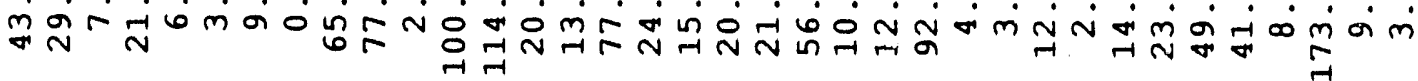

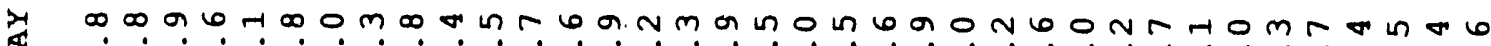

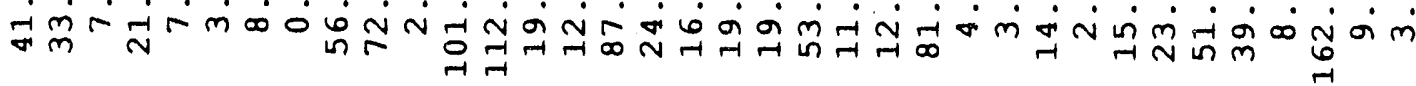

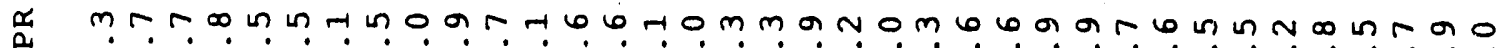

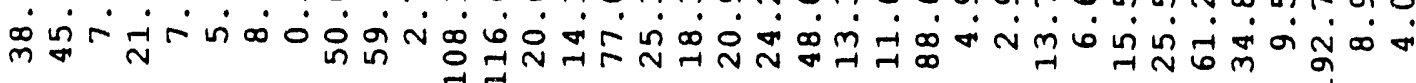

r nom

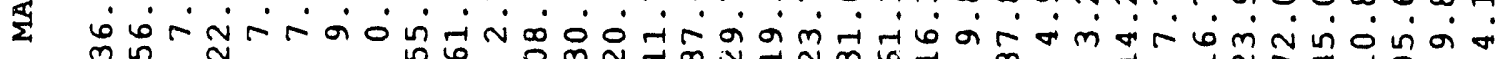

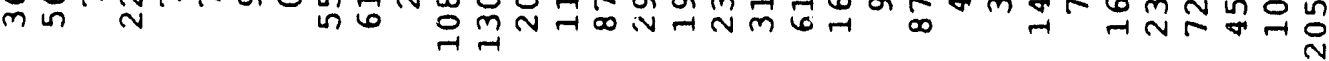

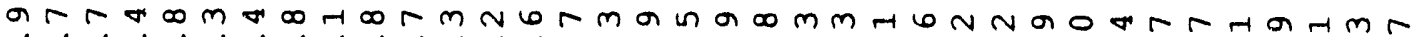

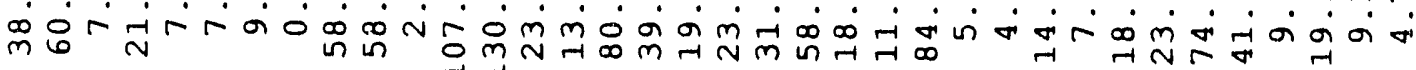

z

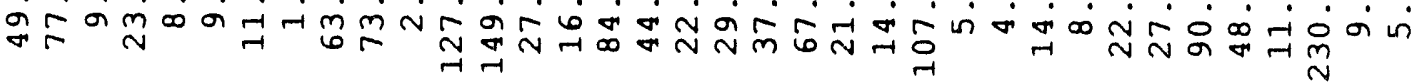
N 


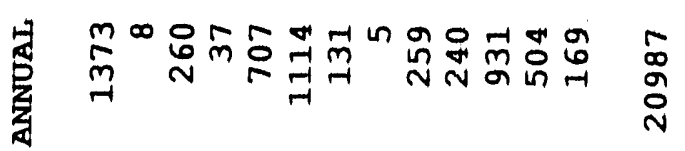

苜

z

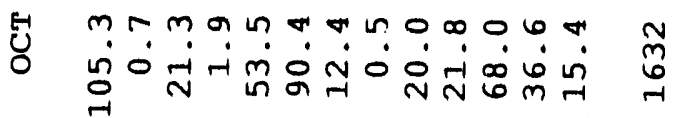

幽

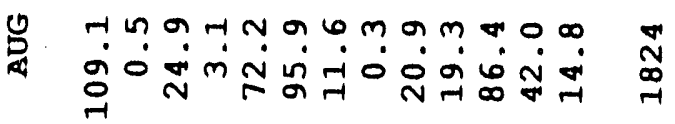

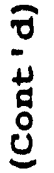

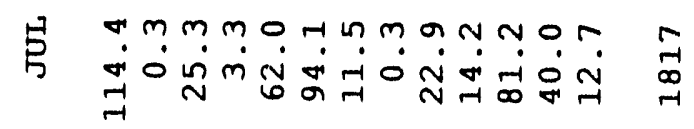

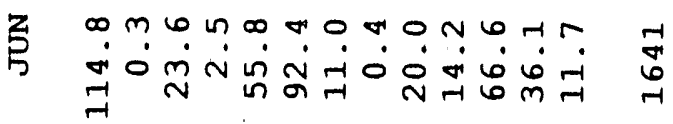

选

a a

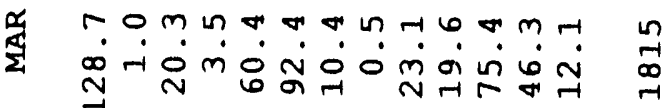

m Thon?

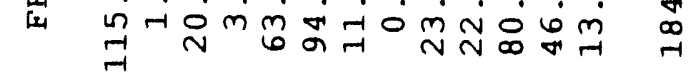

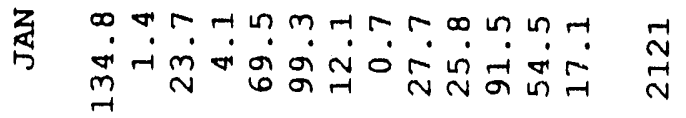

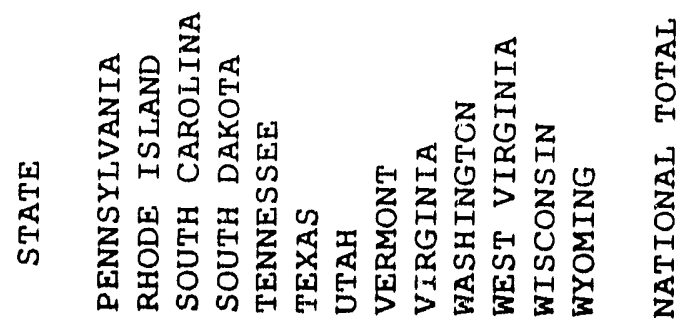




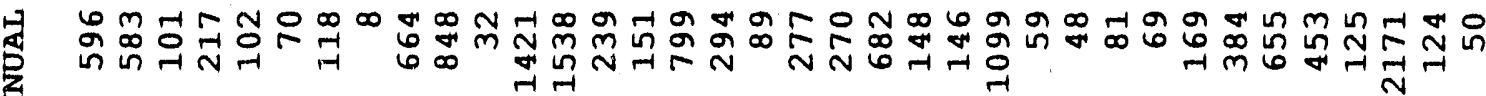

a mom जं

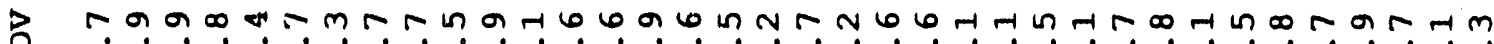

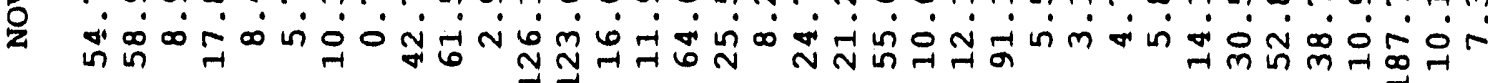

H m mamanin

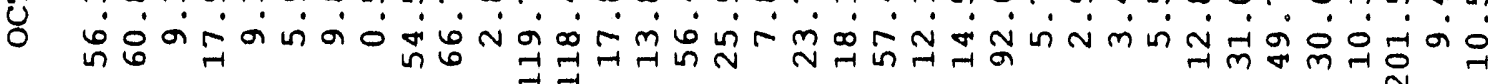

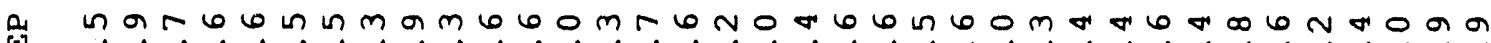

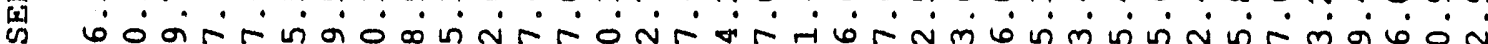
in

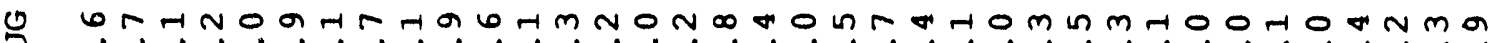
ব

与 0 a

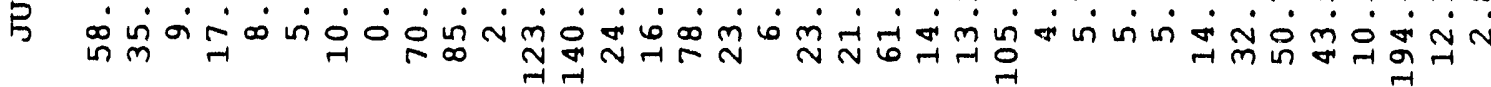

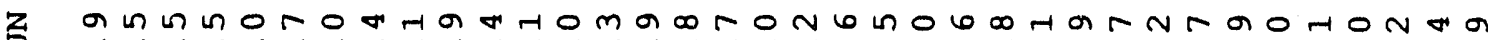

h

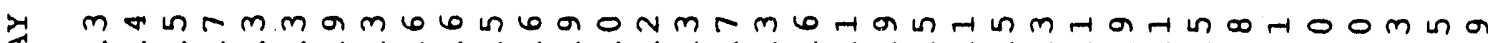

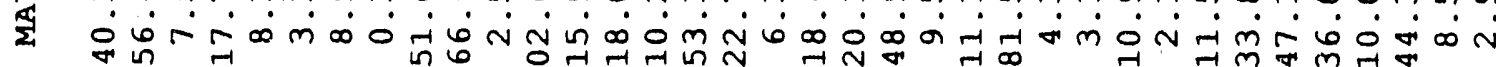

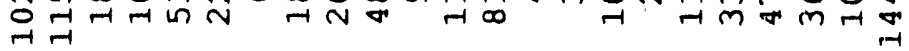

a n

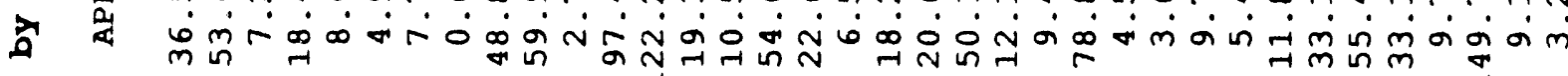

$\Rightarrow \quad$ ㅇำ

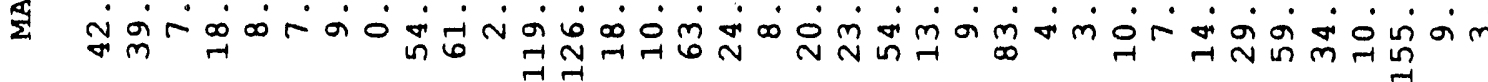

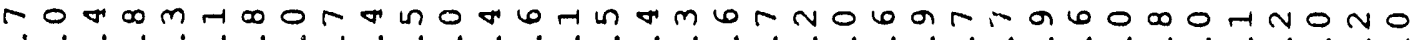

lu

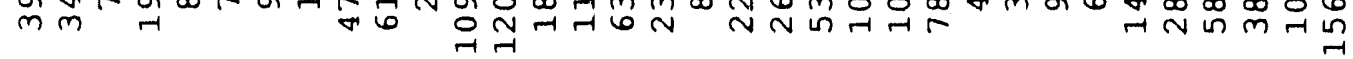

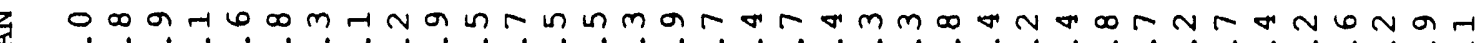

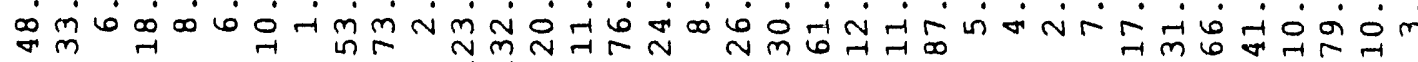

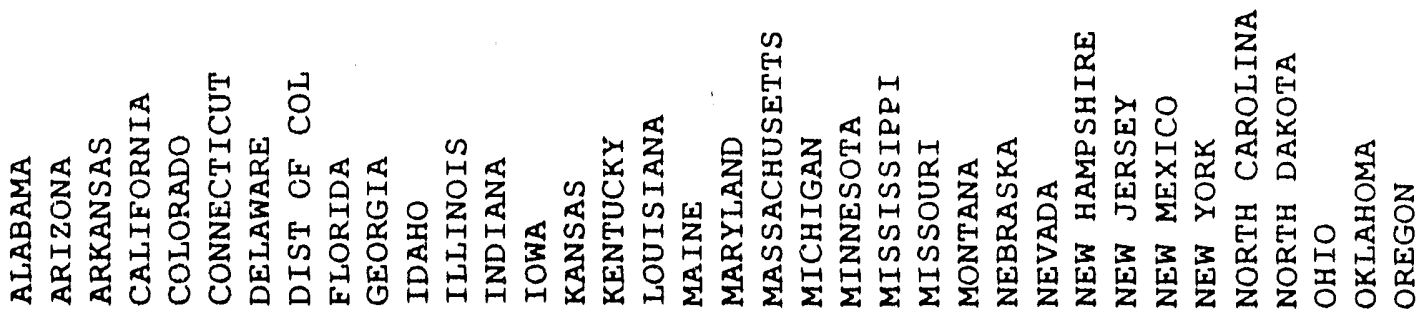




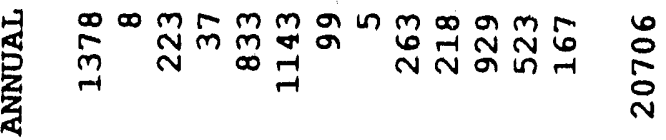

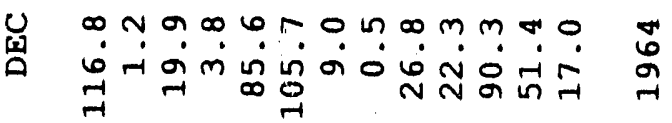

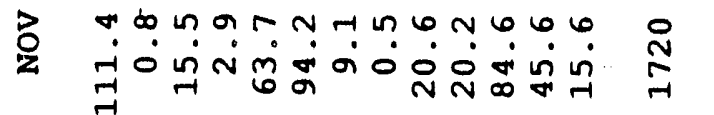

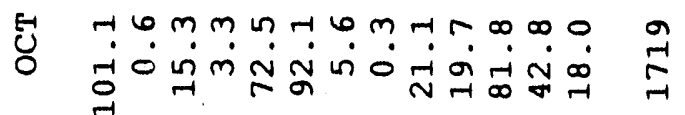

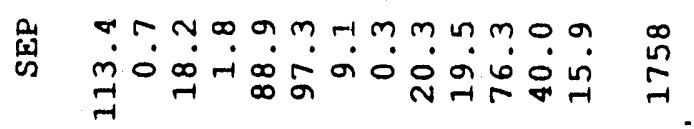

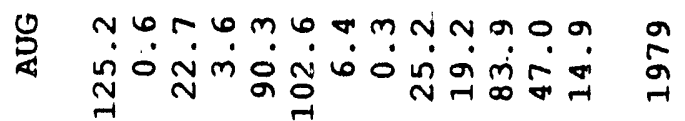

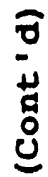

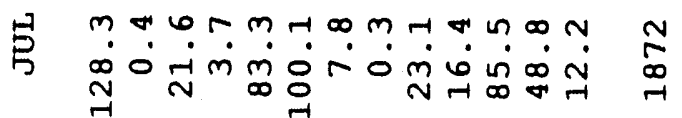

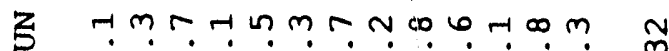

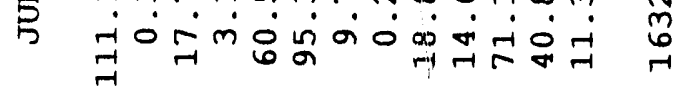

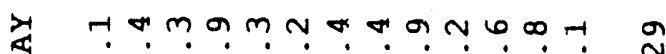

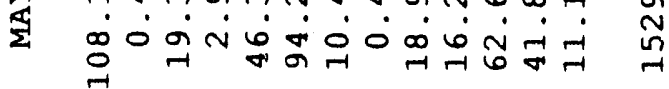

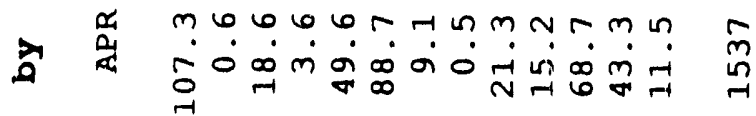

:

委

m

怎

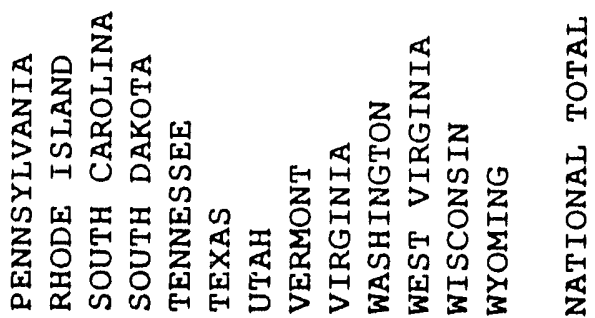


占

U og nN

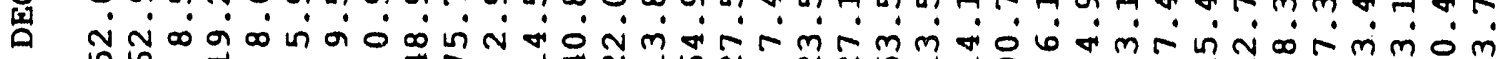

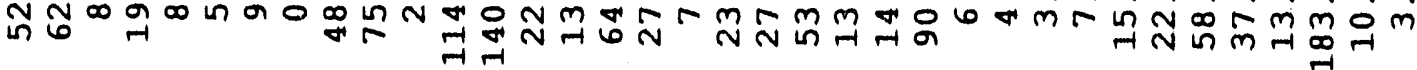

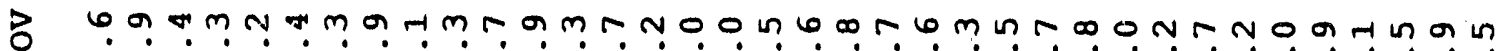

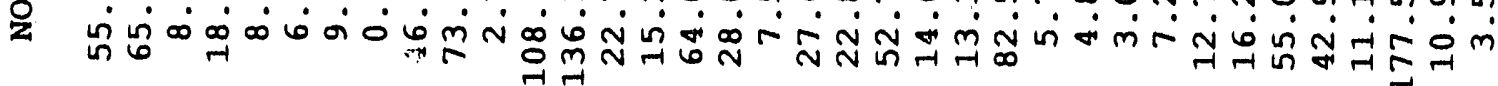

H O i

M ڤ

(y)

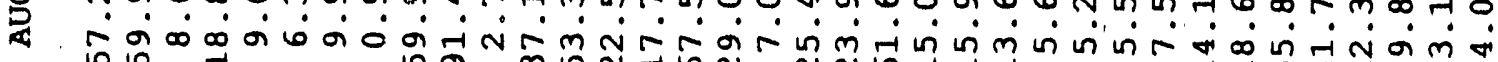

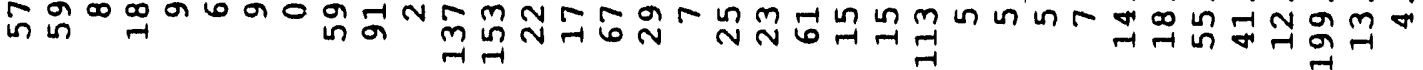

月

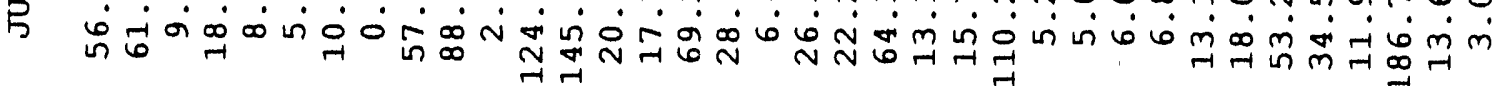

z 0 J m n m

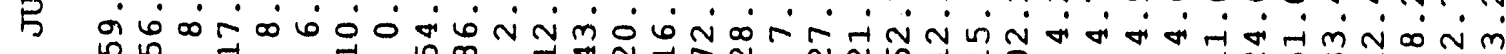

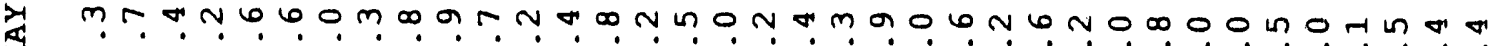

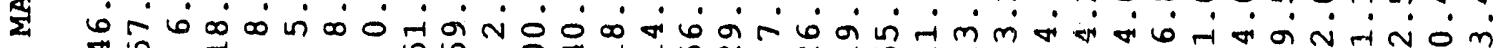

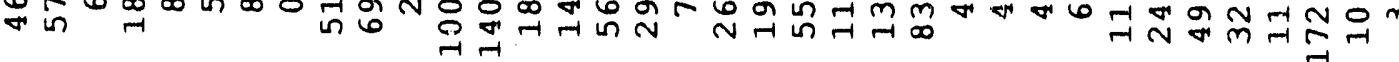

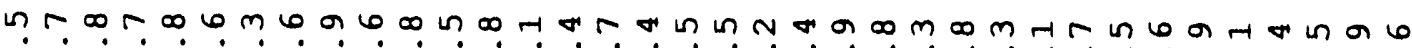

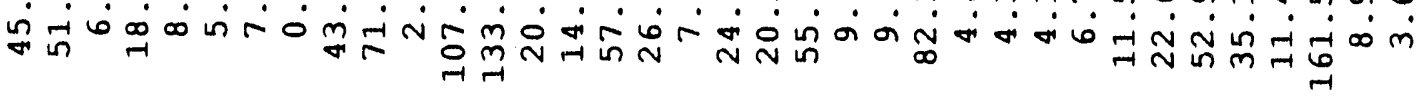

Hmomor

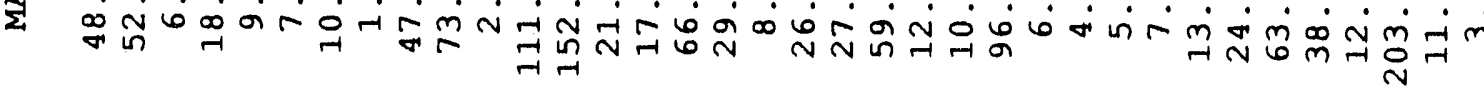

mro o

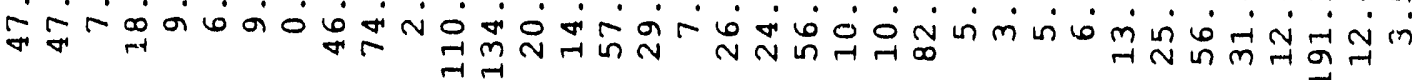

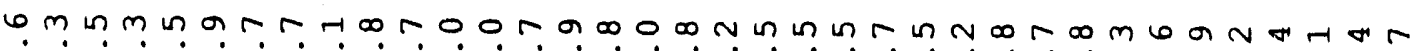

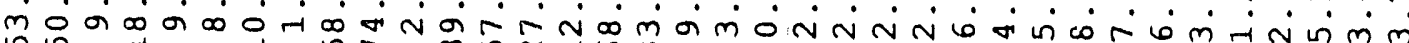

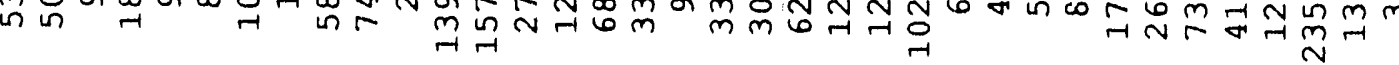




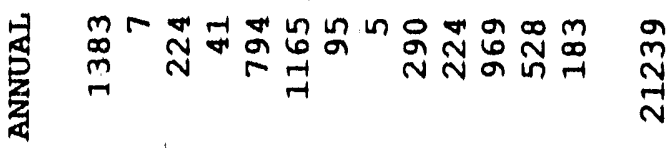

㠃

z

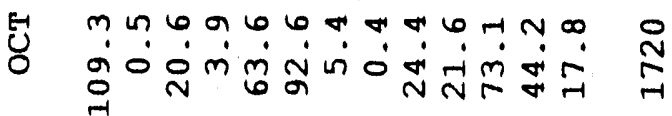

燢

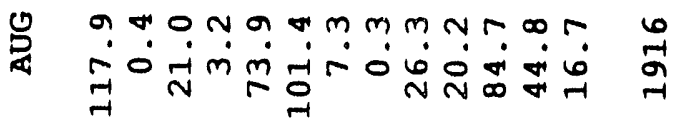

ฮิ

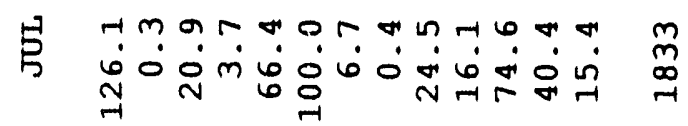

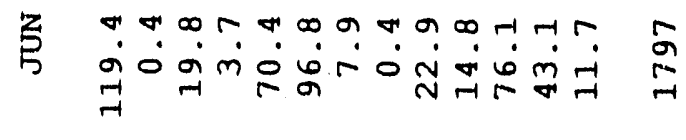

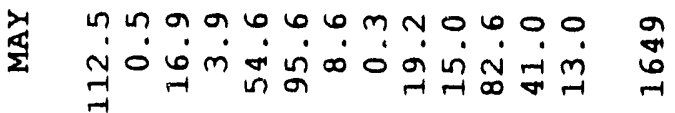

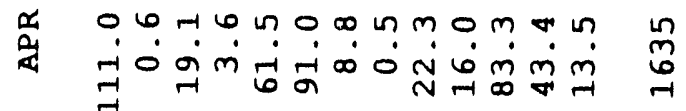

爱

m

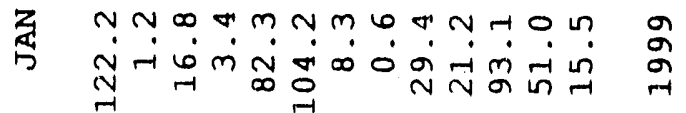

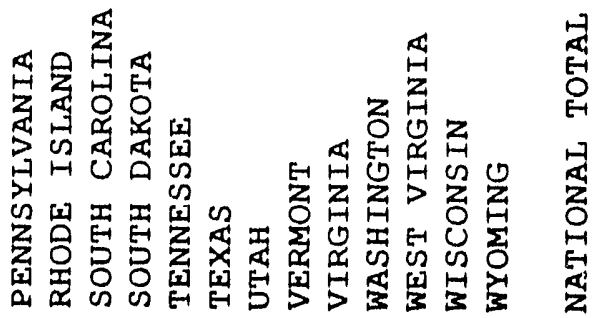




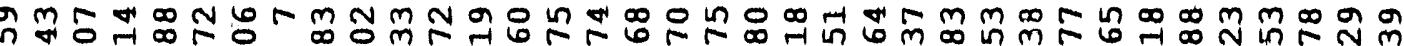

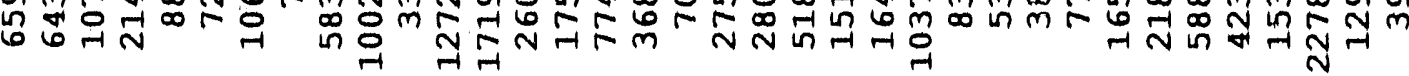

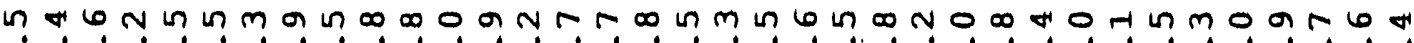
ठै

"

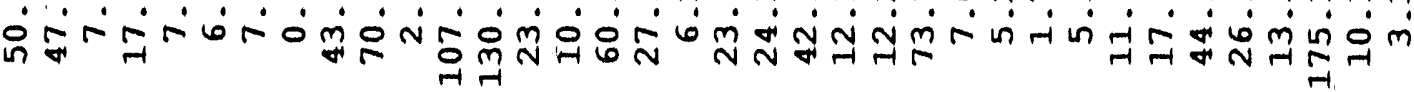

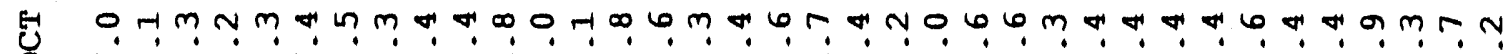
மூ

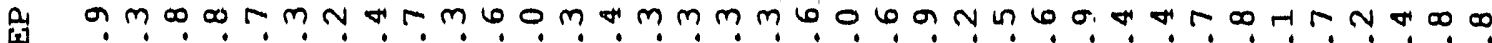

क ம்

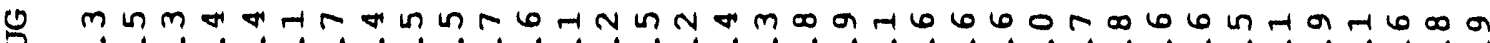

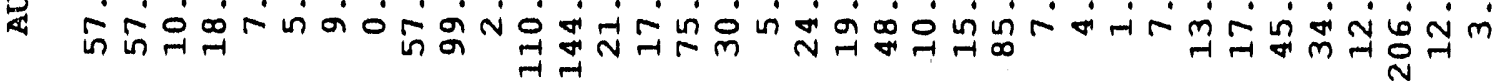

J 5 J 5 бூ

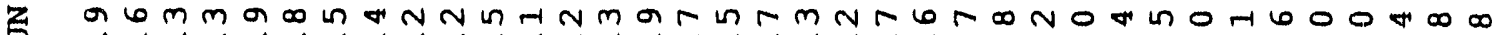

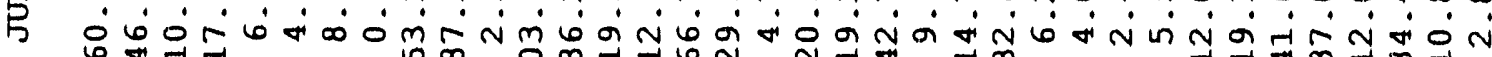

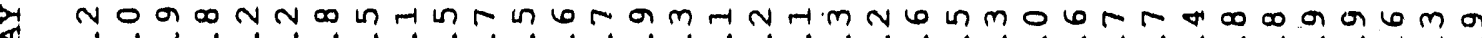
ம

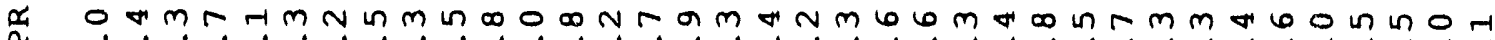
年

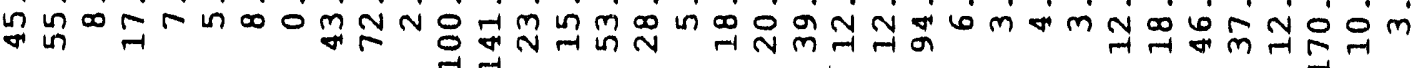

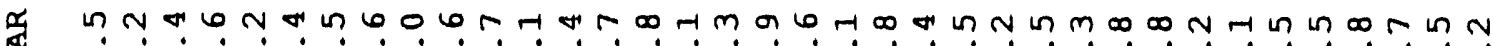
运

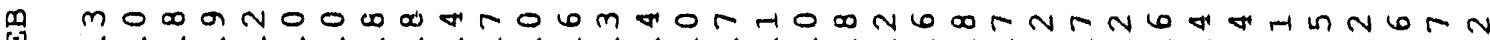
a

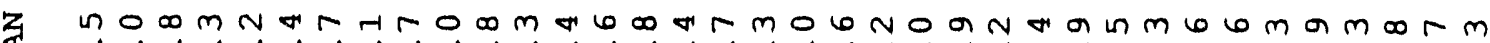

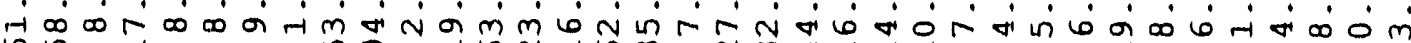

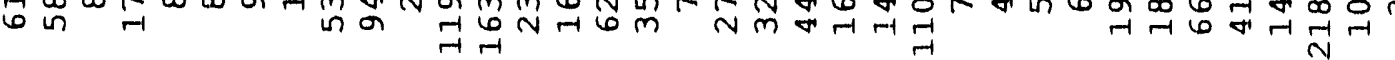




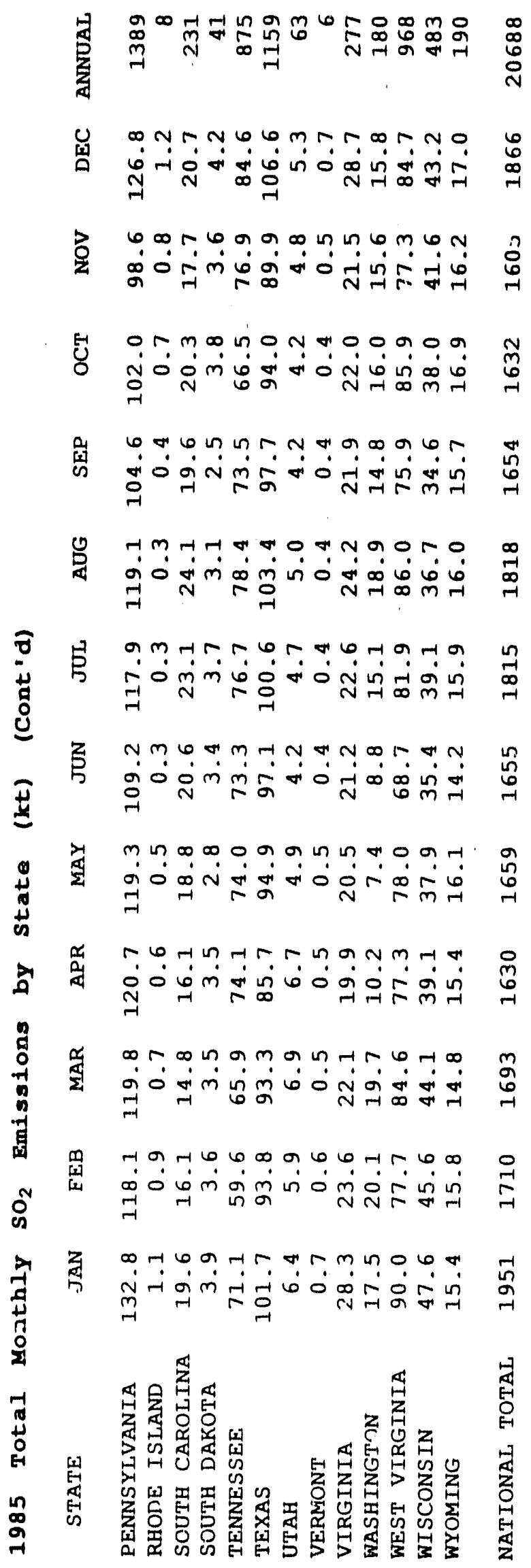


₹ 6

क

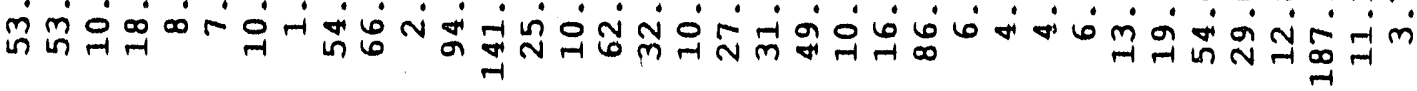

의?

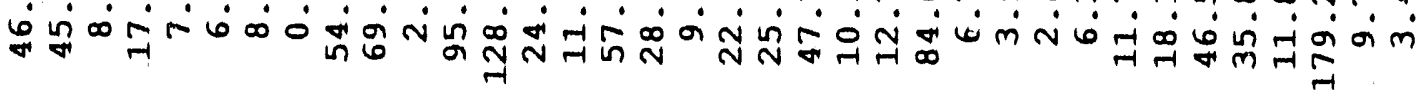

o

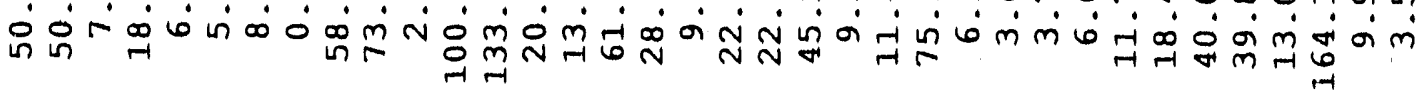

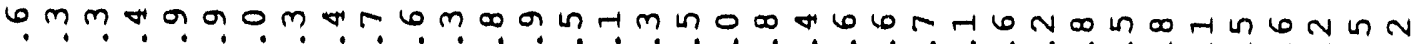
ம்

6r.

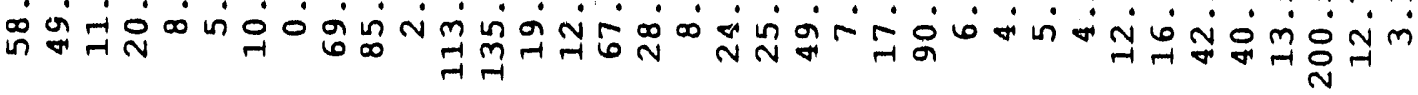

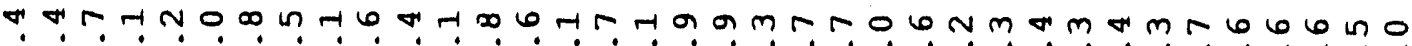
চூ

Th In

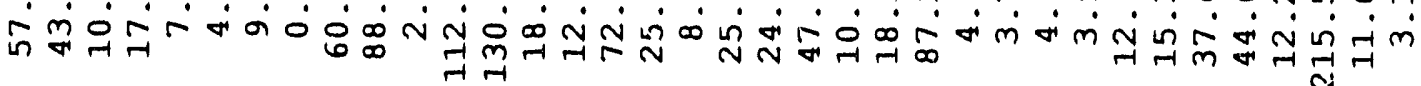

म-

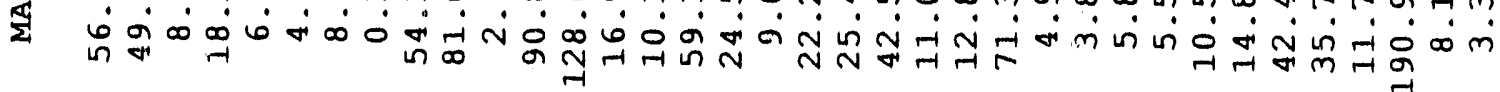

a $\quad \infty$ in

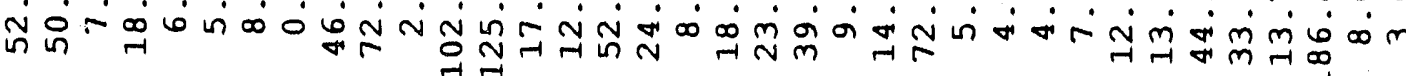

Inmorom an

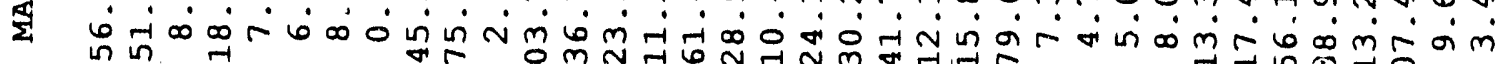

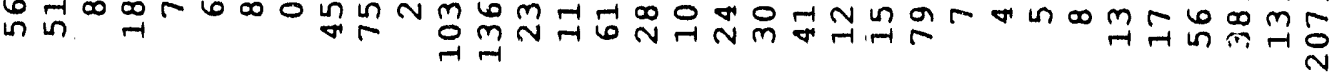

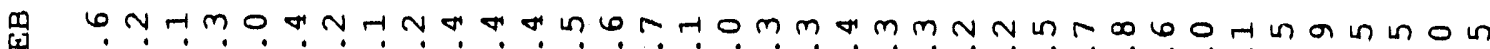

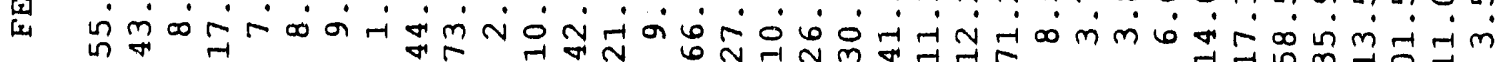

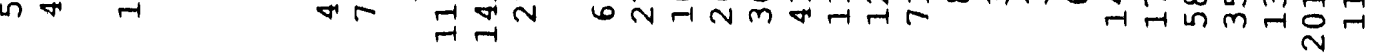

द bo

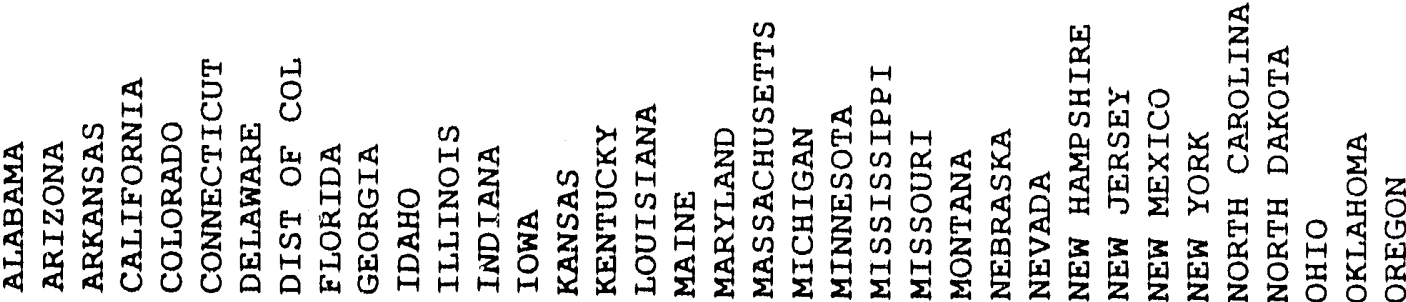




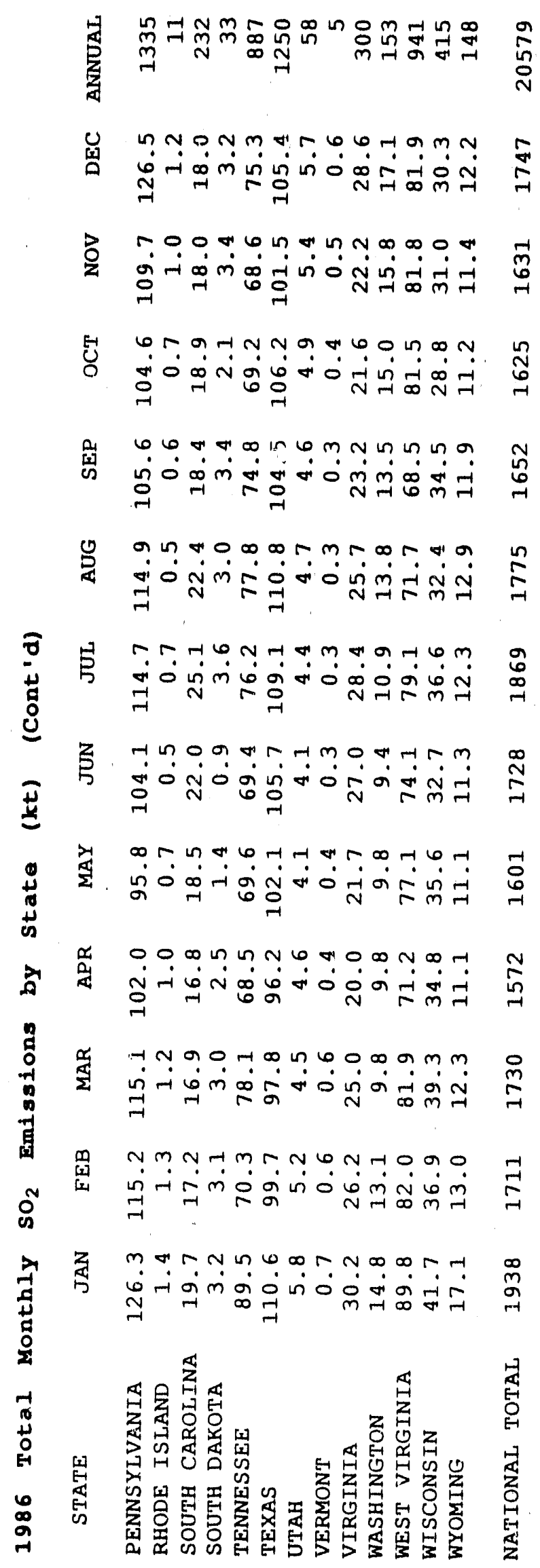




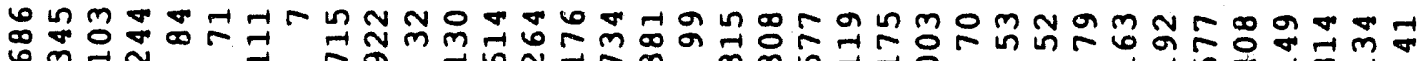

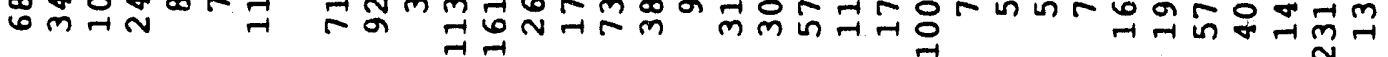

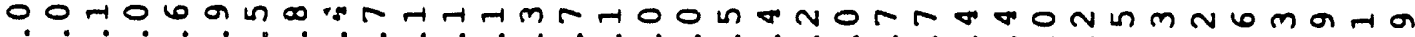

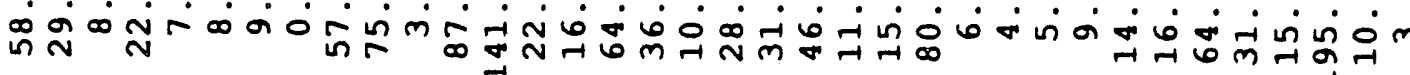

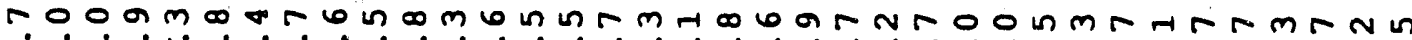

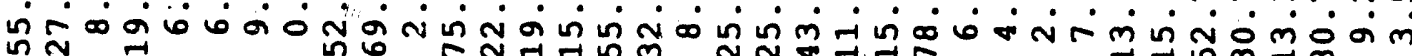
N

星

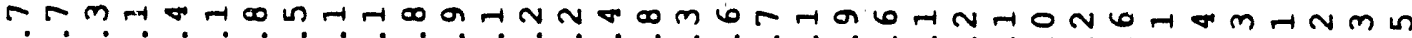

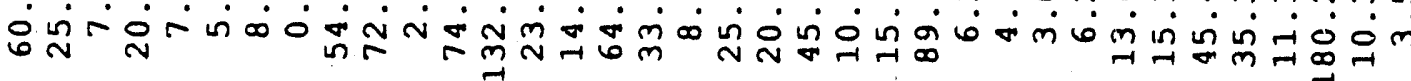

on

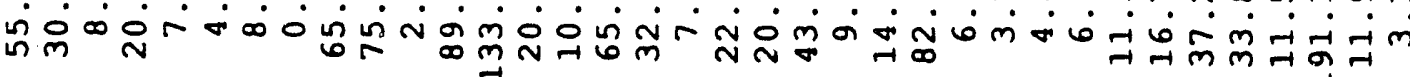

nan

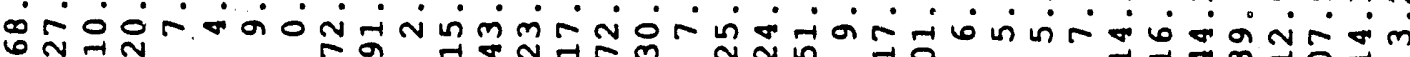

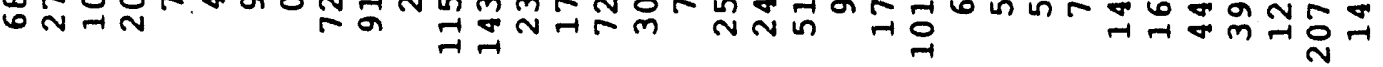

Nmm

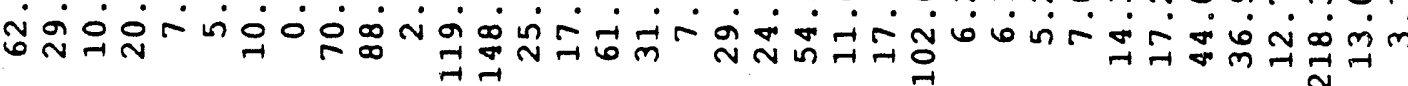

marlod

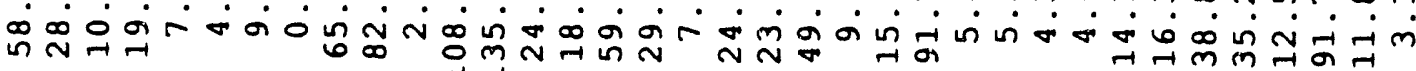

স

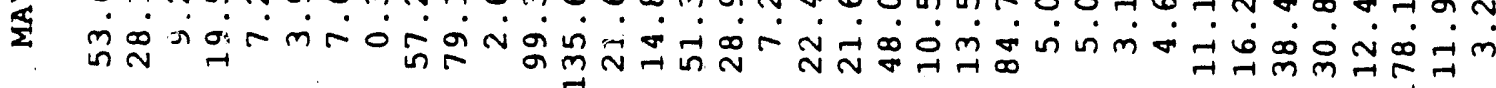

- w wo n

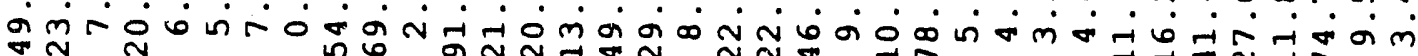

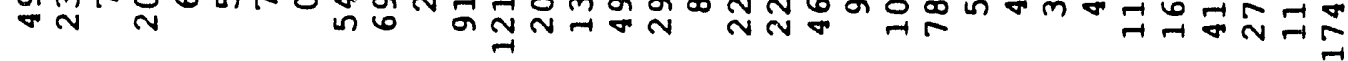

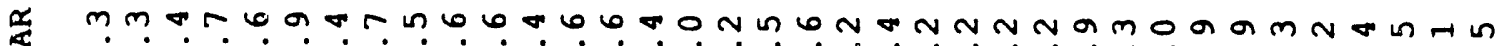

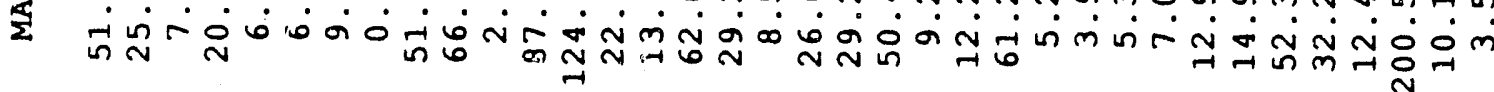

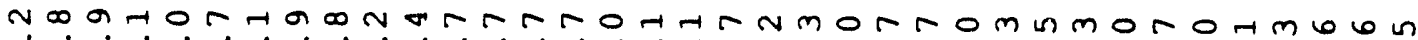

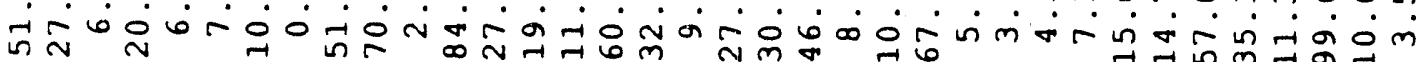

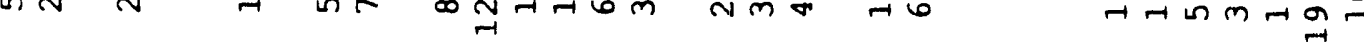

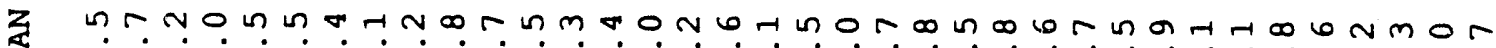

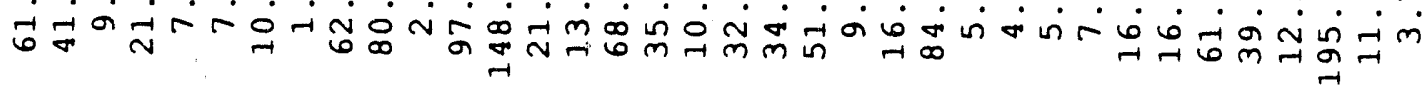




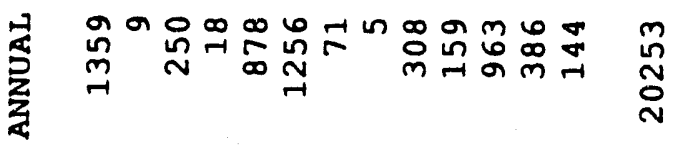

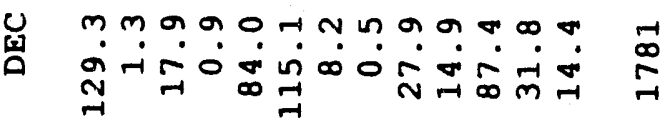

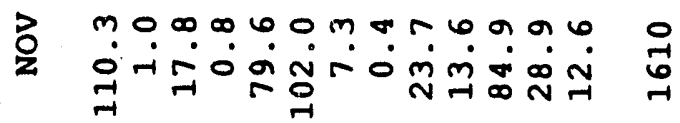

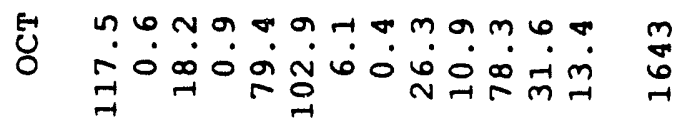

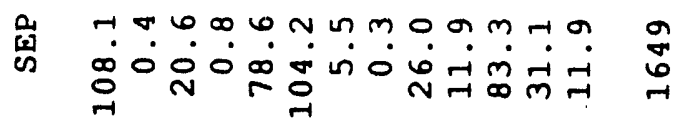

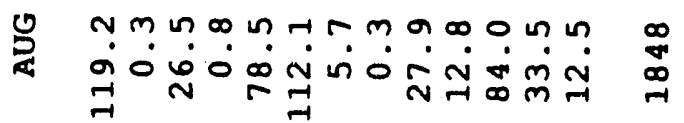

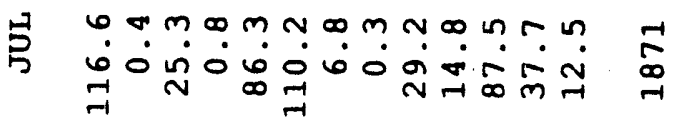

z $\because m a r \infty m \infty m a r \infty \div \infty$

S $\therefore$ o

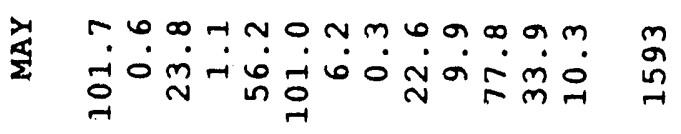

a

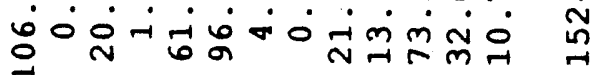

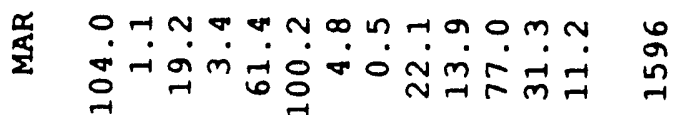

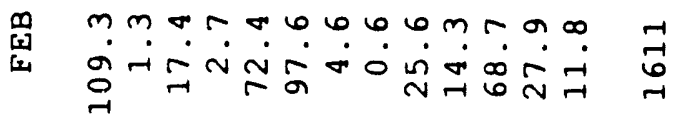

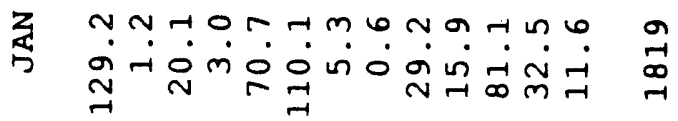

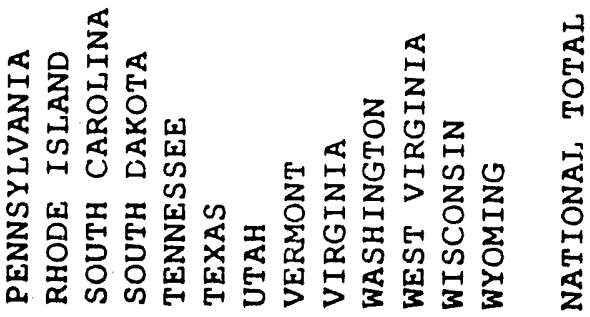




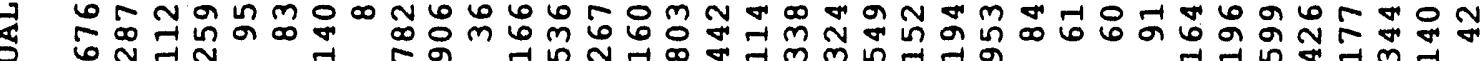

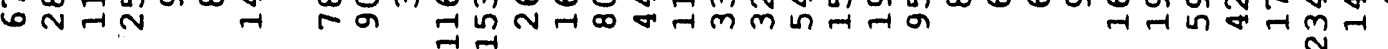

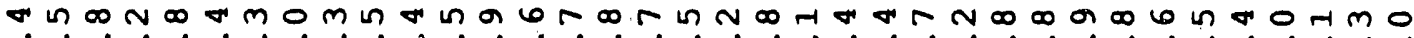

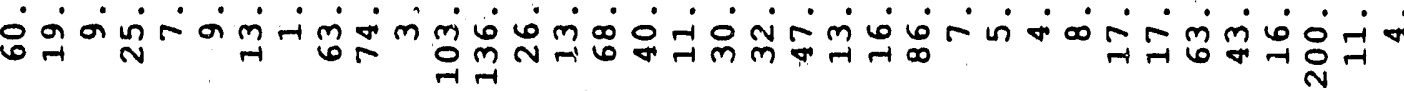

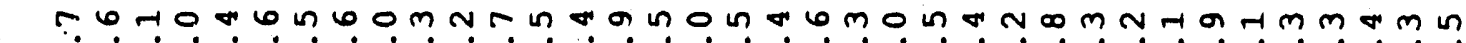

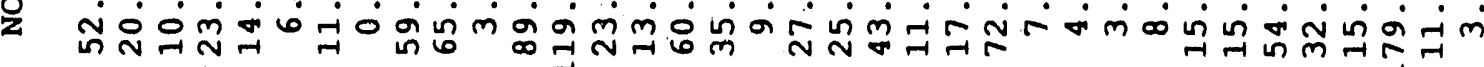

E mothinm

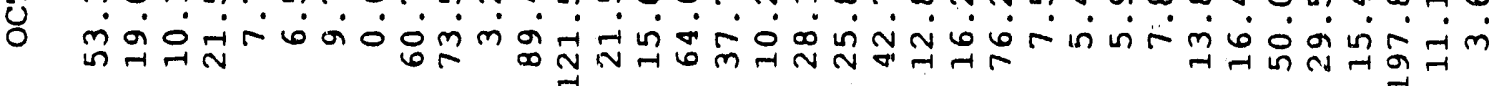

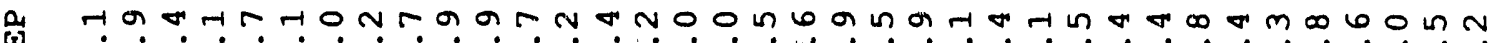

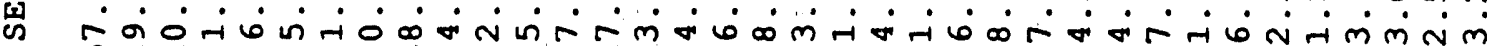

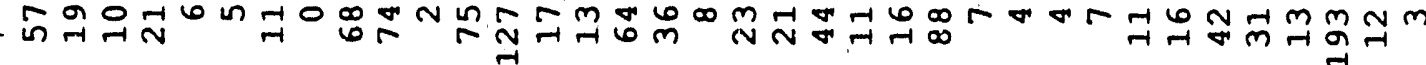

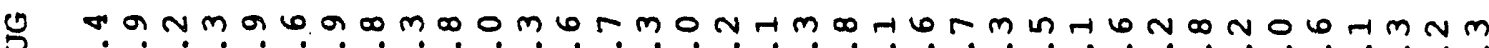

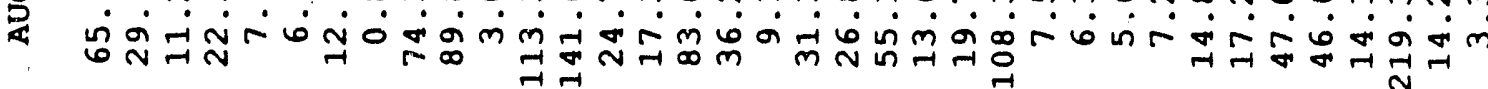

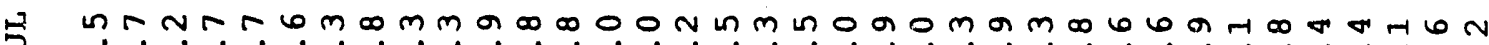

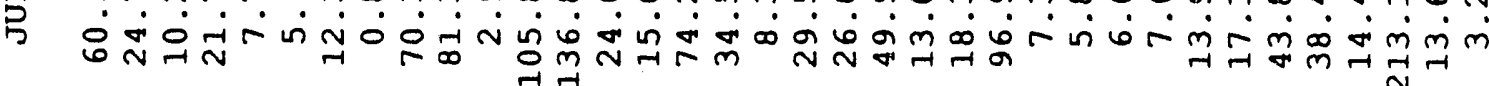

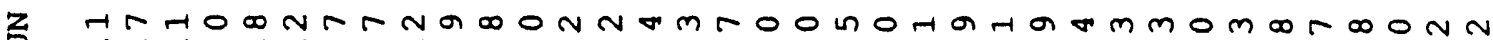

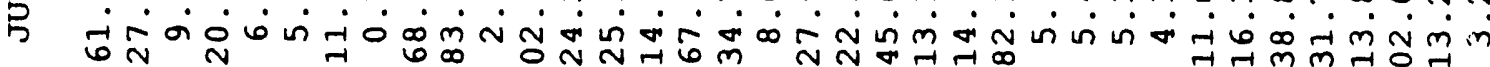

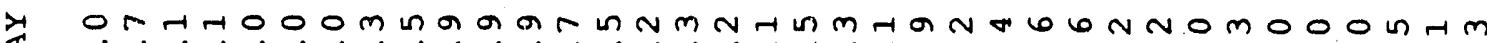

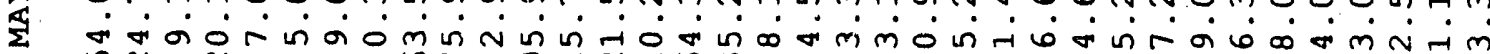

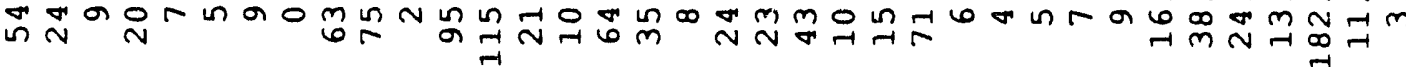

a om 0 m

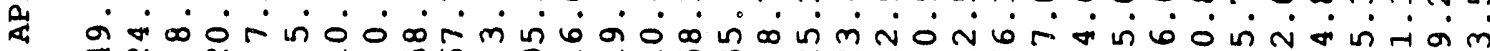

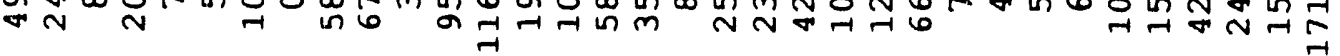

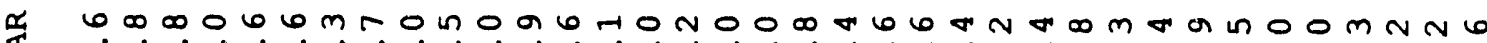

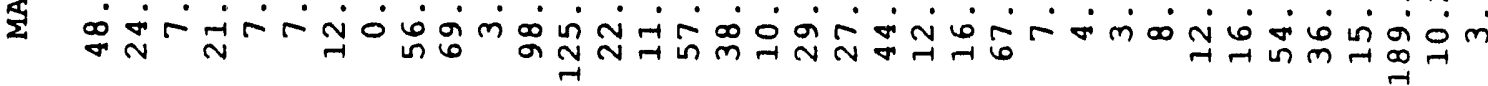

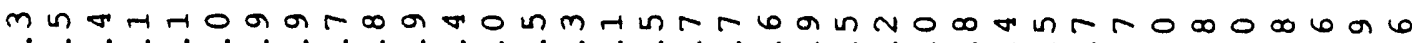

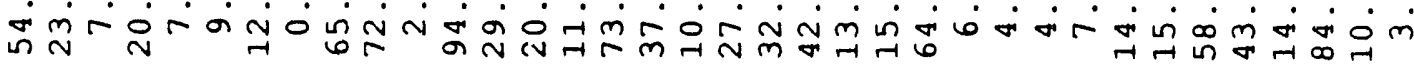
a

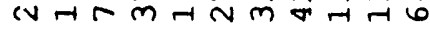
$\rightarrow \rightarrow \infty_{n \rightarrow \infty}^{\infty}$

z

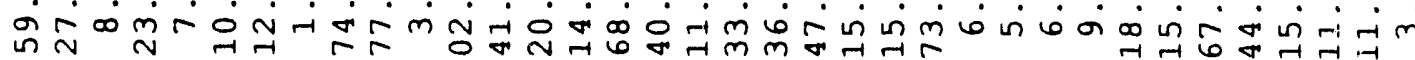

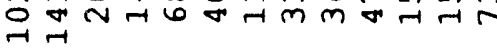
$\stackrel{-1}{N}$

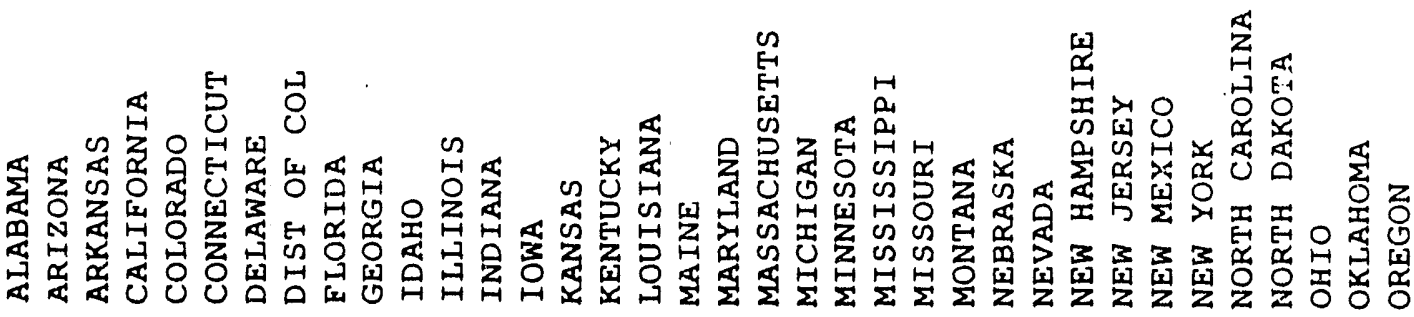




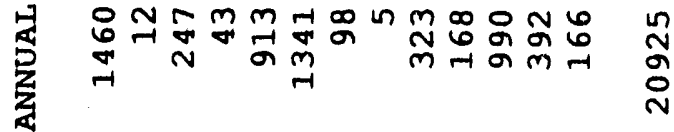

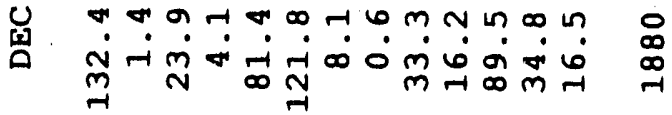

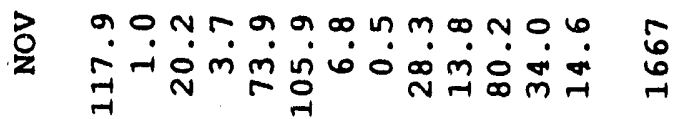

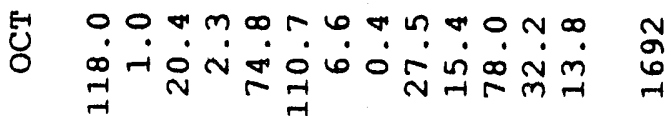

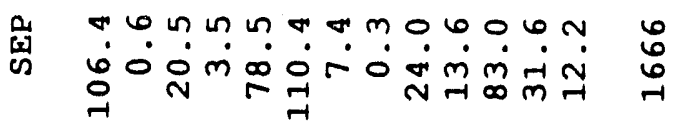

$$
\begin{aligned}
& \text { 象 }
\end{aligned}
$$

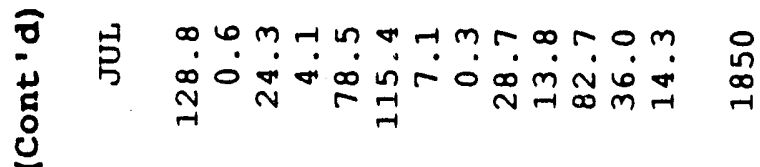

$$
\begin{aligned}
& \text { I } \quad \begin{array}{l}
n \\
\text { I }
\end{array}
\end{aligned}
$$

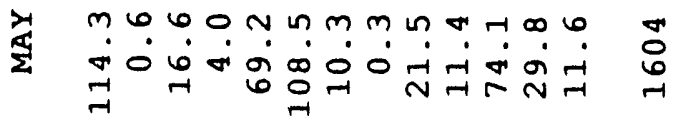

$$
\begin{aligned}
& \text { a }
\end{aligned}
$$

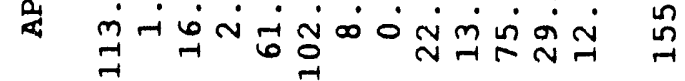

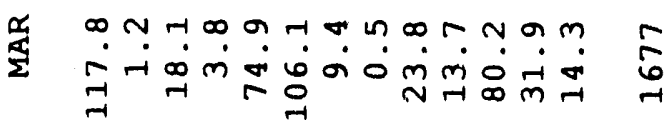

$$
\begin{aligned}
& \text { 界 } r m m n m-r \omega \infty \sigma \infty \sigma 0 \quad \ddot{m}
\end{aligned}
$$

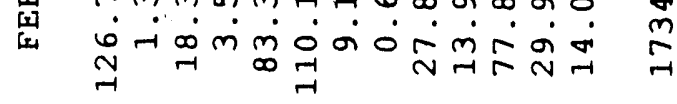

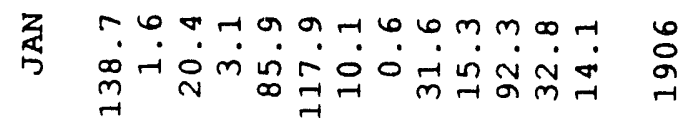

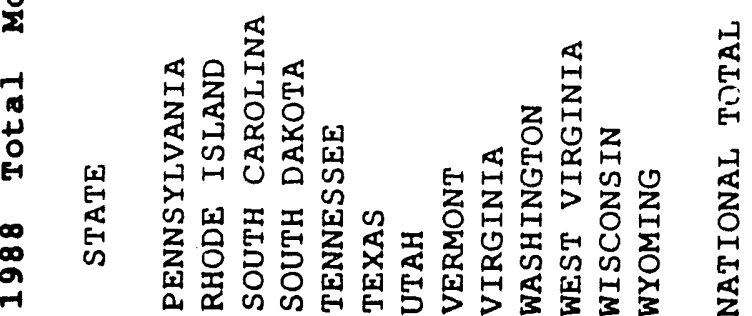


B.3 VOC Emissions by Month and State 


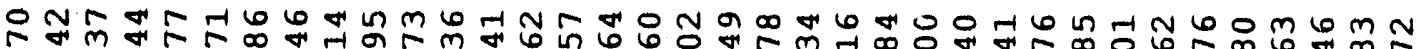
ก

U m. 皇

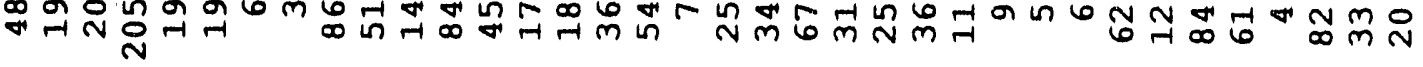

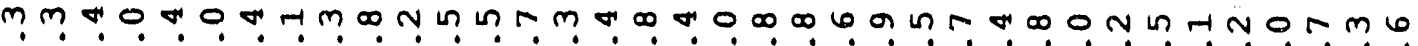

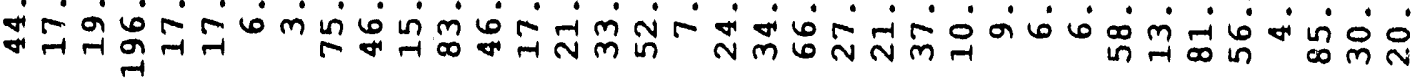

mo 0 " w m

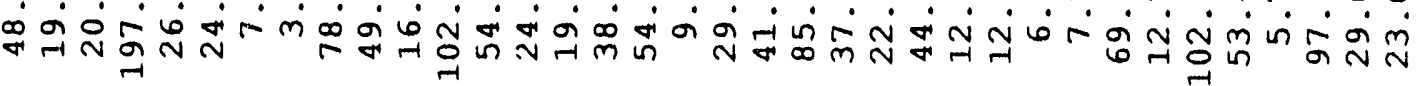

Hc! ঝ

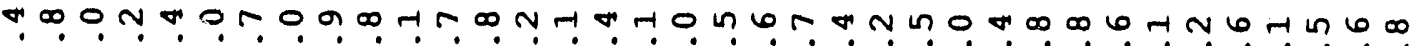

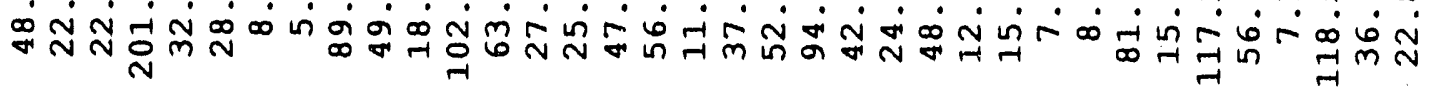

6.

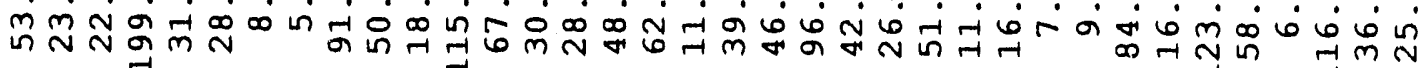

* 6 6 a 0 m

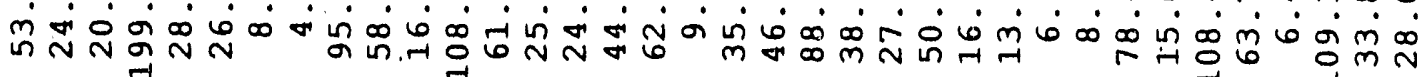

m $\mathrm{H}$.

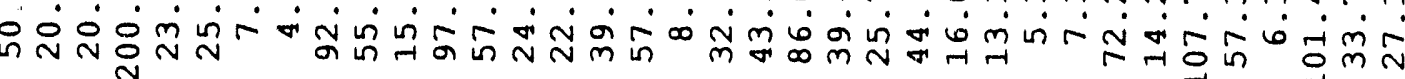

?

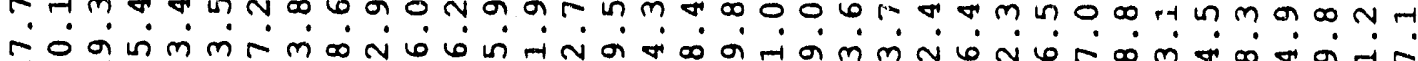

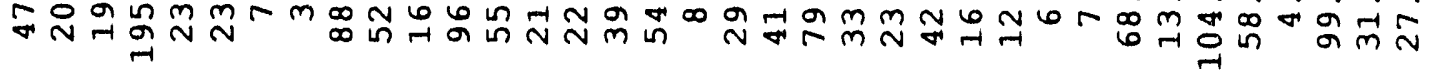
b n m m m

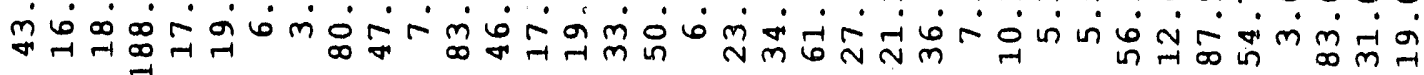

omammoram

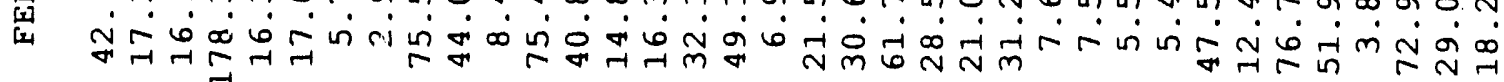

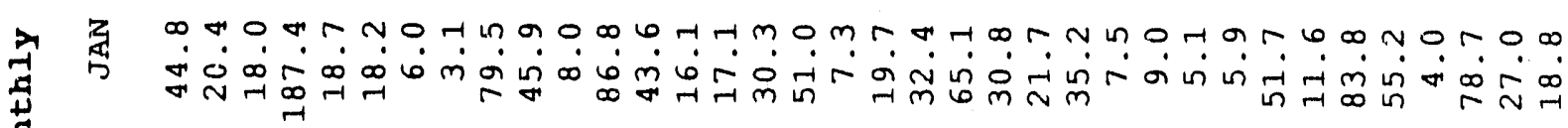




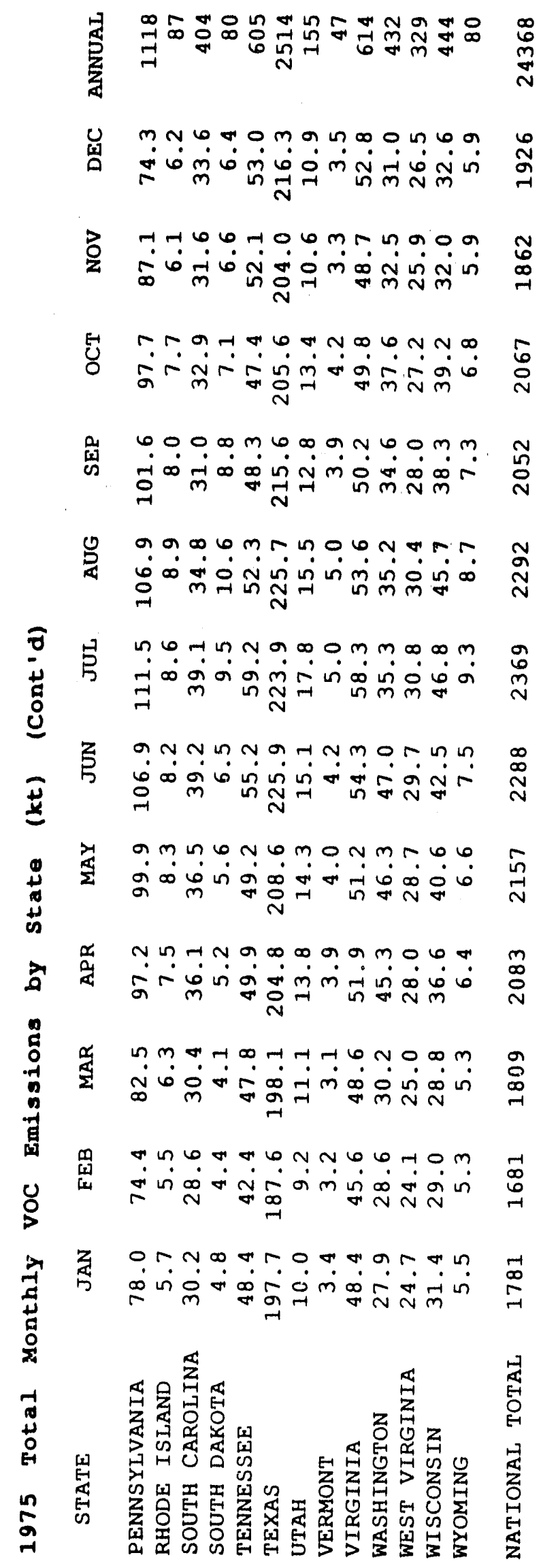




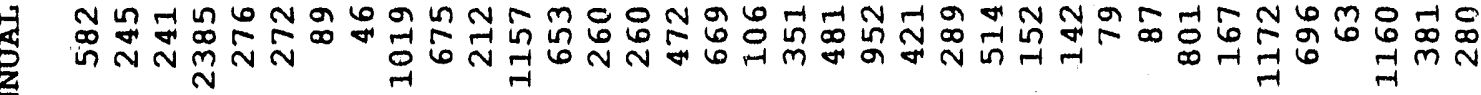

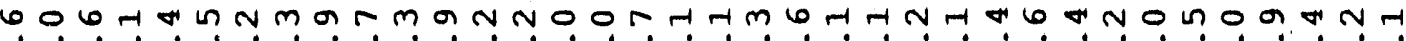

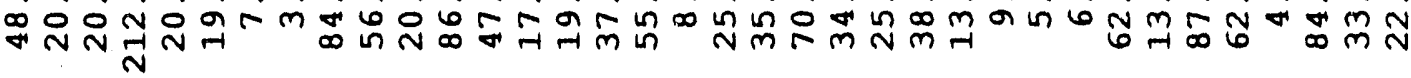

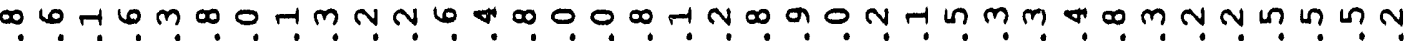

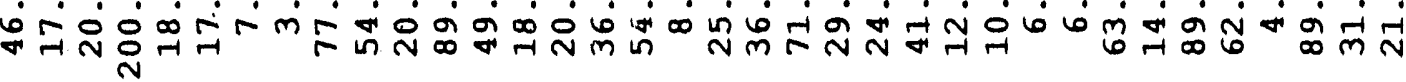

H NONDN

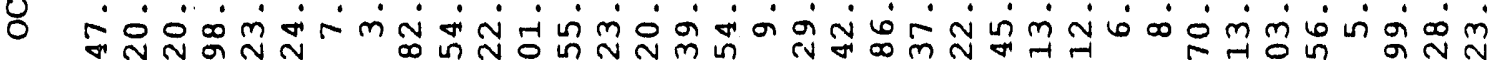
"N

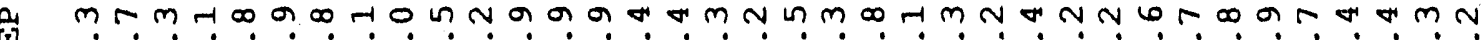

๒

U N n n ब

H $\infty$ n

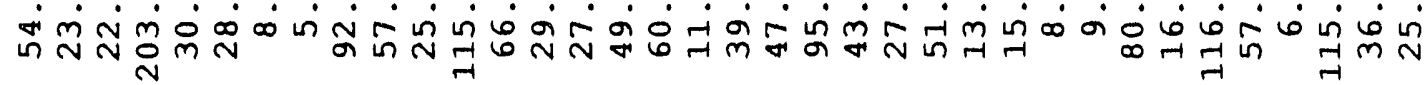

z n MNN

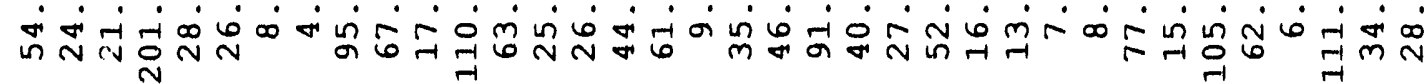

ᄀ a a

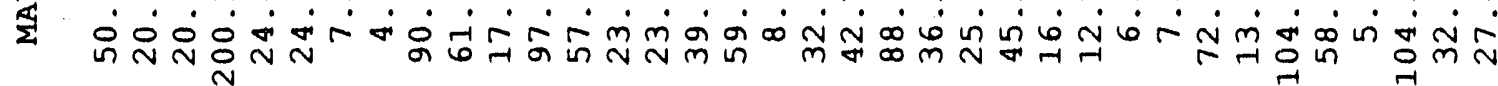

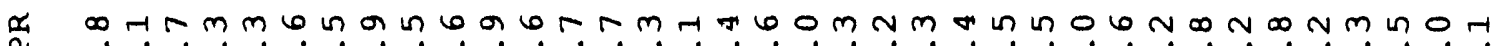

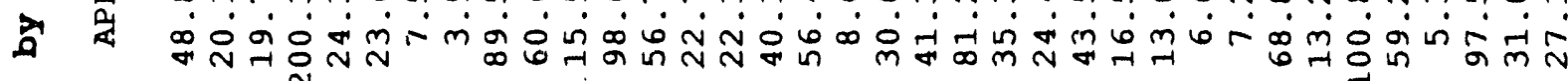

a nmRn

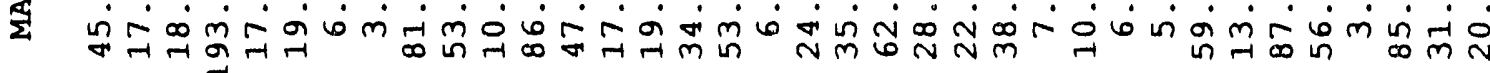

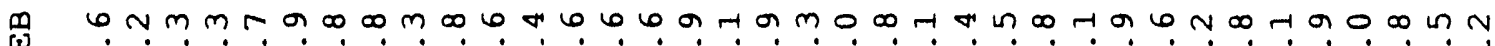

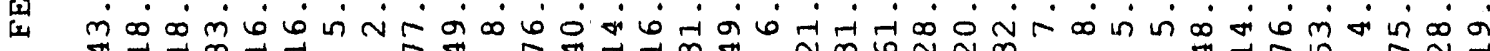

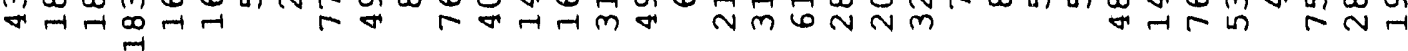

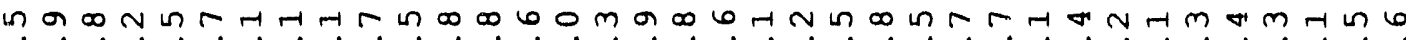

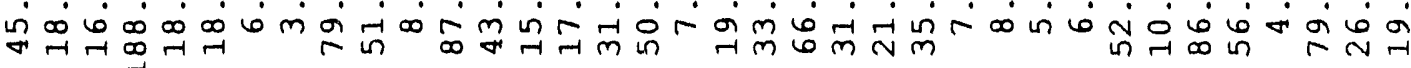




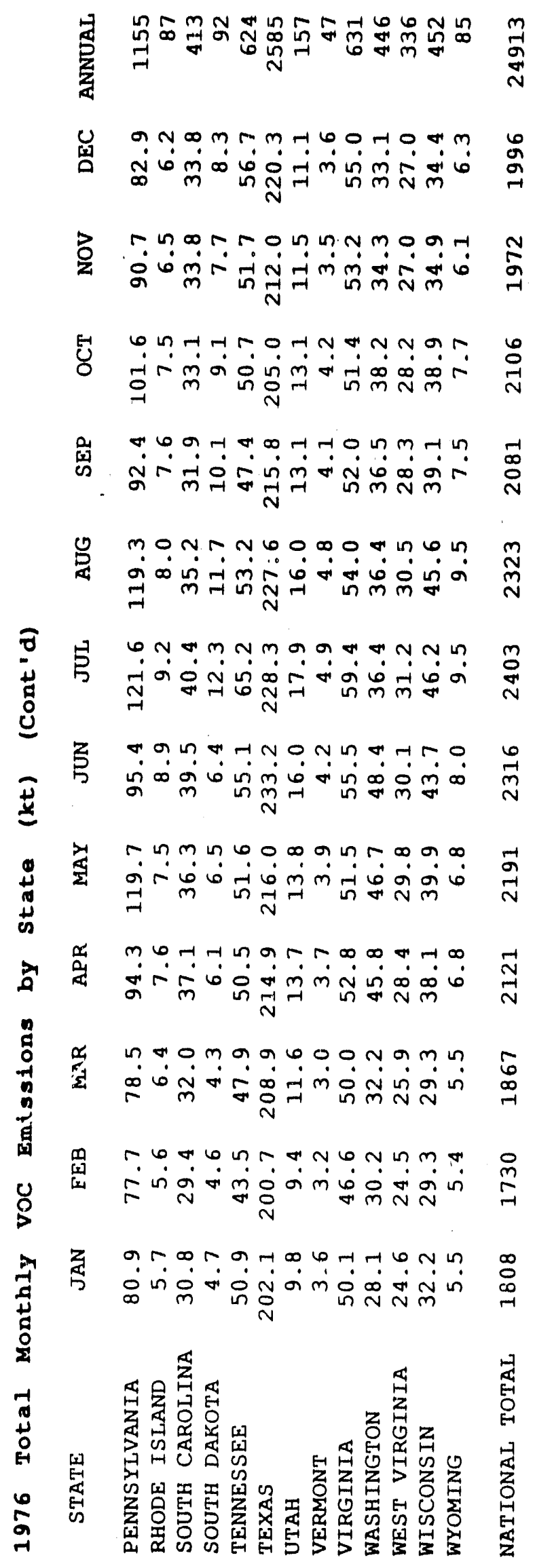




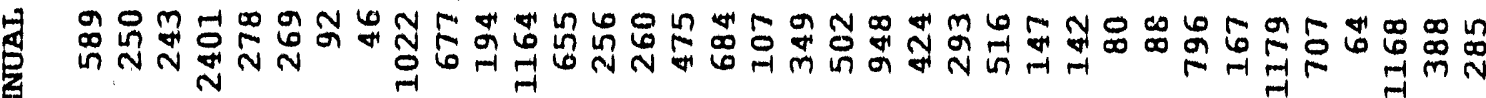

统

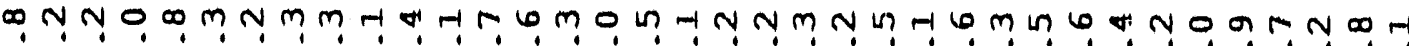

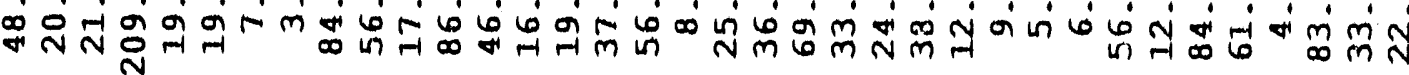

60, 0 \%

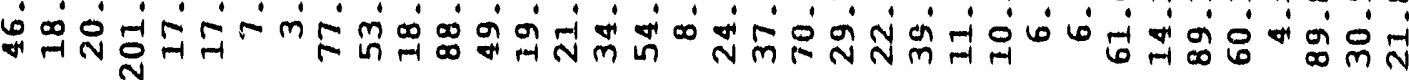

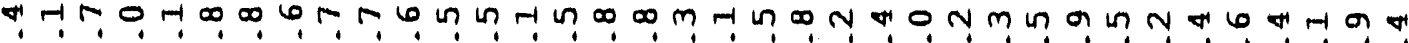
क D

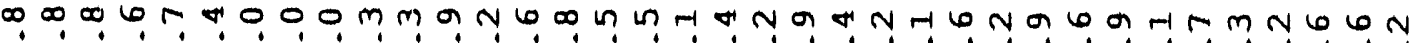

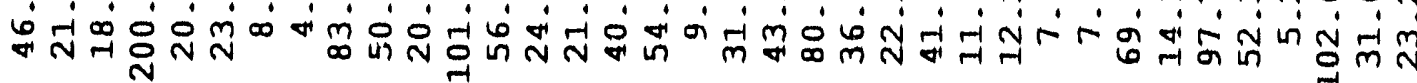

a Nang Ham

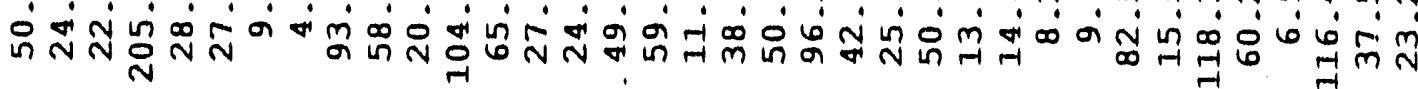

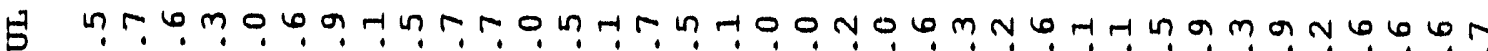

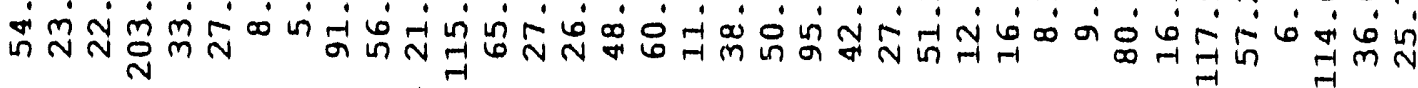

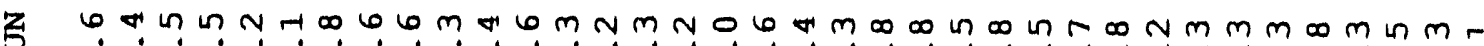

5 म 虫 N

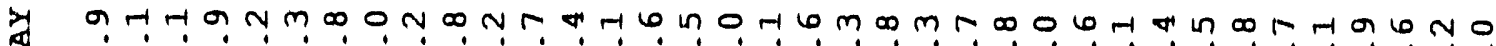
है

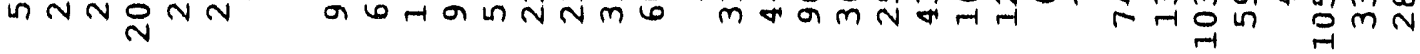

מ r. ThN

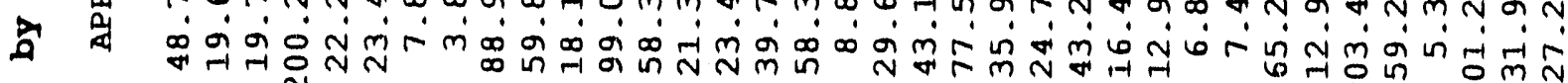

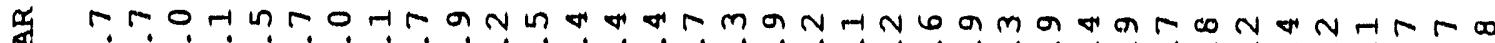
य

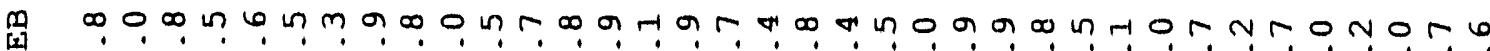

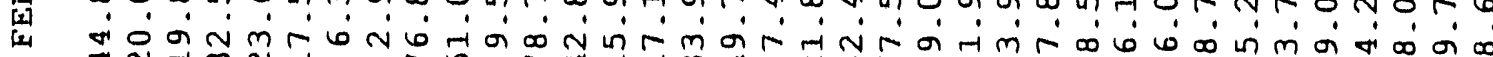

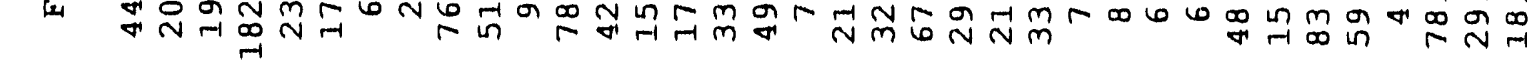

3 N $\mathrm{k}$ W 台 ம் ́ं

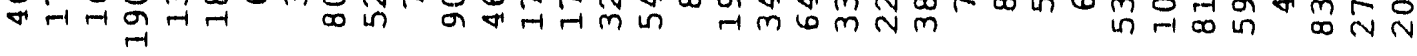




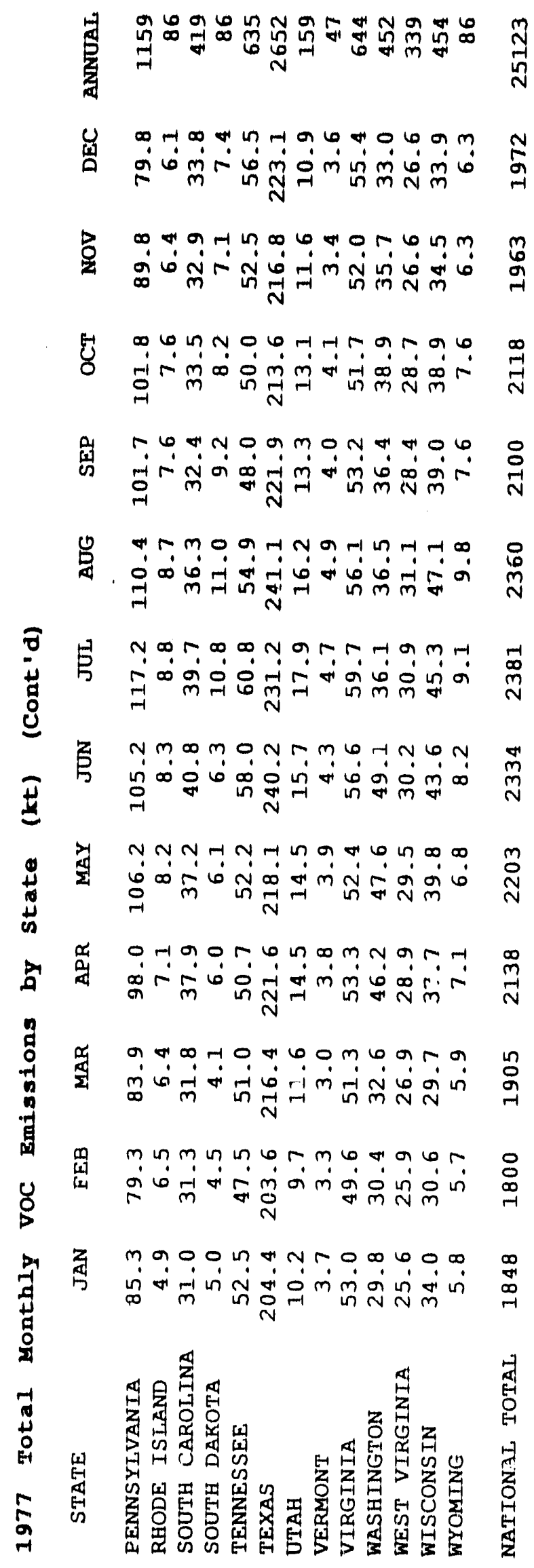




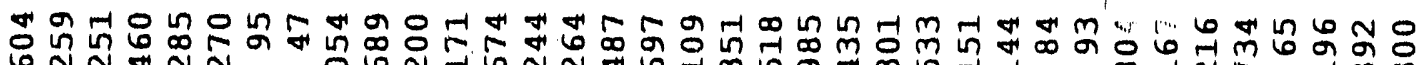

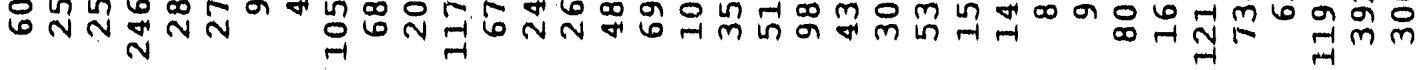

ש

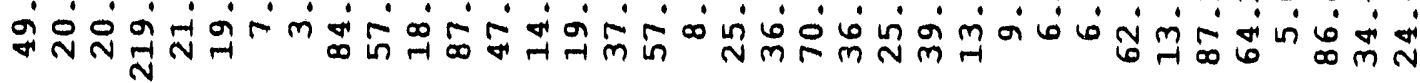

m

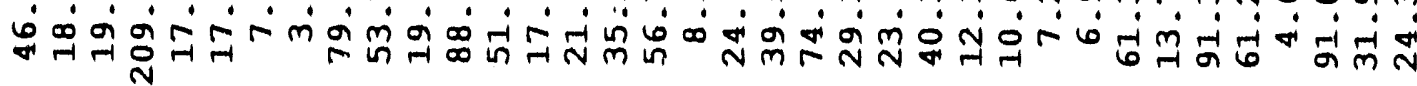

O 临

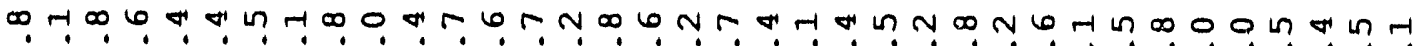

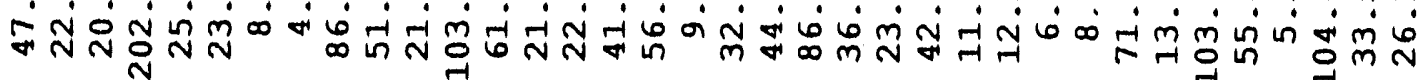

พ

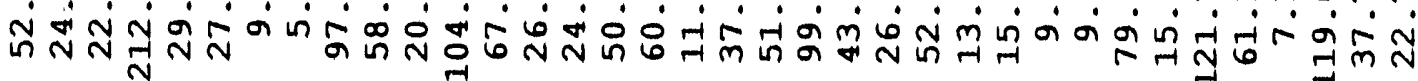

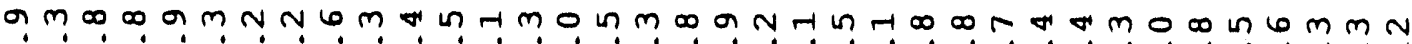
nீ

Z

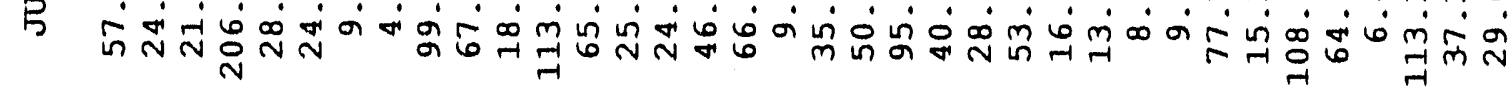

ᄀ

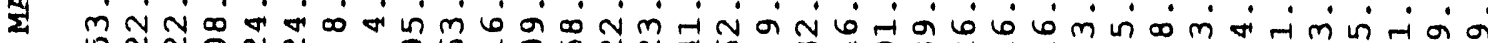

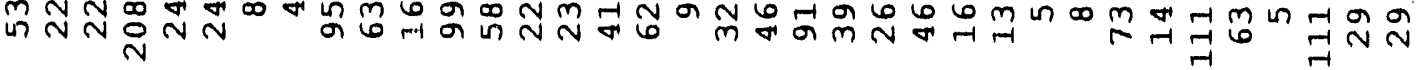

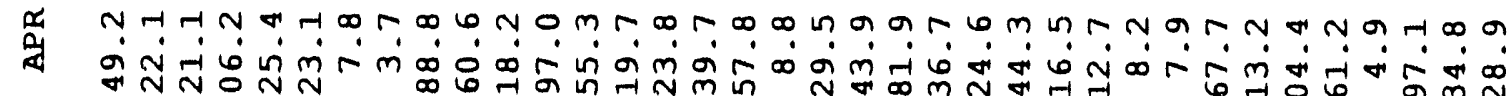

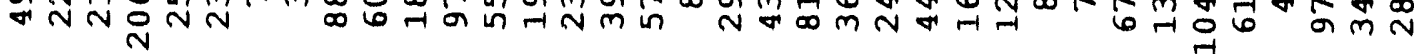

6r

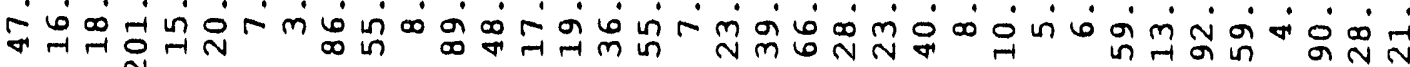

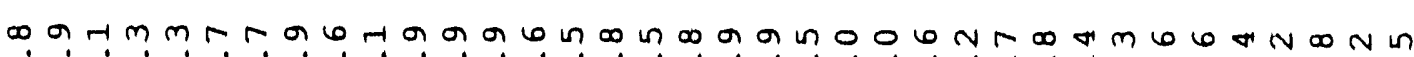
[I]

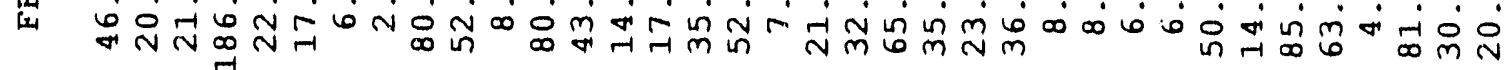

Z

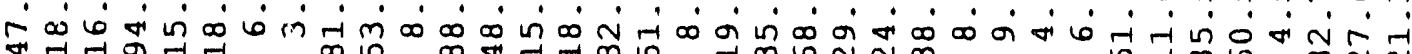

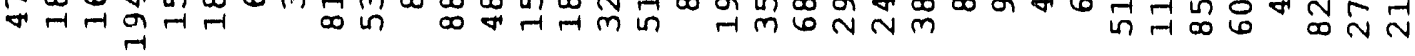




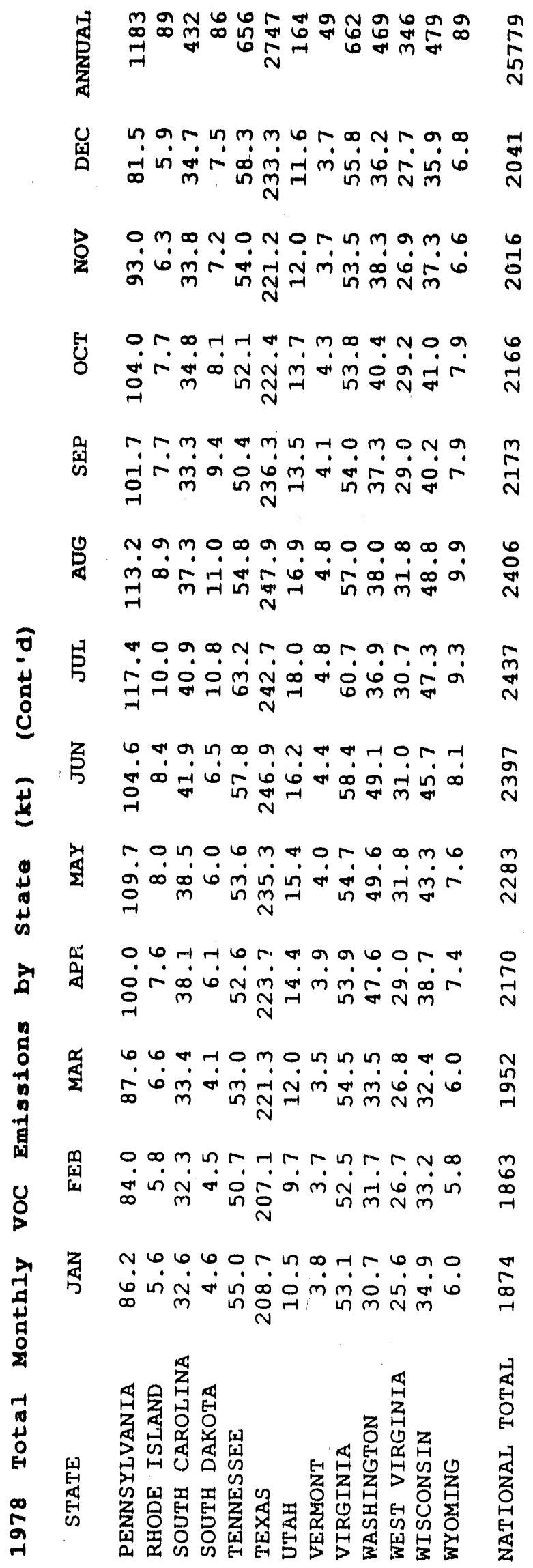




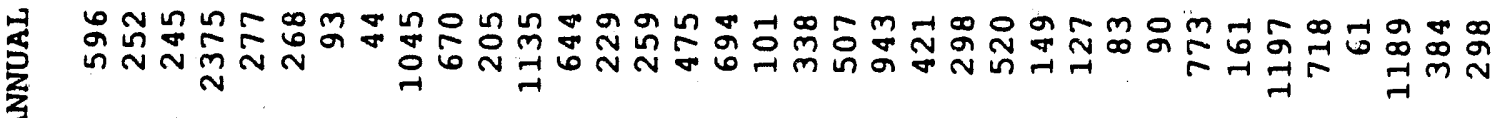

U

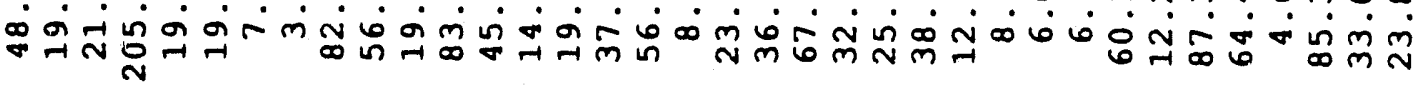

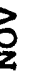

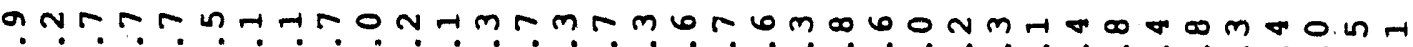

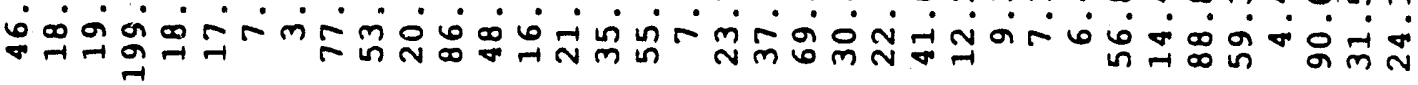

Eั

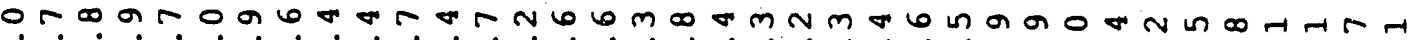

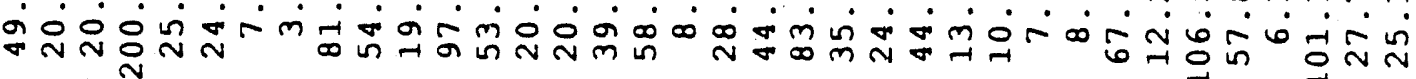

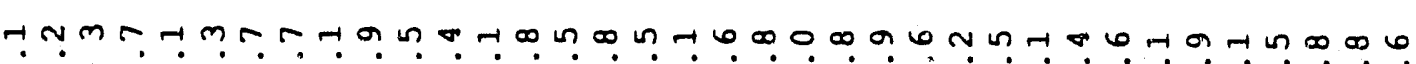

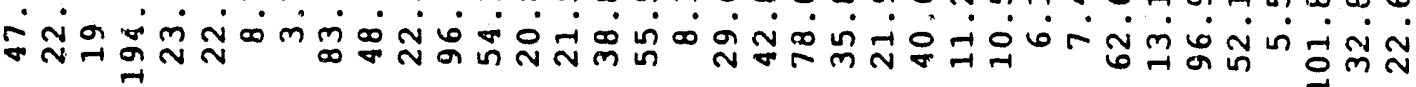

Nha H-H n

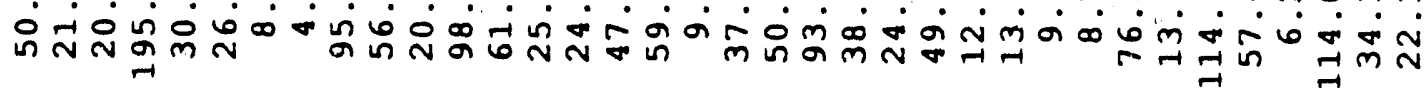

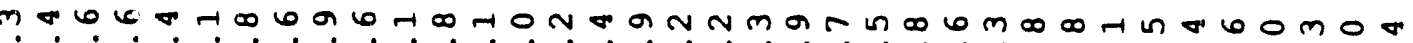

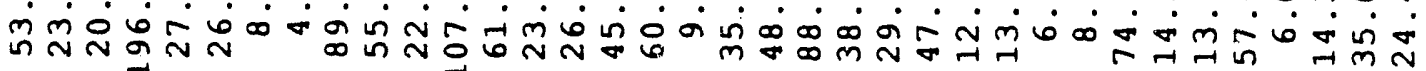

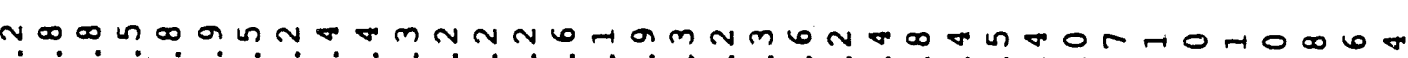

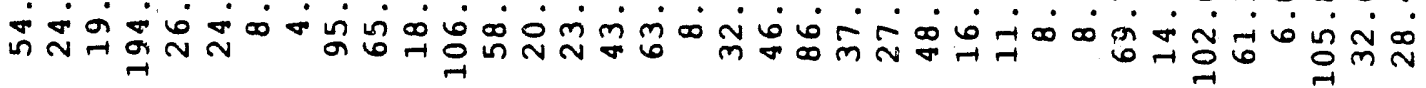

* 0 -

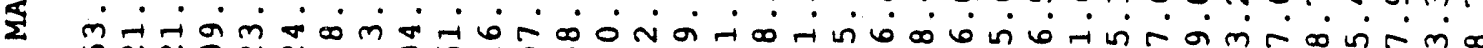

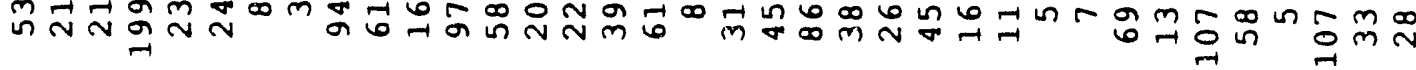

는

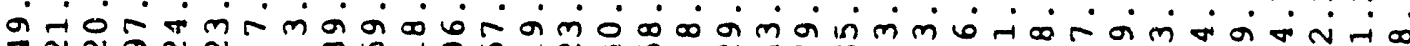

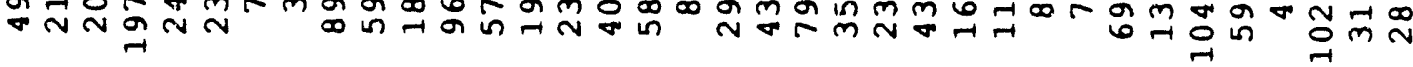

n

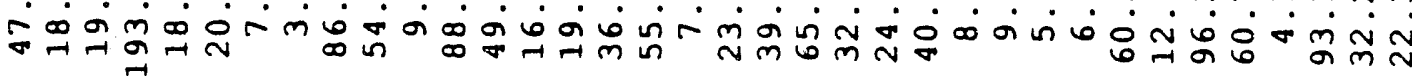

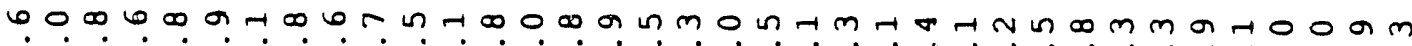

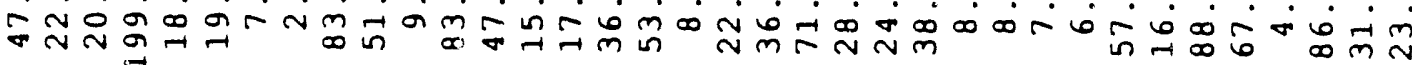

ogbrmabriantrin

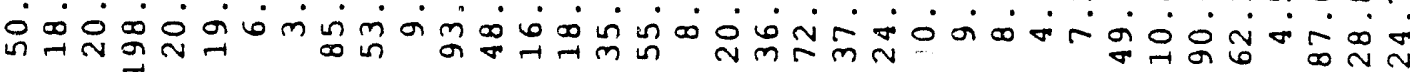

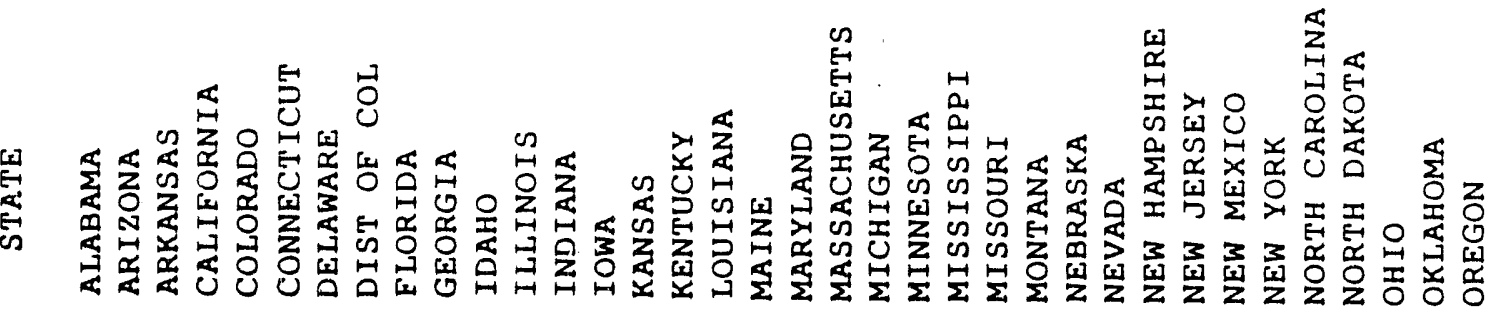




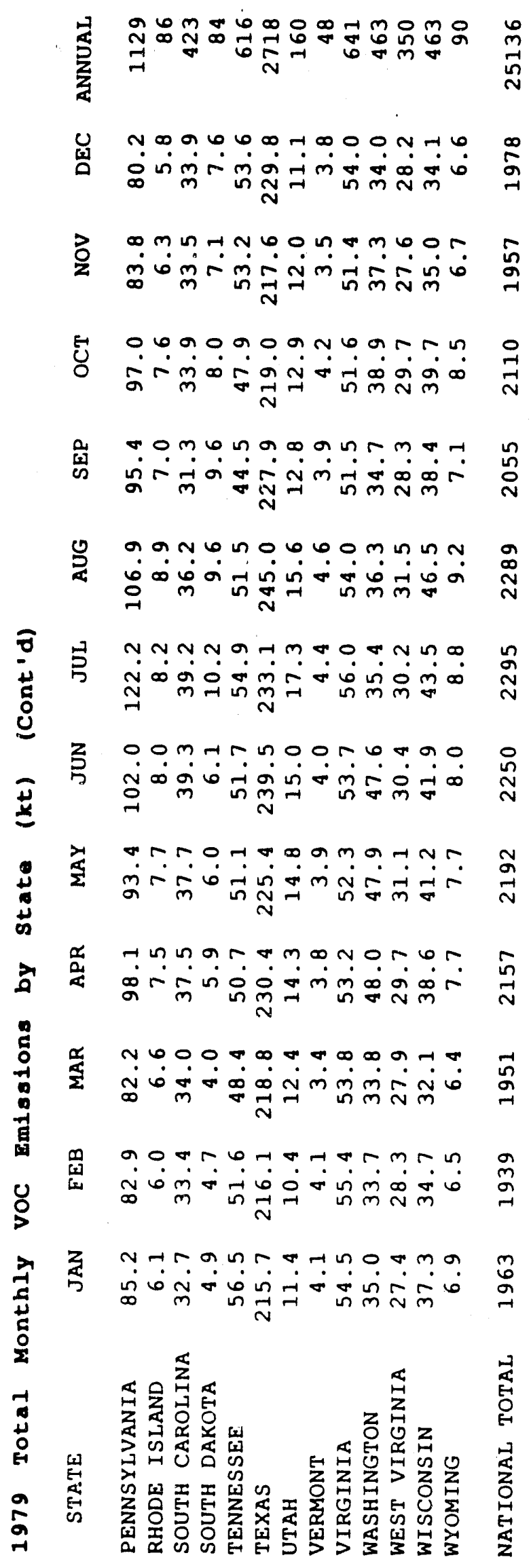


药

o d R N

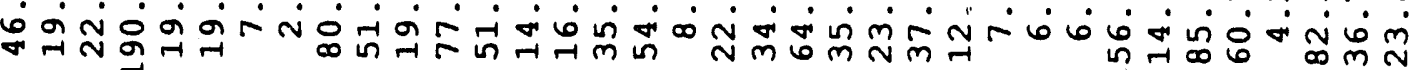

oan

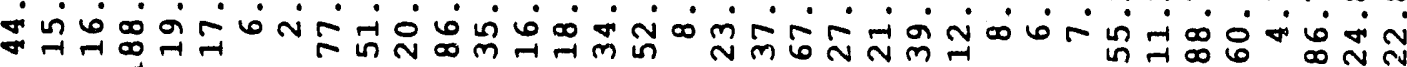

ยู

6 6 N

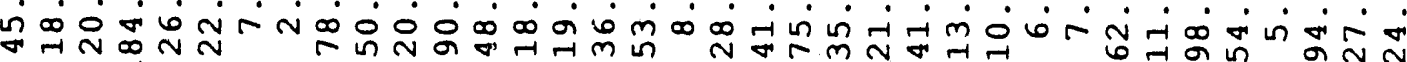

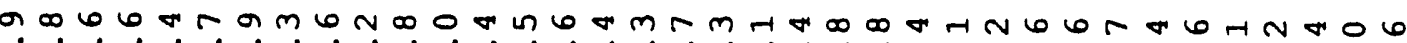

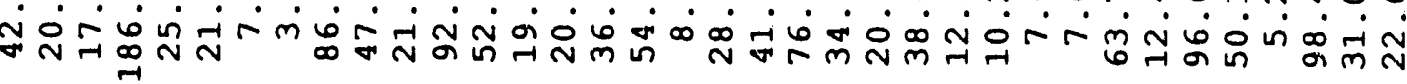

Nogrnmurmon 正

Num an a m

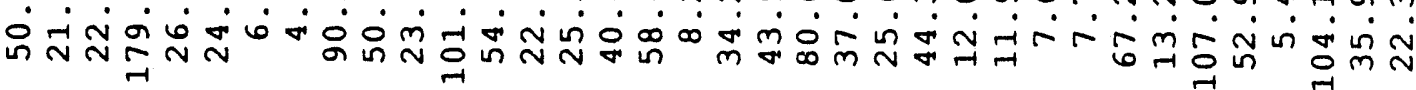

6 H r.

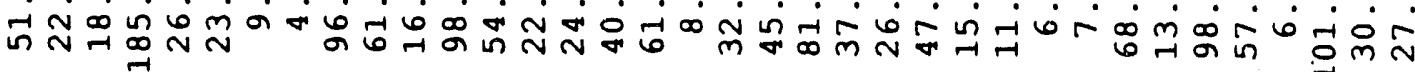

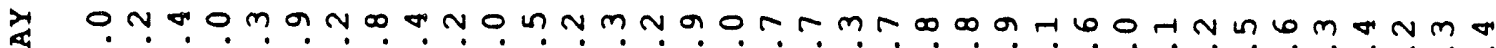

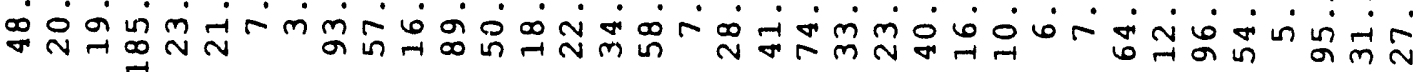

$\frac{\sim}{a}$

a baganm

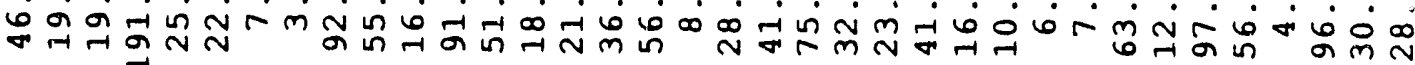

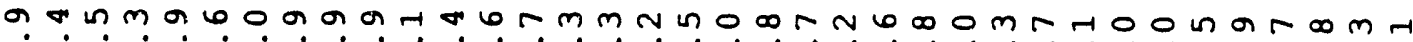

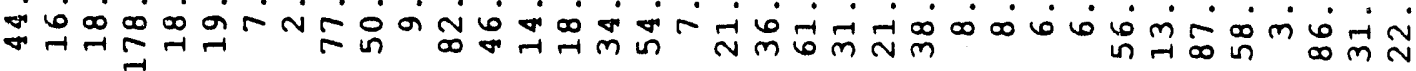

n

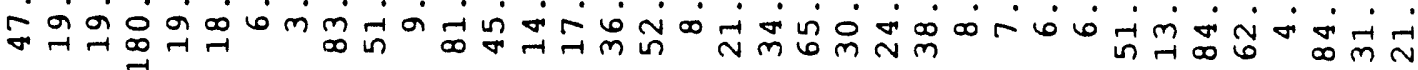

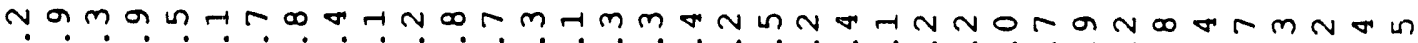

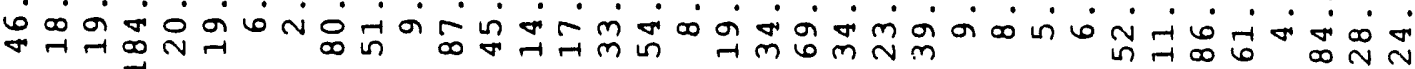




$$
\begin{aligned}
& \text { 存 }
\end{aligned}
$$

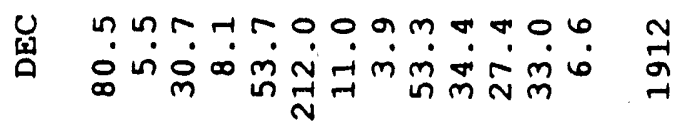

$$
\begin{aligned}
& \text { z } \\
& \text { 范 }
\end{aligned}
$$

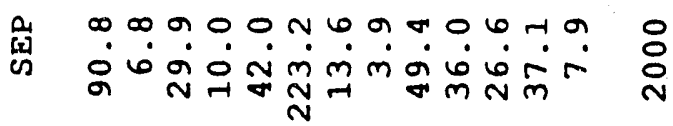

$$
\begin{aligned}
& \text { \ }
\end{aligned}
$$

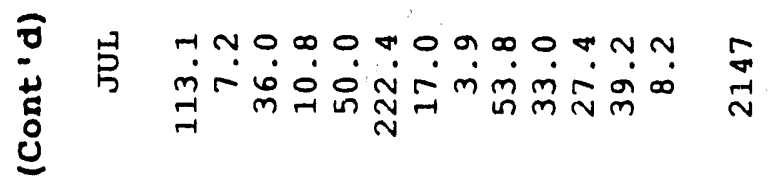

$$
\begin{aligned}
& \text { I }
\end{aligned}
$$

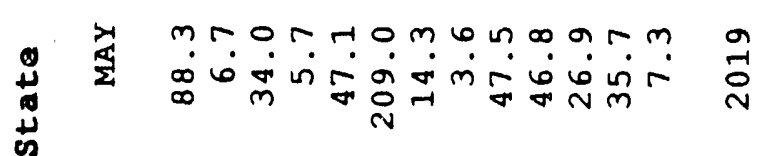

$$
\begin{aligned}
& \text { a व }
\end{aligned}
$$

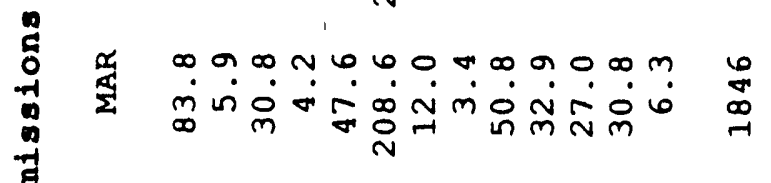

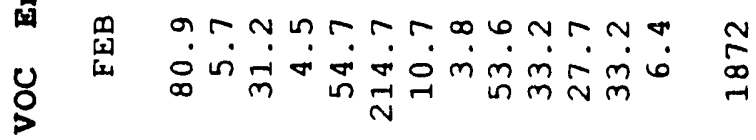

$$
\begin{aligned}
& \text { 滎 }
\end{aligned}
$$

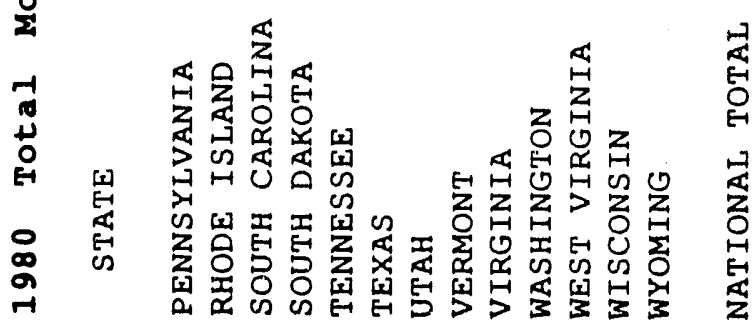


是

6 几 0 स"

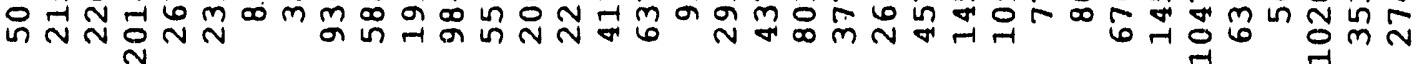

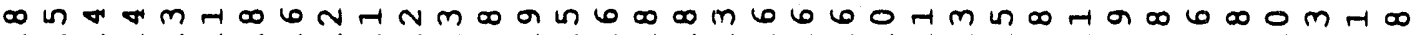

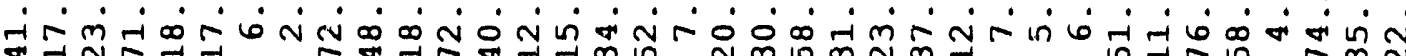

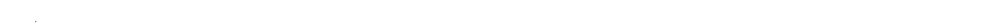

z

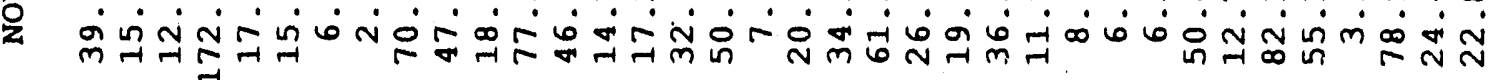

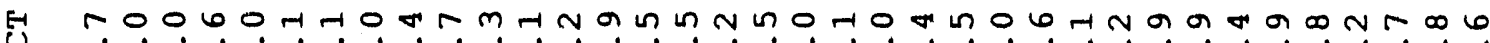

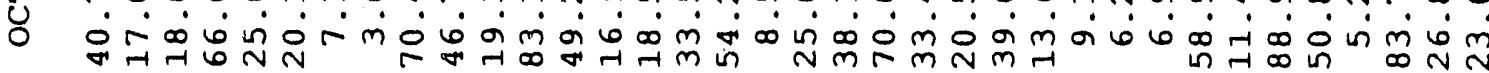

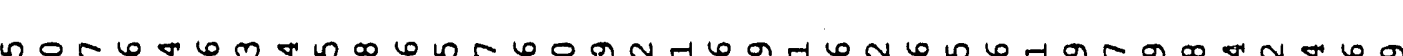

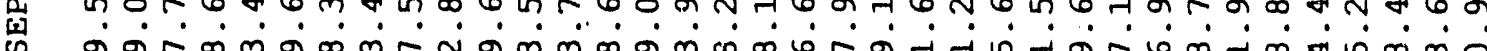

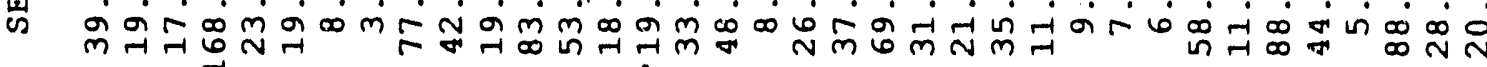

(b) $\quad$ r $-1, m m 0$ a

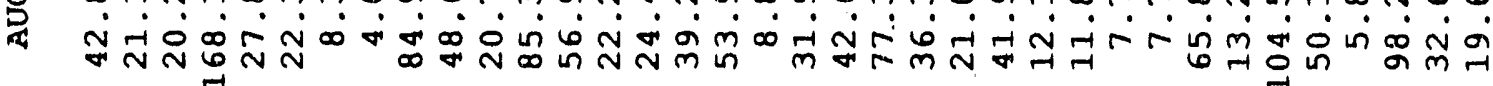

月 ח

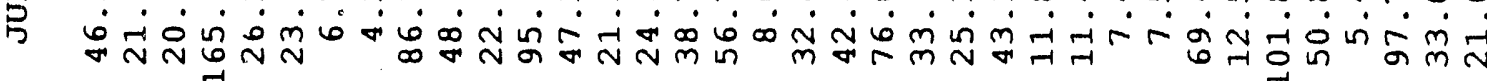

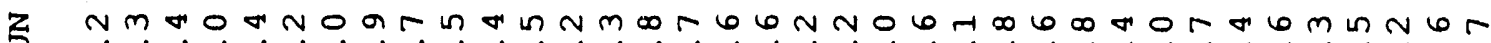

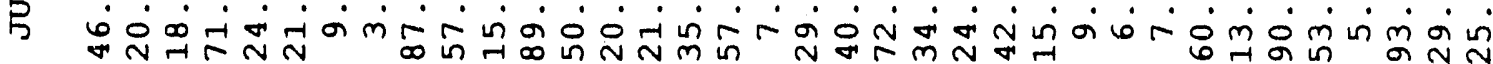

2)

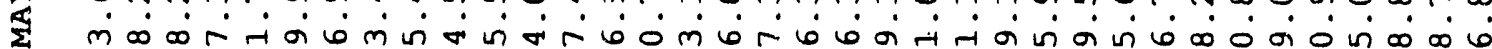

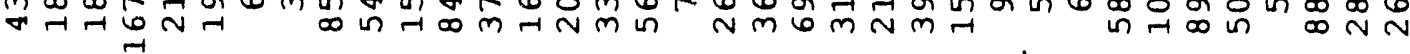

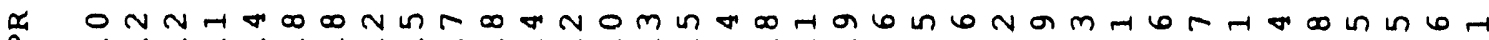

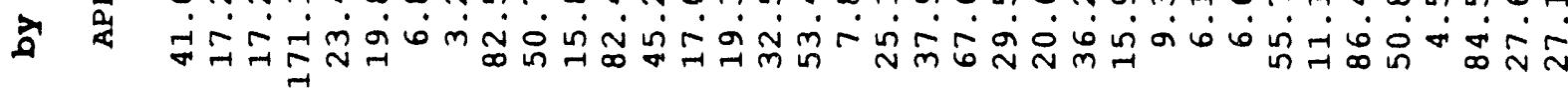

a

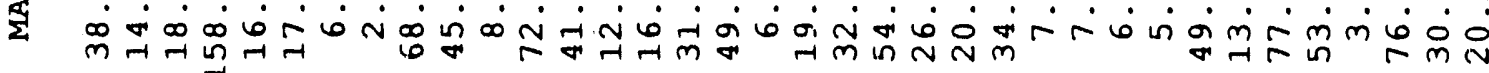

m $\quad \pi-10060$ n |

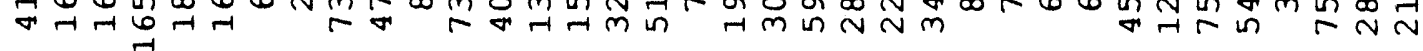

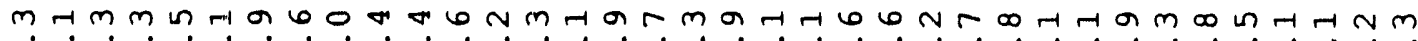

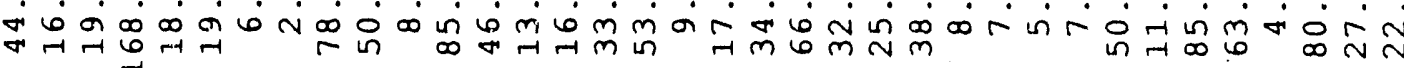

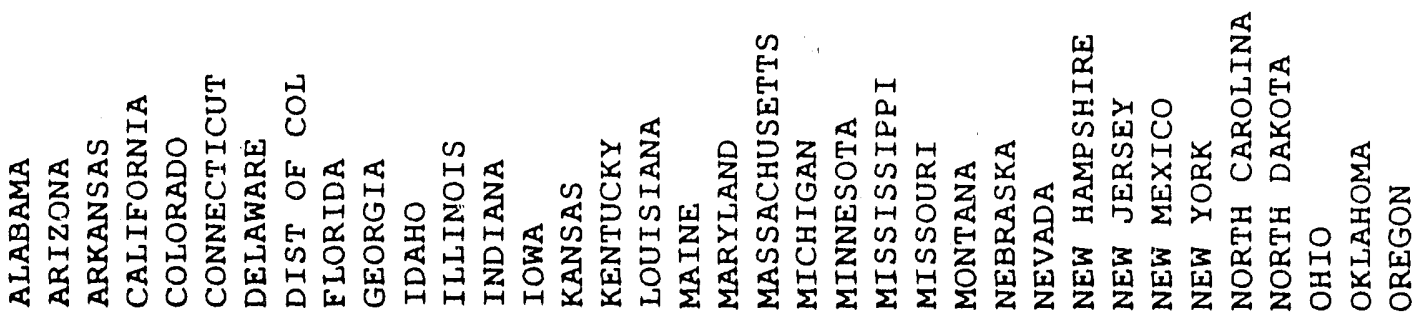




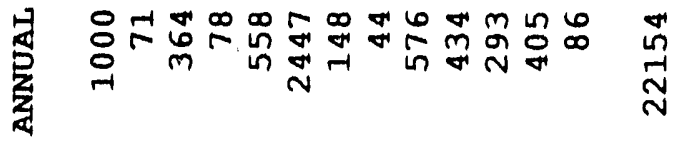

$$
\begin{aligned}
& \text { U }
\end{aligned}
$$

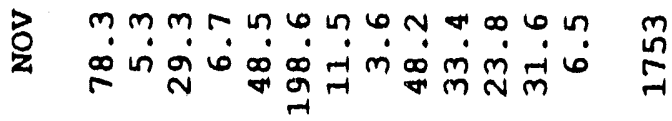

$$
\begin{aligned}
& \text { ర }
\end{aligned}
$$

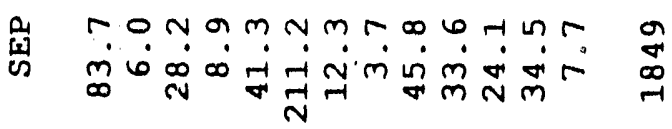

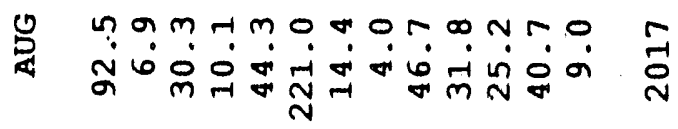

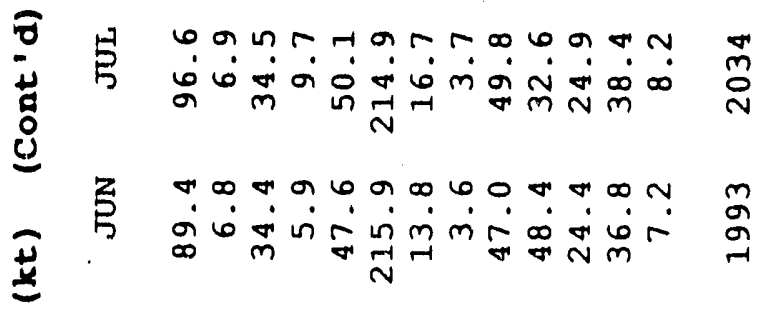

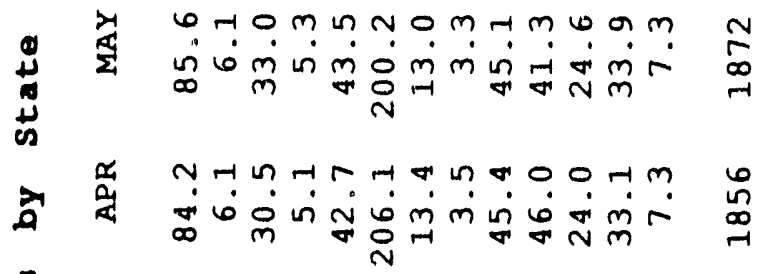

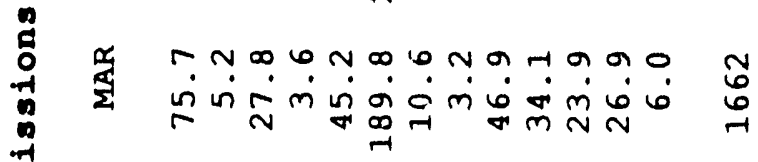

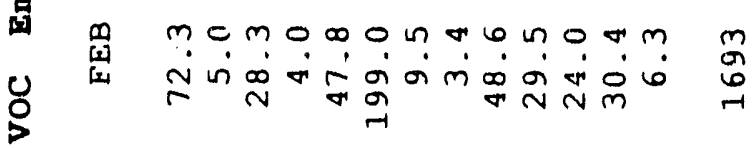

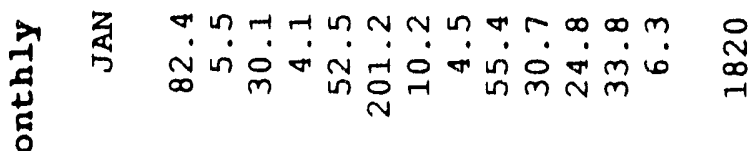

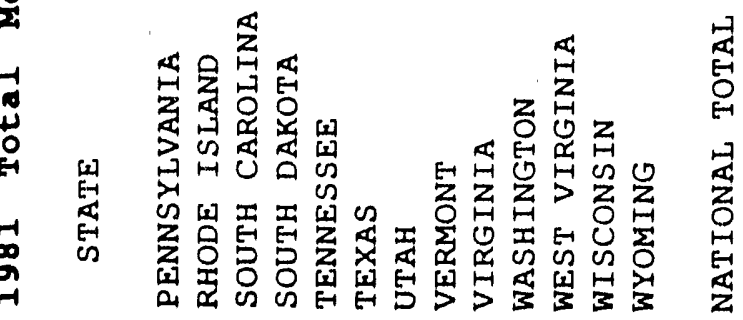


뉴윰ㅇㅇㅠ * N $\infty N \underset{N}{\infty} \infty$ in

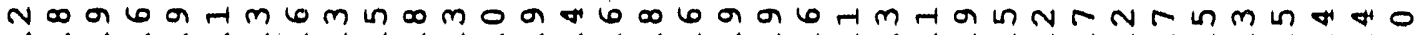

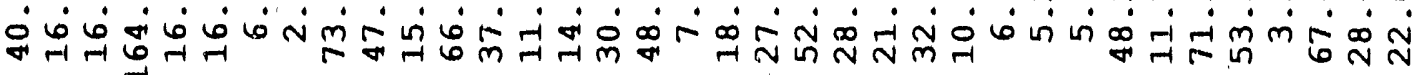

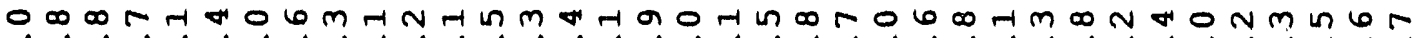

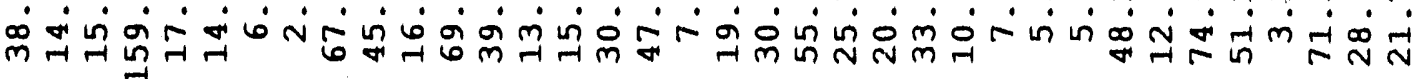

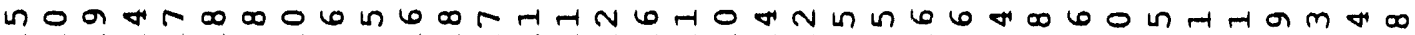

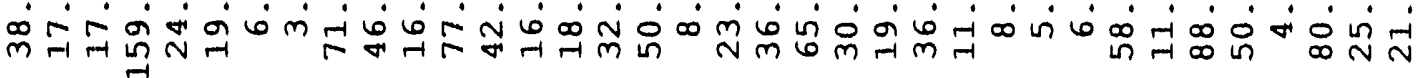

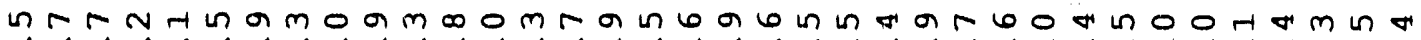

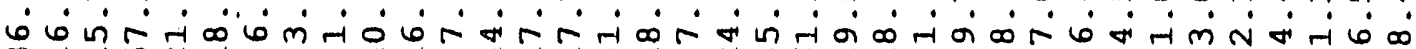

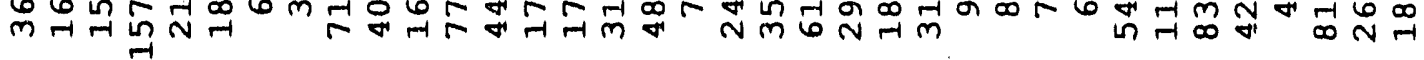

g. ก ? ब

S 4 -

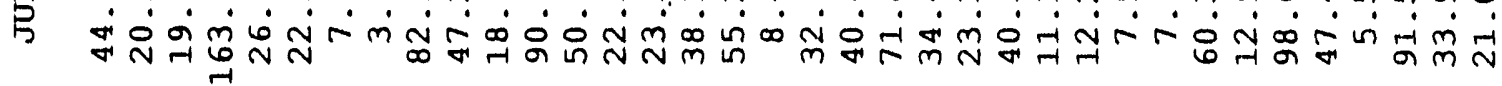

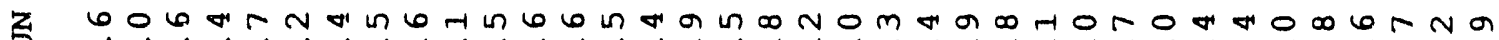

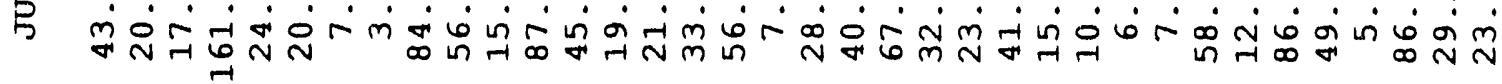

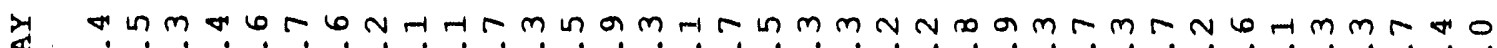

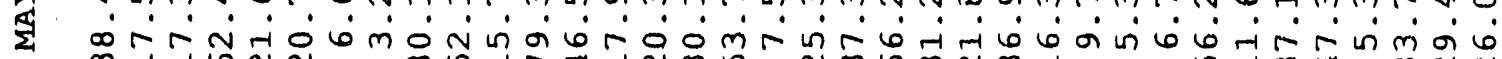

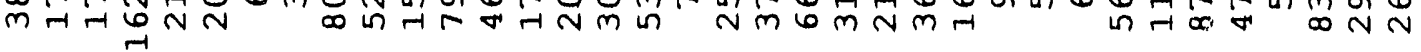

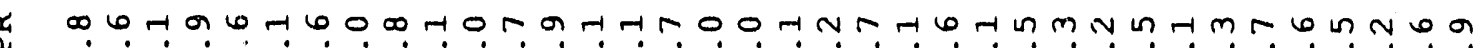

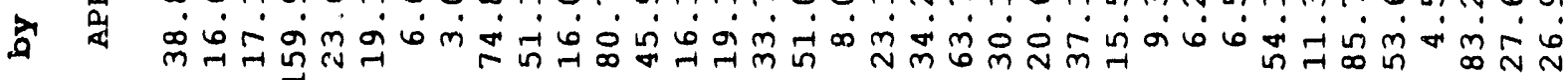

$66 m \pi$ m

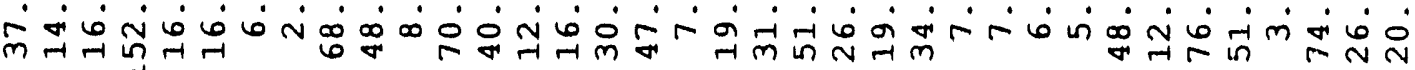
$m \sim \infty \infty$ a

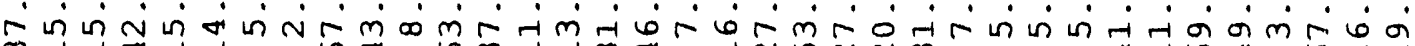

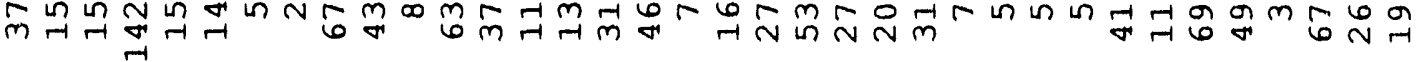
nat a d o $0 \mathrm{~mm}$ a

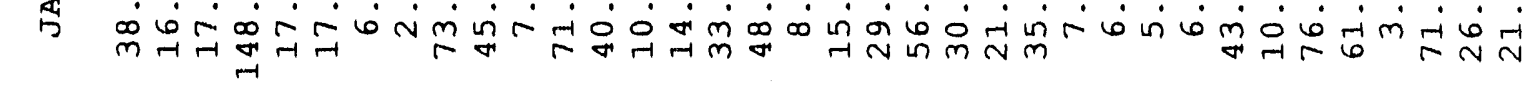

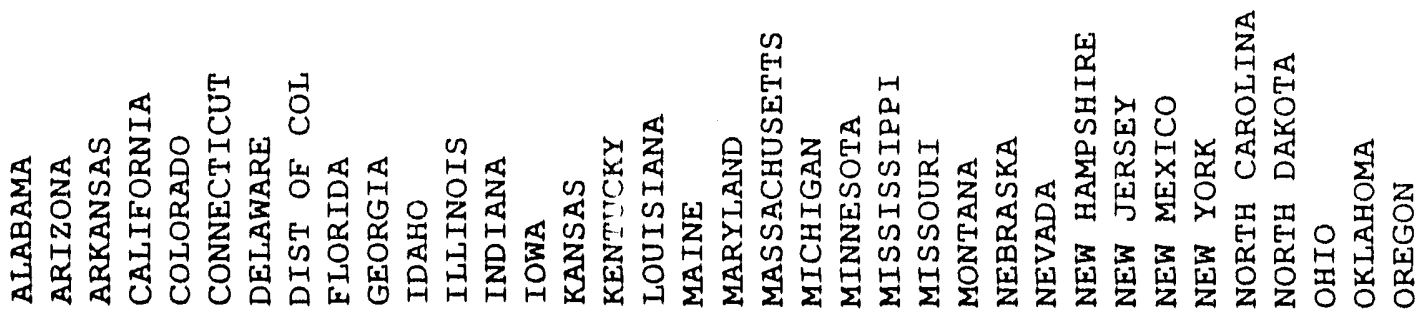




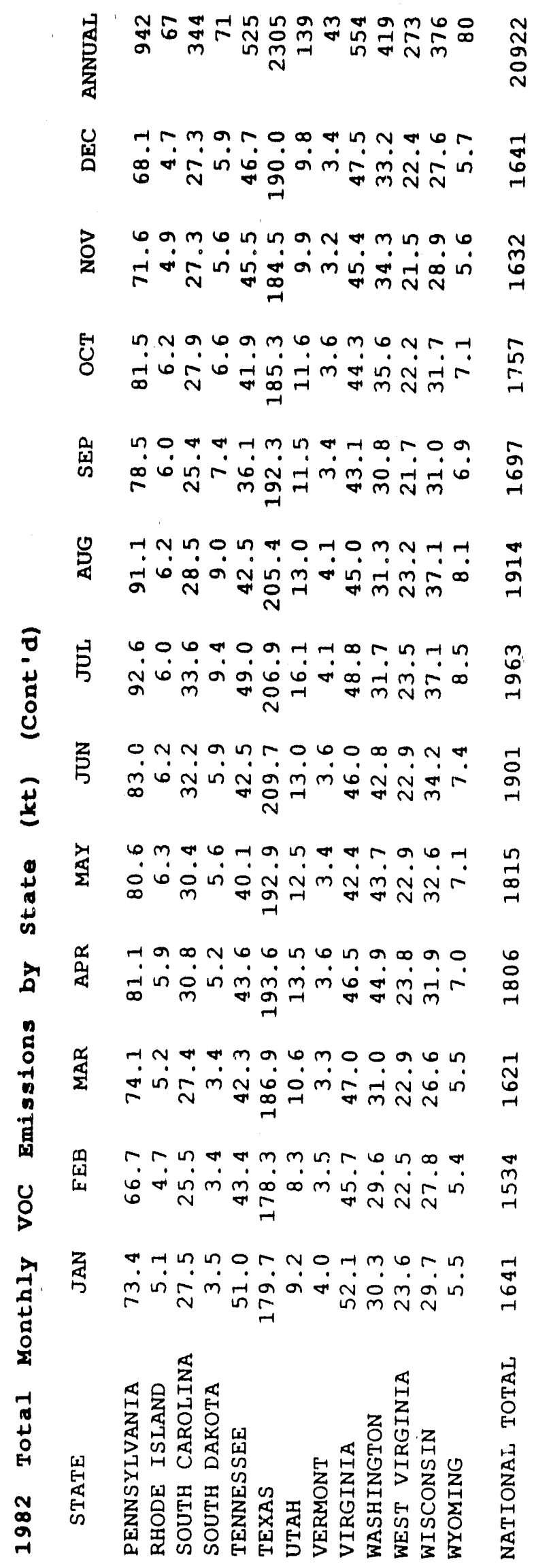


最

य r. 厸 Fतन

8 ח.

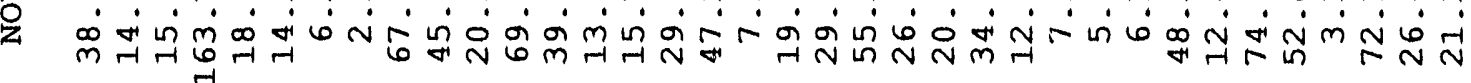

H O

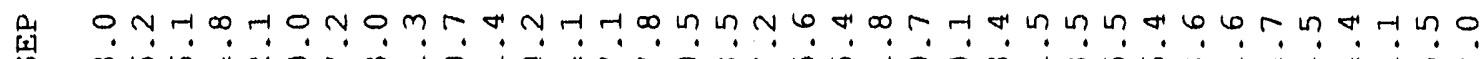

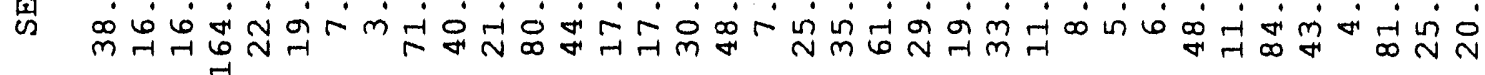

de 0 Hnd द

H Ho

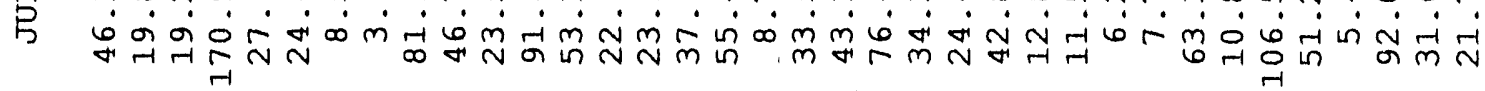

3 Hnmronlom

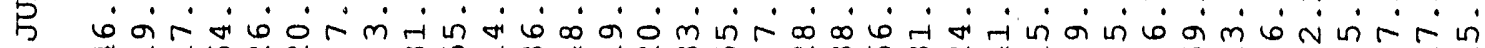

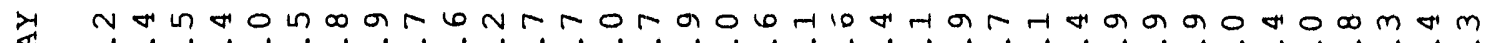

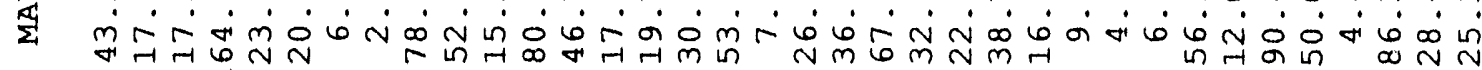

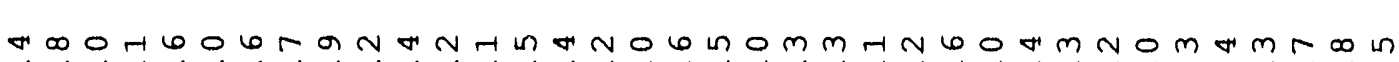
दै

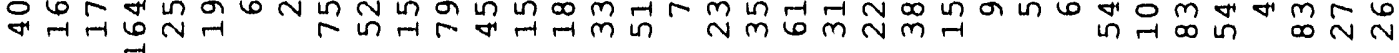

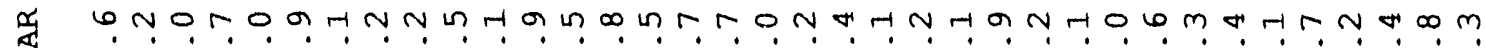

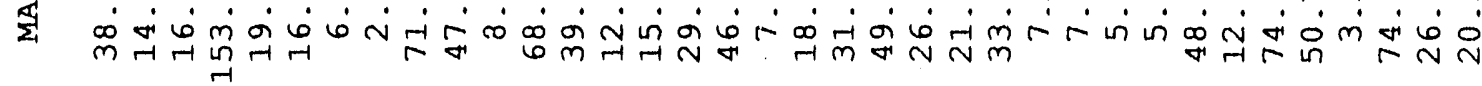

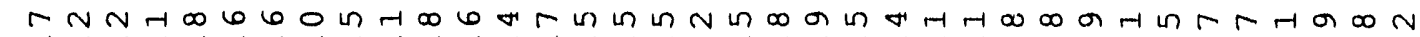
य ru @

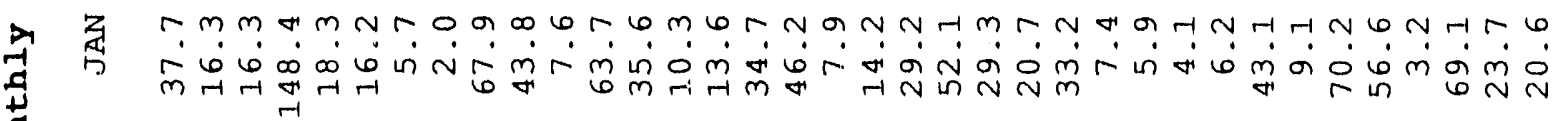




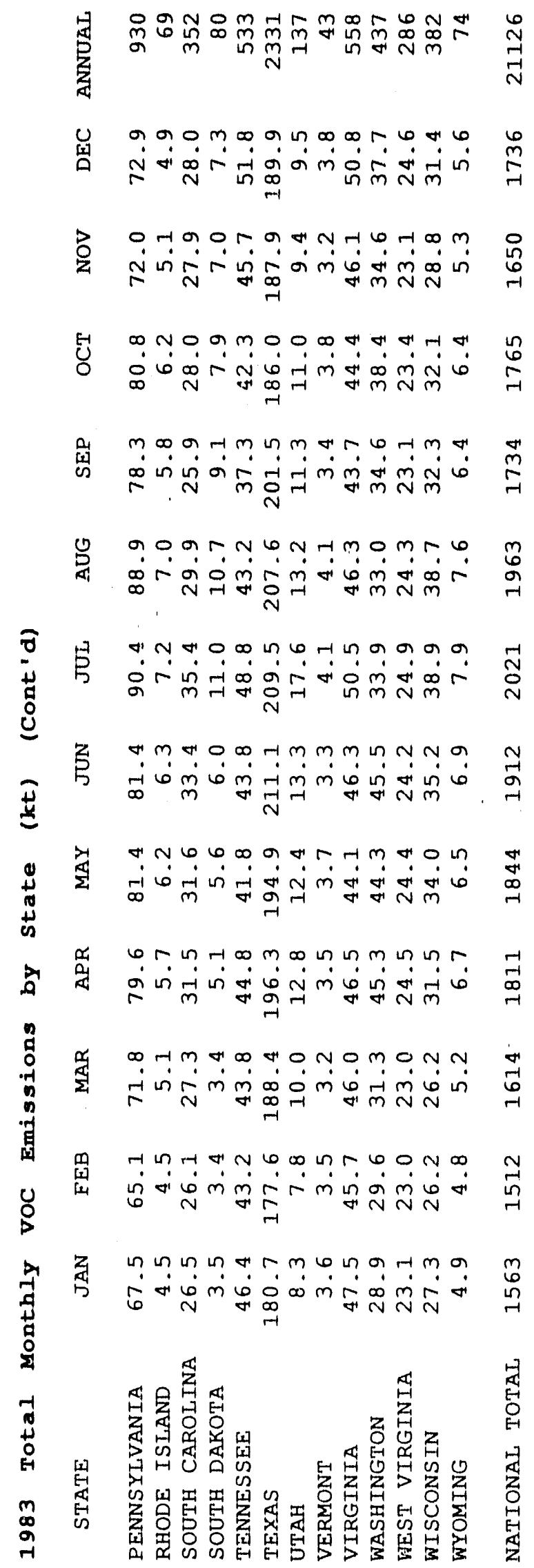




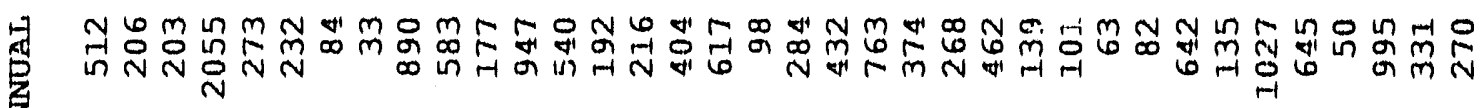

U 呂 $\quad$ -

b $m ?$ ㄴ.

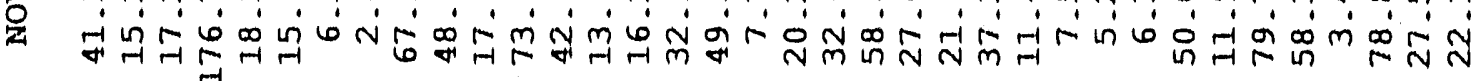

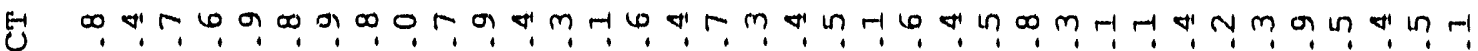
O O

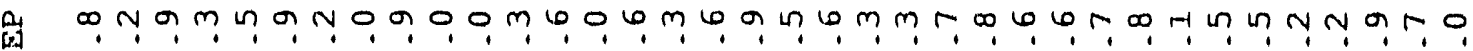
ब

D

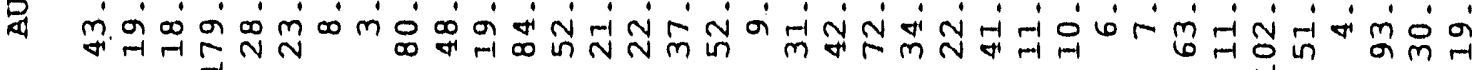

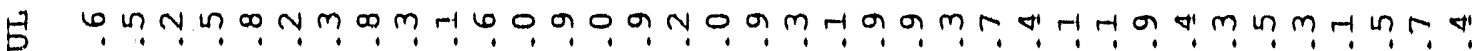

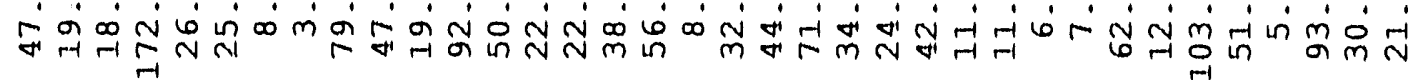

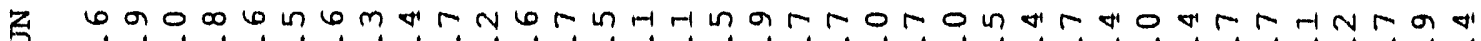

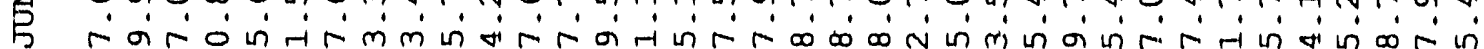

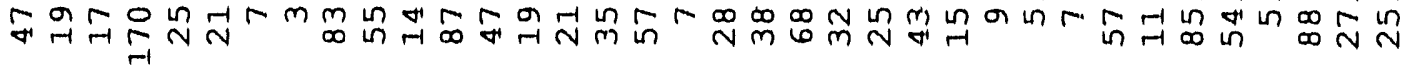

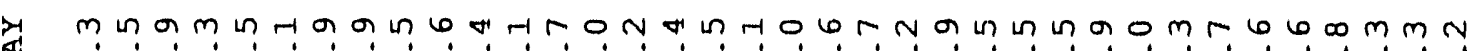

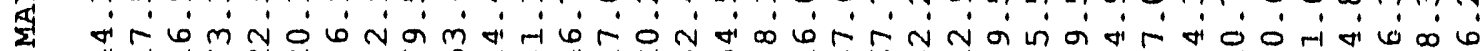

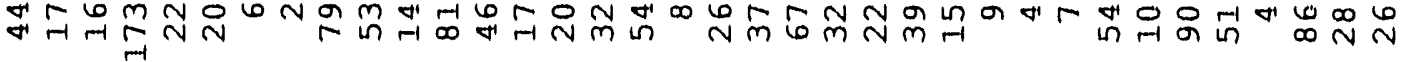
a a

a

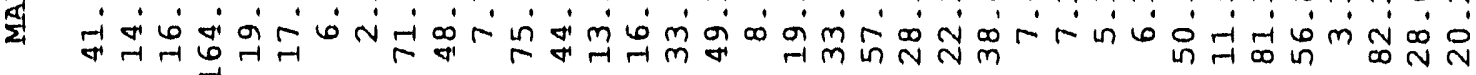
年 发 H 6 6 क ல் ம்

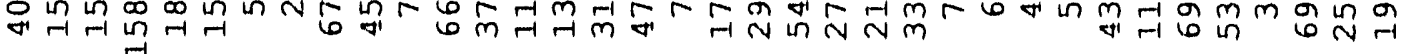




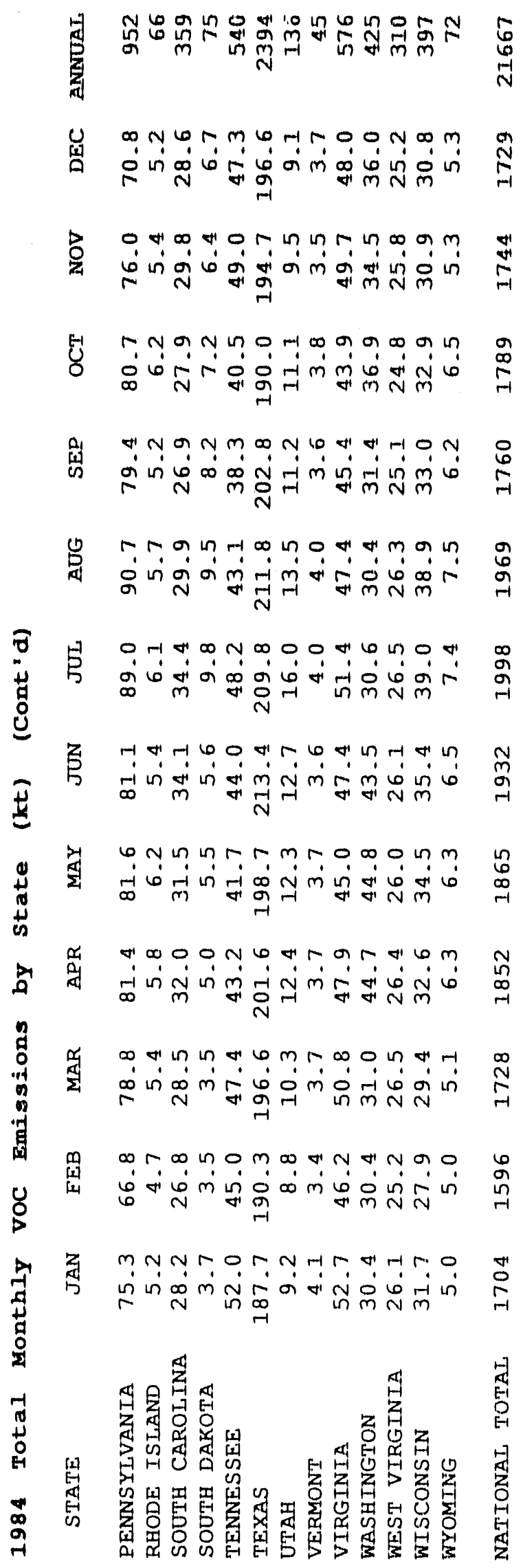




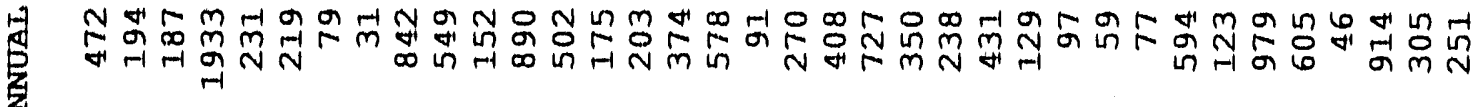

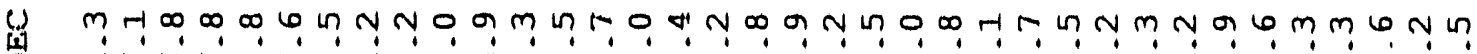

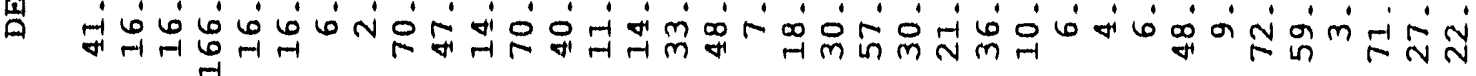

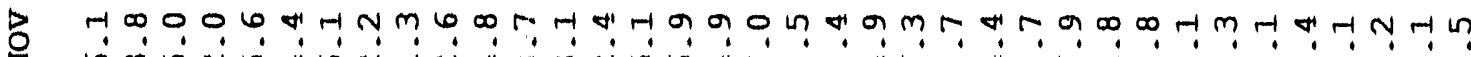

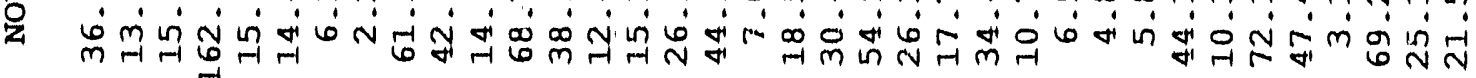

E

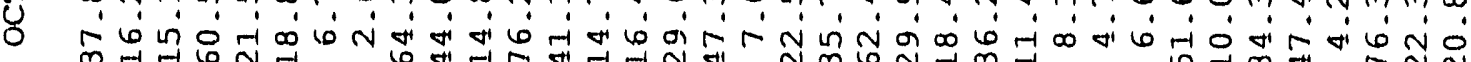

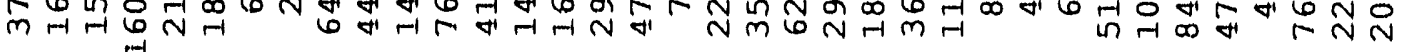

䔀 $m$ ?

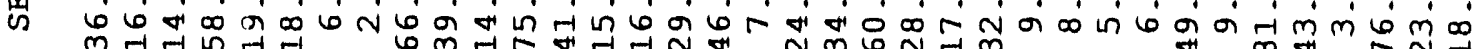

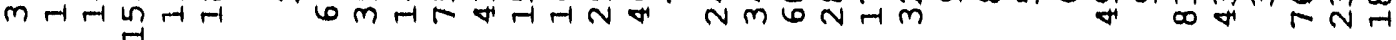

y $99000 m \infty$ m

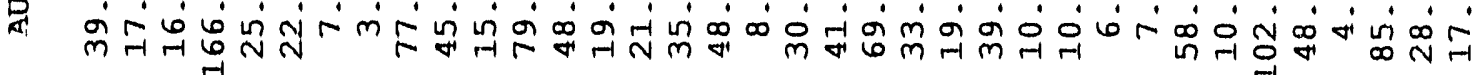

H "I T M

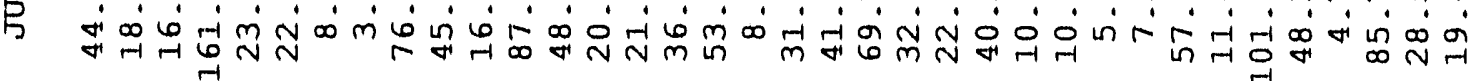

z m $m$ -

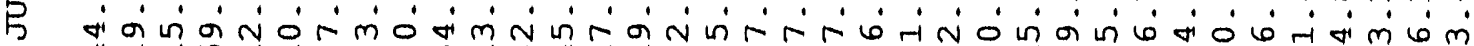

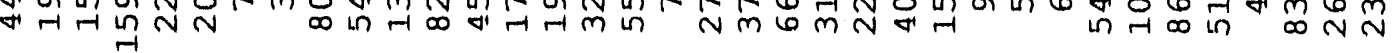

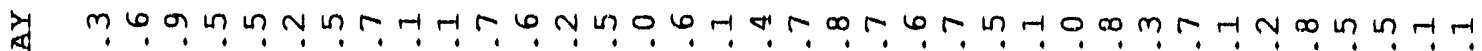

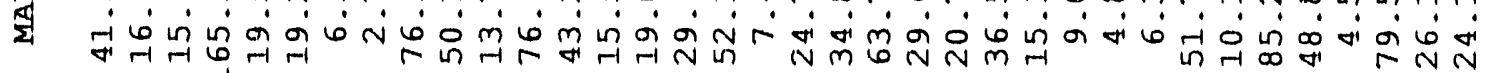

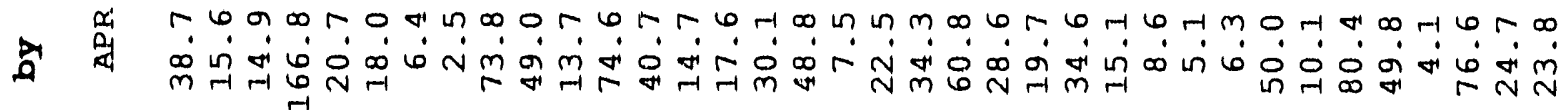

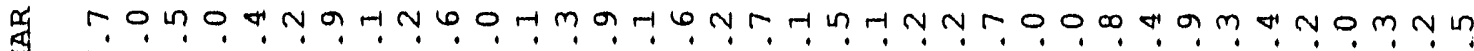

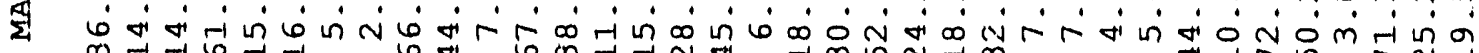

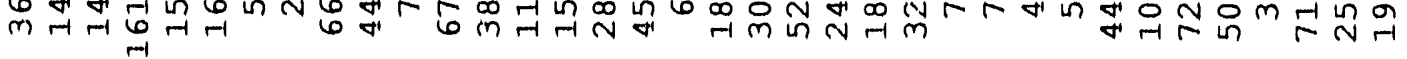

m

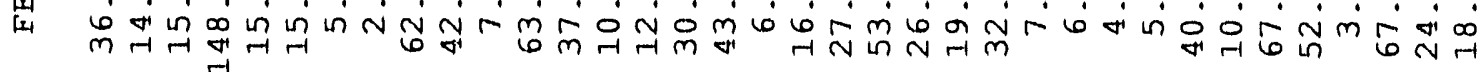

巳

丞

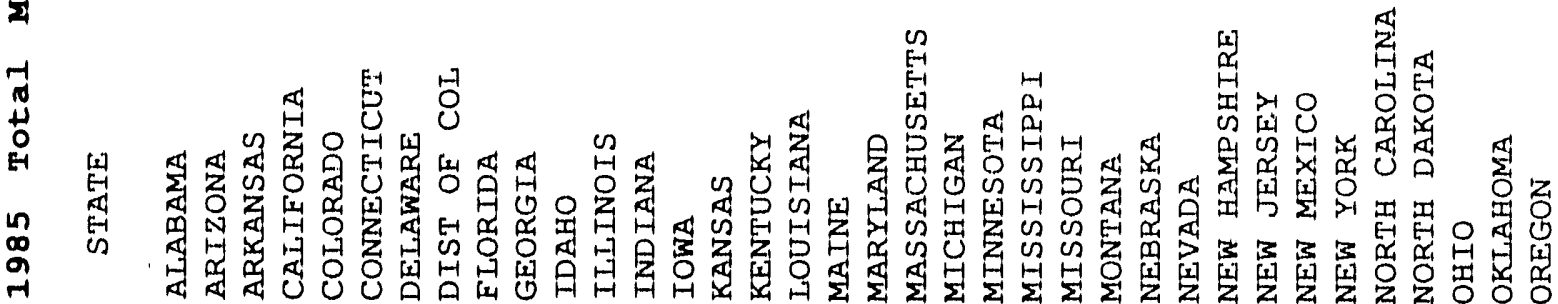




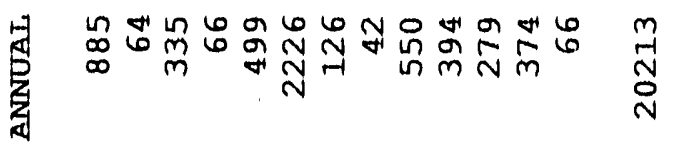

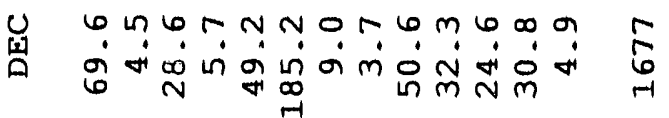

总

包

界

尊

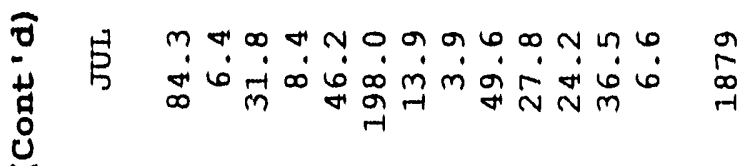

E 节

嵌

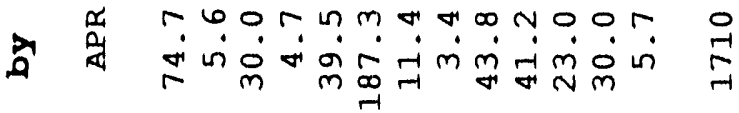

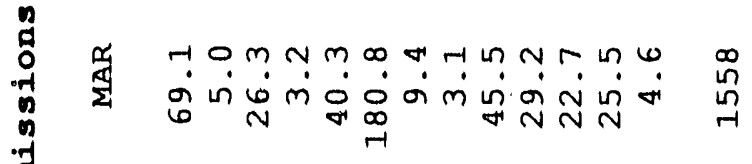

m man

\&

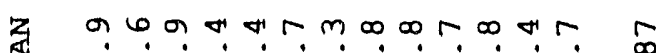

虫

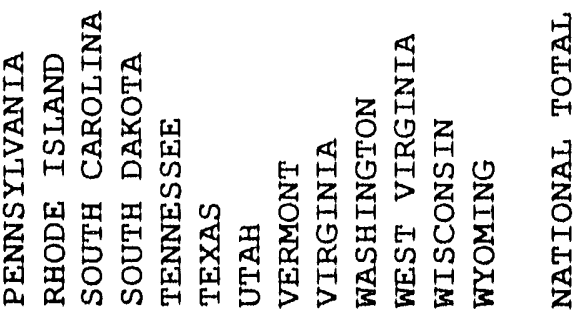


क

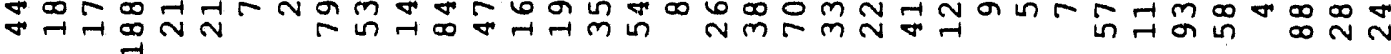

b

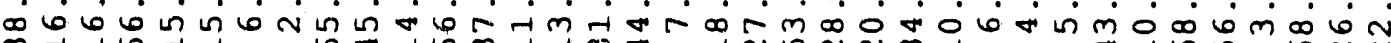

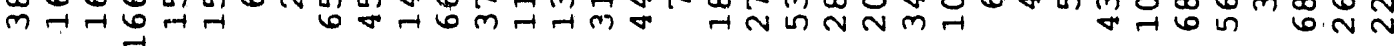

ow ம்

E-

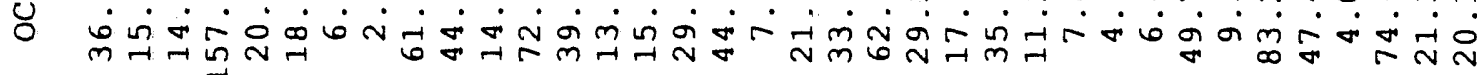

amant

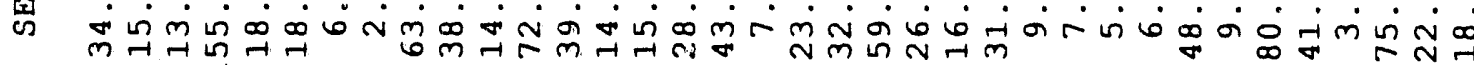

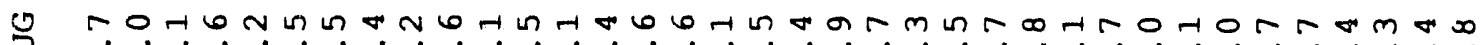

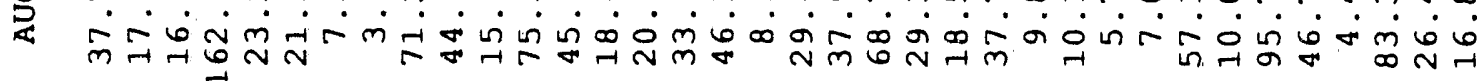

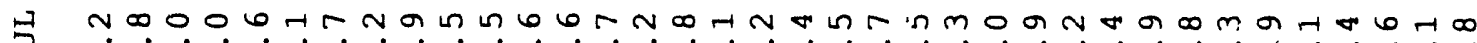

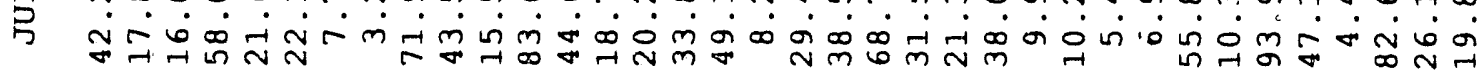

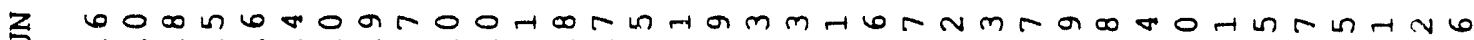

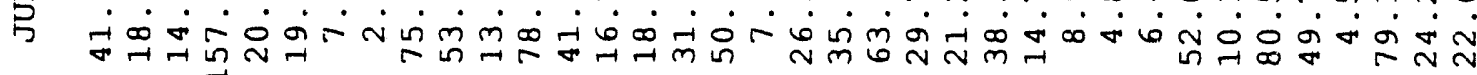

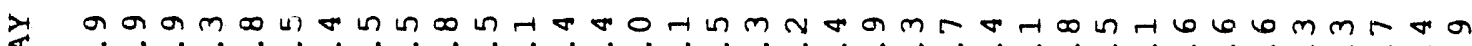

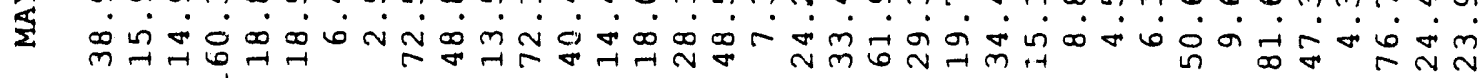

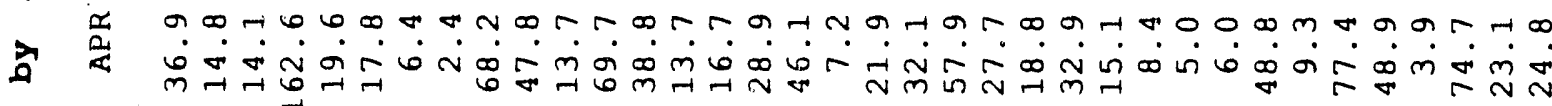

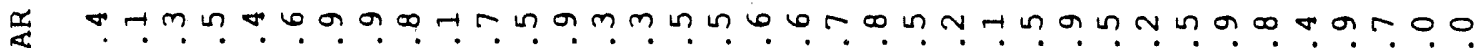

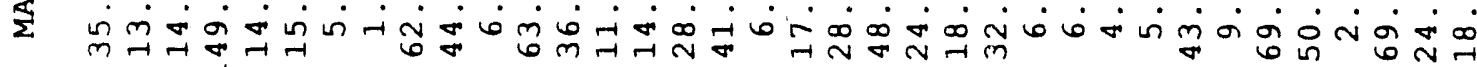

m HownNHw⿻

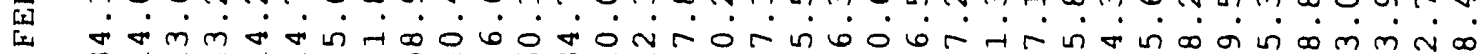

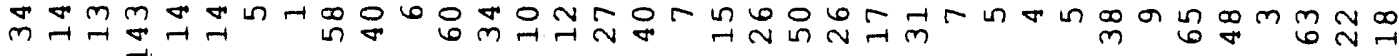

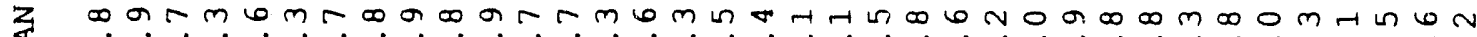

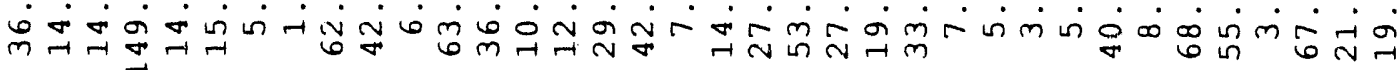




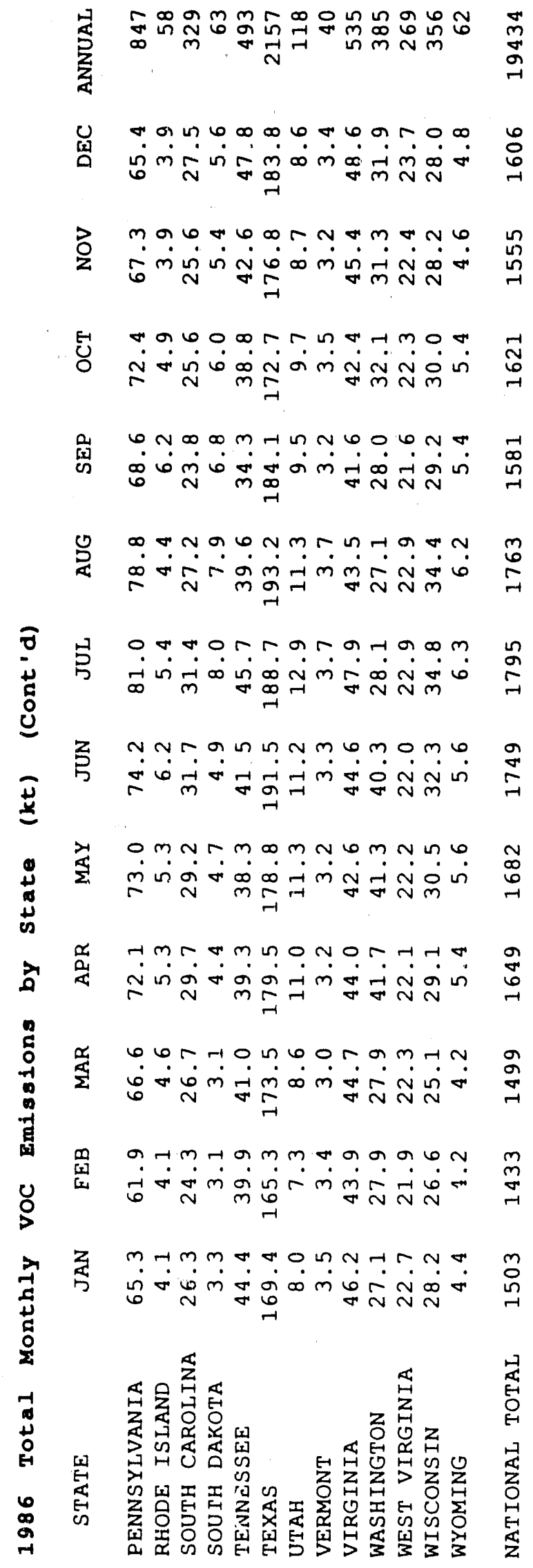


宏

Norrmamor

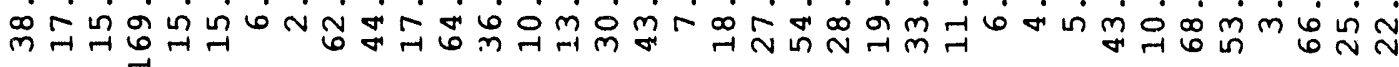

b 0 .

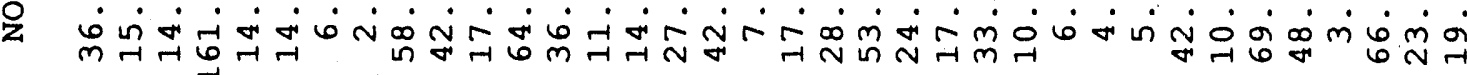

E

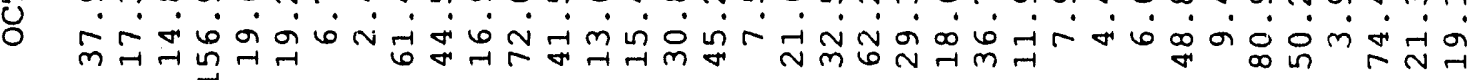

a d m ब

U $\quad$ a

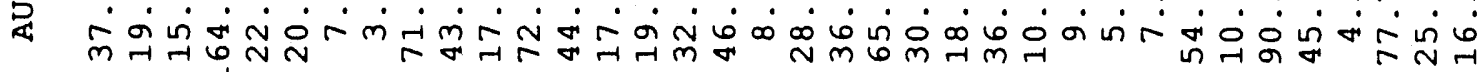

日 $\quad 0$.

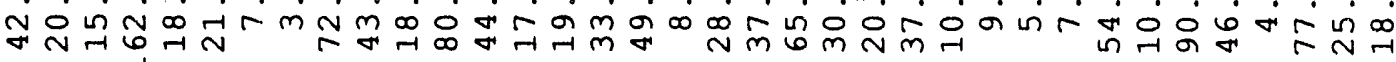

z GDR

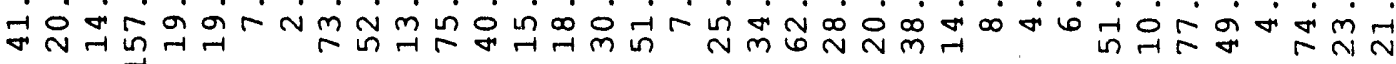

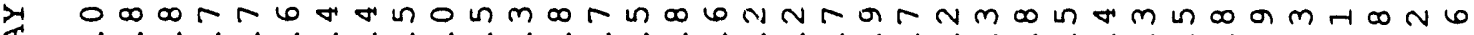
运

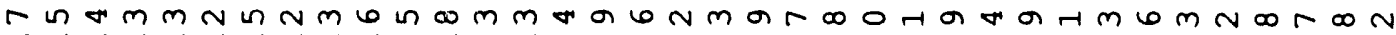

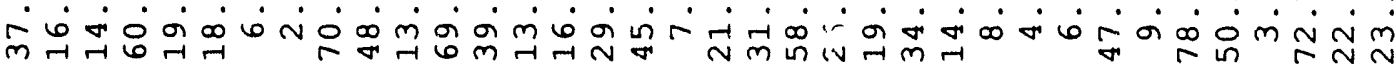

a

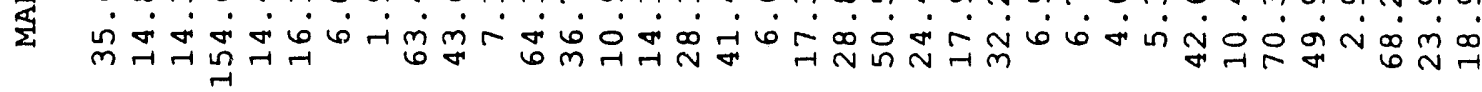

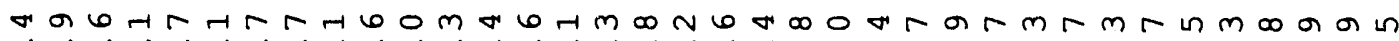

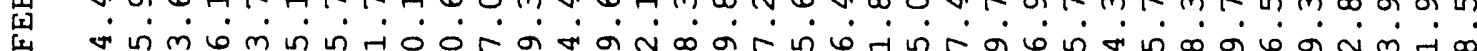
$\stackrel{\bigcup}{\$}$ m

द

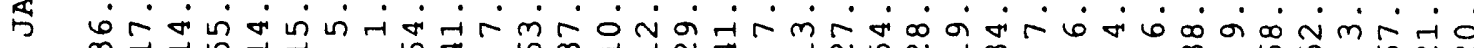
mન ન્ન

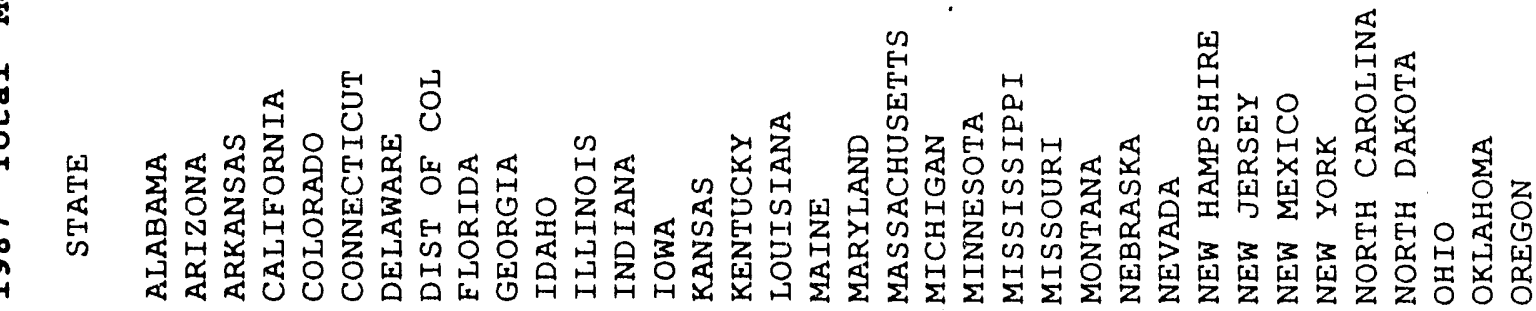




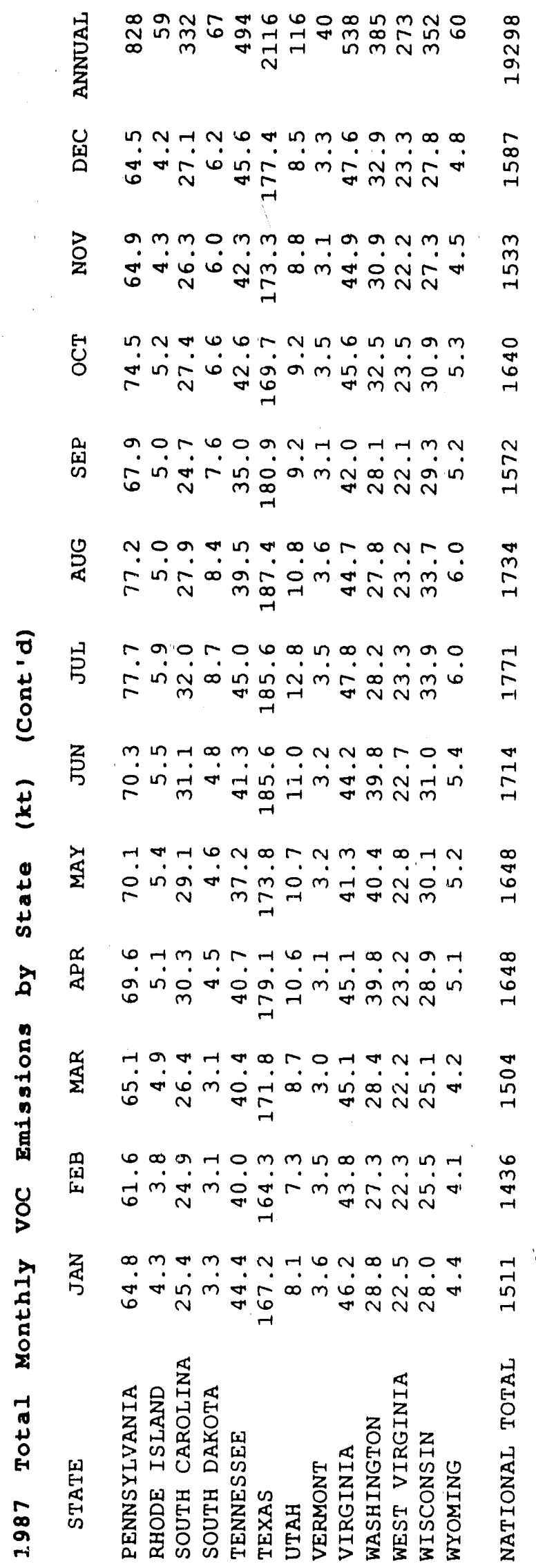


분

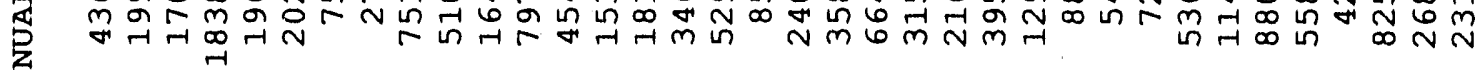

U 0 . 参

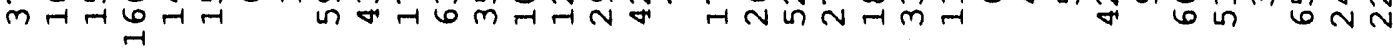

b amn

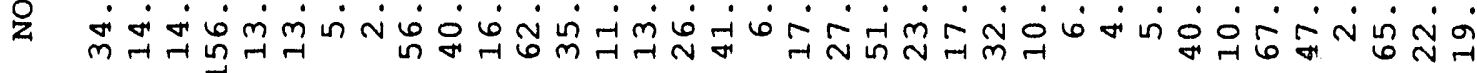

U

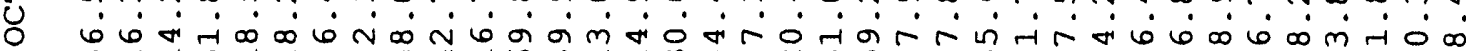

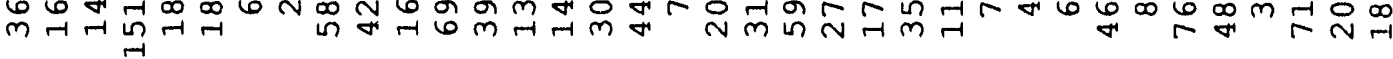

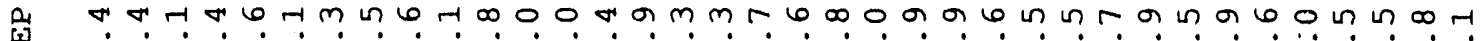

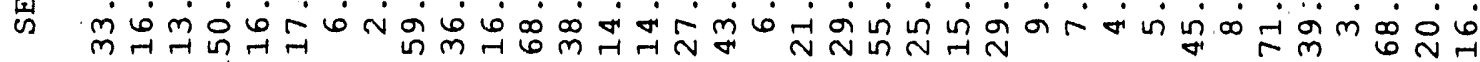

y Hra

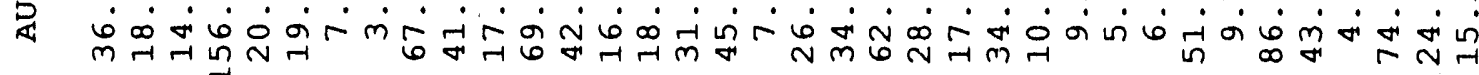

A nा m

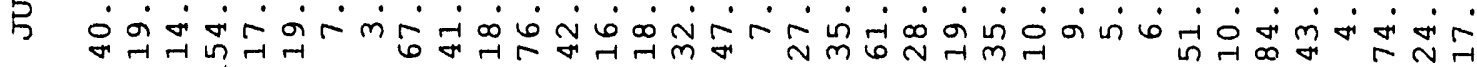

z H

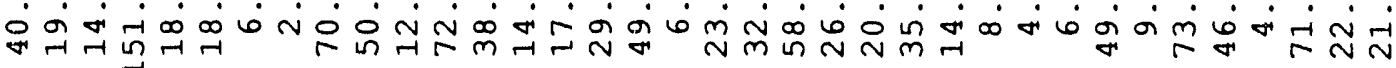

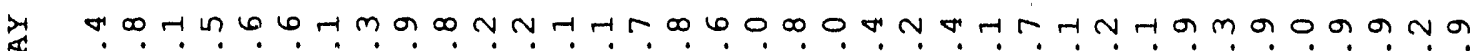

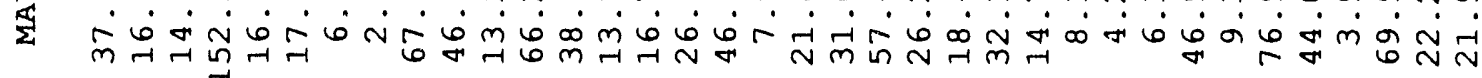

4 $m$ ต

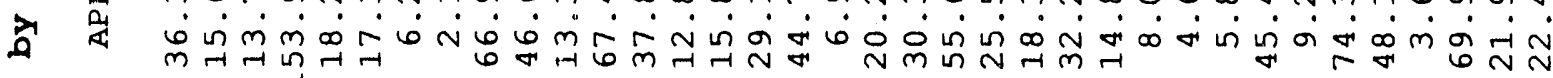

身

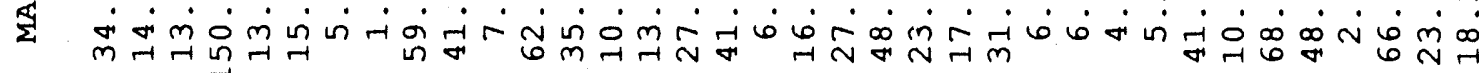

m

lu mं

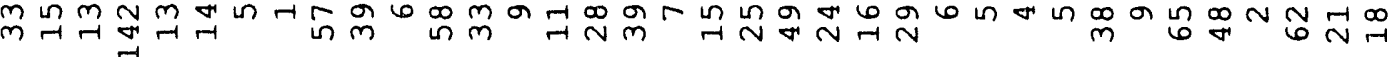

arNR-N .

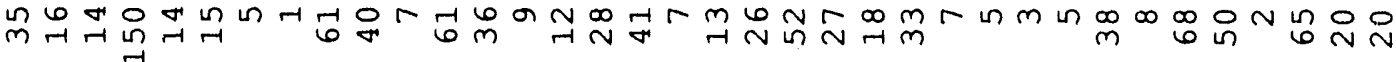

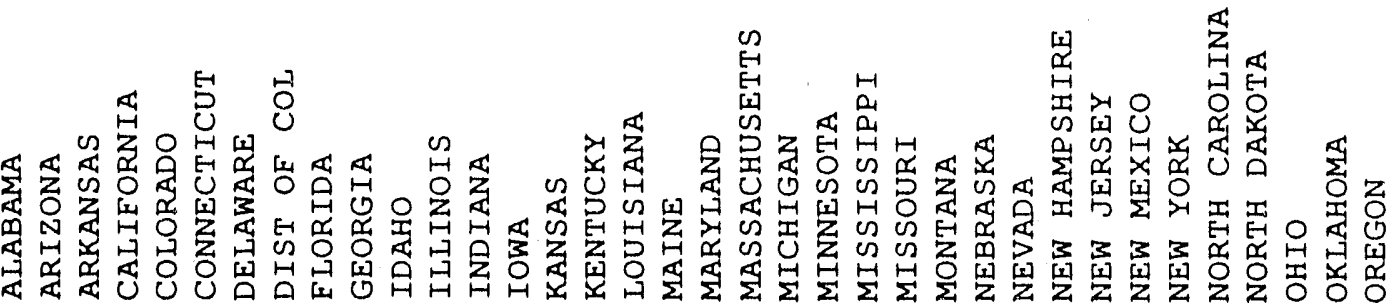




$$
\begin{aligned}
& \text { 宏 }
\end{aligned}
$$

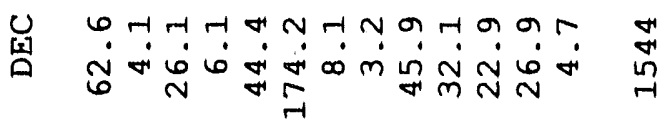

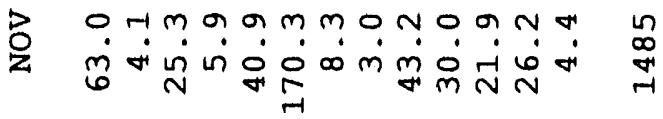

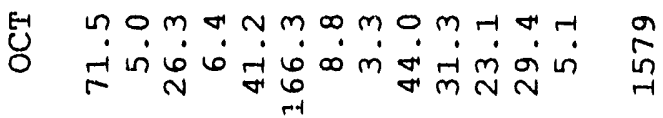

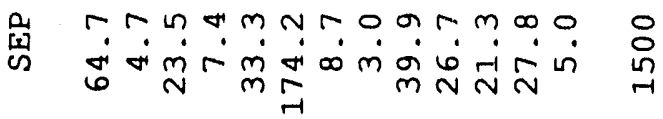

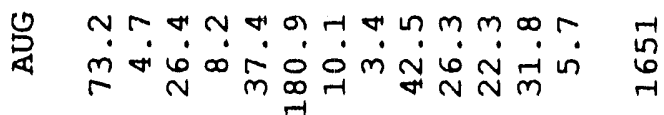

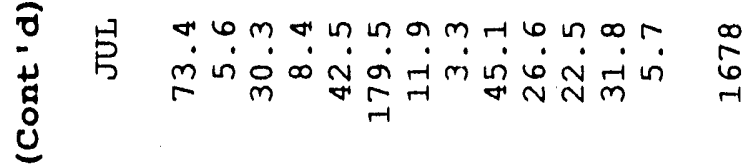

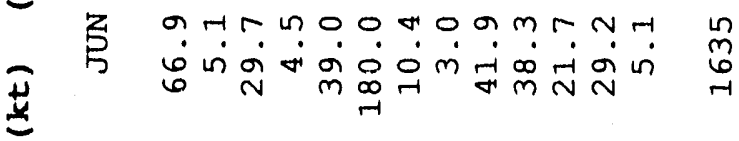

$$
\begin{aligned}
& \text { 嵌 } \\
& \text { a d a } \quad \text { a }
\end{aligned}
$$

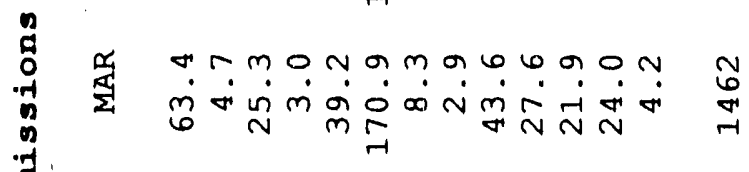

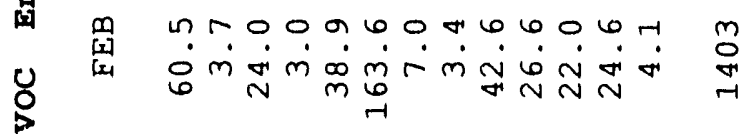

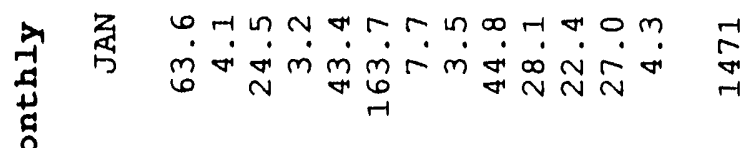

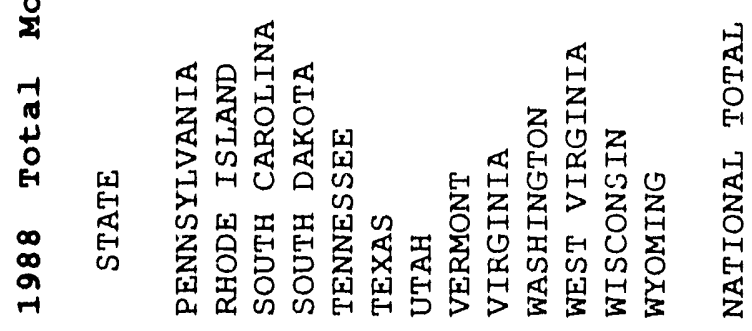


B.4 $\mathrm{NO}_{x}$ Emissions

by Geographic Region and Season 
1975 Sectoral NOX Emissions by Geographic

\begin{tabular}{|c|c|c|c|c|c|}
\hline & $\begin{array}{r}\text { ANNUAL } \\
\text { JAN75 } \\
\text {-DEC75 }\end{array}$ & $\begin{array}{r}\text { WINTER } \\
\text { DEC74 } \\
\text {-EEB75 }\end{array}$ & $\begin{array}{r}\text { SPRING } \\
\text { MAR75 } \\
\text {-MAY75 }\end{array}$ & $\begin{array}{r}\text { SUMMER } \\
\text { JUN75 } \\
\text {-AUG75 }\end{array}$ & $\begin{array}{r}\text { EALL } \\
\text { SEP75 } \\
\text {-NOV75 }\end{array}$ \\
\hline \multicolumn{6}{|l|}{ Northeast } \\
\hline Electric Utility & 2609.2 & $N / A$ & 616.8 & 696.3 & 612,3 \\
\hline Commercial/Residential & 485.3 & $\mathrm{~N} / \mathrm{A}$ & 136.2 & 24.3 & 84.3 \\
\hline Industrial Fuel & 1118.9 & $N / A$ & 283.3 & 236.0 & 262.1 \\
\hline Industrial Processes & 180.7 & $\mathrm{~N} / \mathrm{A}$ & 45.6 & 46.1 & 46.5 \\
\hline Miscellaneous & 45.6 & $N / A$ & 12.0 & 11.4 & 11.1 \\
\hline Transportation & 3792.6 & $N / A$ & 940.4 & 1067.6 & 956.3 \\
\hline Total & 8232.4 & $\mathrm{~N} / \mathrm{A}$ & 2034.3 & 2081.8 & 1972.6 \\
\hline \multicolumn{6}{|l|}{ Southeast } \\
\hline Electric Utility & 1059.7 & $N / A$ & 247.4 & 295.0 & 261.6 \\
\hline Commercial/Restedential & 69.1 & $N / A$ & 16.8 & 4.4 & 11.0 \\
\hline Industrial Fuel & 327.7 & $\mathrm{~N} / \mathrm{A}$ & 83.8 & 73.9 & 78.4 \\
\hline Industrtal Processes & 110.7 & N/A & 26.6 & 28.6 & 29.6 \\
\hline Miscellaneous & 42.9 & $N / A$ & 16.9 & 10.5 & 7.8 \\
\hline Transportation & .1570 .7 & $\mathrm{~N} / \mathrm{A}$ & 396.5 & 396.0 & 393.8 \\
\hline \multirow[t]{2}{*}{ Total } & 3180.8 & $\mathrm{~N} / \mathrm{A}$ & 787.9 & 808.4 & 782.2 \\
\hline & ' & & & & \\
\hline \multicolumn{6}{|l|}{ West } \\
\hline Electric Utility & 1352.5 & $N / A$ & 298.0 & 385.3 & 336.9 \\
\hline Commercial/Residential & 211.4 & $\mathrm{~N} / \mathrm{A}$ & 53.7 & 20.3 & 36.2 \\
\hline Industrial Fuel & 2275.4 & $\mathrm{~N} / \mathrm{A}$ & 553.0 & 537.4 & 561.6 \\
\hline Industrial Processes & 395.4 & $N / A$ & 95.9 & 105.3 & 103.5 \\
\hline Miscellaneous & 112.8 & $\mathrm{~N} / \mathrm{A}$ & 36.2 & 30.5 & 27.1 \\
\hline Transportation & 3505.4 & $N / A$. & 859.0 & 949.3 & 907.9 \\
\hline Total & 7853.0 & $\mathrm{~N} / \mathrm{A}$ & 1895.8 & 2028.1 & 1973.2 \\
\hline \multicolumn{6}{|l|}{ National } \\
\hline Electric Utility & 5021.4 & $\mathrm{~N} / \mathrm{A}$ & 1162.1 & 1376.6 & 1210.7 \\
\hline Commercial/Residential & 765.8 & $\mathrm{~N} / \mathrm{A}$ & 206.6 & 49.0 & 131.5 \\
\hline Industrial Euel & 3722.1 & $N / A$ & 920.1 & 847.3 & 902.2 \\
\hline Industrial Processes & 686.9 & $N / A$ & 168.1 & 180.0 & 179.5 \\
\hline Miscellaneous & 201.3 & $\mathrm{~N} / \mathrm{A}$ & 65.2 & 52.3 & 46.0 \\
\hline Transportation & 8868.7 & $\mathrm{~N} / \mathrm{A}$ & 2195.8 & 2413.0 & 2258.0 \\
\hline Total & 19266.2 & $\mathrm{~N} / \mathrm{A}$ & 4718.0 & 4918.3 & 4728.0 \\
\hline
\end{tabular}




\begin{tabular}{|c|c|c|c|c|c|}
\hline & $\begin{array}{r}\text { ANNUAL } \\
\text { JAN7 } 6 \\
\text {-DEC7 } 6\end{array}$ & $\begin{array}{r}\text { WINTER } \\
\text { DEC75 } \\
\text {-EQB76 }\end{array}$ & $\begin{array}{r}\text { SPRING } \\
\text { MAR76 } \\
- \text { MAY76 }\end{array}$ & $\begin{array}{r}\text { SUMMER } \\
\text { JUN76 } \\
\text {-AUG76 }\end{array}$ & $\begin{array}{r}\text { EALI } \\
\text { SEP7 } 6 \\
\text {-NOV7 } 6\end{array}$ \\
\hline \multicolumn{6}{|l|}{ Northeast } \\
\hline $\begin{array}{l}\text { Electrio Utility } \\
\text { Commerolal/Residential }\end{array}$ & $\begin{array}{r}2699.5 \\
527.2\end{array}$ & $\begin{array}{l}701.9 \\
223.7\end{array}$ & $\begin{array}{l}649.7 \\
127.8\end{array}$ & $\begin{array}{r}685.5 \\
25.7\end{array}$ & $\begin{array}{l}650.7 \\
110.1\end{array}$ \\
\hline Industrial Euel & 1195.6 & 367.9 & 294.9 & 255.6 & 285.8 \\
\hline Industrial Processes & 185.0 & 43.8 & 47.8 & 49.5 & 46.6 \\
\hline Miscellaneous & 46.0 & 11.8 & 12.1 & 11.5 & 11.3 \\
\hline Transportation & 3930.7 & 758.9 & 974.2 & 1098.9 & 998.8 \\
\hline Total & 8584.0 & 2108.0 & 2106.4 & 2126.8 & 2103.2 \\
\hline \multicolumn{6}{|l|}{ Southeast } \\
\hline Electrlo Utility & 1180.9 & 251.6 & 269.1 & 325.3 & 294.7 \\
\hline Commercial/Residential & 80.8 & 58.1 & 16.7 & 4.8 & 16.4 \\
\hline Industrial Fuel & 348.6 & 106.3 & 87.5 & 79.1 & 84.5 \\
\hline Industrial Processes & 114.9 & 22.9 & 29.7 & 30.2 & 29.2 \\
\hline Miscellaneous & 43.5 & 10.7 & 17.0 & 10.7 & 8.1 \\
\hline Transportation & 1694.8 & 363.6 & 429.6 & 426.8 & 426.1 \\
\hline Total & 3463.6 & 813.2 & 849.5 & 876.8 & 859.0 \\
\hline \multicolumn{6}{|l|}{ West } \\
\hline Electric Utility & 1495.9 & 422.0 & 331.1 & 421.5 & 372.3 \\
\hline Commercial/Resldential & 225.0 & 132.2 & 54.2 & 21.1 & 42.3 \\
\hline Industrial Fuel & 2537.5 & 672.1 & 616.5 & 601.0 & 626.6 \\
\hline Industrial Processes & 404.2 & 90.7 & 102.9 & 107.9 & 102.8 \\
\hline Miscellaneous & 142.2 & 20.2 & 37.6 & 40.7 & 40.0 \\
\hline Transportation & 3653.5 & 972.0 & 898.7 & 988.0 & 943.4 \\
\hline Total & 8458.3 & 2309.3 & 2041.1 & 2180.2 & 2.27 .4 \\
\hline \multicolumn{6}{|l|}{ National } \\
\hline Electric Utility & 5376.2 & 1375.5 & 1249.9 & 1432.3 & 1317.7 \\
\hline Commercial/Residential & 833.1 & 414.0 & 1.98 .7 & 51.6 & 168.8 \\
\hline Industrlal Fuel & 4081.8 & 11.46 .3 & 998.9 & 935.6 & 996.9 \\
\hline Industrial Processes & 704.1 & 157.5 & 180.4 & 1.87 .6 & 1.78 .6 \\
\hline Miscellaneous & 231.7 & 42.8 & 66.6 & 63.0 & 59.4 \\
\hline Transportation & 9278.9 & 2094.5 & 2302.5 & 2513.7 & 2368.2 \\
\hline Total & 20505.8 & 5230.6 & $4997.0^{\circ}$ & 5183.8 & 5089.6 \\
\hline
\end{tabular}


1977 seatoxal NOX Emtsatons by Goographta

Ragion

and season

(kt)

\begin{tabular}{|c|c|c|c|c|c|}
\hline & $\begin{array}{r}\text { ANNUAL } \\
\text { JAN777 } \\
\text {-DEC777 }\end{array}$ & $\begin{array}{r}\text { WINTER } \\
\text { DEC76 } \\
\text { - EQB77 }\end{array}$ & $\begin{array}{r}\text { SPRING } \\
\text { MAR77 } \\
\text {-MAY77 }\end{array}$ & $\begin{array}{r}\text { SUMMER } \\
\text { JUN77 } \\
\text {-AUG77 }\end{array}$ & $\begin{array}{r}\text { TALI } \\
\text { SEP77 } \\
\text {-NOV77 }\end{array}$ \\
\hline \multicolumn{6}{|l|}{ Northeast } \\
\hline Electrio utility & 2729.1 & 706.2 & 639.6 & 713.6 & 654.1 \\
\hline Commercial/Resident lal & 490.1 & 227.3 & 113.8 & 25.2 & 89.2 \\
\hline Industrial Fuel & 1173.2 & 366.8 & 291.6 & 252.8 & 276.4 \\
\hline Industrlal Prodesses & 191.4 & 43.6 & 50.3 & 51.2 & 48.7 \\
\hline Miscellaneous & 46.0 & 11.8 & 12.1 & 11.5 & 11.3 \\
\hline Transportation & 3975.8 & 758.4 & 992.6 & 1122.9 & 1012.1 \\
\hline Total & 8605.6 & 2114.1 & 2099.9 & 2177.2 & 2091.8 \\
\hline \multicolumn{6}{|l|}{ Southeast } \\
\hline Electrio Ut1lity & 1203.5 & 271.5 & 254.1 & 353.3 & 288.1 \\
\hline Commerclal/Restdential & 82.5 & 61.4 & 16.1 & 4.9 & 12.6 \\
\hline Industrdal Fuel & 349.8 & 107.1 & 88.0 & 80.0 & 84.1 \\
\hline Industrlal Processes & 127.2 & 22.4 & 30.7 & 31,1 & 29.9 \\
\hline Misoellaneous & 43.5 & 10.7 & 17.0 & 10.7 & 8.1 \\
\hline Transportation & 1742.9 & 362.1 & 446.1 & 442.9 & 440.5 \\
\hline Total & 3539.4 & 835.2 & 852.0 & 922.8 & 863.3 \\
\hline \multicolumn{6}{|l|}{ West } \\
\hline Electric Utility & 1693.9 & 452.8 & 387.3 & 485.9 & 411.3 \\
\hline Commerclal/Resldentlal & 225.0 & 136.6 & 52.8 & 20.1 & 37.7 \\
\hline Industrial Fuel & 2604.0 & 684.4 & 632.1 & 617.9 & 642.1 \\
\hline Industrlal Processes & 413,4 & 89.6 & 1.06 .8 & 111,1 & 106.7 \\
\hline Miscellaneous & 142.2 & 20.2 & 37.6 & 40.7 & 40,0 \\
\hline Transportation & 3829.9 & 987.9 & 949.3 & 1041.5 & 992.3 \\
\hline Total & 8908.5 & 2371.5 & 2165.8 & 2317.2 & 2230.2 \\
\hline \multicolumn{6}{|l|}{ National } \\
\hline Electric utility & 5626.4 & 1430.5 & 1281.0 & 1552.8 & 1.353 .5 \\
\hline Commerctal/Restdenttal & 797.6 & 425.2 & 182.7 & 50.2 & 139.6 \\
\hline Industrial Fuel & 4127.1 & 1158.3 & 1011.7 & 950.6 & 1002.7 \\
\hline Induatrial Processes & 722.0 & 155.6 & 187.8 & 193.3 & 185,3 \\
\hline Miscellaneous & 231.7 & 42.8 & 66.6 & 63.0 & 59.4 \\
\hline Transportation & 9548.6 & 2108.4 & 2388.1 & 2607.3 & 2444.9 \\
\hline Total. & 21053.5 & 5320.8 & 5117.8 & 5417.3 & 5185.2 \\
\hline
\end{tabular}


by Geographia

ANNUAL
JAN77
-DEC78

Northeast

Wlootrio Utility Commerolal/Resiclential

Industrial Fuel

Industrtal Processes

Misoellaneous

Transportation

Total

Southeast

Electrio Utility

Commerola1/Res Ldentlal

Industrial Fuel

Industrial Processes

Miscellaneous

Transportation

Total

West

Electric Utlitty

Commerolal/Residential

Industrial Fuel

Industrial Processes

Miscellaneous

Transportation

Total

National

Electrio Utility

Commercial/Residential.

Industrial Fuel

Industrial Processes

Miscelilaneous

Transportation

Total
2655.2

511.2

1167.1

199.6

46.0

3975.1

8554.1

1188.0

84.5

349.6

119.1

43.5

1785.8

3570.5

1734.1

234.3

2613.5

422.0

1.42 .2

3950.3

9096.5

5577.3

830.0

4130.3

740.7

231.7

9711.1

21221.1
670.9
Region

WINTER
DEC77
- TEB 78

SPRING
MAR718
-MAY78

and

season

(kt)

225.9

353.6

46.1

11.8

743.5

2051.8

618.5

135.2

286.6

51.4

12.1

987.2

2090.9

278.1

60.4

104.0

23.3

10.7

371.2

847.7

257.8

18.8

87.0

31.0

17.0

456.2

867.7

SUMMER
JUN78
-AUG78

EALL

SEP 78

-NOV7 8

692.4

26.7

257.9

52.5

11. 5

1133.1

2174.3

2113.4

657.8

92.3

281.8

51.9

11.3

1018.3

288.3

11.6

85.9

30.8

8.1

454.1

878.8
476.3

138.3

684.8

92.3

20.2

1019.3

2431.3

371.8

55.0

633.3

108.3

37.6

974.7

2180.7

1425.4

424.7

1142.5

161.6

42.8

2134.0

5330.9
1248.0
209.1
1006.8
190.7
66.6
2418.1

5139.3
496.9

21.3

623.5

112.4

40.7

1077.6

2372.4

2283.4

$$
\begin{array}{rr}
1530.1 & 1371.8 \\
53.2 & 143.1 \\
963.0 & 1014.0 \\
195.9 & 192.5 \\
63.0 & 59.4 \\
2664.4 & 2494.7 \\
& \\
5469.4 & 5275.6
\end{array}
$$


1979 Sectoral NOx missions by Geographla Region and season (kt)

\begin{tabular}{|c|c|c|c|c|c|}
\hline & $\begin{array}{r}\text { ANNUAL } \\
\text { JAN79 } \\
- \text {-DEC79 }\end{array}$ & $\begin{array}{r}\text { WINTER } \\
\text { DEC78 } \\
- \text { FEB79 }\end{array}$ & $\begin{array}{r}\text { SPRING } \\
\text { MAR79 } \\
- \text { MAY79 }\end{array}$ & $\begin{array}{r}\text { SUMMER } \\
\text { JUN79 } \\
- \text { AUG79 }\end{array}$ & $\begin{array}{r}\text { EALL } \\
\text { SEP79 } \\
\text {-NOV79 }\end{array}$ \\
\hline $\begin{array}{l}\text { Northeast } \\
\text { Eleotrid Utility } \\
\text { Commercial/Restdential } \\
\text { Industrial Fuel } \\
\text { Industrial Prooesses } \\
\text { Miscellaneous } \\
\text { Transportation }\end{array}$ & $\begin{array}{r}2761.7 \\
432.4 \\
1095.2 \\
195.5 \\
46.0 \\
3808.4\end{array}$ & $\begin{array}{r}675.2 \\
198.8 \\
329.5 \\
46.6 \\
11.8 \\
743.6\end{array}$ & $\begin{array}{r}665.9 \\
109.9 \\
274.8 \\
51.2 \\
1.2 .1 \\
965.7\end{array}$ & $\begin{array}{r}709.4 \\
24.1 \\
239.0 \\
52.0 \\
11.5 \\
1063.3\end{array}$ & $\begin{array}{r}658.8 \\
76.4 \\
252.4 \\
49.2 \\
11.3 \\
950.2\end{array}$ \\
\hline Total & 8339.1 & 2005.4 & 2079.5 & 2099.3 & 1998.3 \\
\hline $\begin{array}{l}\text { Southeast } \\
\text { Electrid Utllity } \\
\text { Commerolal/Residentlal } \\
\text { Industrial Fuel } \\
\text { Industrial Processes } \\
\text { Miscellaneous } \\
\text { Transportation }\end{array}$ & $\begin{array}{r}1198.0 \\
79.9 \\
374.2 \\
121.4 \\
43.5 \\
1733.9\end{array}$ & $\begin{array}{r}281.1 \\
51.6 \\
113.2 \\
23.4 \\
10.7 \\
377.2\end{array}$ & $\begin{array}{r}273.8 \\
17.1 \\
95.4 \\
31.4 \\
17.0 \\
447.8\end{array}$ & $\begin{array}{r}344.0 \\
5.0 \\
86.5 \\
32.0 \\
10.7 \\
429.9\end{array}$ & $\begin{array}{r}276.6 \\
12.7 \\
88.9 \\
31.2 \\
8.1 \\
433.3\end{array}$ \\
\hline Total & 3550.8 & 857.1 & 882.5 & 908.1 & 850.8 \\
\hline $\begin{array}{l}\text { West } \\
\text { Electric Utilty } \\
\text { Commercial/Residential } \\
\text { Industrial Fuel } \\
\text { Industrlal Processes } \\
\text { Miscellaneous } \\
\text { Transportation }\end{array}$ & $\begin{array}{r}1861.8 \\
268.7 \\
2464.8 \\
429.1 \\
142.2 \\
3854.8\end{array}$ & $\begin{array}{r}548.0 \\
154.0 \\
653.4 \\
93.9 \\
20.2 \\
1018.7\end{array}$ & $\begin{array}{r}411.2 \\
61.2 \\
599.4 \\
109.6 \\
37.6 \\
959.9\end{array}$ & $\begin{array}{r}509.0 \\
23.9 \\
587.0 \\
114.0 \\
40.7 \\
1013.8\end{array}$ & $\begin{array}{r}466.3 \\
46.3 \\
604.9 \\
111.4 \\
40.0 \\
993.6\end{array}$ \\
\hline Total & 9021.4 & 2488.2 & 2178.8 & 2288.5 & 2262.5 \\
\hline $\begin{array}{l}\text { National } \\
\text { Electric Utility } \\
\text { Commercial/Residential } \\
\text { Industrial Fuel. } \\
\text { Industrial Processes } \\
\text { Miscelianeous } \\
\text { Transportation }\end{array}$ & $\begin{array}{r}5821.4 \\
781.0 \\
3934.2 \\
746.0 \\
231.7 \\
9397.0\end{array}$ & $\begin{array}{r}1504.2 \\
404.4 \\
1096.1 \\
163.9 \\
42.8 \\
2139.4\end{array}$ & $\begin{array}{r}1350.8 \\
188.2 \\
969.6 \\
192.2 \\
66.6 \\
2373.4\end{array}$ & $\begin{array}{r}1562.4 \\
53.0 \\
912.5 \\
198.1 \\
63.0 \\
2507.0\end{array}$ & $\begin{array}{r}1401.6 \\
135.4 \\
946.2 \\
191.8 \\
59.4 \\
2377.1\end{array}$ \\
\hline & 20911.3 & 5350.8 & 5140.8 & 5295.9 & 5111.6 \\
\hline
\end{tabular}




Northeast
Electrio Utility
Commerolal/Residential
Industrial Fuel
Industrial Processes
Misoelianeous
Transportation
Total
Southeast
Electric Utildty
Commercial/Residential
Industrial Fuel
Industrial Prooesses
Miscelianeous
Transportation
Total

West

Electric Utiltty

Commercial/Residential

Industrial Fuel

Industrial. Processes

Miscellaneous

Transportation

Total
2741.1

451.4

933.7

179.9

46.0

3627.9

7979.9

1274.5

74.7

329.0

115.3

43.5

1651.4

3488.5

1955.0

229.5

2085.8

401.1

142.2

3707.1

8520.7
5970.6
755.5
3348.5
696.3
231.7
8986.3

19989.1 by Geographio

WINTER
DEC79
- EEB80

Region

and

SPRING
MAR80
-MAY80

$$
\begin{array}{r}
\text { SUMME'R } \\
\text { JUN80 } \\
\text {-AUG60 }
\end{array}
$$

683.1

198.8

284.1

46.7

11.8

724.7

646.0

116.8

238.4

46.3

12.1

887.9

1949.3

1947.5

708.8

23.2

197.9

43.3

11.5

1012.6

1997.4

295.7

50.5

96.2

24.8

10.7

367.8

845.6

$$
\begin{array}{r}
284.1 \\
17.4 \\
84.6 \\
29.5 \\
17.0
\end{array}
$$

416.6

849.2

363.

4.7

74.4

28.4

10.7

407.4

889.5

559.8

20.8

495.6

129.8

559.1

97.7

20.2

987.0

433.7

56.6

507.9

101.4

37.6

101.2

40.7

913.7

975.6

2370.3

2050.9

2193.9

2126.3

1555.2

379.1

939.4

169.2

42.8

2079.5

1.363.

190.8

830.9

177.2

66.6

2218.2

5165.2

4847.6
1632.5

48.8

768.0

173.0

63.0

2395.6

5080.8 (kt)

EALI
SEP 80

-NOV 80

641.6

83.8

216.9

45.9

11.3

918.5

1918.0

301.7

12.6

78.3

29.5

8. 1

419.9

850.1

475.4

40.5

514.2

101.6

40.0

954.7

1418.6

136.9

309.3

177.0

59.4

2293.1

4894.3 
1981 Sectoral Nox Emissions by Geographic Region and Season (kt)

\begin{tabular}{|c|c|c|c|c|c|}
\hline & $\begin{array}{r}\text { ANNUAL } \\
\text { JAN81 } \\
- \text {-DEC81 }\end{array}$ & $\begin{array}{r}\text { WINTER } \\
\text { DEC80 } \\
\text {-FEB81 }\end{array}$ & $\begin{array}{r}\text { SPRING } \\
\text { MAR81 } \\
\text {-MAY81 }\end{array}$ & $\begin{array}{r}\text { SUMMER } \\
\text { JUN81 } \\
\text {-AUG81 }\end{array}$ & $\begin{array}{r}\text { FALL } \\
\text { SEP } 81 \\
\text {-NOV81 }\end{array}$ \\
\hline \multicolumn{6}{|l|}{ Northeast } \\
\hline Electric Utility & 2654.9 & 664.1 & 635.1 & 693.5 & 626.6 \\
\hline Commercial/Residential & 417.8 & 184.3 & 107.2 & 23.8 & 79.0 \\
\hline Industrial Fuel & 877.8 & 264.7 & 219.4 & 194.0 & 206.1 \\
\hline Industrial Processes & 177.5 & 43.1 & 47.6 & 46.3 & 43.1 \\
\hline Miscellaneous & 46.0 & 11.8 & 12.1 & 11.5 & 11.3 \\
\hline Transportation & 3495.7 & 708.4 & 825.0 & 988.5 & 903.5 \\
\hline Total & 7669.7 & 1876.4 & 1846.3 & 1957.6 & 1869.6 \\
\hline \multicolumn{6}{|l|}{ Southeast } \\
\hline Electric Utility & 1285.0 & 296.6 & 288.3 & 372.6 & 295.8 \\
\hline Commercial/Residential & 72.6 & 45.9 & 16.5 & 4.8 & 11.9 \\
\hline Industrial Fuel & 323.4 & 88.6 & 81.8 & 75.5 & 77.6 \\
\hline Industrial Processes & 113.2 & 23.0 & 30.2 & 29.3 & 28.0 \\
\hline Miscellaneous & 43.5 & 10.7 & 17.0 & 10.7 & 8.1 \\
\hline Transportation & 1583.5 & 350.2 & 392.2 & 402.4 & 399.1 \\
\hline Total & 3421.3 & 815.0 & 826.0 & 895.3 & 820.5 \\
\hline \multicolumn{6}{|l|}{ West } \\
\hline Electric Utility & 2045.7 & 564.6 & 470.4 & 584.8 & 496.4 \\
\hline Commercial/Residential & 205.4 & 118.6 & 49.4 & 18.8 & 35.6 \\
\hline Industrial Fuel & 2024.3 & 539.7 & 491.5 & 485.3 & 498.9 \\
\hline Industrial Processes & 383.1 & 89.0 & 99.8 & 99.0 & 95.5 \\
\hline Miscellaneous & 142.2 & 20.2 & 37.5 & 40.7 & 40.0 \\
\hline Transportation & 3635.8 & 945.0 & 886.1 & 977.4 & 937.2 \\
\hline Total & 8436.5 & 2277.2 & 2034.9 & 2206.0 & 2103.6 \\
\hline \multicolumn{6}{|l|}{ National } \\
\hline Electric Utility & 5985.6 & 1525.3 & 1393.8 & 1650.9 & 1418.9 \\
\hline Commercial/Residential & 695.8 & 348.8 & 173.1 & 47.4 & 126.4 \\
\hline Industrial Fuel & 3225.5 & 893.1 & 792.8 & 754.8 & 782.6 \\
\hline Industrial Processes & 673.8 & 155.1 & 177.5 & 174.6 & 166.6 \\
\hline Miscellaneous & 231.7 & 42.8 & 66.6 & 63.0 & 59.4 \\
\hline Transportation & 871.5 .0 & 2003.5 & 2103.3 & 2368.3 & 2239.8 \\
\hline Total & 19527.5 & 4968.7 & 4707.1 & 5058.9 & 4793.8 \\
\hline
\end{tabular}




\begin{tabular}{|c|c|c|c|c|c|}
\hline & $\begin{array}{r}\text { ANNUAL } \\
\text { JAN82 } \\
\text {-DEC82 }\end{array}$ & $\begin{array}{r}\text { WINTER } \\
\text { DEC81 } \\
\text {-FEB82 }\end{array}$ & $\begin{array}{r}\text { SPRING } \\
\text { MAR82 } \\
\text {-MAY } 82\end{array}$ & $\begin{array}{r}\text { SUMMER } \\
\text { JUN82 } \\
\text {-AUG82 }\end{array}$ & $\begin{array}{r}\text { FALL } \\
\text { SEP } 82 \\
\text {-NOV82 }\end{array}$ \\
\hline \multicolumn{6}{|l|}{ Northeast } \\
\hline Electric Utility & 2535.4 & 680.7 & 619.1 & 644.5 & 582.5 \\
\hline Commercial/Residential & 419.9 & 186.9 & 1.12 .5 & 26.3 & 73.7 \\
\hline Industrial Fuel & 878.0 & 275.3 & 226.4 & 190.6 & 200.6 \\
\hline Industrial Processes & 145.2 & 34.8 & 38.8 & 37.5 & 35.7 \\
\hline Miscellaneous & 45.6 & 11.8 & 12.0 & 11.4 & 11.1 \\
\hline Transportation & 3277.7 & 587.9 & 820.6 & 958.5 & 839.8 \\
\hline Total & 7301.8 & 1777.5 & 1829.5 & 1868.8 & 1743.3 \\
\hline \multicolumn{6}{|l|}{ Southeast } \\
\hline Electric Utility & 1159.8 & 276.6 & 273.5 & 330.2 & 268.9 \\
\hline Commercial/Residential & 66.5 & 43.7 & 15.5 & 4.4 & 11.0 \\
\hline Industrial Fuel & 350.7 & 96.5 & 90.7 & 80.3 & 82.2 \\
\hline Industrial Processes & 100.8 & 19.8 & 26.5 & 25.9 & 25.7 \\
\hline Miscellaneous & 42.9 & 8.5 & 16.9 & 10.5 & 7.8 \\
\hline Transportation & 1518.4 & 311.0 & 387.6 & 388.9 & 388.4 \\
\hline Total & 3239.0 & 756.0 & 810.7 & 840.2 & 784.2 \\
\hline \multicolumn{6}{|l|}{ West } \\
\hline Electric Utility & 1985.4 & 512.3 & 445.6 & 559.7 & 479.7 \\
\hline Commercial/Residential & 220.0 & 120.3 & 52.9 & 20.7 & 38.5 \\
\hline Industrial Fuel & 2073.5 & 548.8 & 507.8 & 494.7 & 506.4 \\
\hline Industrial Processes & 330.2 & 75.9 & 86.5 & 86.1 & 83.0 \\
\hline Miscellaneous & 112.8 & 17.5 & 36.2 & 30.5 & 27.1 \\
\hline Transportation & 3501.5 & 868.1 & 877.9 & 966.0 & 902.8 \\
\hline Total & 8223.5 & 2143.0 & 2006.9 & 2157.6 & 2037.5 \\
\hline \multicolumn{6}{|l|}{ National } \\
\hline Electric Utility & 5680.6 & 1469.7 & 1338.2 & 1534.4 & 1331.1 \\
\hline Commercial/Residential & 706.5 & 350.9 & 180.9 & 51.4 & 123.2 \\
\hline Industrial Fuel & 3302.2 & 920.6 & 824.8 & 765.6 & 789.2 \\
\hline Industrial Processes & 576.2 & 130.5 & 151.8 & 149.5 & 144.3 \\
\hline Miscellaneous & 201.3 & 37.7 & 65.2 & 52.3 & 46.0 \\
\hline Transportation & 8297.5 & 1767.0 & 2086.1 & 2313.3 & 2131.1 \\
\hline Total & 18764.3 & 4676.5 & 4647.1 & 4866.6 & 4564.9 \\
\hline
\end{tabular}




\begin{tabular}{|c|c|c|c|c|c|}
\hline & $\begin{array}{r}\text { ANNUAL } \\
\text { JAN8 } 3 \\
\text {-DEC83 }\end{array}$ & $\begin{array}{r}\text { WINTER } \\
\text { DEC82 } \\
\text {-FEB83 }\end{array}$ & $\begin{array}{r}\text { SPRING } \\
\text { MAR8 } 3 \\
\text {-MAY8 } 3\end{array}$ & $\begin{array}{r}\text { SUMMER } \\
\text { JUN8 } 3 \\
\text {-AUG8 } 3\end{array}$ & $\begin{array}{r}\text { FALL } \\
\text { SEP 8 } 3 \\
\text {-NOV8 } 3\end{array}$ \\
\hline \multicolumn{6}{|l|}{ Northeast } \\
\hline Electric Utility & 2604.8 & 608.5 & 586.0 & 702.7 & 645.1 \\
\hline Commercial/Residential & 386.0 & 167.2 & 103.8 & 22.1 & 68.4 \\
\hline Industrial Fuel & 756.6 & 231.0 & 186.6 & 166.9 & 183.3 \\
\hline Industrial Processes & 144.7 & 33.0 & 36.5 & 38.1 & 38.4 \\
\hline Miscellaneous & 46.0 & 11.8 & 12.1 & 11.5 & 11.3 \\
\hline Transportation & 3113.5 & 542.5 & 768.4 & 948.1 & 796.6 \\
\hline Total & 7051.5 & 1594.1 & 1693.4 & 1889.4 & 1743.2 \\
\hline \multicolumn{6}{|l|}{ Southeast } \\
\hline Electric Utility & 1169.5 & 248.4 & 246.5 & 346.8 & 288.5 \\
\hline Commercial/Residential & 73.1 & 44.7 & 17.7 & 4.9 & 11.6 \\
\hline Industrial Fuel & 338.8 & 88.3 & 84.3 & 79.0 & 83.7 \\
\hline Industrial Processes & 100.7 & 19.4 & 25.6 & 26.2 & 26.7 \\
\hline Miscellaneous & 43.5 & 10.7 & 17.0 & 10.7 & 8.1 \\
\hline Transportation & 1518.3 & 303.9 & 389.1 & 394.0 & 386.3 \\
\hline Total & 3244.0 & 715.4 & 780.2 & 861.6 & 804.9 \\
\hline \multicolumn{6}{|l|}{ West } \\
\hline Electric Utility & 2001.2 & 598.4 & 445.1 & 574.2 & 491.8 \\
\hline Commercial/Residential & 199.9 & 115.6 & 49.9 & 19.3 & 33.8 \\
\hline Industrial Fuel & 1849.1 & 491.8 & 446.8 & 443.8 & 460.2 \\
\hline Industrial Processes & 331.8 & 74.3 & 82.9 & 87.8 & 88.4 \\
\hline Miscellaneous & 142.2 & 20.2 & 37.6 & 40.7 & 40.0 \\
\hline Transportation & 3542.7 & 850.7 & 887.4 & 994.6 & 912.9 \\
\hline Total & 8067.0 & 2150.9 & 1949.6 & 2160.4 & 2027.1 \\
\hline \multicolumn{6}{|l|}{ National } \\
\hline Electric Utility & 5775.5 & 1455.3 & 1277.6 & 1623.7 & 1425.4 \\
\hline Commercial/Residential & 659.0 & 327.6 & 171.5 & 46.2 & 113.8 \\
\hline Industrial Fuel & 2944.4 & 811.1 & 717.6 & 689.7 & 727.2 \\
\hline Industrial Processes & 577.3 & 126.7 & 145.0 & 152.1 & 153.5 \\
\hline Miscellaneous & 231.7 & 42.8 & 66.6 & 63.0 & 59.4 \\
\hline Transportation & 8174.5 & 1697.1 & 2044.9 & 2336.8 & 2095.8 \\
\hline Total & 18362.5 & 4460.4 & 4423.2 & 4911.4 & 4575.1 \\
\hline
\end{tabular}




Northeast
Electric Utility
Commercial/Residential
Industrial Fuel
Industrial processes
Miscellaneous
Transportation
Total

\section{ANNUAL \\ JAN 84 \\ -DEC84}

2698.7

395.0

803.9

160.4

46.0

3039.6

7143.6

\section{Southeast}

Electric Utility

Commercial/Residential

Industrial Fuel

Industrial processes

Miscellaneous

Transportation

Total

West

Electric Utility

Commercial/Residential

Industrial Fuel

Industrial Processes

Miscellaneous

Transportation

Total

National

Electric Utility

Commercial/Residential

Industrial Fuel

Industrial processes

Miscellaneous

Transportation

Total

$$
\begin{array}{r}
1200.6 \\
73.9 \\
365.5 \\
108.4 \\
43.5 \\
1500.2 \\
3292.1
\end{array}
$$

2134.0

201.4

2025.0

359.0

142.2

3557.7

8419.3

6033.3

670.3

3194.4

627.8

231.7

8097.6

1.8855 .1 by Geographic

WINTER
DEC83
-FEB84

Region
SPRING
MAR8 4
-MAY 84

648.9

168.1

251.0

37.7

11.8

538.5

1656.0

$$
\begin{array}{r}
639.0 \\
113.0 \\
206.6 \\
42.3 \\
12.1 \\
740.3
\end{array}
$$

1753.4

and

Season

(kt)

$$
\begin{array}{r}
\text { SUMMER } \\
\text { JUN84 } \\
\text {-AUG84 }
\end{array}
$$

FALL

SEP 84

-NOV 84

256.0
44.4

274.4
18.5

18.5

94.9

21.4

28.0

17.0

10.7

296.6

383.5

724.1

815.3

725.6
23.5
176.3

42.2

11.5

92.5 .0

1904.0

1730.1

640.2

70.2

186.8

40.0

11.3

781.7

337.8

4.6

85.1

28.1

10.7

393.4

859.6

300.0

12.3

87.4

27.6

8.1

382.8

818.1

604.0

111.1

533.9

82.0

20.2

859.2

483.2
49.4

49.4
494.8

91.5

37.6

891.3

2047.9

2210.5

1508.9
323.6
879.7
141.2
42.8

1396.7

180.9

795.4

161.9

66.6

1694.3

2015.1

4590.6
E?0.2

485.1

95.0

40.7

994.4

2244.5

2090.8

1673.6
47.2

746.4

165.2

63.0

2312.7

513.7

36.0

498.2

91.9

40.0

911.0

1453.8

118.6

772.4

159.4

59.4

2075.4

$5008.1 \quad 4639.0$ 
1.985 Sectoral NOx Emissions by Geographic Region and Season (kt)

\begin{tabular}{|c|c|c|c|c|c|}
\hline & $\begin{array}{r}\text { ANNUAL } \\
\text { JAN8 } 5 \\
- \text { DEC8 } 5\end{array}$ & $\begin{array}{r}\text { WINTER } \\
\text { DEC8 4 } \\
\text {-FEB85 }\end{array}$ & $\begin{array}{r}\text { SPRING } \\
\text { MAR8 } 5 \\
\text {-MAY } 85\end{array}$ & $\begin{array}{r}\text { SUMMER } \\
\text { JUN8 } 5 \\
\text {-AUG85 }\end{array}$ & $\begin{array}{r}\text { FALL } \\
\text { SEP } 85 \\
\text {-NOV85 }\end{array}$ \\
\hline \multicolumn{6}{|l|}{ Northeast } \\
\hline Electric Utility & 2712.6 & 676.8 & 643.2 & 693.6 & 642.4 \\
\hline Commercial/Residential & 373.6 & 171.1 & 93.7 & 25.5 & 59.9 \\
\hline Industrial Fuel & 749.7 & 230.6 & 191.8 & 164.7 & 172.4 \\
\hline Industrial Processes & 160.4 & 36.9 & 42.0 & 42.2 & 40.9 \\
\hline Miscellaneous & 45.6 & 11.8 & 12.0 & 11.4 & 11.1 \\
\hline Transportation & 2924.5 & 520.7 & 725.8 & 879.4 & 743.0 \\
\hline Total & 6966.4 & 1647.9 & 1708.5 & 1816.8 & 1669.8 \\
\hline \multicolumn{6}{|l|}{ Southeast } \\
\hline Electric Utility & 1300.9 & 275.6 & 302.3 & 366.1 & 308.3 \\
\hline Tommercial/Residential & 69.8 & 49.4 & 14.0 & 4.6 & 8.3 \\
\hline Industrial Fuel & 350.6 & 94.9 & 90.3 & 81.5 & 81.9 \\
\hline Industrial processes & 108.2 & 21.4 & 28.0 & 28.1 & 27.5 \\
\hline Miscellaneous & 42.9 & 8.5 & 16.9 & 10.5 & 7.8 \\
\hline Transportation & 1388.9 & 272.0 & 357.8 & 365.1 & 351.6 \\
\hline Total & 3261.4 & 721.8 & 809.4 & 855.8 & 785.5 \\
\hline \multicolumn{6}{|l|}{ West } \\
\hline Electric Utility & 2137.7 & 653.5 & 499.7 & 592.3 & 492.0 \\
\hline Commercial/Residential & 194.5 & 115.3 & 43.6 & 18.5 & 34.0 \\
\hline Industrial Fuel & 1880.2 & 502.5 & 454.3 & 450.4 & 464.9 \\
\hline Industrial Processes & 360.5 & 81.2 & 93.3 & 95.7 & 91.9 \\
\hline Miscellaneous & 112.8 & 17.5 & 36.2 & 30.5 & 27.1 \\
\hline Transportation & 3295.9 & 802.8 & 829.4 & 917.0 & 844.6 \\
\hline Total & 7981.6 & 2172.8 & 1956.5 & 2104.4 & 1954.5 \\
\hline \multicolumn{6}{|l|}{ National } \\
\hline Electric Utility & 6151.2 & 1605.9 & 1445.1 & 1652.1 & 1442.7 \\
\hline Commercial/Residential & 637.9 & 335.7 & 151.3 & 48.6 & 102.2 \\
\hline Industrial Fuel & 2980.5 & 828.0 & 736.4 & 696.6 & 719.2 \\
\hline Industrial Processes & 629.1 & 139.5 & 163.2 & 166.0 & 160.4 \\
\hline Miscellaneous & 201.3 & 37.7 & 65.2 & 52.3 & 46.0 \\
\hline Trans) ortation & 7609.3 & 1595.6 & 1913.1 & 2161.4 & 1939.2 \\
\hline Total & 18209.4 & 4542.4 & 4474.4 & 4777.0 & 4409.7 \\
\hline
\end{tabular}




\section{Sectoral NoX}

\begin{tabular}{|c|c|c|c|c|c|}
\hline & $\begin{array}{r}\text { ANNUAL } \\
\text { JAN8 } 6 \\
\text {-DEC } 86\end{array}$ & $\begin{array}{r}\text { WINTER } \\
\text { DEC85 } \\
\text {-FEB86 }\end{array}$ & $\begin{array}{r}\text { SPRING } \\
\text { MAR8 } 6 \\
- \text { MAY } 86\end{array}$ & $\begin{array}{r}\text { SUMMER } \\
\text { JUN86 } \\
\text {-AUG86 }\end{array}$ & $\begin{array}{r}\text { EALL } \\
\text { SEP } 86 \\
- \text { NOV8 } 6\end{array}$ \\
\hline \multicolumn{6}{|l|}{ Northeast } \\
\hline Electric Utility & 2691.4 & 653.7 & 638.8 & 724.2 & 615.7 \\
\hline Commercial/Residential & 402.2 & 176.3 & 103.8 & 24.4 & 74.1 \\
\hline Industrial Fuel & 760.7 & 237.1 & 198.5 & 164.6 & 172.3 \\
\hline Industrial Processes & 151.5 & 37.4 & 39.8 & 39.0 & 37.8 \\
\hline Miscellaneous & 45.6 & 11.8 & 12.0 & 11.4 & 11.1 \\
\hline Transportation & 2859.6 & 496.3 & 706.9 & 866.8 & 731.6 \\
\hline Total & 6910.9 & 1612.5 & 1699.8 & 1830.3 & 1642.6 \\
\hline \multicolumn{6}{|l|}{ Southeast } \\
\hline Electric Utility & 1310.9 & 279.5 & 302.8 & 381.9 & 315.6 \\
\hline Commercial/Residential & 73.5 & 47.1 & 16.9 & 4.6 & 10.7 \\
\hline Industrial Fuel & 352.5 & 94.6 & 92.4 & 80.7 & 81.0 \\
\hline Industrial Processes & 106.4 & $21: 4$ & 27.2 & 27.4 & 27.0 \\
\hline Miscellaneous & 42.9 & 8.5 & 16.9 & 10.5 & 7.8 \\
\hline Transportation & 1361.7 & 263.1 & 347.5 & 365.4 & 345.9 \\
\hline Total & 3248.0 & 714.1 & 803.7 & 870.5 & 788.0 \\
\hline \multicolumn{6}{|l|}{ West } \\
\hline Electric Utility & 2056.6 & 614.3 & 454.3 & 587.6 & 490.0 \\
\hline Commercial/Residential & 185.6 & 105.6 & 44.5 & 18.8 & 34.7 \\
\hline Industrial Fuel & 1848.8 & 493.7 & 447.7 & 442.8 & 457.1 \\
\hline Industrial Processes & 351.8 & 81.6 & 89.8 & 91.4 & 89.8 \\
\hline Miscellaneous & 112.8 & 17.5 & 36.2 & 30.5 & 27.1 \\
\hline Transportation & 3196.9 & 777.8 & 796.1 & 903.1 & 817.7 \\
\hline Total & 7752.5 & 2090.4 & 1868.7 & 2074.2 & 1916.4 \\
\hline \multicolumn{6}{|l|}{ National } \\
\hline Electric Utility & 6058.9 & 1547.5 & 1395.9 & 1693.7 & 1421.3 \\
\hline Commercial/Residential & 661.2 & 328.9 & 165.1 & 47.8 & 119.4 \\
\hline Industrial Fuel & 2962.1 & 825.3 & 738.7 & 688.1 & $710 \cdot 4$ \\
\hline Industrial processes & 609.7 & 140.4 & 156.8 & 157.9 & 154.6 \\
\hline Miscellaneous & 201.3 & 37.7 & 65.2 & 52.3 & 46.0 \\
\hline Transportation & 7418.2 & 1537.2 & 1850.5 & 2135.3 & 1895.2 \\
\hline Total & 17911.4 & 44.17 .1 & 4372.2 & 4775.0 & 4347.0 \\
\hline
\end{tabular}




Northeast
Electric Utility
Commercial/Residential
Industrial Fuel
Industrial Processes
Miscellaneous
Transportation
Total

\section{Southeast}

Electric Utility

Commercial/Residential

Industrial Fuel

Industrial Processes

Miscellaneous

Transportation

Total

West

Electric Utility

Commercial/Residential

Industrial Fuel

Industrial Processes

Miscellaneous

Transportation

Total
1308.8

73.2

343.1

127.7

42.9

1349.2

3244.9 by Geographic

WINTER
DEC8 6
-FEB87

606.9

227.4

38.4

11.8

489.4

1537.2
Region

SPRING
MAR87
-MAY87

SUMMER
JUN87
-AUG87

$$
660.9
$$

98.6

180.6

39.6

12.0

685.0

1676.7

and

777.9

22.4

162.9

40.9

11.4

829.6
Season

(kt)

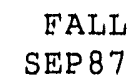

-NOV8 7

$$
\begin{array}{r}
277.7 \\
44.2 \\
85.1 \\
25.2 \\
8.5
\end{array}
$$

259.8

700.5

$$
\begin{array}{r}
291.5 \\
17.7 \\
84.6 \\
32.1 \\
16.9
\end{array}
$$

345.6

788.3
632.6
75.4
179.1
40.5
11.1
704.2

$1845.1 \quad 1642.9$

641.0
104.6
515.3
84.7
17.5
761.5

491.2

46.1

449.1

92.2

36.2

778.6

2124.

1893.5

627.7
17.8

453.9

95.7

30.5

884.3

4.2

80.9

33.0

10.5

360.4

876.0

319.4

13.1

86.5

32.6

7.8

341.9

801.2

506.9

32.5

456.2

94.7

27.1

806.7

7831.8

$$
\begin{array}{r}
6223.7 \\
639.9 \\
2961.3 \\
649.5 \\
201.3 \\
7247.0
\end{array}
$$

17922.6

$$
\begin{array}{r}
1525.6 \\
312.3 \\
827.8 \\
148.2 \\
37.7
\end{array}
$$

1510.7

4362.3

$$
\begin{array}{r}
1443.5 \\
162.3 \\
714.4 \\
163.9 \\
65.2
\end{array}
$$

1809.2

4358.5
2109.9

1924.1

$\begin{array}{rr}1792.7 & 1458.9 \\ 44.4 & 120.9 \\ 697.6 & 721.8 \\ 169.6 & 167.8 \\ 52.3 & 46.0 \\ 2074.2 & 1852.7 \\ & \\ 4830.9 & 4368.2\end{array}$

458.9

67.8

46.0

4368.2 
Region

Northeast

Electric Utility

Commercial/Residential

Industrial Fuel

Industrial Processes

Miscellaneous

Transportation

Total

Southeast

Electric Utility

Commercial/Residential

Industrial Fuel

Industrial Processes

Miscellaneous

Transportation

Total

West

Electric Utility

Commercial/Residential

Industrial Euel

Industrial Processes

Miscellaneous

Transportation

Total
ANNUAL

JAN8 8

-DEC 88

2737.3

400.9

779.3

185.8

45.6

2619.6

6768.4

1346.2

76.9

355.4

142.4

42.9

1264.4

3228.2

2283.6

199.2

1956.6

420.6

112.8

3028.8

8001.5

6367.1

677.0

3091.3

748.7

201.3

6912.7

17998.2

WINTER
DEC87
-EEB88

SPRING
MAR8 8
-MAY 88

SUMMER

JUN8 8

-AUG8 8

655.9

173.4

231.0

45.7

11.8

463.9

1581.6

618.6

102.9

192.3

47.9

12.0

648.6

1622.3

759.6
23.0

174.3

48.6

11.4

786.6

1803.6

1633.0

$$
\begin{array}{r}
306.2 \\
46.3 \\
88.1 \\
28.5 \\
8.5
\end{array}
$$

244.1

721.8

290.6

385.8

4.5

82.6

36.8

10.5

339.2

16.9

323.3

772.4

859.4

786.4

$$
676.3
$$

528.9

49.2

480.6

513.8

97.7

17.5

107.1

36.2

729.4

751.7

2147.7

1953.8

$$
\begin{array}{r}
1638.4 \\
332.7 \\
832.8 \\
172.0 \\
37.7
\end{array}
$$

1438.0

65.2

1.437 .4

1723.6

4451.1
4348.5
665.4

20.0

468.1

110.0

30.5

857.6

2151.6

1967.0

1810.8

47.6

725.0

195.5

52.3

1983.4

526.4

34.2

491.7

107.2

27.1

780.4

1482.1

126.7

773.0

190.2

46.0

1768.3

$4814.6 \quad 4386.4$ 
B.5 $\mathrm{SO}_{2}$ Emissions

by Geographic Region and Season 
1975 Seatoral $\mathrm{SO}_{2}$ misusions by Geographio Ragion and season (kt)

\begin{tabular}{|c|c|c|c|c|c|}
\hline & $\begin{array}{r}\text { ANNUAL } \\
\text { JAN75 } \\
- \text {-DEC75 }\end{array}$ & $\begin{array}{r}\text { WINTER } \\
\text { DEC74 } \\
\text {-TEB75 }\end{array}$ & $\begin{array}{r}\text { SERING } \\
\text { MAR75 } \\
- \text { MAY75 }\end{array}$ & $\begin{array}{r}\text { SUMMER } \\
\text { JUN75 } \\
- \text {-AUG75 }\end{array}$ & $\begin{array}{r}\text { EALII } \\
\text { SEP75 } \\
\text {-NOV75 }\end{array}$ \\
\hline $\begin{array}{l}\text { Northeast } \\
\text { Eleotrio Utility } \\
\text { Commerolal/Residential } \\
\text { Industrial Fuel } \\
\text { Industrial Processes } \\
\text { Misoellaneous } \\
\text { Transportation }\end{array}$ & $\begin{array}{r}10327.6 \\
640.3 \\
2113.0 \\
691.0 \\
16.5 \\
215.5\end{array}$ & $\begin{array}{l}N / A \\
N / A \\
N / A \\
N / A \\
N / A \\
N / A\end{array}$ & $\begin{array}{r}2428.0 \\
176.6 \\
537.9 \\
176.8 \\
4.1 \\
53.1\end{array}$ & $\begin{array}{r}2732.1 \\
29.5 \\
476.0 \\
170.0 \\
4.1 \\
62.1\end{array}$ & $\begin{array}{r}2472.6 \\
122.5 \\
514.7 \\
174.6 \\
4.1 \\
55.7\end{array}$ \\
\hline Total & 14004.0 & $N / A$ & 3376.6 & 3473.8 & 3344.2 \\
\hline $\begin{array}{l}\text { Southeast } \\
\text { Electrio Utility } \\
\text { Commercial/Resldential } \\
\text { Industrial Fuel } \\
\text { Industrial Processes } \\
\text { Miscellaneous } \\
\text { Transportation }\end{array}$ & $\begin{array}{r}4543.1 \\
66.1 \\
349.0 \\
365.9 \\
4.4 \\
98.8\end{array}$ & $\begin{array}{l}N / A \\
N / A \\
N / A \\
N / A \\
N / A \\
N / A\end{array}$ & $\begin{array}{r}1041.4 \\
14.4 \\
88.1 \\
91.8 \\
1.3 \\
24.8\end{array}$ & $\begin{array}{r}1252.9 \\
2.6 \\
78.8 \\
90.1 \\
1.1 \\
26.3\end{array}$ & $\begin{array}{r}1143.2 \\
11.2 \\
85.4 \\
94.0 \\
1.0 \\
25.4\end{array}$ \\
\hline Total & 5427.1 & $\mathrm{~N} / \mathrm{A}$ & 1261.7 & 1451.8 & 1360.3 \\
\hline $\begin{array}{l}\text { West } \\
\text { Electric Utildty } \\
\text { Commerclal/Residential } \\
\text { Industrial Fuel } \\
\text { Industrial Processes } \\
\text { Miscellaneous } \\
\text { Transportation }\end{array}$ & $\begin{array}{r}1937.2 \\
113.8 \\
664.3 \\
3058.1 \\
16.3 \\
318.2\end{array}$ & $\begin{array}{l}\text { N/A } \\
\text { N/A } \\
N / A \\
N / A \\
N / A \\
N / A\end{array}$ & $\begin{array}{r}409.8 \\
27.8 \\
164.3 \\
791.6 \\
4.3 \\
78.3\end{array}$ & $\begin{array}{r}509.0 \\
3.7 \\
155.0 \\
746.5 \\
4.1 \\
86.5\end{array}$ & $\begin{array}{r}469.6 \\
21.7 \\
166.5 \\
762.1 \\
4.0 \\
83.1\end{array}$ \\
\hline Total & 6107.9 & $\mathrm{~N} / \mathrm{A}$ & 1476.2 & 1504.9 & 1507.0 \\
\hline $\begin{array}{l}\text { Nationdl. } \\
\text { Electric Utility } \\
\text { Commercial/Residential } \\
\text { Industrial Fuel } \\
\text { Industrial Processes } \\
\text { Miscelianeous } \\
\text { Transportation }\end{array}$ & $\begin{array}{r}16807.9 \\
820.3 \\
3126.3 \\
4114.9 \\
37.2 \\
632.5\end{array}$ & $\begin{array}{l}N / A \\
N / A \\
N / A \\
N / A \\
N / A \\
N / A\end{array}$ & $\begin{array}{r}3879.2 \\
218.8 \\
790.3 \\
1060.2 \\
9.8 \\
156.1\end{array}$ & $\begin{array}{r}4493.9 \\
35.8 \\
709.8 \\
1006.6 \\
9.4 \\
174.9\end{array}$ & $\begin{array}{r}4085.4 \\
155.4 \\
766.6 \\
1030.6 \\
9.2 \\
164.3\end{array}$ \\
\hline Total & 25539.0 & $N / A$ & 6114.4 & 6430.4 & 6211.5 \\
\hline
\end{tabular}


amis st ons

ANNUAL
JAN76
.DEC76

Northeast

Eleotrio Utildty
Commerolal/Residentlal

10333.8

708.8

Industrtal Fuel

Industrial processes

Miscellaneous

Transportation

Total

Southeast

Electrio Ut1lity
Commercial/Residentdal

Industrial Fuel

Industrial Processes

Miscellaneous

Transportation

Total

West

Electric Utility

Commercial/Restdential

Industrial Fuel

Industrial Processes

Miscellaneous

Transportation

Total

National

Electric Utility

Commercial/Residential

Industrial Fuel

Industrtal processes

M.tscellaneous

Transportation

Total
2204.8

661.1

16.5

230.8

14155.9

4970.1

76.7

416.5

341.0

4.4

108.8

5917.5

2247.7

131.8

786.6

16.3

349.2

6172.8

17551.6

917.4

3407.8

3643.4

37.2

688.8

26246.3
2641.3

by Geographio

WINTER
DEC75
- EEB76

Region

and season

(kt)

2602.7
288.3
510.7
150.2
3.6
45.2

SPRING
MAR76
-MAY76

SUMMER

JUN7 6

-AUG76

FALL

SEP76

-NOV76

3600.6

2478.2

2631.6

2496.3

$32.1 \quad 173.5$

$509.7 \quad 554.5$

175.0

4.1

167.3

169.1

4.1

56.9

65.9

4.1

60.0

3399.6

3418.4

3455.7

1023.5
73.6
127.0
82.2
1.2
21.5

1127.5
11.3
100.7
86.5
1.3
27.3

1.377 .6

2.3

95.6

87.5

1.1

28.9
1229.8
18.8
105.1
87.5
1.0
28.0

1329.2

1354.5

1593.1

1470.3

952.0
100.2
288.4
648.7
4.1
83.5

2076.9

475.0

26.2

191.5

680.4

4.3

86.0

1463.4

589.4

4.0

187.3

652.2

4.1

94.6

1531.7

1550.3

4578.2
462.1
926.2
881.0
8.9
150.2

4080.7

829.0

935.9

9.8

170.2

7006.7

6217.5

4598.6

38.4

792.6

914.7

9.4

189.5

4291.7

224.9

859.9

911.7

9.2

178.9

6543.2

6476.3 


Northeast
Electric Utilty
Commercial/Residential
Industrial Fuel
Industrial Processes
Misolianeous
Transportation
Total

$$
\begin{aligned}
& \text { ANNUAL } \\
& \text { JAN77 }
\end{aligned}
$$

-DEC77

$$
\begin{array}{r}
10238.9 \\
669.5 \\
2189.0 \\
702.8 \\
16.5 \\
233.8
\end{array}
$$

14050.6

Southeast

Electric Utility

Commercial/Resldenttal

Industrial Fuel

Industrial Processes

Miscellaneous

Transportation

Total

West

Electric Utility

Commercial/Residential

Industrial Fuel

Industrial Processes

Miscellaneous

Transportation

Total

81.7

457.8

352.9

4.4

113.6

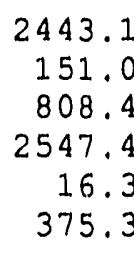

6341.6

17714.6

902.2

3455.1

3603.2

37.2

722.8

26435.1

\section{by Geographic}

WINTER
DEC76
- EEB77

2548.8

312.1

522.3

157.3

3.6

45.8

3590.0

$$
\begin{array}{r}
\text { SPRING } \\
\text { MAR77 } \\
\text {-MAY } 77
\end{array}
$$

and Season

$(k t)$

2426.7

136.5

540.3

183.0

4.1

58.0

SUMMER
JUN77

-AUG 77

EALL

SEP 77

-NOV77

3348 .
2675.2
33.7
507.0
184.4
4.1
67.4

2453.2

136.3

537.3

178.4

4.1

60.4

$3471.9 \quad 3369.9$

1110.3
80.3
134.5
83.0
1.2
22.

1067.2

1460.9
2.8
105.6

111.7

91.5

91.4

1.1

30.5

1204.1

1.3

28.8

1431.3

1311.4

1692.2

12.7

112.8

89.7

1. 0

29.2

1449.6

939.0
119.3
291.9
631.3
4.1
87.8

554.9

663.0

3.5

191.8

197.6

598.3

4.1

4.3

93.3

1.02 .1

2073.4

1569.0

1562.8

1526.1

572.3

25.8

202.2

624.2

4.0

97.5

$\begin{array}{rrrr}4598.1 & 4048.9 & 4799.2 & 4229.7 \\ 511.7 & 175.6 & 40.0 & 174.9 \\ 948.8 & 849.6 & 804.4 & 852.4 \\ 871.6 & 965.1 & 874.1 & 892.3 \\ 8.9 & 9.8 & 9.4 & 9.2 \\ 155.6 & 180.1 & 199.9 & 187.2 \\ 7094.7 & 6229.1 & 6727.0 & 6345.6\end{array}$


Emisolons by Geographio

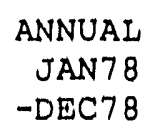

Northeast

Eleotrlo Utility

Commercial/Residential

Industrial Fuel

Industrial Processes

Miscellaneous

Transportation

Total

Southeast

Electric Utility

Commercial/Residential

Industrial Fuel

Industrial processes

Miscellaneous

Transportation

Total

West

Electric Utility

Commerclal/Residential

Industrial Fuel

Industrial Processes

Miscellaneous

Transportation

Total

National

Electric Utility

Commercial/Residential

Industrial Fuel

Industrial Processes

Miscelianeous

Transportation

Total
9555.2

618.9

2096.1

671.6

16.5

239.2

13197.5

4432.1

75.9

434.5

359.3

4.4

119.5

5425.8

2264.0

156.1

870.3

2460.6

16.3

409.8

6177.1

16251.4

850.9

3400.9

3491.5

37.2

768.5

24800.4
885.3

WINTER
DEC77
-FEB78

Region

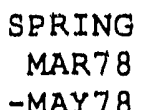

and

Season

(kt)

2265.8

263.7

460.1

150.0

3.6

46.9

3190.0

2207.8

155.4

500.6

169.2

4.1

59.4

3096.4

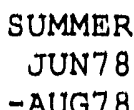

FALL SEP78

-NOV78

2521.2

35.9

508.4

176.6

4.1

68.9

2411.4

126.8

540.6

176.1

4.1

62.0

$3315.1 \quad 3321.1$

1017.8
67.1

120.5

85.0

1.2

23.3

961.6
14.2

104.4

91.2

1.3

30.2

1314.8

1202.9

1271.1

3. 3

104.7

92.8

1.1

32.0

1074.1

10.1

111.2

93.2

1.0

30.9

$1504.8 \quad 1320.5$

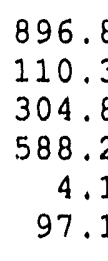

477.8
30.4

211.0

623.9

4.3

101. 3

2001.2

1448.7

597.5

6.7

212.0

640.7

4.1

110.7

1571.6

1511.8

4180

441.1

823.1

8.9

167.2

3647.2
200.0
815.9
884.3
9.8
190.9

4389.8
45.9

825.0

910.0

9.4

211.6

6506.0

5748.1

6391.6

547.4

27.0

222.8

604.7

4.0

105.8

4032.9

163.9

874.6

874.1

9.2

198.7

6153.4 
Region

WINTER
DEC78
-EEB79

SPRING

MAR79

-MAY79

$-D E C 79$

Northeast

Electric Utility

Commercial/Residential

Industrial Fuel

Industrial Processes

Miscellaneous

Transportation

Total

9775.0

450.7

1918.6

686.5

16.5

236.5

13083.9

Southeast

Electric Utility

Commercial/Residential

Industrial Fuel

Industrial Processes

Miscellaneous

Transportation

Total

West

Electric Utility

Commercial/Residential

Induscrial Fuel

Industrial Processes

Miscellaneous

Transportation

Total

\section{National}

Electric Utility

Commercial/Residential

Industrial Euel

Industrial Processes

Miscellaneous

Transportation

Total

$$
\begin{array}{r}
4314.1 \\
68.4 \\
409.9 \\
363.1 \\
4.4 \\
120.7
\end{array}
$$

5280.5

2357.4

194.4

876.5

2504.0

16.3

436.8

6385.2

16446.5

713.5

3205.0

3553.6

37.2

793.9

24749.6

$$
\begin{array}{r}
2219.5 \\
207.8 \\
434.4 \\
155.4 \\
3.6 \\
48.0
\end{array}
$$

2335.8

103.6

481.1

177.7

4.1

59.4

3068.6

3161.8

\section{5}

26.7

463.8

182.0

4.1

67.5

3253.6

3139.6

1026.7
51.6

114.1

86.4

1.2

24.3

979.2

11.8
102.5

92.5

1.3

30.8

1304.3

1218.0

1225.6

3.3

99.0

94.2

1.1

31.8

2347.1

91.5

464.6

172.0

4.1

60.2

997.5

11.6

99.3

92.6

1.0

30.8

$1454.9 \quad 1232.8$

1122.2
128.5

514.9

33.3

218.2

298.5

604.0

607.3

4.3

4.1

104.3

108.7

598.4

7.2

213.8

634.4

4.1

115.6

1486.7

1573.5

1591.9

2261.6

4368.5
387.8

3829.9

148.7

801.8

877.5

9.8

198.9

4333.5

37.2

776.5

910.6

3912.5

139.7

779.7

919.8

176.5

$\begin{array}{llll}6634.5 & 5866.5 & 6282.1 & 5964.3\end{array}$
9.4

214.9

9.2 $\begin{array}{llll}6634.5 & 5866.5 & 6282.1 & 5964.3\end{array}$ 
Geographic

Region

and Season

(kt)

\begin{tabular}{|c|c|c|c|c|c|}
\hline & $\begin{array}{r}\text { ANNUAL } \\
\text { JAN8 } 0 \\
-D E C 80\end{array}$ & $\begin{array}{r}\text { WINTER } \\
\text { DEC79 } \\
\text {-EEB80 }\end{array}$ & $\begin{array}{r}\text { SPRING } \\
\text { MAR8 } 0 \\
\text {-MAY } 80\end{array}$ & $\begin{array}{r}\text { SUMMER } \\
\text { JUN80 } \\
\text {-AUG80 }\end{array}$ & $\begin{array}{r}\text { FALL } \\
\text { SEP } 80 \\
\text {-NOV } 80\end{array}$ \\
\hline \multicolumn{6}{|l|}{ Northeast } \\
\hline Electric Utility & 9208.3 & 2124.2 & 2147.1 & 2372.3 & 2188.6 \\
\hline Commercial/Residential & 494.8 & 222.7 & 118.8 & 21.0 & 105.3 \\
\hline Industrial Fuel & 1676.5 & 399.8 & 430.1 & 381.2 & 404.7 \\
\hline Industrial Processes & $637.3^{\prime \prime}$ & 159.7 & 164.5 & 151.8 & 161.8 \\
\hline Miscellaneous & 16.5 & 3.6 & 4.1 & 4.1 & $4 . i$ \\
\hline Transportation & 237.1 & 49.9 & 58.6 & 66.8 & 60.9 \\
\hline Total & 12270.5 & 2959.8 & 2923.2 & 2997.2 & 2925.4 \\
\hline \multicolumn{6}{|l|}{ Southeast } \\
\hline Electric Utility & 4429.8 & 1062.2 & 988.9 & 1257.3 & 1039.3 \\
\hline Commercial/Residential & 66.5 & 56.3 & 13.1 & 3.8 & 12 . \\
\hline Industrial Fuel & 394.3 & 108.0 & 100.2 & 90.2 & 96.0 \\
\hline Industrial Processes & 358.0 & 90.5 & 91.1 & 88.3 & 90.7 \\
\hline Miscellaneous & 4.4 & 1.2 & 1.3 & 1.1 & 1 . \\
\hline Transportation & 121.3 & 24.9 & 30.6 & 31.6 & 31.2 \\
\hline Total & 5374.3 & 1343.1 & 1225.1 & 1472.3 & 1270.7 \\
\hline \multicolumn{6}{|l|}{ West } \\
\hline Electric Utility & 2465.0 & 1104.2 & 545.7 & 683.2 & 589.2 \\
\hline Commercial/Residential & 176.5 & 106.7 & 37.8 & 5.0 & 34 . \\
\hline Industrial Fuel & 817.8 & 278.8 & 204.8 & 191.7 & 203. \\
\hline Industrial Processes & 2115.8 & 593.5 & 670.9 & 411.3 & 437. \\
\hline Miscellaneous & 16.3 & 4.1 & 4.3 & 4.1 & 4. \\
\hline Transportation & 462.2 & 111.6 & 114.9 & 121.3 & 118.5 \\
\hline Total & 6053.6 & 2198.9 & 1578.5 & 1416.6 & 1386.7 \\
\hline \multicolumn{6}{|l|}{ National } \\
\hline Electric utility & 16103.1 & 4290.6 & 3681.6 & 4312.8 & 3817.0 \\
\hline Commercial/Residential & 737.9 & 385.7 & 169.8 & 29.8 & 152 \\
\hline Industrial Fuel & 2888.5 & 786.6 & 735.0 & 663.0 & 703.9 \\
\hline Industrial Processea & 3111.1 & 843.7 & 926.5 & 651.4 & 689. \\
\hline Miscellaneous & 37.2 & 8.9 & 9.8 & 9.4 & 9. \\
\hline Transportation & 820.7 & 186.4 & 204.0 & 219.6 & 210. \\
\hline Total & 23698.4 & 6501.9 & 5726.7 & 5886.1 & 5582.8 \\
\hline
\end{tabular}


1981 Sectoral $\mathrm{SO}_{2}$ Emissions by Geographic Region and Season (kt)

\begin{tabular}{|c|c|c|c|c|c|}
\hline & $\begin{array}{r}\text { ANNUAL } \\
\text { JAN81 } \\
\text {-DEC81 }\end{array}$ & $\begin{array}{r}\text { WINTER } \\
\text { DEC80 } \\
- \text { FEB81 }\end{array}$ & $\begin{array}{r}\text { SPRING } \\
\text { MAR81 } \\
\text {-MAY } 81\end{array}$ & $\begin{array}{r}\text { SUMMER } \\
\text { JUN81 } \\
\text {-AUG81 }\end{array}$ & $\begin{array}{r}\text { FALL } \\
\text { SEP 81 } \\
\text {-NOV81 }\end{array}$ \\
\hline \multicolumn{6}{|l|}{ Northeast } \\
\hline Electric Utility & 8778.8 & 2088.7 & 2087.0 & 2252.7 & 2067.6 \\
\hline Commercial/Residential & 419.2 & 189.7 & 98.4 & 22.9 & 92.9 \\
\hline Industrial Euel & 1517.9 & 350.4 & 372.1 & 369.0 & 375.9 \\
\hline Industrial Processes & 613.0 & 142.7 & 163.3 & 159.3 & 147.8 \\
\hline Miscellaneous & 16.5 & 3.6 & 4.1 & 4.1 & 4.1 \\
\hline Transportation & 232.6 & 48.9 & 56.1 & 66.5 & 60.5 \\
\hline Total & 11577.9 & 2824.0 & 2781.0 & 2874.3 & 2748.8 \\
\hline \multicolumn{6}{|l|}{ Southeast } \\
\hline Electric Utility & 4465.8 & 1039.4 & 1013.4 & 1300.9 & 1022.0 \\
\hline Commercial/Residential & 61.0 & 45.3 & 11.7 & 3.3 & 10.9 \\
\hline Industrial. Fuel & 343.6 & 86.4 & 84.3 & oง.8 & 85.1 \\
\hline Industrial Processes & 341.7 & 82.9 & 90.5 & 87.6 & 83.1 \\
\hline Miscellaneous & 4.4 & 1.2 & 1.3 & 1.1 & 1.0 \\
\hline Transportation & 119.0 & 24.2 & 29.7 & 31.9 & 30.2 \\
\hline Total & 5335.6 & 1279.3 & 1230.9 & 1508.5 & 1232.2 \\
\hline \multicolumn{6}{|l|}{ West } \\
\hline Electric Utility & 2404.0 & 1031.7 & 525.7 & 659.0 & 591.4 \\
\hline Commercial/Residential & 161.4 & 102.9 & 31.0 & 5.1 & 27.5 \\
\hline Industrial Fuel & 851.7 & 273.9 & 209.7 & 210.8 & 211.8 \\
\hline Industrial Processes & 2273.6 & 542.5 & 590.5 & 578.5 & 559.8 \\
\hline Miscellaneous & 16.3 & 4.1 & 4.3 & 4.1 & 4.0 \\
\hline Transportation & 458.6 & 109.1 & 113.6 & 121.8 & 117.7 \\
\hline Total & 6165.4 & 2064.2 & 1474.9 & 1579.4 & 1512.2 \\
\hline \multicolumn{6}{|l|}{ National } \\
\hline Electric Utility & 15648.5 & 4159.8 & 3626.0 & 4212.7 & .3681 .0 \\
\hline Commercial/kesidential & 641.6 & 337.9 & 141.2 & 31.3 & 131.3 \\
\hline Industrial Fuel & 2713.1 & 710.6 & 666.1 & 663.7 & 672.7 \\
\hline Industrial Processes & 3228.3 & 768.1 & 844.3 & 825.4 & 790.6 \\
\hline Miscellaneous & 37.2 & 8.9 & 9.8 & 9.4 & 9.2 \\
\hline Transportation & 810.1 & 182.2 & 199.5 & 220.1 & 208.4 \\
\hline Total & 23078.9 & 6167.5 & 5486.9 & 5962.5 & 5493.2 \\
\hline
\end{tabular}


Emissions by Geographic

$$
\begin{array}{r}
\text { ANNUAL } \\
\text { JAN82 } \\
\text {-DEC82 }
\end{array}
$$

Northeast
Electric Utility
Commercial/Residential
Industrial Fuel
Industrial Processes
Miscellaneous
Transportation
Total

Southeast

Electric Utility

Commercial/Residential

Industrial Fuel

Industrial Processes

Transportation

Total

8353.2

444.6

1502.0

476.7

16.5

217.2

11010.3

3762.0

46.2

334.8

292.2

4.4

112.2

4551.8

2192.5
193.6

362.6

111.8

3.6

42.6

2906.7
872.9
37.2
86.5
71.3
1.2
21.9

1091.0
Miscellaneous

2331.1

162.6

790.0

1712.5

16.3

412.8

5425.3

Total

National

Electric Utility

Commercial/Residential

Industrial Fuel.

Indistrial Processes

Miscellaneous

Transportation

Total
14446.2
653.5
2626.8
2481.5
37.2
742.3

20987.4

WINTER
DEC81
-EEB82

Region

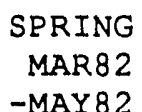

$$
\begin{array}{r}
2021.7 \\
112.9 \\
388.4 \\
124.4 \\
4.1 \\
54.0
\end{array}
$$

2705.5

$$
\begin{array}{r}
890.0 \\
9.3 \\
86.7 \\
74.8 \\
1.3 \\
28.5
\end{array}
$$

1090 .

1071.3
3.3

79.0

74.3

1.1

29.9

1258.9

1054.5

764.8
98.7

255.8

455.5

4.1

97.0

1675.9

$$
\begin{array}{r}
514.8 \\
31.2 \\
201.5 \\
443.7 \\
4.3 \\
103.2
\end{array}
$$

1298.6

630.1

5.7

191.0

407.2

4.1

110.7

1343.8

863.1

9.1

78.5

73.9

1.0

29.0

572.1

29.7

190.1

404.0

4.0

106.2

1306.0

$$
\begin{array}{r}
3830.2 \\
329.5 \\
704.9 \\
638.7
\end{array}
$$

8.9

161.5

5673.6

$$
\begin{array}{r}
3426.5 \\
153.3 \\
676.5 \\
642.9 \\
9.8 \\
185.6
\end{array}
$$
3797.
41.9
624.3
604.6
9.4
204.1
3366.1
128.7
621.1
595.3
9.2
191.1

5094.6

5282.0
4911.5 
Emissions by Geographic

Region

WINTER
DEC82
-EEB83

SPRING
MAR8 3

-MAY 83

$-D E C 83$

Northeast

Electric Utility

Commercial/Residential

Industrial Fuel

Industrial Processes

Miscellaneous

Transportation

Total

8545.7

367.5

1207.2

448.0

16.5

206.0

10791.0

Southeast

Electric Utility

Commercial/Residential

Industrial Fuel

Industrial Processes

Miscellaneous

Transportation

Total

West

Electric Utility

Commercial/Residential

Industrial Fuel

Industrial Processes

Miscellaneous

Transportation

Total

National

Electric Utility

Commercial/Residential

Industrial Fuel

Industrial Processes

Miscellaneous

Transportation

Total
3735.3

61.3

338.6

306.5

4.4

115.8

4561.8

2383.9

101.1

661.6

1799.8

16.3

390.7

5353.4

14664.9

529.9

2207.5

2554.3

37.2

712.5

20706.2
1867.8

144.6

265.9

100.4

3.6

39.2

2421.5
1904.6
93.1
287.8
110.4
4.1
50.6

2450.7

2289.2

26.9

291.7

117.4

4.1

62.2

2791.6

2112.0

77.4

312.0

120.2

4.1

53.1

2678.9

$$
\begin{array}{r}
796.1 \\
37.6 \\
75.2 \\
74.4 \\
1.2 \\
21.8
\end{array}
$$

1006.3
780.9
13.6
80.8
75.7
1. 3
29.4

1112.0
5.3

82.1

76.9

1.1

31.2

981.8

1308.6

1132.4

1120.9
72.7

514.2

230.9

408.5

4.1

89.3

158.4

468.7

4.3

97.7

1926.41266

$1926.4 \quad 1266.1$

669.7

6.1

163.3

433.4

4.1

106.9

1383.6

921.1

11.2

87.5

81.8

1.0

29.9

3784.8

3199.7

129.5

527.1

572.1

654.8

583.3

8.9

150.4

9.8

177.7

5354.2

4698.5
4070.9

38.4

537.1

627.6

9.4

200.3

5483.7
3636.9

107.3

571.2

688.6

9.2

1. 84.0

5197.2 
Total

Southeast

Electric Utility

Commercial/Residential

Industrial Fuel

Industrial processes

Miscellaneous

Transportation

Total

West

Electric Utility

Commercial/Residential

Industrial Fuel

Industrial processes

Miscellaneous

Transportation

Total

\section{National}

Electric Utility

Commercial/Residential

Industrial Fuel.

Industrial Processes

Miscellaneous

Transportation

Total
Region

WINTER
DEC83
-FEB84

SPRING
MAR8 4
- MAY 84

209.9

11139.8

$$
\begin{array}{r}
3677.2 \\
60.5 \\
367.8 \\
323.2 \\
4.4 \\
119.1
\end{array}
$$

4552.0

2457.0

108.6

789.9

1769.1

16.3

406.3

5547.0
2003.8

14.8

295.6

114.1

3.6

39.9

$$
\begin{array}{r}
795.8 \\
36.8 \\
83.7 \\
78.0 \\
1.2 \\
22.3
\end{array}
$$

1017.7
1006.2
69.8
256.9
422.8
4.1
92.9

1852.7
2087.5

113.1

332.4

132.1

4.1

51.2

2720.5

$$
\begin{array}{r}
834.0 \\
14.2 \\
94.8 \\
82.4 \\
1.3 \\
30.3
\end{array}
$$

1057.0

542.7

23.7

201.3

451.6

4.3

101.8

1325.4

3805.8
255.4
636.2
614.8
8.9
155.1

5476.2

$$
\begin{array}{r}
3464.2 \\
151.0 \\
628.5 \\
666.1 \\
9.8 \\
183.3
\end{array}
$$

5102.8 anc Seation

$$
\begin{array}{r}
\text { SUMMER } \\
\text { JUN84 } \\
\text {-AUG84 }
\end{array}
$$

$$
\begin{array}{rr}
2312.9 & 2040.0 \\
35.0 & 82.1 \\
309.0 & 310.1 \\
131.8 & 124.5 \\
4.1 & 4.1 \\
64.2 & 54.3 \\
& \\
2857.0 & 2615.1
\end{array}
$$

$$
\begin{array}{r}
1039.3 \\
4.2 \\
88.3 \\
83.6 \\
1.1 \\
32.3
\end{array}
$$

1248.8

1120.7

$$
689.7
$$

6.0

192.5

437.6

4.1

310.9

907.2

11.7

88.5

81.5

1.0

30.7

110.9

1440.9

1378.0

21238.8
4041.9

45.2

589.7

653.0

9.4

207.4

5546.7
597.7

23.0

194.1

454.7

4.0

104.5

3544.8

116.9

592.8

660.7

9.2

189.5

5113.8 
1985 Sectoral $\mathrm{SO}_{2}$ Emissions by Geographic Region and season (kt)

\begin{tabular}{|c|c|c|c|c|c|}
\hline & $\begin{array}{r}\text { ANNUAI } \\
\text { JAN8 } 5 \\
- \text { DEC85 }\end{array}$ & $\begin{array}{r}\text { WINTER } \\
\text { DEC84 } \\
\text {-EEB85 }\end{array}$ & $\begin{array}{r}\text { SPRING } \\
\text { MAR8 } 5 \\
\text {-MAY } 85\end{array}$ & $\begin{array}{r}\text { SUMMER } \\
\text { JUN8 } 5 \\
\text {-AUG85 }\end{array}$ & $\begin{array}{r}\text { EALI } \\
\text { SEP 85 } \\
\text {-NOV85 }\end{array}$ \\
\hline \multicolumn{6}{|l|}{ Northeast } \\
\hline Electric Utility & 8403.1 & 1978.4 & 2002.3 & 2140.4 & 1964.5 \\
\hline Commercial/Residential & 353.9 & 151.1 & 80.5 & 31.7 & 67.9 \\
\hline Industrial Fuel & 1235.3 & 281.3 & 310.5 & 297.5 & 301.8 \\
\hline Industrlal Processes & 492.2 & 109.5 & 128.0 & 128.8 & 125.8 \\
\hline Miscellaneous & 16.5 & 3.6 & 4.1 & 4.1 & 4.1 \\
\hline Transportation & 206.2 & 39.0 & 51.1 & 61.8 & 52.9 \\
\hline \multirow[t]{2}{*}{ Total } & 10707.3 & 2562.9 & 2576.6 & 2664.3 & 2517.0 \\
\hline \multirow{2}{*}{\multicolumn{6}{|c|}{ Southeast }} \\
\hline & & & & & \\
\hline Electric Utility & 3818.9 & 799.7 & 877.0 & 1077.2 & 915.2 \\
\hline Commercial/Residential & 62.0 & 47.1 & 9.9 & 3.6 & 7.1 \\
\hline Industrial Fuel & 398.3 & 89.1 & 100.1 & 96.1 & 97.3 \\
\hline Industrial processes & 319.2 & 77.3 & 81.8 & 81.7 & 80.9 \\
\hline Miscellaneous & 4.4 & 1.2 & 1.3 & 1.1 & 1.0 \\
\hline Transportation & 107.5 & 20.3 & 27.4 & 29.1 & 27.5 \\
\hline Total & 4710.3 & 1034.6 & 1097.4 & 1288.9 & 1129.1 \\
\hline \multicolumn{6}{|l|}{ West } \\
\hline Electric Utility & 2320.5 & 1083.5 & 553.8 & 619.3 & 525.4 \\
\hline Commercial/Residential & 107.4 & 76.8 & 18.6 & 7.6 & 21.5 \\
\hline Industrial Fuel & 786.2 & 263.6 & 195.8 & 192.4 & 194.4 \\
\hline Industrial Processes & 1673.0 & 409.1 & 444.4 & 411.6 & 405.5 \\
\hline Miscellaneous & 16.3 & 4.1 & 4.3 & 4.1 & 4.0 \\
\hline Transportation & 367.2 & 85.7 & 91.6 & 100.0 & 94.5 \\
\hline Total & 5270.5 & 1922.7 & 1308.5 & 1335.0 & 1245.3 \\
\hline \multicolumn{6}{|l|}{ National } \\
\hline Electric Utility & 14542.5 & 3861.5 & 3433.1 & 3836.9 & 3405.2 \\
\hline Commercial/Residential & 523.3 & 274.9 & 108.9 & 42.9 & 96.5 \\
\hline Industrial Fuel & 2419.8 & 634.0 & 606.3 & 586.0 & 593.4 \\
\hline Industrial Processes & 2484.4 & 595.9 & 654.2 & 622.1 & 61.2 .2 \\
\hline Miscellaneous & 37.2 & 8.9 & 9.8 & 9.4 & 9.2 \\
\hline Transportation & 680.9 & 145.0 & 170.1 & 190.9 & 174.8 \\
\hline Total & 20688.1 & 5520.2 & 4982.5 & 5288.2 & 4891 . \\
\hline
\end{tabular}




\begin{tabular}{|c|c|c|c|c|c|}
\hline & $\begin{array}{r}\text { ANNUAL } \\
\text { JAN8 } 6 \\
\text {-DEC8 } 6\end{array}$ & $\begin{array}{r}\text { WINTER } \\
\text { DEC85 } \\
\text {-FEB8 } 6\end{array}$ & $\begin{array}{r}\text { SPRING } \\
\text { MAR8 } 6 \\
\text {-MAY } 86\end{array}$ & $\begin{array}{r}\text { SUMMER } \\
\text { JUN86 } \\
\text {-AUG8 } 6\end{array}$ & $\begin{array}{r}\text { FALL } \\
\text { SEP } 86 \\
\text {-NOV8 } 6\end{array}$ \\
\hline \multicolumn{6}{|l|}{ Northeast } \\
\hline Electric Utility & 8212.6 & 1880.2 & 1943.4 & 2184.5 & 1907.7 \\
\hline Commercial/Residential & 396.4 & 162.3 & 94.3 & 28.6 & 87.1 \\
\hline Industrial Fuel & 1320.4 & 315.1 & 344.7 & 307.0 & 311.8 \\
\hline Industrial Processes & 509.1 & 118.7 & 132.0 & 130.3 & 127.8 \\
\hline Miscellaneous & 16.5 & 3.6 & 4.1 & 4.1 & 4.1 \\
\hline Transportation & 206.2 & 38.4 & 50.8 & 63.2 & 53.0 \\
\hline Total & 10661.1 & 2518.2 & 2569.3 & 2717.7 & 2491.5 \\
\hline \multicolumn{6}{|l|}{ Southeast } \\
\hline Electric Utility & 3920.2 & 850.7 & 902.6 & 1130.5 & 935. \\
\hline Commercial/Restdential & 70.8 & 48.0 & 14.6 & 3.2 & 10.6 \\
\hline Industrial. Fuel & 419.2 & 95.2 & 109.4 & 97.6 & 99.0 \\
\hline Industrial Processes & 311.3 & 77.2 & 79.3 & 78.4 & 79. \\
\hline Miscellaneous & 4.4 & 1.2 & 1.3 & 1.1 & 1. \\
\hline Transportation & 106.8 & 19.6 & 27.1 & 29.8 & 27.3 \\
\hline Total & 4832.6 & 1091.8 & 1134.3 & .1340 .4 & 1152.7 \\
\hline \multicolumn{6}{|l|}{ West } \\
\hline Electric Utility & 2228.9 & 977.2 & 475.4 & 636.0 & 544 . \\
\hline Commercial/Residential & 97.9 & 69.4 & 20.3 & 6.0 & 20.8 \\
\hline Industrial Fuel & 800.9 & 269.1 & 203.6 & 191.2 & 196.7 \\
\hline Industrial Processes & 1575.9 & 389.2 & 404.5 & 376.3 & 403.3 \\
\hline Miscellaneous & 16.3 & 4.1 & 4.3 & 4.1 & 4.0 \\
\hline Transportation & 365.3 & 83.9 & 91.0 & 100.9 & 93.4 \\
\hline Total & 5085.1 & 1793.0 & 1199.1 & 1314.6 & 1262.9 \\
\hline \multicolumn{6}{|l|}{ National } \\
\hline Electric Utility & 14361.7 & 3708.2 & 3321.4 & 3951.0 & 3387.9 \\
\hline Commercial/Residential & 565.1 & 279.7 & 129.2 & 37.7 & 118.5 \\
\hline Industrial Fuel & 2540.4 & 679.4 & 657.7 & 595.8 & 607.5 \\
\hline Industrial processes & 2396.3 & 585.1 & 615.8 & 585.0 & 610.3 \\
\hline Miscellaneous & 37.2 & 8.9 & 9.8 & 9.4 & 9. \\
\hline Transportation & 678.2 & 141.9 & 168.9 & 193.8 & 173.7 \\
\hline Total & 20578.9 & 5403.0 & 4902.7 & 5372.7 & 4907.1 \\
\hline
\end{tabular}


Region

WINTER
DEC8 6

Northeast
Electrio Utility
Commercial/Residential
Industrial luel
Industrial Processes
Miscellaneous
Transportation
Total

Southeast

Electric Utility

Commerctal/Residential

Industrial Fuel

Industrial Processes

Miscellaneous

Transportation

Total

$$
\begin{array}{r}
8099.1 \\
393.6 \\
1260.9 \\
532.3 \\
16.5 \\
213.7
\end{array}
$$

10516.2
-EEB87

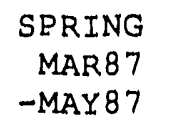

1714.7

161.3

289.4

122.8

3.6

40.0

2331.9

1903.3

92.8

303.7

131.7

4.1

52.7
73.4

401.4

326.0

115.8

2488.3
833.2
48.7
86.8
80.4
1.2
21.4
839.8
14.7
96.7
81.2
1.3
29.5

1071.7

1063.2

4767.1

and

Season

(kt)

Total

West

Electric Utility
Commercial/Residential
Industrial Fuel
Industrial Processes
Miscellaneous
Transportation

2279.3

119.3

789.7

1363.6

16.3

401.8

4970.0

1110.2
2.3
97.4
83.5
1.1

31.9
2229.7
25.9
305.4
138.8
4.1
64.9

2768.8

2500.2

954.4

14.5

101.9

83.6

1.0

29.6

1326.

1184.9
1025.0
80.0
266.4
335.6
4.1
93.6

$$
\begin{array}{r}
507.7 \\
24.8 \\
189.6 \\
334.0 \\
4.3 \\
100.0
\end{array}
$$

1804.

1160.5

667.7
7.4

7.4
94.1

348.1

4.1

110.1

542.0

24.9

200.4

343.3

4.0

102.9

1331.6

1217.5

$$
\begin{array}{r}
14224.6 \\
586.4 \\
2452.0 \\
2221.9 \\
37.2 \\
731.4 \\
20253.4
\end{array}
$$

$\begin{array}{rrrr}3572.9 & 3250.9 & 4007.7 & 3389.6 \\ 290.0 & 132.3 & 35.5 & 128.5 \\ 642.6 & 590.1 & 597.0 & 622.4 \\ 538.8 & 546.9 & 570.4 & 565.7 \\ 8.9 & 9.8 & 9.4 & 9.2 \\ 155.1 & 182.1 & 207.0 & 187.2 \\ 5208.3 & 4712.1 & 5426.8 & 4902.6\end{array}$




Northeast
Eleotric Utility
Commerclal/Residential
Industrial Fuel
Industrial Processes
Miscellaneols
Transportation
Total

Southeast

Electrio Utility

Commercial/Residential

Industrial Fuel.

Industrial Processes

Miscellaneous

Transportation

Total

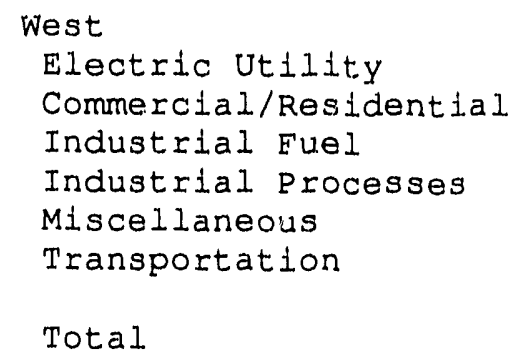

National

Electric Utility

Commercial/Residential

Industrial Fuel

Industrial processes

Miscellaneous

Transportation

Total

by Geographic

Region

and season

(kt)

ANNUAL
JAN88
-DEC8 8

8242.7

393.7

1357.2

566.4

16.5

213.7

10790.2

WINTER
DEC87
-FEB88

1809.9

157.9

312.6

131.3

3.6

40.0

2455.3

3963.0

71.4

433.4

361.6

4.4

113.3

4947.0

2324.3

116.5

871.6

1454.9

16.3

403.8

5187.4

14529.9

581.6

2662.2

2382.9

37.2

730.8

20.924 .6

21.1

1167.3

1078.7

78.1

289.5

352.5

4.1

93.9

1896.7

3796.7

282.2

702.8

573.7

8.9

155.0

5519.3
SPRING

MAR8 8

-MAY 88

SUMMER

JUN8 8

-AUG88

FALI

SEP 88

-NOV 88

1891.6

91.7

330.5

143.8

4.1

52.7

2239.9

28.6

322.6

147.0

4.1

64.9

1928.7

90.8

343.9

144.7

4.1

54.7

2514.4

2807.1

2567.0
866.9

14.0

105.5

90.8

1.3

28.8

1107.4

1121.6
2.5
103.1
91.8
1.1
31.2

1351.3

1185.1

501.3

24.3

211.7

371.7

4.3

100.5

1213.8

1385.1
3259.8
130.0
647.7
606.3
9.8
182.0

4040.8

39.0

636.0

611.7

9.4

206.7

4835.6
679.2

7.8

210.3

373.0

4.1

110.7

1385.1

564.2

25.0

221.9

354.9

4.0

103.4

1273.4

3432.0

130.4

675.7

591.2

9.2

187.1

$5543.5 \quad 5025.5$ 
B.6 VOC Emissions

by Geographic Reglon and Season 


\begin{tabular}{|c|c|c|c|c|c|}
\hline & $\begin{array}{r}\text { ANNUAL } \\
\text { JAN75 } \\
- \text { DEC75 }\end{array}$ & $\begin{array}{r}\text { WINTER } \\
\text { DEC74 } \\
\text {-FEB75 }\end{array}$ & $\begin{array}{r}\text { SPRING } \\
\text { MAR75 } \\
\text {-MAY75 }\end{array}$ & $\begin{array}{r}\text { SUMMER } \\
\text { JUN75 } \\
\text {-AUG75 }\end{array}$ & $\begin{array}{r}\text { EALL } \\
\text { SEP75 } \\
\text {-NOV75 }\end{array}$ \\
\hline \multicolumn{6}{|l|}{ Northeast } \\
\hline Eleotrlo Utility & 14.8 & $N / A$ & 3.4 & 4.1 & 3.1 \\
\hline Commerolal/Restdentdal & 324.1 & $N / A$ & 93.3 & 2.7 & 57.1 \\
\hline Industrlal Fuel & 48.2 & $N / A$ & 11.9 & 10.4 & 11.7 \\
\hline Industrial Processes & 2831.9 & $\mathrm{~N} / \mathrm{A}$ & 689.9 & 726.6 & 720.3 \\
\hline Miscellaneous & 1559.1 & $\mathrm{~N} / \mathrm{A}$ & 393.1 & 394.3 & 389.6 \\
\hline Transportation & 5526.1 & $\mathrm{~N} / \mathrm{A}$ & 1356.5 & 1917.7 & 1361.8 \\
\hline Total & 10304.2 & $\mathrm{~N} / \mathrm{A}$ & 2548.1 & 3055.8 & 2543.6 \\
\hline \multicolumn{6}{|l|}{ Southeast } \\
\hline Electric Utility & 5.8 & $N / A$ & 1.3 & 1.8 & 1.4 \\
\hline Commercial/Residential & 125.5 & $N / A$ & 29.2 & 0.2 & 21.1 \\
\hline Industrial Fuel & 17.9 & $N / A$ & 4.4 & 4.3 & 4.5 \\
\hline Industrial Processes & 1102.9 & $\mathrm{~N} / \mathrm{A}$ & 268.1 & 283.4 & 280.1 \\
\hline Miscellaneous & 910.5 & $\mathrm{~N} / \mathrm{A}$ & 252.1 & 229.6 & 216.9 \\
\hline Transportation & 2453.9 & $\mathrm{~N} / \mathrm{A}$ & 607.9 & 748.5 & 572.0 \\
\hline Total & 4616.4 & $N / A$ & 1163.0 & 1267.8 & 1096.0 \\
\hline \multicolumn{6}{|l|}{ West } \\
\hline Electric Utility & 9.5 & $\mathrm{~N} / \mathrm{A}$ & 2.0 & 2.8 & 2.3 \\
\hline Commercial/Residential & 158.7 & $N / A$ & 43.4 & 5.1 & 31.1 \\
\hline Industrial Fuel & 52.4 & $\mathrm{~N} / \mathrm{A}$ & 12.8 & 12.5 & 13.1 \\
\hline Industrial Processes & 2898.8 & $\mathrm{~N} / \mathrm{A}$ & 697.4 & 753.3 & 737.5 \\
\hline Miscelilaneous & 2083.7 & $\mathrm{~N} / \mathrm{A}$ & 550.3 & 535.9 & 519.3 \\
\hline Transportation & 4244.4 & $\mathrm{~N} / \mathrm{A}$ & 1032.5 & 1316.2 & 1037.7 \\
\hline Total & 9447.5 & $\mathrm{~N} / \mathrm{A}$ & 2338.4 & 2625.8 & $2341 \cdot 0$ \\
\hline \multicolumn{6}{|l|}{ National } \\
\hline Electric Utility & 30.1 & $\mathrm{~N} / \mathrm{A}$ & 6.8 & 8.7 & 6.8 \\
\hline Commercial/Residential & 608.3 & $\mathrm{~N} / \mathrm{A}$ & 165.9 & 8.0 & 1.09 .4 \\
\hline Industrial Fuel & 118.5 & $\mathrm{~N} / \mathrm{A}$ & 29.1 & 27.2 & 29.3 \\
\hline Industrial processes & 6833.6 & $\mathrm{~N} / \mathrm{A}$ & 1655.3 & 1763.3 & 1737.9 \\
\hline Miscellaneous & 4553.3 & $N / A$ & 1195.5 & 1159.8 & 1125.8 \\
\hline Transportation & 12224.3 & $\mathrm{~N} / \mathrm{A}$ & 2996.9 & 3982.4 & 2971.5 \\
\hline Total & 24368.1 & $\mathrm{~N} / \mathrm{A}$ & 6049.5 & 6949.4 & 5980.6 \\
\hline
\end{tabular}


1976 Sectoral VOC Emis

\begin{tabular}{|c|c|c|c|c|c|}
\hline & $\begin{array}{r}\text { ANNUAL } \\
\text { JAN7 } 6 \\
\text {-DEC76 }\end{array}$ & $\begin{array}{r}\text { WINTER } \\
\text { DEC75 } \\
\text {-EEB76 }\end{array}$ & $\begin{array}{r}\text { SRRING } \\
\text { MAR76 } \\
\text {-MAY76 }\end{array}$ & $\begin{array}{r}\text { SUMMER } \\
\text { JUN7 } 6 \\
- \text { AUG76 }\end{array}$ & $\begin{array}{r}\text { FALL } \\
\text { SER7 } 6 \\
\text {-NOV76 }\end{array}$ \\
\hline \multicolumn{6}{|l|}{ Northeast } \\
\hline $\begin{array}{l}\text { Electrio Utility } \\
\text { Commerolal/Restdential }\end{array}$ & $\begin{array}{r}15.2 \\
356.6\end{array}$ & $\begin{array}{r}4.0 \\
165.9\end{array}$ & $\begin{array}{r}3.5 \\
77.3\end{array}$ & $\begin{array}{l}3.7 \\
3.2\end{array}$ & $\begin{array}{r}3.6 \\
86.4\end{array}$ \\
\hline Industrial Fuel & 50.1 & 14.3 & 12.2 & 10.8 & 12.3 \\
\hline Industrlal Processes & 3053.9 & 674.2 & 758.2 & 777.6 & $770 . \varepsilon$ \\
\hline M1scellaneous & 1519.2 & 343.6 & 383.1 & 384.9 & 379.7 \\
\hline Transportation & 5459.4 & 778.1 & 1342.4 & 1877.7 & 1357.5 \\
\hline Total & 10454.4 & 1979.9 & 2576.6 & 3057.9 & 2610.1 \\
\hline \multicolumn{6}{|l|}{ Southeast } \\
\hline Electric Utility & 6.6 & 1.6 & 1.4 & 1.9 & 1.7 \\
\hline Commercial/Residential & 139.5 & 66.8 & 21.7 & 0.4 & 36.2 \\
\hline Industrial Fuel & 20.4 & 6.0 & 5.0 & 4.9 & 5.2 \\
\hline Industrial Processes & 1189.3 & 267.8 & 295.3 & 303.4 & 300.4 \\
\hline Miscellaneous & 888.0 & 185.6 & 246.3 & 224.3 & 211.6 \\
\hline Transportation & 2527.2 & 460.4 & 627,8 & 772.8 & 588.5 \\
\hline Total & 4770.9 & 988.2 & 1197.5 & 1307.6 & 1143.6 \\
\hline \multicolumn{6}{|l|}{ West } \\
\hline Electric utility & 10.2 & 2.9 & 2.2 & 3.0 & 2.5 \\
\hline Commercial/Residential & 177.8 & 126.0 & 44.1 & 6.3 & 39.7 \\
\hline Industrial Fuel & 60.9 & 15.9 & 14.9 & 14.6 & 15.2 \\
\hline Industrial Processes & 3064.9 & 846.0 & 757.8 & 787.1 & 769.8 \\
\hline Miscellaneous & 2145.0 & 533.8 & 546.8 & 560.5 & 552.1 \\
\hline Transportation & 4229.1 & 1041.7 & 1038.7 & 1304.4 & 1025.7 \\
\hline Total & 9688.0 & 2566.2 & 2404.5 & 2675.8 & 2405.0 \\
\hline \multicolumn{6}{|l|}{ National } \\
\hline Electric Utility & 31.9 & 8.4 & 7.0 & 8.6 & 7.8 \\
\hline Commerclal/Residential & 673.9 & 358.7 & 143.1 & 9.8 & 162.3 \\
\hline Industrial Fuel & 131.3 & 36.1 & 32.2 & 30.3 & 32.6 \\
\hline Industrial Processes & 7308.1 & 1788.0 & 1811.3 & 1868.1 & 1840.8 \\
\hline Miscellaneous & 4552.2 & 1062.9 & 1176.1 & 1169.7 & 1143.5 \\
\hline Transportation & 1.2215 .7 & 2280.2 & 3000.9 & 3954.8 & 2971.8 \\
\hline Total & 24913.3 & 5534.3 & 6178.6 & 7041.4 & 6158.8 \\
\hline
\end{tabular}




\section{mis}

\section{ANNUAL \\ JAN 77 \\ -DEC77}

Northeast

Electric Utility
Commercial/Resident

Industrial Fuel

Industrial Processes

Miscellaneolss

Transportation

Total

$$
\begin{array}{r}
15.5 \\
400.3 \\
54.6 \\
3155.7 \\
1524.8 \\
5364.4 \\
10515.4
\end{array}
$$

Southeast

Electric Utility
Commercial/Residential
Industrial Fuel
Industrial Processes
Miscellaneous
Transportation

Total

7.1
157.6
22.2
1239.5
894.6
2496.3

4817.3

WINTER
DEC76
-EEB77

and season (kt)

$\begin{array}{rrr}\text { SPRING } & \text { SUMMER } & \text { EALL } \\ \text { MAR77 } & \text { JUN77 } & \text { SEP77 } \\ \text {-MAY77 } & \text {-AUG77 } & \text {-NOV77 }\end{array}$

$\begin{array}{rrrr}4.2 & 3.4 & 4.1 & 3.4 \\ 217.5 & 76.7 & 5.6 & 75.9 \\ 15.6 & 13.3 & 12.0 & 13.3 \\ 694.5 & 789.0 & 804.1 & 794.2 \\ 343.9 & 384.6 & 386.5 & 381.4 \\ 750.6 & 1326.9 & 1852.3 & 1343.4 \\ 2026.3 & 2594.0 & 3064.7 & 2611.5\end{array}$

1.7

1.4

96.6

6.5

277.0

182.8

441.7

20.4

.5 .5

309.9

248.0

622.9

1006.2

1208.2

1318.4

1144.3

\section{West}

Electric Utility 12.3

Commercial/Residential 200.9

Industrial Fuel

65.2

Industrial processes

3188.7

2101.5

4221.9

Transportation

9790.5

Total

$\begin{array}{rrrr}3.3 & 2.7 & 3.7 & 2.9 \\ 147.6 & 48.3 & 4.3 & 40.1 \\ 16.9 & 16.0 & 15.7 & 16.2 \\ 875.9 & 794.1 & 818.3 & 798.8 \\ 530.7 & 545.6 & 545.0 & 532.6 \\ 1013.1 & 1036.6 & 1305.5 & 1035.4 \\ 2587.5 & 2443.3 & 2692.5 & 2426.1\end{array}$

$\begin{array}{rrrr}9.2 & 7.5 & 10.2 & 7.8 \\ 461.7 & 145.5 & 10.1 & 141.6 \\ 39.0 & 34.7 & 33.1 & 35.1 \\ 1847.4 & 1893.0 & 1939.2 & 1904.3 \\ 1057.4 & 1178.2 & 1157.8 & 1127.4 \\ 2205.3 & 2986.4 & 3925.1 & 2965.7 \\ 5620.1 & 6245.4 & 7075.5 & 6181.9\end{array}$




Northeast
Electric Utility
Commercial/Residential
Industrial Fuel
Industrial Processes
Miscellaneous
Transportation
Total

\section{ANNUAL \\ JAN 78 \\ -DEC78}

15.4

472.7

54.1

3434.0

1530.4

5265.3

10771.9
Southeast

Electric Utility

Commercial/Residential

Industrial Fuel

Industrial processes

Miscellaneous

Transportation

Total

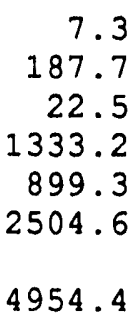

4954.4
Geographic

WINTER
DEC77
-EEB78

SPRING
MAR7 8

-MAY78

4.5

244.7

15.0

756.2

344.8

713.7

2079.

1.9
$112 \cdot 4$

. 6.4

297.8

183.5

440.9

1042.9

12.9

239.5

66.1

3385.7

2112.0

4236.2

1.0052 .4
35.5

899.9

142.6

8152.9

4541.7

12006.1
25778.7
3.5

164.0

17.1

933.9

533.0

1004.1

2655.4

2496.4
3.6

120.8

13.4

851.1

385.4

1287.7

2662.0

\footnotetext{
Total

National

Electric Utility

Commercial/Residential

Industrial Fuel

Industrial Processes

Miscellaneous

Transportation

Total
}

and season

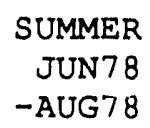

FALL SEP 78 -NOV78
3.3

84.7

13.1

870.4

384.7

1324.5

1845.2

$3126.3 \quad 2680.8$

$\begin{array}{rr}873.7 & 870.4 \\ 386.8 & 384.7 \\ 845.2 & 1324.5 \\ 126.3 & 2680.8\end{array}$


1979 Sectoral voc Emissions by Geographic Region and Season (kt)

\begin{tabular}{|c|c|c|c|c|c|}
\hline & $\begin{array}{r}\text { ANNUAL } \\
\text { JAN79 } \\
\text {-DEC79 }\end{array}$ & $\begin{array}{r}\text { WINTER } \\
\text { DEC78 } \\
\text {-FEB79 }\end{array}$ & $\begin{array}{r}\text { SPRING } \\
\text { MAR79 } \\
\text {-MAY79 }\end{array}$ & $\begin{array}{r}\text { SUMMER } \\
\text { JUN79 } \\
\text {-AUG79 }\end{array}$ & $\begin{array}{r}\text { FALL } \\
\text { SEP } 79 \\
- \text { NOV79 }\end{array}$ \\
\hline \multicolumn{6}{|l|}{ Northeast } \\
\hline Electric Utility & 14.9 & 4.1 & 3.4 & 3.7 & 3.4 \\
\hline Commercial/Residential & 570.3 & 298.5 & 135.5 & 7.3 & 103.7 \\
\hline Industrial Fuel & 43.3 & 12.3 & 10.8 & 9.7 & 10.2 \\
\hline Industrial Processes & 3390.7 & 755.8 & 850.4 & 856.4 & 848.3 \\
\hline Miscellaneous & 1554.6 & 351.3 & 392.2 & 393.2 & 388.9 \\
\hline Transportation & 4885.2 & 705.8 & 1229.9 & 1666.7 & 1198.4 \\
\hline Total & 10459.0 & 2127.9 & 2622.3 & 2937.1 & 2552.8 \\
\hline \multicolumn{6}{|l|}{ Southeast } \\
\hline Electric Utility & 6.4 & 1.6 & 1.5 & 2.0 & 1.4 \\
\hline Commercial/Residential & 228.8 & 129.0 & 39.2 & 0.6 & 37.6 \\
\hline Industrial Fuel & 22.8 & 6.1 & $\because .7$ & 5.6 & 5.7 \\
\hline Industrial Processes & 1322.1 & 298.3 & 331.1 & 334.6 & 331.4 \\
\hline Miscellaneous & 908.7 & 187.9 & 251.6 & 229.4 & 217.0 \\
\hline Transportation & 2352.1 & 439.6 & 593.1 & 708.4 & 545.0 \\
\hline Total & 4840.9 & 1062.4 & 1222.3 & 1280.6 & 1138.0 \\
\hline \multicolumn{6}{|l|}{ West } \\
\hline Electric Utility & 13.5 & 3.9 & 2.6 & 3.7 & 3.4 \\
\hline Commercial/Residential & 292.1 & 210.1 & 66.3 & 7.0 & 56.5 \\
\hline Industrial Fuel & 63.5 & 16.6 & 15.6 & 15.3 & 15.7 \\
\hline Industrial Processes & 3326.6 & 932.8 & 828.6 & 839.8 & 831.7 \\
\hline Miscellaneous & 2180.2 & 548.4 & 560.7 & 566.1 & 556.7 \\
\hline Transportation & 3959.9 & 977.8 & 981.6 & 1184.0 & 966.8 \\
\hline Total & 9835.7 & 2689.8 & 2455.5 & 2615.8 & 2430.7 \\
\hline \multicolumn{6}{|l|}{ National } \\
\hline Electrir Utility & 34.9 & 9.6 & 7.5 & 9.4 & 8.1 \\
\hline Commercial/Residential & 1091.3 & 637.6 & 241.1 & 14.9 & 197.7 \\
\hline Industrial Fuel & 129.6 & 35.1 & 32.2 & 30.6 & 31.5 \\
\hline Industrial Processes & 8039.3 & 1986.9 & 2010.1 & 2030.8 & 2011.5 \\
\hline Miscellaneous & 4643.4 & 1087.7 & 1204.6 & 1188.7 & 1162.5 \\
\hline Transportation & 111.97 .1 & 2123.2 & 2804.6 & 3559.2 & 2710.2 \\
\hline Total & 25135.6 & 5880.1 & 6300.1 & 6833.5 & 6121.5 \\
\hline
\end{tabular}




\begin{tabular}{|c|c|c|c|c|c|}
\hline & $\begin{array}{r}\text { ANNUAL } \\
\text { JAN8 } 0 \\
- \text { DEC8 } 0\end{array}$ & $\begin{array}{r}\text { WINTER } \\
\text { DEC79 } \\
\text {-EEB80 }\end{array}$ & $\begin{array}{r}\text { SPRING } \\
\text { MAR80 } \\
\text {-MAY80 }\end{array}$ & $\begin{array}{r}\text { SUMMER } \\
\text { JUN8 } 0 \\
\text {-AUG8 } 0\end{array}$ & $\begin{array}{r}\text { FAL, } \\
\text { SEP } 80 \\
\text {-NOV80 }\end{array}$ \\
\hline \multicolumn{6}{|l|}{ Northeast } \\
\hline Electric Utility & 14.2 & 3.7 & 3.1 & 3.8 & 3.2 \\
\hline Commercial/Residential & 658.4 & 315.8 & 162.1 & 7.7 & 134.6 \\
\hline Industrial Fuel & 33.4 & 9.8 & 8.4 & 7.3 & 8.1 \\
\hline Industrial Processes & 3160.3 & 723.0 & 787.1 & 781.9 & 793.3 \\
\hline Miscellaneous & 1460.2 & 333.1 & 369.3 & 367.3 & 363.8 \\
\hline Transportation & 4560.0 & 668.5 & 1096.1 & 1577.1 & 1140.5 \\
\hline Total & 9886.6 & 2053.9 & 2426.1 & 2745.3 & 2443.4 \\
\hline \multicolumn{6}{|l|}{ Southeast } \\
\hline Electric Utility & 6.7 & 1.4 & 1.4 & 2.2 & 1.5 \\
\hline Commercial/Residential & 264.9 & 137.7 & 54.0 & 0.4 & 49.6 \\
\hline Industrial Fuel & 20.8 & 5.3 & 5.2 & 5.0 & 5.2 \\
\hline Industrial Processes & 1229.5 & 284.0 & 306.5 & 306.3 & 308.8 \\
\hline Miscellaneous & 863.5 & 182.0 & 240.7 & 216.7 & 204.8 \\
\hline Transportation & 2211.1 & 420.1 & 540.4 & 671.6 & 524.9 \\
\hline Total & 4596.5 & 1030.5 & 1148.3 & 1202.2 & 1094.8 \\
\hline \multicolumn{6}{|l|}{ West } \\
\hline Electric Utility & 13.1 & 3.6 & 2.9 & 3.8 & 3.1 \\
\hline Commercial/Residential & 335.1 & 231.0 & 87.2 & 11.5 & 66.7 \\
\hline Industrial Fuel & 51.7 & 13.7 & 12.8 & 12.4 & 12.9 \\
\hline Industrial Processes & 3136.8 & 898.0 & 782.4 & 778.7 & 776.8 \\
\hline Miscellaneous & 2117.9 & 527.4 & 540.9 & 551.3 & 544.2 \\
\hline Transportation & 3734.0 & 908.9 & 905.9 & 1134.8 & 916.4 \\
\hline Total & 9388.5 & 2582.6 & 2332.1 & 2492.4 & 2320.1 \\
\hline \multicolumn{6}{|l|}{ National } \\
\hline Electric: Utility & 33.9 & 8.8 & 7.4 & 9.8 & 7.8 \\
\hline Commercial/Residential & 1258.4 & 684.5 & 303.2 & 19.6 & 250.9 \\
\hline Industrial Fuel & 106.0 & 28.8 & 26.4 & 24.7 & 26.1 \\
\hline Industrial Processes & 7526.7 & 1905.0 & 1876.0 & 1866.9 & 1878.9 \\
\hline Miscellaneous & 4441.6 & 1042.5 & 1150.9 & 1135.4 & 1112.9 \\
\hline Transportation & 10505.1 & 1997.4 & 2542.5 & 3383.5 & 2581.7 \\
\hline Total & 23871.7 & 5667.0 & 5906.5 & 6439.8 & 5858.4 \\
\hline
\end{tabular}




\section{1 sectoral voc}

Eimt s by

Northeast

Electric Utility

Commercial/Residential

Industrial Fuel

Industrial processes

Miscellaneous

Transportation

Total

Southeast

Electric Utility

Commercial/Residential

Industrial Fuel.

Industrial processes

Miscellaneous

Transportation

Total

West

Electric Utility

Commercial/Residential

Industrial Fuel

Industrial Processes

Miscellaneous

Transportation

Total

National

Electric Utility

Commercial/Residential

Industrial Fuel

Industrial Processes

Miscellaneous

Transportation

Total
ANNUAL

JAN81

-DEC81
12.9

710.0

32.8

2748.1

1265.4

4343.9

9113.1
Geographic

WINTER
DEC80
-EEB81

Region

SPRING

3.4

347.1

9.5

621.4

289.0

652.4

1922.8

1.5

150.8

5.0

250.3

158.7

395.7

962.0

4264.6

13.1

361.2

53.0

2888.1

1841.8

3619.4

8776.6

32.5

1356.8

107.0

6744.3

3866.5

10047.2

22154.3
3.3

260.9

13.9

801.2

453.2

$864 . .8$

2397.3
320.8
MAR81

-MAY 81
1.4

53.2

5.3

276.4

214.9

495.8

1047.0 and Season

(kt)

$$
\begin{array}{r}
\text { SUMMER } \\
\text { JUN81 } \\
\text {-AUG81 }
\end{array}
$$

FALL SEP 81

-NOV 81

$$
\begin{array}{r}
3.2 \\
168.9 \\
8.2
\end{array}
$$

683.7

1002.9

2187.8

\section{5}

6.5

7.5

700.5

319.2

1512.4

2549.6

2267.1

$\begin{array}{rr}2.0 & 1.5 \\ 0.1 & 50.0 \\ 5.3 & 5.3 \\ 283.0 & 276.6 \\ 191.0 & 178.3 \\ 646.8 & 493.5 \\ 128.1 & 1005.2\end{array}$

2.8

86.6

13.1

714.9

477.1

860.1

1128.1

1005.2
3.3

75.2

13.1

718.1

$\begin{array}{rr}480.0 & 469.9 \\ 1125.8 & 887.4\end{array}$

480.0
1125.8

$2365.4 \quad 2167.0$

$\begin{array}{rrrr}8.2 & 7.4 & 9.3 & 7.5 \\ 758.8 & 308.7 & 16.1 & 273.0 \\ 28.4 & 26.6 & 25.8 & 26.2 \\ 1672.9 & 1675.1 & 1716.9 & 1679.5 \\ 900.9 & 1012.7 & 990.2 & 962.7 \\ 1912.9 & 2358.8 & 3285.0 & 2490.4 \\ 5282.1 & 5389.4 & 6043.2 & 5439.3\end{array}$

7.5

73.0

26.2

62.7

490.4

$5282.1 \quad 5389.4 \quad 6043.2 .5439 .3$ 


\section{Sectoral VoC Emis}

\begin{tabular}{|c|c|c|c|c|c|}
\hline & $\begin{array}{r}\text { ANNUAL } \\
\text { JAN82 } \\
- \text {-DEC82 }\end{array}$ & $\begin{array}{r}\text { WINTER } \\
\text { DEC81 } \\
\text {-FEB82 }\end{array}$ & $\begin{array}{r}\text { SPRING } \\
\text { MAR82 } \\
\text {-MAY } 82\end{array}$ & $\begin{array}{r}\text { SUMMER } \\
\text { JUN82 } \\
\text {-AUG82 }\end{array}$ & $\begin{array}{r}\text { FALI } \\
\text { SEP } 82 \\
\text {-NOV82 }\end{array}$ \\
\hline \multicolumn{6}{|l|}{ Northeast } \\
\hline Electric Utility & 11.3 & 3.2 & 2.7 & 2.8 & 2.5 \\
\hline Commercial/Residential & 776.3 & 393.2 & 199.9 & 15.0 & 141.2 \\
\hline Industrial Fuel & 32.9 & 9.7 & 8.4 & 7.5 & 7.8 \\
\hline Industrial Processes & 2452.6 & 535.2 & 614.8 & 628.9 & 619.2 \\
\hline Miscellaneous & 1195.3 & 271.6 & 302.1 & 302.3 & 298.9 \\
\hline Transportation & 4100,4 & 522.6 & 1011.7 & 1470.5 & 1029.3 \\
\hline Total & 8568.9 & 1735.5 & 2139.6 & 2427.0 & 2098.8 \\
\hline \multicolumn{6}{|l|}{ Southeast } \\
\hline Electric Utility & 5.4 & 1.4 & 1.2 & 1.6 & 1.2 \\
\hline Commercial/Residential & 313.1 & 172.5 & 61.8 & 0.7 & 54.5 \\
\hline Industrial Fuel & 21.0 & 5.1 & 5.3 & 5.1 & 5.1 \\
\hline Industrial Processes & 992.0 & 221.5 & 248.1 & 253.8 & 249.5 \\
\hline Miscellaneous & 725.3 & 146.9 & 205.6 & 183.0 & 171.2 \\
\hline Transportation & 1998.7 & 345.1 & 490.6 & 633.2 & 473.5 \\
\hline Total & 4055.5 & 892.5 & 1012.6 & 1077.4 & 955.1 \\
\hline \multicolumn{6}{|l|}{ West } \\
\hline Electric Utility & 11.8 & 3.0 & 2.6 & 3.3 & 2.8 \\
\hline Commercial/Residential & 395.9 & 257.7 & 96.1 & 10.6 & 82.0 \\
\hline Industrial Fuel & 52.0 & 13.5 & 12.9 & 12.6 & 12.7 \\
\hline Industrial Processes & 2651.0 & 711.2 & 661.8 & 687.6 & 664.3 \\
\hline Miscellaneous & 1714.5 & 423.9 & 453.2 & 444.6 & 431.9 \\
\hline Transportation & 3472.5 & 779.3 & 862.5 & 1114.9 & 838.4 \\
\hline Total & 8297.8 & 2188.7 & 2089.1 & 2273.6 & 2032.2 \\
\hline \multicolumn{6}{|l|}{ National } \\
\hline Electric Utility & 28.6 & 7.6 & 6.6 & 7.7 & 6.5 \\
\hline Commercial/Residential & 1485.3 & 823.5 & 357.8 & 26.3 & 277.7 \\
\hline Industrial Euel & 105.9 & 28.3 & 26.7 & 25.2 & 25.6 \\
\hline Industrial Processes & 6095.7 & 1467.8 & 1524.6 & 1570.3 & 1533.0 \\
\hline Miscellaneous & 3635.1 & 842.5 & 960.8 & 929.9 & 901.9 \\
\hline Transportation & 9571.6 & 1647.0 & 2364.7 & 3218.6 & 2341.2 \\
\hline Total & 20922.2 & 4816.6 & 5241.3 & 5778.0 & 508.1 \\
\hline
\end{tabular}


mis
Geographic

WINTER
DEC82
-FEB83

Northeast

Electric Utility

Commercial/Residential

Industrial Euel

Industrial processes

Miscellaneous

Transportation

Total

Southeast

Electric Utility

Commercial/Residential

Industrial Fuel

Industrial processes

Miscellaneous

Transportation

Total

West

Electric Utility 11.9

Commercial/Residential $\quad 397.6$

Industrial Euel

Industrial processes

Miscellaneous

Transportation

Total

\section{National}

Electric Utility 29.4

Commercial/Residential 1491.6

Industrial Fuel

Industrial processes

Miscellaneous

Transportation

Total
98.6

6373.7

3929.0

9203.4

50.7

2696.5

1897.7

3355.8

8410.3

21125.7

Region

and

(kt)

2.9

377.0

8.2

557.2

286.5

471.5

1703.2

SPRING
MAR8 3
-MAY 83

SUMMER

JUN83

-AUG83

2.6

205.8

6.6

652.3

319.9

947.8

2135.0

2477.2

3.4

5.2

6.1

681.1

320.6

1460.9

2108.6
1.2

160.4

4. 6

231.1

161.3

327.8

886.3

3.3

291.0

13.1

716.8

455.5

741.2

2221.0

1. 2

70.5

5.1

263.5

216.1

480.0

1036.4

1. 7

0.6

5.2

273.7

194.8

618.9

1094.8

960.2

1. 4

49.6

5.5

269.8

181.6

452.3

2.6

101.7

12.3

670.3

480.6

830.1

3.4

11.8

12.4

706.7

501.6

1088.3

2097.6

2324.3

2080.7
FALL

-NOV83

2.9

142.7

6.6

666.0

315.7

974.6
7.4

828.3

25.9

1505.2

903.3

1540.5

4810.6
6.3

378.0

24.1

1586.1

1016.5

2258.0

5269.0
2.9

75.0

12.9

685.2

494.8

809.9

$$
\begin{array}{rr}
8.5 & 7.2 \\
17.6 & 267.4 \\
23.7 & 25.0 \\
1661.5 & 1620.9 \\
1017.0 & 992.2 \\
3168.1 & 2236.9 \\
5896.3 & 5149.5
\end{array}
$$


1984 Sectoral Voc Emissions by Geographic

Region

and

ANNUAL
JAN84
$-D E C 84$

WINTER
DEC83
-FEB84

SPRING
MAR84
-MAY84

SUMMER
JUN84
-AUG84

(kt)

Northeast

Electric Utility

12.2

799.1

26.2

Industrial Fuel

3001.1

Industrial Processes

Miscellaneous

1394.7

3644.8

8878.2
3.0
373.4
8.2
654.6
315.9
453.0

FALI

SEP 84

-NOV 84

Total

1808.0

2.7
239.0

3.5

5.8

5.9

6.7

751.6

763.0

353.8

871.9

1347.3

2.8

151.9

6.2

757.8

348.0

918.7

Southeast

Electric Utility

Commercial/Residential

5.5

322.9

Industrial Fuel

21.2

Industrial Processes

1182.4

837.8

Transportation

1830.0

Total

4199.7

1.2

172.0

4.7

2223.1

2479.2

2185.4

261.7

172.4

309.2

1.3
77.4

1.5

0.2

1.3

5.3

57.5

295.5

300.8

213.2

5.3

2.33 .3

584.0

199.0

921.

453.1

431.1

1065.8

1105.1

992.9

\author{
West \\ Electric Utility \\ Commerctal/Residential \\ Industrial Fuel \\ Industrial Processes \\ Miscellaneous \\ Transportation \\ Tota.l
National
Electric Utility
Industrial Fuel
Miscellaneous
Transportation
Total

12.6

408.2

51.7

2904.4

2008.2

3204.0

8589.2

3.3
252.7
13.3
806.5
497.6

2.8

100.7

12.8

729.5

516.9

727.0

794.1

2300.5

2156.7

3.7
11.0
12.6

3.1

88.8

12.8

741.6

726.6

513.2

525.5

30.4

1530.2

99.2

7087.8

4240.7

8678.8

21667.1

$$
\begin{array}{r}
7.5 \\
798.1 \\
26.2 \\
1722.9 \\
985.9 \\
1489.2 \\
5029.8
\end{array}
$$

769.6

1020.7

2315.0

2114.1 
1985 Sectoral VOC Emissions by Geographic Region and Season (kt)

\begin{tabular}{|c|c|c|c|c|c|}
\hline & $\begin{array}{r}\text { ANNUAL } \\
\text { JAN85 } \\
\text {-DEC85 }\end{array}$ & $\begin{array}{r}\text { WINTER } \\
\text { DEC8 } 4 \\
\text {-FEB85 }\end{array}$ & $\begin{array}{r}\text { SPRING } \\
\text { MAR8 } 5 \\
\text {-MAY85 }\end{array}$ & $\begin{array}{r}\text { SUMMER } \\
\text { JUN8 } 5 \\
\text {-AUG85 }\end{array}$ & $\begin{array}{r}\text { FALL } \\
\text { SEP } 85 \\
\text {-NOV85 }\end{array}$ \\
\hline \multicolumn{6}{|l|}{ Northeast } \\
\hline Electric Utility & 11.8 & 3.1 & 2.7 & 3.0 & 2.8 \\
\hline Commercial/Residential & 704.1 & 375.4 & 149.5 & 11.9 & 120.8 \\
\hline Industrial Fuel & 25.9 & 8.0 & 6.6 & 5.8 & 6.1 \\
\hline Industrial Processes & 2920.3 & 637.3 & 726.0 & 750.5 & 736.1 \\
\hline Miscellaneous & 1204.3 & 271.8 & 305.4 & 306.6 & 300.0 \\
\hline Transportation & 3458.7 & 426.3 & 840.5 & 1281.8 & 859.6 \\
\hline Total & 8325.1 & 1721.9 & 2030.7 & 2359.7 & 2025.4 \\
\hline \multicolumn{6}{|l|}{ Southeast } \\
\hline Electric Utility & 5.9 & 1.4 & 1.4 & 1.7 & 1.3 \\
\hline Commercial/Residential & 284.0 & 175.5 & 44.1 & 0.4 & 26.9 \\
\hline Industrial Tuel & 21.0 & 4.8 & 5.3 & 5.2 & 5.2 \\
\hline Industrial Processes & 1146.0 & 253.6 & 285.7 & 293.7 & 289.0 \\
\hline Miscellaneous & 732.2 & 147.4 & 208.0 & 186.4 & 172.0 \\
\hline Transportation & 1725.6 & 282.7 & 432.2 & 558.8 & 401.3 \\
\hline Total & 3914.8 & 865.3 & 976.6 & 1046.1 & 895.7 \\
\hline \multicolumn{6}{|l|}{ West } \\
\hline Electric utility & 13.2 & 3.6 & 2.9 & 3.8 & 3.1 \\
\hline Commercial/Residential & 359.9 & 284.7 & 73.1 & 7.2 & 78.7 \\
\hline Industrial Fuel & 51.7 & 13.5 & 12.8 & 1.2 .6 & 12.8 \\
\hline Industrial Processes & 2809.5 & 774.4 & 701.9 & 722.8 & 704.8 \\
\hline Miscellaneous & 1729.7 & 424.8 & 458.2 & 451.4 & 434.2 \\
\hline Transportation & 3009.0 & 677.1 & 759.4 & 954.2 & 719.4 \\
\hline Total & 7972.9 & 2178.1 & 2008.2 & 2152.0 & 1953.0 \\
\hline \multicolumn{6}{|l|}{ National } \\
\hline Electric Utility & 30.9 & 8.1 & 7.0 & 8.4 & 7.2 \\
\hline Commercial/Residential & 1347.9 & 835.6 & 266.7 & 19.4 & 226.3 \\
\hline Industrial Fuel & 98.6 & 26.3 & 24.6 & 23.6 & 24.1 \\
\hline Industrial Processes & 6875.8 & 1665.3 & 1713.6 & 1767.1 & 1729.9 \\
\hline Miscellaneous & 3666.2 & 844.0 & 971.6 & 944.4 & 906.2 \\
\hline Transportation & 8193.3 & 1386.1 & 2032.1 & 2794.8 & 193 \\
\hline Total & 20212.8 & 4765.3 & 5015.5 & 5557.8 & 4874.1 \\
\hline
\end{tabular}


1986 Sectoral VUC Emiss

\begin{tabular}{|c|c|c|c|c|c|}
\hline & $\begin{array}{r}\text { ANNUAL } \\
\text { JAN8 } 6 \\
- \text { DEC86 }\end{array}$ & $\begin{array}{r}\text { WINTER } \\
\text { DEC85 } \\
\text {-FEB86 }\end{array}$ & $\begin{array}{r}\text { SPRING } \\
\text { MAR8 } 6 \\
\text {-MAY } 86\end{array}$ & $\begin{array}{r}\text { SUMMER } \\
\text { JUN8 } 6 \\
\text {-AUG8 } 6\end{array}$ & $\begin{array}{r}\text { FALL } \\
\text { SEP } 86 \\
\text {-NOV8 } 6\end{array}$ \\
\hline \multicolumn{6}{|l|}{ Northeast } \\
\hline Electric Utility & 12.2 & 3.0 & 2.8 & 3.4 & 2.8 \\
\hline Commercial/Residential & 704.8 & 351.9 & 162.4 & 9.7 & 146.9 \\
\hline Industrial Fuel & 26.0 & 8.1 & 6.7 & 5.8 & 6.2 \\
\hline Industrial Processes & 2719.0 & 597.6 & 672.5 & 698.7 & 689.0 \\
\hline Miscellaneous & 1204.2 & 271.2 & 305.3 & 307.0 & 300.0 \\
\hline Transportation & 3312.6 & 404.4 & 807.0 & 1217.4 & 831.8 \\
\hline Total & 7978.9 & 1636.2 & 1956.8 & 2241.9 & 1976.5 \\
\hline \multirow{2}{*}{\multicolumn{6}{|c|}{ Southeast }} \\
\hline & & & & & \\
\hline $\begin{array}{l}\text { Electric Utility } \\
\text { Commercial/Residential }\end{array}$ & 6.3 & 1.3 & 1.5 & 1.9 & 1.5 \\
\hline & 284.1 & 150.2 & 55.8 & 0.1 & 43.0 \\
\hline Industrial Fuel & 21.0 & 4.8 & 5.3 & 5.1 & 5.2 \\
\hline Industrial Processes & 1100.2 & 243.3 & 272.6 & 280.9 & 278.4 \\
\hline Miscellaneous & 737.2 & 147.6 & 209.2 & 188.5 & 173.4 \\
\hline Transportation & 1626.7 & 268.5 & 404.1 & 525.0 & 381.6 \\
\hline Total & 3775.6 & 815.7 & 948.4 & 1001.5 & 883.1 \\
\hline \multicolumn{6}{|l|}{ West } \\
\hline Electric Utility & 12.4 & 3.3 & 2.6 & 3.6 & 3.1 \\
\hline Commercial/Residential & 359.0 & 256.6 & 80.5 & 8.2 & 82.5 \\
\hline Industrial Fuel & 51.1 & 13.3 & 12.6 & 12.4 & 12.7 \\
\hline Industrial Processes & 2705.1 & 742.1 & 667.1 & 697.5 & 684.7 \\
\hline Miscellaneous & 1730.2 & 424.5 & 458.3 & 452.2 & 434.4 \\
\hline Transportation & 2822.2 & 650.3 & 703.0 & 888.6 & 679.9 \\
\hline Total & 7680.0 & 2090.1 & 1924.1 & 2062.6 & 1897.2 \\
\hline \multicolumn{6}{|l|}{ National } \\
\hline Electric Utility & 30.9 & 7.7 & 6.8 & 8.9 & 7.4 \\
\hline Commercial/Residential & 1347.9 & 758.7 & 298.8 & 18.1 & 272.4 \\
\hline Industrial Fuel & 98.1 & 26.2 & 24.5 & 23.3 & 24.0 \\
\hline Industrial Processes & 6524.3 & 1583.0 & 1612.2 & 1677.1 & 1652.0 \\
\hline Miscellaneous & 3671.6 & 843.3 & 972.9 & 947.6 & 907.8 \\
\hline Transportation & 7761.6 & 1323.2 & 1914.1 & 2631.0 & 1893.3 \\
\hline Total & 19434.4 & 4542.1 & 4829.3 & 5306.1 & 4756.8 \\
\hline
\end{tabular}




\section{voc}

Emissions b

by Geographic

Region

and

seagon (kt)

\begin{tabular}{|c|c|c|c|c|c|}
\hline & $\begin{array}{r}\text { ANNUAL } \\
\text { JAN87 } \\
\text {-DEC87 }\end{array}$ & $\begin{array}{r}\text { WINTER } \\
\text { DEC86 } \\
\text {-FEB87 }\end{array}$ & $\begin{array}{r}\text { SERING } \\
\text { MAR87 } \\
\text {-MAY } 87\end{array}$ & $\begin{array}{r}\text { SUMMER } \\
\text { JUN8 } 7 \\
\text {-AUG } 87\end{array}$ & $\begin{array}{r}\text { EALL } \\
\text { SEP } 87 \\
\text {-NOV87 }\end{array}$ \\
\hline \multicolumn{6}{|l|}{ Northeast } \\
\hline Electric Utility & 12.8 & 2.8 & 2.9 & 3.8 & 2.9 \\
\hline Commercial/Residential & 705.1 & 349.2 & 166.1 & 5.1 & 153.6 \\
\hline Industrial Fuel & 25.2 & 8.0 & 6.2 & 5.6 & 6.2 \\
\hline Industrial Processes & 2785.7 & 611.7 & 691.0 & 714.6 & 704.2 \\
\hline Miscellaneous & 1210.8 & 272.5 & 306.1 & 309.2 & 302.6 \\
\hline Transportation & 3119.4 & 388.9 & 763.6 & 1134.9 & 781.9 \\
\hline Total & 7858.9 & 1633.2 & 1935.8 & 2173.2 & 1951.4 \\
\hline \multicolumn{6}{|l|}{ Southeast } \\
\hline Electric Utility & 6.1 & 1.3 & 1.3 & 1.9 & 1.5 \\
\hline Commercial/Residential & 284.0 & 148.0 & 57.5 & 0.1 & 55.6 \\
\hline Industrial Fuel & 20.7 & 4.5 & 5.1 & 5.1 & 5.3 \\
\hline Industrial Processes & 1142.2 & 251.4 & 284.3 & 291.6 & 288.4 \\
\hline Miscellaneous & 741.8 & 151.4 & 209.5 & 189.9 & 175.4 \\
\hline Transportation & 1572.0 & 259.8 & 393.2 & 5113.6 & 367.6 \\
\hline Total & 3766.8 & 816.6 & 950.9 & $99 \hat{2} .3$ & 893.9 \\
\hline \multicolumn{6}{|l|}{ West } \\
\hline Electric Utility & 13.3 & 3.5 & 2.9 & 3.9 & 3.2 \\
\hline Commercial/Residential & 358.8 & 250.5 & 80.5 & 9.1 & 72.5 \\
\hline Industrial Fuel & 52.1 & 13.7 & 12.4 & 12.8 & 13.0 \\
\hline Industrial Processes & 2763.8 & 760.8 & 684.4 & 712.7 & 696.6 \\
\hline Miscellaneous & 1777.8 & 429.3 & 459.7 & 468.5 & 456.1 \\
\hline Transportation & 2706.1 & 626.8 & 672.5 & 846.3 & 658.4 \\
\hline Total & 7671.9 & 2084.7 & 1912.4 & 2053.4 & 1899.8 \\
\hline \multicolumn{6}{|l|}{ National } \\
\hline Electric Utility & 32.2 & 7.7 & 7.1 & 9.6 & 7.6 \\
\hline Commercial/Residential & 1347.9 & 747.7 & 304.1 & 14.3 & 281.7 \\
\hline Industrial Fuel & 98.1 & 26.3 & 23.7 & 23.6 & 24.5 \\
\hline Industrial Processes & 6691.7 & 1623.9 & 1659.6 & 1718.9 & 1689.2 \\
\hline Miscellaneous & 3730.3 & 853.2 & 975.2 & 967.6 & 934.2 \\
\hline Transportation & 7397.5 & 1275.5 & 1829.2 & 2484.8 & 1808.0 \\
\hline Total & 19297.6 & 4534.4 & 4799.1 & 5218.9 & 4745.1 \\
\hline
\end{tabular}


1988 Sectoral VOC Emissions by Geographlc

Region

and Season

(kt)

\begin{tabular}{|c|c|c|c|c|c|}
\hline & $\begin{array}{r}\text { ANNUAI } \\
\text { JAN8 } 8 \\
- \text {-DEC } 88\end{array}$ & $\begin{array}{r}\text { WINTER } \\
\text { DEC87 } \\
- \text { FEB88 }\end{array}$ & $\begin{array}{r}\text { SPRING } \\
\text { MAR8 } 8 \\
\text {-MAY8 } 8\end{array}$ & $\begin{array}{r}\text { SUMMER } \\
\text { JUN8 } 8 \\
\text {-AUG8 } 8\end{array}$ & $\begin{array}{r}\text { FALL } \\
\text { SEP } 88 \\
\text {-NOV8 } 8\end{array}$ \\
\hline $\begin{array}{l}\text { Northeast } \\
\text { Electric Utility } \\
\text { Commarcial/Residential } \\
\text { Inductrial Fuel } \\
\text { Industrial Processes } \\
\text { Miscellaneous } \\
\text { Transportation }\end{array}$ & $\begin{array}{r}13.7 \\
705.9 \\
30.1 \\
2685.8 \\
1212.4 \\
2889.5\end{array}$ & $\begin{array}{r}3.2 \\
349.7 \\
9.1 \\
600.0 \\
273.4 \\
359.7\end{array}$ & $\begin{array}{r}2.8 \\
166.3 \\
7.4 \\
664.2 \\
306.8 \\
708.3\end{array}$ & $\begin{array}{r}4.1 \\
5.1 \\
6.8 \\
683.8 \\
309.2 \\
1049.5\end{array}$ & $\begin{array}{r}3.0 \\
153.8 \\
7.5 \\
677.7 \\
302.6 \\
725.7\end{array}$ \\
\hline Total & 7537.4 & 1595.1 & 1855.8 & 2058.5 & 1870.1 \\
\hline $\begin{array}{l}\text { Southeast } \\
\text { Electric Utility } \\
\text { Commercial/Residential } \\
\text { Industrial Fuel } \\
\text { Industrial Processes } \\
\text { Miscellaneous } \\
\text { Transportation }\end{array}$ & $\begin{array}{r}6.5 \\
284.1 \\
22.8 \\
1095.6 \\
743.1 \\
1457.8\end{array}$ & $\begin{array}{r}1.6 \\
148.2 \\
5.0 \\
243.6 \\
152.1 \\
241.1\end{array}$ & $\begin{array}{r}1.3 \\
57.6 \\
5.6 \\
271.9 \\
210.1 \\
364.9\end{array}$ & $\begin{array}{r}2.0 \\
0.1 \\
5.6 \\
277.1 \\
190.0 \\
466.3\end{array}$ & $\begin{array}{r}1.5 \\
55.6 \\
5.8 \\
277.8 \\
175.4 \\
341.1\end{array}$ \\
\hline Total & 3609.8 & 791.6 & 911.4 & 941.0 & 857.3 \\
\hline $\begin{array}{l}\text { West } \\
\text { Electric Utility } \\
\text { Commercial/Residential } \\
\text { Industrial Fuel } \\
\text { Industrial Processes } \\
\text { Miscellaneous } \\
\text { Transportation }\end{array}$ & $\begin{array}{r}14.6 \\
358.9 \\
56.7 \\
2701.6 \\
1779.8 \\
2509.2\end{array}$ & $\begin{array}{r}3.9 \\
250.5 \\
14.5 \\
748.6 \\
430.4 \\
582.9\end{array}$ & $\begin{array}{r}3.2 \\
80.5 \\
13.9 \\
670.7 \\
460.7 \\
624.8\end{array}$ & $\begin{array}{r}4.4 \\
9.2 \\
13.8 \\
687.5 \\
468.6 \\
781.2\end{array}$ & $\begin{array}{r}3.5 \\
72.5 \\
14.4 \\
679.5 \\
456.0 \\
611.0\end{array}$ \\
\hline Total & 7420.2 & 2030.9 & 1853.9 & 1964.6 & 1837.0 \\
\hline $\begin{array}{l}\text { National } \\
\text { Electric Utility } \\
\text { Commercial/Residential } \\
\text { Industrial Fuel } \\
\text { Industrial Processes } \\
\text { Miscellaneous } \\
\text { Transportation }\end{array}$ & $\begin{array}{r}34.7 \\
1348.9 \\
109.6 \\
6482.5 \\
3735.2 \\
6856.5\end{array}$ & $\begin{array}{r}8.7 \\
748.3 \\
28.7 \\
1592.3 \\
855.9 \\
1183.7\end{array}$ & $\begin{array}{r}7.4 \\
304.4 \\
26.9 \\
1606.7 \\
977.6 \\
1698.0\end{array}$ & $\begin{array}{r}10.5 \\
14.3 \\
26.3 \\
1648.4 \\
967.7 \\
2297.0\end{array}$ & $\begin{array}{r}8.0 \\
281.9 \\
27.7 \\
1635.1 \\
933.9 \\
1677.8\end{array}$ \\
\hline Total & 18567.4 & 1417.6 & 4621.1 & 4964.2 & 4564.5 \\
\hline
\end{tabular}


B.7 NOx Emissions

by Federal Region and Season 
(kt)

Fed. Region / Sector

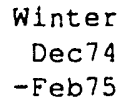

Federal Region 1 Electric Utility

Commercial/Residential Industrial Fuel

Industrial Processes

Miscellaneous

Transportation Total

Federal Region 2

Electric Utility

Commercial/Residential

Industrial Euel

Industrial Processes

Miscellaneous

Transportation rotal

Federal Region 3

Electric Utility

Commercial/Residential

Industrial Fuel

Industrial Processes

Miscellaneous

Transportin: ion Total

Federal Region 4

Electric Utility

Commercial/Residential

Industrial ruel

Industrial Processes

Miscellaneous

Transportation Total

Federal Region 5

Electric Utility

Commercial/Residential

Industrial Fuel

Industrial Processes

Miscellaneous

Transportation

$$
\text { rotal }
$$

Federal Region 6

Electric Utility

Commercial/Residential

Industrial Fuel

Industrial processes

Miscellaneous

Transportation

$$
\text { Total }
$$

$\mathrm{N} / \mathrm{A}$

$N / A$

$N / A$

$N / A$

$\mathrm{N} / \mathrm{A}$

$N / A$

$N / A$

N/A

$V / A$

$V / A$

N/A

$N / A$

$N / A$

$\mathrm{N} / \mathrm{A}$

$N / A$

$N / A$

$N / A$

$\mathrm{N} / \mathrm{A}$

$N / A$

$N / A$

$\mathrm{N} / \mathrm{A}$

$N / A$

$N / A$

$N / A$

$N / A$

$N / A$

$N / A$

$\mathrm{N} / \mathrm{A}$

$N / A$

$N / A$

$N / A$

$N / A$

$N / A$

$N / A$

$\mathrm{N} / \mathrm{A}$

$N / A$

$N / A$

$N / A$

$N / A$

$N / A$

$N / A$

$N / A$

Spring
Mar 75
- May 75

Summer
Jun 75
-Aug 75

Autumn
Sep 75
- Muv 75

Annual

Jan 75

-Dec 75

24.2
19.6

18.6

0.6

1.4

97.1

161.5

48.4

41.0

44.5

4.5

2.7

162.2

304.0

$$
\begin{array}{r}
26.4 \\
1.8 \\
16.9 \\
0.6 \\
1.3 \\
114.6 \\
161.5
\end{array}
$$

$$
\begin{array}{r}
22.6 \\
11.6 \\
19.1 \\
0.6 \\
1.3 \\
96.3 \\
151.5
\end{array}
$$

57.0

47.9

22.9

43.4

38.7

4.6

2.5

185.4

292.4

4.6

2.5

155.0

276.2

178.8

3.8

58.5

19.5

2.8

19.2

2.9

226.6

506.7

247.5

511.0

161.4

14.1

63.3

19.5

2.8

232.6

493.9

$$
\begin{array}{r}
247.4 \\
16.8 \\
83.8 \\
26.6 \\
16.9 \\
396.5 \\
787.9
\end{array}
$$

295.0

4.4

73.9

28.6

10.5

396.0

808.4

261.6

11.0

78.4

29.6

7.8

393.8

782.2

$$
\begin{array}{r}
380.9 \\
51.4 \\
149.6 \\
21.3 \\
5.0 \\
453.9 \\
1062.1
\end{array}
$$

434.1
14.6

121.9

21.4

4.7

520.1

1116.9

380.3

35.7

136.3

21.7

4.6

472.4

1051.0
173.4

5.2

380.4

70.9

4.2

308.7

942.8
141.3

11.2

383.4

69.4

3.7

310.0

919.2
102.2

66.3

76.3

2.4

5.2

394.3

646.8

204.5

138.6

178.8

18.2

10.2

644.5

1194.8

686.8

85.6

275.9

76.1

11.2

904.5

2040.2

1059.7

69.1

327.7

110.7

42.9

1570.7

3180.8

1615.6

194.8

588.0

84.1

18.9

1849.2

4350.6

299.

890.6
577.7

70.7

1551.5

267.6

17.0

1202.1

3686.6 
Fed. Region / Sector

Federal Region 7

Electric Utility

Commercial/Residential

Industrial Fuel

Industrial Processes

Misce. laneous

Transportation Total

Federal Region 8

Electric Utility

Commercial/Residential

Industrial Fuel.

Industrial Processes

Miscellaneous

Transportation Total

Federal Region 9

Electric Utility

Commerclal/Residential

Industrial Fuel

Industrial Processes

Miscelianeous

Transportation Total

Federal Region 10

Electric Utility

Commercial/Residential

Industrial Fuel

Industrial Processes

Miscellaneous

Transportation Total.

National Totals

Electric Utility

Commercial/Residential

Industrial Fuel

Industrial Processes

Miscellanenus

Transportation

Total

Region and

\section{Season}

(kt)

(Cont'd)

winter

Dec74

-Feb75

$N / A$

$N / A$

$N / A$

$\mathrm{N} / \mathrm{A}$

$N / A$

$N / A$

$N / A$

$\mathrm{N} / \mathrm{A}$

$N / A$

$N / A$

$N / A$

$N / A$

$N / A$

$\mathrm{N} / \mathrm{A}$

$N / A$

$\mathrm{N} / \mathrm{A}$

$N / A$

$N / A$

$N / A$

$N / A$

$\mathrm{N} / \mathrm{A}$

$N / A$

N/A

$N / A$

$N / A$

$N / A$

$N / A$

$\mathrm{N} / \mathrm{A}$

$N / A$

$\mathrm{N} / \mathrm{A}$

$N / A$

$N / A$

$N / A$

$N / A$

$N / A$

Spring
Mar 75
-May 75

Summer

Jun 75

-Aug 75

79.4

10.0

40.0

11.3

1.7

148.9

291.2

106.5
3.5
37.6
12.8
1.5
168.9
330.8

37.9

7.9

48.5

7.0

7.3

87.9

196.5

47.5

14.7

73.2

9.2

6.2

242.6

393.5

2.5

5.0

17.4

3.5

15.6

80.2

124.1

$$
\begin{array}{r}
1162.1 \\
206.6 \\
920.1 \\
168.1 \\
65.2 \\
2195.8 \\
4718.0
\end{array}
$$

42.6
2.3
40.0
7.2
6.2
113.6
212.0

59.4
7.8
64.3
10.7
6.2
260.4
408.8

3.4

1.5

15.2

3.7

12.2

97.7

133.7

1376.6

49.0

847.3

180.0

52.3

2413.0

4918.3
Autumn
Sep 75

- Nov 75

87.4

6.5

40.4

12.4

1.5

158.8

307.0

42.5

5.0

45.7

7.3

5.6

100.4

206.4

61.3

9.9

75.0

10.5

5.9

252.5

415.2

Annual
Jan 75
$-\operatorname{Dec} 75$

369.5

40.4

167.6

46.6

6.1

607.1

1237.3

168.5

27.9

192.3

28.1

22.7

379.9

819:5

223.1

54.6

294.7

38.7

22.1

986.7

1619.9

4.4

3.6

17.1

3.8

10.4

86.2

125.5
1210.7

131.5

902.2

179.5

46.0

2258.0

4728.0
13.8

17.8

69.3

14.5

44.9

329.6

489.8

5021.4

765.8

3722.1

686.9

201.3

8868.7

19266.2 


Spring
Mar76
-May 76

Federal Region 1 Electric Utility

Commerclal/Residential

Industrial Fuel

Industrial processes

Miscellaneous

Transportation Total

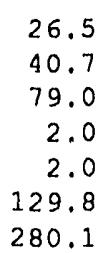

Federal Region 2

Electric Utility

Commercial/Residential

Industrial Fuel

Industrial Processes

Miscelláneous

Transportation Total

Federal Region 3

Electric Utility

Commercial/Residential

Industrial Fuel

Industrial processes

Miscellaneous

Transportation

$$
\text { Total }
$$

Federal Region 4

Electric Utility

Commercial/Residential

Industrial Fuel

Industrial Processes

Miscellaneous

Transportation

$$
\text { Total }
$$

Federal Region 5

Electric Utility

Commercial/Residential

Industrial Fuel

Industrial Processes

Miscellaneous

Transportation

$$
\text { Total }
$$

Federal Region 6

Electric Utility

Commercial/Residential

Industrial Fuel

Industrial Processes

Miscellaneous

Transportation

$$
\text { Total }
$$

253.8

210.0

37.2

67.3

21.5

3,4

175.2

514.6

251.6

58.1

106.3

22.9

10.7

363.6

813.2

427.1

91.6

165.3

16.8

4.7

354.2

1059.6

106.5

45.6

343.4

46.0

3.7

289.9

835.2

$$
\begin{array}{r}
21.4 \\
18.1 \\
23.9 \\
0.6 \\
1.4 \\
97.9 \\
163.2
\end{array}
$$

$$
\begin{array}{r}
23.7 \\
1.6
\end{array}
$$

22.3

0.6

1.3

114.9

164.4

$$
21.7
$$

15.7

25.6

0.6

1.3

100.3

165.2

52.8

47.0

33.4

54.3

4.7

2.5

162.8

304.7

163.1

309.1

183.

295.8

178.3

21.4

71.3

20.0

3.0

242.6

536.6

188.1

4.3

61.2

20.8

3.0

201.5

538.8

177.4

19.5

66.5

19.6

2.9

241.5

527.5

269.1

325.3

294.7

16.7

87.5

29.7

17.0

429.6

849.5

402.3
50.2

147.1

22.3

5.0

470.6

1097.5

16.4

84.5

29.2

8.1

426.1

859.0

133.6

16.0

425.0
69.3

5.5

314.1

963.5
421.0

15.1

124.3

23.3

4.7

539.4

1127.7

177.8

5.7

431.2

404.5

41.5

139.3

21.8

4.6

494.1

1105.9

71.9

4.4

321.7

1012.7
154.1

16.3

434.3

68.7

3.9

320.9

998.3
93.8

72.7

100.5

2.4

5.2

400.2

674.6

201.7

157.0

218.1

18.9

10. 2

651.9

1257.9

735.1

91.6

285.1

77.7

11.6

959.1

2160.1

1180.9

80.8

348.6

114.9

43.5

1694.8

3463.6

1668.9

205.9

592.0

86.0

19.0

1919.5

4491.3

610.3

79.7

1759.0

272.0

17.4

1253.7

3992.1 


\section{NOX Emisstons by}

Fed. Region / sector

Federal Region 7

Electric Utility

Commercial/Residential

Industrial Fuel

Industrial processes

Miscellaneous

Transportation Total

Federal Region 8

Electric Utility

Commercial/Residential

Industrial Fuel.

Industrial Processes

Miscellaneous

Transportation

Total

Federal Region 9

Electric Utility

Commercial/Residential

Industrial Euel

Industrial Processes

Miscellaneous

Transportation

Total

Federal Region 10

Electric Utility

Commerclal/Residential

Industrial Fuel

Industrial Proresses

Miscellaneous

Transportation Total

National Totals

Electric Utility

Commercial/Residential

Industrial Fuel

Industrial Processes

Miscellaneous

Transportation

Total

Region and Season

(kt) (Cont'd)

\section{Winter \\ Dec75}

-Feb7 6

Spring
Mar76
-May76

Summer
Jun 76
-Aug 76
Autumn
Sep76
-Nov 76

Annua 1
Jan76
-Doc76

127.5

23.6

55.2

10.5

3.2

136.1

356.1

87.9
10.3
44.3
12.3
1.7
155.5
311.9

112.3

3.7

42.3

13.0

1.6

177.1

350.0

96.3
7.5
45.2
12.3
1.5
167.0
329.7

101.0

43.2

186.9

97.8

6.2

634.7

1319.8

125.7

30.5

47.5

8.4

52.6

7.4

20.8

6.8

256.7

615.6

7.7

92.3

215.8

52.2
2.5
43.9
7.9
8.8
118.7
234.0

49.3

5.5

50.2

7.4

8.7

104.4

225.5

204.8

30.3

210.2

2.9 .1

29.9

397.6

901.9

$\begin{array}{rr}56.7 & 59.6 \\ 22.0 & 14.6 \\ 69.3 & 77.6 \\ 7.9 & 10.1 \\ 2.4 & 6.6 \\ 185.8 & 251.0\end{array}$

76.9
7.5
68.2
11.4
9.1
267.2
440.3

67.3
9.4
79.6
10.7
9.6
259.1
435.8

265.7

53.8

312.4

40.6

30.4

1015.7

1718.7

$\begin{array}{rr}5.6 & 2 . \\ 10.4 & 5 . \\ 28.9 & 17 . \\ 5.6 & 3 . \\ 4.2 & 16 . \\ 103.6 & 85 . \\ 158.2 & 130.4\end{array}$

2. 6

17.1

3.7

16.2

85.8

2.2
1.6

15.5

3.8

16.9

103.3

143.3

5.3
3.6

17.3

3.7

16.3

92.1

1. 38.2

$14 . ?$

18.1

69.1

14.6

58.3

351.8

525.9

1375.5
414.0
$i 146.3$
157.5
42.8
2094.5
5230.6
1249.9
198.7
998.9
180.4
66.6
2302.5
4997.0

1317.7
168.8
996.9
178.6
59.4
2368.2
5089.6
5376.2

833.1

4081.8

704.1

231.7

9278.9

20505.8 
(kt)

\begin{tabular}{|c|c|c|c|c|c|}
\hline & $\begin{array}{l}\text { Winter } \\
\text { Dec7 } 6\end{array}$ & $\begin{array}{r}\text { Spring } \\
\operatorname{Mar} 77\end{array}$ & $\begin{array}{r}\text { Summer } \\
\text { Jun } 77\end{array}$ & $\begin{array}{r}\text { Autumn } \\
\text { Sep } 77\end{array}$ & $\begin{array}{r}\text { Annual } \\
\operatorname{Jan} 77\end{array}$ \\
\hline Fed. Reglon / Sector & -Eeb77 & - May 77 & - Aug 77 & - Nov 77 & \\
\hline \multicolumn{6}{|l|}{ Federal Region 1} \\
\hline Electric Utility & 28.2 & 21.1 & 23.0 & 22.1 & 94.7 \\
\hline Commercial/Residential & 40.4 & 16.2 & 2.1 & 12.3 & 66.8 \\
\hline Industrial Fuel & 83.4 & 23.7 & 22.4 & 24.8 & 99.2 \\
\hline Industrtal Processes & 2.2 & 0.6 & 0.6 & .0 .6 & 2.5 \\
\hline Miscellaneous & 2.0 & 1.4 & 1.3 & 1.3 & 5.2 \\
\hline Transportation & 130.9 & 101.7 & 120.5 & 103.6 & 415.4 \\
\hline Total & 287.0 & 164.7 & 169.9 & 1.64 .6 & 683.7 \\
\hline \multicolumn{6}{|l|}{ Federal Region 2} \\
\hline Electric Utility & 43.2 & 48.2 & 58.8 & 49.3 & 213.7 \\
\hline Commercial/Resident Lal & 57.2 & 33.6 & 4.8 & 25.9 & 144.4 \\
\hline Industrial Fuel & 54.1 & 51.0 & 46.7 & 51.2 & 210.0 \\
\hline Industrial Processes & 3.4 & 5.1 & 5.1 & 4.9 & 19.6 \\
\hline Miscellaneous & 1.8 & 2.7 & 2.5 & 2.5 & 10.2 \\
\hline Transportation & 99.1 & 164.6 & 190.2 & 166.0 & 658.0 \\
\hline Total. & 258.7 & 305.3 & 308.2 & 299.8 & 1256.0 \\
\hline \multicolumn{6}{|l|}{ Federal Region 3} \\
\hline Electric Utiilty & 213.2 & 173.6 & 189.9 & 169.9 & 726.4 \\
\hline Commercial/Residential & 40.3 & 19.4 & 4.2 & 15.4 & 87.8 \\
\hline Industrial Fuel & 67.0 & 70.3 & 60.3 & 64.5 & 279.7 \\
\hline Industrial Processes & 21.3 & 21.1 & 21.6 & 20.5 & 80.6 \\
\hline Miscellaneous & 3.4 & 3.0 & 3.0 & 2.9 & 11.6 \\
\hline Transportation & 175.4 & 246.1 & 267.3 & 250.4 & 975.0 \\
\hline Total & 520.6 & 533.6 & 546.3 & 523.7 & 2161.1 \\
\hline \multicolumn{6}{|l|}{ Federal Region 4} \\
\hline E.lectric utility & 271.5 & 254.1 & 353.3 & 288.1 & 1203.5 \\
\hline Commercial/Residential & 61.4 & 16.1 & 4.9 & 12.6 & 82.5 \\
\hline Industrial Fuel & 107.1 & $88.0^{\prime}$ & 80.0 & 84.1 & 349.8 \\
\hline Industrial Processes & 22.4 & 30.7 & 31.1 & 29.9 & 117.2 \\
\hline Miscellaneous & 10.7 & 17.0 & 10.7 & 8.1 & 43.5 \\
\hline Transportation & 362.1 & 446.1 & 442.9 & 440.5 & 1742.9 \\
\hline Total & 835.2 & 852.0 & 922.8 & 863.3 & 3539.4 \\
\hline \multicolumn{6}{|l|}{ Federal Reglon 5} \\
\hline Electric Ut1lity & 421.5 & 396.6 & 441.8 & 412.9 & 1694.2 \\
\hline Commercial/Residential. & 89.5 & 44.6 & 14.1 & 35.6 & 191.1 \\
\hline Industrial Fuel & 162.3 & 146.6 & 123.5 & 136.0 & 584.3 \\
\hline Industrial Processes & 16.7 & 23.4 & 23.9 & 22.6 & 88.7 \\
\hline Miscellaneous & 4.7 & 5.0 & 4.7 & 4.6 & 19.0 \\
\hline Transportation & 353.0 & 480.2 & 544.9 & 492.1 & 1927.4 \\
\hline Total & 1047.7 & 1096.4 & 1152.9 & 1103.7 & 4504.7 \\
\hline \multicolumn{6}{|l|}{ Federal Region 6} \\
\hline Electric utility & 118.0 & 152.0 & 207.5 & 161.3 & 675.8 \\
\hline Commercial/Residential & 53.1 & 17.0 & 6.1 & 1.3 .0 & 88.0 \\
\hline Industrial Fuel & 351.4 & 438.4 & 445.5 & 448.6 & 1817.9 \\
\hline Industrial Processes & 44.4 & 71.3 & 73.7 & 71.2 & 276.9 \\
\hline Miscellaneous & 3.7 & 5.5 & 4.4 & 3.9 & 17.4 \\
\hline Transportation & 285.6 & 331.9 & 342.5 & 339.2 & 1317.0 \\
\hline Total & 856.1 & 1016.1 & 1079.7 & 1037.3 & 4193.1 \\
\hline
\end{tabular}


1977 NOX Emisatons by

Fed. Region / sector

Federal Region 7

Electric Ut1lity

Commerclal/Residential

Industrial Fuel

Industrial processes

Miscellaneous

Transportation Total.

Federal Region 8

Electric Utility

Commercial./Residential

Industrial Fuel

Industrial processes.

Miscellaneous

Transportation

Total

Federal Region 9

Electric Utility

Commerclal/Residential

Industrial Fuel.

Industrial processes

Miscellaneous

Transportation Total.

Federal Region 10

Electric Utility

Commercial/Residential

Industrial. Fuel.

Industrial Processes

Miscellaneous

Transportation

Total

National Totals

Electric Utility

Commerclal/Residential

Industrial Fuel

Industrial processes

Miscellaneous

Transportation

Total

\section{Region and}

Seazon

Winter
Dec 76

-Feb77

Spring
Mar 77

Mar 77
- May 77

Summer
Jun 77
- Aug 77

Autumn
Sep 77
-Nov 77

Annual

Jan77

-1)ec 77

\section{3.}

23.3

55.7

9.9

3.2

142.8

368.7

122.4

28.6

177.9

21.4

6.8

259.1

616.1

$$
\begin{array}{r}
93.0 \\
9.4 \\
45.6 \\
12.7 \\
1.7 \\
161.2 \\
323.7
\end{array}
$$

$$
\begin{array}{r}
120.3 \\
3.5 \\
43.6 \\
13.2 \\
1.6 \\
182.5 \\
364.6
\end{array}
$$

72.2

21.4

70.2

8.1

2.4

194.9

369.2

6.5

10.2

29.2

5.7

4.2

105.4

161.3

1430.5

425.2

1158.3

155.6

42.8

2108.4

5320.8
55.5

7.5

52.2

7.8

7.7

97.6

228.2

$$
\begin{array}{r}
81.8 \\
14.1 \\
78.6 \\
11.0 \\
6.6 \\
267.8 \\
460.0
\end{array}
$$

$$
\begin{array}{r}
63.2 \\
2.3 \\
43.6 \\
8.0 \\
8.8 \\
123.6 \\
249.5
\end{array}
$$

$$
\begin{array}{r}
91.7 \\
7.1 \\
69.5 \\
12.0 \\
9.1 \\
284.4 \\
473.8
\end{array}
$$

5.0

4.7

17.3

4.0

16.2

90.7

137.8

1281.0
182.7
1011.7
187.8
66.6
2388.1
5117.8

1552.8

50.2

950.6

193.3

63.0

3.3

1.2

15.6

4.0

16.9

108.6

149.6

2607.3

5417.3
104.0

6.7

46.4

12.6

1.5

173.1

344.3

58.1

5.0

49.4

7.7

8. 7

109.2

238.1

82.3

9.1

80.4

11.3

9.6

274.9

467.5

5.6

4.0

17.3

3.8

16.3

95.9

142.9

$$
\begin{array}{r}
1353.5 \\
139.6 \\
1002.7 \\
185.3 \\
59.4 \\
2444.9 \\
5185.2
\end{array}
$$

42.9 .9

40.9

192.3

48.2

6.2

659.3

1376.7

241.4

27.3

207.8

29.9

29.9

415.8

952.2

328.0

51.3

316.1

43.0

30.4

1070.0

1839.2

18.8

17.5

69.6

15.3

58.3

367.8

547.3

5626.1

797.6

4127.1

722.0

231.7

21053.5
9548.6 
and

Season

(kt)

Fed. Region / sector

Winter
Dec77
-Feb78

Spring
Mar 78
- May 78

Summer

Jun78

Autumn
Sep 78
- Nov78

Annual

-Aug 78

Jan 78

- Dec78

Federal Region 1

Electric Utility

Commerclal/Residentlal

Industrlal Fuel

Industrial processes

Miscellaneous

Transportation Total

$$
\begin{array}{r}
29.3 \\
37.7 \\
82.7 \\
2.2 \\
2.0 \\
128.2 \\
282.2
\end{array}
$$

Federal Region 2

Electric Utility

Commercial/Residential

Industrial Fuel

Industrial processes

Miscellaneous

Transportation Total

Foderal Region 3

Electric Utility

Commercial/Residential

Industrial Fuel

Industrial processes

Miscellaneous

Transportation

$$
\text { l'otal }
$$

Federal Region 4

Electric Utility

Commercial/Residential

Industrial Fuel

Industrial processes

Miscellaneous

Transportation

$$
\text { Total }
$$

Federal Region 5

Electric Utility

Commercial/Residential.

Industrial Fuel

Industrial Processes

Miscellaneous

Transportation

$$
\text { Total }
$$

Federal Region 6

Electric Utilty

Commerclal/Residentlal

Industrial Fuel

Industrlal Processes

Miscellaneous

Transportation Total

42.6

54.9

47.9

3.6

1.8

97.0

247.8

195.9

40.1

62.6

22.2

3.4

176.0

500.2

278.1

60.4

104.0

23.3

10.7

371.2

847.7

403.1

93.2
160.4

17.9

4.7

342.3

1021.6

135.1

54.2

358.9

45.5

3.7

298.7

896.0
22.1

18.5

22.7

0.6

1.4

101.5

166.8

22.7

21.9

13.0

22.9

0.6

1.3

103.4

163.1

121.4

169.1

46.8

5.5 .4

4.8

45.6

48.9

5.2

2.7

165.5

309.3

5.0

2.5

189.5

302.8

45.7

26.2

49.2

5.0

2.5

163.6

292.2

182.9

166.0

23.6

67.7

21.5

3.0

246.2

527.9

4.6

60.7

21.9

3.0

269.0

542.0

182.6

15.6

65.2

21.6

2.9

252.8

540.7

257.8

18.8

87.0

31.0

17.0

456.2

867.7

340.7

288.3

5.1

81.5

30.9

10.7

453.7

922.7

11.6

85.9

30.8

8.1

454.1

878.8

383.6

53.0

147.3

24.1

5.0

474.0

1086.9
163.0

18.6

149.7

72.3

5.5

340.9

1050.0
431.4

15.5

130.5

25.1

4.7

553.2

1160.3

407.5

37.5

144.5

24.7

4. 6

498.5

1117.3

$$
\begin{array}{r}
221.6 \\
6.4 \\
457.8 \\
74.3 \\
4.4 \\
357.8 \\
1122.4
\end{array}
$$

171.0

12.6

461.0

72.8

3.9

352.9

1074.3
94.6

66.5

91.9

2.5

5.2

411.4

672.1

202.6

146.2 .

199.2

19.9

10.2

656.1

1234.3

711.1

90,8

274.3

83.1

11.6

978.7

2149.7

1188.0

84.5

349.6

119.1

43.5

1785.8

3570.5

1646.9

207.7

601.6

94.0

19.0

1928.8

4498.0

778.9

91.1

1864.9

281.8

17.4

1364.0

4318.0 


\section{Nox Emisatons by}

Fed, Regton / sector

Federal Region 7

Electrlo Utility

Commerclal/Residential.

Industrlal Fuel

Industrial processes

Miscellaneous

Transportation

Total

Federal Region 8

Electrlc Utility

Commercial/Residentlal

Industrial Fuel

Industrlal Processes

Miscellaneous

Transportation Total

Federal Region 9

Electric Utility

Commerclal/Resldential

Industrial Fuel

Industrial Processes

Miscellaneous

Transportation Total

Federal Region 10

Electric Utility

Commercial/Resldent lal

Industrial Fuel.

Industrial Processes

Miscellaneous

Transportation Total.

National Totals

Electric Utility

Commerclal/Resldent 1 al

Industrial Fuel

Industrial. Processes

Miscellaneous

Transportation Total.
Fedexal

Winter

Dec77

-Feb78

Spring
$\operatorname{Mar} 78$

- May 78

Summer
Jun 78
- Aug 78

147,5

23.6

54.3

10.4

3.2

136.9

376.0

139.4

30.3

178.9

22.3

6.8

273.6

651.1

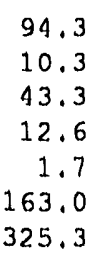

127.1
3.9

3.9
42.4

13.0

1.6

184.5

372.4

59.5

68.9

2.7

44.8

8.6

8.8

52.6

7.7

101.0

236.8

130.6

264.4

48.4

20.5

62.6

8.3

2.4

202.0

344.1

51.9

13.3

69.3

11.4

6.6

274.7

427.2

78.1

7.0

61.6

12.5

9.1

292.0

460.3

\section{0}

9.9

30.2

5.7

4.2

108.2

164.1

1425.4

424.7

1142.5

161.6

42.8

2134.0

5330.9

$$
3.0
$$

4.8

18.3

4.0

16.2

95.1

141.4

1248.0

209.1

1006.8

190.7

66.6

2418.1

5139.3
1.2

112.7

1530.1 (kt) (Cont'd)

$\begin{array}{rr}\text { Autumn } & \text { Annual } \\ \text { Sep78 } & \text { Jan'l8 } \\ \text {-Nov78 } & \text {-Dec78 }\end{array}$

$$
\begin{array}{r}
108.8 \\
7.2 \\
45.1 \\
12.6 \\
1.5 \\
172.1 \\
347.3
\end{array}
$$

Dec78

$\begin{array}{rr}64.7 & 250.4 \\ 5.6 & 29.8 \\ 50.8 & 211.1 \\ 8.5 & 32.1 \\ 8.7 & 29.9 \\ 113.5 & 434.0 \\ 251.8 & 997.3\end{array}$

76.2

9.4

71.1

12.0

9.6

281.0

459.2

273.9

51.3

279.0

41.8

30.1

1108.7

1788.0

14.7

5.0

18.8

73.8

15.3

58.3

387.3

568.1

102.8

150.8

5577.3

1371.8

830.0

1130.3

$963.0 \quad 1014.0$

$195.9 \quad 192.5$

740.7

231.7

$63.0 \quad 59.4$

$2664.4 \quad 2494.7$

9711.1

$5469.4 \quad 5275.6$

21221.1 


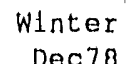

Dec78
- Feb79

Spring
$\operatorname{Mar} 79$

- May 79

Jun 79

-Aug 79

Foderal RegLon 1

Electrlc Utility

Commerclal/Residentlal

Industrlal Fuel

Industrlal processes

Mlscellaneous

Transportation Total

38.8
34.4
68.8
2.3
2.0
127.4
273.7

$$
\begin{array}{r}
25.1 \\
13.2 \\
13.9 \\
0.6 \\
1.4 \\
100.6 \\
154.7
\end{array}
$$

22.9
1.7
13.1
0.6
1.3
111.6
151.3

Autumn
Sep79

-Nov 79

21.9

9.1

13.6

0.6

1.3

96.0

142.5

Foderal. Region 2

Electric Utilty

Commercial/Resident lal

Industrlal Fuel

Industrlal Processes

Miscellaneous

'rransportation

$$
\text { Total }
$$

Federal Region 3

E.lectric Ut111ty

Commerclal/Residential

Industrial Fuel.

Industrlal processes

Miscellaneous

Transportation Total

Federal Region 4

Electric Utility

Commerclal/Residential

Industrlal Fuel

Industrial Processes

Miscellaneous

Transportation

$$
\text { Total }
$$

Federal Reglon 5

Electric Utility

Commerclal/Residential

Industrlal Fuel

Industrial processes

Miscellaneous

Transportation

$$
\text { Total. }
$$

Federal Region 6

Electric Utiltty

Commerclal/Resident tal

Industrlal Fuel

Industrlal processes

Miscellancous

'Transportatitun

$$
\text { 'otal. }
$$

$\begin{array}{rr}38.0 & 45.2 \\ 44.2 & 28.9 \\ 44.3 & 46.0 \\ 3.8 & 5.4 \\ 1.8 & 2.7 \\ 99.2 & 164.6 \\ 231.3 & 292.8\end{array}$

54.3

4.5

42.9

5.2

2.5

175.0

284.4

45.2

19.5

43.9

5.1

2.5

152.3

268.5

203.6

179.7

14.7

65.6

20.7

2.9

62.8

21.8

3.0

3.4

165.4

3.0

227.4

255.8

228.3

$551.2 \quad 512.0$

535.5

281.1

273.8

17.1

113.2

95.4

31.4

23.4

17.0

377.2

$44 \% .8$

857.1

882.5

344.0

276.6

12.7

86.5

32.0

10.7

429.9

908.1

88.9

31.2

8.1

433.3

850.8

433.2

406.1
46.8

428.6
13.6

412.0

33.1

141.6

150.9

141.6
23.8

120.2

24.1

129.3

22.7

4.7

5.0

351.6

473.2

1.039 .2

1096.5

520.

1. 6

473.5

1075.2

$\begin{array}{rr}194.8 & 171.3 \\ 63.5 & 22.9 \\ 328.3 & 403.7 \\ 46.8 & 73.4 \\ 3.7 & 5.5 \\ 303.5 & 349.7 \\ 910.7 & 1026.3\end{array}$

219.5

186.5

1.9 .1

411.1

410.3

75.6

74.9

3.9

353.2

343.8

1048.7
1112.4
Annual.

$\operatorname{Jan} 79$

-Dec79
98.0

50.3

55.6

2.5

5.2

396.7

608.2

194.2

112.6

184.3

20.6

10.2

631.6

1153.6

771.9

86.1

293.7

82.1

11.6

908.0

2153.4

1198.0

79.9

374.2

121.4

43.5

1733.9

3550.8

1697.6

183.4

561.6

90.3

19.0

1872.1

4423.9

759.0

118.8

1.671 .1

288.5

17.4

1377.9

4233.0 


\section{NOX Emisolons by}

Fed. Reglon / Sector

Federal Region 7

Electric Ut11.1ty

Commerclal/Residential

Industrial Fuel

Industrial processes

Mlscellaneous

Transportation Total

Federal Region 8

Electric Ut1lity

Commerclal/Residential

Industrial Fuel

Industrial processes

Miscellaneous

Transportation Total

Federal Regiton 9

Electric ut $111 t y$

Commerclal/Residential

Industrlal Fuel

Industrlal processes

Miscellaneous

Transportation

$$
\text { Total }
$$

Federal Region 10

Electric Ut1lity

Commerclal/Residential

Industrial Fuel.

Industrial processes

Miscellaneous

Transportation Total.

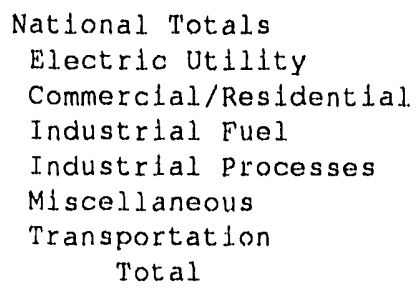

Region and

Season

(kt) (Cont'd)

Winter
Dec78
-Feb79

$\begin{array}{rr}\text { Spring } & \text { Summer } \\ \text { Mar79 } & \text { Jun79 } \\ \text {-May79 } & \text {-Aug79 }\end{array}$

Autumn
Sep79
-Nov79

Annual
Jan'l9
-Dec79

$$
\begin{array}{r}
158.1 \\
24.1 \\
64.6 \\
10.5 \\
3.2 \\
130.4 \\
390.9 \\
\\
108.4 \\
31.5 \\
165.2 \\
22.2 \\
6.8 \\
272.4 \\
606.5
\end{array}
$$

104.7
11.0
50.6
12.9
1.7
149.9
335.8

121.6

4.0

54.5

13.5

1.6

165.0

360.2
110.9
7.7
57.1
13.1
1.5
157.3
347.6
167.1
46.1
236.5
49.8
6.2
603.6
1409.2

$$
\begin{array}{r}
64.1 \\
8.3 \\
51.9 \\
8.0 \\
7.7 \\
101.3 \\
241.1
\end{array}
$$

73.3

74.3

5.6

48.4

7.8

8.7

111.8

256.5

288.6

30.3

201.6

30.8

29.9

423.2

121.8

258.7

1007.5

$\begin{array}{rr}73.6 & 65.8 \\ 23.7 & 14.4 \\ 63.8 & 70.8 \\ 8.4 & 11.4 \\ 2.4 & 6.6 \\ 208.2 & 268.7 \\ 380.1 & 437.7\end{array}$

$$
91.0
$$

$$
90.1
$$

10.0

71.4

11.8

12.6

9.1

275.9

9.6

276.0

$459.1 \quad 468.9$

326.8

54.9

283.4

44.6

30.4

1083.4

1823.5

$\begin{array}{rr}13.1 & 5.2 \\ 11.2 & 4.7 \\ 31.6 & 17.4 \\ 5.9 & 4.0 \\ 4.2 & 16.2 \\ 104.1 & 90.4 \\ 170.1 & 137.9\end{array}$

5.2

4.7

3. 6

1.4

15.6

4.0

16.9

107.4

148.9

4.5

3.8

16.9

3.9

16.3

95.4

1.40 .8

20.3

18.6

69.0

15.1

58.3

366.6

548.2

$\begin{array}{rr}1504.2 & 1350.8 \\ 404.4 & 188.2 \\ 1096.1 & 969.6 \\ 163.9 & 192.2 \\ 42.8 & 66.6 \\ 2139.4 & 2373.4 \\ 5350.8 & 5140.8\end{array}$

1562.4

1401.6

5821.4

53.0

135.4

946.2

191.8

781.0

198.1

59.4

63.0

2377.

$5295.9 \quad 5111.6$

3934.2

746.0

231.7

9397.0

20911.3 
Region and

'(x't)

Fod. Region / Sector

Winter
Dec79
-Feb80

Spring
Mar 80
-May 80

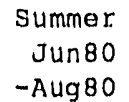

Autumn
Sep 80

Annual.

Federal Region 1

Electr1c Ut111ty

Commerclal/Resldent lal

Industrial Fuel

Industrial processes

Miscellaneous

Transportation

$$
\text { Total }
$$

38.9
33.8
55.9
2.0
2.0
126.3
258.9

$$
\begin{array}{r}
24.9 \\
14.1 \\
11.5 \\
0.6 \\
1.4 \\
92.9 \\
145.4
\end{array}
$$
26.0
2.0
10.6
0.6
1.3
106.7
147.2

- Nov80

Jan 80

$-\operatorname{Dec} 80$

Federal Region 2

Electric Utility

Commerclal/Resident lal.

Industrlal Fued

Industrial Processes

Mlscellaneous

Transportation

$$
\text { Total }
$$

40.3

47.2

56.6

5.0

32.3

36.8

37.0

4.0

5.0

4.4

2.5

1.8

2.7

226.0

148.6

170.7

273.0

271.5

$$
\begin{array}{r}
25.4 \\
10.6 \\
11.6 \\
0.6 \\
1.3 \\
95.7 \\
145.2
\end{array}
$$

108.7

53.5

46.1

2.4

5.2

380.7

596.6

Federal Region 3

Electric Utility

Commerclal/Residential

Industrial Fuel

Industrlal Processes

Miscellaneous

Transportation.

$$
\text { Total }
$$

177.2

180.5

22.8

38.8
59,3

201.7

4.4

66.2

54.1

18.6

22.6

19.5

3.0

166.0

213.1

467.4

505.0

47.3

205.4

24.0

35.2

126.9

145.7

4.8

19.2

2,5

10.2

153.1

266.9

Federal Region 4

Electric Utilty

Commerclal/Residential

Industrial Fuel

Industrlal. Processes

Miscellaneous

Transportation

$$
\text { 'Totial }
$$

295.7
50.5
96.2
24.8
10.7
367.8
845.6

284.1

17.4

84.6

29.5

17.0

416.6

849.2

187.4

16.9

58.2

19.3

2.9

244.3

224.2

526.0

509.0

777.1

90.7

256.6

76.0

11.6

876.9

2088.9

Federal Region 5

Electric Utility

Commercial/Residential

Industrial ivel

426.7

393.5

363.8

301.7

1274.5

4.7

12.6

74.7

74.4

78.3

329.0

115.3

10.7

29.5

43.5

419.9

1651.4

407.4

850.1

3488.5

Industrlal Processes

Miscellaneous

Transportition

$$
\text { Tota.. }
$$

81.1

47.2

123.9

18.1

21.2

4.7

5.0

334.4

433.3

997.0

1024.1

424.5

381.5

1649.9

32.3

100.9

111.8

21.1

180.4

485.3

19.8

4. 6

82.2

4.7

445.5

19.0

996.8

1764.8

Federal Region 6

Electric Utility

Commercjal/Residential

Industrial Fuel

Industrial Processes

Miscellaneous

Transportation

$$
\text { Total }
$$

$\begin{array}{rr}202.7 & 182.9 \\ 49.2 & 19.0 \\ 284.1 & 353.8 \\ 49.6 & 68.5 \\ 3.7 & 5.5 \\ 303.7 & 334.3 \\ 892.9 & 963.9\end{array}$
263.0
5.9
358.4
67.8
334.9
1034.4

210.7

14.8

361.8

67.9

3.9

337.6

996.7

851.0

87.3

1464.6

270.4

17.4

1336.9

4027.7 
1980 NOX

Ems a ions

Fed. Region / Seator

Wederal Region 7

Electric Utilty

Commercial/Residential

Industrial Fuel

Industrlal processes

Miscellaneous

Transportation Total

Federal Region 8

Electric Utility

Commerclal/Resldentlal

Industrial Fuel

Industrial processes

Miscellaneous

Transportation

Total

Federal Region 9

Electric Utility

Commercial/Residentlal

Industrial Fuel

Industrial processes

Miscellaneous

Transportation Total.

Federal Region 10

Electric Utility

Commerclal/Residential.

Industrial Fuel

Industrial processes

Miscellaneous

Transportation Total.

National Totals

Electric Utility

Commercial/Residential

Industrial Fuel

Industrial Processes

Miscellaneous

Transportation

Total by

Federal
Whiter
Dea79

-Feb80

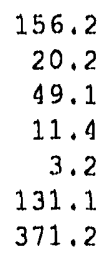

$$
\begin{array}{r}
113.5 \\
9.7 \\
40.2 \\
11.8 \\
1.7 \\
138.1 \\
314.9
\end{array}
$$

123.9

28.4

145.9

22.2

6.8

251.2

578.3

76.4

21.0

53.6

8.7

2.4

197.3

359.3

66.5

7.6

38.4

7.3

7.7

100.3

227.7

66.8

15.3

59.4

10.1

6.6

255.4

413.6

17.3

11.0

26.4

5.9

4.2

103.8

168.6

1555.2

379.1

939.4

169.2

42.8

2079.5

5165.2
4.2

5.1

15.9

3.7

16.2

85.6

130.8

1363.9

190.8

830.9

177.2

66.6

2218.2

4847.6

$$
\begin{array}{r}
144.1 \\
3.4 \\
38.4 \\
12.1 \\
1.6 \\
160.5 \\
360.1
\end{array}
$$

71.4

2.3

32.1

6.9

8. 8

119.2

240.6

78.8

7.6

52.6

10.8

9.1

262.1

421.0

$$
\begin{array}{r}
107.0 \\
6.6 \\
10.8 \\
12.2 \\
1.5 \\
150.5 \\
318.6
\end{array}
$$

$$
73.1
$$$$
5.0
$$$$
35.7
$$$$
7.2
$$

8.7

114.8

244.6

77.0

9.9

60.3

10.7

9.6

261.4

428.9

2.5

1.7

14.1

3.6

16.9

98.9

137.8

7.6

4.1

15.6

3.7

16.3

90.3

137.4

1632.5
48.8
768.0
173.0
63.0
2395.6
5080.8

1418.6

136.9

809.3

177.0

59.4

2293.1

4894.3
Anriual.

$\operatorname{Jan} 80$

$-1) e c 80$

493.1

39.7

1.69 .5

47.3

6.2

571.6

" 1327.1

293.1

27.5

150.8

28.2

29.9

124.5

954.1

297.1

55.2

238.0

40.7

30.4

1025.5

1687.2

20.0

19.7

63.0

14.6

58.3

318.5

524.1

5970.6

755.5

3348.5

696.3

231.7

8986.3

19989.1 
1981 Nox Emissions by

Fed. Region / Sector

Federal Region 1

Electric Utility

Commercial/Residential

Industrial Fuel

Industrial Processes

Miscellaneous

Transportation Total

Federal Region 2

Electric Utility

Commercial/Residential

Industrial Fuel

Industrial Processes

Miscellaneous

Transportation Totai

32.9

32.6

52.7

2.1

2.0

124.0

246.3

37.5

39.7

29.1

3.7

1.8

96.0

207.7

Federal Region 3

Electric Utility

Commercial/Residential

Industrial Fuel

industrial Processes

Miscellaneous

Transportation

Total

Federal Region 4

Electric Utility

Commercial. /Residential

Industri $\perp$ Fuel

Industria! Processes

Miscellaneous

Transportation

$$
\text { Total }
$$

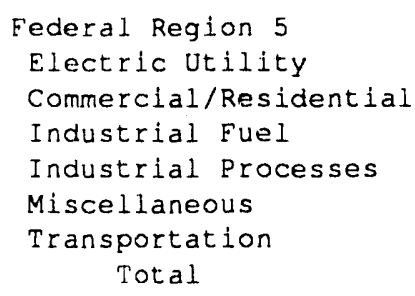

172

35.6

56.4

20.8

3.4

162.6

451.8

296.6

23.0

10.7

350.2

815.0

420.7

76.5

126.5

16.6

4.7

325.7

970.7

209.8
Region and Soason

(xt)

$\begin{array}{rrrr}\text { Spring } & \text { Summer } & \text { Autumn } & \text { Annual } \\ \text { Mar81 } & \text { Jun81 } & \text { Sep81 } & \text { Jan81 } \\ \text {-May81 } & \text {-Aug81 } & \text {-Nov81 } & \text {-Dec81 }\end{array}$

$$
\begin{array}{r}
20.8 \\
12.9 \\
10.8 \\
0.6 \\
1.4 \\
86.2 \\
132.6
\end{array}
$$

$$
\begin{array}{r}
24.1 \\
1.9 \\
10.5 \\
0.6 \\
1.3 \\
104.1 \\
142.5
\end{array}
$$

23.4

10.1

10.8

0.6

1.3

94.6

140.8

52.5

28.6

29.1

5.2

2.7

136.9

255.0

56.6

5.1

26.9

4.9

2.5

171.0

267.0

$$
140.8
$$

45.5

21.6

27.9

4.6

2.5

148.0

250.0

177.4

21.4

62.5

20.0

3.0

202.2

486.5

200.9

176.1

16.0

57.1

18.4

2.9

215.5

486.1

514.6

288.3

372.6

295.8

11.9

77.6

28.0

30.2

17.0

392.2

826.0

8.1

399.1

820.5

895.3

384.4

44.3

117.0

21.8

5.0

399.7

972.1

411.9

12.1

102.5

21.2

4.7

481.1

1033.5

381.6

31.3

110.4

19.5

4.6

445.3

992.7

44.2

272.8

45.9

3.7

293.7

870.0
271.9

5.4

346.8

66.0

4.4

342.0

1036.4
211.2

10.6

346.8

64.3

3.9

341.1

977.9
96.8

49.6

43.1

2.5

5.2

366.8

564.0

204.2

111.0

116.1

19.2

10.2

587.5

1048.3

1285.0

72.6

323.4

113.2

43.5

1583.5

3421.3

1599.6

172.4

471.0

80.7

19.0

1701.1

4043.7

$$
\begin{array}{r}
891.4 \\
72.4 \\
1405.9 \\
257.8 \\
17.4 \\
1342.4 \\
3987.4
\end{array}
$$

754.3
84.9
247.5
75.2
11.6
840.2
2013.7 
1981 NOX Emissions by

Fed. Region / Sector

Federal Region 7

Electric Utility

Commercial/Residential

Industrial Fuel

Industrial Processes

Miscellaneous

Transportation Total

Federal Region 8

Electric Utility

Commercial/Residential

Industrial Fuel

Industrial Processes

Miscellaneous

Transportation

Total

Federal Region 9

Electric Utility

Commercial/Residential

Industrial Fuel

Industrial Processes

Miscellaneous

Transportation Total

Federal Region 10

Electric Utility

Commercial/Residential

Industrial Fuel

Industrial processes

Miscellaneous

Transportatior. Total

National Totals

Electric Utility

Commercial/Residential

Industrial Fuel

Industrial Processes

Miscellaneous

Transportation

Total
Federal

Winter
Dec 80

-Feb81

152.8

18.6

45.8

10.2

3.2

120.6

351.3

112.3

26.7

141.2

19.5

6.8

241.6

548.1

111.7
8.6
36.8
12.0
1.7
131.6
302.4

136.3

3.2

35.7

11.5

1.6

157.9

346.2

75.4

6.4

39.2

7.1

7.7

93.8

229.6

70.2

18.6

53.9

8.0

2.4

192.2

345.3

19.6

10.4

26.0

5.4

4.2

97.0

162.6

1525.3
348.8
893.1
155.1
42.8
2003.5
4968.7
.76 .8

14.5

60.6

10.2

6.6

244.3

412.9

4.3

5.0

15.7

3.8

16.2

83.8

128.9

1393.8

173.1

792.8

177.5

66.6

2103.3

4707.1
77.2

2.2

33.7

7.0

8. 8

118.3

247.2

96.5

6.6

54.4

10.7

9.1

258.3

435.6

2.9

1.5

14.6

3.7

16.9

100.9

140.5

1650.9
47.4

47.4
754.8

174.6

63.0

2368.3

5058.9 (kt) (Cont'd)

$\begin{array}{rr}\text { Autumn } & \text { Annua1 } \\ \text { Sep81 } & \text { Jan81 } \\ \text {-Nov81 } & \text {-Dec81 }\end{array}$

113.1

6.3

37.8

11.1

1.5

145.3

315.0

-Dec 81

488.4

36.6

156.0

44.6

6.2

555.5

1287.4

315.9

23.7

157.0

26.7

29.9

405.2

958.5

110.7

247.0

326.6

53.8

242.8

39.3

30.4

992.5

1685.4

428.5

23.4

18.8

62.6

14.6

58.3

340.1

517.9

86.4

135.2

5985.6

695.8

3225.5

673.8

231.7

8715.0

19527.5 


\section{NOX Emissions by}

\begin{tabular}{|c|c|c|c|c|c|}
\hline & $\begin{array}{r}\text { Winter } \\
\text { DecB1 }\end{array}$ & $\begin{array}{r}\text { Spring } \\
\text { Mar } 82\end{array}$ & $\begin{array}{r}\text { Summer } \\
\text { Jun } 82\end{array}$ & $\begin{array}{l}\text { Autumn } \\
\text { Sep82 }\end{array}$ & $\begin{array}{r}\text { Annual } \\
\operatorname{Jan} 82\end{array}$ \\
\hline Fed. Region / Sector & - Feb82 & - May 82 & - Aug 82 & - Nov82 & -Dec 82 \\
\hline \multicolumn{6}{|l|}{ Federal Region 1} \\
\hline Electric Utility & 35.0 & 23.4 & 24.0 & 28.0 & 105.6 \\
\hline Commercial/Residential & 31.5 & 14.1 & 2.6 & 8.9 & 50.2 \\
\hline Industrial Fuel & 57.1 & 16.1 & 15.2 & 15.5 & 63.1 \\
\hline Industrial Processes & 1.8 & 0.6 & 0.6 & 0.6 & 2.4 \\
\hline Miscellaneous & 2.0 & 1.4 & 1.3 & 1.3 & 5.2 \\
\hline Transportation & 108.9 & 85.3 & 105.7 & 89.5 & 351.1 \\
\hline Total & 236.3 & 140.8 & 149.4 & 143.8 & 577.5 \\
\hline \multicolumn{6}{|l|}{ Federal Region 2} \\
\hline Electric Utility & 37.0 & 46.7 & 51.4 & 46.7 & 196.5 \\
\hline Commercial/Residentlal & 42.9 & 31.5 & 6.0 & 19.8 & 114.4 \\
\hline Industrial Fuel & 34.4 & 31.1 & 27.3 & 28.0 & 120.1 \\
\hline Industrial Processes & 3.0 & 4.2 & 3.8 & 3.8 & 15.6 \\
\hline Miscellaneous & 1.8 & 2.7 & 2.5 & 2.5 & 10.2 \\
\hline Transportation & 78.4 & 137.3 & 162.5 & 142.6 & 553.8 \\
\hline Total & 197.5 & 253.5 & 253.5 & 243.4 & 1010.6 \\
\hline \multicolumn{6}{|l|}{ Federal Region 3} \\
\hline Electric Utility & 201.1 & 182.1 & 184.8 & 161.5 & 723.7 \\
\hline Commercial/Residential & 35.6 & 21.5 & 4.9 & 14.2 & 81.5 \\
\hline Industrial Fuel & 57.3 & 61.6 & 50.9 & 53.2 & 235.4 \\
\hline Industrial'Processes & 16.4 & 16.4 & 15.8 & 15.0 & 61.3 \\
\hline Miscellaneous & 3.4 & 2.9 & 2.8 & 2.8 & 11.2 \\
\hline Transportation & 136.5 & 202.7 & 228.1 & 206.5 & 803.1 \\
\hline Total & 450.3 & 487.2 & 487.5 & 453.2 & 1916.2 \\
\hline \multicolumn{6}{|l|}{ Federal Region 4} \\
\hline Electric Utility & 276.6 & 273.5 & 330.2 & 268.9 & 1159.8 \\
\hline Commercial/Residential & 43.7 & 15.5 & 4.4 & 11.0 & 66.5 \\
\hline Industrial Fuel & 965 & 90.7 & 80.3 & 82.2 & 350.7 \\
\hline Industrial Processes & 19.8 & 26.5 & 25.9 & 25.7 & 100.8 \\
\hline Miscellaneous & 8.5 & 16.9 & 10.5 & 7.8 & 42.9 \\
\hline Transportation & 311.0 & 387.6 & 388.9 & 388.4 & 1518.4 \\
\hline Total & 756.0 & 810.7 & 840.2 & 784.2 & 3239.0 \\
\hline \multicolumn{6}{|l|}{ Federal Region 5} \\
\hline Electric Utility & 407.6 & 367.0 & 384.2 & 346.2 & 1509.6 \\
\hline Commercial/Residential & 76.9 & 45.5 & 12.8 & 30.7 & 173.9 \\
\hline Industrial Fuel & 126.5 & 117.6 & 97.2 & 103.9 & 459.4 \\
\hline Industrial Processes & 13.6 & 17.6 & 17.3 & 16.2 & 65.9 \\
\hline Miscellaneous & 4.6 & 5.0 & 4.7 & 4.6 & 18.9 \\
\hline Transportation & 264.1 & 395.4 & 462.1 & 401.2 & 1569.8 \\
\hline Total & 893.4 & 948.0 & 978.4 & 902.8 & 3797.5 \\
\hline \multicolumn{6}{|l|}{ Federal Region 6} \\
\hline Electric Utility & 178.3 & 208.2 & 269.5 & 217.1 & 908.7 \\
\hline Commercial/Residential & 44.8 & 15.9 & 6.0 & 12.4 & 78.4 \\
\hline Industrial Fuel & 279.6 & 349.6 & 353.2 & 352.5 & 1438.4 \\
\hline Industrial Processes & 39.3 & 58.5 & 57.4 & 55.5 & 223.0 \\
\hline Miscellaneous & 3.7 & 5.4 & 4.2 & 3.7 & 17.0 \\
\hline Transportation & 268.7 & 327.8 & 331.0 & 334.4 & 1288.8 \\
\hline Total & 814.3 & 965.4 & 1021.4 & 975.6 & 3954.3 \\
\hline
\end{tabular}


(kt) (Cont'd)

Fed. Region / sector

Federal Region 7

Electric Utility

Commercial/Residential

Industrial Fuel

Industrial Processes

Miscellaneous

Transportation Total

Federal Region 8

Electric Utility

Commercial/Residential

Industrial Fuel

Industrial Processes

Miscellaneous

Transportation

$$
\text { Total. }
$$

Federal Region 9

Electric Utility

Commercial/Residential

Industrial Fuel

Industrial processes

Miscellaneous

Transportation Total

Federal Region 10

Electric Utility

Commercial/Residential

Industrial Fuel

Industrial Processes

Miscellaneous

Transportation Total

National Totals

Electric Utility

Commercial/Residential

Industrial Fued

Industrial processes

Miscellaneous

Transportation

Total

Winter
Dec81

Spring

-Feb82

Mar 82

-Müy 82

Jun 82

-Aug 82

139.1

19.2

48.7

7.5

2.8

106.7

324.0

$$
\begin{array}{r}
98.7 \\
9.4 \\
39.8 \\
9.9 \\
1.7 \\
137.0 \\
296.6
\end{array}
$$
135.1
3.4
38.2
9.9
1.5
161.1
349.3
109.6
6.5
40.2
9.6
1.5
142.2
309.5

108.3

27.5

139.8

17.6

5.2

232.2

530.6

75.9
7.5
44.6
5.9
7.3
92.3
233.4

77.9

2.4

37.2

5.9

6.2

114.6

244.2

61.7

61.1

75.6

7.3

51.3

51.8

14.3

57.5

6.9

2.1

171.7

8.8

6.2

241.5

9.6

6.2

263.1

389.4

413.2

25.0

10.8

28.8

4.6

3.7

88.8

161.8

1469.7

350.9

920.6

130.5

37.7

1767.0

4676.5
1.7

5.8

16.3

3.4

15.6

79.3

122.1

1338.2

180.9

824.8

151.8

65.2

2086.1

4647.1
1.6

1.5

14.7

3.3

12.2

96.2

129.5

1534.4

51.4

765.6

149.5

52.3

2313.3

4866.6
80.3

5.1

41.2

5.6

5.6

98.0

235.7

67.0

9.9

57.1

9.0

5.9

246.9

395.9

5.7

4.7

15.4

3.2

10.4

81.3

120.7

1331.1

123.2

789.2

144.3

46.0

2131.1

4564.9
Annual

Jan8 2

-Dec832

466.4

39.0

167.6

37.2

6.1

546.3

1262.6

327.6

27.5

175.2

22.5

22.7

377.3

953.0

266.6

53.9

228.6

34.6

22.1

971.8

1577.6

16.1

21.3

63.6

12.9

44.9

317.2

476.0

5680.6

706.5

3302.2

576.2

201.3

8297.5

18761.3 
(kt)

Fed. Region / Sector

$\begin{array}{rr}\text { Winter } & \text { Spring } \\ \text { Dec82 } & \text { Mar83 } \\ \text {-Feb83 } & \text {-May83 }\end{array}$

Summer
Jun 83
-Aug 83

$$
\begin{array}{r}
\text { Autumn } \\
\text { Sep83 } \\
\text {-Nov83 }
\end{array}
$$

Annual.

$\operatorname{Jan} 83$

$-\operatorname{Dec} 83$

\section{Federal Region 1 \\ Electric Utility \\ Commercial/Residential \\ Industrial Fuel. \\ Industrial. Processes \\ Miscellaneous \\ Transportation}

$$
\text { Total }
$$

37.0
28.3
49.2
1.8
2.0
106.8
225.1

$$
\begin{array}{r}
25.0 \\
12.3 \\
10.2 \\
0.6 \\
1.4 \\
80.9
\end{array}
$$$$
130.4
$$

37.4

Federal Region 2

Electric Utility

Commercial/Residential

Industrial Fuel.

Industrial Processes

Miscellaneous

Transportation

$$
\text { Total. }
$$

Federal Region 3

Electric Utility

Commercial/Residential

Industrial Fuel

Industrial processes

Miscellaneous

Transportation

Total.

$$
32.9
$$

23.7

2.8

1.8

69.9

168.5

$$
47.0
$$

2.6 .0

19.2

4.0

2.7

129.4

228.3

138.3

34.3

47.5

15.4

3.4

121.5

360.4

$$
\begin{array}{r}
167.1 \\
21.4 \\
54.0 \\
15.3 \\
3.0 \\
187.4 \\
448.2
\end{array}
$$

Federal Region 4

Electric Utility

Commercial/Residential

Industrial Fuel

Industrial processes

Miscellaneous

Transportation

$$
\text { Total }
$$

$$
248 .
$$

44.7

246.5

17.7

84.3

88.3

19.4

10.7

303.9

715.4

25.6

17.0

389.1

780.2

Federal Region 5

Electric Utility

Commercial/Residential.

Industrial Fuel

Industrial Processes

Miscellaneous

Transportation

$$
\text { Total }
$$

Federal Region 6

Electric utility

Commercial/Residential.

Industrial Fuel

Industrial processes

Miscellaneous

Transportation

$$
\text { Total. }
$$

395.8
71.8
110.6
13.0
4.7
244.2

840.1

215.5
38.7
249.5
38.0
3.7
257.5
802.9

217.2

15.1

312.9

56.0

5.5

318.5

925.2
29.1
1.7
10.0
0.6
1.3
104.5
147.2

25.9

8.1

10.7

0.6

1.3

84.2

130.8

59.9

49.7

16.5

19.0

4.0

2.5

132.7

224.3

254.0

206.9

4.2

47.6

15.8

3.0

222.2

499.7

187.1

14.5

51.5

16.0

2.9

194.1

466.1

346.8

4.9

79.0

26.2

10.7

394.0

861.6

288.5

11.6

83.7

26.7

8.1

386.3

804.9

406.9

382.4

29.4

102.0

17.8

4.6

385.6

921.9

988.5

278.5

230.3

5.5

320.7

58.3

4.4

323.6

990.9
9.5

32.4 .4

59.1

3.9

320.9

947.0
110.7
44.0
41.2
2.4
5.2
334.3
537.8

208.9

93.8

77.5

15.3

10.2

529.1

934.8

755.7

81.8

215.0

60.5

11.6

751.1

1875.8

1169.5

73.1

338.8

100.7

43.5

1518.3

3244.0

1529.5

166.4

422.8

66.6

19.0

1498.9

3703.1

$$
\begin{array}{r}
954.6 \\
67.1 \\
1300.5 \\
223.4 \\
17.4 \\
1246.9 \\
3809.9
\end{array}
$$


1983 NO $_{X}$ Imtsetons by

Fed. Region / Sector

Federal Region 7

Electric Utility

Commerclal/Residentlal

Industrial Fuel

Industrlal processes

Miscellaneous

Transportation Total

Federal Region 8

Electric Ut1lity

Commercial/Residentlal.

Industrial Fuel

Industrial Processes

Miscellaneous

Transportation Total

Federal Region 9

Electric Ut11ty

Commercial/Resident 1 al.

Industrial Fuel

Industrial processes

Miscellaneous

Transportation

Total

Federal Region 10

Electric Utility

Commercial/Residential

Industrial Fuel

Industrial Processes

Miscellaneous

Transportation Total

National Totals

Electric Utility

Commercial/Residential

Industrial Fuel.

Industrial processes

Miscellaneous

Transportation

$$
\text { rotal. }
$$

\section{Region and}

Season

(kt) (Cont'd)

Whinter
Dec82

Spring
Mar83
- May83

Summer
Jun 83

Autumn
Sep83
-Nov83

Annual

-Aug 83

$-100083$

$\begin{array}{rr}142.9 & 101.8 \\ 18.9 & 9.1 \\ 42.7 & 32.4 \\ 7.4 & 9.0 \\ 3.2 & 1.7 \\ 102.9 & 130.0 \\ 318.1 & 284.1\end{array}$
146.1
3.3
31.6
9.9
1.6
137.8
350.2
115.7
6.2
33.7
9.9
1.5
136.5
303.5

480.6

37.3

138.1

36.2

6.2

523.7

1222.1

116.3

30.0

128.8

17.2

6.8

240.3

539.3

$$
\begin{array}{r}
73.1 \\
7.6 \\
38.2 \\
5.7 \\
7.7 \\
117.0 \\
249.3
\end{array}
$$

80.9

2.3

32.9

6.3

8.8

139.4

270.6

$$
\begin{array}{r}
80.6 \\
5.0 \\
37.1 \\
6.3 \\
8.7 \\
124.8 \\
262.6
\end{array}
$$

320.9

27.2

153.4

23.4

29.9

472.4

1027.3

$$
\begin{array}{r}
63.3 \\
17.0 \\
45.0 \\
7.1 \\
2.4 \\
163.6 \\
298.5
\end{array}
$$

50.7

65.4

58.8
8.7

13.1

50.5

8.9

6.6

240.5

370.3

6.6

46.5

10.2

9.1

271.4

409.1

52.8

9.8

9.6

246.9

386.5

228.6

48,5

205.1

36.2

30.4

971.0

1519.7

60.4

2.2

3.4

1.7

12.7

25.6

12.1

3.2

16.2

4.2

81.4

120.8

16.9

102.4

192.1

139.7

6.3

16.5

4.4

13.3

3.3

16.3

83.8

127.4

19.9

51.9

12.6

58.3

328.8

488.0

$\begin{array}{rr}1455.3 & 1277.6 \\ 327.6 & 171.5 \\ 811.1 & 717.6 \\ 126.7 & 145.0 \\ 42.8 & 66.6 \\ 1697.1 & 2044.9 \\ 4460.4 & 4423.2\end{array}$

1623.7
46.2
689.7
152.1
63.0
2336.8
4911.4

1425.4

113.8

727.2

153.5

59.4

2095.8

4575.1

5775.5

659.0

2914.1

577.3

231.7

8174.5

1.8362 .5 
1984 NOX Emlssions b

Fed. Region / Sector.
Federal

\section{Winter \\ Dec83}

- FebBa

Region and

season

(kt)

$\begin{array}{rr}\text { Spring } & \text { Summer } \\ \text { Mar84 } & \text { Jun84 } \\ \text {-May84 } & \text {-Aug84 }\end{array}$

Autumn
Sep84
-Nov84

Annual
Jan84
- Dec84

Federal Region 1

Electrdc Ut $111 \mathrm{ty}$

Commercial/Resident 1 al

Industrial Fuel

Industrial processes

Miscellaneous

Transportation Total.

32.7
26.0
54.1
1.9
2.0
104.8
221.4

28.7
13.5
10.6
0.6
1.4
75.7
130.5

33.9

1.7

9.6

0.6

1.3

103.0

150.1

30.0

8.5

10.2

0.6

1.3

81.7

132.3

Federal Region 2

Electric Utilty

Commerclal/Res ldential

Industrial Fuel

Industrial processes

Miscellaneous

Transportation Total

Federal Region 3

Electric Utility

Commerclal/Restdentlal.

Industrial Fuel.

Industrial processes

Miscellaneous

Transportation Total

Federal Region 4

Electr1c Ut111ty

Commerclal/ikes ldent lal

Industrlal Fuel

Industrial Processes

Miscellaneous

Transportation Total

Federal Region 5

Electric Utility

Commercial/Residential

Industrial Fuel.

Industrial Processes

Miscellaneous

Transportation 'Total

Federal Region 6

Electric Utility

Commerclal/Resident:lal

Industrial Fuel.

Industrial Processes

Miscellaneous

Trarisportation Total.

37.2

33.1

25.5

3.4

1. 8

68.4

169.4

44.4

28.2

21.4

4. 6

2.7

122.5

223.8

168.2

34.4

52.2

17.7

3.4

121.0

396.9

256.0

44.4

94.9

21.4

10.7

296.6

724.1

191.1

23.4

61. 2

17.6

3.0

182.1

478.3

274.4

18.5

93.9

28.0

17.0

383.5

815.3

410.8

74.6

119.2

14.7

4.7

244.3

868.3

242.8

39.6

271.8

42.0

3.7

254.8

854.6
374.9

47.9

113.5

19.6

5.0

360.0

920.8

228.0

15.0

343.4

61.4

5.5

318.7

972.0
59.8

4.7

18.2

4.3

2.5

157.4

246.8

210.7

4.2

52.1

17.6

3.0

217.9

505.5

337.8

4.6

85.1

28. 1

10.7

393.4

859.6

49.1

16.5

19.1

4. 3

2. 5

131.7

223.2

184.7

14.5

54.4

16.7

2.9

190.9

464.1

300.0

12.3

87.4

27.6

8.1

382.8

818.1

421.3

12.8

96.3

19.7

4.7

446.7

1001.5

376.4

30.7

103.1

18.3

4.6

377.3

910.5

223.5

11.0

348.5

61.5

3.9

323.1

971.4
124.2

44.5

40.7

2.4

5,2

322.1

539.1

204.8

94.0

81.8

17.5

10.2

509.6

917.9

788.5

81.8

235.2

66.9

11.6

738.0

1921.9

1200.6

73.9

365.5

108.4

43.5

1500.2

3292.1

1581.3

174.8

446.1

73.7

19.0

1469.9

3764.7

977.9

68.4

1414.6

241.2

17.4

1252.9

3972.4 
1984 NOX Emfosions by

Fed, Region / Sector

Federal Region 7

Electric Ut1lity

Commerclal/Restdential

Industrial Fuel

Industrial Processes

Miscellaneous

Transportation

Total

Federal Region 8

Electr1c Ut11ty

Commerclal/Residentlal

Industrial Fuel

Industrlal processes

Miscellaneous

Transportation Total

Federal Region 9

Electric Utility

Commercial/Residential

Industrial Fuel

Industrlal Processes

Mlscellaneous

Transportation

Total

Federal Region 10

Electric Utility

Commernlal./Resldentlal

Indusurial Fuel

Industrtal processes

Miscellaneous

Transportation Total

National Totals

Electric Utility

Commercial/Resident 1 al

Industrlal Fuel

Industrial processes

Miscellaneous

Transportation Total yederal Re

Regton and Seamon

(kt) (Cont'd)

Winter
Dec83
-Feb84

Spring
Mar84
-May 84
Summer
Jun 84
-Aug 84
Autumn
Sep84
- Nov84

148.0

122.1

6.4

37.7

10.5

1.5

136.6

314.8

358.9

306.4

335.1

125.3

27.1

137.3

18.9

6.8

243.5

558.9

82.0

7.8

42.8

6.8

7.7

118.5

265.5

91.2

2.4

36.3

6.9

8. 8

142.1

287.7

89.7

5.3

40.4

6.5

8.7

126.6

277.2

58.6

15.8

50.3

7.7

2.4

172.7

307.4

$$
\begin{array}{r}
53.4 \\
11.8 \\
57.4 \\
9.7 \\
6.6 \\
248.4 \\
387.2
\end{array}
$$

79.4

6.1

52.0

10.8

9.1

271.0

428.3

71.0

8.7

57.9

10.1

9.6

216.8

404.1

517.1

38.0

156.3

40.1

6.2

525.4

1283.1

23.0

10.3

27.8

4.9

4.2

84.4

154.5

\section{2}

5.3

14.1

3,4

16.2

76.5

116.7

\section{2}

1.6

12.8

3.4

16.9

94.5

133.6

1508.9

1396.7

180.9

795.4

161.9

879.7

141.2

42.8

66.6

1694.3

4590.6

2015

4616.6
1673.6

47.2

746.4

165.2

63.0

2312.7

5008.1
7.5

4.6

13.7

3.3

16.3

77.9

123.3

1453.8

118.6

772.4

159.4

59.4

2.075 .4

1639.0
362.1

28.3

169.5

26.0

29.9

480.2

1096.1

258.8

16.2

229.2

38.5

30.4

991.4

1594.5

18.0

20.1

55.1

13.2

58.3

307.8

173.2

6033.3

670.3

3191.4

627.8

231.7

8097.6

188555.1 


\section{NOX Emlssions by}

Fed. Region / Sector

Federal Region 1

Electric Utilty

Commerclal/Residential

Industrlal Fuel

Industrial processes

Miscellaneous

Transportation Total.

Federal Region 2

Electric Utility

Commerclal/Restdentilal.

Industrial Fuel

Industrial prooesses

Miscellaneous

Transportation T'ota.l

Foderal Rogion 3

Electric Utility

Commerclal/Residential

Industrial Fuel

Industrial processes

Miscellaneous

Transportation Total

Federal Region 4

Electric Utility

Commerclal/Resident 1 al

Industrial Fuel

Industrial Processes

Miscellaneous

Transportation Total

Federal Region 5

Electric Utility

Commercial/Residential

Industrtal. Fuel.

Industrlal. Processes

Miscellaneous

Transportation Total

Federal Reglon 6

Electric Utidty

Commerclal/Residential

Industrial Fue 1

Industrial Processes

Miscellaneous

Transportation Tolial.
Federal Region and

Season

(kt)

$\begin{array}{rrrrr}\text { Winter } & \text { Spring } & \text { Summer } & \text { Autumn } & \text { Annual } \\ \text { Dec84 } & \text { Mar85 } & \text { Jun85 } & \text { Sep85 } & \text { Jan85 } \\ \text {-Feb85 } & \text { - May85 } & \text {-Aug85 } & \text {-Nov85 } & \text {-Dec85 }\end{array}$

37.7
28.4
48.2
2.0
2.0
98.1
216.6

$$
\begin{array}{r}
27.5 \\
11.6 \\
9.3 \\
0.6 \\
1.4 \\
76.7 \\
127.1
\end{array}
$$
31.9
2.2
8.6
0.6
1.3
98.3
143.0

30.7
7.9
9.1
0.6
1.3
81.3
130.9

124.5

44.4

36.6

2,4

5.2

319.2

532.2

$$
\begin{array}{r}
39.8 \\
34.0 \\
22.0 \\
3.4 \\
1.8 \\
66.5 \\
16 \% .5
\end{array}
$$

46.0

53.8

5.5

17.8

20.0

4.5

2.7

120.2

216.8

4.4

2.5

155.2

239.1

45.3

198.6

14.5

18.4

4.1

2.5

124.1

209.3

$\begin{array}{rr}183.0 & 191.8 \\ 34.1 & 17.7 \\ 47.9 & 54.5 \\ 17.2 & 17.5 \\ 3.4 & 2.9 \\ 120.4 & 182.0 \\ 406.1 & 466.3\end{array}$

201. 4

4.7

45.5

17.6

2.8

212.0

484.1

182.8

11.2
46.9

17.0

2.8

185.5

446.1

91.6

78.1

17.5

10.2

495.0

891.1

$\begin{array}{rr}275.6 & 302.3 \\ 49.4 & 14.0 \\ 94.9 & 90.3 \\ 21.4 & 28.0 \\ 8.5 & 16.9 \\ 272.0 & 357.8\end{array}$

$721.8 \quad 809.4$

366.1

308.3

8.3

81.9

81.5

27.5

10.5

7.8

365.1

855.8

351.6

785.5

416.3
74.6
112.5
14.3
4.6
235.4
857.7

377.9
41.0
108.0
19.3
5.0
347.0
898.2

406.5

383.6

26.3

98,0

18.9

92.7

19.6

4.7

413.9

950.5

4.6

352.1

883.4

266.2
39.3
252.9
41.8
3.7
234.6
838.5

235.0
11.5
315.0
62.7
5.4
300.1
929.7

295.5

230.0

8.5

5.1
323.3

324.1

63.6

4.2

309.7

61.5

3.7

300.9

928.7
793.0

73.7

209.0

66.9

11.2

724.3

1878.2

1300.9

69.8

350.6

108.2

42.9

1388.9

3261.4

1596.4

163.9

425.9

73.6

18.9

1386.1

3664.8

1011.2

61.1

1312.3

242.7

17.0

1175.1

3819.3 


\section{Nox Im1saton by ro}

Fed. Region / Sector:

Federal Region 7

Eleotrio Ut11ty

Commerclal/Restdential

Industrdal Fuel

Industrlal processes

Miscellaneous

Transportation

Total.

Federal Region 8

Electrlc Utilty

Commerclal/Resldentlal

Industrlal Fuel

Industrial processes

Mlscellaneous

Transportation Total

Federal Reglon 9

Electric Ut11ty

Commercial/Residential

Industrial Fuel.

Industrlal Processes

Miscellaneous

Transportation Total.

Federal Region 10

Electric Ut111ty

Commerclal/Residential

Industrial Fuel

Industrlal processes

Miscellaneous

Transportation Total

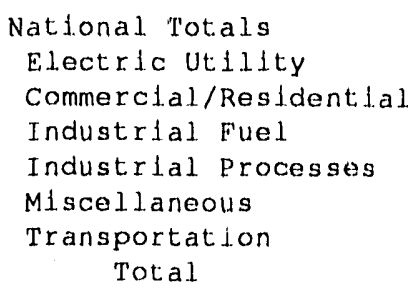

rederal.

Region

and

Seavon

(kt) (Cont'd)

Winter
Deo84

Sprlng
Mar85
- May85

Summer
Jun85
-Aug85

Autumn
Sop 35

-NOVBS

Armual

-Feb85

153.9
18.6
41.9
8.3
2.8
95.4
324.0

$$
\begin{array}{r}
108.2 \\
7.7 \\
34.7 \\
10.6 \\
1.7 \\
123.5 \\
286.3
\end{array}
$$

$$
\begin{array}{r}
116.3 \\
3.4 \\
35.1 \\
11.0 \\
1.5 \\
147.2 \\
314.5
\end{array}
$$

136.2

28.7

136.4

18.8

5.2

220.7

546.0

$$
\begin{array}{r}
90.9 \\
7.2 \\
40.5 \\
6.7 \\
7.3 \\
84.1 \\
236.8
\end{array}
$$

$$
\begin{array}{r}
99.3 \\
6.1 \\
40.2 \\
10.3 \\
1.5 \\
128.4 \\
286.1
\end{array}
$$

392.0

169.4
313.6

25.3

11.5

22.8

4.7

3.7

82.6

150.7

$$
2.6
$$

5.1

12.2

3.4

15.6

72.9

111.7

1605.9

335.7

828.0

139.5

37.7

1595.6

1542.4

$$
\begin{array}{r}
1445.1 \\
151.3 \\
736.4 \\
163.2 \\
65.2 \\
1913.1 \\
4474.4
\end{array}
$$

$$
\begin{array}{r}
91.9 \\
2.5 \\
33.3 \\
6.9 \\
6.2 \\
106.6 \\
250.6
\end{array}
$$
78.8
6.2
47.9
10.7
6.2
263.9
413.6

$$
\begin{array}{r}
91.1 \\
5.5 \\
36.8 \\
6.7 \\
5.6 \\
89.7
\end{array}
$$$$
2.35 .1
$$

66.1

8.5

51.9

10.1

5.9

250.1

392.9

$$
6.9
$$

1.3

10.8

3.4

12.2

89.7

124.3

$$
\begin{array}{r}
5.5 \\
5.1 \\
11.9 \\
3.3 \\
10.4 \\
75.1 \\
111.3
\end{array}
$$

$\begin{array}{rr}1652.1 & 1442.7 \\ 48.6 & 102.2 \\ 696.6 & 719.2 \\ 166.0 & 160.4 \\ 52.3 & 46.0 \\ 2161.4 & 1939.2 \\ 4777.0 & 4409.7\end{array}$

6151.2

637.9

2980.5

629.1

201.3

1609.3

18209.1 
1986 NO'X EmLetons by

Fad, Rogton / Sector

Federal Region 1

E.leotr lo Ut111ty

Indurtrlal Fuel

Industrial processes

Miscellanoous

'Transportation

Foderal Roglon 2

Electria Utilty

Commerclal/Resldent 1 al.

Industrial Fuel.

Industrial processos

M.lacell laneous

Transportation

Foderal Reglon 3

Pilectrlc Utility

Commerclal/Rosident 1 al

Industirlal Fuel

Industrial processes

Miscellaneous

Transportation

Foderal Region $A$

Electric Utility

Industrlal Fuel

Industrla.l processes

Miscellaneous

Transportation.

and

seacon

(kt)

\section{Autumn \\ Sep86 \\ -NOV86}

Annual.
Jan86
-10086

Commorctal/Resldent tal

I'otal rotal

T'otal

Commercial/Resldential Total.

39.3
30.1
50.3
2.1
2.0
91.3
215.1

$$
\begin{array}{r}
32.0 \\
13.3 \\
11.9 \\
0.6 \\
1.1 \\
71.6 \\
133.8
\end{array}
$$

$$
\begin{array}{r}
33.9 \\
38.9 \\
19.8 \\
3.4 \\
1.8 \\
62.9
\end{array}
$$

160.7

$$
\begin{array}{r}
41.7 \\
27.5 \\
1.8 .9 \\
1.4 \\
2.7 \\
117.8 \\
215.9
\end{array}
$$

175.8

34.6

50.3

17.6

3.1

114.6

396,3

180.5
20.0
55.8
16.5
2.9
176.1
151.9

206.1

29.1

2,3

10,8

0.6

1.3

96.2

140.3

122.7
51.1
46.5
2.1
5.2
305.8
533.7

182.9

106.7

72.4

16.9

10.2

479.5

868,6

122.2
206.6

182.9

14.5

46.1

15.7

2.8

177.7

439.7

478.5

279.5

47.1

94.6

21.4

8.5

263.1

714.1

302.8

16.9

92.4

$2 \%, 2$

16.9

317.5

803.7

381.9

1.6
80.7

27.4

10.5

365.4

870.5

315.6
10.7

81.0

27.0

7.8

345.9

788.0

437.2

12.4

92.7

18.1

4.7

116.0

981.0

366.2

28.7

97.5

17.3

4.6

354.3

868.7

338.5

$$
\text { Totial. }
$$

227.5

263.5

222.7

305.2

5.4

318.3

60.8

4.2

296.0

990.1
290.2
9.8

320.5

60.2

3.7

286.4

920.8
780.3

79.8

209.6

62.8

11.2

696.8

1840.5

1310.9

73.5

352.5

106.1

42.9

1361.7

3248.0

1605.5

164.6

432.2

69.4

18.9

1377.5

3668,2

1009.1

58.5

1295.1

236.6

17.0

1118.9

3735.8 
1986 NOX Emlasions by

Fed. Region / Sector

Federal Region 7

Electric Utility

Commerclal/Residential.

Industrial Fuel

Industrial processes

Miscellaneous

Iransportation Total

Federal Region 8

Electrlo Utility

Commerctal/Resldential

Industrial Fuel

Industrlal processes

Miscellaneous

Transportation T'otal.

Federal Region 9

Electric Ut1lity

Commerclal/Resldent lal

Indust.rlal Fuel

Industrlal processes

Miscellaneous

Transportation T'otal

Federal Region 10

Electric Utility

Commercial/Residentlal

Industrlal Fuel

Industrtal processes

Mlscellaneous

Transportation Tot:al

National Totals

Electr1c Ut.11ity

Commerclal/Resident lal

Industrial Fuel

Industrlal processes

Miscellaneous

Transportation

$$
\text { Total }
$$

Taderal

Winter

- Deo85

-Fob8 6

137.2

17.9
41.7

41.7

8. 1

2.8

93.6

301.3

143.8

26.9

135.0

18.8

5.2

213.5

543.3

65.3

15.4

44.7

8.0

2.1

16 ? . 8

298.3

4.9

11.1

23.6

9.7

3.7

80.1

127.6

1547.5

328.9

825.3

140.1

37.7

1537.2

4417.1
Spring
Mar86

-May 86

$$
\begin{array}{r}
98.9 \\
0.5 \\
31.7 \\
9.9 \\
1.7 \\
117.9 \\
268.6
\end{array}
$$

82.2

6.9

39.5

6.5

7.3

81.8

224.2

50.9

11.9

5.1 .8

9.8

6.2

210.5

370.8

seacon

Summer
Jun8 6
-Aug86

126.

31.6

10.1

1.5

145.3

318.5

89.9

2.4

31.9

6.6

6.2

106.0

243.0

63.1

6.5

48.5

10.6

6.2

263.9

399.1

0.0

5.1

13.9

3.3

15.6

73.1

111.0

1395.9

165.1

738.7

156.8

65.2

1850.5

1372.2

123.5

1693.7

688.1

157.9

52.3

2135.3

4775.0 (kt) (Cont'd)

Autumn
Sep8 6

-Nov8 6

Annual

JanB 6

-Doc86

136.0

35.8

140.6

38 .?

6.1

480.5

1137.3

124.2

279.2

374.2

26.8

151.8

25.2

22.7

338.5

939.2

231.0

225.5

15.0

206.1

38.9

22.1

964.7

1502.5

2.45 .9

375.5

11.5

19.5

54.6

12.9

44.9

294.3

137.8

74.1

109.9

1421.3

119.4

710.4

154.6

46.0

1895.2

4347.0
6058.9

661.2

2962.1

609.7

201.3

7418.2

17911.4 
1987 Nox Emisatons by

Fed. Regton / sector

Fedoral Reglon 1

Electric Ut 11.ty

Commerclal/Residential

Industrial Fuel

Industrial processes

Miscellanoous

Transportation 'T'otal

Fodoral Reglon 2

Electrlc Ut 11 ty

Commerclal/Residentlal

Industrial fuel

Industrlal processes

MIsce 11 aneous

Transportation Total

Foderal Region 3

E.lectric Ut111ty

Commerclal/Resident lal.

Industrlal. Fue 1

Industrial. Processes

Miscellaneous

Transportation Total

Federal Region 4

Electr1c Uti1tty

Commercial/Resldent lal

Industrtal Fuel

Industrlal Processes

Mlscellaneous

Transportation

Total

Federal Region 5

Electrlc Ut1lty

Commerclal. Residential.

Industrial Fuel

Industrtal processes

Miscelianeous

Transportation Total.

Foderal Region 6

Electric Ut11ty

Commerclal. Residential

Industrlal Fuel

Industrlal processes

Miscellaneous

iransportation

$$
\text { T'otal. }
$$

Rogion and

Season

(kt)

Winter

Dec86

-Feb81

Spring
Mar87
-May 87

summer

Jun 87

- Aug 87

Autumn
Sep8'
-Nov87

Annual

$\operatorname{Jan} 87$

-Dec87

$\begin{array}{rr}32.8 & 27.1 \\ 28.6 & 13.2 \\ 50.7 & 10.8 \\ 2.5 & 0.7 \\ 2.0 & 1.4 \\ 90.1 & 74.7 \\ 206.6 & 128.1\end{array}$

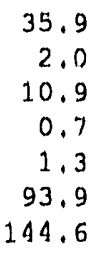

32.4

130,9

9.7

11.1

0.7

1,3

76.1

131.8

48.8

44.5

2.8

5.2

304.1

536,3

$\begin{array}{rrr}32.5 & 42.6 & 61.2 \\ 36.9 & 26.1 & 4.6 \\ 23.4 & 18.5 & 16.9 \\ 3.5 & 4.5 & 4.4 \\ 1.8 & 2.7 & 2.5 \\ 63.2 & 115.6 & 142.7 \\ 161.3 & 210.1 & 232.4\end{array}$

49.8
19.6
18.9
4.5
2.5
116.1
210.9

201.8

100.6

75.3

17.8

10.2

462.8

868.6
151.1
33.8
45.2
18.3
3.4
11.2 .2
364.0
178.3
20.4
54.0
16.6
2.9
171.1
443.3
220.1
4.5
47.8
17.0
2.8
202.6
494.9

196.6

15.9

51.7

16.8

2.8

177.7

461.4

794.1

80.4

2] 3.7

65.3

11.2

687.6

1852.1

277.7
44.2
85.1
25.2
8.5
259.8
700.5

291.5
1.7 .7
84.6
32.1
16.9
345.6
788.3

387.1

319.4

1308.8

4.2

80.9

33.0

10.5

360.4

876.0

13. 1

86.5

32.6

7.8

341.9

801.2

73.2

343.1

127.7

42.9

1349.2

3244.9

390.5

412.6

460.7

353.8

30.2

97.6

18.1

18.7

14.2

97.4

17.8

5.0

4.6

223.8

805.2

323.6

895.3

4.7

390.4

973.2

4.6

334.1

838.7

1633.1

152.3

103.9

70.5

18.9

1309.8

3588.6

285.4
34.9
259.1
42.8
3.7
220.6
846.5

233.5
14.5
316.2
62.0
5.4
274.2
905.8

305.2
4.9
327.1
63.6
4.2
289.6
994.6

2. 30.3

10.0

1005.3

61.6

320.1

1322.7

245.5

17.0

3.7

1088.0

3740.0 


\section{NoX Emisatons}

Fed, Reglon / Sector

Federal Region 7

Electric Ut1lity

Commerclal/Restdentlal

Industrlal Fuel

Industrial processes

Miscellaneous

Transportation

T'otal.

Federal Region 8

Electric Utility

Commercial/Residential

Industrial Fuel

Industrial Processes

Miscellaneous

Transportation Total

Federal Region 9

Electric Ut111ty

Commercial/Restdential

Industrlal Fuel

Industrial Processes

Miscellaneous

Transportation Total.

Federal Region 10

Electric Utility

Commerclal/Residential

Industrlal Fuel

Industrlal Processes

MIscellaneous

Transportation Total

National Totals

Electric Utility

Commerclal/Resldentlal

Industrlal Fuel.

Industrial Processes

Miscellaneous

Transportation Total

Region and

Season

(kt) (Cont'd)

\section{Winter \\ Dec 86}

- Feb87
Sprlng
Mar 87
-May 87

Summer
Jun87
-Aug87

Autumn
Sep87
-Nov87

Annual

$\operatorname{Jan} 8 \%$

$-\operatorname{Dec} 8 \%$
143.5
16.0
43.7
8.3
2. 8
89.7
303.9

$$
\begin{array}{r}
99.6 \\
8.0 \\
31.0 \\
10.1 \\
1.7 \\
114.4 \\
267.7
\end{array}
$$

141.6

26.6

132.6

19.1

5.2

205.2

530.4

66.3

16.9

51.5

8.6

2. 1

167.0

312.4

4.3

10.2

28.3

5.8

3.7

79.1

131.4

$\begin{array}{rr}1525.6 & 1443.5 \\ 312.3 & 162.3 \\ 827.8 & 714.4 \\ 148.2 & 163.9 \\ 37.7 & 65.2 \\ 1510.7 & 1809.2 \\ 4362.3 & 4358.5\end{array}$

$$
\begin{array}{r}
96.8 \\
6.7 \\
35.5 \\
6.4 \\
7.3 \\
77.8 \\
230.5
\end{array}
$$

$$
\begin{array}{r}
56.7 \\
12.4 \\
50.6 \\
9.9 \\
6.2 \\
242.9 \\
378.7
\end{array}
$$

$$
\begin{array}{r}
141.1 \\
3.2 \\
32.8 \\
10.5 \\
1.5 \\
141.2 \\
330.3
\end{array}
$$

$$
\begin{array}{r}
110.5 \\
6.2 \\
34.1 \\
10.4 \\
1.5 \\
122.6 \\
285.6
\end{array}
$$

$$
\begin{array}{r}
104.2 \\
2.0 \\
32.9 \\
6.8 \\
6.2 \\
100.2 \\
252.4
\end{array}
$$

$$
\begin{array}{r}
96.1 \\
4.3 \\
37.1 \\
6.8 \\
5.6 \\
83.9 \\
234.0
\end{array}
$$

72.6

6.4

48.9

10.8

6.2

266.0

411.1

$$
\begin{array}{r}
66.6 \\
8.3 \\
51.0 \\
10.3 \\
5.9 \\
246.6 \\
388.8
\end{array}
$$

$\begin{array}{rr}4.6 & 4.6 \\ 4.4 & 1.3 \\ 12.8 & 12.3 \\ 3.9 & 4.0 \\ 15.6 & 12.2 \\ 69.4 & 87.3 \\ 110.7 & 121.6\end{array}$

4. 6

1.3

2.3

4.0

12.2

121.6
1792.7
44.4
697.6
169.6
52.3
2074.2
4830.9

\section{4}

3.6

13.3

3.9

10.4

71.9

106.5

1458.9
120.9
721.8
167.8
16.0
1852.7
1368.2
165.7

33.2

113.6

39.1

6.1

466.7

1154.7

403.8

2.3 .9

149.4

25.7

22.7

322.7

948.2

261.6

48.0

213.1

39.3

22.1

974.3

1558.4

18.6
17.8
51.8
15.4
14.9
281.7
130.3

6223.7

639.9

2961.3

649.5

201.3

7217.0

17922.6 
1988

NOX Entsstons by

Region

Season

(kt)

Fed. Region / Sector
Federal Region 1
Electric Utility
Commercial/Residential
Industrial Fuel
Industrial Processes
Miscellaneous
Transportation
Total

Federal Region 2

Electric Utility

Commercial/Residential

Industrial $i \ldots+1$

Irdustrial Processes

Miscellaneous

Transportation Total

Federal Region 3

Electric Utility

Commercial/Residential

Industrial Fuel

Industrial Processes

Miscellaneous

Transportation Total

44.1
29.6
51.6
2.7
2.0
85.3
215.3

\section{Winter \\ Dec87}

-Feb88

Spring
Mar 88
- May 88

Summer
Jun 88
-Aug 88

Autumn
Sep88
-Nov88

Annual

$\operatorname{Jan} 88$

- Dec 88

215.3

45.7

38.1

24.4

3.9

1.8

60.3

174.1

29.7
13.4
13.2
0.8
1.4
70.3
128.8

110.0

207.7

166.6

35.2

47.4

22.2

3.4

106.1

380.8

$$
\begin{array}{r}
171.8 \\
21.2 \\
54.0 \\
20.2 \\
2.9 \\
162.3 \\
432.4
\end{array}
$$

Federal Region 4

Electric Utility

Commercial/Residential

Industrial Fuel

Industrial Processes

Miscellaneous

Transportation

$$
\text { Total }
$$

Eederal Region 5

Electric Utility

Commercial/Residential

Industrial Fuel

Industrial Processes

Miscellaneous

Transportation

$$
\text { Total }
$$$$
306
$$

306

46.3

290.6

17.8

87.8

36.0

28.5

8.5

16.9

244.1

323.3

721.8

772.4

399.5

375.9

41.1

103.7

107.7

17.0

21.8

5.0

306.0

2.12 .2

811.4

853.4

Federal Region 6

Electric Utility

Commercial/Residential

Industrial Fuel

Industrial Processes

Miscellaneous

Transportation Total
295.5

243.9
1.5 .4
335.6
71.8
5.4
266.6
938.7

$\begin{array}{rr}295.5 & 243.9 \\ 37.7 & 15.4 \\ 254.5 & 335.6 \\ 49.6 & 71.8 \\ 3.7 & 5.4 \\ 211.7 & 266.6 \\ 852.7 & 938.7\end{array}$

33.8
2.1
13.0
0.8
1.3
88.4
139.3

31.3

9.9

14.0

0.8

1. 3

71.8

129.1

64.5

4.9

19.0

5.1

2.5

136.0

232.1

315.3

212.2

49.8

20.5

2.8

192.8

482.6

50.6

20.3

20.7

5.1

2.5

110.4

209.6

189.3

16.2

54.8

19.7

2.8

168.6

451.5

385.8

4.5

82.6

36.8

10.5

339.2

859.4

449.1

365.4
32.1

1.02 .8

21.5

92.6

22.3

4.7

369.5

949.7

4.6

316.3

842.9
241.9
10.3
346.6
71.8
3.7
274.3
948.6

1049.8

66.5

1375.4

282.9

17.0

1059.4

3850.9
136.0

54.3

3.1

286.2

534.6

216.0

104.3

20.2

10.2

440.9

784.5

83.4

78.2

11.2

652.7

1829.9

1346.2

76.9

142.4

42.9

1264.4

3228.2

1600.8

163.4

84.3

18.9

1239.7

3527.4

283.7

1018.3 
(kt) (Cont'd)

Fed. Region / Sector

Federal Region 7

Electric Utility

Commercial/Fesidential

Industrial Fuel

Industrial Processes

Miscellaneous

Transportation Total

Federal Region 8

Electric Utility

Commercial/Residential

Industrial Fuel

Industrial Processes

Miscellaneous

Transportation

Total

Federal Region 9

Electric Utility

Commercial/Residential

Industrial Fuel

Industrial Processes

Miscellaneous

Transportation Total

Federal Region 10

Electric Utility

Commercial/Residential

Industrial Fuel

Industrial Processes

Miscellaneous

Transportation Total

National Totals

Electric Utility

Commercial/Residential

Industrial Fuel

Industrial Processes

Miscellaneous

Transportation Total winter

Dec87

-Feb88

152.1

17.8

45.3

10.0

2.8

86.2

314.2

129.9

28.1

137.3

21.9

5.2

197.0

519.3

71.2

18.5

43.7

9.5

2.1

159.7

304.7

27.7

11.0

33.1

6.8

3.7

74.7

156.9

1638.4

332.7

832.8

172.0

37.7

1437.4

4451.1
Spring
Mar 88

-May 88

Summer
Jun 88

-Aug 88

$$
\begin{array}{r}
101.7 \\
8.8 \\
38.1 \\
11.9 \\
1.7 \\
110.6 \\
272.7
\end{array}
$$

$$
\begin{array}{r}
147.5 \\
3.5 \\
35.3 \\
12.2 \\
1.5 \\
137.0 \\
337.0
\end{array}
$$

111.0
7.2
38.3
7.7
7.3
75.5
247.0

112.7

2.1

33.3

8.0

6.2

97.4

259.7

67.9

13.1

54.9

11.2

6.2

233.5

386.9

Autumn

Sep88

- Nov8 8

112.4

6.2

31.5

11.8

1.5

118.9

282.3

104.0

4.5

37.2

7.8

5.6

81.5

240.6

84.9

7.3

50.4

12.1

6.2

257.2

418.1

63.2

9.5

62.7

11.5

5.9

237.7

390.6

5.0

1.3

13.0

4.5

12.2

82.3

118.5

65.5

108.5

1438.0

1810.8

47.6

725.0

195.5

52.3

191.0

65.2

1723.6

4348.5

1983.4

4814.6
4.8

3.7

13.7

4.4

10.4

68.0

104.9

1482.1

126.7

773.0

190.2

46.0

1768.3

4386.4
Annual

Jan88

-Dec88

486.1

36.0

146.4

45.9

6.1

452.0

1172.5

449.8

26.1

152.9

30.4

22.7

313.4

995.3

278.6

52.2

226.0

43.9

22.1

937.9

1560.7

19.3

$\therefore 18.5$

55.9

17.6

44.9

266.1

422.2

6367.1

677.0

3091.3

748.7

201.3

6912.7

17998.2 
321

B.8 $\mathrm{SO}_{2}$ Emissions

by Federal Region and Season 
$1975 \mathrm{SO}_{2}$ Emisstons by

Fed. Regton / sector

Pederal Region 1

Electric Utility

Commercial/Residential

Industrial Fuel

Industrial processes

Miscellancous

Transportation T'otal

Federal Region 2

Electric Utility

Commercial/Residential

Industrial Fuel

Industrial. Processes

Miscellaneous

Transportation Total

Federal Region 3

Electric Utility

Commercial/Residential

Industrial Fuel

Industrial processes

Miscellaneous

Transportation

Total

Federal Region 4

Electric Utility

Commercial/Residential

Industrial Fuel

Industrial processes

Miscellaneous

Transportation Total.

Federal Region 5

Electric Utility

Commercial/Residential

Industrial Fuel

Industrial. Processes

Miscellaneous

Transportation

$$
\text { Total }
$$

Federal Region 6

Electric Utility

Commercial/Residenti.al

Industrial Fuel

Industrial processes

Miscellaneous

Transportation

Total

Region and

Searon

(kt)

Winter
Dec74

-Feb75
Spring
Mar 75
-May 75

45.8

34.3

56.3

1.1

0.7

4.5

142.7

$N / A$

$\mathrm{N} / \mathrm{A}$

$N / A$

$N / A$

$N / A$

$N / A$

$N / A$

$N / A$

$\mathrm{N} / \mathrm{A}$

$N / A$

$N / A$

$N / A$

$N / A$

$N / A$

$N / A$

$N / A$

$N / A$

$N / A$

$N / A$

$N / A$

$N / A$

$N / A$

$N / A$

$N / A$

$N / A$

$N / A$

$N / A$

$N / A$

$\mathrm{N} / \mathrm{A}$

$\mathrm{N} / \mathrm{A}$

$\mathrm{N} / \mathrm{A}$

$N / A$

$\mathrm{N} / \mathrm{A}$

$N / A$

$N / A$

$N / A$

$\mathrm{N} / \mathrm{A}$

140.1

61.3

93.7

6.5

1.3

9.8

312.7

645.0

36.9

114.3

60.5

1.0

13.6

871.2
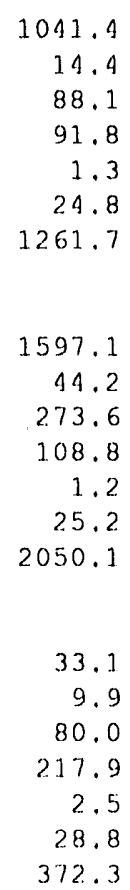

Summer
Jun 75
-Aug 75

Autumn

Sep 75

-Nov 75

$$
\begin{array}{r}
52.8 \\
1.5 \\
51.4 \\
1.2 \\
0.7 \\
5.6 \\
113.2
\end{array}
$$
156.3
2.4
83.9
5.9
1. 3
11.3
261.0

$$
\begin{array}{r}
697.4 \\
3.2 \\
101.0 \\
57.0 \\
1.0 \\
15.4 \\
875.0
\end{array}
$$

1252.9
2.6
78.8
90.1
1.1
26.3
1451.8

1143.2

11.2

85.4

94.0

1.0

25.4

1360.3

650.1

22.9
108.4

58.7

1.0

14.2

855.3
1825.5
22. 4
239.8
105.8
1.2
29.8
2224.5

1636.9
44.6
255.6
108.4
1.2
27.1
2073.8

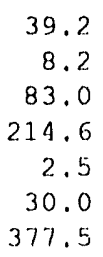

Annual

Jan 75

-Dec 75

204.3

116.2

$23^{\circ} .4$

1.7

2.6

18.6

579.8

587.8

205.5

377.8

25.0

5.1

39.3

1240.7

2709.8

132.1

445.5

233.8

3.8

54.5

3579.6

4543.1

66.1

349.0

365.9

4.4

98.8

5427.1

6825.7

186.1

1056.4

427.1

1.9

103.0

8603.9

166.1

50.1

328.0

856.8

9.9

115.6

$1527 . ?$ 
Federal Region 7

Electric Utility

Commerclal/Resident lal.

Industrial Fuel

Industrial processes

Miscellaneous

Transportation

Total.

Federal Region 8

Electric Utility

Commerclal/Residentlal.

Industrial Fuel.

Industrial processes

Miscellaneous

Transportation Total

Federal Region 9

Electric Ut11ty

Commerofal/Residential

Industrial Fuel

Industrial processes

Miscellaneous

Transportation Total.

Federal Region 10

Electric Utı1ty

Commercial/Residential

Industrial Fuel

Industrlal Processes

Miscellaneous

Transportation Total

National Totals

Electric Utility

Comme"cial/Residential

Industrial Fuel

Industrial Processes

Miscellaneous

Transportation

$$
\text { Total }
$$

$\begin{array}{lr}N / A & 282.0 \\ N / A & 3.4 \\ N / A & 28.7 \\ N / A & 26.6 \\ N / A & 0.3 \\ N / A & 9.2\end{array}$

N/A $\quad 350.2$

$N / A$
$N / A$
$N / A$
$N / A$
$N / A$
$N / A$
$N / A$

45.5

5.2

26.9

138.5

0.4

6.8

223.2

365.2
1.2
25.3
29.9
0.3
10.9
432.8

323.5
3.1
26.6
30.3
0.3
10.1
394.0

1349.5

11.2

109.9

109.8

1.3

37.8

1622.5

204.1

18.3

109.3

524.7

1.1

28.5

886.6

$\begin{array}{lrrrr}\text { N/A } & 43.4 & 39.4 & 44.7 & 183.9 \\ \text { N/A } & 3.7 & 0.4 & 2.0 & 11.1 \\ \text { N/A } & 9.7 & 8.9 & 9.9 & 39.1 \\ \text { N/A } & 370.0 & 344.1 & 34 \% .2 & 1410.9 \\ \text { N/A } & 0.4 & 0.5 & 0.4 & 1.9 \\ \text { N/A } & 26.3 & 28.3 & 27.7 & 107.1 \\ \text { N/A } & 453.5 & 421.5 & 431.9 & 1754.1\end{array}$

$\begin{array}{lrrrr}\text { N/A } & 5.9 & 8.3 & 10.6 & 33.0 \\ \text { N/A } & 5.7 & 1.3 & 4.1 & 19.5 \\ \text { N/A } & 19.1 & 17.6 & 19.4 & 77.7 \\ \text { N/A } & 38.6 & 34.2 & 11.0 & 155.8 \\ \text { N/A } & 0.7 & 0.5 & 0.5 & 2.0 \\ \text { N/A } & 7.2 & 8.2 & 7.6 & 29.2 \\ \text { N/A } & 77.0 & 70.1 & 83.4 & 317.2\end{array}$

$\begin{array}{lrrrr}\text { N/A } & 3879.2 & 4193.9 & 1085.4 & 16807.9 \\ \text { N/A } & 218.8 & 35.8 & 155.4 & 820.3 \\ \text { N/A } & 790.3 & 709.8 & 766.6 & 3126.3 \\ \text { N/A } & 1060.2 & 1006.6 & 1030.6 & 1114.9 \\ \text { N/A } & 9.8 & 9.4 & 9.2 & 37.2 \\ \text { N/A } & 156.1 & 174.9 & 164.3 & 632.5 \\ \text { N/A } & 6114.4 & 6430.4 & 6211.5 & 25539.0\end{array}$


Federal

Winter

Deo75

Fed, Reglon / sector
Region and

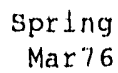

Mar 76

- May76

Federal Region 1

Electric Ut111ty

Commerclal/Residential

Industrial Fuel

Industrial processos

Miscellaneous

Transportation Tota!

\section{Federal. Region 2 \\ Electric Ut11.ty" \\ Commercial/Residential \\ Industrial. Fuel \\ Industrial processes \\ Mlscellaneous \\ Transportiation Total}

Federal Region 3

Electric Utility

Commerclal/Restdential

Industrial Fuel

Industrlal processes

Miscellaneous

Transportation Total

Federal Region 4

Electric Uti11ty

Commerclal/Residential.

Industrlal Fuel

Industrial processes

Miscellaneous

Transportation Total

Federal Region 5

Electric Utility

Commercial/Residential

Industrlal Fuel

Industrial processes

Miscellaneous

Transportation Total

Federal Region 6

Elect.ric Uti1tty

Commerclal/Resident.tal.

Industrlal. Fuel

Industrial processos

Miscellaneous

Transportation Total.

58.3
70.6
92.7
1.9
0.7
8.5
232.2

51.4

75.5

1.3

0.7

4. 6

165.2

106.6

137.1

54.0

108.3

83.2

5.8

0.9

6.6

284.3

5.8

1.3

10.6

$31 \%, 2$

837.8

55.7

672.7

28.2

109.9

59.3

48.8

0.8

11.1

1.0

15.1

1064.0

886.0

1023.5

1127.5

11.3

100.7

127.0

82.2

86.5

1.3

27.3

21.5

1329.2

1354.5

1599.9

80.7

1617.0

10.5

243.1

102.7

94,2

1.2

19.0

1.2

26.6

2020.1

2031.1

58.0

44.8

99.3

193.6

31.5

25.

31.5

380.1 season

(xt)

Summer
Jun 76
- Aug 76

Autumn
Sep 76
- Nov7 6

Annual

Jan 76

$-1)$ ec76

136,1

144.5

102.0

267.9

720.9

908.9

1377.

1593.1

1709.9

2105.6
56.3

1.3

70.9

1.3

0.7

5.7

2.4

5.8

1.3

12.0

54.0

29.7

81.7

1. 3

0.7

4.8

172.2

134.8

53.7

111.0

5.7

1.3

10,8

320,3

3.8

104.9

61.4

1.0

16.8

662.4

34.6

112.6

57.7

1.0

15.5

883.6

2. 3

95.6

87.5

1.1

28.9

1229.8

18.8

105.1

87.5

1.0

28.0

1470.3

24.6

231.9

106.1

1.2

31.4

1645.1

55.6

246.2

102.6

1.2

28.8

2079.6

69.8

0.1

97.9

189.4

2.5
62.6

18.1

104.7

200.0

2.5

32.7

120.4
226.6

131.8

321.6

5.1

2. 6

19.0

706.8

570.3

235.1

451.8

22.8

5.1

42.8

1328.2

2768.2

138.2

148.0

229.5

3. 8

60.0

3647.7

1970.1

76.7

4.16 .5

341.0

4.4

108.8

5917.5

6768.8

203.5

983.3

403.8

4.9

109.0

$8473 . ?$

3.3 .4

393.1
241.8

65.0

109.4

771.9

9.9

126.1

1627.3 


\section{$1976 \mathrm{SO}_{2}$ mistatons by}

Fed, Regton / Sectior

Foderal Reglon 7

Electric Utilitiy

Commerclal/Residental

Industrial Fuel

Industrlal processos

Miscellaneous

Transportation sotal

Federal Region 8

Electrlo Ut $11.1 \mathrm{ty}$

Commerclal/Resident 1 al

Industrlal ruel.

Industrtal processes

Misceldaneous

Transportation

Total

Federal Regton 9

Electrlc Utility

Commerclaj/Residentlal

Industrlal. Fuel.

Industrlal processes

Miscellianeous

Transportation Total

E'ederal Region 10

Electric Utility

Commerclal/Rosldentilal

Industrtal. Fuel

Industrial processes

Miscellaneous

Transportation

Total

National Totals

Electric Utility

Commerclal/Restdential

Industrlal Fuel

Industrial processes

Miscellaneous

Transportation 'Total

Tederal Region and

Season

(kt) (Cont'd)

WJinter
Dec75

- Peb76

523.7

15.2
45.9

23.6

0.3

8.1

616,8

249.1

23.4

83.2

116.0

1,1

22.2

195.4

Sprling
Mar76
-May76

Summor
Jur1 76

-Aug76

$$
\begin{array}{r}
316.6 \\
3.1 \\
28.6 \\
28.9 \\
0.3 \\
9.8 \\
387.3
\end{array}
$$

$$
\begin{array}{r}
395.3 \\
1.1 \\
27.5 \\
32.6 \\
0.3 \\
11.6 \\
168.5
\end{array}
$$

56.0

5.1

32.8

132.6

0.1

7.1

235.9

100.2

11.3

19.1

276.6

0.3

20.1

127.9

49.3
3.7

10.9

285.7

0.1

29.1

379.5

20.6

11.0

28.1

41.1

0.3

7.9

109.3

1578.2
462.1
926.2
881.0
8.9
150.2
7006.7

63.6

0.9

32.2

126.6

0.4

8,9

2.32 .5 .

31.5

366.1

$$
5.5
$$

1.6

19.2

35.5

0.5

9.2

71.5

80.5

4080.7
191.9
829.0
935.9
9.8
170.2
6217.5

4598.6
38.1
792.6
914.7
9.4
189.5
6543.2

370.8
1.0
28.6
30.6
0.3
10.8
115.2

1490.2

15.2

111,3

115.7

1.3

40.3

$1 \% \% .0$

256.8
19.5
134.1
503.5
1.1
30.0
915.1

223.9

11,6

15.5

1.101 .6

1.7

119.6

1501.0

30.8

372.3

13.2
1.3
21.1
30.6
0.5
8.6
78.3

35.0

20.5

83.1

115.5

2.0

33.0

319.0

4291.7
22.9
859.9
911.7
9.2
178.9
6176.3

17551.6

917.1

3107.8

3643.4

$3 \%, 2$

688.8

26216.3 
(kt)

Fod. Regton / soctor

Wtinter
Dec7e

Sprting
Mar77
-May 77

Summer
Jun $7 \%$

Aut: umn
sop $7 \%$

$-\operatorname{Aug} 77$

-Nov77

Annual

- Feb77

- May 77

62.8
71.9
96.5
1.9
0.7
8.8
242.2

52.2
27.9
77.6
1.9
0.7
4.7
164.5

55.7

2.2

74.1

1.1

0.7

5.9

Transportation 'Total.

139,9

$$
\begin{array}{r}
55.3 \\
22.6 \\
81.8 \\
1.3 \\
0.7 \\
1.9 \\
166.6
\end{array}
$$

$-10077$

roderal. Reglon?

Eleotrice Utilit:y

Commercial / Ros ldential

Industrial puel

Industital Procosses

Mlscellaneous

'Transportation 'Iotial.

$\begin{array}{rr}111.9 & 113.7 \\ 91.0 & 48.4 \\ 87.7 & 107.5 \\ 5.8 & 6.0 \\ 0.9 & 1.3 \\ 6.9 & 11.0 \\ 310.1 & 317.9\end{array}$
166.7
3.6
101.5
5.9
1.3
12.6
2.91 .6
142.9
11.2
109.9
5.8
1.3
11.3
311.9

232.0

119.8

329.4

5.3

2.6

19.5

708.7

Fodoral Region 3

bilect $r$ le Utilltiy

Commerclal / Rosident la 1

Industrlat Fuel

$807.8 \quad 655.6$

66.1

112.0

25.3

108.7

701.4

4.4

102.1

61.7

62.1

1.0

1.0
15.5

scellaneous

0.8

11.5

17.9

867.7

888.3

627.1

26.2

107.3

59.1

1.0

16.0

$83 \% .0$

616.0

22.2 .4

145,7

23.1

5.1

41.5

1356.9

Foderal Reglon 4

vilectric Utility

Commorclal / Ros ldent lal.

1110.3

1067.2

1460.9

1204.1

12.7

111.7

134.5

2.8

105.6

112.8

91.1

89.7

Industrial procossos

83.0
1.2

91.5

1.1

28.8

Transportation 'rotal.

22.0

30.5

1.0

2.9 .2

$1692.2 \quad 1149.6$

2670.1

136.4

437.3

234.3

3,8

61.7

3541.0

Fedoral Reglon 5

E.lectric Utility

Commerclal / Resldont tal

Industrial fuol

$\begin{array}{rr}1560.2 & 1575.3 \\ 83.0 & 35.0 \\ 226.2 & 216.4 \\ 101.2 & 114.0 \\ 1.2 & 1.2 \\ 18.7 & 26.8 \\ 1990.6 & 1998.7\end{array}$
1751.5
229.4
115,0
1.2
31.5
2.152 .2

1628.4
46.4

238.3

Mlscollaneous

T'ransportation

$$
\text { 'lotal }
$$

1.2

28.2

2054.1

5032.6

81.7

457.8

352.9

1.1

113,6

6043.0

Federal Roglon 6

Fiecticle Ut:1llty

Commerclal/Resident dal

Industrlal Fuel

74.4

74.9

93.3

67.6

10.8

109.0

211.5

215.6

2.5

2.5

31.9

150.5

436.3

6720.6

190.8

976.6

110.1

1.9

108,1

8411.0

Miscellanoous I'otal

476.6

440.1

$$
\begin{array}{r}
315.0 \\
82.2 \\
433.1 \\
839.4 \\
9.9 \\
135.2 \\
1814.8
\end{array}
$$


Fed, Reglon / Sector

Foderal Region 7

Electric Utility

Commerclal/Resldent tal.

Industrial Fuel

Industrlal processos

Miscellaneous

Transportation Total.

Federal Region 8

Electrlc Utility

Commerclal/Restdentlal.

Industrlal Fuel

Industrlal processes

Mlscellaneous

Transportation

Total

Federal Region 9

E.lectrlo Ut111ty

Commercial/Resldential

Industrial Fuel

Industrial processes

Mlscellaneous

Transportation

$$
\text { Total }
$$

Federal Regton 10

Electric Ut11ty

Commerclal / Residential

Industrlal Fuel

Industrlal Processes

Miscellaneous

Transportation Total

National Totals

Electric Utilty

Commerclal/Resldentlal

Industrlal Fuel

Industrial Processes

Miscellaneous

Transportation Total
WLinter

De076

- Feb77

528,3

15,0

45,2

22,6

0.3

8.7

620.3

192,8

21.9

80.0

131.8

1.1

22,8

450.1

Sprling
Mar77
- May77

121.7

11,8

19.4

236.4

0.3

22.2

411.8

21.8

11.3

30.2

42.1

0.3

8.3

114.3

4598.1

511.7

948.8

871.6

8.9

155.6

7094.7
1799.2

40.0

804.4

874.1

9.4

199.9

$672 \% .0$
Summer
Jun 77

-Aug 7\%

419.9

1.0

26,9

34.4

0.3

12.4

494.9

411.7

67.1

5.0

30.7

143.7

0.4

7.7

254.5

61.5

4.5

11.9

263.1

0.4

32.2

373.7

Autumn
Sep77

-Nov7l

361.5

3.2

27.5

31.1

0.3

11.5

138,3

77.6

0.9

29,9

138.5

0.4

9.4

256.7

72.2

4.1

31.4

129.0

0.3

8.5

245.9

63.5

52.8

1.9

12.2

11.3

185.6

225.9

0.4

33.4

326.2

295.6

12.9

6.0

21.9

39.1

0.7

8.8

89.0

8. 9

1,2

20.6

24.1

0.5

9.8

65.1

15.2

5.5

22.2

27.0

0.5

9.2

79.5

4048.9

175.6

849.6

965.1

9.8

180.1

6229.1
4229.7

174.9

852.1

892. 3

9.2

$18 \% .2$

6345.6
Annual.

Jan 77

$-100077$

1538.8

14.2

112.5

119.3

1,3

13,3

1829.1

299.3

19.6

124.9

547.1

1.1

31.8

1021.0

239.7

12.9

48.9

910.1

1.7

129.6

1343.0

50.3

22.1

89.0

131.5

2.0

35.1

330.4

17711.6

902.2

3155.1

3603,2

37.2

122.8

26435.1 


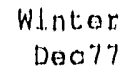

- Fob 78

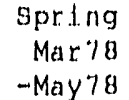

Summer
Jun 78
- Aug 78

Autumn
Sap 78
- Nov 78

Annual

$\operatorname{san} 18$

$-100078$

Fodoral Rogion 1 E.lact rle Utility

Commerclal /Resjdont lal. Industelal fued

Industrlal procossog

Miscoll ancous

I'ransportation 'Iotal

Foderal Roglon 2

Elocticle Ut:11t:y

Commarclal/Resldentilal

Industrlat Fuol

Industrial processes

Miscollanrous

I'ransportation 'total

Fodoral Region 3

E.loctric Utilldty

Commerclal/Rosldont lal

Industrlal luel.

Industrlal processes

Mlscellanoous

Iransportation Total

Fodoral Rogion 4

Electic Utility

Commerclal/Rosldential

Industrial Fuel

Industrlal procosses

Mlscollaneous

Transportation Totial

Fedoral Reglon 5

Elect.ric Utility

Commercial/Restedent lal

Indust rial Fuel.

Industilal Procossos

MIscollaneous

Transportation

fotal

Foderal Reglon 6

Filectife Uthlit.y

Commerclal/Rosidont lal

Industirlal puel

Industrdal processes

Metscollaneous

T'ransportation 'Totial

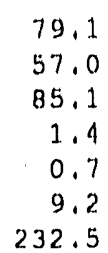

110.0

75.5

73,8

5,8

0,9

7,2

273.2

706.5

55.1

94.6

18.9

0.8

12.1

918.1
1017.8
67.1
120.5
85.0
1.2
23,3
1314.8

1370.2
75.8

2.06 .5

93.9

1.2

18.1

1766.0

$\begin{array}{rr}83.7 & 83.8 \\ 51.7 & 11.1 \\ 125.8 & 117.3 \\ 203.0 & 210.5 \\ 2.1 & 2.5 \\ 28.5 & 36.7 \\ 19 \% .8 & 162.2\end{array}$

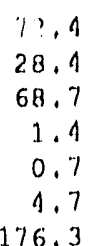

138.5

53.5

99.2

5.8

1. 3

11.8

310.0

589.3

30.3

98.9

59.1

1.0

15.9

791.4

961.6

104.4

91.2

1.3

30,2

1202.9

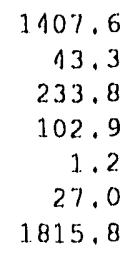

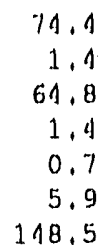

75.0

21.0

69.3

1.1

0.7

1.9

172.1

150.9

135.3

36.8

103.0

5.9

1.3

11.8

294.1

270.9

654.9

5.5

102.2

61.9

1.0

17.9

843.3

650.3

23.5

108.4

61,6

1.0

16.6

861.2

1271.1

1074.1

1.0 .1

111.2

93.

92.8

1.1

32.0

1504,8

1.0

30.9

1320.5

1611.0

1550.8

45.5

259.9

245.0

107.5

1.2

32.0

$10 \%, 3$

1.2

28.8

2052.4

1993.5

$$
\begin{array}{r}
101.3 \\
0.0 \\
116.9 \\
208.8 \\
2.5 \\
39.1 \\
172.0
\end{array}
$$

313,9

103.5

280,6

5,1

2.6

19.4

725.5

$57 \% .5$

197.8

109.5

22,9

5.1

46.9

1259.7

2521.8

124.0

116.0

233.9

3.8

63.7

3363.2

4132.1

75.9

434.5

359.3

1.1

119.5

5125.8

6142.0

193.6

990.0

109.1

4.9

109.2

7849.1

360.7

75.0

181.1

836.1

9.9

$19 \% .6$

1910.6 


\begin{tabular}{|c|c|c|c|c|c|}
\hline Em1 astons & Faderal. & Regition & geason & (Cont'd) & \\
\hline & $\begin{array}{l}\text { WLintor } \\
\text { Deo77 }\end{array}$ & $\begin{array}{l}\text { Sprting } \\
\text { Mar } 78\end{array}$ & $\begin{array}{r}\text { Summar } \\
\text { Jun78 }\end{array}$ & $\begin{array}{l}\text { Autumn } \\
\text { Sop } 78 \\
-N o v+8\end{array}$ & $\begin{array}{c}\text { Annual } \\
\text { Janlo }\end{array}$ \\
\hline Fed, Region / Sactor & $-F a b 78$ & - May 78 & $-A u 978$ & $-\mathrm{Nov} 78$ & $-100 \mathrm{c} 78$ \\
\hline \multicolumn{6}{|l|}{ Fodorat Rogton 7} \\
\hline Eilect:rte Ut:11t:y & 511.1 & 278.3 & 374.7 & 323.6 & 1367.2 \\
\hline Commorola / Res ldenti la & 15.6 & 5.5 & 3.4 & 6.5 & 26.5 \\
\hline Induatirtal Fuel. & 46.3 & 26.1 & 28.2 & 29.8 & 112.1 \\
\hline Industrial prodesses & 23.3 & 32.8 & 36.3 & 35,1 & $12 \% .1$ \\
\hline M1scoldaneous & 0.3 & 0.3 & 0.3 & 0.3 & 1.3 \\
\hline Transportation & 8.7 & 11.0 & 12,6 & 11.7 & 44.0 \\
\hline Total & 605,3 & 351.1 & 155.5 & 106.9 & 1678.1 \\
\hline \multicolumn{6}{|l|}{ Federal Reglon 8} \\
\hline Electrdc ut 11 ty & 226.9 & 67.5 & 71.3 & 70.0 & 287.5 \\
\hline Commerclal/Residentlal & 21.5 & 5. 1 & 1.6 & 5,0 & 21,3 \\
\hline Industrlal vel & 84.3 & 33.1 & 33.4 & 35.0 & 136.2 \\
\hline Industrial Procossos & 100.1 & 108.6 & 106.7 & 104.3 & 124.3 \\
\hline M1scellanoous & 1.1 & 0.4 & 0.1 & 0.3 & 1.4 \\
\hline 'ransportation & 25.7 & 8.0 & 9.9 & 8.9 & 33.3 \\
\hline Total. & 159.9 & 222.7 & 223.2 & 223.5 & 903.9 \\
\hline \multicolumn{6}{|l|}{ Federal Regton 9} \\
\hline Electr1o Utility & 48.2 & 34.5 & 91.8 & 51.3 & 183,1 \\
\hline Commerclal/Resldentlal & 9.9 & 3,1 & 0.3 & 2.2 & 12.1 \\
\hline Industrlal Fuel & 19.1 & 12.2 & 11.9 & 12.7 & 50.1 \\
\hline Industrlal Processes & 220.1 & 234.0 & 250.9 & 213.6 & 918.1 \\
\hline Miscoldanoous & 0.3 & 0.1 & 0.5 & 0.4 & 1.7 \\
\hline Transportation & 25.1 & 35.9 & 38.0 & 37.0 & 1.45 .5 \\
\hline Total & 323.1 & 320.0 & 34.3 .4 & 317.3 & 1310.9 \\
\hline \multicolumn{6}{|l|}{ lederal Region 10} \\
\hline Electric Utility & 26.7 & 13.7 & 5.5 & 22.1 & 65.6 \\
\hline Commerclal/Restdential & 8.6 & 5.3 & 1.3 & 5.1 & 21.0 \\
\hline Industrial Fuel & 28.9 & 2.2 .0 & 21.5 & 22.9 & 90.1 \\
\hline Industrial processes & 91.5 & 38.0 & 38.0 & 38.5 & 159.7 \\
\hline M.Lscellaneous & 0.3 & 0.7 & 0.5 & 0.5 & 2.0 \\
\hline Transportation & 9.0 & 9.8 & 10.8 & 10.3 & 39.1 \\
\hline Total & 115.1 & 89.5 & 77.6 & 99.6 & 373.3 \\
\hline \multicolumn{6}{|l|}{ National Totals } \\
\hline Electric Ut111ty & 4180.3 & 3617.2 & 4389.8 & 1032.9 & 16251.4 \\
\hline Commerctal / Residential. & 441.1 & 200.0 & 45,9 & 163.9 & 850.9 \\
\hline Industrial Fued. & 885.3 & 815.9 & 825.0 & 874.6 & 3100.9 \\
\hline Industrial Procossos & 823.1 & 881.3 & 910.0 & 874.1 & 3491.5 \\
\hline Mlscellaneous & 8.9 & 9.8 & 9.4 & 9.2 & 37.2 \\
\hline Transportation & 167.2 & 190.9 & 211.6 & 198.7 & 168,5 \\
\hline Total & 6506.0 & 5748.1 & 6391.6 & 6153.4 & 21800.1 \\
\hline
\end{tabular}




WInter
Dec78

Spring
Mar79
-Mayl9

Summer
Jun 79
-Aug 79

Autumn
Sep 79
-Nov79

Annual.

Federal Reglon 1

Electric Ut 11.1ty

Commerctal/Resident tal

Industrial Fuol

Industital Processos

Miscellaneous

Transportation 'Total.

Federal Reglon 2

Eloct:rle Uti11ty

Commerclal/Ros Ldentilal.

Induatelal Fuel.

Industidal Processest

MIscollaneous

Transportation Total.

tederal Reglon 3

Electr1c Ut111ty

Commercial/Resldentidal.

Industrial Fuel.

Industrlal processes

Miscellaneous

'Transportation Total.

Federal Regton $A$

Electric Utility

Commerctal/Restdont lal.

Industrial Fuel.

Industrlal Processes

Miscellaneous

Transportation

$$
\text { Total }
$$

Federal Regton 5

Electidc Utility

Commerclad/Restdentlal.

Industrlal Fuel.

Industrial processes

Miscellaneous

Transportation

$$
\text { Total. }
$$

Federal Region 6

Electric Utility

Commerclad/Resident a al.

Industrtal Fuel.

Industrtal. Procestas

Miscellaneous

Transportation

$$
\text { I'otal. }
$$

-Fob\% 9

97.8
52.1
65.5
1.4
0.7
9.5
227.0

84.8
17.8
15.1
1.4
0.7
4.7
154.5

79.0

1.2

43,6

1.1

0.7

5,5

131.4

$\begin{array}{rr}113.5 & 140.9 \\ 55.6 & 33.3 \\ 72.6 & 97.2 \\ 5.9 & 5.9 \\ 0.9 & 1.3 \\ 7.6 & 12.2 \\ 256.0 & 290.8\end{array}$

145.7

2.8

93,6

5.8

1.3

13,2

262,3

82. 0

1.3 .2

14.2

1.1

0.7

4.5

145.9

Jan 19

-Dec79

558.3

650.7

24.8

94.3

105.5

50.5

62.0

1.0

15.3

767.8

859.2

$$
\begin{array}{r}
701.1 \\
4.4 \\
101.9 \\
63.6 \\
1.0 \\
17.5 \\
889.5
\end{array}
$$

120.8

24.4

94.1

5,6

1.3

11.9

258,3

346.6

70.6

183.5

5.4

2.6

18.7

$62 \% .5$

$\begin{array}{rr}1026.7 & 979.2 \\ 51.6 & 11.8 \\ 114.1 & 102.5 \\ 86.4 & 92.5 \\ 1.2 & 1.3 \\ 24.3 & 30.8 \\ 1304.3 & 1218.0\end{array}$

1225.6
3.3

3.3
99.0

94.2

1.1

31.8

1454.9

631.4
20.9

101.9

59.3

1.0

15.6

830.0

558.4

136.5

391.5

2. . 8

5.1

48.1

1162,5

2679.7

112.2

419.6

237.7

3.8

61.1

3511.2

$\begin{array}{rr}1449.9 & 1459.4 \\ 198.0 & 27.8 \\ 202.0 & 233.3 \\ 97.6 & 108.1 \\ 1.2 & 1.2 \\ 19.0 & 27.2 \\ 1817.8 & 1857.3\end{array}$

1583.7
18.3
224.7
111.2
1.2
31.4
1970.5

997.5

11.6

99.3

92.6

1.0

30.8

1232.8

431.1 .1

68.4

409.9

363.1

4,4

120.7

5280.5

6190.3

131.4

923.9

420.7

4.9

108.6

7779.7

$\begin{array}{rr}363.3 & 79.3 \\ 70.0 & 14.9 \\ 125.0 & 121.1 \\ 207.0 & 209.7 \\ 2.1 & 2.5 \\ 31.3 & 41.0 \\ 798.7 & 168.6\end{array}$

87.6

18.9

120.6

214.5

2. 5

41.9

485.8
376.3

116.1

488.7

812.3

9.9

163.1

1996.6 
rederal

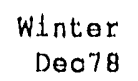

Fed. Region / Sector

Federal Region 7

Electric Ut11ty

Commerclal/Resldent lal

Industrial Fuel.

Industrlal processes

Miscellaneous

Transportation Total

Federal Region 8

Fleotrio Utility

Commerclal/Residentlal

Industrial Fuel

Industrlal processes

Miscellaneous

Transportation Total

Federal Region 9

Llectric Ut11ty

Commerclal/Residential.

Industrlal Fuel

Industrlal Processes

Mlscellaneous

Transportation Total.

535.7
15.4
48.2
25.6
0.3
7.8
633.0

308.0

6.3

31.2

33.2

0.3

9.5

388.4

93.8

21.5

80.8

97.7

1.1

28.0

322.9

68.1

5.2

34.4

102.6

0.4

8.0

219.0

97.1

12.2

19.5

232.0

0.3

27.9

389.1

Federal Region 10

Electric Utility

Commerclal/Residentlal.

Industrial Fuel

Industrlal Processes

Miscellaneous

Transportation Total.

National Totals

Electric Ut111ty

Commerclal/Resldential

Industrlal Fuel

Industrial Processes

Miscellaneous

Transportation

$$
\text { Total }
$$

$\begin{array}{rr}4368.5 & 3829.9 \\ 387.8 & 148.7 \\ 847.0 & 801.8 \\ 845.8 & 877.5 \\ 8.9 & 9.8 \\ 176.5 & 198.9 \\ 6634.5 & 5866.5\end{array}$

\section{and saason (kt) (Cont'd)}

Sumrner
Jun 79

\section{Autumn \\ Sep79}

-Nov79

$$
\begin{array}{r}
\text { Annual } \\
\text { Jan79 } \\
\text {-Doc79 }
\end{array}
$$

1396.8

30.3

123.1

133.0

1.3

38.5

1723.0

11.0

435.9

119.6

302.1

20.8

137.8

428.4

1.4

32.9

923.4

233.5

234.4

207.0

10.9

57.1

947.0

1.7

161.5

1385.2

$320.2 \quad 343.4$

41.1

367.7

75.1

16.0

69.8

153.3

2.0

10.8

$35 \% .0$
4333.5
37.2
776.5
910.6
9.4
214.9
6282.1

3912.5
139.7
779.7
919.8
9.2
203.6
5964.3

16446.5

713.5

3205.0

3553.6

37.2

793.9

24719.6 
$1980 \mathrm{SO}_{2}$ Emissions by Federal

.

Fed. Reqion / Sector

Region

and

Season

$(k t)$

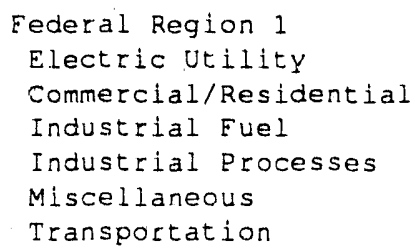

\begin{abstract}
Winter
Dec79
\end{abstract}

-Eeb8o

$\begin{array}{rr}\text { Spring } & \text { Summe } \\ \text { Mar } 80 & \text { Jun } 80 \\ \text {-May80 } & \text {-Aug } 80\end{array}$

-Aug 80

89.5

1.7

35.7

1.4

0.7

5.3

134.3

222.3

148.0

106.6
63.3
58.6
6.0
0.9
8.2
243.4

567.0
56.3
90.2
53.3
0.8
12.8
780.3

122.5

43.5

77.8

5.7

1.3

12.5

263.3

610.5

29.7

97.5

57.5

1.0

15.3

811.5

1062.2

988.9

56.3

108.0

90.5

1.2

24.9

1343.1
13.55 .4
45.1
194.4
99.0
1.2
18.7
1713.9

$$
\begin{array}{r}
1331.8 \\
24.3 \\
216.9 \\
99.9 \\
1.2 \\
26.3 \\
1700.4
\end{array}
$$

$\begin{array}{rr}356.2 & 93.9 \\ 57.7 & 18.2 \\ 112.1 & 108.1 \\ 211.0 & 214.7 \\ 2.1 & 2.5 \\ 34.1 & 43.4 \\ 773.2 & 480.8\end{array}$

140.

3.5

70.7

5.0

1.3

14.0

234.6

695.5

4.9

86.0

51.6

1.0

17.4

856.4

1257.3

3.8

90.2

88.3

1.1

31.6

1472.3

1447.2

10.9

188.8

93.8

1.2

30.1

1771.9

1039.3
12.5
96.0
90.7
1.0
31.2
1270.7

1317.3

24.8

199.2

98.9

1.2

27.4

1668.8

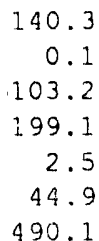

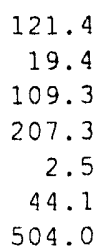

19.4

109.3

207.3

2.5

504.0

\section{Annual \\ $\operatorname{Jan} 80$ \\ -Dec80}

367.7

83.7

154.8

5.7

2.6

18.3

632.8

539.7

177.2

309.8

21.7

5.1

50.9

1104.5

2664.0

129.0

377.9

220.6

3.8

62.

3457.6

4429.8

66.5

394.3

358.0

4.4

121.3

5374.3

5636.8

104.9

834.0

389.3

4.9

105.7

7075.6

465.8

104.3

435.9

832.7

9.9

173.5

2022.2 
Region

and

Winter
Dec79
-Feb80

Spring
Mar80
- May80

Fed. Region / Sector

-Feb80

- May 80

$\begin{array}{rr}507.2 & 326.5 \\ 9.4 & 3.1 \\ 43.3 & 27.6 \\ 24.0 & 27.6 \\ 0.3 & 0.3 \\ 8.1 & 9.1 \\ 592.3 & 394.1\end{array}$

$$
\text { Total }
$$

Federal Region 8

Electric Utility

Commercial/Residential

Industrial Fuel

Industrial Processes

Miscellaneous

Transportation

$$
\text { Total }
$$

Federal Region 9

Electric Utility

Commercial/Residential

Industrial Fuel

Industrial Processes

Miscellaneous

Transportation

$$
\text { Total }
$$

120.7

18.9

76.8

75.1

1.1

28.9

321.6

88.8

10.6

17.8

243.1

0.3

30.5

391.1

Federal Region 10

Electric Utility

Commercial/Residential

Industrial Fuel

Industrial Processes

Miscellaneous

Transportation Total

National Totals

Electric Utility

Commercial/Residential

Industrial Fuel

Industrial Processes

Miscellaneous

Transportation Total
31.4

10.0

28.6

40.3

0.3

10.1

120.7

$$
\begin{array}{r}
4290.6 \\
385.7 \\
786.6 \\
843.7 \\
8.9 \\
186.4 \\
6501.9
\end{array}
$$

$$
\begin{array}{r}
70.4 \\
5.3 \\
33.3 \\
108.0 \\
0.4 \\
8.0 \\
225.5
\end{array}
$$

$$
39.2
$$

5.9

14.2

278.7

0.4

43.5

381.9

76.2

1.2

31.3

54.5

0.4

9.3

172.8

42.8

0.7

13.2

101.9

0.5

44.7

203.7

15.7

5.4

21.5

42.0

0.7

10.9

96.2

8.2

1.7

20.2

24.9

6. 5

11.5

67.0

3681.6

169.8

735.0

926.5

9.8

204.0

5726.7
Summer
Jun 80
-Aug 80

$$
\begin{array}{r}
415.8 \\
1.3 \\
23.8 \\
30.9 \\
0.3 \\
10.8 \\
482.9
\end{array}
$$

(kt) (Cont'd)

$\begin{array}{rr}\text { Autumn } & \text { Annual } \\ \text { Sep80 } & \text { Jan80 } \\ \text {-Nov80 } & \text {-Dec80 }\end{array}$

325.9

3.3

25.0

30.4

0.3

9.9

394.8

1450.4

13.8

105.0

112.9

1.3

37.2

1720.6

315.3

20.2

132.9

278.7

1.4

33.3

781.7

163.2

166.1

17.3

57.1

766.6

1.7

174.8

1183.5

245.3

67.4

20.9

86.9

125.0

2.0

43.4

345.6

$\begin{array}{rr}4312.8 & 3817.0 \\ 29.8 & 152.5 \\ 663.0 & 703.9 \\ 651.4 & 689.5 \\ 9.4 & 9.2 \\ 219.6 & 210.6 \\ 5886.1 & 5582.8\end{array}$

16103.1

$7 ? ? .9$

2888.5

3111.1

37.2

820.7

23698.4 
Fed. Region / Sector

Federal Region 1

Electric Utility

Commercial/Residential

Industrial Fuel

Industrial Processes

Miscellaneous

Transportation Total

Federal Reglon 2

Electric Utility

Commercial/Residential

Industrial Fuel

Industrial Processes

Miscellaneous

Transportation Total

Federal Region 3

Filectric Utility

Commercial/Residential

Industrial Fuel

Industrial Processes

Miscellaneous

Transportation Total

Federal Region 4

Electric Utility

Commercial/Residential

Industrial Fuel.

Industrial Processes

Miscellaneous

Transportation

$$
\text { Total }
$$

Federal Region 5

Electric Utility

Commercial/Residential

Industrial Fuel

Industrial Processes

Miscellaneous

Transportation

$$
\text { Total }
$$

Federal Region 6

Electric Utility

Commercial/Residential

Industrial Fuel.

Industrial processes

Miscellaneous

Transportation

$$
\text { Total }
$$

\section{Winter \\ Dec 80}

-Feb81

Summer

Autumn
Sep 81

Annua 1

Mar 81

-May 81

-Aug 81

-Nov81

Jan8 1

-Dec81

87.6
53.7
50.3
1.4
0.7
10.0
203.8

77.2
17.2
35.6
1.5
0.7
4.2
136.4

84.0

80.5

343.6

$$
35.6
$$

1.4

0.7

5.3

128.4

118.2

141.3

146.0

32.4

53.2

40.3

5.2

5.4

1.3

0.9

12.1

221.0

245.6

527.4

45.5

77.3

45.8

0.8

12.6

709.4

$$
\begin{array}{r}
572.5 \\
25.1 \\
82.3 \\
56.1 \\
1.0 \\
14.9 \\
751.9
\end{array}
$$

52.6

5.1

1.3

14.0

222.4

15.3

35.6

1.4

0.7

4.7

138.1

69.9

144.5

5.6

2. 6

17.9

584.2

120.4

568.7

133.9

216.5

53.4

4.7

1.3

12.7

220.9

20.1

5.1

50.3

994.4
1039.4
86.4
82.9
24.2
1279.3

1013.4

1300.9

3.3

83.8

11.7

84.3

90.5

1.3

29.7

1230.9

640.7

5.2

81.7

54.4

1.0

17.1

800.2

594.4

23.7

83.3

49.8

1.0

15.8

767.9

2467.4

109.4

335.8

207.9

3.8

61.0

3185.4

87.6

1.1

$31 .:$

1508.5

1022.0

4465.8

10.9

85.1

83.1

1.0

30.2

1232.2

61.0

343.6

341.7

4.4

119.0

5335.6

1355.4

$$
1296.0
$$

1382.0

1272.3

25.5

201.0

12.9

182.5

100.3

199.1

98.4

203.6

92.0

1.2

30.0

27.4

18.2

24.9

1723.7

1621.9

5399.1

106.1

821.1

379.4

4.9

103.3

6813.9

$$
\begin{array}{r}
342.2 \\
57.3 \\
118.3 \\
197.0 \\
2.1 \\
33.4
\end{array}
$$$$
104.3
$$$$
12.8
$$

146.0

$$
0.1
$$

120.4

498.6

120.7

121.7

202.3

218.9

121.7

209.3

2.5

45.5

43.4

43.4
485.9

45.5
534.7

44.4

509.1

489.7

828.0

9. 9

$173.9^{\circ}$

2089.8 
1981 $\mathrm{SO}_{2}$ Emissions

Fed. Region / sector.

Federal Region 7

Electric Utility

Commerclal/Resident lal

Industrial Fuel

Industrial processes

Miscellaneous

Transportation , Total

Federal Region 8

Electric Utility

Commercial/Residential

Industrlal Fuel.

Industrial processes

Miscellaneous

Transportation

Total

Feveral Region 9

Electric Utility

Commercial/Residential.

Industrial Fuel

Industrial Processes

Miscellaneous

Transportation T'otal

Federal Region 10

Electric Utility

Commercial/Residential

Industrial Fuel

Industrial Processes

Miscellaneous

Transportation Total

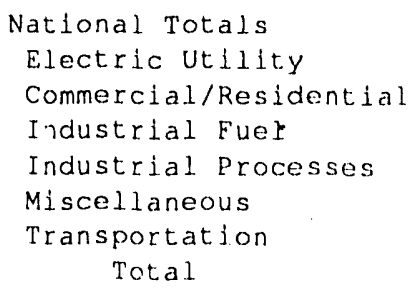

Region

and

Seanon

(kt) (cont'd)

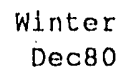

Spring
Mar 81
-May 81

Summer
Jun 81
-Aug 81

Autumn
Sep81
-Nov81

Annual

Jan8 1

-Dec 81

$$
\begin{array}{r}
479.3 \\
10.3 \\
43.1 \\
22.5 \\
0.3 \\
7.7
\end{array}
$$

563.1

$$
\begin{array}{r}
299.6 \\
3.7 \\
27.3 \\
28.3 \\
0.3 \\
8.9 \\
368.2
\end{array}
$$

103.2

16.8

70.4

34.4

1.1

28.2

254.0

70.7
3.2
28.0
43.1
0.4
7.7
153.2

392.3
2.4
27.2
29.4
0.3
10.8
462.4

332.6

4.9

27.8

28.9

0.3

9.7

404.3

68.0

72.2

3.1

28.3

43.1

28.3

52.9

0.4

9.4

160.0

0.3

8.8

155.9

80.4

9.7

16.5

249.3

0.3

30.1

386.4

$$
\begin{array}{r}
37.0 \\
6.6 \\
13.9 \\
274.0 \\
0.4 \\
42.9 \\
374.8
\end{array}
$$

26.6

8.8

25.6

39.4

0.3

9.8

110.4

14.0
4.8
19.8
42.8
0.7
10.8
92.8

4159.8

3626.0

141.2

337.9

710.6

768.1

8.9

182.2

6167.5

844.3

9. 8

199.5

5486.9
43.0

4.3

14.0

244.2

0.4

43.8

349.8

343.3

$$
\begin{aligned}
& 8.1 \\
& 1.3
\end{aligned}
$$

19.8

37.7

0.5

11.6

79.0

4212.7
31.3
663.7
825.4
9.4
220.1
5962.5
23.2

4.3

19.9

34.3

0.5

10.9

93.0

3681.0
131.3
672.7
790.6
9.2
208.4
5493.2
1387.0

18.5

111.7

109.1

1.3

36.9

1664.7

289.6

13.1

113.5

176.7

1.4

' 32.3

626.5

165.1

21.9

56.5

1006.6

1.7

172.6

1424.3

63.7

18.0

80.3

153.1

2.0

42.9

360.1

15648.5

641.6

2713.1

32.28 .3

37.2

810.1

23078.9 
$1982 \mathrm{sO}_{2}$ Emlssions by

Fed. Region / Sector

Federal Reglon 1

Electric Utility

Commercial/Residential

Industrial Fuel

Industrial processes

Miscellaneous

Transportation Total

Federal Reglon 2

Electric Utility

Commerclal/Residential

Industrial Fuel

Industrial processes

Miscellaneous

Transportation

Total.

Federal Reglon 3

Electric Utility

Commerclal/Residential

Industrial Fuel

Industilal processes

Miscellaneous

Transportation Total

Federal Reglon 4

Electric Utility

Commerclal/Residential

Industrial Fuel

Industrial Processes

Miscelilaneous

T'ransportation Total

Federal Region 5

Electric Utility

Commercial/Residentilal.

Industrial Fuel

Industrial Processes

Miscellaneous

Transportation rotal

Federal Region 6

Electric Utility

Commercial/Residential.

Industrial Fuel

Industrial Processes

Miscellaneous

Transportation

$$
\text { 'otial. }
$$

Federal

Winter
Dec81

Region

and

Season

(kt)

-Feb82

Spring
Mar 82

Summer
Jun 82

- May 82

-Aug 82

Autumn
Sep8z

-Nov82

Annual.

$\operatorname{Jan} 82$

-Dec82

$$
\begin{array}{r}
79.3 \\
19.3 \\
60.9 \\
1.4 \\
0.7 \\
4.2 \\
165.7
\end{array}
$$

107.4

54.9

40.7

4.4

0.9

6.9

215.2

$$
\begin{array}{r}
122.3 \\
38.3 \\
54.6 \\
4.3 \\
1.3 \\
11.2 \\
231.9
\end{array}
$$

656.5

46.1

81.5

37.8

0.8

10.9

833.6

$$
\begin{array}{r}
574.8 \\
26.5 \\
77.7 \\
44.7 \\
1.0 \\
14.5 \\
739.2
\end{array}
$$

872.9

37.2

86.5

71.3

1.2

21.9

1091.0

$$
\begin{array}{r}
890.0 \\
9.3 \\
86.7 \\
74.8 \\
1.3 \\
28.5 \\
1090.5
\end{array}
$$

1071.3

1258.9

$+332.1$

1245.3

28.8

177.5

68.3

1.2

15.9

1638.9

195.2

74.0

1.2

24.1

1568.6

1304.1

1601.0

$\begin{array}{rr}163.2 & 115.7 \\ 58.0 & 12.9 \\ 107.2 & 111.6 \\ 186.3 & 190.0 \\ 2.1 & 2.5 \\ 29.5 & 39.3 \\ 546.3 & 472.0\end{array}$

72.8

2.6

58.7

1.4

0.7

5.5

141.6

127.0

5.7

50.4

4.1

1. 3

12.7

201.3
592.4
6.6
70.4
43.7
1.0
16.4
730.5

3.3

79.0

74.3

1.1

29.9

18.1

174.8

73.9

1.2

28.8

90.1

13.0

58.5

1.4

0.7

4.6

168.1

116.4

26.2

50.3

4.0

1. 3

11.5

209.7

528.9

20.7

70.0

41.2

1.0

14.9

676.6

863.1

9.1

78.5

73.3

1.0

29.0

1054.5

1195.6

30.1

173.7

70.8

1.2

25.1

1496.5
1.49 .5
0.2
107.4
183.1
2.5
40.8
483.4

132.0

14.4

106.9

188.9

2.5

40.3

481.9
348.4
70.3
240.7
5.4
2.6
17.8
685.1

511.5

143.4

212.3

16.6

5.1

15.?

937.1

2313.9

106.5

299.5

169.2

3.8

57.7

2950.5

3762.0

46.2

334.8

292.2

4.4

112.2

4551.8

5176.4

124.4

749.5

285.6

4.9

96.6

6437.6

534.1

93.4

440.2

748.8

9.9

156.0

1982.1 


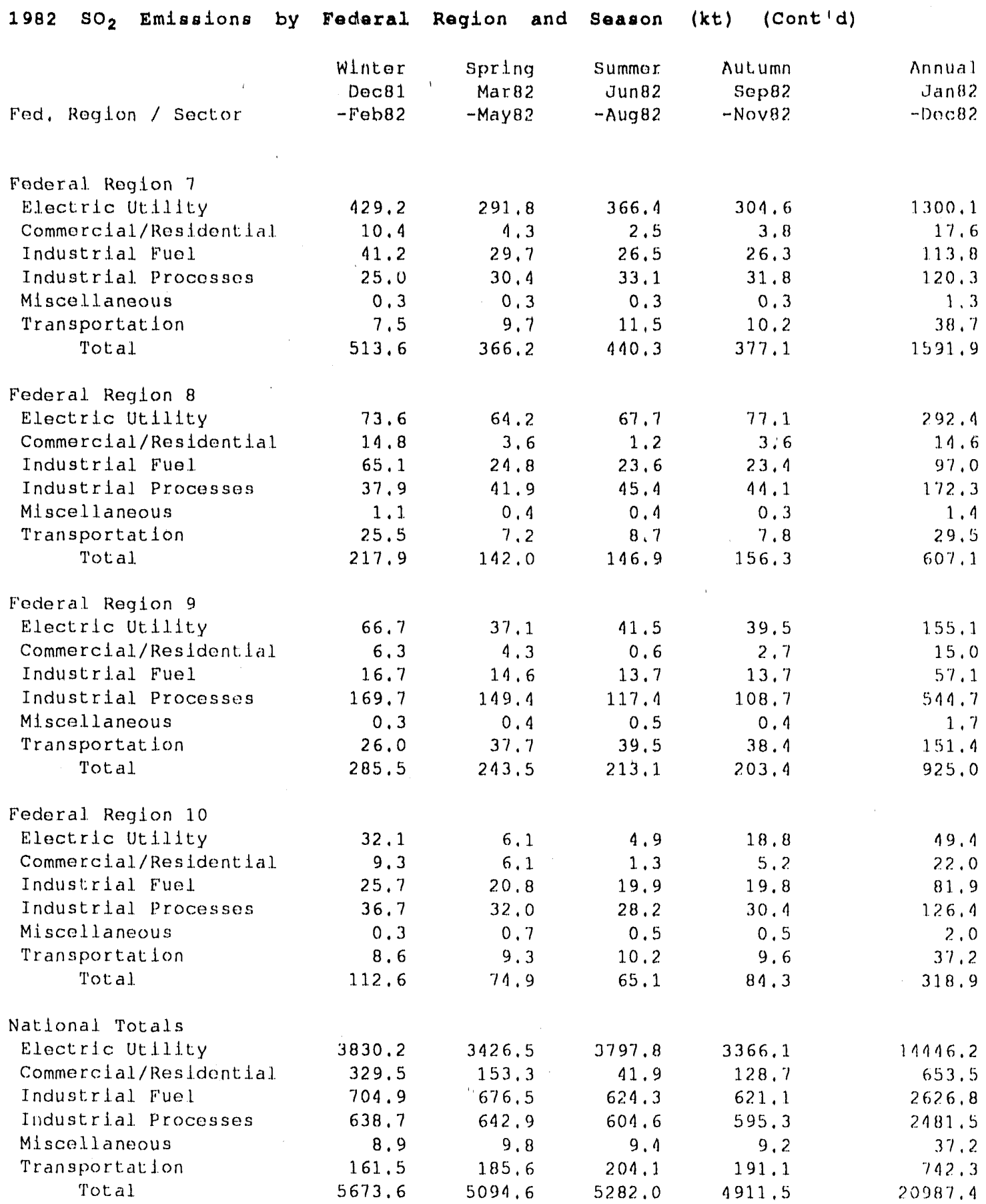


(kt)

Fod, Roglon / sector

\begin{tabular}{|c|c|c|c|}
\hline $\begin{array}{r}\text { Whiner } \\
\text { Dec82 }\end{array}$ & $\begin{array}{l}\text { Spr.1ng } \\
\text { Mar:83 }\end{array}$ & $\begin{array}{r}\text { Summer } \\
\text { Jun83 }\end{array}$ & $\begin{array}{r}\text { Autumn } \\
\text { Sep83 }\end{array}$ \\
\hline$-\mathrm{Feb} 3$ & - May 83 & - Aug 83 & - Nov 83 \\
\hline
\end{tabular}

Pederal Roglon 1

filocitric Utildty

Commorelal/Rostdont lal

Industrlal Fuol

Indugtrlal processos

M.lscellaneous

Transportation

$$
\text { Totial. }
$$

Federal Roglon 2

Electric Utilty

Commorcla.l /Resident la.l

Indust.rlal puel

Indust.rlad procosges

Mlscollaneous

T'ransportation

T'otal

Foderal Reglon 3

Electric Utility

Commorclal/Resident.lal

Inaustrial Fuel

Industrlal Processes

Miscellaneous

Transportation Total

federal Reglon 4

Electic Utidity

Commorclal/Residential

Industrtal Fuel

Industrial Procosses

Mlscollanoous

Transportation l'otal

Federal Rogion 5

Ejectrle Ut 1.jty

Commercial / Resident 1 al

Industrial fued

Industrlal Processes

Miscollaneous

Transportation 'T'otal

Fedural Regton 6

Electrle Ut.illty

Commerclal/Rosidentidal

Industrial. Fuol

Indust rial Procosesos

Miscollaneousi

T'ransportation

$$
\text { T'(ot. al }
$$

$$
94.9
$$

32.7

37,3

1.3

0.7

8.8

175.2

$\begin{array}{rr}103.7 & 130.8 \\ 29.8 & 23.3 \\ 22.7 & 30.8 \\ 1.3 & 1.2 \\ 0.9 & 1.3 \\ 5.8 & 9.8 \\ 167.1 & 200.2\end{array}$

75.3

24,0

1.1

0.7

$4 . ?$

119.0

200.2

418.8

38.9

56.7

35.6

0.8

9.4

560.1

536.5
24.7
66.1
41.4
1.0
13.0

683.0

83.2

1.1

24.8

1.1

0.7

5.5

116.7

144.4

2.4

31.0

4.1

1. 3

11.9

195.0

79.5

9.5

25.6

1.5

0.7

4.1

116.1

124.6

16.1

32.9

1.3

1.3

10.1

189.3

640.9

5.3

67.4

44.1

1.0

15.7

774.9

579.7

20.1

72.2

45.0

1.0

13.6

731.6

796.1

37.6

75.2

74.4

1.2

21.8

1006.3

780.9
13.6
80.8
75.7
1.3
29.4
981.8

1112.0

5.3

82.1

76.9

1.1

31.2

1308.6

921.1

11.2

87.5

81.8

1.0

29.9

1132.4

1250.9

1162.0

1420.7

1333.2

31.6

13.2
149.2

59.2

1.2

15.3

1519.0

31.8
166.6

63.4

1,2

23,6

1498.5

18.2
168.5

67.8

1.2

29.1

81.3

69.5

1.2

25.0

1705.5

1641.8

$\begin{array}{rr}259.1 & 136.7 \\ 27.4 & 7.6 \\ 93.0 & 90.3 \\ 207.6 & 213.6 \\ 2.1 & 2.5 \\ 26.5 & 35.5 \\ 615.9 & 486.2\end{array}$

179.7

0.0

93.5

216.2

2.5

37.4

529.2

153.9

1.5

97.5

220.2

2.5

36.2

514.9
$33 \% .2$

19.?

99.5

5.6

2.6

17.1

511.5

547.2

85.8

128.3

16.6

5.1

40.2

823.3

2.368 .5

100.3

278.9

167.8

3.8

52.6

2972.0

3735.3

61.3

338.6

306.5

1.1

115.8

1561.8

5292.7

132.2

700.5

258.1

1.9

95.8

6484.2

621.1

10.3

$376 . ?$

858.0

9.9

110.83

20196.6 


\begin{abstract}
1983 $\mathrm{SO}_{2}$

Emlastons by
\end{abstract}

Fed, Reglon / sector

Federal Roglon?

Electrle Ut11ty

Commerclal/Resldont ial

Industrlal Fuol

Industrlal procossos

Mlscel laneous

Transportation total.

Foderal Reglon 8

Electric Utility

Commerclal / Ros ldent 1 al

Industirlal Fuel

Industrlal Processes

Miscellaneous

Transportation Total

Fedoral Region 9

Electric Utillty

Commerclal/Rosldential

Industrial Fuol.

Industrlal processes

Miscellaneous

Transportation Total

433.8
12.0
42.1
22.3
0.3
8.0
518.4

274.3
3.8
26.2
26.5
0.3
9.7
340.8

121.1

19.6

61.5

29.9

1,1

25.3

258.6

65.5

1.3

19.9

38.8

0.4

11.5

140.5

78.1

28.9

2.9

10.7

13.2

113.2

0.3

21.8

231.8

158.8

0.4

32.6

231.3

228.5

8.5

21.2

35.5

0.3

7.7

301.7
3784.8
254.8
572.1
583.3
8.9
150.4
5354.2
3199.7
129.5
527.1
654.8
9.8
177.7
4698.5

366.9

3.3

26.6

31.5

0.3

11.7

410.3

73.6

1.1

20.6

31.5

0.4

12. 8

143.0

(kt) (Cont'd)

$\begin{array}{rr}\text { Autumn } & \text { Annual } \\ \text { Sop83 } & \text { JanB3 } \\ \text {-Nov83 } & -D \text { DeB3 }\end{array}$

306.6

5.1

28,6

30.7

0.3

10.3

381.6

1256.0

19.0

110.2

111.0

1,3

39.1

1536.6

301.7

16.3

83.2

141.4

1.1

45.7

589.7

12.3

153.6

132.6

9.2

44.5

561.8

1.7

131.1

881.0

35.3

204.9

13,6

30.2

72.3

16.4

47.5

11.7

29.1

0.5

9.7

66.1

12.3

32.9

127.6

2.0

33.8

8. 6

88.1

299.5

14664.9

529.9

$220 \% .5$

2551.3

$3 \% .2$

712.5

20706.2 
$1984 \mathrm{SO}_{2}$ Emianions by

Faderal Ragion and searon

(kt)

Fod, Raglon / soctor

$\begin{array}{rrr}\text { WIntor } & \text { Spring } & \text { Summer } \\ \text { Dec83 } & \text { Mar84 } & \text { Jun84 } \\ \text {-Fob84 } & \text { - May84 } & \text {-Aug81 }\end{array}$

$\begin{array}{rr}\text { Autumn } & \text { Annual } \\ \text { Sep8A } & \text { Jan8A } \\ \text {-Nov81 } & \text {-Doa8A }\end{array}$

Fodoral Reglon 1 .

Eloctirlo Utiditiy

Commerclal/Roaldont lal

Industital Fuel

Indust.rtal procossese

Mlacollanoous

Transportation 'Total

fiederall Reglon?

F.lectide Utility

Commorclal/Rouldont lal

Industrlal fuel

Induatirial procossos

Mlscoll anoous

Transportation total al

Faderal Roglon 3

Eloctrde Utillty

Commorctad/Rosldont lal

Industrtal fuel

Industrtal Procosses

M.l soollanoous

I'ransportation fortal.

Federal Region $A$

Eloctilc ULilliy

Commerclal/Realdontial

Industirial Fuel

Industrtal Procossos

MLscellanoous

T'ransportat lon rotal

Federal Rogion 5

Electrie Ut.111ty

Commerclal/Rostelent Lal

Industirlal ruel

Indust.rlal procesges

M.lscellanoous

Iransportation T'ot:al

Federal Roglon 6

Filectrle Ut:lit.y

Commerclal/Restdential.

Industrlal Fuol

Industrlal Procossos;

MIscollanoous

Transportaliton Total

$\begin{array}{rr}86.4 & 81.0 \\ 29.2 & 16.1 \\ 12.1 & 27.0 \\ 1.1 & 1.5 \\ 0.7 & 0.1 \\ 9.0 & 1.1 \\ 169.1 & 133.3 \\ & \\ 103.3 & 121.9 \\ 31.1 & 27.1 \\ 26.4 & 36.1 \\ 1.5 & 4.6 \\ 0.9 & 1.3 \\ 6.0 & 9.9 \\ 172.4 & 201.6\end{array}$

93.0

1.3

21.9

1.6

$0 . \%$

5.8

127.2

-NOVBA

$-100089$

$\begin{array}{rr}80.7 & 355.1 \\ 10.9 & 53.1 \\ 25.3 & 103.9 \\ 1.5 & 6.0 \\ 0.9 & 2.6 \\ 1.4 & 17.5 \\ 123.5 & 538.9 \\ & \\ 119.1 & 527.3 \\ 17.1 & 90.3 \\ 33.7 & 140.6 \\ 1.3 & 17.6 \\ 1.3 & 5.1 \\ 10.5 & 11.0 \\ 186.3 & 821.9\end{array}$

$481.2 \quad 590.6$

$41.1 \quad 29.6$

$66.9 \quad 83.3$

40.1

19.2

1,0

9.7

639.8

13.3

766.9

194.5

3.0

33.4

4.9

1.3

12. 1

198.8

186.3

634.4

5.8

77.8

18.1

1.0

16.0

783.4

363.9

20.9

77.9

45.3

1.0

14.0

722.9

2402.4

101.6

323.7

181.8

3.8

53,9

3073,3

795.8
36.8
83.7
78.0
1.2
22.3
1017.7

834.0

1039.3

907.2

11.7

88.5

81.5

1.0

30.7

1120.7

1248.8

1332.9

1291.0

1440.9

25.0

40.0
185.7

172.9

159.9

76.8

1.2

1.2

15.3

24.0

1621.4

1618.7

77.1

1.2

30.2

1747.6

1276.0

33.2

173.2

73.3

1,2

25.4

1582.4

$36 \% .2$

60.5

367.8

323.2

1.1

119.1

4552.0

$33 \% .2$

130.2

179.3

0.1

140.1

7.1

119.1

110.9

114.5

1.80 .8

115.5

176.9

2.5

37.7

38.9

510.9

179.7
5436.9

151.2

721.3

291.0

1.9

97.5

$6 \% 05.8$

601.2

41.8

168.1

739.7

9.9

146.5

$200 \% .5$ 
WIntor

Dea83

Heb8a

112.3

11,5

42.5

26.7

0,3

8.1

531.1

Transportintion

$$
\text { 'lotal }
$$

Federal. Reglon $B$

ELectrlo Utility

Commorctal/Rosldontial.

Industrial Fuel

Industidal. Processos

MI. scel. Lanoous

Iransportation

$$
\text { Toutal }
$$

Faderal Reglong

kloct.rle Ut:11ity

Commorclal/Resddontital

Industrtal. Fuel.

Industirlal Procossos

ML scoll taneous

'I'ransportation

$$
\text { 'Total }
$$

Federal Region 10

Eloctirle Utillty

Commerctal/Resldentilal.

Industrtal Fuel.

Industrlal Procossos

Miscollaneous

'Transportation

$$
\text { l'otial }
$$

National Totals

Electric Ut lidty

Commerelal/Rosident lal

Industirlal Fuel

Industrilal. Procosses

Míscelitanoous

Transportation

$$
\text { T'ot:al }
$$

122.8

16.2

65.8

28,8

1.1

2.6 .3

260.9

74.2

4,4

147.6

0.3

23.3

265.2

29.7

7.7

22.4

32.9

0.3

8.0

100.9

3805.8

636.2

614.8

8.9

155.1

$\begin{array}{rr}\text { Spring } & \text { Summe } \\ \text { MarbA } & \text { Jung } \\ \text {-MayBd } & \text {-AugB }\end{array}$

Autiumn
Sepgd
- Novid

Arnual

Janyi

$-1)$ oc8 81

$$
\begin{array}{r}
301.7 \\
5.2 \\
30.1 \\
30.5 \\
0.3 \\
9.9 \\
380.8
\end{array}
$$

300.

318.0

5,1

28.2

30,9

2,9
28.2

32,1

0,3

12. 2

0.3

10,6

456.1

393.1

1330.1

21.0

$11 \%, 2$

120.2

1,3

40,2

1629.9

74.6

82,4

1.4

21.9

32,3

25,6

39.2

0.4

12.0

0.4

13,5

156.3

151.7

28.7

38.1

83.9

1.4

25,0

31.8

0.3

12.8

158.2

331,9

18.0

101.0

135,3

1.1

47.6

635.1

15.3

2.3

13.2

152.0

0.4

34,4

231.0

1.6
1.6
13.3
31.9
0.7
8.5
66.6

14.3

1.5

12,6

30,6

0.5

9.7

69,3

31.6

2.1

12.6

181.1

0.1

34.7

262.8

130.9

9.9

51.1

612.7

1.7

137.7

974.3

3461.2

4041.9

45.2

589.7

151.0

628.5

666,1

9,8

653.0

9.4

207.4

183.3

$5176.2 \quad 5102.8$
2.1 .2

4.4

12,8

33.7

0.5

8.7

84.2

3541.8

116.9

592.8

660,7

9.2

189.5

51.13 .8
62.9

17.9

51.9

1.31. 2

2.0

31.2

300.2

11856.3

568.5

2417.2

2594.6

37.2

735.3

21238.8 


$\begin{array}{rrr}\text { Winter } & \text { Sprlng } & \text { Summer } \\ \text { Dec84 } & \text { Mar85 } & \text { Jun85 } \\ \text { - Peb85 } & \text {-May85 } & \text {-Aug85 }\end{array}$

$\begin{array}{rr}\text { Autumn } & \text { Annual } \\ \text { Sap8s } & \text { Jan8s } \\ \text {-Nov8s } & \text { Daces }\end{array}$

fodoral Roglon 1

Eleotide Utility

$\begin{array}{rr}93.1 & 71.1 \\ 35.5 & 13.1 \\ 39.5 & 22.7 \\ 1.1 & 1.5 \\ 0.7 & 0.7 \\ 8.3 & 1.5\end{array}$

78.9
1.8
22.3
1.5
0.7
5.8
111.0

84.0
16.1
22.1
1.5
0.7
1.9
12.3 .5

341.2

53,7

91,2

Industrlal fuol.

117.2

123.5

5,9

2,6

18,8 total.

178,8

111,0

Fodaral Reglon?

Flootilo Ut.Lifiy

Commerctal/Rosddont lal

97.

108.5

116.8

4.2

25.7

33.2

4.5

Induatirlal procosaga

MLscollanoous

Trnngportation 'fot.al.

Federal keglon 3

Eloctrle Utillty

Commorclal / Rosldont lal

industrlal puel.

$512.8 \quad 592.3$

611.4

555.5

15.3

68.8

$57.1 \quad 70.7$

Industrial Processes

10.1

6.3
$6 \% .8$

19.3

48.0

1.0

15.9

1.0

11.0

$751 \cdot 8$

702.6

458.6

91.5

138.1

17.9

5,1

40.8

752.1

'I'ransportation t'otal

660.7

716.2

Fodoral Rogion 4

Eloctrlo Ut LItity

Commerclal/Rosldentlal

799.7

17.1

877.0

1.077 .2

915.2

7.1

100.1

89.1

3.6

96.1

甘1. 7

Industirlal processes

Mlscollaneous

Transportiation 'rotial

1.2

81.8

1. 3

1.1

29.1

20.3
1031.6

27.1

1097.1

1288.9

$9 \%, 3$

80.9

1.0

27.5

1129.1

2103.5

89.6

281.3

188.6

3.8

51.1

3021.2

liederal Roglon 5

Electric Utildty

Commerclal/Restdential.

1274.7

1227.1

1333.3
19.3

26.1

182.3

158.7

72,6
182.3

174.2

Industrtal processes

63.5

73.5

1.2

Mlscell ancous

Iransportation Total

1225.3

26.5

$17 \% .0$

71.8

1.2

28.0

1629.5

23.7

1525.5

3818.9

62.0

398.3

319.2

4. 1

1.07 .5

4710.3

Fodoral Reglon 6

Electirle Ut.l11ty

Commerclal/Resldont lal

388.3

126.1

173.2

137.5

3.8

110.0

114.0

0.1

Indust rlal Fuel

190.2

113.0

113.9

181.3

188.1

187.3

2.5

25.0

2.5

31.0

Transportation

738.0

171.0

36.0

2.5

34.5

179.5

$5199 \cdot 8$

119.1

721.7

279.9

4.9

92,2

6120.5

589.3

39.4

459.8

747.9

9.9

134.9

1981.2 
Federal

Fod, Roglon / Soctor

Fedoral Reglon 7

Eloctide Utidtey

Commerclal/Rosldent la

Industirlal fuol.

Industral Procosgos

Miscollanoous

Transportiation tutial.

Fedoral Rogion 8

Electide Utillty

Cormerclal. Resident tal.

Indust $r$ lal Fue 1

Industirlal procosses

M.1scollaneous

Transportation

I'otal

Federal Region 9

Eloctic Ut:11ty

Commerclal/Resldent Lal

Industirla.l. Fuel

Induatrlal. Processes

M.lscellaneous

iransportation

$$
\text { Total }
$$

Federat Reglon 10

Eiectrdc Utjilty

Commerclal/Ros Ldent Lal

Induatrlal. Fue 1

Industrlal Processes

M.lscollaneous

Transportation

$$
\text { Total }
$$

National 'Iot:als

Electric Utillty

Commerclaj/Restdent: Lal.

Industrlal Fuel

Industrlal Procosses

Miscellanoous

'Transportation

$$
\text { t'ot:al. }
$$

\section{Winter. \\ DacBa}

- Fab8s

Region and seanon

Sprlng
Mar85
-May85

summer
Jun 85

$-A 4985$

455.3
12.6
46.5
29.9
0.3
7.2
551.8

$$
\begin{array}{r}
301.6 \\
1.6 \\
32.0 \\
38.1 \\
0.3 \\
9.1 \\
386.3
\end{array}
$$

$$
\begin{array}{r}
309.0 \\
1.7 \\
30.6 \\
10.0 \\
0.3 \\
11.2 \\
395.9
\end{array}
$$

126.3

17.2

69.0

25.6

1.1

23.0

262.1

84.2

3,8

25.9

33.4

0.1

6.8

154.5

85.8

1.6

25,5

27.4

0.1

8,5

149.1

81.0

6.0

15.1

148.3

0.3

22.5

273.5

30.4

1.7

13,1

162.9

0.1

33.3

211.8

32.7

9.7

22.7

24.1

0.3

8.0

97.3

$$
\begin{array}{r}
11.2 \\
1.6 \\
10.7 \\
19.5 \\
0.7 \\
8.2 \\
54.7
\end{array}
$$

3861.5

274.9

634.0

595.9

8.9

145.0

5520.2
108.9

606.3

654.2

9.8

1.70 .1

1982.5
3433.1
27.4

0.2

12.8

139.9

0.5

35.0

215.7

23.9

1.0

10.5

15.7

0.5

9.3

60.9

3836.9

42.9

586.0

622.1

9.4

190.9

5288.2 (kt) (Cont'd)

$\begin{array}{rr}\text { Autumn } & \text { Annual } \\ \text { Sop85 } & \text { Jan85 } \\ \text {-Nov85 } & - \text { Doc85 }\end{array}$

$\begin{array}{rr}254.0 & 1188.6 \\ 6.6 & 21.8 \\ 31.1 & 127.2 \\ 37.2 & 145.5 \\ 0.3 & 1.3 \\ 9.9 & 37.6 \\ 339.2 & 1525.0\end{array}$

86.7

351,7

17.3

103.8

116.2

25,8

26.8

1.1

28.0

7.1

151.1

$61.8,5$

$$
23.5
$$

1,1

12.9

138.8

0.1

34.1

211.1

110.8

6.6

52.1

589.6

1.7

133.5

894.5

80,1

19,3

12.9

73.7

2.0

33.2

8,6

64.0

251.3

$$
\begin{array}{r}
3405.2 \\
96.5 \\
593.4 \\
612.2 \\
9.2 \\
174.8 \\
4891.3
\end{array}
$$

14512.5

523.3

2.119 .8

2184.1

37.2

680.9

20688.1 


\begin{tabular}{|c|c|c|c|c|c|}
\hline & $\begin{array}{l}\text { WLinter } \\
\text { Dec85 }\end{array}$ & $\begin{array}{r}\text { 3pring } \\
\text { Mar } 86\end{array}$ & $\begin{array}{l}\text { Summer } \\
\text { Jun8 } 6\end{array}$ & $\begin{array}{l}\text { Autumn } \\
\text { sop86 }\end{array}$ & $\begin{array}{r}\text { Annual } \\
\text { Jang6 } \\
-10086\end{array}$ \\
\hline Fod, Reglon / Sector & $-F a b 86$ & $-\operatorname{May} 36$ & $-A u g B 6$ & - Nov86 & \\
\hline \multicolumn{6}{|l|}{ Fedoral Rogion 1} \\
\hline Electr1e Ut:11ty & 96.1 & 92,6 & 89.7 & 78.9 & 367.3 \\
\hline Commerclal./Restdont lal. & 38.5 & 15,9 & 2,0 & 14.2 & 63,9 \\
\hline Indust $[$ lal Fuol. & 45.0 & 35.3 & 33.0 & 35.2 & 139.8 \\
\hline Indust rlal Procosses & 1.5 & 1.5 & 1.5 & 1,5 & 6.0 \\
\hline Mlscollaneous & 0.7 & 0.7 & 0.7 & 0.7 & 2.6 \\
\hline Transportation & 8.0 & 4.4 & 6.0 & 1.7 & 18.1 \\
\hline 'T'otial. & 189.7 & 150.4 & 132,9 & 135.1 & 598.0 \\
\hline \multicolumn{6}{|l|}{ Federal Reglon? } \\
\hline Electrlo Uti11ty & 85.5 & 104.0 & 110.8 & 89.2 & 418.8 \\
\hline Commercial/Res Ldential & 11.2 & 27.0 & 3.7 & 23.2 & 111,2 \\
\hline Industrlal fuel & 24.2 & 32.0 & 28.6 & 29.5 & 123.4 \\
\hline Industrlal procossos & 4.5 & 4.5 & 4.3 & 4.3 & 17.3 \\
\hline Mlscollaneous & 0.9 & 1.3 & 1.3 & 1.3 & 5.1 \\
\hline Transportation & 5.5 & 9.7 & 12.0 & 10.0 & 39.5 \\
\hline Total & 161.8 & 178.5 & 160,5 & 157.4 & 715.1 \\
\hline \multicolumn{6}{|l|}{ Federall Reglon 3} \\
\hline Elacitric Utility & 195.4 & 540.7 & 610.4 & 562.9 & 2353.1 \\
\hline Cesmmerclal / Rosldont lal & 40.8 & 22,6 & 4.9 & 20.5 & 97.7 \\
\hline Industatial fued & 68.4 & 77.7 & 69.0 & 69.6 & 296.6 \\
\hline Industrial Procossos & 39.8 & 46.9 & 16.1 & 44.9 & 179.8 \\
\hline Mescollaneous & 0.8 & 1.0 & 1.0 & 1.0 & 3.8 \\
\hline Transportation & 10.0 & 13.3 & 15.7 & 13.6 & 53.0 \\
\hline Total & 655.1 & 702.0 & 747.1 & 712,3 & 2984.2 \\
\hline \multicolumn{6}{|l|}{ Federal Reglon $A$} \\
\hline E.1ectric Ut 111 ty & 850.7 & 902.6 & 1.130 .5 & 935,5 & 3920.2 \\
\hline Commercla l. Resldentlal. & 48.0 & 14.6 & 3.2 & 10.6 & 70.8 \\
\hline Industrlal Fuel & 95,2 & 109.1 & 97.6 & 99.0 & $4 \div 9.2$ \\
\hline Industrtal processes & 77.2 & 79.3 & 78.4 & 79.3 & 311,3 \\
\hline MIscellaneous & 1.2 & 1.3 & 1.1 & 1.0 & 4.4 \\
\hline Trásportation & 19.6 & 27.1 & 29.8 & 27.3 & 106.8 \\
\hline Total & 1091.8 & 1134.3 & 1340.4 & .1152 .7 & 4832.6 \\
\hline \multicolumn{6}{|l|}{ Foderal Region 5} \\
\hline Eloctrlc Utility & 1203.2 & 1206.1 & 1373.6 & 1176.7 & 5073.3 \\
\hline Commercial/Restdential & 41.9 & 28.9 & 18.0 & 29.3 & 123.5 \\
\hline Industrtal fuel. & 177.5 & 199.7 & 176.4 & 177.5 & 760.5 \\
\hline Industrial Procosses & 72.9 & 79.1 & 78.9 & 77.1 & 306.0 \\
\hline Mlscellaneous & 1.2 & 1.2 & 1.2 & 1.2 & 4.9 \\
\hline 'Transportation & 14.8 & 23.4 & 29.5 & 24.8 & 95.3 \\
\hline T'otal & 1511.5 & 1538.4 & 1677.1 & 1486.6 & 6363.6 \\
\hline \multicolumn{6}{|l|}{ Fodoral Region 6} \\
\hline Eloctrlo Ut1lity & 386.7 & 132.9 & 196.2 & 162.7 & 657.1 \\
\hline Commerctal/Rastant lal & 25.3 & 5,3 & 0.2 & 5.8 & 36.3 \\
\hline Industrial Fuel. & 107.1 & 110.0 & 105.5 & 109.3 & 438.1 \\
\hline Industrlal Procoseas & 187.1 & 186.2 & 184.1 & 193.5 & 751.4 \\
\hline MJacollaneous & 2.1 & 2.5 & 2.5 & 2.5 & 9.9 \\
\hline Transportation & 25.0 & 33.6 & 35.8 & 31.2 & 133.8 \\
\hline Total & 733.4 & 470.6 & 524.2 & 507.9 & 2026.6 \\
\hline
\end{tabular}


(kt) (Cont'd)

Fod, Ragion / sactor

Winter
Dec85

Febo 6

Fodoral Rogion?

Electrlc Utility

Commerclal/Resldential.

Industrlal Fuel

Industrla1 Procossos

Miscellaneous

Transportation Total

Federal Regton 8

E.lectric Utility

Commerclal/Resident 1 al

Industrlal Fue 1

Industrial processes

MIscellaneous

Transportation Total.

Fedoral Reglon 9

Electrlc Utility

Commerclal/Resldentlal

Industrial Fuel

Industrla) processes

Miscollaneous

Transportation T'otal

Federal Region 10

E1ectric Ut111ty

Commerclal/Residontial

Industrtal Fuel

Industrlal Processes

Mlscellaneous

Transportation Total

National l'otals

Electric Utility

Commerclal/Residential

Industrtal Fuel

Industrial Processes

M.lscellaneous

Transportation Total

48.2

$120 . ?$

16.5

70.5

22.4

1.1

21.9

253.0

68.8

7.8

18.4

132.3

0.3

21.1

248.8

10.2

8.8

16.0

0.3

8.7

69.5

3708.2

279.7

679.4

585.1

8.9

141,9

5403.0

$\begin{array}{rr}\text { Spring } & \text { Summer } \\ \text { Mar86 } & \text { Jun86 } \\ \text {-May86 } & \text {-Aug86 }\end{array}$

Aut.umn
Sep86

-Nov8 6

268.1

5.1

2.9.6

36.4

0.3

9.6

349.6

328.6

405.5

66.6

3.7

27.9

25.7

0.4

6.7

131.0

73.4

1. 0

26.3

25.7

0.1

8.6

135.4

28.5

2.4

15.2

143.2

0.4

31.7

221.5

35.2

0.2

14.1

115.0

0.5

33.8

198.7

72.0

4. 1

26.7

26.8

0.3

7.2

137.1

25.3

1,9

14.6

131.3

0.4

32.3

205.9

0.0

4.1

16,8

16.0

0.7

9.9

47.5

3321.4
129.2

657.7

615.8

9.8

168.9

4902.7
7.3

0.9

15.7

14.9

0.5

11.2

50.6

3951.0

37.7

595.8

585.0

9.4

193.8

5372.7
16.1

3.9

16.4

15.2 .

0.5

10.0

62.1

3387.9

118.5

607.5

610.3

9.2

173.7

4907.1
Annual
$\operatorname{Jan} 86$
$-\operatorname{Doc} 86$

1111.0

20.7

127.8

137.8

1,3

37,0

1435.7

301.2

15.8

109.3

101.1

1.1

27.7

559.1

120.3

9.1

59.6

521.5

1.7

127.0

$839 . ?$

39.3

16.0

66,1

61.0

2.0

39.7

224.1

14361.7

565.1

2540.1

2396.3

37.2

678.2

20578.9 
$1987 \mathrm{SO}_{2}$ Emissions by

Fed. Region / Sector
Federal

legion and

Season

(kt)

$\begin{array}{rrrrr}\text { Winter } & \text { Spring } & \text { Summer } & \text { Autumn } & \text { Annual } \\ \text { Dec86 } & \text { Mar87 } & \text { Jun87 } & \text { Sep87 } & \text { Jan87 } \\ \text { - Feb87 } & \text {-May87 } & \text {-Aug87 } & \text {-Nov87 } & \text {-Dec87 }\end{array}$

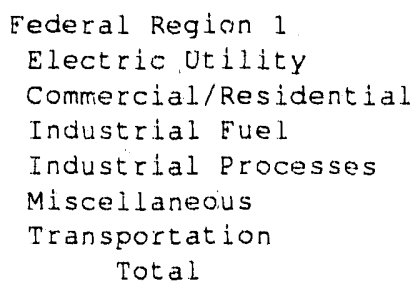

Eederal Region 2

Electric Utility

Commercial/Residential

Industrial Fuel

Industrial Processes

Miscellaneous

Transportation Total

\begin{tabular}{rr}
89.7 & 78.6 \\
38.0 & 16.0 \\
49.3 & 30.8 \\
1.5 & 1.6 \\
0.7 & 0.7 \\
8.5 & 4.5 \\
\hline 7.7 & 132.2
\end{tabular}

89.6
1.3
31.9
1.6
0.7
6.0
131.1

76.9
13.2
32.9
1.6
0.7
4.7

130.0

$\begin{array}{rrrr}85.3 & 93.8 & 117.4 & 101.7 \\ 41.6 & 26.5 & 2.3 & 23.0 \\ 23.9 & 31.0 & 31.0 & 32.5 \\ 4.5 & 4.3 & 4.3 & 4.4 \\ 0.9 & 1.3 & 1.3 & 1.3 \\ 6.5 & 11.1 & 13.1 & 11.3 \\ 162.7 & 167.9 & 169.5 & 174.1\end{array}$

Federal Region 3

Electric Utility

Commercial/Residential

Industrial Fuel

Industrial Processes

Miscellaneous

Transportation Total

Federal. Region 4

Electric Utility

Commercial/Residential

Industrial Fuel

Industrial Processes

Miscellaneous

Transportation

$$
\text { Total }
$$

\footnotetext{
Eederal Region 5

Electric Utility

Commercial/Residential

Industrial Fuel

Industrial Processes

Miscellaneous

Transportation$$
\text { Total }
$$

Federal Region 6

Electric Utility

Commercial/Residential

Industrial Fuel

Industrial Erocesses

Miscellaneous

Transportation

$$
\text { Total }
$$
}
425.3
45.5
62.0
39.5
0.8
10.3
583.5
547.4
25.6
71.3
44.9
1.0
14.1
704.3

833.2

$$
\begin{array}{r}
839.8 \\
14.7 \\
96.7 \\
81.2 \\
1.3 \\
29.5 \\
1063.2
\end{array}
$$
646.5
5.5
71.6
47.7
1.0
16.9
789.2

598.0

24.3

75.1

47.8

1.0

14.7

761.0

1110.2
2.3
97.4
83.5
1.1
31.9
1326.4

954.4

14.5

101.9

83.6

1.0

29.6

1184.9
1114.4
36.2
154.2
77.2
1.2
14.7
1398.0

$$
\begin{array}{r}
1183.6 \\
24.7 \\
170.6 \\
80.9 \\
1.2 \\
23.0 \\
1484.0
\end{array}
$$
1376.2
16.8
170.8
85.1
1. 2
28.8
1679.0

1116.6
28.6
179.6
85.0
1.2
24.1
1435.1

442.1
30.5
110.4
186.2
2.1
27.4
798.6

137.8
9.5
110.6
191.3
2.5
36.7
488.4

187.1
0.3
113.9
195.1
2.5
39.1
538.0
351.5

62.3

130.5

0.2

2.6

18.8

572.0

435.0

109.1

128.9

17.2

5.1

44.8

740.1

2414.6

111.0

295.3

182.1

3.8

56.9

3063 . 1

3846.1

73.4

401.4

326.0

4.4

115.8

4767.1

4898.1

111.3

706.2

326.8

4.9

93.2

6140.4

632.5
49.3
461.5
766.1
9.9
146.4
2065.7 
$1987 \mathrm{SO}_{2}$ Emlssions by

Fed. Region / Sector

Federal Region 7

Electric Utility

Commercial/Residential

Industrial Fuel

Industrial Processes

Miscellaneous

Transportation

$$
\text { Total }
$$

Federal Region 8

Electric Utility

Commercial/Residential

Industrial Fuel

Industrial Processes

Miscellaneous

Transportation

rotal

Eederal Region 9

Electric Utility

Commercial/Residential

Industrial Fuel

Industrial Processes

Miscellaneous

Transportation Total

Federal Region 10

Electric Utility

Commercial/Residential

Industrial Fuel

Industrial processes

Miscellaneous

Transportation

Total

National Totals

Electric Utility

Commercial/Residential

Industrial Fuel

Industrial Processes

Miscellaneous

Transportation Total

Region and

season (kt) (Cont'd)

386.7

12.3

45.8

26.2

0.3

7.1

478.4

111.7

19.9

68.4

23.5

1.1

24.5

249.2

70.8

8.4

17.4

83.5

0.3

25.9

206.4

13.7

8.9

24.4

16.2

0.3

8.6

72.2

3572.9

290.0

642.6

538.8

8.9

155.1

5208.3

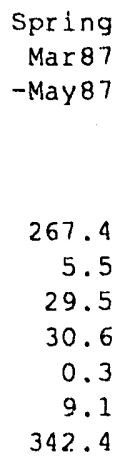

66.4

3.3

24.4

24.9

0.4

6.5

125.9

24.1

2.8

11.7

71.7

0.4

38.4

149.2

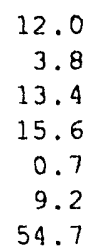

54.7

3250.9
132.3
590.1
546.9
9.8
182.1
4712.1
Summer

Jun 87

-Aug 87

355.8

5.2

29.5

36.5

0.3

11.4

438.7

71.1

0.8

24.9

30.5

0.4

8.4

136.0

37.6

0.4

12.0

70.1

0.5

40.7

161.2

16.2

0.8

13.8

15.9

0.5

10.5

57.7

4007.7
35.5
597.0
570.4
9.4
207.0
5426.8
Autumn
Sep87

-Nov87

280.1

8.1

31.1

35.3

0.3

9.8

364.7

66.6

3.3

25.8

31.6

0.3

7.0

134.7

32.6

1.9

12.4

67.2

0.4

39.0

153.5

10.8

3.4

14.3

16.4

0.5

9.4

54.8

3389.6
128.5
622.4
565.7
9.2
187.2
4902.6

14224.6

2452.0

2221.9

20253.4
586.4

37.2

731.4

28.7

121.7

28.5

37.2

1496.3

278.9

14.0

114.0

1.4

536.1

131.4

11.8

292.0

1.7

154.3

640.5

57.7

56.2

63.0

37.1

231.5 


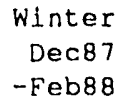

Spring
Mar 88
-May 88

Summer
Jun 88
$-A . u g 88$

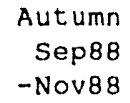

Annua 1 $\operatorname{Jan} 88$ $-\operatorname{Dec} 88$

Federal Region I

Electric Utility

Commercial/Residential

Industrial Fuel.

Industrial Processes

Miscellaneous

Transpuctation Total

Federal Region 2

Electric Utility

Commercial/Resideritiai

Industrial fuei

Industrial processes

Miscellaneous

Transportation

$$
\text { Total }
$$

Federal Region 3

Electric Utidity

Commercial/Residential

Industrial Fuel

Industrial processes

Miscellaneous

Transportation

$$
\text { Total }
$$

Federal Region 4

Electric Utility

Commercial/Residential

Industrial Fuel

Industrial Processes

Miscellaneous

Transportation

$$
\text { Total }
$$

Federal Region 5

Electric Utility

Commercial/Residential

Industrial Fuel

Industrial Processes

Miscellaneous

Transportation

$$
\text { Total }
$$

Federal Region 6

Electric Utility

Commercial/Residential

Industrial Fuel

Industrial Processes

Miscell laneous

Transportation

$$
\text { Total }
$$

85.3

15.1

38.3

1.6

0.7

4.5

145.5

93.2

39.2

27.1

4.9

0.9

6.6

171.9

$$
\begin{array}{r}
89.2 \\
25.2 \\
35.1 \\
4.7 \\
1.3 \\
11.2 \\
166.7
\end{array}
$$

92.5

$$
1.3
$$

37.8

1.6

0.7

6.1

140.0

113.6

2.5

4.6

1.3

13.3

169.3

86.8
12.6
40.3
1.6
0.7
4.7
146.8

383.2

59.1

158.9

6.4

2.6

18.8

467.4

588.4

45.5

68.0

42.7

0.8

10.3

634.7

26.2

76.2

49.9

1.0

14.1

755.8

695.5
5.4
74.5
51.0
1.0
16.9
844.2

111.4

21.9

36.3

4.6

1.3

11.4

187.0

446.6

103.7

144.0

18.6

5.1

45.4

763.4

908.1

866.9

1121.6

2. 5

103.1

91.8

1.1

31.2

105.5

90.0

1.2

21.1

1.3

28.8

1167.3

1107.4

1351.3

606.5

24.3

79.3

50.1

1.0

14.7

775.8

2578.7

111.7

312.5

195.8

3.8

56.9

3259.4

$$
\begin{array}{r}
1144.7 \\
36.6 \\
165.2 \\
82.1 \\
1.2 \\
14.7
\end{array}
$$

1128.7
25.2

1338.4
19.5

181.0

87.5

1.2

22.8

176.3

89.7

1.2

28.6

1446.5

1653.6

939.0

3963.0

14.6

109.9

91.6

1.0

28.9

1185.1

1444.5

1124.0
31.9
188.0
88.3
1.2
23.9
1457.4

4834.1

119.2

741.8

345.6

4.9

92.6

6138.3

457.4

145.8

195.7

158.0

666.8

45.7

519.6

125.8

132.2

121.5

126.0

211.0

211.5

2.5

2.5

39.6

2.1
27.6

37.2

841.6

9.9

38.0

549.9

148.3

2231.9
629.1

574.7 


\section{$1988 \mathrm{SO}_{2}$ Emissions by}

Fed. Region / sector

Federal Region 7

Electric Utlity

Commerclal/Res Idential

Industrlal Fuel

Industrlal Processes

Miscellaneous

Transportaticn Total

Federal Region 8

Electric utility

Commercial/Residential

Industrial Fuel

Industrial processes

Miscellaneous

Transportation Total

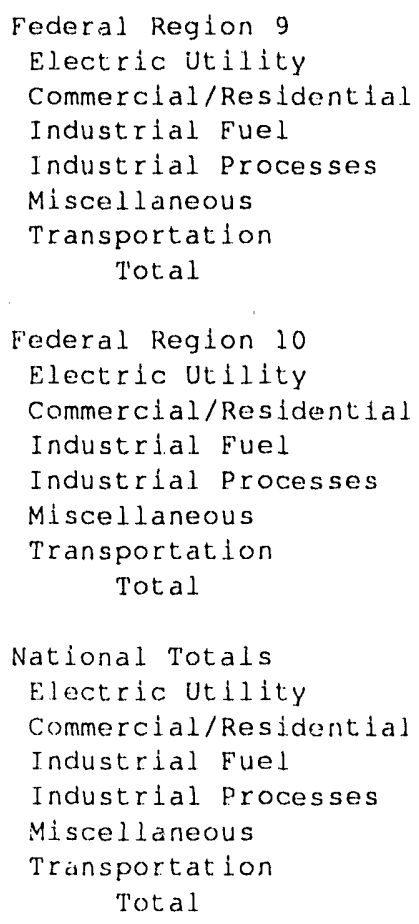

Region and

(kt) (Cont'd)

$$
\begin{array}{r}
\text { Winter } \\
\text { Dec } 87
\end{array}
$$$$
-F e b 88
$$

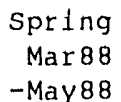

Summer
Jun 88
-Aug 88

Autumn
Sep88
-Nov88

Annual

$\operatorname{Jan} 88$
$-\operatorname{Dec} 88$

$$
\begin{array}{r}
366.8 \\
13.0 \\
47.7 \\
34.2 \\
0.3 \\
7.1
\end{array}
$$

469.2

$$
\begin{array}{r}
224.6 \\
6.2 \\
30.5 \\
42.7 \\
0.3 \\
9.2 \\
313.6
\end{array}
$$

135.8

19.5

74.1

33.1

1.1

24.6

288.2

77.3

7.8

19.5

58.6

0.3

25.9

189.3

41.5

8.5

26.8

18.5

0.3

8.6

104.2

3796.7

282.2

702.8

573.7

8.9

155.0

5519.3
87.6
3.2
26.0
39.1
0.4
6.5
162.8

32.7

90.2
0.8
26.0
36.4
0.4
8.4
162.1

45.4

0.3

13.4

63.4

0.5

40.7

163.7

149.2

$$
\begin{array}{r}
10.6 \\
3.6 \\
15.5 \\
18.0 \\
0.7 \\
9.1 \\
57.4
\end{array}
$$

$$
\begin{array}{r}
3259.8 \\
130.0 \\
647.7 \\
606.3 \\
9.8 \\
182.0 \\
4835.6
\end{array}
$$

14.4

0.8

15.4

17.9

0.5

10.4

59.4

4040.8

39.0

636.0

611.7

9.4

206.7

5543.5
333.6
5.6
29.8
44.3
0.3
11.6
425.2

$$
\begin{array}{r}
261.1 \\
9.0 \\
31.7 \\
44.2 \\
0.3 \\
10.0 \\
356.3
\end{array}
$$

89.9

3.3

27.2

38.2

0.3

7.1

166.1

40.2

1.7

14.5

42.8

0.4

39.0

138.7
15.0

3.3

16.3

18.1

0.5

9.4

62.5

3432.0

130.4

675.7

591.2

9.2

187.1

5025.5
1080.4

31.3

124.9

165.5

1.3

37.7

1441.0

363.8

13.7

106.7

150.7

1.4

26.9

663.1

156.9

11.0

56.4

225.8

1.7

154.2

506.0

56.4

14.8

64.0

71.4

2.0

36.8

245.3

11529.9

581.6

2662.2

2382.9

37.2

730.8

20924.6 
Fed. Region / Sectior

Winter

Dec74

-Feb 75

Spring
Mar 75
-May 75

Summer

-Aug 75

Autumn
Sep 75
-Nov 75

Annual

Jan 75

-Dec75

Federal kiegion 1

Electric Utility

Commerclal/Residential

Industrlal Fuel

Industrial. Processes

Miscellaneous

Transportation Total

$\begin{array}{lr}\text { N/A } & 0.3 \\ \text { N/A } & 12.1 \\ N / A & 1.9 \\ N / A & 60.8 \\ N / A & 41.1 \\ N / A & 148.0 \\ N / A & 264.1\end{array}$

0.3
0.6
1.8
63.8
41.1
219.2
326.7

0.3

7.6

2.0

63.5

40.6

146.6

260.4

Total

Foderal Region 3

filectric Utility

Commercial/Resident ial

Industirial Fuel

Industrial processes.

Miscellaneous

Transportation Total

Federal Region $A$

Electric Utility

Commercial/Residential

Industrial Fue].

Industrlal Processes

Miscellaneous

Transportation

$$
\text { Total. }
$$

Federal Region 5

Ejectric Utility

Commercial/Residential

Industrial Fuel

Industrial Processes

Miscellaneous

Transpe tation

$$
\text { Tolal }
$$

Federal Region 6

Electric Utility

Commercial/Residential.

Industrial Fue]

Industrial Processes

Mlscellaneous

Transportation

$$
\text { Total }
$$

$N / A$

$N / A$

$N / A$

$N / A$

$N / A$

$\mathrm{N} / \mathrm{A}$

$N / A$

$N / A$

$N / A$

$N / A$

$N / A$

$N / A$

$N / A$

$N / A$

0.6

16.2

4.9

122.2

79.0

275.2

498.1

0.8

0.3

4.3

129.5

78.5

379.3

592.8

0.5

8.8

4.9

125.8

77.6

261.8

479.4

25.6

1.2

167.2

106.6

329.5

631.0

$\mathrm{N} / \mathrm{A}$

$N / A$

$\mathrm{N} / \mathrm{A}$

$N / A$

$N / A$

$N / A$

$\mathrm{N} / \mathrm{A}$

1163.0

$N / A$

$N / A$

$N / A$

$N / A$
$N / A$

$N / A$

1154.8

$N / A$

$N / A$

$N / A$

$N / A$

$N / A$

$N / A$

$N / A$
1. 3

29.2

4.4

268.1

252.1

607.9

1.7

39.5

3.9

339.7

166.3

603.8

1.

4. 3

283.4

229.6

748.5

1267.8

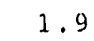

1.4

3.3

357.1

167.2

870.3

1401.2

0.8

6.8

8.5

346.4

235.5

369.5

967.5

1.2

0.1

8.5

380.7

233.1

451.6

1075.2
1.0

0.5

1.0

176.2

107.4

448.9

735.0

0.8

15.1

1.1

175.8

106.2

333.7

633.0

1.4

21.1

4.5

280.1

216.9

572.0

1096.0

1.5

25.4

3.7

355.2

165.1

619.8

1170.7
0.9

8.6

371.9

229.0

360.5

976.4

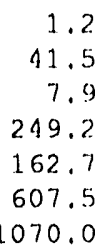

2.7

53.9

20.1

499.8

311.8

1088.7

1977.0

3.7

89.9

4.8

687.6

424.2

1331.6

2541.8

5.8

125.5

17.9

1102.9

910.5

2453.9

4616.1

7.2

138.8

15.5

1395.2

660.4

2498.2

4715.3

3.8

31.9

34.7

1455.7

$922 . ?$

1507.7

3956.0 


$\begin{array}{rr}\text { Winter } & \text { Sprling } \\ \text { Dec74 } & \text { Mar75 } \\ \text {-Feb75 } & \text {-May75 }\end{array}$

(kt) (Cont'd)

F'ederal Region?

Electric Utility

Commerclal/Residential

Industrial Fuel.

Industrial processes

Miscellaneous

Transportation Total

$N / A$
$N / A$
$N / A$
$N / A$
$N / A$
$N / A$
$N / A$

Summer
Jun 75

-Aug 75

Autumn
Sep75

Annual

Jan 15

-Dec75

Federal Region 8

Electric Utility

Commercial/Residentlal.

$N / A$

$N / A$

Industrial Fued.

Industrial processes

Miscellaneous

Transportation Total

$N / A$

$N / A$

$N / A$

$N / A$

$N / A$

0.5
6.8
0.4
69.9
41.0
167.9
286.6

0.8

0.1

0.4

76.6

40.9

238.6

357.4

-Nov'15

Federaj. Region 9

Electric Ut 11 thy

Commercial/Residentlal

Industrial Fuel

Industrial processes

Miscellaneous

I'ransportation

Total

$\begin{array}{lr}\text { N/A } & 0 . \\ \text { N/A } & \% \\ \text { N/A } & 1 . \\ \text { N/A } & 207 . \\ \text { N/A } & 115 . \\ \text { N/A } & 295 . \\ \text { N/A } & 658.8\end{array}$

0.2
5.7
1.1
38.8
16.2
98.8

0.3

0.8

0.9

41.5

43.6

166.0

253.1

0.6
1.7
0.1
75.5
39.9
165.1
286.3

2.5

2.7 .1

1.8

294.3

1.60 .1

673.7

286.3

1159.8

Federal Region 10

Electric Ut 11 ity

Commerclal/Resident.lal.

Industrial Fuel

Industrial Processes

Miscellaneous

Transportation Total

National Totals

Electric Utility

Commercial/Residential

Industrial Fuel

Industrial Processes

Miscellaneous

Transportation Total

$\begin{array}{lrr}\text { N } / A & 0.0 & 0.0 \\ \text { N/A } & 16.3 & 3.5 \\ \text { N/A } & 1.1 & 1.1 \\ \text { N/A } & 31.3 & 36.2 \\ \text { N/A } & 82.1 & 71.5 \\ \text { N/A } & 100.9 & 134.2 \\ \text { N } / A & 234.8 & 246.5\end{array}$

0.3
4.5
1.1
40.7
41.0
107.1
194.7

1.0

20.0

4.5

161.0

163.2

441.1

793.8

$\mathrm{N} / \mathrm{A}$

658.8

0.5

0.7

0.5

1.2

1.7

218.4

146.8

325.7

693.6

213.4

144.5

300.2

664.5

2.1

24.2

6.8

316.5

570.0

1211.9

2661.6

$\begin{array}{lr}\text { N/A } & 6.8 \\ \text { N/A } & 165.9 \\ \text { N/A } & 29.1 \\ \text { N/A } & 1655.3 \\ \text { N/A } & 1195.5 \\ \text { N/A } & 2996.9 \\ \text { N/A } & 6049.5\end{array}$

$$
\begin{array}{r}
8.7 \\
8.0 \\
27.2 \\
1763.3 \\
1159.8 \\
3982.4 \\
6949.4
\end{array}
$$
0.0
104.8
219.1

0.1

55.5

4.6

141.3

267.9

406.9

876.3

876.3

$$
\begin{array}{r}
6.8 \\
109.4 \\
29.3 \\
1737.9 \\
1125.8 \\
2971.5 \\
5980.6
\end{array}
$$

30.1

608.3

118.5

6833.6

1553.3

12224.3

24368.1 
B.9 VOC Emissions

by Federal Region and Season 
Federal

WLinter

Dec 75

Fed, Roglon / Soctor
Ragion and

Sprlng
Mar 76
- May 76

Summer

Jun 76

-Aug 76

$(k t)$

Faderal Regton 1

Eilectids Uthity

Commerclal/Resldental

Industitial fiues

Industrlal processos

Mlscollaneous

Transportat lon

$$
\text { lotal }
$$

$\begin{array}{rr}0.1 & 0.3 \\ 29.2 & 11.2 \\ 2.9 & 2.1 \\ 91.1 & 67.7 \\ 60.5 & 10.2 \\ 110.4 & 193.2 \\ 321.5 & 264.6\end{array}$

0.3
0.5
2.0
68.8
10.2
210.1
32.2 .2

Autumn
Sop 76
- Nov 76

Annual

$\operatorname{Jan} 76$

$-10076$

Federal Reglon?

Electide Ut ld tey

Commerclat/Residontal

Industirlal Fuel

Industrial procossos

Mlscellanoous

Iransiportation

$$
\text { 'ot.al }
$$

$$
\begin{array}{r}
0.3 \\
10.1 \\
2.2 \\
68.6 \\
39.6 \\
117.7 \\
268.7
\end{array}
$$

1.2

16.4

8.7

271.9

158.8

592.0

1079.0

Foderal Reglon 3

Filectrlo Ut11tey

commercial/Residontel 1

Industr tal fues

Industrial processes

Mlscedtaneous

Transportation

$$
\text { rotal }
$$

$\begin{array}{rr}1.0 & 0.9 \\ 15.5 & 19.6 \\ 1.7 & 1.3 \\ 169.9 & 185.0 \\ 86.9 & 101.3 \\ 178.7 & 338.6 \\ 483.7 & 649.7\end{array}$

0.9
0.7

1.1

189.7

105.7

452.3

750.1

Federal Reglon 9

Elocteric Utility

Commerclal/Resldent al

Industilal fuel

Industrial Processos

Miscellaneous

Iransportation

$$
\text { Total }
$$

Fouteral Region 5

filecterle Utility

Commorcial/Rosidential

Industirial fuel

Industerlal Processos

Mlscollaneous

Iransportation

$$
\text { Tot.al }
$$

Foderal keglon 6

Eilecterie UL111ty

Commercial/Rosidential

Industrial Fuel

Industrial procosses

Miscellaneous:

Transportation

$$
\text { Trital }
$$

\section{6}

66.8

6.0

267.8

185.6

460.4

988.2

1.1

21.7

5.0

295.3

246.3

627.8

$119 \% .5$

1.9

0.4

4.9

303.1

221.3

772.8

1307.6$$
2.0
$$

68.3

4.8

321.8

144.0

347.8

888.7

1.7
32.8
3.8
371.5
161.2
598.2
1169.3

1,8

1.7

3.4

381.9

162,1

860.1

1411.2

$\begin{array}{rrr}0.9 & 0.9 & 1.2 \\ 34.1 & 5.9 & 0.1 \\ 8.0 & 10.1 & 10.2 \\ 317.3 & 378.7 & 395.3 \\ 192.4 & 232.0 & 229.5 \\ 329.9 & 376.0 & 452.8 \\ 877.7 & 1003.5 & 1089.0\end{array}$

$\begin{array}{rr}0.5 & 0.6 \\ 22.9 & 13.6 \\ 1.8 & 5.0 \\ 91.3 & 131.0 \\ 52.3 & 77.1 \\ 111.3 & 262.1 \\ 283.1 & 493.1\end{array}$

0.7

0.1

4.4

137.3

76.9

354.6

574.2

$$
\begin{array}{r}
0.6 \\
13.6 \\
5.1 \\
135.7 \\
75.9 \\
262.7 \\
493.5
\end{array}
$$

2.7

59.7

20.6

539.0

305.1

1046.0

1973.1

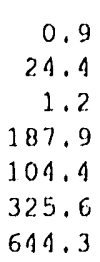

3.9

96.4

5.1

744.5

115.8

1342.3

2608.0

1.7

36.2

5.2

300.1

211.6

588.5

11.13 .6

6.6

139.5

20.4

1189.3

888.0

2527.2

4770.9

1.0
9.7
10.3
385.1
225.6
357.3
989.2

4.1

36.0

41.1

1539.3

908.2 .

1518.1

1042.4 


\begin{tabular}{|c|c|c|c|c|c|}
\hline Eim1satong & Tederal & Region & Season & (Cont'd) & \\
\hline & $\begin{array}{r}\text { Whitor } \\
\text { Dec75 }\end{array}$ & $\begin{array}{l}\text { Spring } \\
\text { Mart } 6\end{array}$ & $\begin{array}{l}\text { summer } \\
\text { Jun } 76\end{array}$ & $\begin{array}{l}\text { Autiumn } \\
\text { Sop' } 6\end{array}$ & $\begin{array}{c}\text { Annual. } \\
\text { Janto }\end{array}$ \\
\hline Fod, Roglon / soctor & $-F e b 76$ & - May 16 & $-\operatorname{Aug} 76$ & -Nov76 & $-1) 0076$ \\
\hline \multicolumn{6}{|l|}{ Federal Roglon 7} \\
\hline Eloctrdo Ut $111 t y$ & 0.6 & 0.5 & 0.7 & 0,6 & 2.1 \\
\hline Commorelad/Rostdontidal & 18.3 & 5.0 & 0.2 & 7.8 & $30 . ?$ \\
\hline Industrial Fuel & 0.7 & 0.5 & 0.5 & 0.5 & 2.1 \\
\hline Industrial procossos & 83.2 & 79.2 & 81.0 & 80.3 & 318,5 \\
\hline Miscollanoous & 43.1 & 39.2 & 39.1 & 38.1 & 153.1 \\
\hline Transportation & 105.8 & 166.4 & 237.3 & 161.9 & 668,6 \\
\hline Total & 251.8 & 291.6 & 358.8 & 292.2 & 1175.0 \\
\hline \multicolumn{6}{|l|}{ Foderal Rogton 8} \\
\hline Electric utildty & 0.7 & 0.3 & 0.3 & 0.3 & 1.2 \\
\hline Commerclal/Resldential & 31.2 & 5.9 & 0.8 & 5.3 & 22.1 \\
\hline Industrlal Fuel. & 3.7 & 1.3 & 1.1 & 1.2 & 5.2 \\
\hline Industrlal procosses & 227.2 & 41.2 & 43.5 & 42.5 & 168.8 \\
\hline Miscellanoous & 143.1 & 16.7 & 51.2 & 50.6 & 189.1 \\
\hline Transportation & 277.0 & 100.9 & $163 . \%$ & 105.7 & 413.3 \\
\hline T'otal & 683.0 & 195.7 & 260.6 & 205.7 & 82.4 .6 \\
\hline \multicolumn{6}{|l|}{ Fedoral Reglon 9} \\
\hline E.lectric vililty & 0.5 & 0.5 & 0.7 & 0.6 & 2.5 \\
\hline Commercial/Restdontlal & 13.3 & 8.6 & 0.6 & 3,8 & 27.2 \\
\hline Industrlal puel. & 1.9 & 1.8 & 1.7 & 1.9 & 7.3 \\
\hline Industrial Processos & 159.2 & 221.5 & 228.7 & 2.23 .5 & 892.? \\
\hline M1scellaneous & 104.0 & 115.8 & 155.1 & 155.1 & 592.1 \\
\hline Transportation & 218.4 & 292.4 & 316.5 & 291.8 & 11.86 .1 \\
\hline Total. 1. & 497.4 & 670.6 & 703.3 & 676.6 & 2707.9 \\
\hline \multicolumn{6}{|l|}{ Federal Reglon 10} \\
\hline Electric Utildty & 0.2 & 0.0 & 0.0 & 0.1 & 0.1 \\
\hline Commerctal/Res ldontidal & 28.8 & 17.8 & 4.6 & 13.1 & 62.2 \\
\hline Industrial Fuol. & 1.5 & 1.2 & 1.2 & 1,3 & 1.9 \\
\hline Industrtal Procossos & 59.1 & 37.2 & 38.6 & 38.2 & 151.1 \\
\hline Miscellaneous & 51.3 & 83.2 & 85.7 & 82.8 & $30 \%, 3$ \\
\hline Transportation & 115.6 & 103.5 & 134.0 & 106.1 & 1.12 .4 \\
\hline T'otal & 256.3 & 243.0 & 264.1 & 241.1 & 938.1 \\
\hline \multicolumn{6}{|l|}{ NatLonal 'Totals } \\
\hline Electrle Utidity & 8.4 & 7.0 & 8.6 & 7.8 & 31.9 \\
\hline Commercial/Resldential & 358.7 & 143.1 & 9.8 & 162.3 & 673.9 \\
\hline Industrial fuel & 36.1 & 32.2 & 30.3 & 32.6 & 131.3 \\
\hline Industrial processes & 1788.0 & 1811.3 & 1868.1 & 1890.8 & 1308.1 \\
\hline MLscollanoous & 1062.9 & 1176.1 & 1169.7 & 1143.5 & 1552.2 \\
\hline Transportation & 22.80 .2 & 3008.9 & 3954.8 & 2971.8 & 12215.7 \\
\hline Total & 5534.3 & 6178.6 & 7041.4 & 6158.8 & 24913.3 \\
\hline
\end{tabular}




Whtier
Dec76
- Fob77

Sprdng
Mar77
- May77

Summer.

Junt7

-Aug $7 \%$
Annual.
Jan 77
-Dac77

Fodoral Roglon 1

Eloctirte Utillty

Commarcial/Ros ldent lal

indugtital puol

Industrlal prodesses

M.lsoolitaneous

Transportation 'lotal.

0.3
34.3
3.4
93.0
60.7
135.5
327.2

0.2

12.0

2.1

70.3

10,1

114.7

269.7

Foderal Reglon 2

Elloctrte Utility

Commerclal / Resident dal

Industrtal fuol.

Induatrlal processes

Mlacol Laneous

'l'ransportiation 'totall

Federad Reglon 3

Flocterlo Utithty

Commerclal/Residential

Industrlal puel.

Industirlal Processes

Miscolilaneous

Transportatiton 'T'otal

Federal Roglon 1

bloctide Ut 11Lty

Commercial/Restaontial.

Industrlal Fuel

Industrlal Processes

Mlscell taneous

Transportation 'otial

Fodoral Region 5

Electric Utilitiy

Commerclal/Residential.

Industrital Fuel

Industrtal processes

Mlscollaneous

I'ransportatifon trotial

Fodoral Reglon 6

Fiectida Utility

Commerclal/Rosidentlal.

Industrlal ruel

Industrial Procosses

Miscell aneous

T'ransporticton 'J'ot.al.

$\begin{array}{rr}1.7 & 1.4 \\ 96.6 & 20.4 \\ 6.5 & 5.5 \\ 277.0 & 309.9 \\ 182.8 & 248.0 \\ 141.7 & 622.9 \\ 1006.2 & 12.08 .2\end{array}$

$\begin{array}{rr}0.6 & 0.6 \\ 29.7 & 14.1 \\ 5.1 & 5.6 \\ 92.9 & 137.3 \\ 52.3 & 77.7 \\ 1.06 .1 & 258.2 \\ 287.4 & 493.8\end{array}$

0.9

0.7

5.0

140.8

77.3

356.6

581.3

0.3
9.9
2.5
70.6
39.6
148.4
271.2

1.2

51.8

9.9

280.9

158.5

596.8

1099.1

$\begin{array}{rr}1.2 & 0.9 \\ 62.0 & 19.9 \\ 1.8 & 1.3 \\ 176.7 & 194.0 \\ 86.5 & 104.6 \\ 171.1 & 328.5 \\ 199.3 & 619.1\end{array}$

1.1

1.0

1.2

198.1

105.7

444.1

751.2
0.5
12. 2
5.6
138.1
76.3
2.58 .9
491.6

2.8

66.5

2.3 .2

549.0

306.4

1026.6

1971.5

328.5

0.9

20.1

1.2

195.9

104.5

330.2

652.7

1.1

109.0

5.3

777.0

116.3

1317.3

2.629 .0

2.4
0.2
5.1
316.7
226.3
767.3
318.4

1.5

7.1

157.6

22.2

1239.5

891.6

2196.3

1817.3

1144.3

$\begin{array}{rr}2.1 & 1.7 \\ 91.6 & 30.5 \\ 5.0 & 4.0 \\ 332.0 & 387.4 \\ 111.3 & 162.2 \\ 337.5 & 595.5 \\ 912.5 & 1181.4\end{array}$

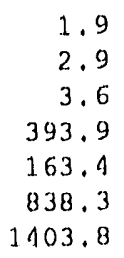

1.7
33.8
3.9
389.7
161.1
605.9
1196.1

7.5

173.0

16.3

1548.8

613.6

2123.6

1812.8

$\begin{array}{rr}0.9 & 1.0 \\ 13.2 & 6.5 \\ 8.5 & 10.8 \\ 331.2 & 398.1 \\ 192.3 & 231.6 \\ 307.6 & 377.9 \\ 883.7 & 1026.2\end{array}$

1.6

0.1

10.9

112.7

22.8 .6

465.1

1.119 .3
5.0
10.7
41.3
1602.4
905.8
1531.9
1133.1 
Region and

Season

(kt) (Cont'd)

Fod, Reglon / Soctor

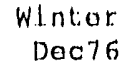

-Feb77

Sprdng
Mar 17
-May 17
Summer
Jun77
-Aug 77

Autumn
sep 77

-Nov77
Arinual

$\operatorname{Jan} 7 \%$

- Dec77

Federal Reglon 7

Electrlo Ut 11 t:y

Commerclal/Ros dential

Industrtal Fuol

Industrial prooesses

Milscellanoous

I'ransportat Ion T'otal.

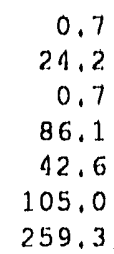

$$
0.5
$$

0.8

0.1

0,5

0,5

84.2

82.2

39.7

39.7

160.5

227.9

288.5

353.2

0.5
6.3
0.5
82.7
38.7
162.0
290.7

2.1

33.9

2. 1

330.0

155.2

650.1

1173.7

Foderal. Reglon 8

Electric Utility

Commerclal/Resldential.

Industidal Fuel

Industirlal Processos

Miscellaneous

Transportation Total

0.8

0.3

6.6

33.1
3.9

232.9

141.3

273.3

685.3

1.3

43.2

46,3

100.4

198.2

0.4

0.6

1.1

44.5

47.4

160.0

254.0

0.3
5.8
1.2
41.0
15.8
106.8
203.9

1.9

2.5 .5

5.2

174.9

173.2

110.1

820.5

fiederal. Reglon 9

Electric Utility

Commerclal/Restdent lal

Industrlal Fuel

Industrial processes

Mlscellaneous

I'ransportation

Total.

0.7

14.9

0.9

0.9

0.5

0.8
0.5

3.4

1.8

164.1

2.0
231.3

237.0

145.7

293.0

151.2

214.4

500.3

683.5

317.0

708.5

2.0

231.7

149.9

291.6

683.6

30.6

8.0

921.7

581.3

1184.0

2732.0

Federal Region 10

Electrlc Utility

Commerclal/Resldential

Industrial Fuel

0.2

0.1

0.0

0.1

0.2

32.2

1.7

19.4

1.4

2,9

17.1

1.9

1.4

39.4

73.4

50.8

MIsce 1 laneous

Transportation

82.3

39.9

78.2

104.8

135.1

106.2

258.9

247.0

257.5

238.0

70.2

5.6

156.6

286.0

112.5

931.2

National Totals

Electr Ic Utility

Commerclal/Residential

9.2

7.5

10.2

10.1

7.8
141.6

34.7

33.1

35.1

1939.2

1904.3

Industrial Processes

1847.4

1893.0

$1057.4 \quad 1178.2$

1157.8

1.1 2.7 .4

2986.4

3925.1

2965.7

5620.1

6245.4

7075.5

35,0

758.8

142.0

7583.9

1520.9

12082.5

2512.3 .2 


WInter
Dec77
-liab78

Spring
Mar78
- May78

fodoral Region 1

Electide Uti11ty

Commorclal/Residential

Industrial Fuel.

Industrial procossea

Mlscollaneous

'J ransportation 'rotal.

$\begin{array}{rr}0.3 & 0.3 \\ 37.0 & 16.6 \\ 3.2 & 2.2 \\ 103.5 & 78.2 \\ 60.9 & 10.1 \\ 129.1 & 112.1 \\ 331.1 & 279.5\end{array}$

0.3
0.8
2.1
79.3
40.0
212.7
335.3

0,3

1.2

12,6

2,3

79.2

39.7

145,3

279.1

61.3

9,1

313.6

158.6

583.3

$112.7,1$

\author{
Foderal Reglon 2 \\ Eloctrlo Utillty \\ Commerclal/Rosldent lal \\ Industrlat Fuol \\ Mlacollaneous \\ 'I'ransportation$$
\text { Total }
$$

0.6

0.5

21.1

5.7

5.1

100.7

52.1

1.02 .0

294.3

1.18 .4

77.9

254.2

508.1

0.7
0.6
5.1
152.5
77.3
352.0
588.2

0.5

14.2

5.6

150.7

76.8

253.5

501,2

$$
\begin{array}{r}
2.4 \\
78.4 \\
23.0 \\
597.1 \\
307.3 \\
1011.9 \\
2020.1
\end{array}
$$

Federal Reglon 3

E.lectific Uti11ty

Commorclal/Residential

1,3

72.0

1. 0

1.0

0.9

22.0

1,1

1.3

190.5

Industrlal. Processes

Miscel laneous

206.2

86.7

104.8

Iransportation Totial.

166.3

323.1

667.9

0.8

1.2

212.2

105.8

439.1

211.9

105.4

326.1

667.5

$12 \% .0$

5.2

833.6

417.8

1296.8

2684.5

Fedoral Region 4

Electrlc Utility

Commerctal/Restdent al

Industrial Fuel

1.9

1.6

112.4

6.4

36.0

5.5

297.8

330.5

Industrial. Processes

183.5

248.8

62.3 .8

Transportation Total.

1042.9

1246.1

2.2
0.2
5.5
340.5
226.8
779.3
1349.5

1.6

7.3

$18 \% .7$

22,5

5.7

337.2

1333.2

$215.9 \quad 899.3$

$589.7 \quad 2501.6$

$1174.7 \quad 4954.1$

Foderal Roglon 5

E. lectric Ut 11 lity

Commerclal/Resldent lal

Industrlal Fuel

Industrlal procesges

Miscellaneous

2.3

1.8

51.3

9.1

102.1
5.0

361.6

144.8

418.3

162.7

Transportation

316.3

568,3

Total

932.1

1206.5

1.

2.5

3.7

429.7

163.7

841.4

1412.7

1.7

7.6

35,9

4.1

128.6

162.9

599.6

1232.8

205.9

16.8

1689.7

646.8

2373.2

1910.2

Federal Reglon 6

biloctrlc Utillty

Commerclat/Residentlal.

1,1

48.2

1.2

1.7

0.1

1.3

5.6

11.0

11.1

11,3

48.6

45.2

315.8

114.3

Industrial procosses

193.0

232.7

431.3

425.8

227.3

1678.6

911.5

181.3

375.0

1565.0

1051,6

1047.0

4254.5 
1978

VOC

Emiationa

lied, Region / sector

Fedoral Reglon 7

Electr1c Ut1.1.ty

Commerctal/Restadont lal

Induat rlal. Euel

Indust rlal Processes

MLscellaneous

Transportation T'otal

Federal Reglon 8

Electric Utility

Commerclal/Residential

Industrlal Fuel

Industiclal. processes

Miscoll lanoous

Transportation Total

Federal Region 9

Electrlc Utility

Commerclal/Res Ldent 1 a $\perp$

Industrtal Fuel

Industrial processes

Miscellaneous

Transportation 'total

Federal Regton 10

Electrlc Utility

Commercial/Restdent lal

Industrlal Fuel

Industrla! Processes

Miscellaneous

Transportation 'total

National Totals

Electric Ut dilty

Commerclal/Residontlal

Industrial. Fuel

Industrial Processes

Mlscellaneous

'Transportat Lon Total.

\section{Ragion and}

Seavon

Spring

Mar78

- May 78

-Fab78

0.7

27.0

0.7

93.2

43,0

95,9

260.5

1.0

38.5

4.0

252.3

141.9

274.1

711.8

0.5
8.7
0.5
88.4
40.3
156.5
291.8

0.8

0.2

0.5

91.1

40.4

224.2

$35 \%, 1$

294.8

0.5

16.4

2.0

175.8

104.0

211.8

510.6

0.1

33.9

1.7

66.7

51.0

112.7

266.2

9.9

521.1

38.5

1987.9

1061.3

2158.7

5777.3
0.3

7.3

1.3

45,5

46.2

99.3

200.0

0.6
9.1
1.9
$24 \% .6$
145.9
290.9
695.9

695.9

0.0

21.5

1.4

12.1

82.3

106.7

254.1

0.4

1.0

1.1

47.5

47.2

165.8

263.1

0.7

0.6

1.8

253.8

151.2

318.0

726.1

0.0

3.4

1.4

43,2

78.2

$13 \% .3$

263.5

7.9

211.3

35.1

2019.5

1181.7

2949.1

6404.6

\section{5}

10.3

33.6

2081.1

1160,3

3946.1

7211.0 (xt) (Cont'd)

Autumn
Sop 78
- Nov 78

Arinual

dant8

$-120078$

$\begin{array}{rr}0.6 & 2.6 \\ 6.5 & 10.6 \\ 0.5 & 2.1 \\ 90.6 & 357.9 \\ 39.9 & 158.2 \\ 153.5 & 621.5 \\ 291.7 & 1185.9\end{array}$

\section{1}

6.8

1.3

$4 \% .3$

45.9

105.3

207.0

1.5

30.1

5.3

186.5

173,1

413.3

840.1

$$
\begin{array}{r}
0.9 \\
6.5 \\
2.0 \\
219.8 \\
151.0 \\
292.0 \\
102.1
\end{array}
$$

3,0

36.6

7.6

992.3

583.0

1179.7

2802.1

0.1

0.2

2.4

1.5

43.3

73.7

112.1

252.1

83.1

170.4

286.9

$423 . \%$

969.8

8.2

35.4

2064.3

1138.4

2952.2
35.5

899.9

112.6

8152.9

1511.7

12006.1

25778.7 
1979

\section{Winter \\ Dec78}

- Feb79

Summer
Jun 79
-Aug 79

Autumn
Sep 79
-Nov79

Annua 1
Jan 79
- Dec 79

Fecteral Region 1

Electric Utility

Commercial/Resiciontial

Industrial Fuel

Industrial processes

Miscellaneous

Transportation Total

Eederal Region 2

Electris Utility

Commercial/Residential.

Industrial Fuel

Industrial Processes

Miscel.laneous

Transportation Total

Federal Region 3

Fiectric Utility

Commercial/Residential

Industrial Fuel.

Industrial Pros oses

Miscellaneous

Transportation

$$
\text { Total }
$$

Federal Region 4

Electric Utility

Commercial./Residential

Industrial Fuel

Industrial processes

Miscellaneous

Transportation

$$
\text { rotal }
$$

Federal Region 5

Electric Utility

Commercial/Resiciential

Industrial Euel

Industrial Processes

Miscellaneous

Transportation

$$
\text { Total }
$$

Federal Region 6

Electric Utility

Commercial/Residential.

Indust : ial. Euel

industrial procosses

Miscel Laneous

Transportation

$$
\text { total. }
$$

\begin{abstract}
0.4
46.6

2.4

102.3

62.0

126.2

33.9 .9
\end{abstract}

'

0.4

41.9

4.1

101.2

53.9

105.1

306.7

1.0

85.0

1.5

190.6

88.5

155.4

522.0

1.6

129.0

6.1

298.3

187.9

439.6

1062.4

2.2

225.0

4.3

361.7

146.9

319.2

959.3

1.3

57.9

8.3

350.3

199.5

307.6

924.9
0.3

18.6

1.4

72.2

40.9

135.5

274.9

0.3

1.2

1.3

78.4

40.8

190.8

31.2 .8

0.3

14.0

1.4

78.1

40.3

133.4

267.3

1.2

73.9

5.5

311.8

161.3

544.7

1098.6

0.6

4.1

147.0

79.5

318.5

550.7

250.8

506.1

0.5

16.2

2.2

93.3

4.2

18.0

146.2

585.2

315.7

233.2

955.4

479.0

1969.7

0.9

1. 1

1.0

4.2

34.2

1.3

206.3

106.9

290.4

640.0

1.6

210.9

107.8

408.5

731.0

27.5

1.2

207.7

106.8

288.0

632.1

154.1

5.2

827.5

425.4

1179.2

2595.6

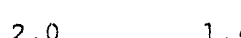

1.4
37.6

6.4

0.6

5.7

5.7

331.1

251.6

593.1

1222.3

334.6

229.4

331.4

217.0

$708.4 \quad 545.0$

1280.6

1138,0

228.8

22.8

1322.1

908.7

2352.1

4840.9

7.3

249.0

14.7

1666.1

652.1

22.05 .8

4795.1

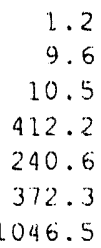

1. 6

1.4

5.7

59.7

42.7

10.5

420.1

237.4

437.8

1.107 .7

10.5

414.2

233.9

354.8

1025.0
1655.6

941.9

1496.9

4202.4

$\begin{array}{rr}1.7 & 1.7 \\ 59.9 & 3.5 \\ 3.7 & 3.2 \\ 418.4 & 420.1 \\ 164.4 & 165.1 \\ 553.1 & 749.0 \\ 1201.2 & 1342.7\end{array}$

1.7
46.0
3.4
416.3
163.2
543.8
1174.4 


\begin{tabular}{|c|c|c|c|c|c|}
\hline Emissions & Federal & Region & Searon & (Cont'd) & \\
\hline & $\begin{array}{r}\text { Winter } \\
\text { Dec78 }\end{array}$ & $\begin{array}{r}\text { Spring } \\
\operatorname{Mar} 79\end{array}$ & $\begin{array}{r}\text { Summer } \\
\text { Jun } 79\end{array}$ & $\begin{array}{r}\text { Aut umn } \\
\text { Sep } 79\end{array}$ & $\begin{array}{r}\text { Annual } \\
\text { Jan } 79\end{array}$ \\
\hline Fed, Region / Sector & - Feb79 & - May 79 & $-A u g 79$ & $-N o v 79$ & $-\operatorname{Dec} 79$ \\
\hline \multicolumn{6}{|l|}{ Federal Region 7} \\
\hline Electric Utility & 0.8 & 0.5 & 0.7 & 0.6 & 2.5 \\
\hline Commercial/Residential & 33.2 & 10.2 & 0.3 & 8.6 & 49.6 \\
\hline Industrial Fuel & 0.8 & 0.6 & 0.6 & 0.6 & 2.7 \\
\hline Industrial Processes & 92.3 & 87.9 & 88.4 & 88.9 & 352.5 \\
\hline Miscellaneous & 42.9 & 39.8 & 39.8 & 38.8 & 155.6 \\
\hline Transportation & 92.6 & 145.7 & 197.1 & 140.4 & 571.8 \\
\hline Total & 262.6 & 284.7 & 327.2 & 2.78 .0 & 1134.7 \\
\hline \multicolumn{6}{|l|}{ Federal Reqion 8} \\
\hline Electric utility & 0.9 & 0.3 & 0.4 & 0.4 & 1.7 \\
\hline Commercial/Residential & 45.1 & 9.5 & 1.1 & 8.1 & 37.1 \\
\hline Industrial Fuel & 3.8 & 1.3 & 1.1 & 1.3 & 5.3 \\
\hline Industrial Processes & 243.5 & 45.4 & 46.4 & 45.3 & 182.9 \\
\hline Miscellaneous & 146.3 & 46.6 & 49.2 & 48.2 & 178.8 \\
\hline Transportation & 255.9 & 98.4 & 146.0 & 101.7 & 416.2 \\
\hline Total & 695.7 & 201.5 & 244.2 & 205.1 & 822.0 \\
\hline \multicolumn{6}{|l|}{ Eederal Region 9} \\
\hline Electric Utility & 0.7 & 0.6 & 0.9 & 0.9 & 3.3 \\
\hline Commercial/Residential & 23.5 & 11.8 & 0.7 & 7.5 & 44.6 \\
\hline Industrial Fuel & 2.0 & 1.9 & 1.8 & 1.9 & 7.5 \\
\hline Industrial Processes & 180.9 & 241.2 & 242.4 & 241.4 & 967.7 \\
\hline Miscellaneous & 107.8 & 150.8 & 157.8 & 157.4 & 606.6 \\
\hline Transportation & 214.9 & 263.6 & 277.7 & 268.4 & 1081.1 \\
\hline Total & 529.8 & 569.8 & 681.2 & 677.6 & 2710.8 \\
\hline \multicolumn{6}{|l|}{ Federal Region 10} \\
\hline Electric Utility & 0.2 & 0.0 & 0.1 & 0.1 & 0.4 \\
\hline Commercial/Restdential & 50.4 & 25.2 & 4.7 & 22.1 & 101.1 \\
\hline Industrial Fuel & 1.7 & 1.3 & 1.3 & 1.3 & 5.3 \\
\hline Industrial Processes & 65.8 & 41.9 & 42.5 & 41.9 & 167.9 \\
\hline Miscellaneous & 51.8 & 82.9 & 82.0 & 78.2 & 297.3 \\
\hline Transportation & 106.9 & 101.5 & 125.1 & 101.4 & 393.8 \\
\hline Total & 276.8 & 252.9 & 255.6 & 245.0 & 965.8 \\
\hline \multicolumn{6}{|l|}{ National Totals } \\
\hline Electric utility & 9.6 & 7.5 & 9.4 & 8.1 & 34.9 \\
\hline Commercial/Residential & 637.6 & 241.1 & 14.9 & 197.7 & 1091.3 \\
\hline Industrial Fuel & 35.1 & 32.2 & 30.6 & 31.5 & 129.6 \\
\hline Industrial Processes & 1986.9 & 2010.1 & 2030.8 & 2011.5 & 8039.3 \\
\hline Miscellaneous & 1087.7 & 1204.6 & 1188.7 & 1162.5 & 4643.4 \\
\hline Transportation & 2123.2 & 2804.6 & 3559.2 & 2710.2 & 11197.1 \\
\hline Total & 5880.1 & 6300.1 & 6833.5 & 6121.5 & 25135.6 \\
\hline
\end{tabular}




\section{VOC Emissions by}

Fed. Region / Sector

\section{Federal}

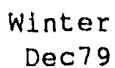

-Feb8o
Region
Season

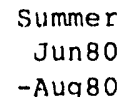

(kt)

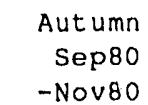

Annual

$\operatorname{Jan} 80$

-Dec80

\author{
Federal Region 1 \\ Electric Utility \\ Commerclal/Residential \\ Industrial Fuel \\ Industrial Processes \\ Miscellaneous \\ Transportation \\ Total \\ Federal Region 2 \\ Electric Utility \\ Commercial/Residential \\ Industrial Fuel \\ Industrial Processes \\ Miscellaneous \\ Transportation \\ Total
}

Federal Region 3

Electric Utility

Commercial/Residential

Industrial Fuel

Industrial Processes

Miscellaneous

Transportation Total

Eederal Region 4

Electric Utility

Commercial/Resiciential

Industrial Fuel

Industrial Processes

Miscellaneous

Transportation Total

Federal Region 5

Electric Utility

Commercial/Rosidential

Industrial Fuel

Industrial Processes

Miscellaneous

Transportation

$$
\text { poial }
$$

Federal Region 6

Electric Utility

Commercial/Residential

Industrial Fuel

Industrial processes

Miscellaneous

Transportation

$$
\text { Total }
$$

$\begin{array}{rr}0.4 & 0.3 \\ 51.2 & 21.6 \\ 1.9 & 1.1 \\ 96.7 & 72.5 \\ 58.5 & 38.2 \\ 120.9 & 123.6 \\ 329.5 & 257.3\end{array}$

\section{3}

1.4

1.0

71.2

37.8

179.5

291.3

$\begin{array}{ll}0.5 & 0.5\end{array}$

42.8

3.0

97.2

51.2

102.6

297.3

$$
\begin{array}{r}
26.7 \\
3.1
\end{array}
$$

135.7

75.7

222.7

464.5

0.9

89.7

1.3

183.4

84.6

151.5

511.5

0.8
41.9
1.0
191.8
101.1
265.9
602.5

0.7

1. 1

2.7

135.6

74.7

304.5

519.4

$$
\begin{array}{r}
0.3 \\
17.9 \\
1.1 \\
73.3 \\
37.4 \\
130.7 \\
260.7
\end{array}
$$

1.0

1.5

0.9

192.6

101.2

391.1

688.4

$$
\begin{array}{r}
0.5 \\
21.4 \\
3.0 \\
137.4 \\
72.9 \\
228.3 \\
464.5
\end{array}
$$

1.4

137.7

5.3

284.0

182.0

430.2

$1.03 \% .5$

$$
\begin{array}{r}
1.4 \\
54.0 \\
5.2 \\
306.5 \\
240.7 \\
540.4 \\
1148.3
\end{array}
$$

1.9

132.1

3.7

345.6

138.8

293.5

915.6

1.5

71.9

3.1

387.0

154.3

483.9

1101.8

2.2

0.4

5.0

30.3

216.7

671.6

1202.2

0.9
36.4

0.9

193.7

100.5

276.6

608.9

1.5
49.6
5.2
308.8
204.8
524.9
1094.8

6.7

264.9

20.8

1229.5

863.5

2211.1

4596.5

1.3

63.9

1. 3

14.5

6.7

346.8

8.' 5

391.2

231.3

347.3

295.5

994.2

905.6
1.8
3.7
2.7

382.4

153.6

702.0

1246.2

1.5

58.9

3.0

389.0

152.0

504.9

1109.3

1. 8

0.1

8.5

388.7

227.6

424.3

1051.0

$$
\begin{array}{r}
1.5 \\
13.1 \\
8.6
\end{array}
$$

385.6

224.1

335.3

968.2
$6: 6$

287.2

12.5

1551.7

610.3

2029.5

4497.8

6.1

68.4

34.7
1568.0

904.2

142.7

4011.1 
1980 VoC Emisstons b

Fed. Region / Sector

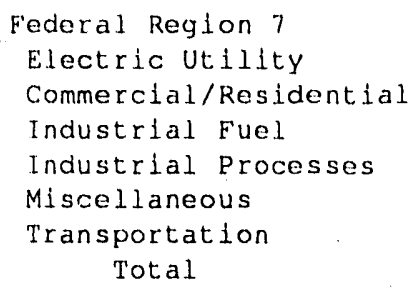

by Federal

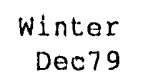

$$
\text { -Feb8o }
$$

Reglon and

Season

(kt) (Cont'd)

$\begin{array}{rr}\text { Spring } & \text { Summer } \\ \text { Mar } 80 & \text { Jun } 80 \\ \text {-May } 80 & \text {-Aug } 80\end{array}$

$$
\begin{array}{r}
\text { Autumn } \\
\text { Sep80 } \\
\text {-Nov80 }
\end{array}
$$

Annual.

$\operatorname{Jan} 80$

- Dec 80

$\begin{array}{rr}0.7 & 0.5 \\ 35.6 & 13.3 \\ 0.5 & 0.4 \\ 89.8 & 81.7 \\ 41.2 & 37.2 \\ 90.1 & 130.3 \\ 257.9 & 263.4\end{array}$

0.8
0.1
0.4
81.4
36.6
194.7
314.1

$$
\begin{array}{r}
0.5 \\
10.5 \\
0.4 \\
81.6 \\
35.8 \\
132.9 \\
261.7
\end{array}
$$

$\begin{array}{rr}0.8 & 0.4 \\ 53.2 & 11.5 \\ 3.1 & 0.9 \\ 228.2 & 43.4 \\ 141.3 & 45.6 \\ 229.6 & 98.4 \\ 656.2 & 200.1\end{array}$

0.7

23.5

1.7

170.5

103.6

190.7

490.7

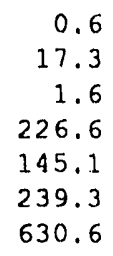

0.2

54.8

1.6

62.7

50.0

103.0

272.3

$$
\begin{array}{r}
0.0 \\
30.7 \\
1.3 \\
39.5 \\
81.7 \\
90.6 \\
243.8
\end{array}
$$

$$
1.3
$$$$
0 . B
$$$$
43.3
$$$$
49.7
$$

145.3

240.7

$$
\begin{array}{r}
0.4 \\
9.4 \\
0.8 \\
43.2 \\
49.3 \\
108.6 \\
211.8
\end{array}
$$

$$
\begin{array}{r}
0.7 \\
1.6 \\
1.5 \\
225.8 \\
153.7 \\
255.5 \\
638.9
\end{array}
$$

$$
0.6
$$

8.4

1.7

226.7

153.9

243.9

635.3

$$
\begin{array}{r}
0.0 \\
8.4 \\
1.3 \\
39.4 \\
83.7 \\
114.9 \\
247.7
\end{array}
$$

0.1

25.3

1.3

39.7

81.1

95.6

243.1

8.8

684.5

28.8

1905.0

1042.5

1997.4

5667.0
7.4

303.2

26.4

1876.0

1150.9

2542.5

5906.5
9.8

19.6

24.7

1866.9

1135.4

3383.5

6439.8
7.8

250.9

26.1

1878.9

1112.9

2581.7

5858.4
2.4

56.5

1.6

328.7

144.6

537.1

1071.0

$$
\begin{array}{r}
1.6 \\
41.6 \\
3.5 \\
174.4 \\
179.3 \\
424.1 \\
824.6
\end{array}
$$

$$
\begin{array}{r}
12.7 \\
51.7 \\
6.6 \\
907.0 \\
588.8 \\
979.6 \\
2536.4
\end{array}
$$

$$
0.2
$$

116.9

5.3

158.6

301.0

363.4

945.5

33.9

1258.4

106.0

7526.7

4441.6

10505.1

23871.7 


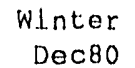

- Feb81

summer

Jung1

-Aug 81

Autumn

-Nov81
Annual.

Jan 81

- Dec 81

Federal Region 1

Electric Utility

Commerclal/Residentlal

Industrial Fuel

Industrial Processos

Miscellaneous

'Jransportation

$$
\text { T'otal }
$$

0.3
57.7
2.0
80.8
50.9
118.2
309.9

Federal Region 2

Electirlc Utlity

Commerclal/Residential

Industrial Fuel.

Industrial Processes

Mlscellaneous

T'ransportition Tutal

Federal Region 3

Electric Ut 11ty

Commercial/Residential.

Industrlal Fuel.

Industrlal Processes

Miscellaneous

Transportation 'otal.

Foderal Region 4

Flect.ric Ut:1ity

Comnorclal/Residential

Industrial Fuel.

Industrial Processes

Miscellaneous

Transportation Total

Gederal Region 5

Eilectric Ut lilty

Commercial/Residential.

Industrial fuel.

Industrial processes

MIscellaneous

Transportation T'ot:al

Foderal Region 6

Electric Utility

Commerclal/Residential

Industrial Fuel

Industrial processes

Miscellaneous

Transportation T'otal

$\begin{array}{rr}0.4 & 0.6 \\ 47.4 & 28.5 \\ 2.5 & 2.6 \\ 83.6 & .116 .9 \\ 44.1 & 65.5 \\ 98.5 & 201.8 \\ 276.5 & 416.0\end{array}$

0.3

22.7

1.3

60.7

33.4

11.3 .2

231.5

416.0

0.8

97.6

1.3

163.0

73.7

147.5

483.9

0.9

44.5

1.1

$1 \% 1.7$

87.1

249.7

555.6

1.5

150.8

5.0

250.3

158.7

395.7

962.0

1.4
53.2
5.3
276.4
214.9
495.8
1047.0

\section{8}

144.3

3.7

294.0

120.3

288.3

852.5

1.4
73.2
3.2
334.5
134.2
438.2
984.7

1.3

74.5

6.8

316.0

163.3

286.3

848.2

0.3
1.2
1.3
61.4
33.0
173.1
270.3

0.3

20.0

1.3

60.0

32.5

124.8

238.8

1.2

91.8

5.2

241.1

131.1

488.4

959.2

2.2

116.1

10.5

474.2

257.0

863.2

1723.1

492.8

219.5

428.2

1.0

1. 1

0.9

175.7

88.0

359.8

626.6

0.7

39.6

1.0

171.8

86.8

262.7

562.6

3.6

191.7

4.2

689.3

347.6

1051.8

2288.2

2.0
0.1
5.3
2.83 .0
191.0
646.8

1.5

50.0

5.3

276.6

178.3

493.5

$1128.1 \quad 1005.2$

6.5

285.6

21.2

1108.1

759.4

2083.8

4264.6

1.6

1.4

6.0

310.4

12.9

1343.3

529.6

1940.5

4142.7

$676.5 \quad 502.5$

$1159.9 \quad 1037.5$

$\begin{array}{rr}1.3 & 1.8 \\ 12.9 & 0.1 \\ 8.6 & 8.8 \\ 368.3 & 377.3 \\ 198.6 & 194.9 \\ 341.2 & 430.6 \\ 930.9 & 1013.4\end{array}$

1.5

12.2

8.7

368.8

190.8

335.7

917.6

6.1

73.7

35.2

1187.5

772.4

1428.6

3803.6 
1981 VOC Emissions by

Fed, Regton / Sector

Federal Region 7

Electric Utility

Commerclal/Residential

Industrial Fuel

Industrial processes

Miscellaneous

Transportation Total

Federal Region 8

Electric Utility

Commerclal/Resldential

Industrtal fuel

Industrlal Processes

Miscellaneous

Transportation Total

Federal Region 9

Electric Utility

Commercial/Residential

Industrial Fuel

Industrlal Processes

Miscellaneous

Transportation

Total

Federal Region 10

Electric Utility

Commercial/Residential

Industrial Fuel

Industrial Processes

Miscellaneous

Transpertation Total

National Totals

Electric Utility

Commercial./Residential

Industrial Fuel.

Industrlal. Processes

Miscellaneous

Transportation T'otal
Federal

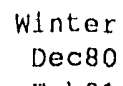

- Feb81

0.6

39.9

0.6

76.2

36.5

81.1

234.9

Ragion and

Seazon

Spring
Mar81

summer

-May81.

Jun 81

-Aug 81

is

0.7

17?

0.3

0.64

0.4

4.3

12.7

32.7

32.0

121.3

189.7

238.2

295.9

0.7

61.9

3.2

202.4

121.2

221.4

610.7

0.4
11.6
0.9
39.2
42.6
90.3
185.0

0.4

1.4

0.8

40.2

45.0

141.8

229.6

(kt) (Cont'd)

$\begin{array}{rr}\text { Autumn } & \text { Annual } \\ \text { Sep81 } & \text { Jan81 } \\ \text {-Nov81 } & \text {-Doc81 }\end{array}$

0.5
11.7
0.4
71.9
31.1
127.3
243.0

2.2

61.0

1.7

287.8

126.4

516.0

995.2

$\begin{array}{rrrrr}0.5 & 0.6 & 0.8 & 0.8 & 2.8 \\ 27.0 & 16.1 & 0.4 & 10.9 & 55.8 \\ 1.8 & 1.7 & 1.6 & 1.7 & 6.9 \\ 151.9 & 201.5 & 207.7 & 203.0 & 814.3 \\ 88.0 & 125.3 & 131.4 & 131.0 & 503.4 \\ 181.2 & 220.3 & 246.6 & 231.0 & 922.3 \\ 450.4 & 565.5 & 588.6 & 578.4 & 2305.5\end{array}$

$\begin{array}{rr}0.2 & 0.0 \\ 57.6 & 34.0 \\ 1.6 & 1.4 \\ 54.7 & 34.6 \\ 44.3 & 77.9 \\ 94.7 & 87.0\end{array}$

0.0

0.1
30.1

30.1

34.7

72.9

90.4

229.6

117.1

253.1

235.0

237.9

8.2

758.8

28.4

1672.9

900.9

1912.9

5282.1
9.3

16.1

25.8

1716.9

990.2

3285.0
6043.2

$$
\begin{array}{r}
7.5 \\
273.0 \\
26.2 \\
1679.5 \\
962.7 \\
2490.4 \\
5439.3
\end{array}
$$

$$
\begin{array}{r}
1.7 \\
44.7 \\
3.8 \\
159.2 \\
162.6 \\
400.6 \\
772.7
\end{array}
$$

2.8

55.8

14.3

922.3

0.2

125.9

5.5

139.3

276.9

351.9

899.7

32.5

1356.8

107.0

6744.3

3866.5

10047.2

22154.3
2305.5 
1982 VOC Emlasions by Federal

Fed. Reglon / sector

Federal Region 1

Eilectrte Ut11tiy

Commerclal/Resldential

Industrial Fuel.

Industrlal Processes

Mlscel.laneous

Transportation

'T'otal

Federal Region 2

Filoctic ut 11 t

Commerclal./Resldontial

Industerlal Fuel

Industrial. Processes

MLiscellaneous

Transportation Total

Federal Region 3

Electric Utility

Commercial/Reslderitial

Industrlal Fuel.

Industrtal Processes

Miscellaneous

Transportation Total

Fodoral Region 4

Electric Utility

Commercial. Restdentlal.

Industirial Fuel.

Industrial Processes

Miscellaneous

Transportation Totial

rederal Reglon 5

Electric Utility

Commerclal/Restdential

Industrlal puel.

Industrlal. Processes

Miscellaneous

Transportation Total

Foderal Regtion 6

Electric Utility

Commerclal/Resldential

Industrial Fuel.

Industrial Procosses

Miscellaneous

Iransportation

$$
\text { T'otal. }
$$

Whter
Dec81

Ragion and

Searon

(kt)

Spring

summer

Jun 82

-Aug 82

Ausumn
Sop82

Annual

Jan 82

-Dec 82

Mar 82
- May 82

-Nov82

0.2

2. 8

1.6

54.4

31.5

174.2

264.8

229.3

283.1

0.4

55.3

2.6

71.7

41.4

78.0

249.4

0.9

112.6

1.4

140.0

69.1

120.3

444.2

1.4

172.5

5.1

221.5

146.9

345.1

892.5

1.6

165.5

3.5

252.3

113.0

222.9

758.7

1.1

72.3

6.7

278.6

153.0

2.58 .1

769.9

0.4

34.4

2.7

107.7

61.7

201.8

408.8

0.8

52.6

1.0

152.8

82.4

247.0

536.5

1. 2

61.8

5.3

248.1

205.6

490.6

1012.6

0.5

2.3

111.1

61.2

287.5

464.5

0.8

2.7

0.8

156.6

83.1

356.0

600.2

1. 6

0.7

5.1

253.8

183.0

633.2

1077.4

1. 3

85.5

3.0

300.5

126.3

448.4

965.1

7.1

306.8

126.4

1097.4

1.3
13.9

8.6

344.1

186.9

339.7

894.5
0.3

8.2

1.7

54.3

31.1

118.5

224.0

0.4

21.9

2.5

109.4

60.4

211.1

405.7

0.7
37.9
0.9
153.5
82.3
250.2
525.5

1.2

54.5

5.1

249.5

171.2

473.5

955.1

1.3

2.7

652.7

1.2
63.1

2.8

301.9

125.1

449.5

943.6

\section{8}

0.2
8.6

354.8

184.5

422.8

972.6
1.4

14.4

8.5

343.2

181.1

325.2

873.8
1.0

100.2

6.8

214.1

124.6

470.9

917.6

1.8

126.6

10.5

431.4

242.7

816.7

1629.8

3.1

209.0

3.8

610.2

327.8

1006.4

2160.4

5.4

313.1

21.0

992.0

725.3

1998.7

4055.5

5.4

340.5

11.8

1196.9

500.2

1806.3

3861.2

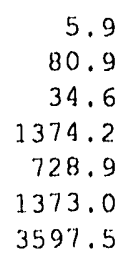


(kt) (Cont'd)

Fed. Region / Sector

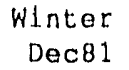

$$
\begin{array}{r}
\text { Spring } \\
\text { Mar } 82 \\
\text {-May } 82
\end{array}
$$

-Feb82
Summer
Jun 82
-Aug 82

Federal Region 7

Elactric Ut11tty

Commerclal/Restdent 1 al

Industrial Fuel

[ndustrial processes

Miscellaneous

Transportation Total
Autumn
Sep82.
-Nov8?

Annual

Jan8?

$-1) \operatorname{ac} 82$

Federal Region 8

Electric Ut1lity

Commercial./Resident lal

Industrial Fuel

Industrial Processes

Miscellanoous

Iransportation

Total

0.7

57.4

3.0

187.5

112.8

210.2

571.6

Federal Reglon 9

Electric Utility

Commercial. / Restdentlal

Industrial Fuel.

Industrlal Processes

Miscellaneous

Transportation

$$
\text { Total }
$$

Federal. Region 10

Electric Utility

Commerclal/Residential

Industrlal Fuel

Industrial Processes

Miscellaneous

Transportation

$$
\text { 'Total }
$$

National Totals

Electric Utility

Commercial/Residential.

Industrial Fuel.

Industrlal Processes

Miscellaneous

Transportation

$$
\text { potal }
$$

0.4

27.0

1.7

129.4

82.3

156.6

397.3

0.2

7.6

28.3

1467.8

842.5

4816.6

0.6
41.6
0.6
66.8
34.0
67.6
211.2

0.4
14.5
0.4
65.1
31.1
124.8
236.3
0.6
0.7
0.4
65.9
30.7
187.5
285.9

0.4
12.7
1.0
36.2
41.0
92.9
184.2

0.4

1.7

0.8

37.9

40.1

141.4

222.4

0.5
16.8
1.6
185.0
118.4
218.6
540.9

0.5

1.9

1.5

196.3

121.1

249.7

571.1

0.5
12.3

0.1

64.4

30.0

116.7

224.2

2.1

66.7

1.7

257.7

120.7

191.8

940.7

$$
\begin{array}{r}
1.8 \\
49.0 \\
1.0 \\
146.8 \\
147.3 \\
380.7 \\
729.6
\end{array}
$$

179.8

0.5

11.1

1.6

188.0

119.9

221.7

542,7

2.0

61.2

6.3

745.8

166.5

893.3

2175.1

0.0

0.0

0.1

32.6

1.3

31.9

62.6

83.2

68.2

113.5

83.2
211.7

0.1

138.1

5.4

126.5

251.1

333.7

854.9

6.6

7.7

6.5

28.6

357.8

26.3

25.2

6.7

1524.6

1570.3

277.7

1485.3

105.9

1533.0

6095.7

929.9

901.9

3635.1

9571.6

2341.2

5778.0

5086.1

20922.2 
1983 Voc Emlasions by

Fod. Rogion / soctor.

Federal Rogion 1

Mloctrlc Ut11ty

Commerclal/Resident lal.

Industirlal. fiuel

Industrtal processes

Miscellaneous

Transportation 'Total

Federal Regiton 2

Electric Utidity

Commorcial/Restdential

Industirlal Fued.

Industrlal processes

M1 scollaneous

Transportat:Lon T'otal

Foderal Roglon 3

Eiloct rlc Ut lifity

Commerctal/Residential

Industrial Fuel

Industrial processes

Miscellaneous

I'ransportation rotal.

Fedoral Region 1

Flectric Utility

Commerclad. / Res ldent la.l

Industrtal Fue 1

Industrial. Processes

Miscellaneous

Transportation

Total.

Federal Region 5

Eilectic Utility

Commercial/Residential

Industrlal Fuel.

Industrial processes

Miscellaneous

Iransportation 'Tot:al.

Federal Region 6

Electric Utility

Commercial/Residential

Industrial Fuel.

Industrial Processes

Mlscoldaneous

Transportation

$$
\text { f'ot.al }
$$

Federal Regton and

Saason

(kt)

$\begin{array}{rrr}\text { Winter } & \text { Spring } & \text { Summer } \\ \text { Dec82 } & \text { Mar83 } & \text { Jun83 } \\ \text { - Feb83 } & \text { - May83 } & \text {-Aug83 }\end{array}$

Autumn
Sep83
-Nov83

Annual.

$\operatorname{Jan} 83$

$-\operatorname{Dec} B 3$

$\begin{array}{rr}0.3 & 0.2 \\ 64.9 & 27.5 \\ 1.8 & 1.2 \\ 75.8 & 59.3 \\ 50.4 & 33.2 \\ 91.2 & 106.4 \\ .287 .4 & 227.8\end{array}$

$$
0.3
$$

1.0

1.1

60.9

33.0

174.5

270.8

$$
\begin{array}{r}
0.2 \\
19.2 \\
1.2 \\
59.8 \\
32.5 \\
112.2 \\
225.1
\end{array}
$$

0.6

0.6

0.3

0.1

34.9

2.0

75.0

43.9

70.4

241.8

1.8

114.2

65.7

190.8

407.3

1.6

121.3

65.3

293.1

482.7

0.5

22.8

1.7

116.8

64.2

195.1

401.0

1.0

1.1

0.8

109.9

1.1

142.1

73.3

108.5

435.5

0.7
53.0
0.9

161.0

87.3

233.4

536.4

168.3

88.4

347.9

607.6

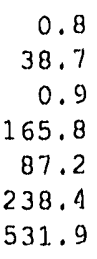

1. 7

0.6

5.2

273.7

194.8

618.9

1094.8

1036.4

886.3

216.1

1.4

49.6

5.5

269.8

181.6

452.3

960.2

1.6

152.0

3.3

264.3

119.0

198.3

738.6

1.2

90.8

2.7

317.8

133.7

417.3

963.5

1.5

2.5

2. 5

330.6

133.9

645.0

1116.1

1. 3

62.0

2.8

323.7

131.9

428.9

950.6

$1.3 \quad 1.4$

1. 8

0.2

8.6

8.4

6.4

277.8

162.6

244.2

343.2

200.0

327.5

775.5
359.4

198.7

404.4

973.1
1.5

11.0

8.7

351.1

194.1

312.1

878.1
1.0

100.5

4.7

236.7

130.5

451.5

924.9

2.0

126.7

7.3

459.8

258.1

785.5

1639.3

3.1

209.7

3.6

618.6

347.3

958.0

2170.6

5.6

315.0

21.1

1059.5

767.0

1933.4

4101.6

5.5

342.0

11.2

1272.7

528.3

1719.4

3879.1

6.2

81.2

34.5

1.377 .9

780.5

1315.3

3595.6 
1983

VOC

Em

Pod. Region / Sector

Federal Reglon 7

E.Lectric Ut lifty

Commerclal/Restdental

Industrial ruel.

Industrtal processes

Mlscellaneous

Transportation

$$
\text { Total }
$$

Federal Region 8

Biectric Ut11.ty

Commerclal/Resldentlal.

Industrial Fuel

Industrial procosses

Miscellaneous

'Transportation Total

Federal Region 9

Electric Utility

Commerclal/Residential

Industrial Fuel.

Industrlal Processes

Miscellaneous

Transportation Total

Federal Region 10

Electric Utilty

Commerclal. Restdent tal.

Industrlal Fuel

Industrial processes

Miscellaneous

Transportation

$$
\text { 'rotal }
$$

National Totals

Electric Utility

Commercial/Residential

Industrial F'uel

Industrial processes

Miscellaneous

Transportation Total
Reglon and seavon

(kt) (Cont'd)

W.Inter

Spring

Summor
JunB 3

Dec8?

Mar83
- May83

-AugB 3

Aut:umn

Sep 83

- Nov83

0.7

0.2

0.3

72.1

32.1

185.2

290.7

116.2

235.2

213.3

0.7

71.3

0.4

13.8

1.0

36.0

43.0

92.3

123.5

205.2

590.8

186.5

0.4
1.5
0.8
37.9
49.1
145.0
234.8

0.5
10.5

0.4

70.1

31.2

112.2

225.1

ont'd)

(1)

0.5

10.6

0.9

37.2

49.1

90.9

189.2

$0.4 \quad 0.4$

0.5

0.4
9.8

30.8

19.2

1.5

131.2

189.3

126.1

87.8

148.3

209.5

400.1

545.9

203.4

137.1

242.1

585.9

1.6

193.2

137.7

2]1. 8

554.5

$\begin{array}{rr}0.3 & 0.0 \\ 62.3 & 34.4 \\ 1.4 & 1.2 \\ 50.4 & 32.5 \\ 45.0 & 79.1 \\ 82.0 & 81.5 \\ 241.3 & 231.8\end{array}$

0.0

8.5

1.2

33.9

84.6

111.6

239.8

0.1
33.2

1. 3

33.3

82.7

82.9

233.1

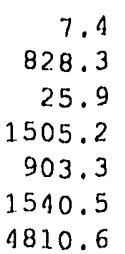

6.3

378.0

24.1

1586.1

1016.5

2258.0

5269.0
8.5

17.6

23.7

1661.5

1017.0

3168.1

5896.3

$$
\begin{array}{r}
7.2 \\
267.4 \\
25.0 \\
1620.9 \\
992.2 \\
2236.9 \\
5119.5
\end{array}
$$

29.4

1491.6

98.6

6373.7

3929.0

9203.4

21125.7 


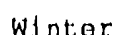

$-\mathrm{Feb} 8 \mathrm{~A}$

Fedoral Reglon 1

E.Lectr1c Ut $111 \mathrm{ty}$

Commerclal/Regldentlal

Incustirlal Fuel.

Industrial processes

Mlscellaneous

'Transportation Total

Foderal Reglon 2

Electric Ut $11 \mathrm{ty}$

Commerclal/Resldential

Industrial Fuel

Industrial processes

Mlscollaneous

Transportation

'lotal

Federal Region 3

Electric Ut $111 \mathrm{ty}$

Commerclal/Res ldent lal

Industrlal Fuel

Industrial processes

MLscellaneous

Transportation 'Total.

Federal Region 4

Electidc Utility

Commerclal/Resldential

Industirial Fuel

Industrial processos

MIscellaneous

'Iransportation 'Iotal

Federal Region 5

Electiclc Ut $111 \mathrm{ty}$

Commerclaj/Res ldent lal.

Industrial Fuel

lindustrial Processes

Miscollaneous

'Tansportat 1 on Total.

Federal Region 6

Electric Ut111ty

Commercial/Residentlal.

Industrial fuel

Industirial processes

Miscollaneous

Transportation 'outial
Dec83

SprLng
Mar 84
-May 84

Summer
Junga

$-\operatorname{Aug} 84$

0.3

56.9

1.9

91.1

55.8

89.0

291.9

0.3

51.5

2.0

86.8

48.7

65.0

'254.3

$$
\begin{array}{r}
0.3 \\
31.5 \\
1.2 \\
71.4 \\
36.7 \\
96.3 \\
237.3
\end{array}
$$

0.4

40.6

129.0

173.9

418.2

0.8

111.2

1.1

163.9

80.4

103.8

460.6

0.8

182.8

217.5

562.0

1.2

172.0

4.7

261.7

172.4

309,2

921.4

1.6

153.9

3.3

313,3

131.0

195.1

798.1

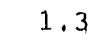

295.5

233.3

453.1

1065.8

1.4

72.9

6.6

305.0

180.3

234.0

800.2
1.3

103.4

2.8

368.4

146.3

383.3

1005.6
1.9

72.4

63.5

0.9

96.5

77.4

5.3

0.3
1.0
1.1
71.6
36.7
162.3
273.0

0.2
20.6

1.1

71.7

36.0

104.3

234.0

0.7

0.6

1. 5

132.8

72.2

266.7

474.5

1.0

1.2

0.8

187.0

97.9

325.7

613.6

0.5
23.4
1.6
131.4
70.9
187.1
415.0

0.8

40.6

0.8

185.1

96.4

225.1

548.8

1.5

0.2

5.3

300,8

213.2

584.0

1105.1

1.3
57.5

5.3

298.6

199.0

431.1

992.9

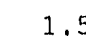

2.9

2.5

371.6

147.0

592.5

1118.1

1.5
17.1
8.6
362.0
219.0
312.2
920.4

1. 9

0.2

8.7

366.0

217.5

385.3

979.6
1. 3

67.3

2.6

369.6

144.6

402.2

987.6

1.5

15.3

8.7

360.9

212.7

298.9

898.1
Annual

Jan 84

-Dec84

1,1

103.2

4. 5

284.6

144.8

417.4

955.6

2.0

129.9

7.2

517.9

285.4

726.2

1668.5

3.5

214.9

3.5

732.1

384.5

900.0

2238.6

5.5

322.9

21.2

1182.4

837.8

1830.0

4199.7

5.6

351.1

11.1

1466.5

580.0

1601.2

4015.6

6.5

83.2

35.0

1439.2

857.3

1258.1

3679.4 


\section{4 \\ Voc Em1satons by}

Fod. Raglon / Sector

Foderal Regton 7

Eiectric Utility

Commerclal/Resldent dal

Industrlal Fuel.

Industrtal prodesses

MIscellaneous

Iransportation

$$
\text { T'otial. }
$$

Federal Region 8

Electric Ut111ty

Commerclal/Resident lal

Industrial Fuel

Industrial processes

Miscellaneous

Transportation T'otal

Federal Region 9

Eloctric Utility

Commerclal/Restdent 1 al

lndustirfal Fuel

Industrial processes

Miscellaneous

Transportation Totial

Federal Region 10

Electric Ut1lity

Commercial/Residential.

Industrial. Fuel.

Industrial processes

Miscellaneous

Transportation

$$
\text { Iot:al }
$$

National Totals

Ejectric Ut11ty

Commerclal/ResLdent lal

Industrlal Fuel.

Industrial Processes

Miscellaneous

Transportation Total.

\section{Tederal \\ Region and}

season

(kt) (Cont'd)

Winter

Spring
Mar 84

Summer
Jun 84

-Feb84

-May8A

-Alug 84

Autumn
SepBA

- Nov84

Annual

Jang 4

-Desa 1

$\begin{array}{rr}0.6 & 0.5 \\ 38.7 & 19.2 \\ 0.6 & 0.4 \\ 81.7 & 79.3 \\ 39.0 & 35.2 \\ 60.5 & 109.8 \\ 221.0 & 244.3\end{array}$

0.7

59.3

3.0

210.8

133.5

202.9

610.2

$$
\begin{array}{r}
0.4 \\
26.6 \\
1.6 \\
150.9 \\
97.2 \\
153.2 \\
430.0
\end{array}
$$

0.4

13.3

1.0

39.3

44.6

85.7

184.3

0.4

14.1

1.6

211.8

137.9

211.1

576.9

$$
0.2
$$

55.2

1.5

58.1

47.8

76.4

239.1

$$
7.5
$$

798.1

26.2

1722.9

985.9

1489.2

5029.8

$$
\begin{array}{r}
0.0 \\
37.0 \\
1.2 \\
37.1 \\
80.2 \\
75.2 \\
230.7
\end{array}
$$

$$
6.7
$$

417.0

24.8

1776.6

1102.1

2118.2

5445.5

0.6
0.2
0.4
80.3
35.1
172.9
289.5

0.5

13,0

0.4

79.3

34.0

105,9

233.1

0.5

1.5

0.8

39.8

47.6

132.6

222.9

0.5
12.3
0.9
39.6
46.3
86.6
186.3

0.6

1.0

1.5

218.0

145.9

232.6

599.6

0.1
13.4
1.6
209.7
194.7
205.5
575.3

1. 7

63.0

6.3

841.2

556.2

852.3

2323.6

0.0
8.0
1.2
37.4
79.3
97.4
223.4

8.7

17.0

23.7

1805.4

1092.5

2952.0

5899.3
0.1

34.9

1.2

37.2

75.4

72.6

221.1

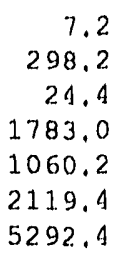

7.2

298.2

24.4

1783.0

211.9 .4

5292.4

0.2

142.3

4. 8

147.9

286.3

289.9

871.4

30.4

1530.2

99.2

7087.8

4240.7

8678.8

21667.1 


\section{Winter \\ DecBA \\ - F'eb85}
Summer Jun 85
-Aug85

\section{Autumn \\ Sep85 \\ -Nov85}

Annual

$\operatorname{Jan} 85$

-Dec 85
Federad Region 1

Electrlo Ut 11 ty

Commernial/Resldentlal

Industrial Fuel

Industrlal processes

Misceldaneous

Transportation

Total

Federal Region 2

Electrlc Ut11tty

Commerclal/Resldent Lal

Industrial Fuel

Industrial processes

Miscellaneous

Transportation

Total

Federal Reglon 3

Electric Ut11ty

Commerclal/Resldentlal

Industrlal Fuel

Industrlal processes

Miscellaneous

Transportation Total

Federal Region 4

Electric Utility

Commerclal/Resldentlal.

Industrdal Fuel.

Industrial processes

Miscellaneous

Transportation Total

Federal Region 5

Electric Utilty

Commerclal/Resident lal.

Industrial Fuel

Industrial processes

Miscellaneous

I'ransportation Total

Federal Region 6

Electric Ut1lity

Commercial/Residential

Industrial Fuel

Industrlal processes

Miscellaneous

Transportation Total

$\begin{array}{rr}0.3 & 0.2 \\ 60.2 & 22.7 \\ 1.8 & 1.1 \\ 89.0 & 68.7 \\ 47.9 & 32.1 \\ 83.5 & 93.8 \\ 282.6 & 218.6\end{array}$

0.2

2.1

1.0

70.4

32.2

155.2

261,1

0.5

139.7

61.9

260.7

384,6

461.0

0.8

34.8

0.9

2.1

175.3

83.6

0.7

158.3

69.5

181.0

84.8

212.5

312.3

436.6

512,9

581.8

1.4

175.5

4.8

253.6

147.4

282.7

865.3

1. 6

157.5

3.2

304.1

112.9

182.5

761.9

1.6

83.6

6.7

289.9

152.9

214.5

719.2
1.4

44,1

5.3

285.7

208.0

432.2

976.6

1. 7

0.4

5.2

293.7

186.4

558.8

1046.1

1,3

60.1

2.8

355.0

127.9

368.0

914.5

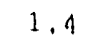

9.8

8.6

345.5

188.5

298.1

852. 2

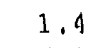

6.1

2.5

364.1

127.8

553.6

1055.7

1. 9

0.1

8,7

356.9

186.4

365.9

920.0
1.3

26.9

5.2

289.0

172.0

401.3

895.7

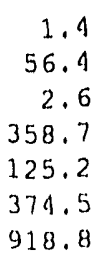

1.5

10.5

8.6

318.7

181.2

278.7

829.2
0.3

16.9

1.1

69.6

31.4

99.9

219.1

0.4

18.9

1.7

129.6

60.6

172.3

383.6

0.7

28.5

0.8

178.2

82.9

212.8

503.9

1.1

91.0

4.2

276.8

126.1

400.9

900.0

1.8

11.4 .8

7.3

514.4

244.2

691.1

1573,6

3.4

189.5

3. 3

704.7

331.4

862.5

2094.9

5.9

284.0

21.0

1146.0

732.2

1725.6

3914.8

5.6
308.9
11.0
1121.1
502.6
1504.2
3756.6

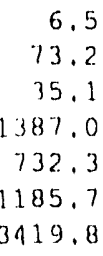




\begin{tabular}{|c|c|c|c|c|c|}
\hline Em1adiona by & Tuderal & Rogton & seacon & (Cont'd) & \\
\hline & $\begin{array}{r}\text { Wher } \\
\text { Dec8 }\end{array}$ & $\begin{array}{l}\text { Spr1ng } \\
\text { Mar85 }\end{array}$ & $\begin{array}{l}\text { Summer } \\
\text { Jungs }\end{array}$ & $\begin{array}{r}\text { Autumn } \\
\text { Sep85 }\end{array}$ & $\begin{array}{r}\text { Annual } \\
\text { Jan85 }\end{array}$ \\
\hline Fed, Regton / Sector & $-F a b 85$ & - May85 & - Aug 85 & -Nov85 & $-D 0085$ \\
\hline \multicolumn{6}{|l|}{ Federal Region 7} \\
\hline Wleatrlo Utditty & 0.6 & 0.4 & 0.6 & 0.5 & 2.0 \\
\hline Commerolal/Res dent La & 43.8 & 9.1 & 0.6 & 11.3 & 60.7 \\
\hline Industrdal Fuel & 0.6 & 0.4 & 0.4 & 0.4 & 1.7 \\
\hline Industrial prooesses & 79.2 & 76.5 & 78.9 & 77.3 & 307.4 \\
\hline Mlscellaneous & 33.9 & 31.3 & 31.0 & 29.9 & 121.0 \\
\hline Transportation & 54.8 & 104.2 & 158.9 & 97.7 & 412.4 \\
\hline $\operatorname{Tota} 1$ & 212.9 & 222.2 & 270.3 & 217.1 & 905.2 \\
\hline \multicolumn{6}{|l|}{ Federal Region 8} \\
\hline Electric Ut 11 tey & 0.8 & 0.5 & 0.5 & 0.5 & 2.2 \\
\hline Commerclal/Residential. & 66.8 & 9.8 & 1.3 & 11.8 & 14.8 \\
\hline Industrtal Euel & 3,2 & 1.0 & 0.8 & 0.9 & 4.0 \\
\hline Industrlal prooesses & 203,7 & 37.6 & 38.9 & 38.1 & 151.8 \\
\hline M1scellaneous & 113.3 & 42.0 & 41.5 & 39.0 & 151.0 \\
\hline "Iransportation" & 187.2 & 75.1 & 116.1 & 73.8 & 310.1 \\
\hline Total & 575.0 & 166.0 & 199.2 & 164.1 & 663.9 \\
\hline \multicolumn{6}{|l|}{ Federal Reglon 9} \\
\hline Eleotrlc Ut111ty & 0.5 & 0.5 & 0.7 & 0.5 & 2.3 \\
\hline Commercial/Regldentlal & 29.2 & 14.3 & 0.5 & 11.1 & 55.6 \\
\hline Industrlal Fuel & 1,6 & 1.6 & 1.5 & 1.6 & 6.3 \\
\hline Industrlal Processes & 145.7 & 206.8 & 211.5 & 205.0 & 820.4 \\
\hline M1sce1Laneous & 82.7 & 120.3 & 123.8 & 121.3 & 473.1 \\
\hline Transportation & 148.7 & 210.7 & 2.21 .4 & 2.02 .5 & 829.6 \\
\hline Total & 408.4 & 554.1 & 559.1 & 542.3 & 2187.3 \\
\hline \multicolumn{6}{|l|}{ Federal Reglon 10} \\
\hline Electrlc Ut $111 t y$ & 0.1 & 0.0 & 0.1 & 0.1 & 0.2 \\
\hline Commerclal/Resident la. & 61,4 & 29.8 & 9.7 & 33.7 & 125.5 \\
\hline Industrlal Fuel & 1.1 & 1.2 & 1.2 & 1.2 & 4.7 \\
\hline Industrlal Processes & $5 \%, 9$ & 35.6 & 36.6 & 35.8 & 142.8 \\
\hline M.tsced. laneous & 41.9 & 76.1 & 68.7 & 62.8 & 252.3 \\
\hline Transportation & 71.8 & 71.0 & 91.9 & 66.8 & 271.2 \\
\hline Total & 232.5 & 213.6 & 203.1 & 200.3 & 796.8 \\
\hline \multicolumn{6}{|l|}{ National Totals } \\
\hline Electric Ut.lity & 8.1 & 7.0 & 8.4 & 7.2 & 30.9 \\
\hline Commerclal/Resldentlal. & 835.6 & 266.7 & 19.4 & 226.3 & 1317.9 \\
\hline Industrlal Fuel & 26.3 & 24.6 & 23.6 & 21.1 & 98.6 \\
\hline Industrlal Processes & 1665.3 & 1713.6 & 1.767 .1 & 1729.9 & 6875.8 \\
\hline Miscellaneous & 844.0 & 971.6 & 944.4 & 906.2 & 3666.2 \\
\hline Transportation & 1386.1 & 2032.1 & 2794.8 & 1980.3 & 8193.3 \\
\hline T'otal & 4765.3 & 5015.5 & 5557.8 & 4871.1 & 202.12 .8 \\
\hline
\end{tabular}


$(k t)$

Fed. Region / Sector

$\begin{array}{rr}\text { Winter } & \text { Spring } \\ \text { Dec85 } & \text { Mar86 } \\ - \text { Feb86 } & \text {-May86 }\end{array}$

Summer
Jun 86
-Aug 86

Annual $\operatorname{Jan} 86$ -Dec86

Federal Region 1

Electric Utility

Commercial/Residential

Industrial Fuel

Industrial Processes

Miscellaneous

Transportation Total

0.

56.7

2.0

$8.3: 1$

47.7

76.9

266.7

Federal Region 2

Electric Utility

Commercial/Residential

Industrial Fuel

Industrial Processes

Miscellaneous

Transportation Total

Federal Region 3

Electric Utility

Commerclal/Restdential

Industrial Fuel

Industrial Processes

Miscellaneous

Transportation Total

Federal Region 4

Electric Utility

Commercial/Residential

Industrial Fuel

Industrial Processes

Miscellaneous

Transportation Total

Federal Region 5

Electric Utility

Commercial/Residential

Industrial Fuel

Industrial processes

Miscellaneous

Transportation

$$
\text { Total }
$$

Federal Region 6

Electric Utility

Commercial/Residential

Industrial Fuel

Industrial Processes

Miscellaneous

Transportation

$$
\text { Total }
$$

0.

48.2

1.7

80.0

41.4

57.4

229.0

0.8

100.4

1.1

151.8

69.14

94.1

417.6

815.7

1.5

146.6

3.3

282.7

112.8

176.1

722.9

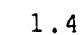

71.4

6.6

280.0

152.7

204.1

716.2

0.3
22.3
1.3
62.4
31.8
91.0
209.2

0.3

2.2

1.2

64.3

31.8

145.7

245.5

0.4

27.5

1.7

118.5

62.1

161.6

371.8

$$
0.8
$$

43.5

0.9

164.3

84.0

205.5

498.8

0.6

1.2

1.4

125.7

61.8

244.4

435.0

0.3

20.2

1.3

63.7

31.1

95.0

211.6

0.4

23.7

1.5

122.6

60.4

167.6

376.1

0.9

1.5

0.7

169.9

85.4

296.3

554.7

$$
\begin{array}{r}
0.8 \\
37.4 \\
0.8
\end{array}
$$

168.0

83.3

203.1

493.4

1.9

55.8

5.3

272.6

209.2

404.1

948.4

1001.5

1.3

69.1

2.8

327.4

127.4

349.0

877.1

1006.7
1.3

11.6

8.4

330.3

188.5

271.4

811.6
0.1

5.1

280.9

188.5

525.0

1.6

4.8

2.5

338.9

128.0

530.9

1.5

43.0

5.2

278.4

173.4

381.6

883.1

1.3

65.6

2.6

334.7

125.2

366.0

895.5

1.9

0.2

8.5

345.4

186.8

330.8

873.5
1.6

15.2

8.5

341.7

181.2

257.7

805.9
1.3

91.0

5.1

252.1

125.0

380.1

854.6

$$
1.8
$$

115.0

6.4

481.3

243.6

659.0

1507.2

3.4

189.8

3.4

663.0

332.7

824.9

2017.2

6.3

284.1

21.0

1100.2

737.2

1626.7

3775.6

5.7

309.0

11.2

1322.6

502.9

1448.6

3599.9

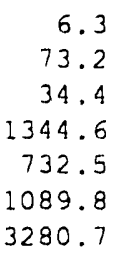




\begin{tabular}{|c|c|c|c|c|c|}
\hline Emiestone by & Federal & Region & Seacon & (cont'd) & \\
\hline & $\begin{array}{r}\text { Winter } \\
\text { Dec85 }\end{array}$ & $\begin{array}{r}\text { Spring } \\
\text { Mar } 86\end{array}$ & $\begin{array}{r}\text { Summer } \\
\text { Jun } 86\end{array}$ & $\begin{array}{r}\text { Autumn } \\
\text { Sep86 }\end{array}$ & $\begin{array}{r}\text { Annual } \\
\text { Jan } 86\end{array}$ \\
\hline Fed. Region / Sector & - Feb8 6 & - May 86 & - Aug 86 & - Nov 86 & $-\operatorname{Dec} 86$ \\
\hline \multicolumn{6}{|l|}{ Federal Region 7} \\
\hline Electric Utility & 0.6 & 0.4 & 0.6 & 0.5 & 1.9 \\
\hline Commercial/Residential & 39.4 & 11.0 & 0.3 & 13.7 & 60.5 \\
\hline Industrial Euel & 0.6 & 0.4 & 0.4 & 0.4 & 1.6 \\
\hline Industrial Processes & 74.1 & 70.9 & 74.4 & 74.2 & 290.3 \\
\hline Miscellaneous & 34.0 & 31.7 & 31.7 & 30.3 & $i<2.7$ \\
\hline Transportation & 5.3 .2 & 97.4 & 148.8 & 92.7 & 389.5 \\
\hline Total & 201.9 & 211.8 & 256.2 & 211.8 & 866.5 \\
\hline \multicolumn{6}{|l|}{ Federal Region 8} \\
\hline Electric Utility & 0.8 & 0.4 & 0.5 & 0.6 & 2.1 \\
\hline Commercial/Residential & 62.2 & 10.8 & 1.2 & 11.8 & 44.6 \\
\hline Industrial Fuel & 3.2 & 1.0 & 0.8 & 0.9 & 3.9 \\
\hline Industrial Processes & 195.7 & 35.8 & 37.1 & 36.3 & 144.5 \\
\hline Miscellaneous & 113.4 & 41.9 & 41.3 & 38.9 & 150.3 \\
\hline Transportation & 182.4 & 69.2 & 106.6 & 68.3 & 285.9 \\
\hline Total & 557.7 & 159.0 & 187.6 & 156.7 & 631.4 \\
\hline \multicolumn{6}{|l|}{ Federal Region 9} \\
\hline Electric Utility & 0.5 & 0.4 & 0.6 & 0.4 & 2.0 \\
\hline Commercial/Residential & 25.9 & 14.3 & 1.1 & 11.2 & 55.4 \\
\hline Industrial Fuel & 1.6 & 1.6 & 1.5 & 1.6 & 6.3 \\
\hline Industrial Processes & 139.1 & 196.4 & 205.6 & 198.3 & 789.5 \\
\hline Miscellaneous & 82.5 & 120.2 & 123.8 & 121.2 & 472.8 \\
\hline ¿ransportation & 140.9 & 197.4 & 214.3 & 196.5 & 797.0 \\
\hline Total & 390.4 & 530.3 & 546.9 & 529.3 & 2123.0 \\
\hline \multicolumn{6}{|l|}{ Federal Region 10} \\
\hline Electric Utility & 0.0 & 0.0 & 0.0 & 0.0 & 0.1 \\
\hline Commercial/Residential & 57.8 & 32.8 & 5.5 & 30.6 & 125.2 \\
\hline Industrial Fuel & 1.4 & 1.2 & 1.2 & 1.3 & 4.9 \\
\hline Industrial Processes & 53.2 & 33.8 & 35.0 & 34.2 & 136.2 \\
\hline Miscellaneous & 41.8 & 76.0 & 68.6 & 62.7 & 251.9 \\
\hline Transportation & 69.6 & 67.6 & 88.1 & 64.7 & 260.0 \\
\hline Total & 223.9 & 211.4 & 198.4 & 193.5 & 778.4 \\
\hline \multicolumn{6}{|l|}{ National Totals } \\
\hline Electric Utility & 7.7 & 6.8 & 8.9 & 7.4 & 30.9 \\
\hline Commercial/Residential & 758.7 & 298.8 & 18.1 & 272.4 & 1347.9 \\
\hline Industrial Euel & 26.2 & 24.5 & 23.3 & 24.0 & 98.1 \\
\hline Industrial Processes & 1583.0 & 1612.2 & 1677.1 & 1652.0 & 6524.3 \\
\hline Miscellaneous & 843.3 & 972.9 & 947.6 & 907.8 & 3671.6 \\
\hline Transportation & 1323.2 & 1914.1 & 2631.0 & 1893.3 & 7761.6 \\
\hline Total & 4542.1 & 4829.3 & 5.306 .1 & 4756.8 & 19434.4 \\
\hline
\end{tabular}


1987

voc
Emisatons by

Fed. Region / Sector

Federal Region 1

Electric Utility

Commercial/Residential

Industrial Fuel

Industrial Processes

Miscellaneous

Transportation

Total

Federal Region 2

Electric Utility

Commercial/Residential

Industrial Fuel

Industrial Processes

Miscellaneous

Transportation

Total

Federal Region 3

Electric Utility

Commerclal/Residential

Industrial Fuel

Industrial Processes

Miscellaneous

Transportation

$$
\text { Total }
$$

Eederal Region 4

Electric Utility

Commercial/Residential

Industrial Fuel

Industrial Processes

Miscellaneous

Transportation

$$
\text { Total }
$$

Federal Region 5

Electric Utility

Commercial/Residential

Industrial Fuel

Industrial Processes

Miscellaneous

Transportation

$$
\text { Total }
$$

Federal Region 6

Electric Utility

Commercial/Residential

Industrial Fuel

Industrial Processes

Miscellaneous

Transportation

$$
\text { Total }
$$

Federal Region and season (kt)

$\begin{array}{rrrrr}\text { Winter } & \text { Spring } & \text { Summer } & \text { Autumn } & \text { Annual } \\ \text { Dec86 } & \text { Mar87 } & \text { Jun87 } & \text { Sep87 } & \text { Jan87 } \\ \text { - Feb87 } & \text {-May87 } & \text {-Aug87 } & \text {-Nov87 } & \text { - Dec87 }\end{array}$

$\begin{array}{rrrrr}0.3 & 0.3 & 0.4 & 0.3 & 1.3 \\ 56.0 & 23.1 & 1.5 & 19.3 & 90.9 \\ 1.9 & 1.2 & 1.2 & 1.2 & 4.8 \\ 84.5 & 63.7 & 65.2 & 64.5 & 256.2 \\ 48.1 & 32.0 & 32.2 & 31.5 & 126.2 \\ 73.6 & 89.4 & 139.8 & 91.6 & 369.0 \\ 264.4 & 209.6 & 240.2 & 208.4 & 848.4\end{array}$

0.3

48.5

1.9

82.0

41.4

55.6

229.7

0.8

102.1

1.0

155.8

69.8

89.6

419.0

1.3

148.0

4.5

251.4

151.4

259.8

816.6

0.4
27.9
1.6
122.4
62.1
154.5
368.9

0.7

0.6

1.3

128.1

61.9

226.0

418.7

0.7

44.5

0.9

170.2

84.0

191.2

491.5

0.5
23.7
1.5
124.4
60.6
154.9
365.7

2.1

114.8

6.4

492.4

243.9

617.7

1477.3

1.5

142.6

3.2

289.4

113.2

170.1

720.1

1. 6

68.7

6.8

284.5

152.9

193.1

707.6
1. 3

57.5

5.1

284.3

209.5

393.2

950.9

1.5

70.6

2.6

334.7

127.9

328.6

365.8

1.4

14.3

8.5

336.7

188.1

253.7

802.7
1.1

0.7

0.8

176.5

86.0

279.4

544.5

0.8

40.8

0.8

174.5

84.1

195.4

496.5

1.9

0.1

5.1

291.6

189.9

503.6

992.3

1.5

55.6

5.3

288.4

175.4

367.6

893.9

1.7

2.2

2. 4

344.9

129.1

489.6

969.8

2.0

0.2

8.9

350.4

186.8

309.5

857.8
1.3

69.8

2.6

340.7

126.4

340.0

880.8

1. 6

13.4

8.8

344.8

181.9

245.3

795.8
3.5

190.5

3.4

687.7

334.6

780.2

1999.9

6.1

284.0

20.7

1142.2

741.8

1572.0

3766.8

5.9

308.8

10.6

1349.3

506.0

1352.5

3533.2

6.5

73.3

35.5

1362.8

732.9

1021.7

3232.7 
1987 voc

Em1satons

Fed. Region / Sector

Fedural Region 7

Electric Utility

Commercial/Residential

Industrial Fuel

Industrial Processes

Miscellaneous

Transportation

Total

Federal Region 8

Electric Utility

Commercial/Residential

Industrial Fuel

Industrial Processes

Miscellaneous

Transportation

Total

Federal Region Q

Electric Utility

Commercial/Residential

Industrial Fuel

Industrial Processes

Miscellaneous

Transportation Total

Federal Region 10

Electric Utility

Commercial/Residential

Industrial Fuel

Industrial Processes

Miscellaneous

Transportation Total

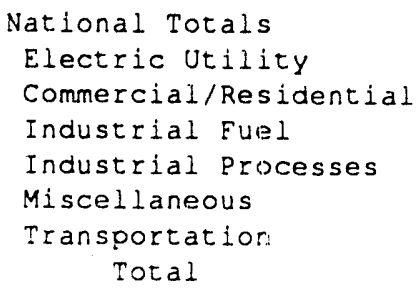

Foderal

Rogion

and

Soason

Winter
Dec86

Spring
Mar 87
-May87

Summer
Jun 87
-Aug 87

(kt) (Cont'd)

- Feb8 7

$$
\begin{array}{r}
0.6 \\
37.6 \\
0.5 \\
76.0 \\
34.8 \\
49.8 \\
199.3
\end{array}
$$

0.8

58.9

3.1

199.9

115.9

171.7

550.3

$$
\begin{array}{r}
0.4 \\
11.8 \\
0.4 \\
73.7 \\
31.6 \\
92.3 \\
210.3
\end{array}
$$

$$
\begin{array}{r}
0.5 \\
11.0 \\
0.9 \\
36.5 \\
42.2 \\
64.4 \\
155.5
\end{array}
$$

0.7
0.2
0.4
76.4
31.7
140.2
249.4

0.5
13.5
0.4
75.3
30.5
89.4
209.5

Autumn
Sep87

- Nov8 7

Annua.

Jan 87

-Dec 87
0.5

27,4

1.8

145.0

83.1

144.6

102. 4

$\begin{array}{rr}0.0 & \\ 57.9 & 0.0 \\ 1.5 & 30.7 \\ 55.5 & 1.2 \\ 42.6 & 34.8 \\ 67.6 & 76.9 \\ 225.1 & 63.9 \\ & 207.5\end{array}$

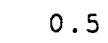

12.7

1. 5

202.7

120.8

198.1

536.4

207.5

7.7

747.7

26.3

1623.9

853.2

1275.5

4534.4

$$
\begin{array}{r}
7.1 \\
304.1 \\
23.7 \\
1659.6 \\
975.2 \\
1829.2 \\
4799.1
\end{array}
$$

0.6

1.5

0.8

37.7

45.3

97.1

183.0

0.6

1.3

1.5

212.1

128.8

216.6

561.0

0.6
10.2
1.0
37.1
44.0
64.3
157.1

0.5

8.5

1.6

204.2

127.7

196.4

539.0

0.0

6.0

1. 2

36.0

75.9

83.0

202.2
0.0
26.9
1.2
35.3
72.1
62.9
198.4

9.6

14.3

23.6

1718.9

967.6

2484.8

5218.9
7.6

281.7

24.5

1689.2

934.2

1808.0

4745.1
2.1

60.8

1.6

297.3

122.7

368.7

853.1

2.3

44.2

3.8

147.6

161.7

264.6

624.2

$$
2.2
$$

55.5

6.5

815.8

487.4

803.7

2171.0

0.2

125.1

4.8

140.3

273.0

247.5

790.9

32.2

1347.9

98.1

6691.7

3730.3

7397.5

19297.6 
Federal

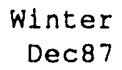

Fed. Reglon / Sector
- Feb88
Region

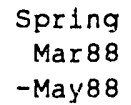

Federal Region 1

Electric Utility

Commercial/Residential

Industrial Fuel

Industrial Processes

Miscellaneous

Transportation Total

Federal Region 2

Electric Utility

Commercial/Residential

Industrial Fuel

Industrlal Processes

Miscellaneous

Transportation Total

\section{Federal Region 3 \\ Electric Utility \\ Commercial/Residential \\ Industrial Fuel \\ Industrial Processes \\ Miscellaneous \\ Transportation \\ Total}

\section{Federal Region 4 \\ Electric Utility \\ Commercial/Residential \\ Industrial Fuel \\ Industrial Processes \\ Miscellaneous \\ Transportation Total}

Federal Region 5

Electric Utility

Commercial/Residential

Industrial Fuel

Industrial Processes

Miscellaneous

Transportation

$$
\text { Toral }
$$

Federal Region 6

Electric Utility

Commercial/Residential

Industrial Fuel

Industrial Processes

Miscellaneous

Transportation

$$
\text { Total }
$$

$\begin{array}{rr}0.4 & 0.3 \\ 56.1 & 23.2 \\ 2.3 & 1.5 \\ 82.1 & 60.5 \\ 48.3 & 32.1 \\ 68.0 & 82.7 \\ 257.2 & 200.3\end{array}$

48.6

2.1

83.0

41.5

51.2

226.9

$$
28.0
$$

2.0

117.5

62.2

142.8

353.0

0.8

0.7

102.2

1.2

153.9

70.1

82.8

411.0

44.5

0.9

164.2

84.3

177.6

472.3

$1.6 \quad 1.3$

148.2

5.0

243.6

152.1

241.1

791.6

57.6

5.6

271.9

210.1

364.9

911.4

1.6

3.6

281.0

113.5

157.7

700.0

1.4

70.6

3.0

321.9

128.2

305.2

830.2

1.7
68.6
7.0
284.5
153.3
178.7
693.9

1.6

14.3

9.4

336.2

188.5

234.7

784.7
$0.4 \quad 0.4$

142.7
Seacon

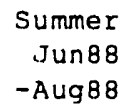

Autumn
Sep88
-Nov88

Annual

$\operatorname{Jan} 88$

-Dec 88
0.3

19.4

1.6

61.9

31.5

84.8

199.5

129.1

226.6

0.9

0.6

1.7

122.6

61.9

208. 3

396.0

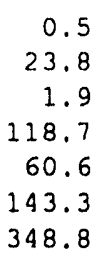

348.8

1.1

0.7

0.9

168.7

86.0

258.7

516.1

0.8

40.8

0.9

168.8

84.1

181.5

476.9

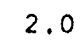

0.1

5.6

277.1

190.0

466.3

941.0

$$
\begin{array}{r}
1.5 \\
55.6
\end{array}
$$

5.8

277.8

175.4

341.1

857.3

1.8

2. 2

2. 8

330.6

129.1

453.4

919.9

1.4
69.8
3.0

3.0
328.3

126.4

316.0

844.9

2.1

0.2

9.5

343.6

186.9

284.4

826.6

1.7

13.4

9.7

340.1

181.8

226.7

773.4
2.5

115.1

7.9

476.9

244.1

570.4

1416.9

3.7

190.7

3.8

664.0

335.1

723.4

1920.7

6.5

284.1

22.8

1095.6

743.1

1457.8

3609.8

6.0

309.0

12.2

1300.1

506.7

1254.7

3388.6
7.0

73.4

38.3

1351.7

733.8

943.1

3147.3 
1988 voc

$\mathrm{r}$

Fed, Region / Sector

Federal Region 7

Electric Utility

Commercial/Residential

Industrial Fuel

Industrial processes

Miscellaneous

Transportation Total

Federal Region 8

Electric Utility

Commercial/Residential

Industrial Fuel

Industrial Processes

Miscellaneous

Transportation Total

Federal Region 9

Electric Utility

Commerclal/Residential

Industrial Fuel

Industrial Processes

Miscellaneous

Transportation Total.

Federal Region 10

Electric Utility

Commercial/Residential

Industrial Fuel

Industrial Processes

Miscellaneous

Transportation Total

National Totals

Electric Utility

Commercial/Residential

Industrial Fuel

Industrial Processes

Miscellaneous

Transportation Total
Federal

Winter

Dec 87

-Feb88

Spring
Mar 88
- May 88

Summer

Jun 88

-Aug 88

Aut umn

Sep88

- Nov 88

Annua 1

$\operatorname{Jan} 88$

$-\operatorname{Dec} 88$

$\begin{array}{rr}0.6 & 0.4 \\ 37.6 & 11.9 \\ 0.6 & 0.4 \\ 74.3 & 70.7 \\ 34.9 & 31.7 \\ 46.4 & 86.0\end{array}$

194.5

201.2

1.0

59.0

3.4

195.7

116.1

159.9

535.0

0.5

27.4

1.8

141.2

83.3

$135 \cdot 3$

389.6

0.2

57.9

1.7

52.9

42.7

62.6

218.0

8.7

748.3

28.7

1592.3

855.9

1183.7

4417.6
0.6

11.0

1.0

35.4

42.3

59.6

149.9

0.5

12.7

1.8

195.6

121.1

184.9

516.6

0.1

30.7

1.3

32.8

76.9

59.5

201.4

7.4

304.4

26.9

1606.7

977.6

1698.0

4621.1
0.7
0.2
0.9
72.5
31.7
129.5
235.0

0.5

13.5

0.4

73.2

30.5

83.3

201.3

0.7

1.5

0.9

36.4

45.3

89.1

173.9

0.8

1.3

1.7

201.0

128.9

201.2

534.9

0.7

10.2

1.0

35.6

44.0

59.5

150.9

0.6

8.5

2.0

197.5

127.6

183.0

519.2

0.0

6.0

1.3

34.0

75.9

76.9

194.2

0.0

26.9

1.4

33.2

72.1

58.6

192.2

10.5

14.3

26.3

1648.4

967.7

2297.0

4964.2
8.0

281.9

27.7

1635.1

933.9

1677.8

4564.5
2.2

60.8

1.7

287.4

123.0

342.2

817.3

2.7

44.2

4.0

142.2

162.9

244.2

599.2

2.4

55.5

7.4

787.3

487.9

749.7

2090.2

0.2

125.1

5.4

132.5

273.2

230.0

766.3

34.7

1348.9

109.6

6482.5

3735.2

6856.5

18587.4 
B.10 $\mathrm{NO}_{x}, \mathrm{SO}_{2}$, and VOC Emissions by Emission Source Group (ESG) 


\begin{tabular}{|c|c|c|c|}
\hline Emission source group (ESG) & NOX & $\mathrm{SO} 2$ & VOC \\
\hline \multicolumn{4}{|l|}{ Commercial/Residential } \\
\hline Comm./Inst. coal combustion & 33.1 & 124.2 & 1.1 \\
\hline Comm./Inst. natural gas combustion & 134.0 & 1.2 & 2.8 \\
\hline Comm./Inst. fuel oil combustion & 191.8 & 465.4 & 4.6 \\
\hline Comm./Inst. other fuels combustion & 5.5 & 0.5 & 2.5 \\
\hline Residential coal combustion & 3.3 & 47.2 & 18.6 \\
\hline Residential natural gas combustion & 247.8 & 1.1 & 0.0 \\
\hline Residential fuel oil combustion & 113.5 & 175.2 & 10.4 \\
\hline $\begin{array}{l}\text { Residential wood combustion } \\
\text { Total }\end{array}$ & $\begin{array}{r}36.6 \\
765.8\end{array}$ & $\begin{array}{r}5.4 \\
820.3\end{array}$ & $\begin{array}{l}568.3 \\
608.3\end{array}$ \\
\hline \multicolumn{4}{|l|}{ Industrial fuel } \\
\hline Industrial coal combustion & 416.3 & 1397.5 & 4,7 \\
\hline Industrial natural gas combustion & 2486.4 & 53.4 & 44.1 \\
\hline Industrial fuel oil combustion & 525.3 & 1326.4 & 36.5 \\
\hline Industrial other fuels combustion & 294.0 & 349.1 & 33.2 \\
\hline Total & 3722.1 & 3126.3 & 118.5 \\
\hline \multicolumn{4}{|l|}{ Industrial processes } \\
\hline Cement production & 111.2 & 205.4 & 0.4 \\
\hline Degreasing & 0.0 & 0.0 & 325.9 \\
\hline Dry cleaning & 0.0 & 0.0 & 241.0 \\
\hline Food proc. and agric. operations & 4.3 & 3.0 & 90.9 \\
\hline Gasoline marketing & 0.1 & 1.1 & 1248.1 \\
\hline Glass manufacturing & 48.7 & 21.7 & 6.2 \\
\hline Iron and steel production & 66.1 & 260.3 & 72.5 \\
\hline Lime manufacturing & 26.3 & 43.1 & 0.9 \\
\hline Mining operations & 8.7 & 20.1 & 3.0 \\
\hline Mineral products processing & 7.5 & 14.6 & 0.6 \\
\hline Miscellaneous industrial processes & 5.9 & 6.3 & 43.3 \\
\hline Oil and gas extraction & 58.5 & 258.1 & 95.3 \\
\hline Organic chemicals manufacture & 32.3 & 12.0 & 267.9 \\
\hline Other chemicals manufacture & 158.7 & 737.8 & 403.4 \\
\hline Other primary metals smelting & 1.0 & 12.6 & 0.0 \\
\hline Primary aluminum smelting & 2.1 & 53.0 & 0.4 \\
\hline Paper and pulp mills operations & 65.0 & 80.6 & 21.6 \\
\hline Primary copper smelting & 1.3 & 1945.8 & 0.0 \\
\hline Plastics production & 8.7 & 1.3 & 301.6 \\
\hline Primary lead and zinc smelting & 1.6 & 48.3 & 0.0 \\
\hline Printing operations & 0.2 & 0.0 & 205.9 \\
\hline Petroleum product storage \& transfer & 0.8 & 0.3 & 608.0 \\
\hline Petroleum refining & 65.2 & 361.8 & 1022.4 \\
\hline Rubber and misc. plastics manufacture & 0.0 & 0.0 & 26.4 \\
\hline Other sec. metal smelting and refining & 4.7 & 8.1 & .1 \\
\hline Secondary lead refining & 0.8 & 18.8 & 0.4 \\
\hline "Indus. organic solvent use, misc." & 0.0 & 0.0 & 55.3 \\
\hline Surface coating & 7.1 & 0.7 & 1783.3 \\
\hline Total & 686.9 & 4114.9 & 6833.6 \\
\hline \multicolumn{4}{|l|}{ Miscellaneous } \\
\hline Forest wild fires & 30.4 & 1.1 & 122.1 \\
\hline Solid waste incineration & 24.3 & 22.5 & 74.4 \\
\hline Nonind. organic solvent use \& disposal & 5.0 & 1.9 & 3359.6 \\
\hline Other miscellaneous sources & 0.6 & 1.3 & 1.2 \\
\hline
\end{tabular}


1975 Emissions by Emission Source Group (ESG) (kt) (cont'd)

Solid waste open burning

Other burning

Asphalt paving operations

Total

Transportation

Aircraft

Heavy-duty diesel trucks (on-highway)

Heavy-duty gasoline trucks (on-highway)

Light-duty diesel trucks (on-highway)

Light-duty gasoline trucks (on-highway)

Automobiles (on-highway)

Other off-highway vehicles

Railroad

Shipping

Total

Electric utility

"Bituminous coal, steam"

"Fuel oil \#2, gas turbine"

"Fuel oil \#2, internal combustion"

"Fuel oil \#2, steam"

"Fuel oil \#6, gas turbine"

"Fuel oil \#6, internal combustion"

"Fuel oil \#6, steam"

"Natural gas, gas turbine"

"Natural gas, internal combustion"

"Natural gas, steam"

"Lignite, steam"

"Subbituminous coal, steam"

Total

1975 National total

$\begin{array}{rrr}53.9 & 7.6 & 467.8 \\ 86.9 & 2.7 & 356.0 \\ 0.0 & 0.0 & 172.2 \\ 201.3 & 37.2 & 4553.3\end{array}$

64.0

1363.3

289.9

0.0

1335.8

4027.5

888.1

801.4

98.8

8868.7

6.9

138.7

10.0

2.9

46.8

127.0

69.8

103.5

126.9

632.5

72.6

179.5

510.3

0.0

2541.9

8078.3

625.9

199.8

15.9

12224.3

3259.5

30.6

2.9

8.9

13.6

34.2

451.8

25.9

57.4

632.3

77.4

427.0

5021.4

14865.6

18.3

0.2

12.9

27.2

11.0

1294.6

0.0

0.0

0.8

137.4

439.8

16807.9

10.7

2.5

0.1

0.1

1.1

0.9

6.3

2.6

1.8

1.9

0.5

1.7

30.1

$19266.2 \quad 25539.0 \quad 24368.1$ 


\section{Emissions by Emission Source Group (ESG) (kt)}

Emission source group (ESG)

Commercial/Residential

Comm. Inst. coal combustion

Comm./Inst. natural gas combustion

Comm./Inst. fuel oil combustion

Comm./Inst. other fuels combustion

Residential coal combustion

Residential natural gas combustion

Residential fuel oil combustion

Residential wood combustion

Total

$\begin{array}{rrr}\text { NOx } & \text { SO2 } & \text { VOC } \\ & & \\ 33.1 & 133.8 & 1.1 \\ 146.2 & 1.2 & 2.8 \\ 215.8 & 529.6 & 4.6 \\ 5.5 & 0.5 & 2.5 \\ 2.7 & 40.5 & 9.3 \\ 259.1 & 1.1 & 0.0 \\ 124.8 & 204.4 & 10.4 \\ 45.8 & 6.3 & 643.3 \\ 833.1 & 917.4 & 673.9\end{array}$

Industrial fuel

Industrial coal combustion

Industrial natural gas combustion

Industrial fuel oil combustion

Industrial other fuels combustion

Total

354.3
2708.9
661.5
357.0
4081.8

Industrial processes

Cement production

Degreasing

Dry cleaning

Food proc. and agric. operations

Gasoline marketing

Glass manufacturing

Iron and steel production

Lime manufacturing

Mining operations

Mineral products processing

Miscellaneous industrial processes

Oil and gas extraction

Organic chemicals manufacture

other chemicals manufacture

Other primary metals smelting

Primary aluminum smelting

Paper and pulp mills operations

Primary copper smelting

Plastics production

Primary lead and zinc smelting

Printing operations

Petroleum product storage \& transfer

Petroleum refining

Rubber and misc. plastics manufacture

Other sec. metal smelting and refining

Secondary lead refining

"Indus. organic solvent use, misc."

Surface coating

Total

Miscellaneous

Forest wild Eires

Solid waste incineration

Nonind. organic solvent use \& disposal

other miscellaneous sources

$\begin{array}{rrr}125.1 & 227.7 & 0.4 \\ 0.0 & 0.0 & 354.9 \\ 0.0 & 0.0 & 262.0 \\ 4.3 & 3.0 & 90.9 \\ 0.1 & 1.1 & 1283.6 \\ 48.7 & 21.7 & 6.2 \\ 66.1 & 251.9 & 74.9 \\ 26.3 & 43.1 & 0.9 \\ 9.2 & 21.3 & 3.2 \\ 8.4 & 16.3 & 0.6 \\ 5.9 & 6.3 & 43.3 \\ 56.7 & 209.7 & 97.1 \\ 32.3 & 15.2 & 310.0 \\ 158.7 & 564.2 & 443.8 \\ 1.1 & 14.1 & 0.0 \\ 2.1 & 61.8 & 0.4 \\ 65.0 & 91.4 & 24.8 \\ 1.4 & 1635.0 & 0.0 \\ 11.2 & 1.6 & 339.3 \\ 1.6 & 48.3 & 0.0 \\ 0.2 & 0.0 & 230.6 \\ 0.8 & 0.3 & 625.2 \\ 65.2 & 370.5 & 1034.0 \\ 0.0 & 0.0 & 26.4 \\ 5.6 & 9.8 & 11.0 \\ 0.8 & 28.2 & 0.4 \\ 0.0 & 0.0 & 61.9 \\ 7.1 & 0.7 & 1982.5 \\ 704.1 & 3643.4 & 7308.1 \\ & & \\ 60.9 & 1.1 & 219.7 \\ 24.3 & 22.5 & 74.4 \\ 5.0 & 1.9 & 3359.6 \\ 0.6 & 1.2 & 1.1 \\ & & \end{array}$




\begin{tabular}{|c|c|c|c|}
\hline $\begin{array}{l}\text { Solid waste open burning } \\
\text { other burning } \\
\text { Asphalt paving operations } \\
\text { Total }\end{array}$ & $\begin{array}{r}53.9 \\
86.9 \\
0.0 \\
231.7\end{array}$ & $\begin{array}{r}7.6 \\
2.7 \\
0.0 \\
37.2\end{array}$ & $\begin{array}{r}374.2 \\
356.0 \\
167.2 \\
4552.2\end{array}$ \\
\hline $\begin{array}{l}\text { Transportation } \\
\text { Alrcraft } \\
\text { Heavy-duty diesel trucks (on-highway) } \\
\text { Heavy-d'ty gasoline trucks (on-highway) } \\
\text { light-duty diesel trucks (on-highway) } \\
\text { Light-duty gasoline trucks (on-highway) } \\
\text { Automobiles (on-highway) } \\
\text { other off-highway vehicles } \\
\text { Railroad } \\
\text { Shipping } \\
\text { Total }\end{array}$ & $\begin{array}{r}66.1 \\
1464.0 \\
289.5 \\
0.0 \\
1385.1 \\
4166.6 \\
979.9 \\
822.6 \\
105.0 \\
9278.9\end{array}$ & $\begin{array}{r}7.1 \\
148.3 \\
10.7 \\
3.0 \\
47.8 \\
131.9 \\
79.6 \\
108.3 \\
152.1 \\
688.8\end{array}$ & $\begin{array}{r}75.3 \\
192.2 \\
513.8 \\
0.0 \\
2570.2 \\
7974.7 \\
664.2 \\
208.8 \\
16.5 \\
12215.7\end{array}$ \\
\hline $\begin{array}{l}\text { Electric utility } \\
\text { "Bituminous coal, steam" }\end{array}$ & 3475.2 & 15293.1 & 11.5 \\
\hline $\begin{array}{l}\text { "Fuel oil \#2, gas turblne" } \\
\text { "Fuel oll \#2, internal combustion" } \\
\text { "Fuel oil \#2, steam" } \\
\text { "Fuel oll \#6, gas turbine" } \\
\text { "Fuel oil \#6, internal combustion" } \\
\text { "Fuel oil \#6, steam" } \\
\text { "Natural gas, gas turbine" } \\
\text { "Natural gas, internal combustion" } \\
\text { "Natural gas, steam" } \\
\text { "Lignite, steam" } \\
\text { "Subbituminous coal, steam" } \\
\text { Total }\end{array}$ & $\begin{array}{r}33.4 \\
2.8 \\
10.0 \\
14.8 \\
33.5 \\
500.7 \\
23.7 \\
50.2 \\
615.0 \\
110.3 \\
506.7 \\
5376.2\end{array}$ & $\begin{array}{r}20.9 \\
0.2 \\
17.0 \\
29.6 \\
10.9 \\
1451.5 \\
0.0 \\
0.0 \\
0.8 \\
186.6 \\
541.0 \\
17551.6\end{array}$ & $\begin{array}{l}2.7 \\
0.1 \\
0.1 \\
1.2 \\
0.9 \\
6.9 \\
2.4 \\
1.5 \\
1.8 \\
0.7 \\
2.1 \\
0.9\end{array}$ \\
\hline 976 National to & 20505.8 & 26246.3 & 24913.3 \\
\hline
\end{tabular}




\section{Emissions by Emission Souzce Group (ESG) (kt)}

Commercial/Residential

Comm./Inst. coal combustion

Comm./Inst. natural gas combustion

Comm./Inst. fuel oil combustion

Comm./Inst. other fuels combustion

Residential coal combustion

Residential natural gas combustion

Residential fuel oil combustion

Residential wood combustion

Total

Industrial fuel

Industrial coal combustion

Industrial natnral gas combustion

Industrial fuel oil combustion

Industrial other fuels combustion

Total

Industrial processes

Cement production

Degreasing

Dry cleaning

Food proc. and agric. operations

Gasoline marketing

Glass manufacturing

Iron alld steel production

Lime manufacturing

Mining operations

Mineral products processing

Miscellaneous industrial processes

Oil and gas extraction

Organic chemicals manufacture

Other chemicals manufacture

other primary metals smelting

Primary aluminum smelting

Paper and pulp mills operations

Primary copper sinelting

Plastics production

Primary lead and zinc smelting

Printing operations

Petroleum product storage \& transfer

Petroleum refining

Rubber and misc. plastics manufacture

Other sec. metal smelting and refining

Secondary lead refining

"Indus. organic solvent use, misc."

Surface coating

Total

Miscelianeous

Forest wild fires

Solid waste incineration

Nonind. organic solvent use \& disposal

other miscellaneous sources

$\begin{array}{rrr}\text { NOx } & \text { SO2 } & \text { VOC } \\ & & \\ 33.1 & 133.8 & 1.1 \\ 134.0 & 1.2 & 2.8 \\ 203.8 & 513.5 & 4.6 \\ 5.5 & 0.5 & 2.5 \\ 2.7 & 40.5 & 13.0 \\ 247.8 & 1.1 & 0.0 \\ 124.8 & 204.4 & 10.4 \\ 45.8 & 7.3 & 724.5 \\ 797.6 & 902.2 & 758.8\end{array}$

372.0

1191.9

53.4

3.1

2718.6

700.4

336.0

1823.8

386.0

$51 \cdot 5$

43.8

43.7

4127.1

345.1

142.0

125.1

259.0

0.4

0.0

0.0

4.3

0.1

58.4

66.1

26.3

9.6

9.0

5.9

57.5

32.3

158.7

1. 2

2.1

65.0

1. 3

12.1

1.6

0.2

0.8

70.6

0.0

5.7

0.8

0.0

7.1

722.0

0.0

0.0

3.0

354.9

272.4

90.9

1. 1

1290.7

6.2

70.1

243.5

43.1

22.2

0.9

3.3

0.7

17.5

43.3

193.6

16.4

100.7

329.2

585.9

14.3

484.1

0.0

0.4

96.8

24.7

1539.8

0.0

358.1

0.0

39.5

0.0

238.8

628.7

387.9

1092.1

31.6

11.1

0.4

72.9

28.2

0.0

2077.3

7583.9

60.9

24.3

1.1

170.9

22.5

74.4

1.9

3359.6

1.1 
1977 Emissions by Emission Source Group (ESG) (kt)

Solid waste open burning

Other burning

Asphalt paving operations

Total

Transportation

Aircraft

Heavy-duty diesel trucks (on-highway)

Heavy-duty gasoline trucks (on-highway)

Light-duty diesel trucks (on-highway)

Light-duty gasoline trucks (on-highway)

Automobiles (on-highway)

Other off-highway vehicles

Railroas

Shipping

Total

Electric utility

"Bituminous coal, steam"

"Fuel oil \#2, gas turbine"

"Fuel oil \#2, internal combustion"

"Fuel o:1 \#2, steam"

"Fuel oil \#6, gas turbine"

"Fuel oil \#6, internal combustion"

"Fuel oil \#6, steam"

"Natural gas, gas turbine"

"Natural gas, internal combustion"

"Natural gas, steam"

"Lignite, steam"

"Subbituminous coal, steam"

Total

1977 National total

$\begin{array}{rrr}53.9 & 7.6 & 374.2 \\ 86.9 & 2.7 & 356.0 \\ 0.0 & 0.0 & 184.6 \\ 231.7 & 37.2 & 4520.9\end{array}$

$\begin{array}{rrr}69.2 & 7.5 & 78.8 \\ 1541.2 & 150.0 & 202.6 \\ 286.0 & 10.9 & 512.8 \\ 0.0 & 3.2 & 0.0 \\ 1419.7 & 48.1 & 2582.2 \\ 4229.7 & 135.0 & 7823.3 \\ 1051.4 & 89.4 & 651.4 \\ 824.0 & 110.3 & 211.0 \\ 127.4 & 168.5 & 20.4 \\ 9548.6 & 722.8 & 12082.5\end{array}$

35.25 .0

42.7

3.5

11.1

15.6

29.2

559.8

29.7

46.6

633.8

124.0

605.5

5626.4

15203.2

21053.5
26.1

0.2

18.6

32.2

9.3

1568.7

0.0

0.0

0.8

198.1

657.3

17714.6

11.7

3.5

0.1

0.1

1.3

0.8

7.7

3.0

1.4

1.9

0.8

2.6

35.0

$26435.1 \quad 25123.2$ 
1978 Emissions by Emission Source Group (ESG) (kt)

Emission source group (ESG)

Commercial/Residential

Comm./Inst. coal combustion

Comm./Inst. natural gas combustion

Comm./Inst. fuel oil combustion

Comm./Inst. other fuels combustion

Residential coal combustion

Residential natural gas combustion

Residential fuel oil combustion

Residential wood combustion

Total

Industrial fuel

Industrial coal combustion

Industrial natural gas combustion

Industrial fuel oil combustion

Industrial other fuels combustion

Total

Industrial processes

Cement production

Degreasing

Dry cleaning

Food proc. and agric. operations

Gasolire marketing

Glass manufacturing

Iron and steel production

Lime manufacturing

Mining operations

Mineral products processing

Miscellanecus industrial processes

Oil and gas extraction

Organic chemicals manufacture

Other chemicals manufacture

Other primary metals smelting

Primary aluminum smelting

Paper and pulp mills operations

Primary copper smelting

Plastics production

Primary lead and zinc smelting

Printing operations

Petroleum product storage \& transfer

Petroleum refining

Rubber and misc. plastics manufacture

Other sec. metal smelting and refining

Secondary lead refining

"Indus. organic solvent use, misc."

Surface coating

Total

Miscellaneous

Forest wild fires

Solid waste incineration

Nonind. organic solvent use \& disposal

Other miscellaneous sources

$\begin{array}{rrr}\text { NOx } & \text { SO2 } & \text { VOC } \\ 44.2 & 172.0 & 2.2 \\ 146.2 & 1.2 & 2.8 \\ 203.8 & 449.3 & 4.6 \\ 5.5 & 0.5 & 2.5 \\ 2.7 & 33.7 & 9.3 \\ 247.8 & 1.1 & 0.0 \\ 124.8 & 185.0 & 10.4 \\ 54.9 & 8.2 & 868.1 \\ 830.0 & 850.9 & 899.9 \\ & & \\ 372.0 & 1233.0 & 3.1 \\ 2699.3 & 53.4 & 51.5 \\ 681.0 & 1658.0 & 43.8 \\ 378.0 & 456.5 & 44.2 \\ 4130.3 & 3400.9 & 142.6\end{array}$

139.0

0.1

58.4

75.6

26.3

10.4

5.9

60.6

32.3

148.1

65.0

1.3

13.4

70.6

740.7

281.

60.9
24.3
5.0
0.6

1. 3
0.0

0.0

4.3

9.8

1.2

2.1

1.6

0.2

0.8

0.0

5.5

0.8

0.0

7.1

0.0

0.0

3.0

1.1

21.7

230.9

43.1

24.1

19.0

6.3

209.7

14.7

585.9

15.3

70.6

96.8

1391.0

2.0

43.9

0.0

0.3

392.3

0.0

9.5

28.2

0.0

0.7

3491.5

1.1

22.5

1. 9

170.9

74.4

3359.6

1.1

398.4

303.9

96.2

1311.9

6.2

65.2

0.9

3.6

0.8

43.3

102.5

336.8

492.2

0.0

0.4

24.9

0.0

414.7

0.0

288.2

639.1

1126.9

31.6

10.7

0.4

72.9

2380.8

8152.9

$$
1 .
$$




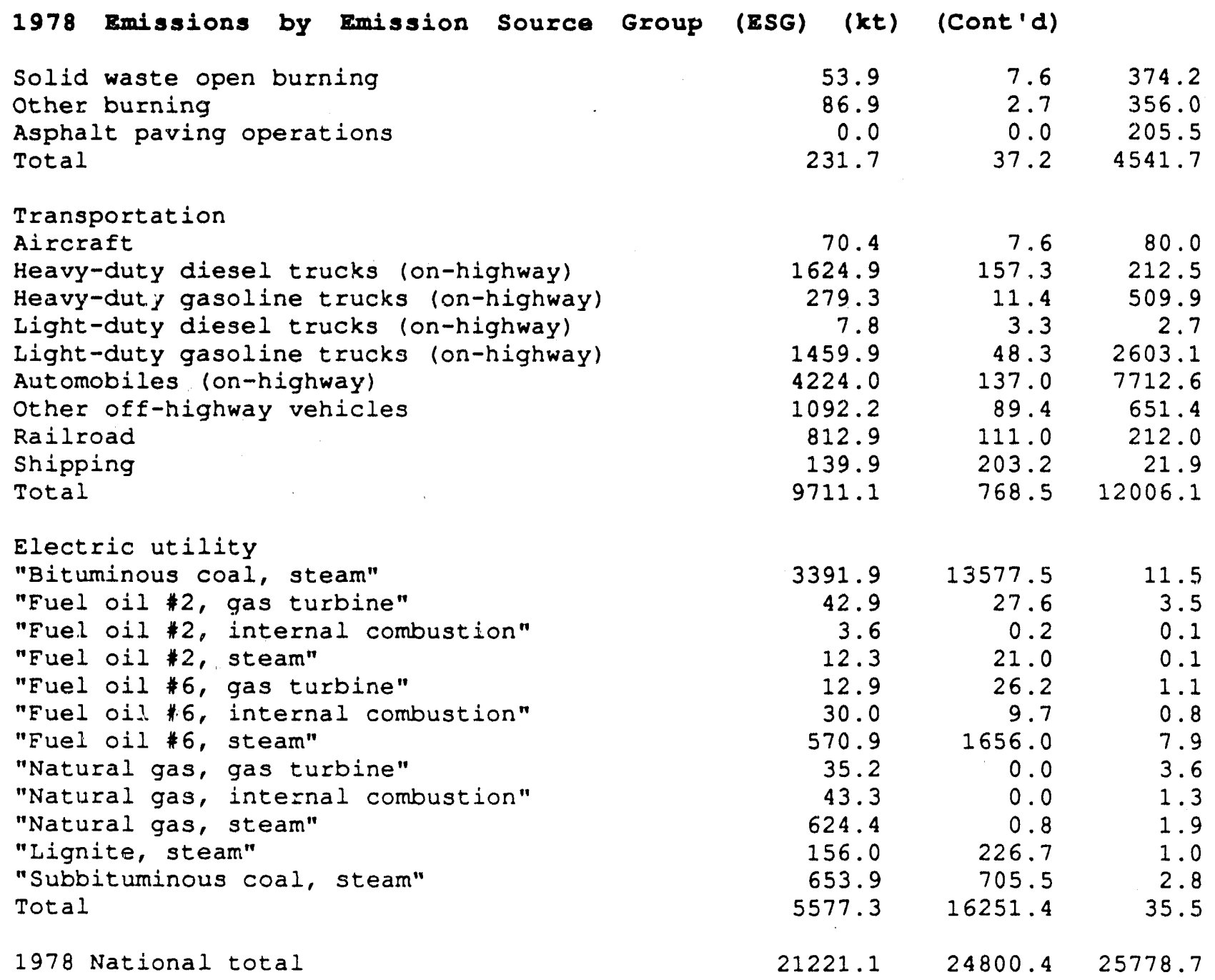


1979 Emissions by Emission Source Group (ESG) (kt)

Emission source group (ESG)

NOx

$\mathrm{SO} 2$

Voc

Commercial/Residential

Comm./Inst. coal combustion

Comm./Inst. natural gas combustion

Comm./Inst. fuel oil combustion

Comm./Inst. other fuels combustion

Residential coal combustion

Residential natural gas combustion

Residential fuel oil combustion

Residential wood combustion

Total

$\begin{array}{rrr}33.1 & 133.8 & 1.1 \\ 158.4 & 1.2 & 3.2 \\ 167.9 & 385.1 & 3.1 \\ 5.5 & 0.5 & 2.5 \\ 2.0 & 27.0 & 9.3 \\ 247.8 & 1.1 & 0.0 \\ 102.1 & 155.7 & 10.4 \\ 64.1 & 9.1 & 1061.7 \\ 781.0 & 713.5 & 1091.3\end{array}$

Industrial fuel

Industrial coal combustion

Industrial natural gas combustion

Industrial fuel oil combustion

Industrial other fuels combustion

Total

407.5
2621.9
505.9
399.0
3934.2

Industrial processes

Cement production

Degreasing

Dry cleaning

Food proc. and agric. operations

Gasoline marketing

Glass manufacturing

Iron and steel production

Lime manufacturing

Mining operations

Mineral products processing

Miscellaneous industrial processes

Oil and gas extraction

Organic chemicals manufacture

Other chemicals manufacture

Other primary metals smelting

Primary aluminum smelting

Paper and pulp mills operations

Primary copper smelting

Plastics production

Primary lead and zinc smelting

Printing operations

Petroleum product storage \& transfer

Petroleum refining

Rubber and misc. plastics manufacture

Other sec. metal smelting and refining

Secondary lead refining

"Indus. organic solvent use, misc."

Surface coating

Total

Miscellaneous

Forest wild fires

Solid waste incineration

Nonind. organic solvent use \& disposal

other miscellaneous sources
139.0

0.0

0.0

4.3

0.1

58.4

66.1

26.3

10.7

10.0

5.9

59.7

37.6

158.7

1.3

2.1

65.0

1.3

14.9

1.6

0.2

0.8

67.9

0.0

5.9

0.8

0.0

7.1

746.0

60.9
24.3
5.0
0.6
1323.5

53.4

1371.6

456.5

3205.0

281.3

0.0

0.0

3.0

1.1

21.7

243.5

43.1

24.8

19.4

6.3

225.9

18.1

564.2

15.5

70.6

96.8

1430.9

2.2

52.7

0.0

0.3

383.6

0.0

10.2

37.6

0.0

0.7

3553.6

1.1

22.5

1.9

1.3
195.3
74.4
3536.5
0.9

4.7

51.5

29.2

44.2

129.6

0.4

405.6

303.9

96.2

.205.6

6.2

70.1

0.9

3.7

0.8

43.3

102.5

j44.5

508.3

0.0

0.4

26.4

0.0

433.5

0.0

288.2

587.2

1126.9

26.4

11.5

0.4

75.1

2371.4

8039.3

$$
0.9
$$




\begin{tabular}{|c|c|c|c|c|}
\hline Emissions by & Group & (ESG) & (Cont'd) & \\
\hline $\begin{array}{l}\text { Solid waste open burning } \\
\text { Other burning } \\
\text { Asphalt paving operations } \\
\text { Total }\end{array}$ & & $\begin{array}{r}53.9 \\
86.9 \\
0.0 \\
231.7\end{array}$ & $\begin{array}{r}7.6 \\
2.7 \\
0.0 \\
37.2\end{array}$ & $\begin{array}{r}280.7 \\
356.0 \\
199.6 \\
4643.4\end{array}$ \\
\hline $\begin{array}{l}\text { Transportation } \\
\text { Aircraft } \\
\text { Heavy-duty diesel trucks (on-highway) } \\
\text { Heavy-duty gasoline trucks (on-highway) } \\
\text { Light-duty diesel trucks (on-highway) } \\
\text { Light-duty gasoline trucks (on-highway) } \\
\text { Automobiles (on-highway) } \\
\text { Other off-highway vehicles } \\
\text { Railroad } \\
\text { Shipping } \\
\text { Total }\end{array}$ & & $\begin{array}{r}71.9 \\
1611.3 \\
260.3 \\
8.0 \\
1403.2 \\
4015.5 \\
1082.0 \\
796.0 \\
148.7 \\
9397.0\end{array}$ & $\begin{array}{r}7.9 \\
150.1 \\
11.0 \\
3.2 \\
45.6 \\
131.9 \\
89.4 \\
110.6 \\
244.2 \\
793.9\end{array}$ & $\begin{array}{r}84.9 \\
209.6 \\
477.7 \\
2.8 \\
2439.0 \\
7112.3 \\
638.7 \\
209.6 \\
22.6 \\
11197.1\end{array}$ \\
\hline $\begin{array}{l}\text { Electric utility } \\
\text { "Bituminous coal, steam" } \\
\text { "Fuel oil \#2, gas turbine" } \\
\text { "Fuel oil \#2, internal combustion" } \\
\text { "Fuel oil \#2, steam" } \\
\text { "Fuel oil \#6, gas turbine" } \\
\text { "Fuel oil \#6, internal combustion" } \\
\text { "Fuel oil \#6, steam" } \\
\text { "Natural gas, gas turbine" } \\
\text { "Natural gas, internal combustion" } \\
\text { "Natural gas, steam" } \\
\text { "Lignite, steam" } \\
\text { "Subbitumino's coal, steam" } \\
\text { Total }\end{array}$ & & $\begin{array}{r}3566.4 \\
24.3 \\
2.8 \\
6.3 \\
11.6 \\
21.4 \\
487.5 \\
43.2 \\
43.6 \\
675.7 \\
180.2 \\
758.3 \\
5821.4\end{array}$ & $\begin{array}{r}13893.5 \\
12.2 \\
0.2 \\
11.2 \\
24.4 \\
7.4 \\
1474.5 \\
0.1 \\
0.0 \\
0.9 \\
237.6 \\
784.6 \\
16446.5\end{array}$ & $\begin{array}{r}12.2 \\
2.0 \\
0.1 \\
0.1 \\
0.9 \\
0.6 \\
6.7 \\
4.4 \\
1.3 \\
2.0 \\
1.2 \\
3.3 \\
34.9\end{array}$ \\
\hline & & 20911.3 & 24749.6 & \\
\hline
\end{tabular}


1980 zmissions by Emission source Group (ESG) (kt)

Emission source group (ESG)

Commerclal/Residential

Comm./Inst. coal combustion

Comm./Inst. natural gas combustion

Comm./Inst. fuel oil combustion

Comm./Inst. other fuels combustion

Residential coal combustion

Residential natural gas combustion

Residential fuel oil combustion

Residential wood combustion

Total

Industrial fuel

Industrial coal combustion

Industrial natural gas combustion

Industrial fuel oil combustion

Industrial other fuels combustion

Total

Industrial processes

Cement production

Degreasing

Dry cleaning

Food proc. and agric. operations

Gasoline marketing

Glass manufacturing

Iron and steel production

Lime manufacturing

Mining operations

Mineral products processing

Miscellaneous industrial processes

Oil and gas extraction

Organic chemicals manufacture

Other chemicals manufacture

Other primary metals smelting

Primary aluminum smelting

Paper and pulp mills operations

Primary copper smelting

Plastics production

Primary lead and zinc smelting

Printing operations

Petroleum product storage \& transfer

Petroleum refining

Rubber and misc. plastics manufacture

Other sec. metal smelting and refining

Secondary lead refining

"Indus. organic solvent use, misc."

Surface coating

Total

Miscellaneous

Forest wild fires

Solid waste incineration

Nonind. organic solvent use \& disposal

other miscellaneous sources

$\begin{array}{rrr}\text { NOx } & \text { SO2 } & \text { VOC } \\ & & \\ 22.1 & 95.5 & 1.1 \\ 146.2 & 1.2 & 2.8 \\ 167.9 & 465.4 & 4.6 \\ 5.5 & 0.5 & 2.5 \\ 2.0 & 27.0 & 9.3 \\ 247.8 & 1.1 & 0.0 \\ 90.8 & 1.36 .3 & 7.8 \\ 73.2 & 10.9 & 1230.3 \\ 755.5 & 737.9 & 1258.4\end{array}$

354.3

$216 \% .2$

428.0

399.0

3348.5

1134.4

53.4

1281.2

419.6

2888.5

125.1

0.0

0.0

4.3

0.1

48.7

56.7

26.3

10.9

9.2

5.9

60.0

26.9

158.7

1.0

2.1

65.0

1.1

13.3

1.6

0.2

0.8

65.2

0.0

5.2

0.8

0.0

7.1

696.3

$\begin{array}{rr}254.5 & 0.4 \\ 0.0 & 369.4 \\ 0.0 & 303.9 \\ 3.0 & 90.9 \\ 1.1 & 1092.1 \\ 21.7 & 6.2 \\ 214.1 & 60.4 \\ 43.1 & 0.9 \\ 25.2 & 3.7 \\ 17.9 & 0.7 \\ 6.3 & 43.3 \\ 225.9 & 100.7 \\ 17.2 & 317.7 \\ 564.2 & 459.9 \\ 12.9 & 0.0 \\ 79.4 & 0.4 \\ 107.5 & 26.9 \\ 1079.9 & 0.0 \\ 1.9 & 405.2 \\ 30.7 & 0.0 \\ 0.0 & 280.0 \\ 0.3 & 532.0 \\ 366.1 & 1126.9 \\ 0.0 & 21.1 \\ 9.0 & 10.1 \\ 28.2 & 0.4 \\ 0.0 & 72.9 \\ 0.7 & 2200.6 \\ 3111.1 & 7526.7\end{array}$

60.9

24.3

5.0

0.6
1.1

22.5

1.9

1. 3
3.1

36.8

21.9

44.2

106.0

0.4

69.4

90.9

6.2

60.4

0.9

3.7

43.3

100.7

317.7

0.0

0.4

26.9

0.0

05.2

80.0

532.0

26.9

21.1

0.4

72.9

219.7

55.8

3359.6

0.8
7526.7 


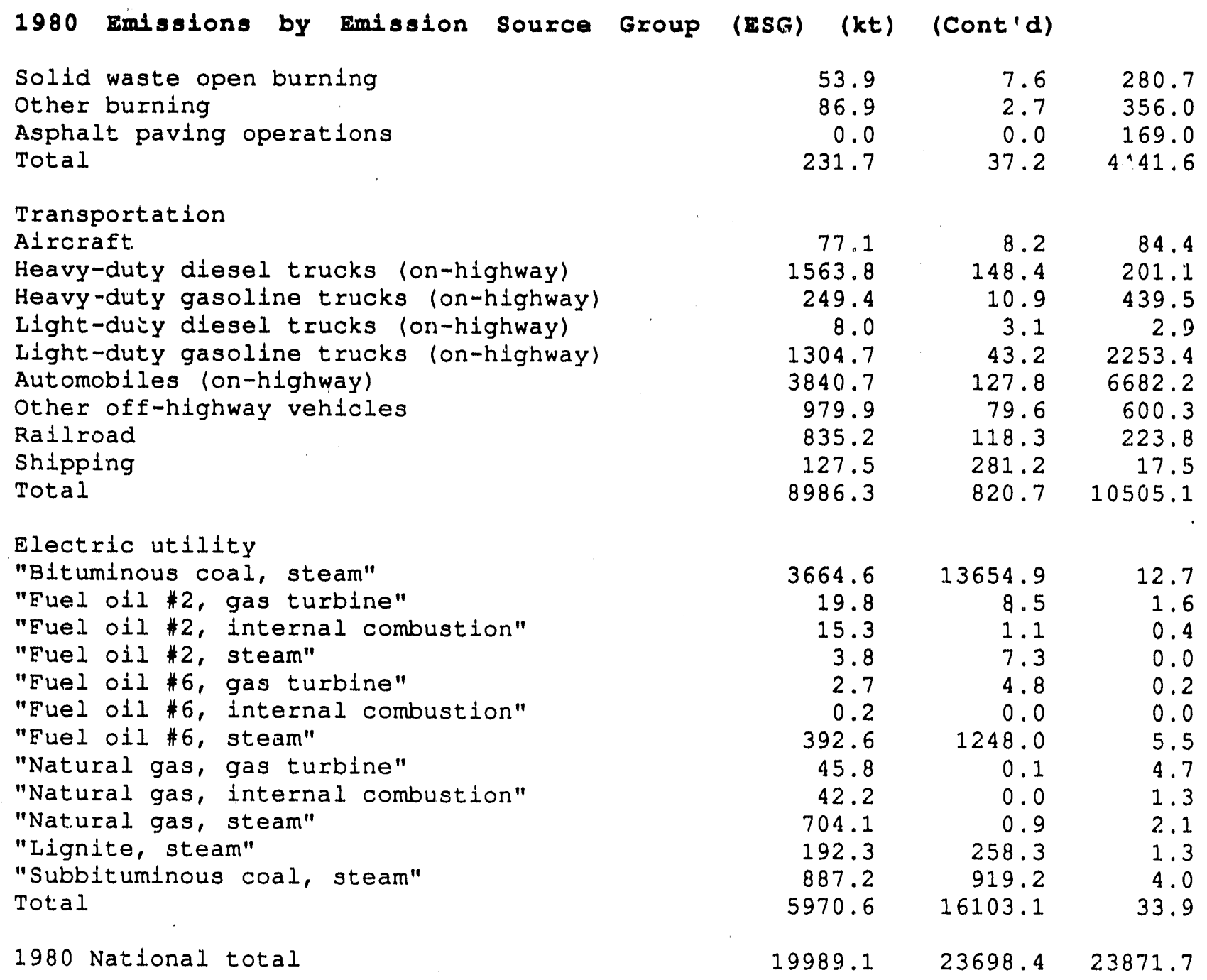


1981 Emissions by Emission Source Group (ESG) (kt)

Emission source group (ESG)

Commercial/Residential

Comm./Inst. coal combustion

Comm. Inst. natural gas combustion

Comm./Inst. fuel oil combustion

Comm./Inst. other fuels combustion

Residential coal combustion

Residential natural gas combustion

Residential fuel oil combustion

Residential wood combustion

Total

Industrial fuel

Industrial coal combustion

Industrial natural gas combustion

Industrial fuel oil combustion

Industrial other fuels combustion

Total

Industrial processes

Cement production

Degreasing

Dry cleaning

Food proc. and agric. operations

Gasoline marketing

Glass manufacturing

Iron and steel production

Lime manufacturing

Mining operations

Mineral products processing

Miscellaneous industrial processes

oil and gas extraction

Organic chemicals manufacture

Other chemicals manufacture

other primary metals smelting

Primary aluminum smelting

Paper and pulp mills operations

Primary copper smelting

Plastics production

Primary lead and zinc smelting

Printing operations

Petroleum product storage \& transfer

Petroleum refining

Rubber and misc. plastics manufacture

Other sec. metal smelting and refining

Secondary lead refining

"Indus. organic solvent use, misc."

Surface coating

Total

Miscellaneous

Eorest wild fires

Solid waste incineration

Nonind. organic solvent use \& disposal

other miscellaneous sources

$\begin{array}{rrr}\text { NOx } & \text { SO2 } & \text { VOC } \\ & & \\ 33.1 & 114.7 & 1.1 \\ 134.0 & 1.2 & 2.8 \\ 131.9 & 353.0 & 3.1 \\ 5.5 & 0.5 & 2.5 \\ 2.0 & 33.7 & 9.3 \\ 236.6 & 1.1 & 0.0 \\ 79.4 & 126.5 & 7.8 \\ 73.2 & 10.9 & 1330.2 \\ 695.8 & 641.6 & 1356.8\end{array}$

407.5

2070.4

369.7

378.0

3225.5

1282.4

53.4

1024.9

352.5

2713.1

4.7

36.8

21.9

43.7

107.0

111.

0.0

0.0

4.3

0.1

58.4

56.7

26.3

11.2

8.9

5.9

59.8

26.9

148.1

1.1

2.1

65.0

1.3

13.5

1.6

0.2

0.8

57.0

0.0

5.1

0.8

0.0

7.1

673.8

245.

0.0

0.4

0.0

304.2

251.5

3.0

1.1

21.7

201.5

43.1

25.9

17.3

6.3

242.0

20.5

499.1

13.6

70.6

107.5

1302.8

2.0

30.7

0.0

0.3

335.6

0.0

8.9

28.2

0.0

0.7

3228.3

96.2

1056.6

6.2

55.6

0.9

3.8

0.7

43.3

97.1

302.4

476.0

0.0

0.4

27.3

0.0

339.3

0.0

214.1

514.7

1115.3

26.4

10.0

0.4

75.1

1726.3

6744.3

60.9

24.3

5.0

0.6
1.1

22.5

1.9

1. 3
195.3

55.8

2829.2

0.8 


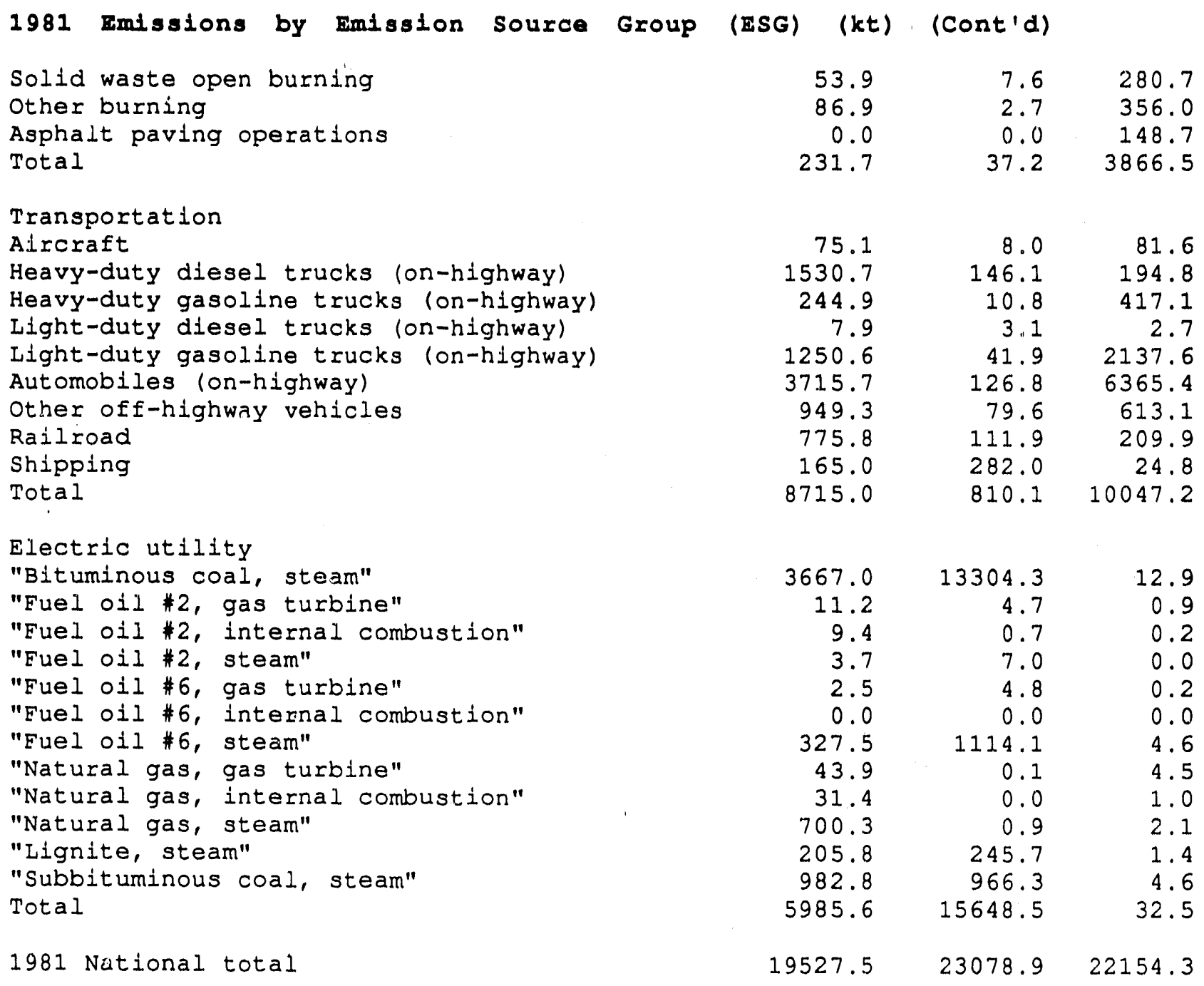




\section{Emissions by Emission Source Group (ESG) (kt)}

Emission source group (ESG) NOx

Commercial/Residential

Comm./Inst. coal combustion

Comm./Inst. natural gas combustion

Comm./Inst. fuel oil combustion

Comm./Inst. other fuels combustion

Residential coal combustion

Residential natural gas combustion

Residential fuel oll combustion

Residential wood combustion

Total

$\begin{array}{rrr}33.1 & 143.3 & 1.1 \\ 146.2 & 1.2 & 2.8 \\ 131.9 & 345.0 & 3.1 \\ 5.5 & 0.5 & 2.5 \\ 2.7 & 33.7 & 9.3 \\ 236.6 & 1.1 & 0.0 \\ 68.1 & 116.8 & 5.2 \\ 82.4 & 11.8 & 1461.4 \\ 706.5 & 653.5 & 1.485 .3\end{array}$

Industrial fuel

Industrial coal combustion

Industrial natural gas combustion

Industrial fuel oll combustion

Industrial other fuels combustion

Total

398.6

2157.5

389.1

357.0

3302.2

Industrial processes

Cement production

Degreasing

Dry cleaning

Food proc. and agric. operations

Gasoline marketing

Glass manufacturing

Iron and steel production

Lime manufacturing

Mining operations

Mineral products processing

Miscellaneous industrial processes

Oil and gas extraction

Organic chemicals manufacture

other chemicals manufacture

Other primary metals smelting

Primary aluminum smelting

Paper and pulp mills operations

Primary copper smelting

Plastics production

Primary lead and zinc smelting

Printing operations

Petroleum product storage \& transfer

Petroleum refining

Rubber and misc. plastics manufacture

other sec. metal smelting and refining

Secondary lead refining

"Indus. organic solvent use, misc."

Surface coating

Total

Miscellaneous

Forest wild fires

Solid waste incineration

Nonind. organic solvent use \& disposal

other miscellaneous sources

$\begin{array}{rrr}97.3 & 214.3 & 0.4 \\ 0.0 & 0.0 & 260.7 \\ 0.0 & 0.0 & 220.1 \\ 4.3 & 3.0 & 96.2 \\ 0.1 & 1.1 & 1014.1 \\ 48.7 & 21.7 & 6.2 \\ 37.8 & 134.4 & 36.2 \\ 26.3 & 28.8 & 0.3 \\ 9.1 & 21.1 & 3.1 \\ 8.0 & 15.6 & 0.6 \\ 5.9 & 6.3 & 43.3 \\ 60.5 & 225.9 & 95.3 \\ 21.5 & 18.3 & 256.4 \\ 105.8 & 390.6 & 411.5 \\ 0.8 & 9.4 & 0.0 \\ 2.1 & 53.0 & 0.4 \\ 65.0 & 107.5 & 27.6 \\ 1.1 & 798.6 & 0.0 \\ 12.2 & 1.8 & 311.0 \\ 1.6 & 70.2 & 0.0 \\ 0.2 & 0.0 & 197.6 \\ 0.8 & 0.3 & 494.0 \\ 54.3 & 322.5 & 1045.6 \\ 0.0 & 0.0 & 21.1 \\ 4.6 & 8.1 & 9.1 \\ 0.8 & 28.2 & 0.4 \\ 0.0 & 0.0 & 64.1 \\ 7.1 & 0.7 & 1479.7 \\ 576.2 & 2481.5 & 6095.7 \\ & & \\ 30.4 & 1.1 & 146.5 \\ 24.3 & 22.5 & 55.8 \\ 5.0 & 1.9 & 2652.3 \\ 0.6 & 1.3 & 0.8 \\ & & \end{array}$


1982 Hmissions by Emisgion Source Group (ESG) (kt) (Cont'd)

Solid waste open burning

other burning

Asphalt paving operations

T'otal

Transportation

A.troraft:

Heavy-duty diesel trucks (on-hlghway)

Heavy-duty gasoline trucks (on-high.ay)

Light-duty diesel trucks (on-highway)

Light duty gasoline trucks (on-highway)

Aut omobilies (on-highway)

other off-highway vehicles

Railroad

Shipping

Total

Eilectric utility

"Bituminous soal, steam"

"Fuel oil \#2, gas turbine"

"Fuel nil \#2, internal combustion"

"Fuel oil \#2, stearn"

"Fuel o.1 \#6, gas turbine"

"Fuel oil \#6, internal combustion"

"Fuel oil \#6, steam"

"Natural gas, gas turbine"

"Natural gas, internal combustion"

"Natural gas, steam"

"lignite, steam"

"Subbituminous coal, steam"

Total

1982 National total

$\begin{array}{rrr}53.9 & 7.6 & 280.7 \\ 86.9 & 2.7 & 356.0 \\ 0.0 & 0.0 & 143.0 \\ 201.3 & 37.2 & 3635.1\end{array}$

71.7

1496.6

240.9

7.4

1.186 .3

3520.9

918.7

721.4

133.6

8297.5

3392.9

5.0

78

3.3

1. 3

0.0

230.5

30.3

24.4

623.9

219.7

1141.5

5680.6

18764.3
7.6

149.3

1...

3.1

40,8

126.8

59.8

106.1

227.8

742.3

12274.2

2. 1

0.5

E. 4

2.6

0.0

840.7

0.0

0.0

0.8

250.8

1068.1

14446.2

20987.4
77.2

1.87 .9

405.7

2.2

2025.4

6068.4

587.6

197.2

20.1

9571.6

12.0

0.4

0.2

0.0

0.1

0.0

3.2

3.1

0.8

1. 9

1. 6

5.3

28.6

20922.2 
198:3 Emissions by Emission Source Group (ESG) (kt)

Emission source group (ESG)

$\begin{array}{rrr}\text { NOx } & \text { SO2 } & \text { VOC } \\ & & \\ 33.1 & 152.9 & 1.1 \\ 134.0 & 1.2 & 2.8 \\ 107.9 & 224.7 & 3.1 \\ 5.5 & 0.5 & 2.5 \\ 2.7 & 40.5 & 9.3 \\ 225.3 & 1.1 & 0.0 \\ 68.1 & 97.3 & 5.2 \\ 82.4 & 11.8 & 1467.6 \\ 659.0 & 529.9 & 1491.6\end{array}$

Industrial fuel

Industrial coal combustion

Industrial natural gas combustion

Industrial fuel oil combustion

Industrial other fuels combustion

Total

407.5

1886.6

272.4

378.0

2944.4

$\begin{array}{rr}1265.9 & 4.7 \\ 53.4 & 36.8 \\ 633.1 & 14.6 \\ 255.1 & 42.6 \\ 2207.5 & 98.6\end{array}$

Industrial processes

Cement production

111.2

232.

0.0

0.4

Degreasing

Dry cleaning

Food proc. and agric. operations

0.0

0.0

4.3

Gasoline marketing

Glass manufacturing

0.1

48.7

Iron and steel production

37.8

Lime manufacturing

Mining operations

Mineral products processing

Miscellaneous industrial processes

26.3

10.2

8.9

5.9

60.6

oil and gas extraction

Organic chemica.ls manufacture

Other chemicals manufacture

Other primary metals smelting

Primary aluminum smelting

Paper and pulp mills operations

Primary copper smelting

Plastics production

Primary lead and zinc smelting

Printing operations

Petroleum product storage \& transfer

Petroleum refining

Rubber and misc. plastics manufacture

Other sec. metal smelting and refining

Secondary lead refining

"Indus. organic solvent use, misc."

Surface coating

Total

26.9

84.6

0.8

2.1

65.0

1.0

13.4

1.6

0.2

0.8

54.3

0.0

4.3

0.8

0.0

7.1

0.0

297.0

3.0

230.5

1.1

21.7

96.2

121.8

992.8

6.2

28.8

33.8

23.6

0.9

17.3

3.5

0.7

6.3

43.3

274.3

95.3

16.3

306.2

412.3

10.4

443.8

53.0

0.0

0.4

112.9

27.7

819.2

0.0

367.5

48.3

0.0

222.4

0.0

483.6

322.5

941.1

0.0

26.4

7.5

8.5

18.8

0.4

66.3

577.3

0.7

1678.9

$2554.3 \quad 6373.7$

Miscellaneous

Forest wild fires

Solid waste incineration

Nonind. organic solvent use \& disposal

60.9

24.3

5.0

1.1

244.1

22.5

55.8

0.6

1.9

2829.2

other miscellaneous sources

0.8 


\begin{tabular}{|c|c|c|c|}
\hline Emissions by & Group & (Cont'd) & \\
\hline $\begin{array}{l}\text { Solid waste open burning } \\
\text { other burning } \\
\text { Asphalt paving operations } \\
\text { Total. }\end{array}$ & $\begin{array}{r}53.9 \\
86.9 \\
0.0 \\
231.7\end{array}$ & $\begin{array}{r}7.6 \\
2.7 \\
0.0 \\
37.2\end{array}$ & $\begin{array}{r}280.7 \\
356.0 \\
162.4 \\
3929.0\end{array}$ \\
\hline $\begin{array}{l}\text { Transportation } \\
\text { Alrcraft } \\
\text { Heavy-duty diesel trucks (on-highway) } \\
\text { Heavy-duty gasoline trucks (on-highway) } \\
\text { Light-duty diesel trucks (on-highway) } \\
\text { light-duty gasoline trucks (on-highway) } \\
\text { Automoblles (on-highway) } \\
\text { Other off-highway vehicles } \\
\text { Railroad } \\
\text { Shipping } \\
\text { Total }\end{array}$ & $\begin{array}{r}74.0 \\
1453.0 \\
242.2 \\
7.5 \\
1145.7 \\
3376.5 \\
918.7 \\
843.5 \\
113.4 \\
8174.5\end{array}$ & $\begin{array}{r}7.8 \\
1.48 .3 \\
11.1 \\
3.1 \\
40.0 \\
126.5 \\
79.6 \\
125.6 \\
170.5 \\
712.5\end{array}$ & $\begin{array}{r}79.5 \\
178.4 \\
398.8 \\
2.2 \\
1932.9 \\
5817.7 \\
549.2 \\
227.0 \\
17.6 \\
9203.4\end{array}$ \\
\hline $\begin{array}{l}\text { Electilc ut1lity } \\
\text { "Bituminous coal, steam" } \\
\text { "Fuel oil \#2, gas turbine" } \\
\text { "Fuel oil \#2, internal combustion" } \\
\text { "Fuel oil \#2, steam" } \\
\text { "Fuel oil \#6, gas turbine" } \\
\text { "Fuel oil \#6, internal combustion" } \\
\text { "Fuel oil \#6, steam" } \\
\text { "Natural gas, gas turblne" } \\
\text { "Natural gas, internal combustion" } \\
\text { "Natural gas, steam" } \\
\text { "Lignite, steam" } \\
\text { "Subbituminous coal, steam" } \\
\text { Total }\end{array}$ & $\begin{array}{r}3501.3 \\
6.7 \\
7.9 \\
3.2 \\
0.5 \\
0.7 \\
221.1 \\
31.2 \\
21.4 \\
555.7 \\
239.9 \\
1186.1 \\
5775.5\end{array}$ & $\begin{array}{r}12504.0 \\
3.1 \\
0.6 \\
6.5 \\
1.8 \\
0.2 \\
749.2 \\
0.0 \\
0.0 \\
0.7 \\
284.4 \\
1114.4 \\
14664.9\end{array}$ & $\begin{array}{r}12.5 \\
0.5 \\
0.2 \\
0.0 \\
0.0 \\
0.0 \\
3.2 \\
3.2 \\
0.7 \\
1.7 \\
1.7 \\
5.6 \\
29.4\end{array}$ \\
\hline 983 National total & 18362.5 & 20706.2 & 21125.7 \\
\hline
\end{tabular}


1984 Emissions by Emission Source Group (ESG) (kt)

Emission source group (BSG)

Commercial/Residential

Chnum./Inst. coal combustion

Comm. / Inst. natural gas combustion

conm./Inst. fuel oill combustion

Comm./Inst. other fuels combustion

Residential coal combustion.

Residential natural gas combustion

Residential fuel o.il combustion

Residential wood combustion

Total

$\begin{array}{rrr}\text { NOX } & \text { SO2 } & \text { VOC } \\ & & \\ 33.1 & 172.0 & 2.2 \\ 134.0 & 1.2 & 2.8 \\ 107.9 & 224.7 & 3.1 \\ 5.5 & 0.5 & 2.5 \\ 2.7 & 40.5 & 9.3 \\ 236.6 & 1.1 & 0.0 \\ 6.8 .1 & 116.8 & 5.2 \\ 8.2 .4 & 11.8 & 1505.1 \\ 5.70 .3 & 5.68 .5 & 1530.2\end{array}$

Industrial fuel

Industrial coal combustion

Industrial natural gas combustion

Industrial fuel oil combustion

Industrial other fuels combustion

Total

460.6

1348.1

5.3 .4

4.7

272.4

723.5

36.8

420.0

322.2

14.6

3194.4

$244 \% .2$

43.1

Industrial processes

Cement production

Degreasing

Dry cleaning

Food proc. and agric. operations

Gasoline marketing

Glass manufacturing

Iron and steel production

Lime manufacturing

Mining operations

Mineral products processing

Miscellaneous industrial processes

Oil and gas extraction

Organic chemicals manufacture

Other chemicals manufacture

other primary metals smelting

Primary aluminum smelting

125.1

0.0

0.0

4.3

0.1

48.7

47.2

26.3

11.3

10.2

5.9

61.1

26.9

105.8

1.0

2.1

Paper and pulp mills operations

65.0

Primary copper smelting

Plastics production

Primary lead and zinc smelting

Printing operations

Fetroleum product storage \& transfer

Petroleum refining

Rubber and misc. plastics manufacture

Other sec. metal smelting and refining

secondary lead refining

"Indus. organic solvent use, misc."

Surface coating

Total

$\begin{array}{rr}250.1 & 0.4 \\ 0.0 & 362.1 \\ 0.0 & 262.0 \\ 3.0 & 85.5 \\ 1.1 & 992.8 \\ 21.7 & 6.2 \\ 147.0 & 41.1 \\ 43.1 & 0.9 \\ 26.1 & 3.9 \\ 19.8 & 0.8 \\ 6.3 & 43.3 \\ 242.0 & 98.9 \\ 19.9 & 333.0 \\ 434.0 & 443.8 \\ 11.7 & 0.0 \\ 70.6 & 0.4 \\ 118.3 & 29.3 \\ 779.0 & 0.0 \\ 2.4 & 452.4 \\ 48.3 & 0.0 \\ 0.0 & 296.5 \\ 0.3 & 483.6 \\ 322.5 & 906.2 \\ 0.0 & 26.4 \\ 7.8 & 8.7 \\ 18.8 & 0.4 \\ 0.0 & 75.1 \\ 0.7 & 2134.2 \\ 2594.6 & 7087.8\end{array}$

Miscellaneous

Forest wild fires

Solid waste incineration

Nonind. organic solvent use \& disposal

Other miscellaneous sources

$\begin{array}{rrr}60.9 & 1.1 & 195.3 \\ 24.3 & 22.5 & 55.8 \\ 5.0 & 1.9 & 31.82 .8 \\ 0.6 & 1.3 & 0.8\end{array}$




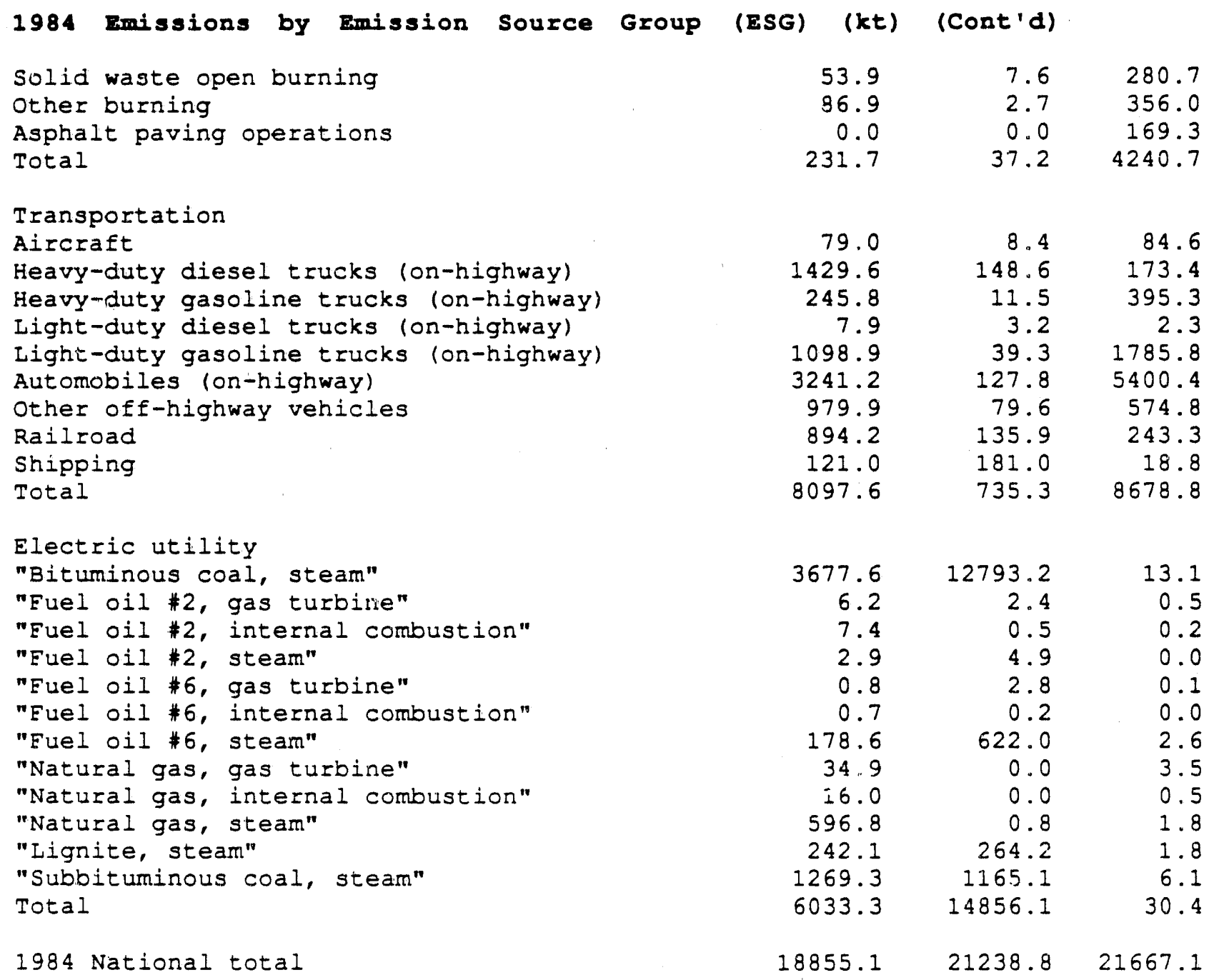


1985 Emissions by Emission Source Group (ESG) (kt)

Emission source group (ESG)

Commercial/Residential

Comm./Inst. coal combustion

Comm./Inst. natural gas combustion

Comm./Inst. fuel oil combustion

Comm./Inst. other fuels combustion

Residential coal combustion

Residential natural gas combustion

Residential fuel oil combustion

Residential wood combustion

Total

Industrial fuel

Industrial coal combustion

Industrial natural gas combustion

Industrial fuel oil combustion

Industrial other fuels combustion

Total

Industrial processes

Cement production

Degreasing

Dry cleaning

Food proc. and agric. operations

Gasoline marketing

Glass manufacturing

Iron and steel production

Lime manufacturing

Mining operations

Mineral products processing

Miscellaneous industrial processes

oil and gas extraction

organic chemicals manufacture

Other chemicals manufacture

Other primary metals smelting

Primary aluminum smelting

Paper and pulp mills operations

Primary copper smelting

Plastics production

Primary lead and zinc smelting

Printing operations

Petroleum product storage \& transfer

petroleum refining

Rubber and misc. plastics manufacture

other sec. metal smelting and refining

Secondary lead refining

"Indus. organic solvent use, misc."

Surface coating

Total

Miscellaneous

Forest wild fires

Solid waste incineration

Nonind. organic solvent use \& disposal

other miscellaneous sources

$\begin{array}{rrr}\text { NOx } & \text { SO2 } & \text { VOC } \\ 33.1 & 143.3 & 1.1 \\ 134.0 & 1.2 & 2.8 \\ 95.9 & 216.6 & 3.1 \\ 5.5 & 0.5 & 2.5 \\ 2.7 & 33.7 & 9.3 \\ 225.3 & 1.1 & 0.0 \\ 68.1 & 116.8 & 5.2 \\ 73.2 & 10.0 & 1324.0 \\ 637.9 & 523.3 & 1347.9\end{array}$

487.2
1905.9
272.4
315.0
2980.5

1372.8

53.4

738.6

255.1

2419.8

4.7

36.8

14.6

42.6

98.6

125.1

0.0

0.0

4.3

0.1

48.7

47.2

26.3

11.3

10.4

5.9

62.6

26.9

105.8

0.9

2.1

65.0

0.9

16.4

1.6

0.2

0.8

54.3

0.0

4.1

0.8

0.0

7.1

629.1

250.1

0.4

0.0

354.9

0.0

230.5

90.9

3.0

1.1

21.7

1007.0

6.2

155.4

28.8

26.3

20.2

6.3

242.0

14.7

434.0

11.5

53.0

118.3

645.4

2.4

96.5

0.0

0.3

326.9

0.0

7.1

18.8

0.0

0.7

2484.4

36.2

0.9

3.9

0.8

43.3

97.1

329.2

411.5

0.0

0.4

28.5

0.0

424.1

0.0

271.8

490.5

836.5

26.4

8.0

0.4

70.7

2105.8

6875.8

30.4
24.3
5.0
0.6

1.1

22.5

146.5

1.9

55.8

1. 3

2652.3

0.8 


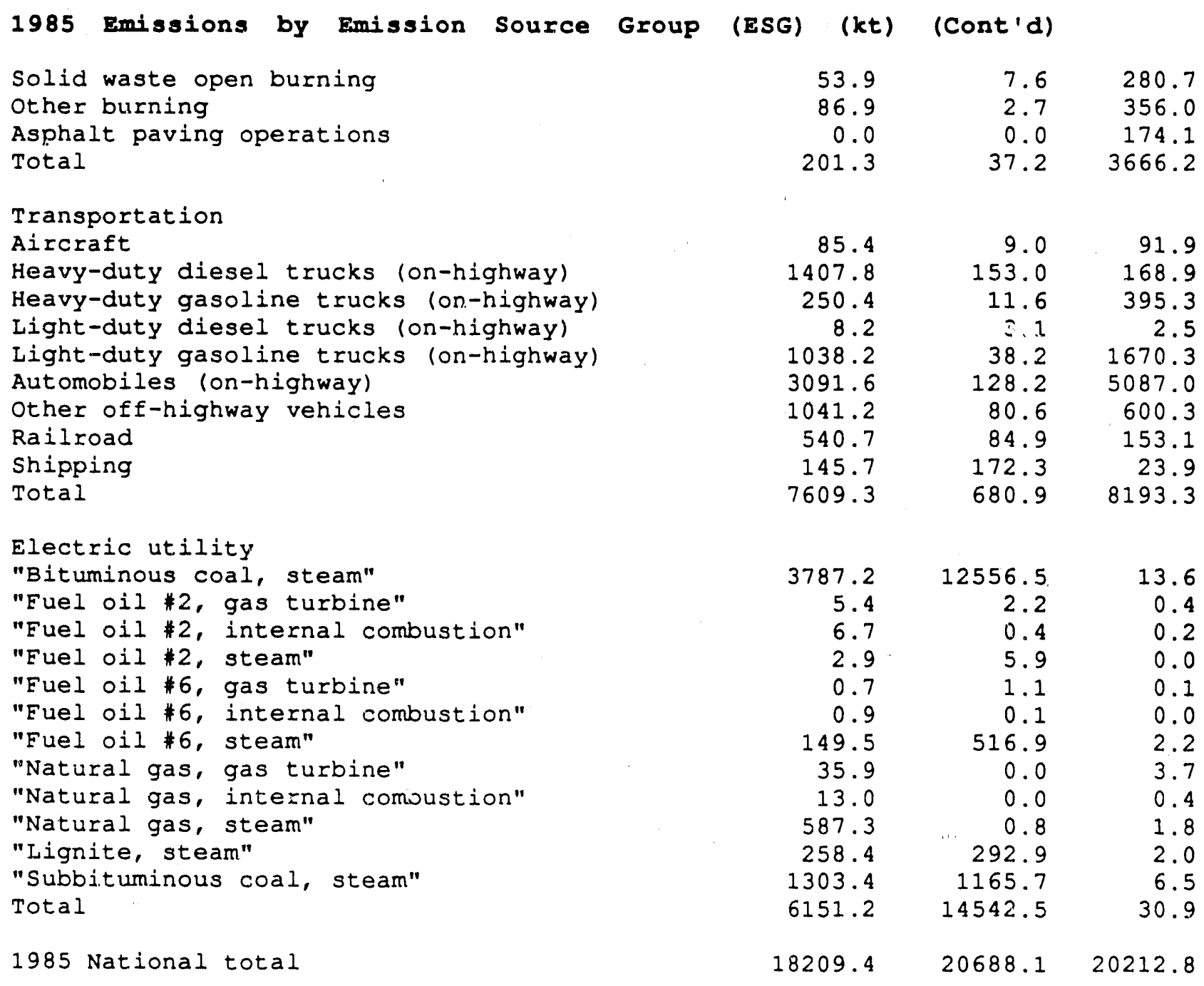


1986 Emissions by Emission Source Group (ESG) (kt)

Emission source group (ESG)

Commercial/Residential

Comm./Inst. coal combustion

Comm./Inst. natural gas combustion

Comm./Inst. fuel oil combustion

Comm. /Inst. other fuels combustion

Residential coal combustion

Residential natural gas combustion

Residential fuel oil combustion

Residential wood combustion

Total

$\begin{array}{rrr}\text { NOx } & \text { SO2 } & \text { VOC } \\ & & \\ 33.1 & 143.3 & 1.1 \\ 134.0 & 1.2 & 2.8 \\ 107.9 & 248.7 & 3.1 \\ 5.5 & 0.5 & 2.5 \\ 2.7 & 33.7 & 9.3 \\ 225.3 & 1.1 & 0.0 \\ 79.4 & 126.5 & 5.2 \\ 73.2 & 10.0 & 1324.0 \\ 661.2 & 565.1 & 1347.9\end{array}$

Industrial fuel

Industrial coal combustion

Industrial natural gas combustion

Industrial fuel oil combustion

Industrial other fuels combustion

Total

496.1

1838.2

291.8

336.0

2962.1

Industrial processes

Cement production

Degreasing

Dry cleaning

Food proc. and agric. operations

Gasoline marketing

Glass manufacturing

Iron and steel production

Lime manufacturing

Mining operations

Mineral products processing

Miscellaneous industrial processes

Oil and gas extraction

Organic chemicals manufacture

Other chemicals manufacture

Other primary metals smelting

Primary aluminum smelting

Paper and pulp mills operations

Primary copper smelting

Plastics production

Primary lead and zinc smelting

Printing operations

Petroleum product storage \& transfer

Petroleum refining

Rubber and misc. plastics manufacture

Other sec. metal smelting and refining

Secondary lead refining

"Indus. organic solvent use, misc."

Surface coating

Total

Miscellaneous

Forest wild fires

Solit waste incineration

Nonind. organic solvent use \& disposal

other miscellaneous sources
125.1

0.0

0.0

4.3

0.1

48.7

37.8

26.3

11.8

10.7

5.9

60.6

32.3

84.6

0.9

2.1

65.0

0.9

17.8

1.6

0.2

0.8

59.7

0.0

4.3

0.8

0.0

7.1

609.7

30.4

24.3

5.0

0.6
1381.0

53.4

783.8

322.2

2540.4

245.6

0.0

0.0

3.0

1. 1

21.7

121.8

28.8

27.4

20.7

6.3

242.0

16.6

390.6

10.7

53.0

123.6

586.5

2.6

83.4

0.0

0.3

383.6

0.0

7.5

18.8

0.0

0.7

2396.3

1.1

22.5

1. 9

1. 3
4.7

36.8

14.6

42.0

98.1

0.4

246.3

167.7

85.5

1035.4

6.2

33.8

0.9

4.0

0.8

43.3

95.3

340.7

411.5

0.0

0.4

30.2

0.0

348.7

0.0

181.2

504.3

801.6

26.4

8.5

0.4

64.1

2086.8

6524.3

146.5

55.8

2652.3

0.8 


\begin{tabular}{|c|c|c|c|}
\hline Emissions by & Group & (Cont'd) & \\
\hline $\begin{array}{l}\text { Solid waste open burning } \\
\text { other burning } \\
\text { Asphalt paving operations } \\
\text { Total. }\end{array}$ & $\begin{array}{r}53.9 \\
86.9 \\
0.0 \\
201.3\end{array}$ & $\begin{array}{r}7.6 \\
2.7 \\
0.0 \\
37.2\end{array}$ & $\begin{array}{r}280.7 \\
356.0 \\
179.5 \\
3671.6\end{array}$ \\
\hline $\begin{array}{l}\text { Transportation } \\
\text { Aircraft } \\
\text { Heavy-duty diesel trucks (on-highway) } \\
\text { Heavy-duty gasoline trucks (on-highway) } \\
\text { light-duty diesel trucks (on-highway) } \\
\text { Light-duty gasoline trucks (on-highway) } \\
\text { Automobiles (on-highway) } \\
\text { Other off-highway vehicles } \\
\text { Railroad } \\
\text { Shipping } \\
\text { Total }\end{array}$ & $\begin{array}{r}88.4 \\
1388.7 \\
253.8 \\
8.6 \\
991.4 \\
2957.5 \\
1071.8 \\
523.0 \\
134.9 \\
7418.2\end{array}$ & $\begin{array}{r}9.3 \\
158.9 \\
11.6 \\
3.2 \\
37.7 \\
128.7 \\
80.6 \\
82.1 \\
166.1 \\
678.2\end{array}$ & $\begin{array}{r}95.5 \\
164.6 \\
358.6 \\
2.7 \\
1561.4 \\
4795.9 \\
613.1 \\
147.9 \\
21.9 \\
7761.6\end{array}$ \\
\hline $\begin{array}{l}\text { Electric utility } \\
\text { "Bituminous coal, steam" } \\
\text { "Fuel oil \#2, gas turbine" } \\
\text { "Fuel oil \#2, internal combustion" } \\
\text { "Fuel oil \#2, steam" } \\
\text { "Fuel oil \#6, gas turbine" } \\
\text { "Fuel oil \#6, internal combustion" } \\
\text { "Fuel oil \#6, steam" } \\
\text { "Natural gas, gas turbine" } \\
\text { "Natural gas, internal combustion" } \\
\text { "Natural gas, steam" } \\
\text { "Lignite, steam" } \\
\text { "Subbituminous coal, steam" } \\
\text { Total }\end{array}$ & $\begin{array}{r}3707.8 \\
6.8 \\
7.0 \\
2.6 \\
0.4 \\
2.0 \\
212.4 \\
32.6 \\
10.4 \\
493.9 \\
313.8 \\
1269.2 \\
6058.9\end{array}$ & $\begin{array}{r}12225.5 \\
2.3 \\
0.4 \\
9.0 \\
0.6 \\
0.1 \\
696.0 \\
0.0 \\
0.0 \\
0.7 \\
375.5 \\
1051.5 \\
14361.7\end{array}$ & $\begin{array}{r}13.4 \\
0.6 \\
0.2 \\
0.0 \\
0.0 \\
0.1 \\
3.0 \\
3.3 \\
0.3 \\
1.5 \\
2.2 \\
6.3 \\
30.9\end{array}$ \\
\hline 1986 National total & 17911.4 & 20578.9 & \\
\hline
\end{tabular}


1987 Emissions by Emission Source Group (ESG) (kt)

Emtssion source group (ESG)

Commerclal/Restdentlal

Comm./Inst. coal combustion

Comm./Inst. natural gas combustion

Comm./Inst. fuel ofl combustion

Comm./Inst. other fuels combustion

Residential coal combustion

Residential natural gas combustion

Residential fuel oil combustion

Residential wood combustion

Total

Industrial fuel

Industrial coal combustion

Industrial natural gas combustion

Industrial tuel ofl combustion

Industrial other fuels combustion

Total

Industrial processes

Cement production

Degreasing

Dry cleaning

Food proc. and agric. operations

Gasoline marketing

Glass manufacturing

Iron and steel production

Lime manufacturing

Mining operations

Mineral products processing

Miscellaneous industrial processes

Oil and gas extraction

Organic chemicals manufacture

other chemicals manufacture

Other primary metals smelting

Primary aluminum smelting

Paper and pulp mills operations

Frimary copper smelting

Plastics production

Primary lead and zinc smelting

Printing operations

Petroleum product storage \& transfer

Petroleum refining

Rubber and misc. plastics manufacture

other sec. metal smelting and refining

Secondary lead refining

"Indus. organic solvent use, misc."

Surface coating

Total

Miscellaneous

Forest wild fires

Solid waste incineration

Nonind. organic solvent use \& disposal

other miscellaneous sources

$\begin{array}{rrr}\text { NOx } & \text { SO2 } & \text { VOC } \\ & & \\ 33.1 & 133.8 & 1.1 \\ 121.8 & 1.2 & 2.8 \\ 107.9 & 272.8 & 3.1 \\ 5.5 & 0.5 & 2.5 \\ 2.7 & 40.5 & 9.3 \\ 225.3 & 1.1 & 0.0 \\ 79.4 & 126.5 & 5.2 \\ 64.1 & 10.0 & 1324.0 \\ 639.9 & 586.4 & 1347.9\end{array}$

487.2

1867.2

291.8

315.0

2961.3

$\begin{array}{rr}1265.9 & 4.7 \\ 53.4 & 36.8 \\ 844.1 & 14.6 \\ 288.7 & 42.0 \\ 2452.0 & 98.1\end{array}$

125.1

0.0

0.0

4.3

0.1

48.7

37.8

26.3

12.3

10.7

5.9

58.3

32.3

95.2

0.9

2.1

97.4

1.0

19.0

1.6

0.2

0.8

57.0

0.0

4.3

0.8

0.0

7.1

649.5

241.1

0.0

0.0

3.0

1.1

14.5

134.4

28.8

28.5

20.9

6.3

274.3

17.9

390.6

11.6

53.0

134.4

372.7

2. 8

70.2

0.0

0.3

379.2

0.0

7.5

28.2

0.0

0.7

2221.9

30.4

24.3

1. 1

5.0

0.6
22.5

1. 9

1. 3
195.3

55.8

0.4

282.5

178.1

85.5

1077.9

6.2

36.2

0.9

4.2

0.8

43.3

95.3

359.8

451.8

0.0

0.4

31.5

0.0

263.9

0.0

156.5

525.1

801.6

26.4

8.4

0.4

72.9

2181.6

6691.7

2652.3

0.8 


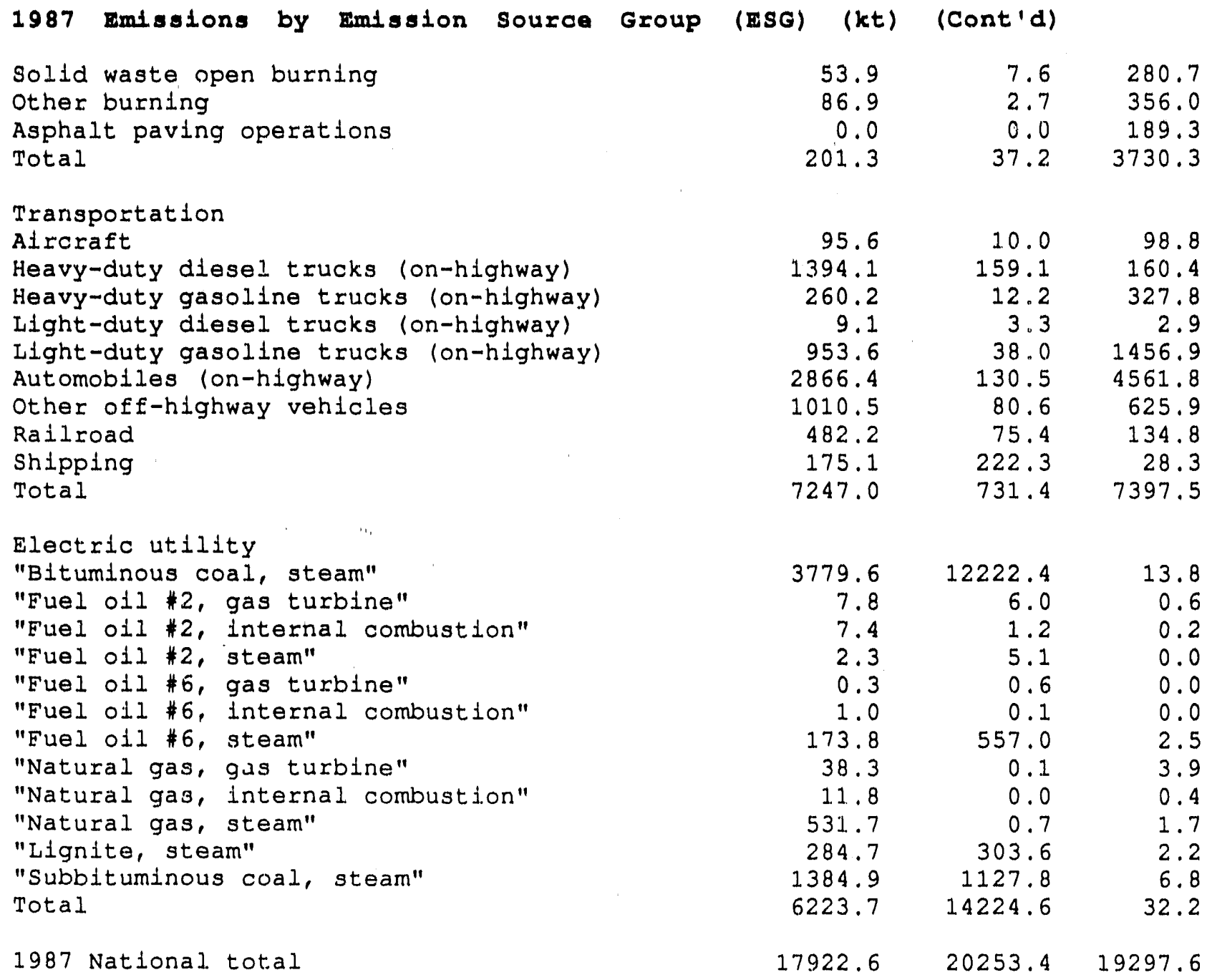


1988 Emissions by Emission Source Group (ESG) (kt)

Emission source group (ESG)

NOX

$\mathrm{SO} 2$

VOC

Commerolal/Residential

Comm./Inst. coal combustion

Comm. / Inst. natural gas combustion

Comm./Inst. fuel oll combustion

Comm./Inst. other fuels combustion

Residential coal combustion

Residential natural gas combustion

Residential fuel oll combustion

Residential wood combustion

Total

33.1

147.8

108.1

5.5

2.9

238.2

77.3

64.1

677.0

Industrial fuel
Industrial coal combustion
Industrial natural gas combustion
Industrial fuel oil combustion
Industrial other fuels combustion
Total

Industrial processes

Cement production

Degreasing

Dry cleaning

Food proc. and agric, operations

Gasoline marketing

Glass manufacturing

Iron and steel production

Lime manufacturing

Mining oporations

Mineral products processing

Miscellaneous industrial processes

Oil and gas extraction

organic chemicals manufacture

other chemicals manufacture

Other primary metals smelting

Primary aluminum smelting

Paper and pulp mills operations

Primary copper smelting

Plastics production

Primary lead and zinc smelting

Printing operations

Petroleum product storage \& transfer

Petroleum refining

Rubber and misc. plastics manufacture

Other sec. metal smelting and refining

Secondary lead refining

"Indus. organic solvent use, misc."

Surface coating

Total

Miscellaneous

Forest wild fires

Solid waste incineration

Nonind. organic solvent use \& disposal

other miscellaneous sources

\section{6 \\ 1905.9 \\ 392.7 \\ 322.0 \\ 3091.3}

136.2

0.0

0.0

4.8

0.1

53.7

54.4

26.3

14.7

12.2

6.5

62.5

36.0

131.2

1.1

2.4

107.4

1.4

16.4

1.7

0.2

0.9

64.7

0.0

4.9

0.9

0.0

7.9

748.7

30.4

24.3

5.0

0.6
151.3

1.2

249.4

0.5

44.2

1.2

123.7

10.0

581.6

1281.6

53.4

1039.0

288.3

2662.2

264.4

0.0

0.0

3.0

1.1

14.5

144.4

28.8

31.0

21.4

6.3

327.6

18.1

486.5

12.8

65.3

136.8

297.0

2.4

119.2

0.0

0.3

364.8

0.0

7.8

28.7

0.0

0.7

2382.9

1.1

22.5

1.9

1.3
1.1

2.8

3.2

2.5

9.3

0.0

6.0

1324.0

1348.9

4.7

36.8

22.1

46.1

109.6

$$
0.4
$$

282.5

178.1

90.9

1070.4

6.2

37.7

0.9

4.6

0.9

43.3

92.8

364.5

438.1

0.0

0.4

32.3

0.0

386.3

0.0

211.6

521.4

801.6

27.6

8.8

0.4

72.9

1.808 .0

6482.5

195.3

55.8

2652.3

0.8 


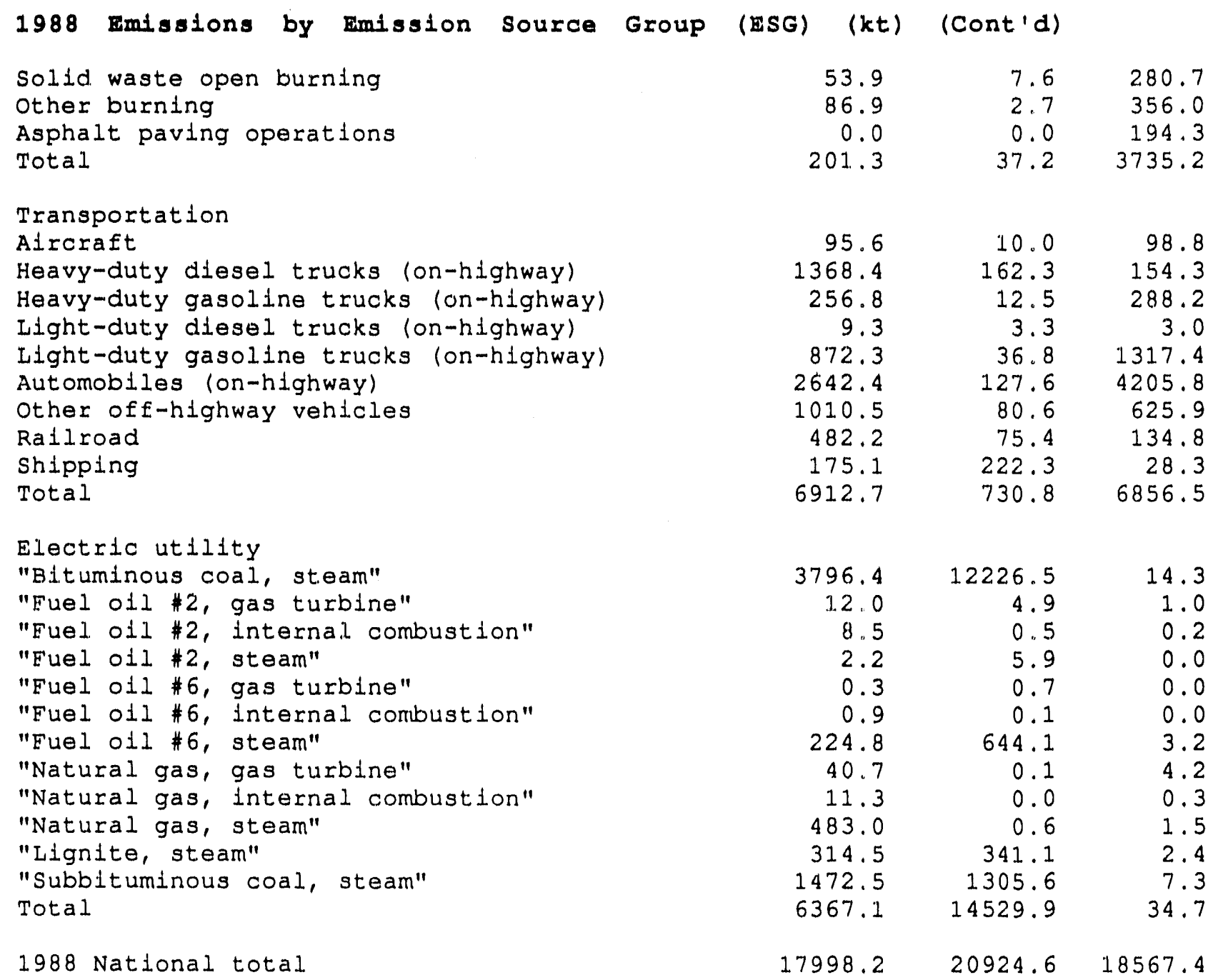




\section{Appendix C: \\ MSCET Copper Smelter \\ Plant-Level $\mathrm{SO}_{2}$ Emissions Inventory}




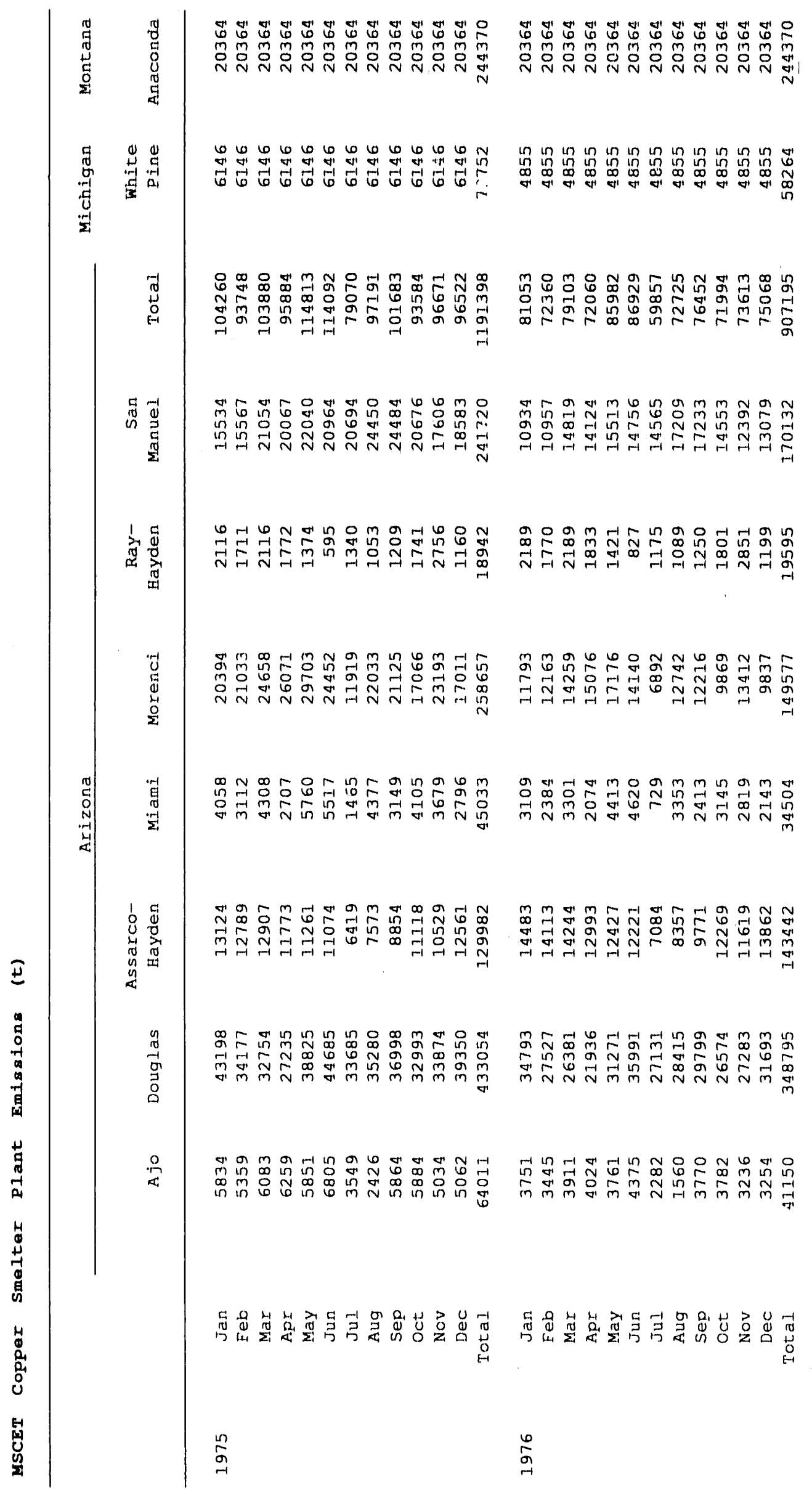




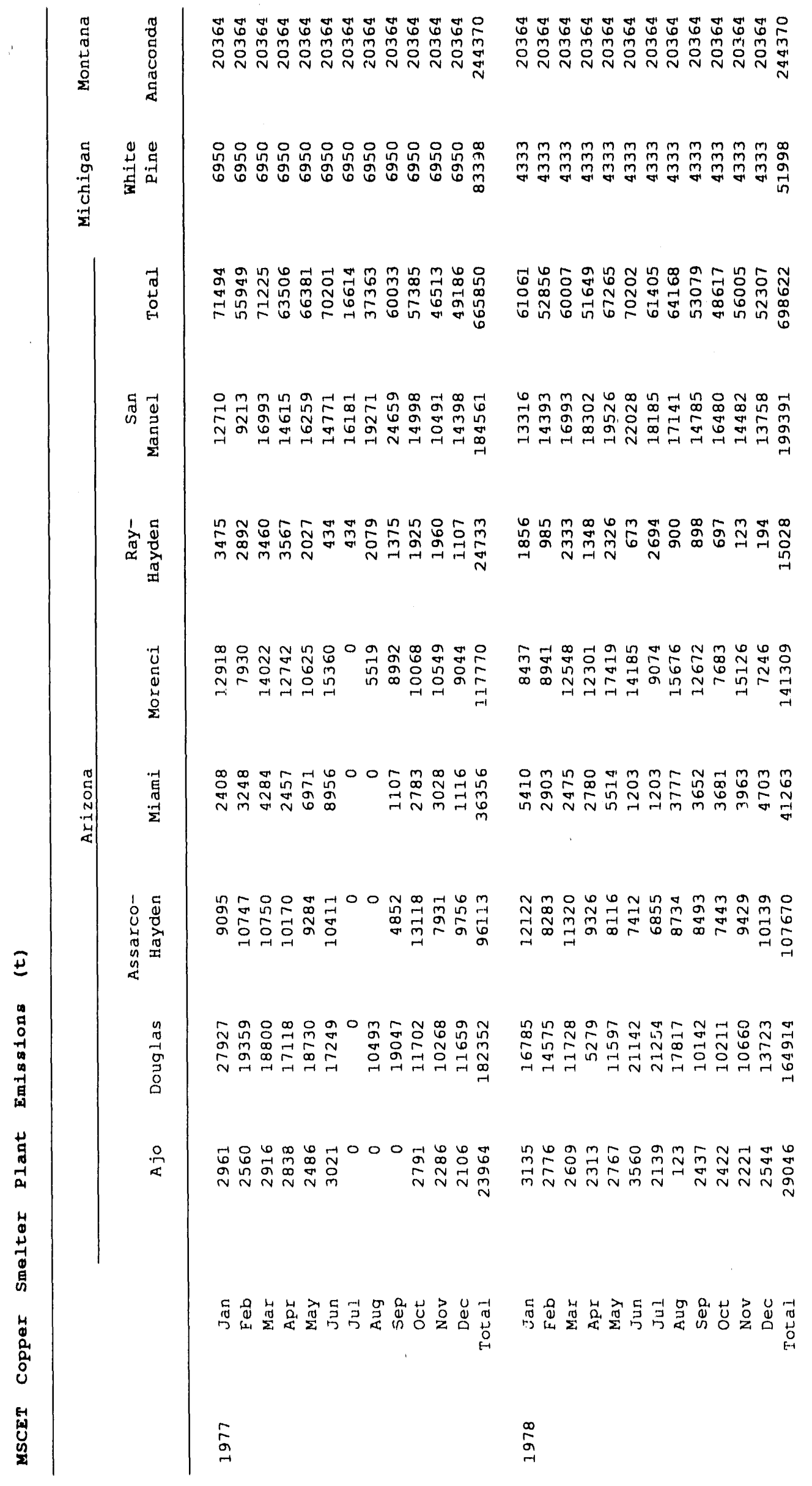




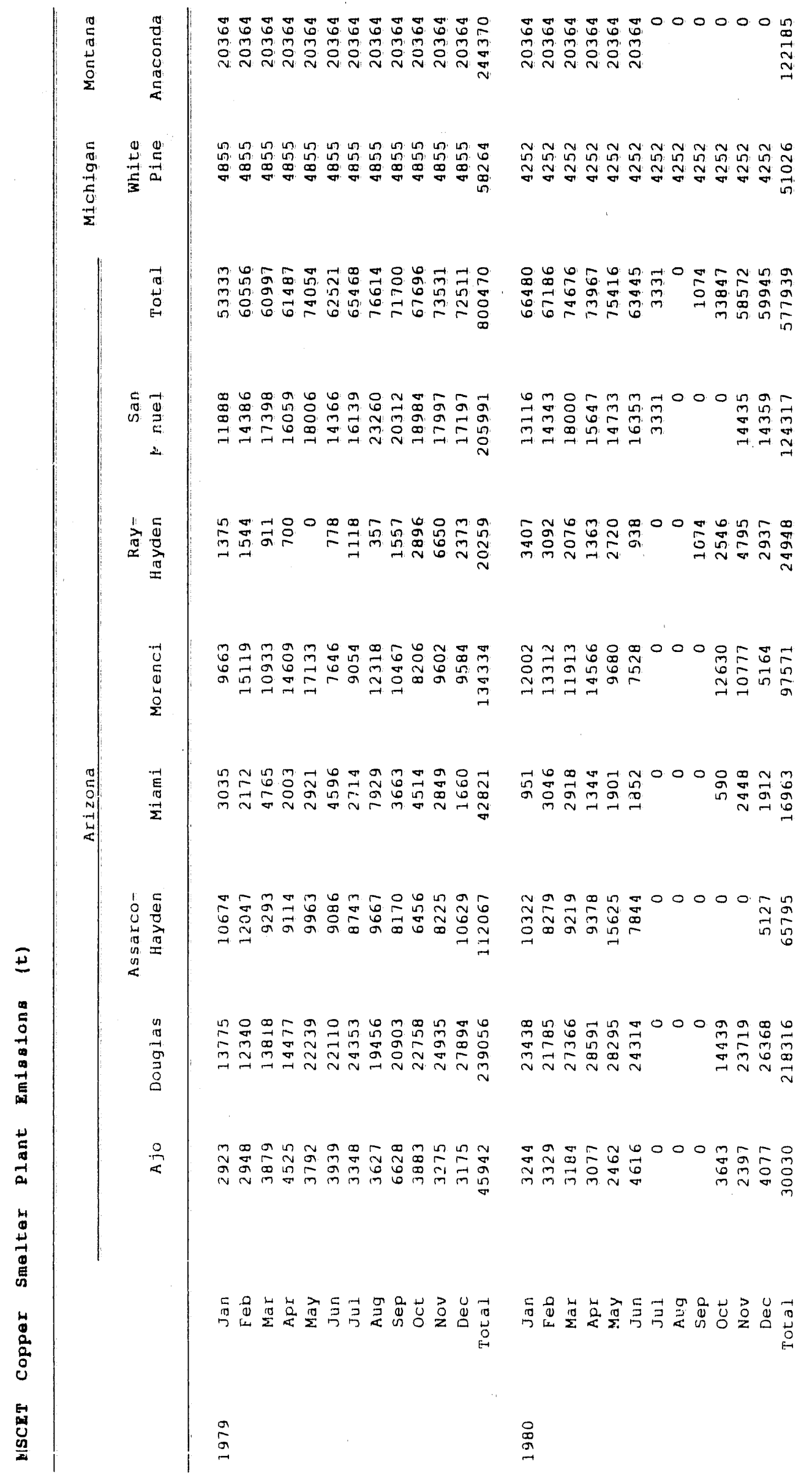




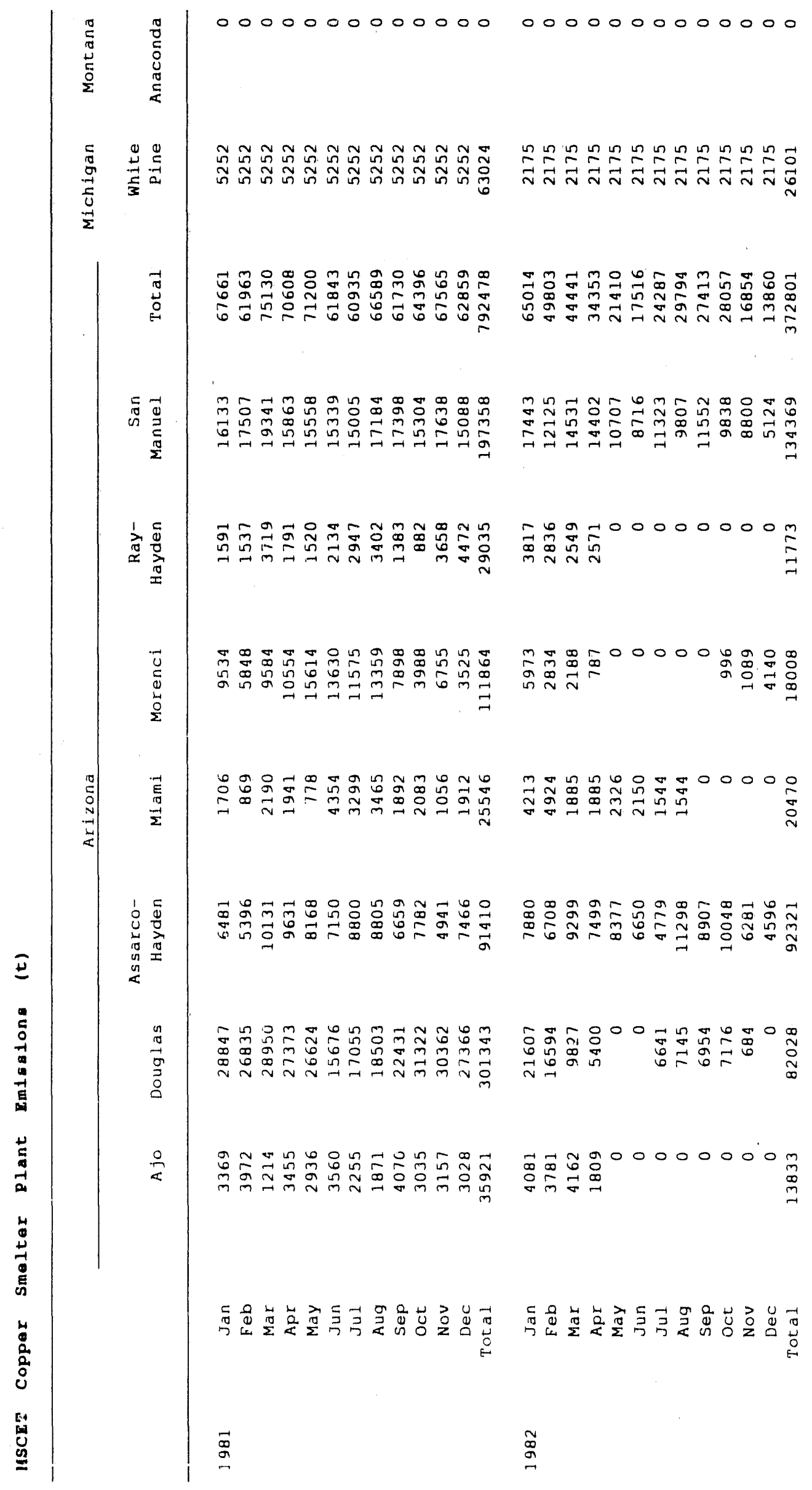




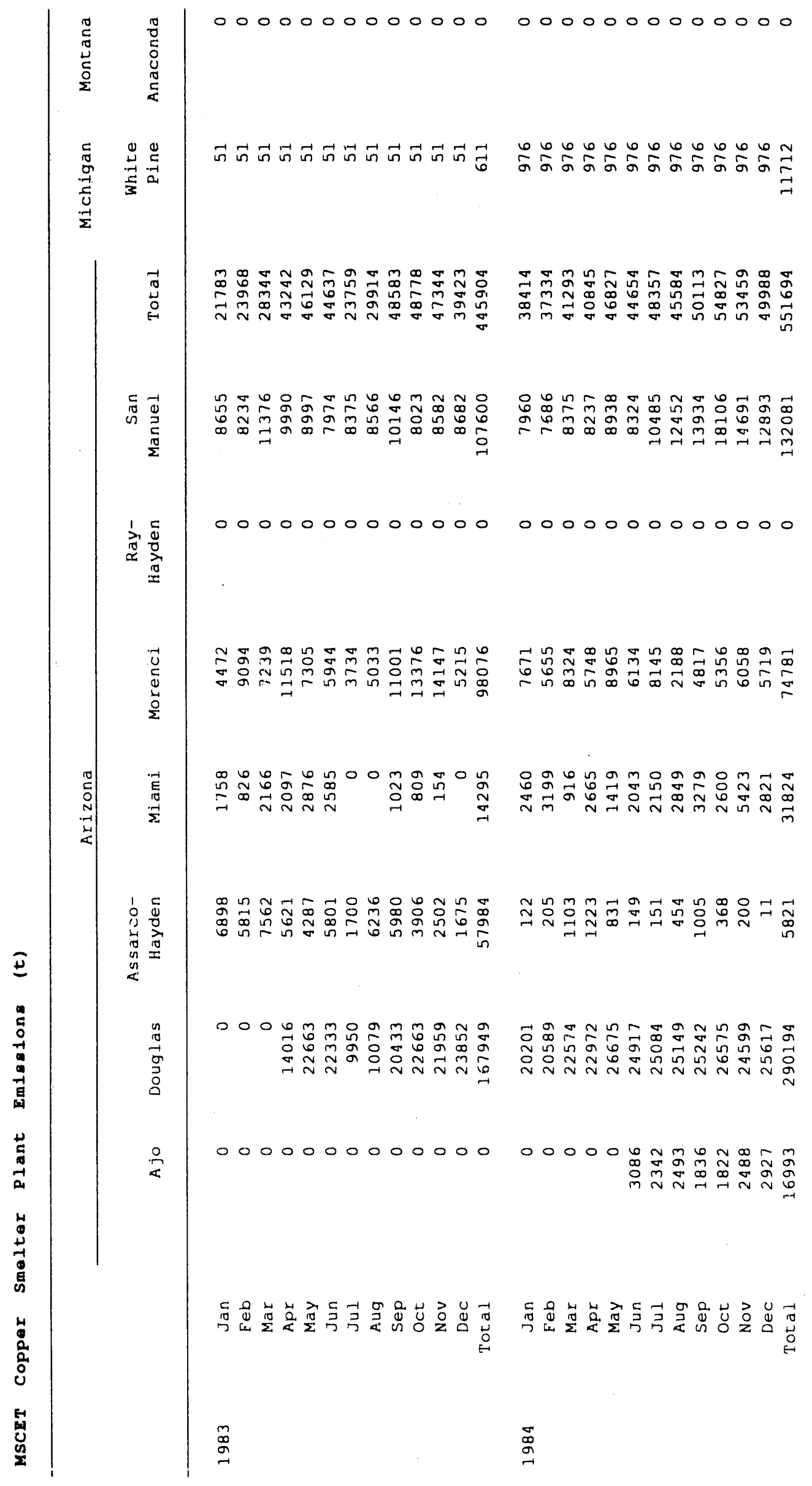




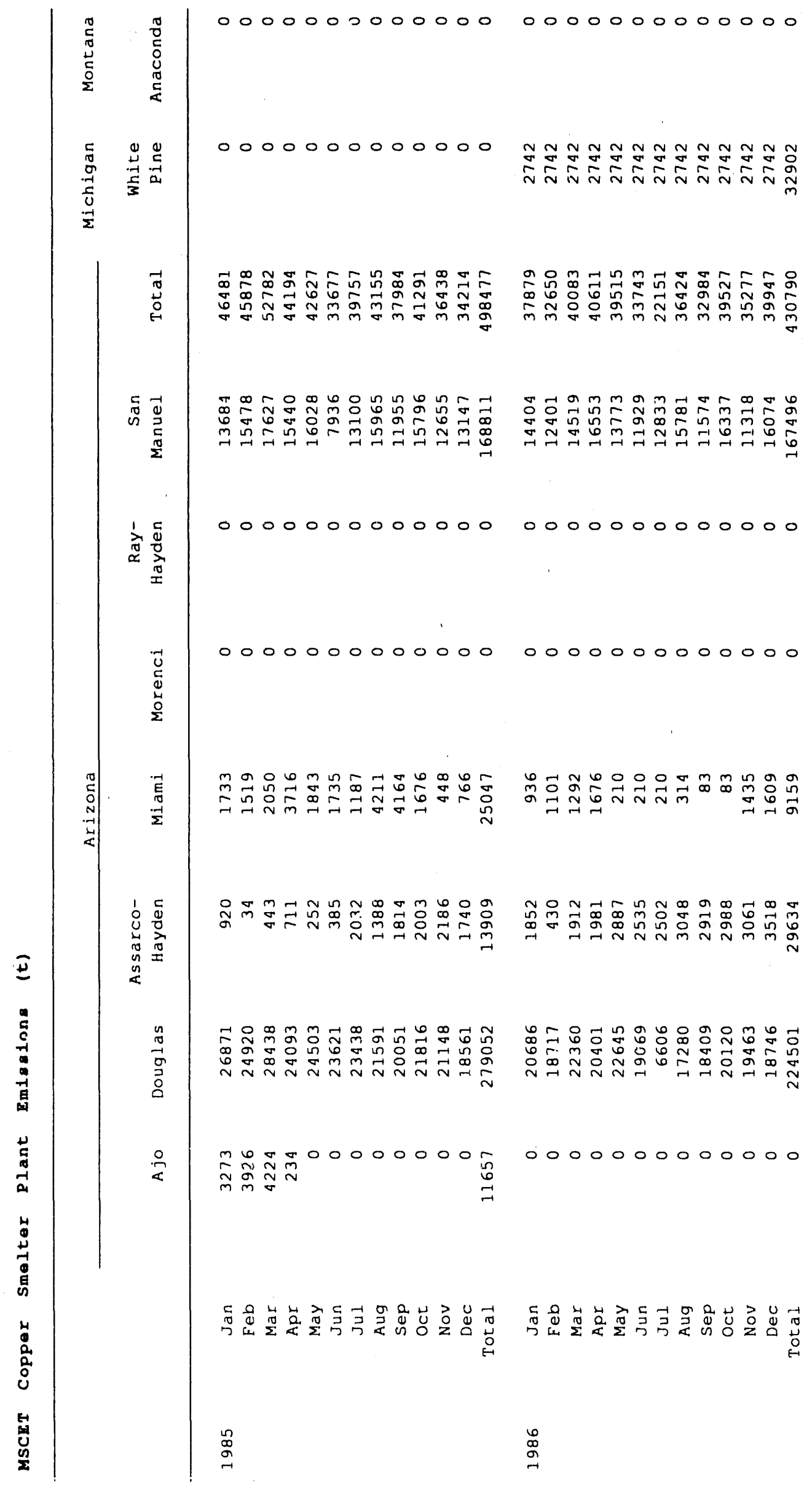




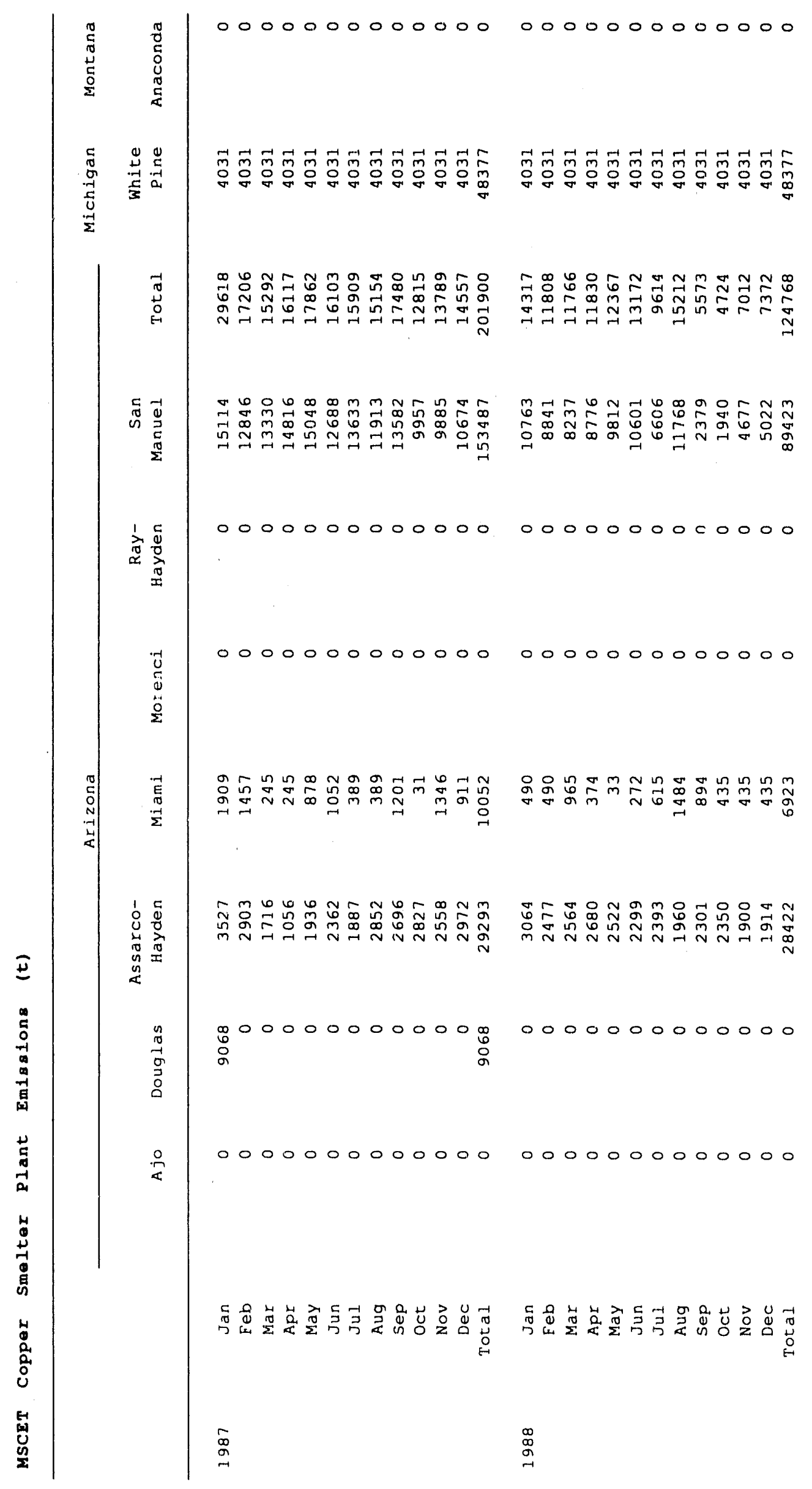




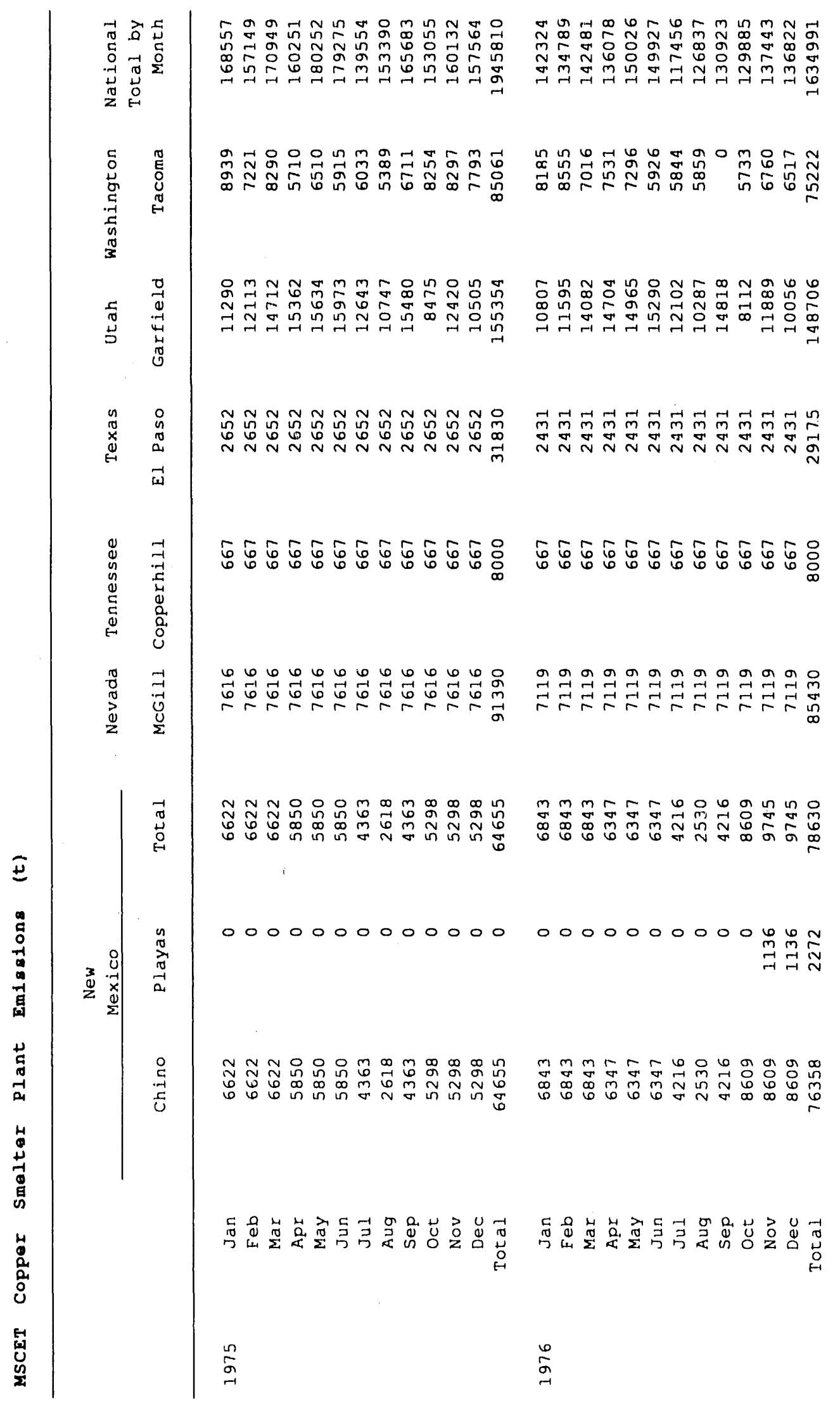




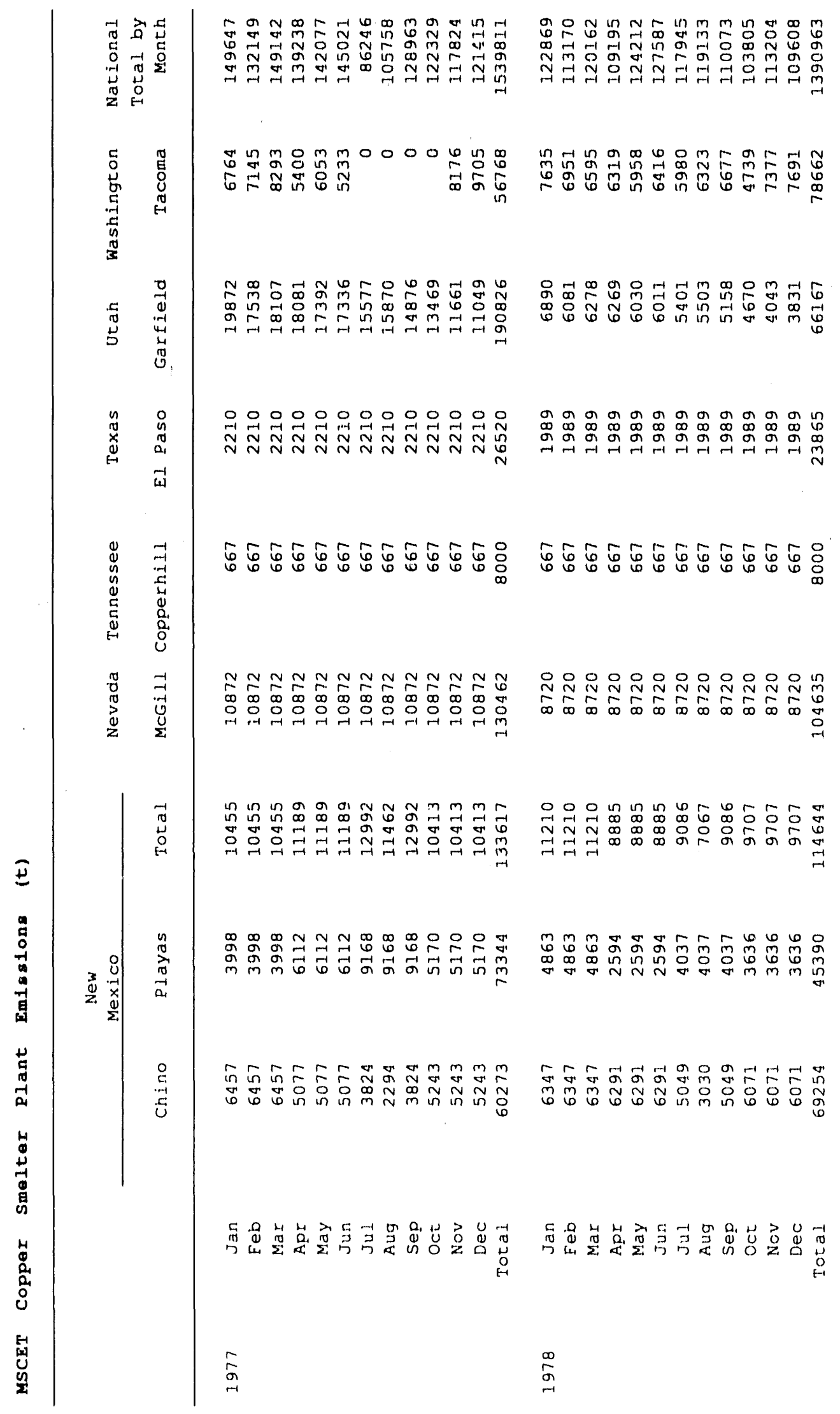




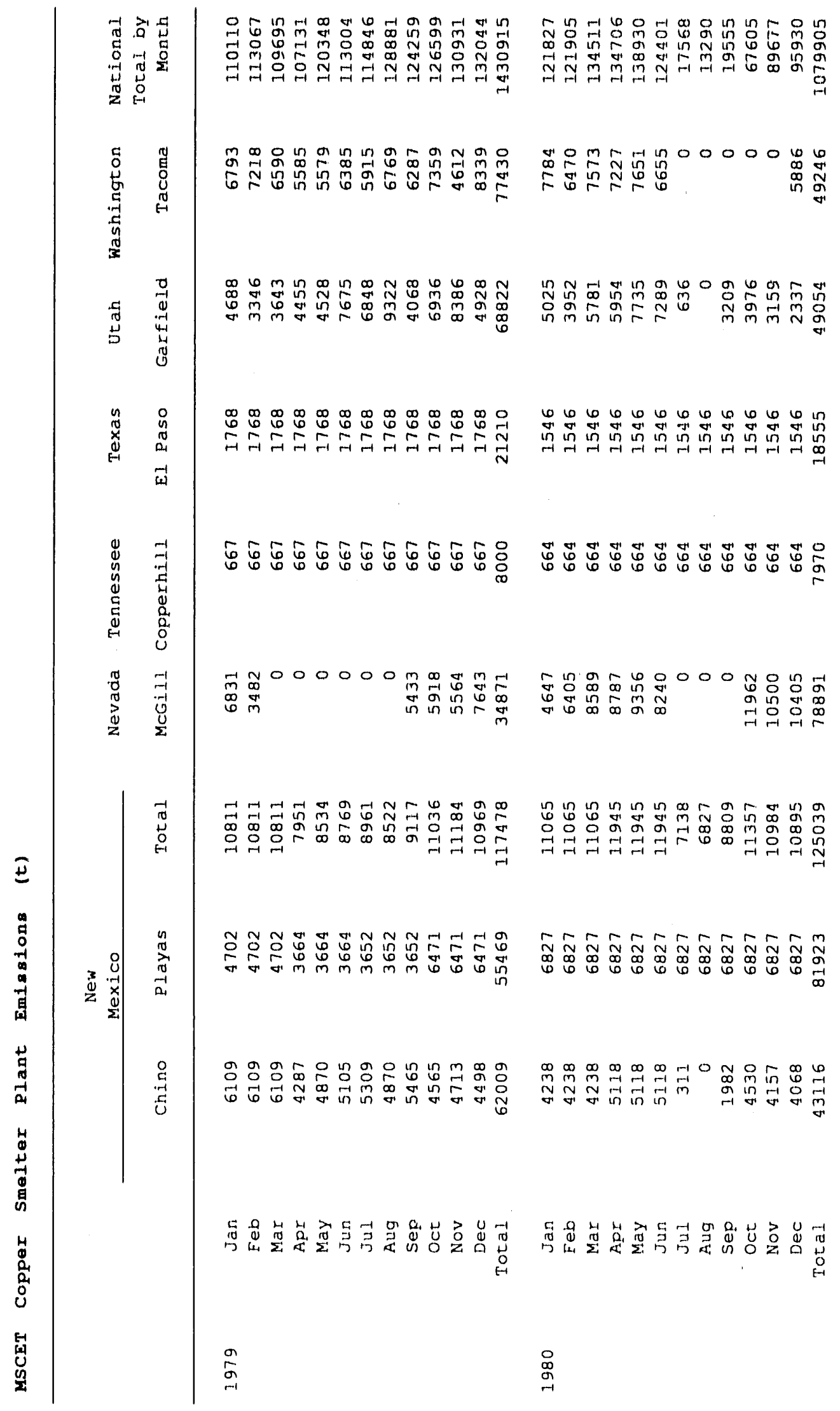




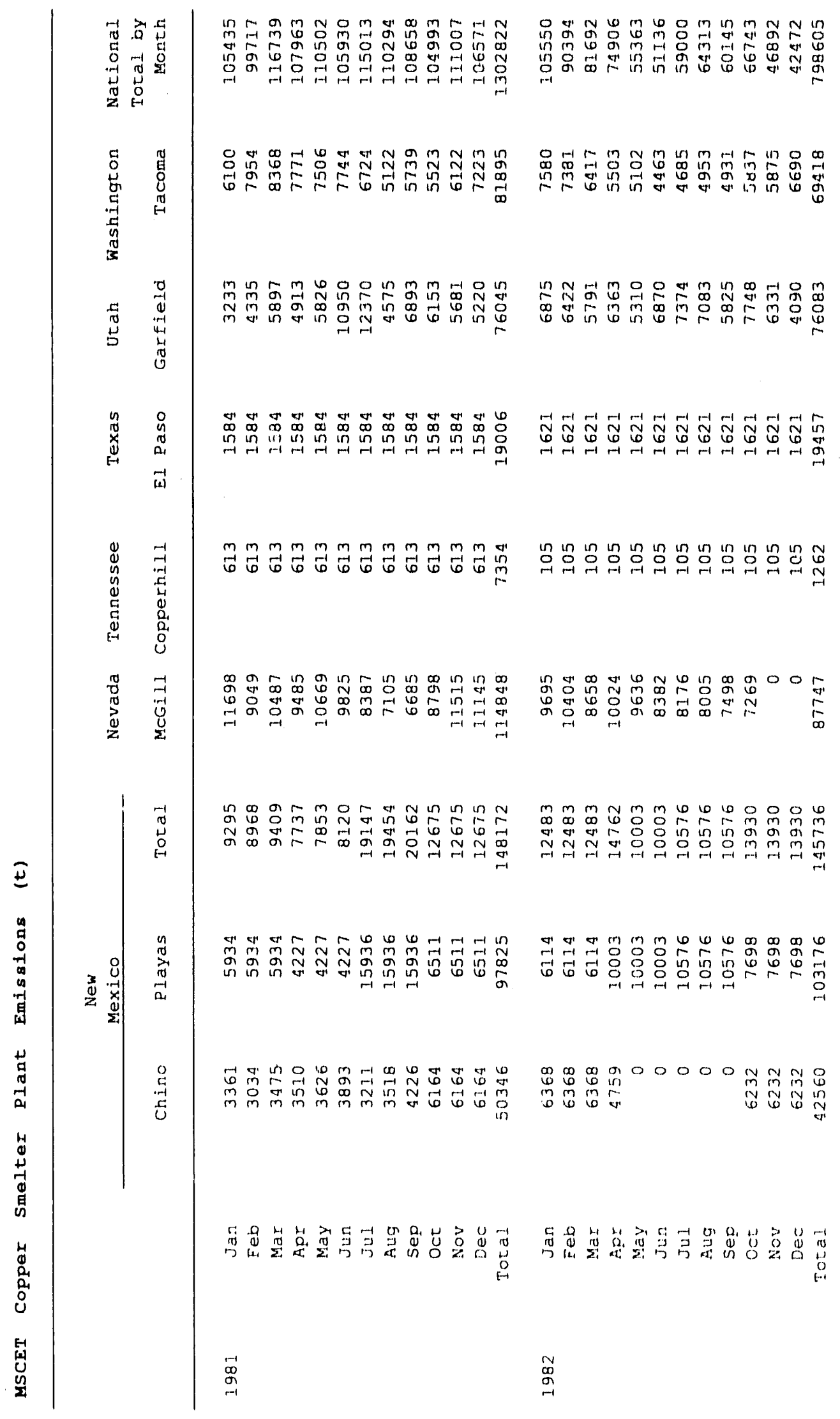




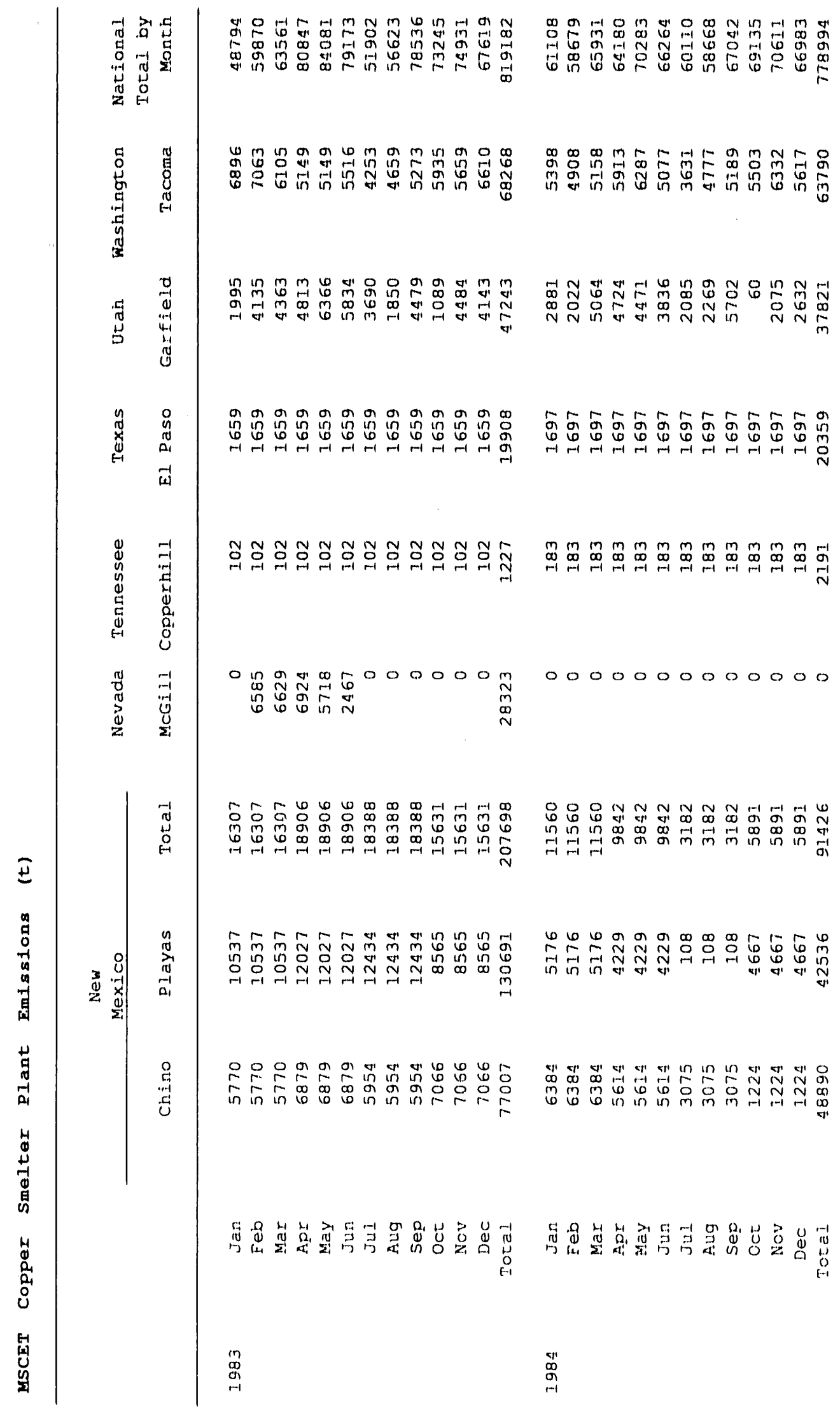




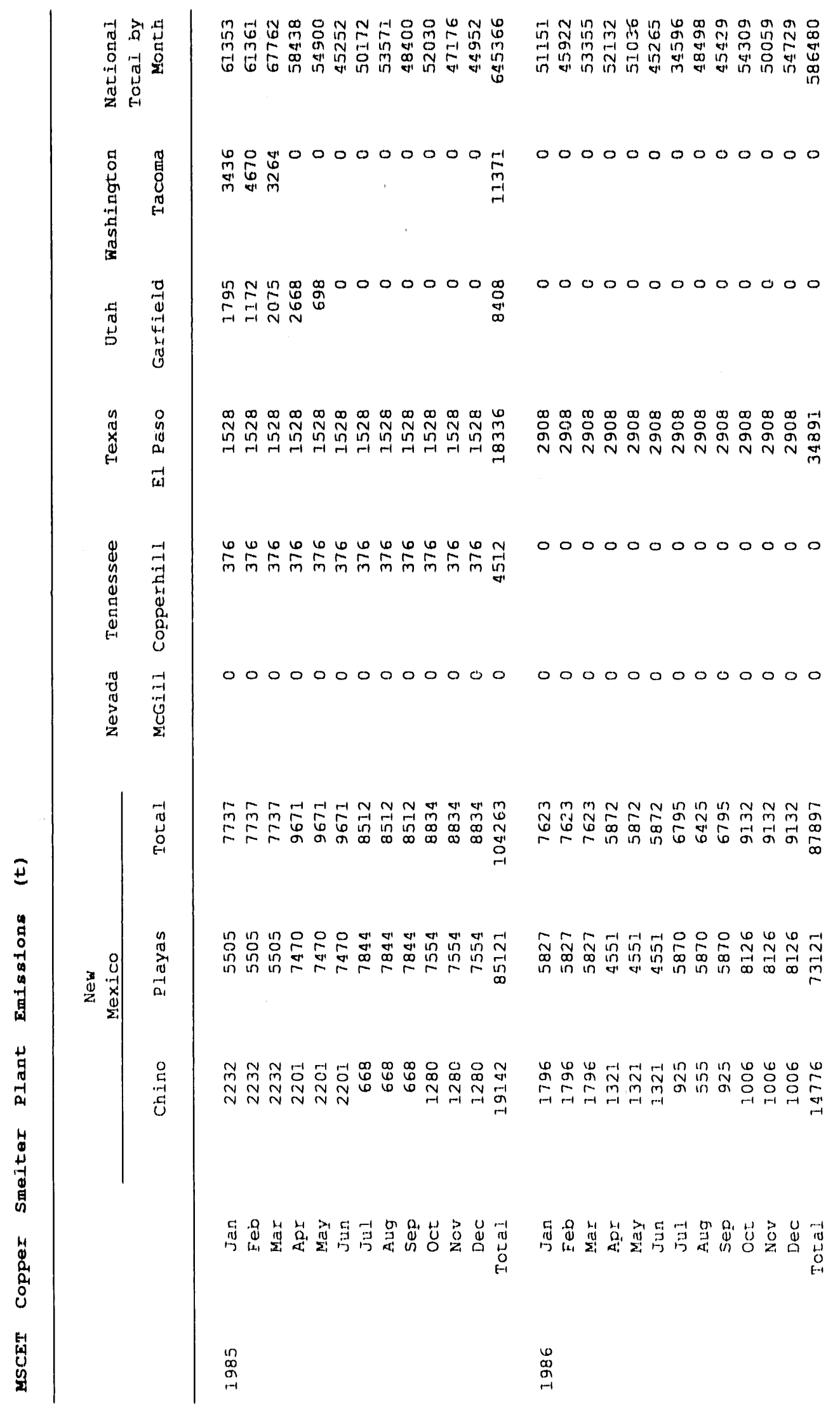




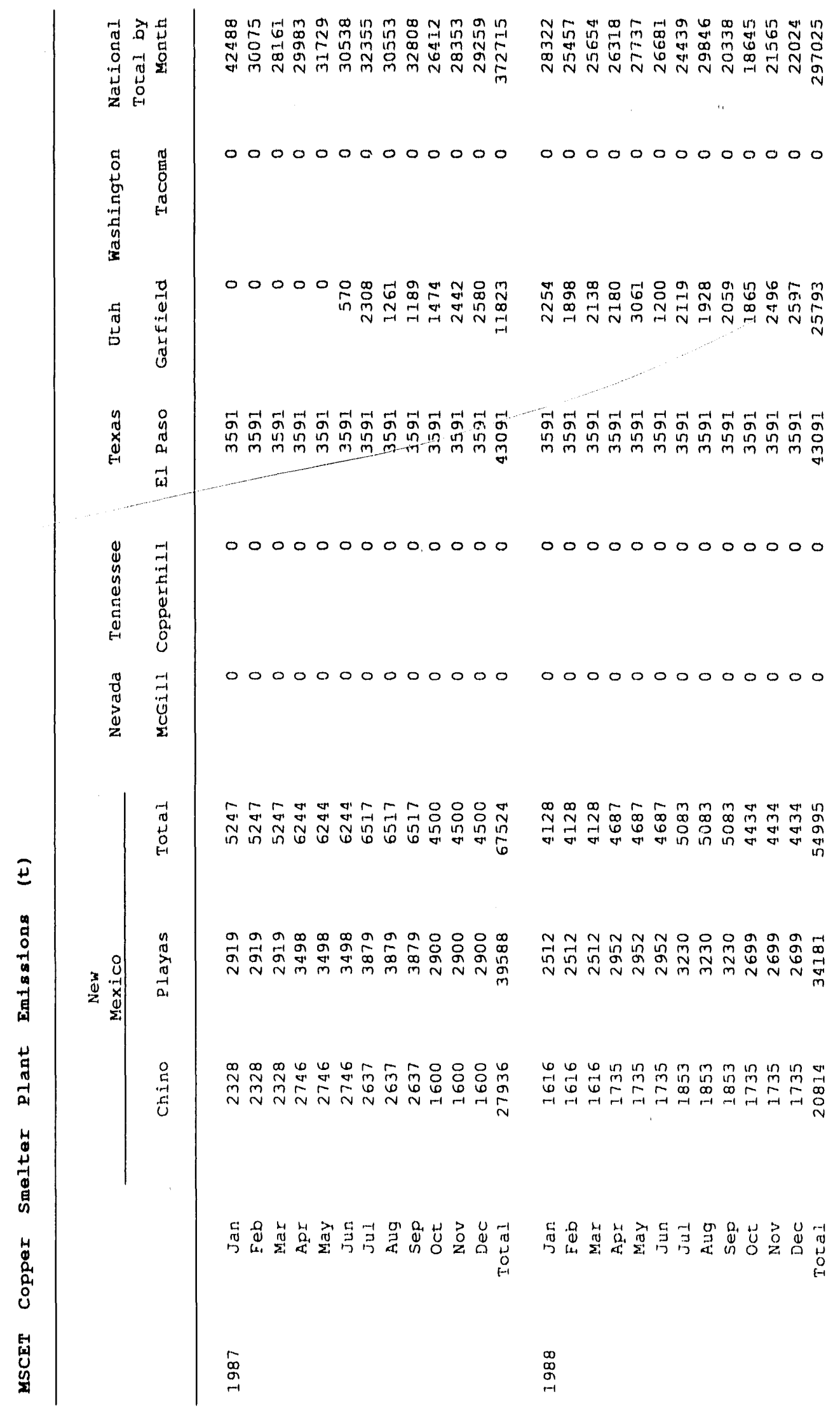



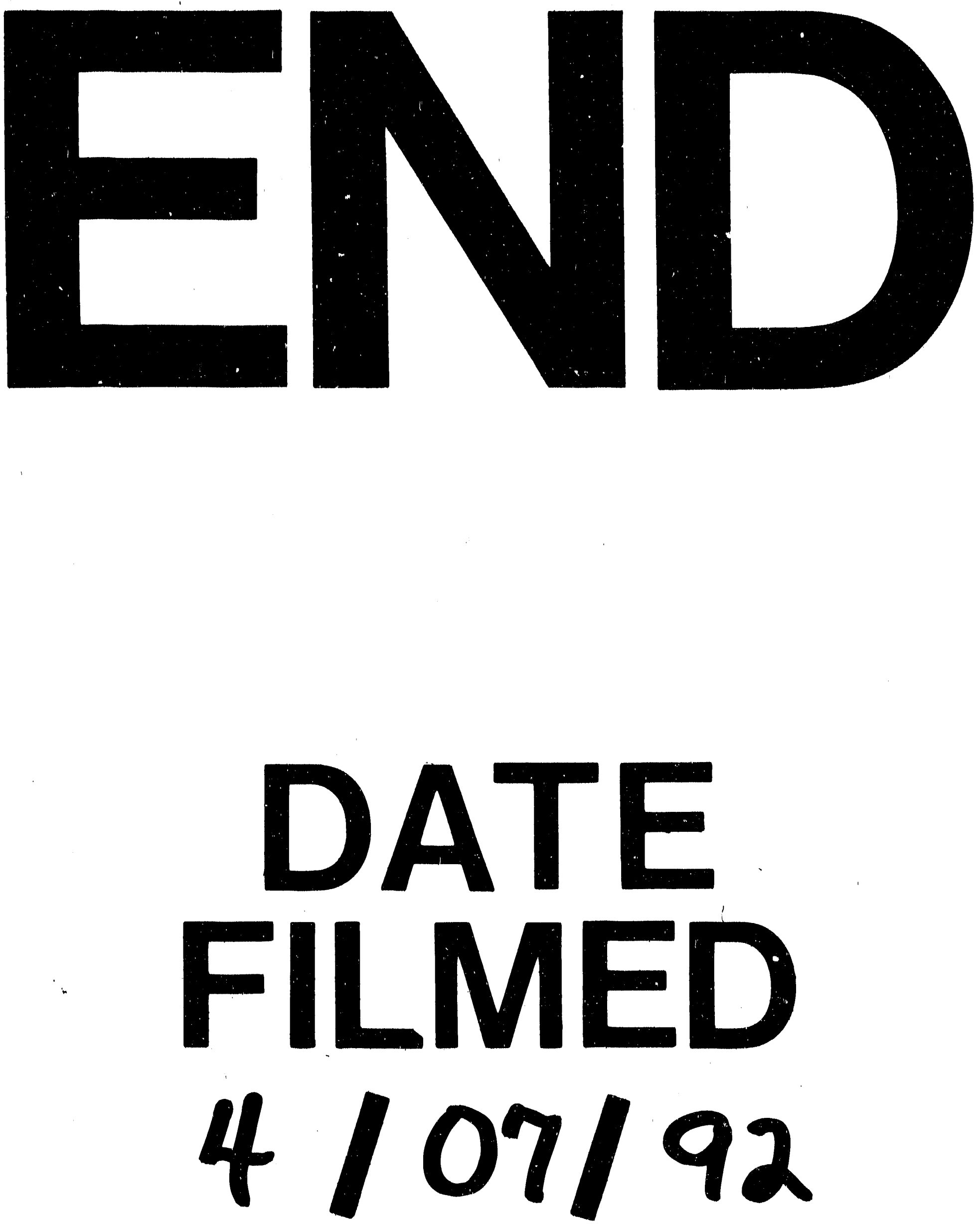

) 
